UNIVERSIDAD POLITÉCNICA DE MADRID ESCUELA TÉCNICA SUPERIOR DE ARQUITECTURA

INFLUENCIA DEL COLOR Y EL ACABADO SUPERFICIAL EN LAS PROPIEDADES DE UN MORTERO FOTOCATALÍTICO COMO SOLUCIÓN DE ENVOLVENTE

TESIS DOCTORAL

AGUSTÍN LAPLAZA GUERRA LICENCIADO EN CIENCIAS QUIMICAS 

DEPARTAMENTO DE CONSTRUCCIÓN Y TECNOLOGÍA ARQUITECTÓNICAS ESCUELA TÉCNICA SUPERIOR DE ARQUITECTURA

INFLUENCIA DEL COLOR Y EL ACABADO SUPERFICIAL EN LAS PROPIEDADES DE UN MORTERO FOTOCATALÍTICO COMO SOLUCIÓN DE ENVOLVENTE

TESIS DOCTORAL

$$
A \cup T O R:
$$

AGUSTÍN LAPLAZA GUERRA

LICENCIADO EN CIENCIAS QUIMICAS

DIRECTORES:

MARTA MARIA CASTELLOTE ARMERO DOCTORA EN CIENCIAS QUIMMICAS ALFONSO GARCÍA SANTOS DOCTOR ARQUITECTO 



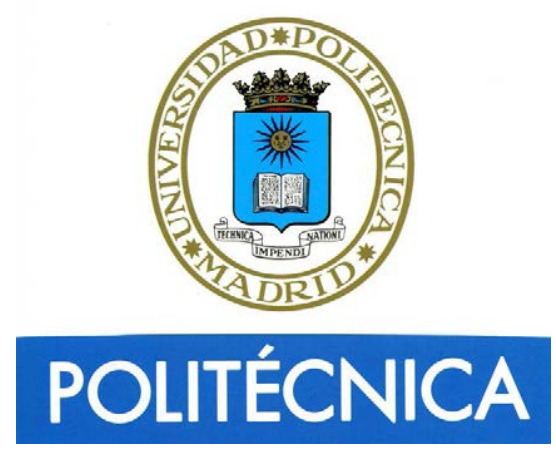

Tribunal nombrado por el Sr. Rector Magfco. de la Universidad Politécnica de Madrid, el día de $20 . . . . . .$.

Presidente:

Vocal:

Vocal:

Vocal:

Secretario:

Suplente:

Suplente:

Realizado el acto de defensa y lectura de la Tesis el día ...... de de 20 en la E.T.S. I. / Facultad

Calificación

EL PRESIDENTE

LOS VOCALES 

En las siguientes líneas me gustaría dejar por escrito mi agradecimiento a todos aquellas personas que, de un modo $u$ otro aparecen en mi pensamiento al sentarme en este momento y reflexionar en el tiempo transcurrido desde el 5 de Julio de 2011 y sin las cuales no habría sido posible conseguirlo.

En el Instituto Eduardo Torroja, mención especial a Maria Grande, por su paciencia y ayuda, a Eva Jimenez, Francisco Rozas y Nicklas Bengtsson sin cuya colaboración habría sido todo más difícil.

A Angel Castillo Talavera y Rosa Corral de la Torre, por su ayuda a la hora de realizar las muestras.

Al personal de la caracola, por su ayuda y colaboración a la hora de realizar las muestras, de los cuales me gustaría hacer especial mención de Javier Jacomé.

A mis compañeros de FYM, por su comprensión y paciencia, Pablo Peña, Juan Chamorro, Rafael Jurado y Jose Antonio Hurtado.

A mis colegas, Jorge Dos Santos y Jose Ferre, por su colaboración, apoyo y amistad.

Al catedrático Alfonso del Águila, por su apoyo, afecto y amistad desde el principio y de quien tanto he aprendido durante el tiempo que he tenido la oportunidad de compartir.

En la ETSA de Madrid, a los profesores del departamento de construcción con los que he coincidido en el MUCTA 2012-2013, por la oportunidad y el trato que me dieron. A Eva Delgado por su paciencia. Mención especial me gustaría hacer de Julia Ayuso, gracias por tu ayuda y ánimos, muchas imágenes de este trabajo son presentables gracias a ella, y a su paciencia con el químico.

A Joaquin Campos Acosta, director del Instituto de Óptica "Daza de Valdés" IO-CSIC por su disposición, ayuda, comentarios y correcciones de los textos referidos a los ensayos de reflectancia que hice en su unidad. A Jose Luis Bris por su colaboración durante los ensayos.

A Alvaro Suarez por su esfuerzo, interés y buenos consejos, en la maquetación de este trabajo.

A Ignacio y a Pilar, por sus clases durante aquellos veranos que quedan ya tan lejos, por su paciencia y cariño. A Enrique, Ana, Alba, Sara y Oscar por la paciencia que han tenido y el interés que me han demostrado.

A mis abuelos, Rafael y Maruja, por el interés que siempre demostraron por mi educación, por su cariño y sus palabras de apoyo, mientras les fue posible, aunque no entiendan porque lo hago y para que servirá.

A mis padres, por su esfuerzo para darme una educación.

A mi hermano Jorge, por su cariño, ayuda, paciencia, por tu interés, por tus palabras de apoyo y aliento, en este proyecto que me propuse. Gracias Jorge. 
A Eva, sin tu ayuda, sin tus ánimos no lo habría conseguido, has creído en mí, en que podria conseguirlo hasta que lograste que yo también lo hiciese, por el tiempo que has sacrificado. Gracias por estar. Coincidir.

A mis directores de tesis, sin cuya tutela, ayuda, aliento y comentarios nada habría terminado.

Al catedrático Alfonso García Santos, mi más sincero agradecimiento por aceptar esta propuesta, por tu interés, consejo, paciencia, sentido común, claridad de ideas e inteligencia, por ayudarme a distinguir lo esencial de lo importante.

Por último y más importante, a Marta Castellote, por aquella conversación, por este reto. Si con alguien tengo que mostrar agradecimiento es con ella. Agradecido a la persona más honesta, integra, comprometida con su trabajo, trabajadora, inteligente, equilibrada, brillante investigadora. Gracias, por tu apoyo, amistad y comprensión durante todo este tiempo.

A mis hijos, Jorge y Elena, por vuestros besos y abrazos, por vuestro cariño puro y sincero. Desearía que alguna vez me perdonéis por el tiempo que os he robado, por la atención que no os he dado.

"If I have seen further it is by standing on the shoulders of giants"

Sir Isaac Newton 
Dedicado a Eva. Dedicado a mis hijos, de vuestro padre que os quiere.

Vuestro cariño me hace crecer.

Dime, ¿cómo se hacen las cosas para que salgan bien?

"La vida no es fácil, para ninguno de nosotros.

Pero... iqué importa! Hay que perseverar y, sobre todo, tener confianza en

uno mismo"

Marie Curie 
INFLUENCIA DEL COLOR Y ELACABADO SUPERFICIALENLASPROPIEDADES DE UN MORTERO FOTOCATALITICO COMO SOLUCIÓN DE ENVOLVENTE 
4.1.1 ¿Qué es la fotocatalisis?

4.2 Semiconductores

4.4 Reacciones heterogéneas

4.4.1.1 Mecanismos de degradación de los principales contaminantes

\section{ESTADO DEL ARTE}

5.1.1 Fotocatalisis

5.1.2 Mediciones a escala real, descontaminación 78

5.1.3 Mediciones a escala real, autolimpieza 85

5.1.4 Acción bactericida

5.2 Antecedentes sectoriales.

5.2.1 Materiales de construcción 91

5.2.1.1 Cemento 92

5.2.1.2 Tipos de cementos y composición 93

5.3 Contaminacion atmosférica 97

5.3.1 Consecuencias a nivel mundial 97

$\begin{array}{ll}\text { 5.3.2 Contaminantes atmosféricos } & 108\end{array}$

5.3.2.1 Principales contaminantes atmosfericos 114

5.3.2.1.1 Partículas en suspensión: $\mathrm{PM}_{10}$ y $P M_{2,5}$

5.3.2.1.2 Dióxido de Nitrógeno: $\mathrm{NO}_{2}$ 
5.3.2.1.3 Ozono Troposférico: $\mathrm{O}_{3}$

5.3.2.1.4 Dióxido de Azufre: $\mathrm{SO}_{2}$

5.3.2.1.5 Compuestos Orgánicos Volátiles: COV 119

5.3.2.1.6 Benzopireno: $\mathrm{C}_{20} \mathrm{H}_{12}$

5.3.2.1.7 Monoxido de carbono: $\mathrm{CO} \quad 120$

5.3.2.1.8 Benceno: $\mathrm{C}_{6} \mathrm{H}_{6} \quad 120$

$\begin{array}{ll}\text { 5.3.2.1.9 Aeroalergenos } & 120\end{array}$

$\begin{array}{ll}\text { 5.3.3 Calidad del aire en Europa . } & 121\end{array}$

5.4 Arquitectura. 125

5.4.1 Contaminación Atmosférica, cómo afecta a los materiales. 125

5.4.2 Efecto Isla de calor, Influencia de los materiales. 131

6. CONCLUSIONES AL ESTADO DEL ARTE

6.1 Conclusiones al estado del arte 145

7. METODOLOGIA EMPLEADA 149

7.1 Metodología empleada 151

8. PROCEDIMIENTO EXPERIMENTAL 155

8.1. Variables Experimentales. 157

8.2 Técnicas de ensayo utilizadas. 160

8.2.1 Fluorescencia Rayos X "FRX" 160

8.2.2 Difracción Rayos X “DRX” 160

8.2.3 Medición de la capacidad fotocatalítica de autolimpieza 162

8.2.4 Medición de la capacidad fotocatalítica de eliminación de $\mathrm{NO}_{x} \quad 165$

8.2.5 Espectrometría de fluorescencia con ácido terftálico 168

8.2.6 Espectroscopia de reflectancia difusa UV-Visible 169

8.2.7 Espoctroscopia de reflectancia difusa UV-VIS-NIR 170

8.2.8 Potencial zeta ( ()$\quad 172$

8.2.9 Determinación de las propiedades del mortero en estado fresco y endurecido 174

8.2.9.1 Determinación del módulo de elasticidad dinámico de las muestras 174

8.2.9.2 Amasado de los morteros 175

8.2.9.3 Determinación de la consistencia de los morteros 175

8.2.9.4 Determinación de la densidad en estado fresco 176

8.2.9.5 Determinación del aire ocluído 176

8.2.9.6 Determinación de la resistencia a flexión y compresión del mortero 176

8.2.9.6.1 Ensayo de flexotracción 177

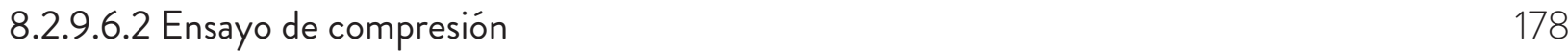


8.3 Materiales.

8.3.1 Mortero fotocatalítico 179

8.3.2 Mortero no fotocatalítico 179

8.3.3 Cemento fotocatalítico 179

8.3.4 Cemento no fotocatalítico 179

$\begin{array}{ll}\text { 8.3.5 Agua } & 179\end{array}$

8.3.6 Árido 180

8.3.7 Pigmentos 180

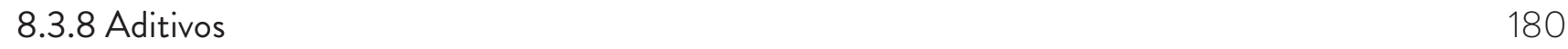

8.4 Plan de Ensayos. 181

8.4.1 Confección de la serie de morteros de revestimiento. 181

8.4.1.1 Determinación del agua de amasado para cada mortero. 181

8.4.1.2 Determinación de las propiedades en estado fresco de cada uno 183

8.4.1.2.1 Amasado de los morteros 183

8.4.1.2.2 Medida de la consistencia 185

8.4.1.2.3 Medida de la densidad en estado fresco. 186

8.4.1.2.4 Medida del aire ocluido 187

8.4.1.3 Fabricación de las probetas de mortero 188

8.4.1.4 Determinación de la resistencia a flexotracción y compresión del mortero. 195

8.4.1.4.1 Ensayo de resistencia a flexotracción. 195

8.4.1.4.2 Ensayo de resistencia a compresión 196

8.4.1.5 Determinación del módulo de la elasticidad dinámico 199

8.4.1.6 Determinación del potencial zeta $(\zeta)$ de los pigmentos 200

8.4.1.7 Determinación por Difraccion de Rayos X de la composición de los pigmentos 202

8.4.1.8 Determinación por Fluorescencia de Rayos X de la composición de los pigmentos y morteros.

8.4.1.9 Medición de la capacidad fotocatalítica de autolimpieza 205

8.4.1.10 Medición de la capacidad fotocatalítica de eliminación de $\mathrm{NO}_{x} \quad 210$

8.4.1.11 Determinación de la reflectancia a la radiación UV-Vis-NIR 217

8.4.1.12 Determinación de la energía de fotoabsorción (Eg) 221

8.4.1.13 Determinación por espectrometría de fluorescencia con ácido terftálico. 222

8.4.2 Confección de la serie de mortero con aditivos $\quad 224$

8.4.2.1 Medición de la capacidad fotocatalítica de autolimpieza. 228

8.4.2.2 Medición de la capacidad fotocatalítica de eliminación de $\mathrm{NO}_{x}$. 


\section{ANALISIS DE RESULTADOS Y DISCUSIÓN}

9.1 Análisis de los resultados y discusión de los ensayos a los morteros.

9.1.1 Propiedades físicas de la serie de morteros.

9.1.2 Difracción de rayos X "DRX".

9.1.3 Fluorescencia de rayos $X$ "FRX".

9.1.4 Potencial zeta ( () .

9.1.5 Espectroscopia de reflectancia difusa UV-VIS-NIR.

9.1.6 Reflectancia difusa UV-VIS. Energía de fotoabsorción (Eg).

9.1.7 Medición de la capacidad fotocatalítica de eliminación de $\mathrm{NO}_{\mathrm{x}}$

9.1.8. Medición de la capacidad fotocatalítica de autolimpieza.

9.1.9. Espectrometría de fluorescencia con ácido terftálico.

9.2 Análisis de los resultados y discusión de los ensayos a los aditivos.

9.2.1 Medición de la capacidad fotocatalítica de autolimpieza.

9.2.2 Medición de la capacidad fotocatalítica de eliminación de $\mathrm{NO}_{x}$.

Tabla de Ensayos

Tabla de Figuras

Tabla de Tablas 
I NDICE 
INFLUENCIA DEL COLOR Y ELACABADO SUPERFICIALENLASPROPIEDADES DE UN MORTERO FOTOCATALITICO COMO SOLUCIÓN DE ENVOLVENTE 
CAPÍTULO1:

RESUMEN 
INFLUENCIA DEL COLOR Y ELACABADO SUPERFICIALEN LAS PROPIEDADES DE UN MORTERO FOTOCATALITICO COMO SOLUCIÓN DE ENVOLVENTE 


\subsection{RESUMEN}

La incorporación de fotocatalizadores, principalmente nano- $\mathrm{TiO}_{2}$ en la arquitectura ha surgido como una tecnología prometedora en el desarrollo de nuevos materiales, materiales con nuevas funcionalidades como la descontaminación del aire, la autolimpieza y la capacidad bactericida con el uso de luz UV-Vis. Existe un creciente interés en el uso de materiales base de cemento (por ejemplo, lechadas, morteros y hormigones), este sustrato ofrece resistencia, durabilidad y una estructura porosa en su estado endurecido. En los últimos años, la atención se ha centrado principalmente en estudiar la capacidad de autolimpieza y el potencial de descontaminación del aire de los materiales base cementos fotocatalíticos, especialmente en la degradación de NOx. En consecuencia, se ha generado una gran cantidad de investigaciones que se han centrado fundamentalmente en la eficiencia y aquello factores que la afectan de un modo global.

En las aplicaciones prácticas de estos materiales, hay una amplia gama de diferentes aditivos y adiciones que pueden utilizarse e interactuar con el fotocatalizador, lo que afectaría a sus capacidades. De hecho, trabajos previos sugieren que el uso de escorias y cenizas volantes como adiciones, pueden tener un efecto negativo sobre la actividad fotocatalítica frente a un cemento portland sin adiciones. En el caso del uso de pigmentos, se han podido encontrar resultados contradictorios. Algunos trabajos experimentales sugieren que la presencia de óxidos de hierro como pigmentos implica una interacción negativa entre el pigmento y $\mathrm{TiO}_{2}$ por varios efectos, incluyendo una adsorción reducida de contaminantes sobre la superficie del catalizador, la introducción de sitios de recombinación para las especies reactivas fotogeneradas o la modificación de absorción o reflexión de la luz solar en algunas longitudes de onda. Otros investigaciones sin embargo han encontrado que la presencia de metales de transición o que las heteroestructuras de algunos óxidos mixtos, por ejemplo los óxidos de hierro, tienen un efecto positivo sobre la actividad fotocatalítica a través de un mecanismo de dopaje, que se utiliza habitualmente para desplazar los espectros de absorción a regiones de energía más baja. Además del efecto de desplazar el intervalo de absorción de radiación del $\mathrm{TiO}_{2}$, puede conllevar beneficios adicionales que han sido demostrados, como la mejora de la captura de electrones para inhibir la recombinación de los pares electron-hueco. Sin embargo, se acepta ampliamente que el efecto de la presencia metales de transición o de óxidos mixtos en la fotoreactividad parece ser función del tipo, proporción en la mezcla, grado de distribución en la matriz y de los niveles de energía, entre otros.

A la vista de los resultados previos, esta investigación se ha centrado en la evaluación de morteros coloreados fotocatalíticos en presencia de pigmentos a base de oxidos de hierro y del acabado superficial. El efecto beneficioso o perjudicial de la interacción bajo luz UV-Vis, entre fotocatalizador $\left(\mathrm{TiO}_{2}\right)$ y los pigmentos en la matriz de morteros para envolventes de fachada. 
I NFLUENCIA DEL COLOR Y EL ACABADO SUPERFICIALEN LASPROPIEDADES DE UN MORTERO FOTOCATALITIICO COMO SOLUCIÓN DE ENVOLVENTE

Parece entonces lógico, el estudio de como las distintas tipologías de aditivos que se utilizan habitualmente en formulaciones de morteros de revestimiento, utilizados como acabado de la envolvente, afectan a la actividad fotocatalítica. Sin embargo no se ha encontrado ningún trabajo de investigación que estudie como afectan y en qué grado a las propiedades fotocatalíticas en un mortero base cemento. 


\section{2 . ABSTRACT}

The incorporation of photocatalysts (mainly nano- $\mathrm{TiO}_{2}$ ) in construction materials has emerged as a promising technology to develop products with special properties as air decontamination, self-cleaning and self-sterilizing ability under UV-Vis light irradiation. Among these materials, there is a growing interest in using cement-based materials (e.g. cement paste or mortar and concrete) as support mainly due to the high area that they can provide their strong binding properties and their porous structure in hardened state. In the past few years, the attention has been mainly focused on studying the self-cleaning capability and air purification potential of photocatalytic cementitious materials, especially on degradation of $\mathrm{NO}_{x}$. Consequently, a large amount of literature generated about photocatalytic cementitious materials has predominantly dealt with efficiency issues and the factors can affect their overall value.

In practical applications, a wide range of different admixtures and matrix constituents can be used, that can interact with the incorporated photocatalyst, which may affect to the photocatalytic activity. In fact, a previous work suggests that the use of slag and fly ash as additions can have a negative effect on the photocatalytic activity when compared with $\mathrm{TiO}_{2}$-ordinary Portland cement. In the case of pigment additions, contradictory results can be found in literature. Some experimental works suggest that the presence of iron oxides as pigments imply a negative interaction between pigment and $\mathrm{TiO}_{2}$ by several effects, including a reduced adsorption of pollutants on the catalyst surface, the introduction of recombination sites for the photogenerated reactive species, or the modification of absorbing and reflecting certain wavelength ranges of solar light. Nevertheless, others have found that the presence of transition metals or on mixed oxides heteroestructures (e.g. iron oxides) have a positive effect on photocatalytic activity by the mechanism of doping, which is commonly used to shift the absorption spectra to a lower energy region. Beside the effect of extending the light absorption range of $\mathrm{TiO}_{2}$, additional benefits, such as improving the trapping of electrons to inhibit electron-hole pair recombination have been demonstrated. However, it was widely accepted that the effect of the presence of transition metal or mixed oxides structures on photoreactivity appears to be a complex function of type, mixture proportion, distribution in the matrix and the energy levels, among others.

In the light of the previous reported results, this investigation was focussed on the evaluation of photocatalytic colored mortars in presence of iron-based pigments and the effect of texture surface. The beneficial or detrimental effect of the interaction between $\mathrm{TiO}_{2}$ photocatalyst and pigments on mortar heterostructures under UV-Vis light was discussed. 
I NFLUENCIA DEL COLOR Y ELACABADOSUPERFICIALEN LAS PROPIEDADES DE UN MORTERO FOTOCATALITICO COMOSOLUCION DE ENVOLVENTE

With respect to the study of how the additives of the different typologies that are usually used in the fomulations of coating mortars used as finish of the envelope, affect the photocatalytic activity of the photocatalytic cements, it would seem logical to think that they have been studied. However, any research work has been found. 
CAPIT ULO 1: RES U MEN 
INFLUENCIA DEL COLOR Y ELACABADO SUPERFICIALENLASPROPIEDADES DE UN MORTERO FOTOCATALITICO COMO SOLUCIÓN DE ENVOLVENTE 
En este capítulo se describe el marco general que ha servido para el desarrollo de esta tesis. Para ello se hace una exposición de la motivación general que ha llevado a afrontar esta tesis, describiendo la situación presente. A continuación se platea la hipótesis de partida, fijando los objetivos que justificarán la hipótesis y la metodología utilizada para conseguirlos. 
INFLUENCIA DEL COLOR Y ELACABADO SUPERFICIALEN LAS PROPIEDADES DE UN MORTERO FOTOCATALITICO COMO SOLUCIÓN DE ENVOLVENTE 
${ }^{1}$ Cassar, L. (2004).

Photocatalysis of cementitious materials: Clean buildings and clean air. MRS Bulletin, 29(05), 328-331.

${ }^{2}$ Synnefa, A., Santamouris, M., \& Livada, I. (2006) A study of the thermal performance of reflective coatings for the urban environment. Solar Energy, 80(8), 968-981.

${ }^{3}$ Santamouris, M., Papanikolaou, N., Livada, I., Koronakis, I., Georgakis, C., Argiriou, A., \& Assimakopoulos, D. N. (2001). On the impact of urban climate on the energy consumption of buildings. Solar energy, 70(3), 201-216.

\subsection{JUSTIFICACIÓN}

La luz desempeña un papel primordial en los procesos biológicos y en el equilibrio medioambiental. Hasta principios de 1900, la producción de energía y materiales derivaban directa e indirectamente de la luz solar. En el siglo pasado, sin embargo, el auge demográfico, la creación de nuevos materiales y el creciente uso del petróleo y la energía nuclear para la producción energética han llevado a una brecha cada vez más grande entre la naturaleza y la sociedad. Hoy, aprovechar la energía solar tienen un papel indiscutible en nuestra sociedad, la cantidad de energía que llega a la superficie de la tierra es de aproximadamente $5 \cdot 10^{24} \mathrm{~J} / a$ ño, más de 100 veces el consumo mundial anual de energía 1 .

Hoy, en día no nos damos cuenta del papel que la energía solar desempeña y cómo influye en el diseño de las estructuras proyectadas por arquitectos e ingenieros, de cómo la infraestructura está construida para oponerse a los efectos de la luz solar.

Este abundante recurso energético de libre acceso, y la necesidad de un medio ambiente más limpio, nos debe empujar a pensar en combinar luz solar y materiales de construcción. La durabilidad y la enorme superficie de los materiales a base de cemento utilizados en nuestras ciudades ofrecen un recurso útil para aprovechar productivamente la energía de la luz y aplicarla a las necesidades de la sociedad.

Debido a las características físico-químicas del cemento, estos materiales presentan un proceso de envejecimiento y deterioro característico, especialmente aquellos que se encuentran expuestos directamente a la intemperie debido a la exposición continua y directa a contaminantes atmosféricos (orgánicos, inorgánicos y material particulado), como a diferentes tipos de microorganismos (tales como algas y hongos), produciéndose un deterioro de las propiedades siendo la primera y más evidente, la calidad estética².

Esta capacidad para mantener el color de la fachada en el caso de un revestimiento blanco podría suponer mantener durante toda su vida útil una capacidad en la reflectancia de la radiación solar. Se ha demostrado que esta capacidad de un recubrimiento reflectante puede reducir la temperatura superficial en una baldosa de hormigón blanco en condiciones de verano en $4^{\circ} \mathrm{C}$ y $2^{\circ} \mathrm{C}$ durante la noche, contribuyendo así a la mitigación del efecto isla de calor, a la reducción del consumo de los edificios en electricidad para el acondicionamiento interior y contaminación exterior ${ }^{3}$.

La actividad fotocatalítica producida por los materiales a base de cemento que incorporan $\mathrm{TiO}_{2}$, ha permitido dotar de nuevas funcionalidades a estos materiales, propiedades de autolimpieza y descontaminación, se ha comprobado que consiguen degradar un determinado espectro tanto de compuestos orgánicos $(\mathrm{COVs})$ como inorgánicos $\left(\mathrm{NO}_{x}, \mathrm{PM}, \mathrm{O}_{3}\right.$, 
$\left.\mathrm{NH}_{3}, \mathrm{SO}_{2}, \ldots.\right)$, los cuales son al mismo tiempo agresivos tanto para las propiedades de algunos materiales, como para el medio ambiente. Por este motivo, el dióxido de titanio podría ser utilizado para incrementar la vida útil de los materiales a base de cemento, al tiempo que es capaz de disminuir substancialmente la concentración de algunos contaminantes del aire; especialmente, en lugares semi-cerrados como son por su configuración calles y avenidas de cualquier ciudad, túneles....

Los resultados han medido que, el potencial en la reducción de la contaminación urbana de origen antropogénico al utilizar este tipo de cemento en diferentes soluciones constructivas, podría reducir un 50\% la contaminación de origen antropogénico con el $15 \%$ de las superficies de una ciudad como Milán 4 .

En el año 2013, que fue declarado el "Año del Aire" por la Comisión Europea. Los datos publicados por al EEA indican que, 420.000 personas murieron de forma prematura debido a la contaminación del aire en la UE en $2010^{5}$.

En torno al $90 \%$ de la población urbana de la Unión Europea está expuesta a concentraciones de contaminantes atmosféricos que Organización Mundial de la Salud considera nocivas para la salud. Así lo demuestra el último estudio sobre la calidad del aire en Europa que ha publicado la Agencia Europea de Medio Ambiente.

Se ha evaluado el daño potencial por ozono en materiales de construcción en el Reino Unido entre 170 - 345 millones $E$ /año ${ }^{6}$.

El sector de la Construcción se encuentra, y cada vez más, condicionado a ofrecer una serie de valores que hasta hace relativamente poco estaban en segundo plano o prácticamente desestimadas. Debido entre otras razones a las propias inquietudes de los proyectistas y promotores que desean mejorar la calidad de sus proyectos en términos de mejora de la sostenibilidad de nuestras construcciones, se empieza a valorar y exigir un mayor grado de sostenibilidad.

El término sostenibilidad se asocia, casi de forma inmediata, a una serie de criterios medioambientales y no podemos olvidar la repercusión de todos los factores que caracterizan y aseguran un mayor grado de la sostenibilidad. Por tanto, no solo se deben tener en cuenta factores medioambientales sino también sociales y económicos.

En este sentido y sin profundizar en el tema, se podría llegar a relacionar de forma negativa el cumplimiento de estos criterios con soluciones que se basan en productos derivados del cemento. La fotocatálisis puede aportar una serie de mejoras importantes para elevar el nivel de sostenibilidad de las envolventes en las que se encuentran. Gracias a las propiedades descontaminantes, la mejora en términos de impacto ambiental es evidente. También las propiedades autolimpiantes que poseen influyen en los factores económico y social?.
4 Italcementi SpA. (2009).

TX active. principio attivo fotocatalitico. Italia: Italcementi SpA

${ }^{5}$ EEA. (2013).

EEA air quality in europe-2013 (No. 9). doi:10.2800/92843

${ }^{6}$ Lee D. S.

Holland M. R. and Falla N. (1996)

The potential impact of ozone on materials in the U.K. Atmospheric Environment 30,1053-1065

${ }^{7}$ Laplaza, A., \& Castro, S. H. (2013).

La fotocatálisis en los materiales de construcción base cemento: fundamentos, métodos de medida y ejemplos de aplicación. Cemento Hormigón, (958), 12-22. 


\subsection{HIPÓTESIS}

Es posible demostrar que, los pigmentos, aditivos y el tipo de acabado superficial influyen en las propiedades de autolimpieza, descontaminacion y reflectancia, de un mortero fotocatalitico blanco de acabado para envolvente, en el intervalo ultravioleta, visible e infrarrojo cercano.

Es posible demostrar la dependencia de las propiedades fotocatalíticas, con los pigmentos, el acabado superficial, y el tipo y dosificación de los aditivos. 
INFLUENCIA DEL COLOR Y ELACABADO SUPERFICIALENLASPROPIEDADES DE UN MORTERO FOTOCATALITICO COMO SOLUCIÓN DE ENVOLVENTE 
CAPÍTULO3: OBJETIVOS

En este capitulo se describen los objetivos generales. 
INFLUENCIA DEL COLOR Y ELACABADOSUPERFICIALENLAS PROPIEDADES DE UN MORTERO FOTOCATALITICOCOMOSOLUCIÓNDE ENVOLVENTE 


\subsection{OBJETIVOS}

A continuacion se enumeran los objetivos cuantificables, necesarios para determinar: la influencia del color y acabado superficial en las propiedades ópticas y fotocatalíticas de un mortero de revestimiento fotocatalítico y la influencia de aditivos en las propiedades fotocatalíticas del cemento.

- Determinar los cambios en estado fresco, por la adición de los pigmentos, en el mortero.

- Cuantificar el efecto de la rugosidad superficial en la autolimpieza y la descontaminación de los morteros

- Cuantificar el efecto de los pigmentos en la eficiencia fotocatalítica de un mortero de revestimiento.

- Cuantificar el efecto descontaminante y autolimpiante que el uso de un cemento fotocatalítico aporta a la solución constructiva.

- Medir los cambios en la energía de fotoabsorción ( $E_{g}$-band gap), de los pigmentos en los morteros de acabado y su efecto en relación con la efectividad bajo radiación UV-Vis.

- Cuantificar el efecto de la adición de cada pigmento en la modificación de la doble capa eléctrica.

- Medir los cambios de reflectancia de un mortero con y sin fotocatalizador, para distintos colores de revestimiento en cada uno de los acabados.

- Determinar cómo varia la actividad de un cemento fotocatalítico a través de las propiedades descontaminante y autolimpiante, en función de la variación de la dosificación de aditivo.

- Determinar cómo varia la actividad de un cemento fotocatalítico a través de las propiedades descontaminante y autolimpiante, en función del tipo de aditivo. 
INFLUENCIA DEL COLOR Y ELACABADO SUPERFICIALENLASPROPIEDADES DE UN MORTERO FOTOCATALITICO COMO SOLUCIÓN DE ENVOLVENTE 


\section{CAPÍTULO 4:}

\section{ASPECTOS TEÓRICOS Y FUNDAMENTACIÓN}

En este capítulo se analiza el estado del marco de la investigación dentro del ámbito de la contaminación atmosférica y los materiales fotocatalíticos base cemento lo que nos va a permitir contextualizar el material. 
INFLUENCIA DEL COLOR Y ELACABADOSUPERFICIALENLAS PROPIEDADES DE UN MORTERO FOTOCATALITICO COMO SOLUCIÓN DE ENVOLVENTE 


\subsection{FOTOCATÁLISIS}

\section{INTRODUCCIÓN.}

${ }^{8}$ FIEC. (2013).

Construction in europe: Key figures. activity 2010. Brussels.

${ }^{9}$ Goulding J, Nadim W, Petridis P, Alshawi M

Construction industry offsite production: a virtual reality interactive training environment prototype. Adv Eng Inform 2012;26:103-16.

10 Lechtenböhmer, S. \& Schüring, A. (2011)

The potential for large-scale savings from insulating residential buildings in the EU. Energy Efficiency, 4(2), 257-270.

1 Roadmap, E. E. (2011) $2050-\operatorname{COM}(2011) 885 / 2$. Brussels:

European Commission.

12 Europea, C. (2011).

Progress Report on Europe 2020 Strategy.

${ }^{13}$ Pacheco-Torgal, F. (2014)

Eco-efficient construction and building materials research under the $\mathrm{EU}$ Framework Programme Horizon 2020. Construction and building materials, 51, 151-162.

16 Feynman, R. P. (1960) There's plenty of room at the bottom. Engineering and science, 23(5), 22-36.

15 Taniguchi, N. (1974). Japan society of precision engineering. In On the Basic Concept of Nanotechnology: Proc. Intl. Conf. Prod. Eng. Tokyo.-1974.-Pt (Vol. 2, pp. 122-126)

16 Pacheco-Torgal, F., \& Jalali, S. (2011) Nanotechnology: advantages and drawbacks in the field of construction and building materials. Construction and Building Materials, 25(2), 582-590.

17 Fujishima, A., Zhang, X., \& Tryk, D. A. (2008). TiO2 photocatalysis and related surface phenomena. Surface Science Reports, 63(12), 515-582.
La industria de la construcción, se trata de la industria europea más importante, representa el 9,1\% del PIB de la UE-27, el 30,2\% del empleo industrial de la UE-27 y un volumen de negocios anual de 82.300 millones de euros ${ }^{8}$. Lamentablemente es una industria con una gran inercia para implementar cambios y que va por detrás de otras en términos de aprovechar nuevas tecnologías?.

En Europa, los edificios son responsables de más del $40 \%$ del consumo de energía y de las emisiones de gases de efecto invernadero ${ }^{10}$, por lo que aumentar la eficiencia energética de los edificios es crucial para la transformación del marco energético de la UE"11. La eficiencia energética es la forma más rentable de reducir las emisiones, mejorar la competitividad y crear empleo. La COM $815^{12}$ menciona que el objetivo de ahorro de energía de la Unión de ahorrar el 20\% de energía en 2020 podría reducir la factura de las viviendas en hasta 1000 euros por hogar al año, ayudando a mejorar la competitividad industrial de Europa favoreciendo la creación de hasta 2 millones de nuevos empleos para 202013.

El sector de la construcción es generalmente muy conservador, en el que se favorecen materiales y técnicas tradicionales. Hoy en día, estos materiales y tecnologías tradicionales no pueden satisfacer las demandas de los gobiernos y los agentes que intervienen en el proceso edificatorio interesados en la mejora de la seguridad, la sostenibilidad y la eficiencia de edificios e infraestructuras.

\section{ANTECEDENTES}

Ese interés en la llamada "Nanociencia" se materializó con el famoso discurso que el físico Richard Feynmam pronuncio en la reunión de la Sociedad Americana de Física en 1959, titulada "There's plenty of room at the bottom" este discurso es considerado como el comienzo de la era de la nanotecnología ${ }^{14}$. Feynman exploró la posibilidad de manipulación de materiales a escala los átomos y moléculas, imaginando la Enciclopedia Británica escrita en la cabeza de un alfiler.

El término "nanotecnología” no se utilizó hasta 1974, cuando Norio Taniguchi, investigador de la Universidad de Tokio, Japón lo utilizó para referirse a la capacidad de diseñar materiales con precisión a nivel de nanómetros, para describir el proceso de deposición de un semiconductor en capa fina ${ }^{15}$. Desde entonces, el interés en esta disciplina no ha dejado de crecer $^{16}$.

Fujishima et al. ${ }^{17}$, señalaban en el año 2008 , la enorme cantidad de trabajos que se publican en ese momento sobre fotoquímica heterogénea y en particular los que utilizan $\mathrm{TiO}_{2}$. Señalaban que el número de publicaciones 
había aumentado drásticamente en la última década, más de 2400 artículos publicados en revistas científicas en 2008 sobre fotoquímica heterogénea, donde aproximadamente el $80 \%$ correspondieron a materiales basados en $\mathrm{TiO}_{2}$. Esto refleja el interés, el potencial de la investigación de este campo en las nuevas aplicaciones.
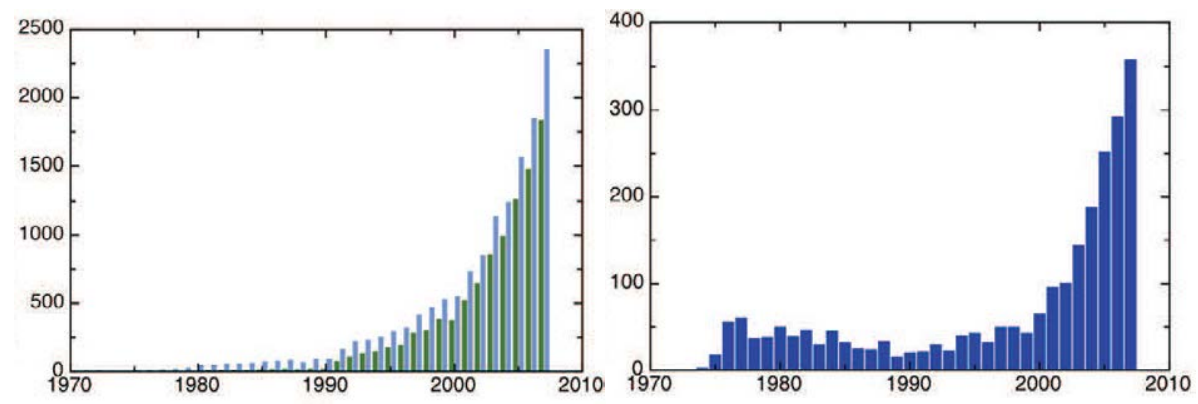

En la actualidad hay comercializados materiales y soluciones con propiedades fotocatalíticas que se han desarrollado ${ }^{18}$. El lanzamiento de estos nuevos materiales requiere pruebas adecuadas para la evaluación de su actividad fotocatalítica y probar la eficacia de estos nuevos materiales.
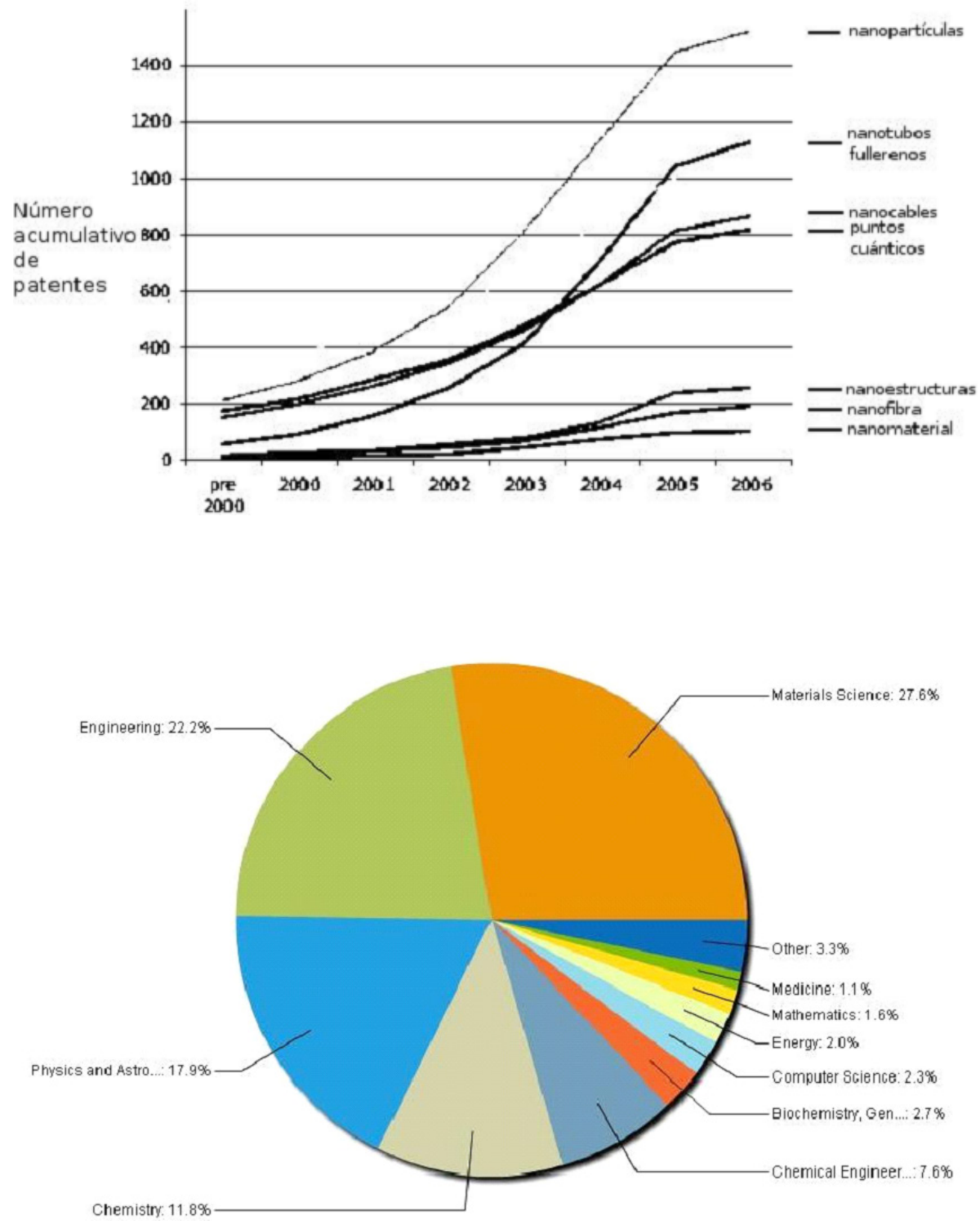

Fig 1. (a) Citas por año del artículo de 1972 publicado en la revista Nature:

"Electrochemical photolysis of water at a semiconductor electrode";

(b) Número de artículos de investigación publicados sobre fotocatálisis por año: resultados de la búsqueda en el período de 1972-2007 en "Web of Science" (Barras azules) por la palabra clave "photocataly"; (Barras verdes) palabras clave "TiO 2 AND photocataly"".

$18 \mathrm{Paz}, \mathrm{Y} .(2010)$

Application of TiO 2 photocatalysis for air treatment: patents' overview. Applied Catalysis B: Environmental, 99(3), 448-460.

Fig 2. crecimiento de las patentes relacionadas con nanomateriales periodo 2000-2006. Fuente: Paz, Y. (2010)

Fig 3. Estadísticas 2003-2013 por disciplina. 68.874 resultados a la búsqueda de la palabra "nanomaterials. Fuente: SCOPUS. 15 de Abril 2013 
${ }^{19}$ Braslavsky, S. E., Braun, A. M., Cassano, A. E., Emeline, A. V. Litter, M. I., Palmisano, L., ... \& Serpone, N. (2011) Glossary of terms used in photocatalysis and radiation catalysis (IUPAC Recommendations 2011). Pure and Applied Chemistry, 83(4), 931-1014.

20 Serpone, N.,

\& Pelizzetti, E. (Eds.). (1989) Photocatalysis: fundamentals and applications.

21 Fujishima, A., Hashimoto, K., \& Watanabe, T. (1999). $\mathrm{TiO} 2$ photocatalysis: fundamentals and applications. BKC Incorporated.

22 Kish, H. (1989)

What is photocatalysis. Photocatalysis: Fundamentals and applications, 1-8.

${ }^{23}$ Kittel, C. (1968) Introduction to Solid State Physics (3d ed.), John Wiley\&Sons. Inc., New York, London, Sydney.

\subsection{1 ¿QUÉ ES LA FOTOCATÁLISIS?}

Las reacciones de fotocatálisis son reacciones catalíticas activadas por la luz. El término fotocatálisis indica la aceleración de una fotorreacción debido a la presencia de un catalizador ${ }^{19}$. Esta definición también toma en cuenta la fotosensibilización, un proceso químico por el cual una molécula se altera fotoquímicamente después de la absorción de radiación por otra molécula denominada fotosensibilizador.

Sin embargo, a diferencia de un proceso fotocatalítico, la fotosensibilización regula la aceleración de una reacción química independientemente de si se produce en una fase homogénea o heterogénea ${ }^{20,21}$.

Excluyendo la fotoaceleración, de la estequiometria de una reacción térmica, ya que de lo contrario cualquier fotorreacción sería catalítica. El catalizador podría acelerar la fotorreacción por la interacción con el sustrato en su estado básico o excitado.

Ostwald definió la catálisis como un fenómeno cinético, un catalizador cambia la velocidad de reacción sin aparecer en los productos y sin cambiar el equilibrio químico. Lo que no implica que no pueda ser inhibido, desactivado o destruido por procesos secundarios, quedando claramente diferenciado de un reactivo ${ }^{22}$.

\section{REACCIÓN CATALÍTICA}

$$
\begin{aligned}
& S+C \rightleftarrows(S \ldots C) \\
& (S \ldots C) \rightarrow P+C
\end{aligned}
$$

Reacción 1

Donde $\mathrm{S}$ es el sustrato, el producto $\mathrm{P}$ y $(\mathrm{S}$... C) un complejo intermedio sustrato-catalizador.

\subsection{SEMICONDUCTORES.}

La conductividad eléctrica es la medida de la capacidad de un material o sustancia para dejar pasar la corriente eléctrica a través de él. Esta es una de las propiedades más importantes de un material, la capacidad para conducir partículas atómicas y subatómicas con carga eléctrica, tales como electrones o iones. La conductividad depende de la estructura atómica y molecular del material. Los metales son buenos conductores porque tienen una estructura donde hay electrones con fuerzas de enlace débiles que permiten su movimiento. La conductividad eléctrica de un material depende, en otros, factores físicos del propio material, y de la temperatura ${ }^{16}$.

Dentro de la mayoría de los sólidos existe un flujo de electrones que provoca una corriente, y a este flujo de electrones se le denomina conducción electrónica. En todos los conductores, semiconductores y en la mayoría de 
los materiales aislados se genera conducción electrónica; la conductividad eléctrica depende en gran medida del número de electrones disponibles para participar en este proceso de conducción. La mayoría de los metales son buenos conductores de electricidad, debido al gran número de electrones libres que pueden ser excitados a un estado de energía vacío y disponible.

Un semiconductor (SC), es un elemento que se puede comportar como un conductor o como un aislante dependiendo de distintos factores como pueden ser, el campo eléctrico o magnético, la presión, una radiación incidente, o la temperatura. El semiconductor puede ser un sólido amorfo, cristalino o un líquido, que tiene un valor de conductividad entre la de un conductor y un aislante. La figura muestra la distribución de la conductividad eléctrica en función del tipo de material ${ }^{24}$.

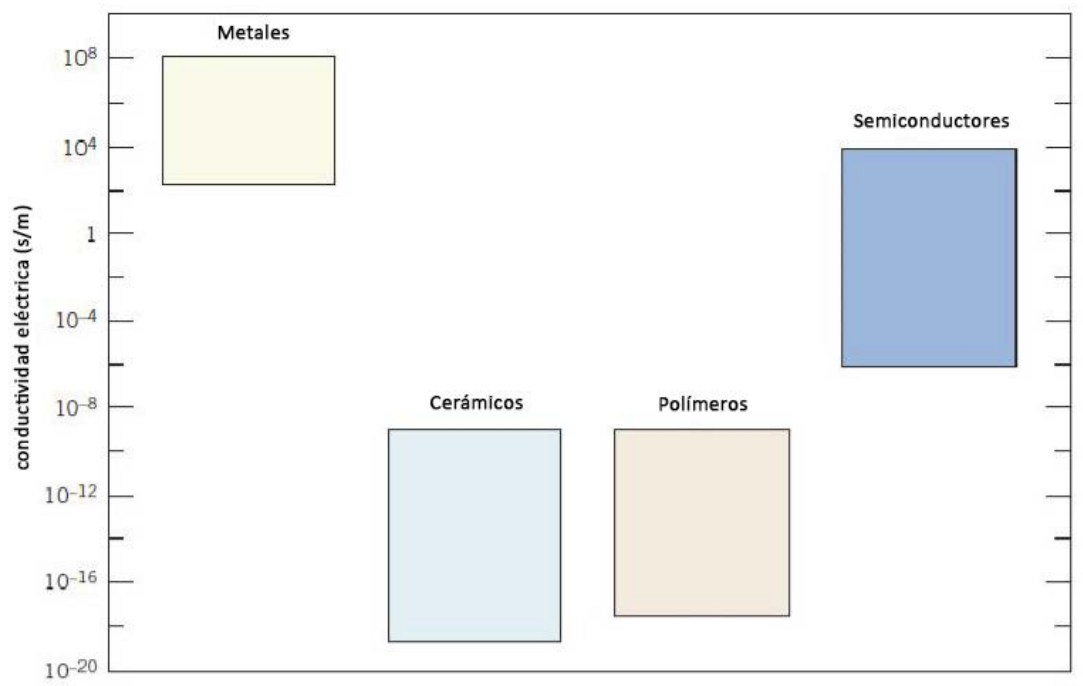

Hay dos tipos diferentes de semiconductores:

1. Semiconductores intrínsecos son semiconductores puros.

2. Semiconductores extrínsecos que son, semiconductores puros a los que se le ha incorporado otras sustancias, adiciones.

Está demostrado que es posible modificar la conductividad de los semiconductores mediante la adición controlada de distintas sustancias, cuando se añade ese elemento, decimos que el semiconductor ha sido "dopado". Los semiconductores son muy sensibles a pequeñas adiciones y las cantidades son muy pequeñas, del orden de $10-6$ a $10-2 \%$.

Dentro de la categoría ii, hay dos tipos diferentes de semiconductores extrínsecos, dependiendo de si la sustancia añadida o dopante, aporta electrones o huecos al semiconductor.

1. Un semiconductor de tipo $n$ es aquel cuya adición le han aportado electrones
${ }^{24}$ Callister, W. D.,

\& Rethwisch, D. G. (2012).

Fundamentals of materials science and engineering: an integrated approach. John Wiley \& Sons.

Fig 4. Diagrama con los rangos de conductividad eléctrica a temperatura ambiente para metales, cerámicas, polímeros y materiales semiconductores 
2. Un semiconductor de tipo p es aquel cuyas adiciones le ha aportado huecos, por ejemplo, la adición de boro (elemento trivalente) en el silicio crea huecos, porque uno de los orbitales de enlace del silicio ahora es capaz de aceptar un electrón del boro ${ }^{16}$.

Algunos de estos materiales semiconductores, con luz de longitudes de onda concreta, pueden excitar electrones fuera de su nivel de energía. Esta propiedad física es el punto de partida de la fotocatálisis.

Si se aplica la teoría de orbitales moleculares para un semiconductor como el $\mathrm{TiO}_{2}$, su orbital molecular $(\mathrm{OM})$ será una combinación lineal de los orbitales atómicos de titanio y oxígeno. Debido a las implicaciones geométricas de la forma de los distintos tipos de orbitales (s, p y d), es importante el tipo de red cristalina que tenga su estructura. En el caso del rutilo, tiene una celda unidad octaédrica, en la que los orbitales $3 d, 4 s$ y $4 p$ del titanio se combinan con los 2 s y $2 p$ del oxígeno.

El modelo de electrones libres explica el comportamiento y las propiedades de los metales pero falla cuando se aplica a materiales semiconductores - aislantes. En la física del estado sólido, la teoría de bandas describe la estructura electrónica de un material como la estructura de las bandas de energía. En todos los materiales conductores, semiconductores o aislantes, hay conducción electrónica. La conductividad depende de cómo actúan esos electrones cuando se aplica un campo eléctr

Un sólido consiste en un gran número de átomos unidos entre sí, en un material cristalino los átomos se disponen con una estructura que se repite en el espacio. En cristales, la longitud de enlace es suficiente para que el campo eléctrico generado por un átomo perturbe los orbitales atómicos de los átomos limítrofes, el número de orbitales de valencia (los niveles de energía más altos) es tan grande y la diferencia de energía entre cada uno de ellos tan pequeña que se considera que esos niveles de energía forman bandas continuas, más que niveles discretos de energía, como ocurre en los átomos aislados. Sin embargo, debido a que algunos intervalos de energía no contienen orbitales, independiente del número de átomos que haya, se crean ciertos saltos energeticos entre las diferentes bandas ${ }^{16}$.

Fig 5. Niveles energéticos (a) átomo

(b) molecula pequeña (c) molecula grande (d) bandas de energía en un solido. (a)

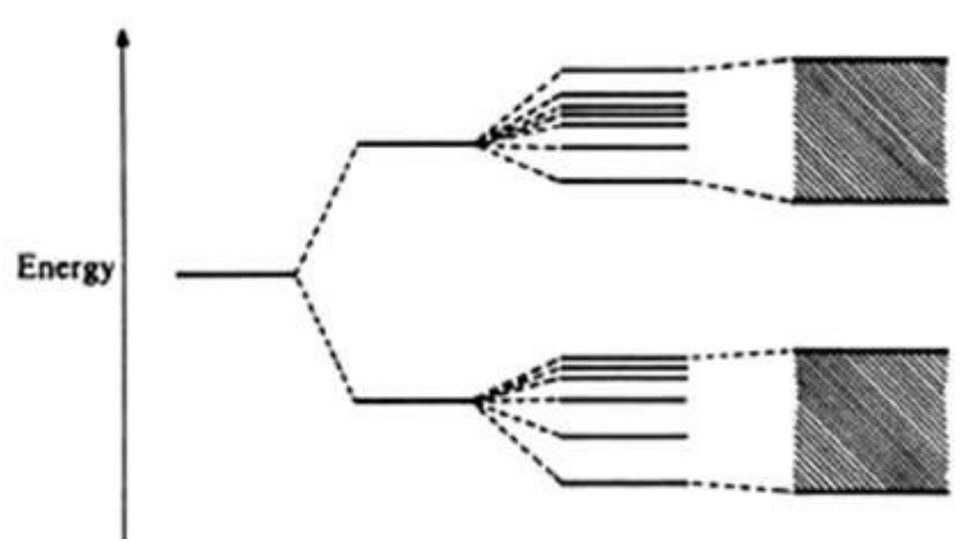


Este intervalo es conocido como "band gap". El band gap es un rango de valores de energía en el que un electrón no puede existir. Ese band gap es característico de cada material y está determinado por las propiedades físicas del material, tales como la longitud del enlace y el número de electrones libres. El orbital más alto ocupado se llama nivel de Fermi y la banda que contiene el nivel de Fermi se denomina banda de valencia (BV).

La banda de valencia (BV) está ocupada por los electrones de valencia, aquellos electrones que se encuentran en la última capa o nivel energético de los átomos. Los electrones de valencia son los que forman los enlaces entre los átomos, pero no participan en la conductividad eléctrica.

La banda de conducción (BC), está ocupada por los electrones libres, es decir, aquellos que se han desligado de sus átomos y pueden moverse fácilmente. Estos electrones son los responsables de conducir la corriente eléctrica. Los electrones que estan en este nivel pueden ser compartidos con el resto de los átomos del sólido. a)

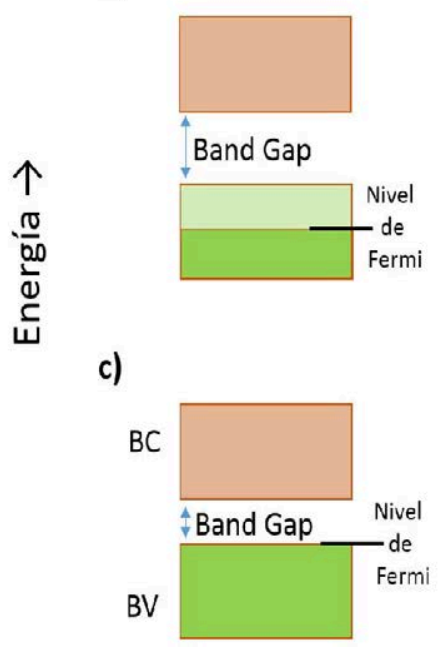

b)

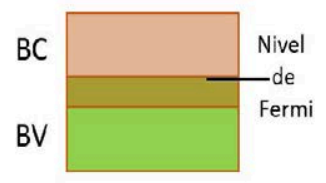

d) $\mathrm{BC}$

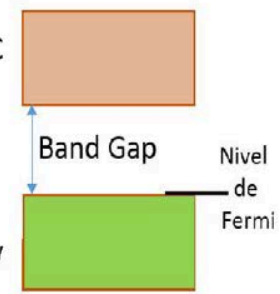

\section{4 . 3 . LUZ. RADIACIÓN ELECTROMAGNÉTICA}

La luz desempeña un papel primordial en los procesos biológicos y en el equilibrio medioambiental. Hasta principios de 1900, la producción de energía y materiales derivaban directa e indirectamente de la luz solar. En el siglo pasado, sin embargo, el auge demográfico, la creación de nuevos materiales y el creciente uso del petróleo y la energía nuclear para la producción energética han llevado a una brecha cada vez más grande entre naturaleza y sociedad. Hoy, aprovechar la energía solar tienen un papel indiscutible en nuestra sociedad. La cantidad de energía que llega a la superficie de la tierra es de aproximadamente $5 \times 10^{24} \mathrm{~J}$ /año, más de 100 veces el consumo mundial anual de energía'.

Cuando hablamos de luz, entendemos la luz visible que se define como la radiación que el ojo humano es capaz de detectar y se ajusta normalmente a longitudes de onda $(\lambda)$ entre $380-760 \mathrm{~nm}$. La radiación electromagnética
Fig 6. Distribución de las bandas de conducción y de valencia en distintos materiales. a) sólido conductor con el nivel de fermi en una banda semillena. b) sólido conductor con la BC y BV solapadas. c) sólido semiconductor d) sólido aislante ${ }^{25}$.

25 Sugráñez Pérez, R. (2016). Nuevos materiales de construcción con propiedades auto-limpiantes y auto-descontaminantes. 
Fig 7. Espectro electromagnético visible por el ojo humano.

Tabla 1. Clasificación del tipo de radiación relativa a las longitudes de onda

Fig 8. ASTM G173-03 Espectro Global de Irradiación total en la superficie inclinada $37^{\circ}$ respecto al sol. existe en una amplia gama de longitudes de onda usadas para distintas finalidades como se definen en la Tabla.

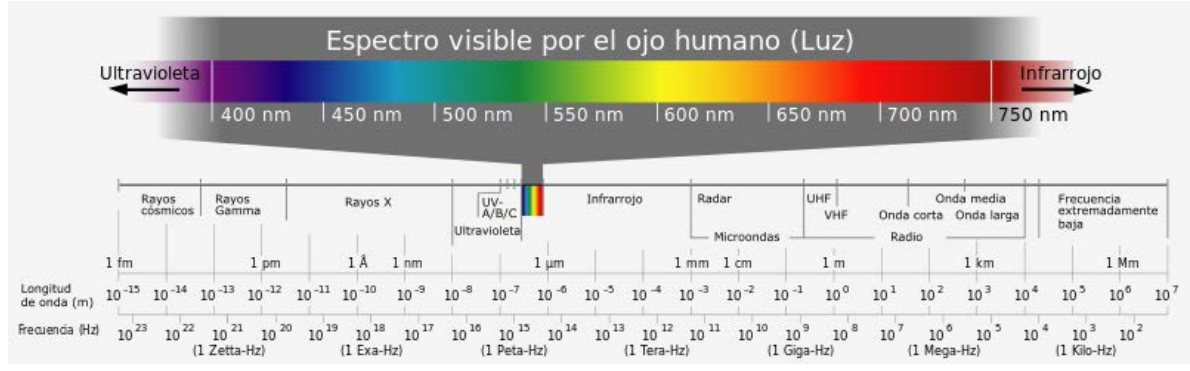

\begin{tabular}{|c|c|c|c|c|c|c|}
\hline \multicolumn{8}{|c|}{ Longitud de Onda (m) } \\
\hline Radio & Microonda & Infrarrojo & Visible & Ultravioleta & Rayos X & Rayos Y \\
\hline$>0,1$ & $0,1-0,0001$ & $0,0001-7 \times 10^{-7}$ & $7 \times 10^{-7}-3,8 \times 10^{-7}$ & $3,8 \times 10^{-7}-1 \times 10^{-7}$ & $1 \times 10^{-9}-1 \times 10^{-11}$ & $<1 \times 10^{-11}$ \\
\hline
\end{tabular}

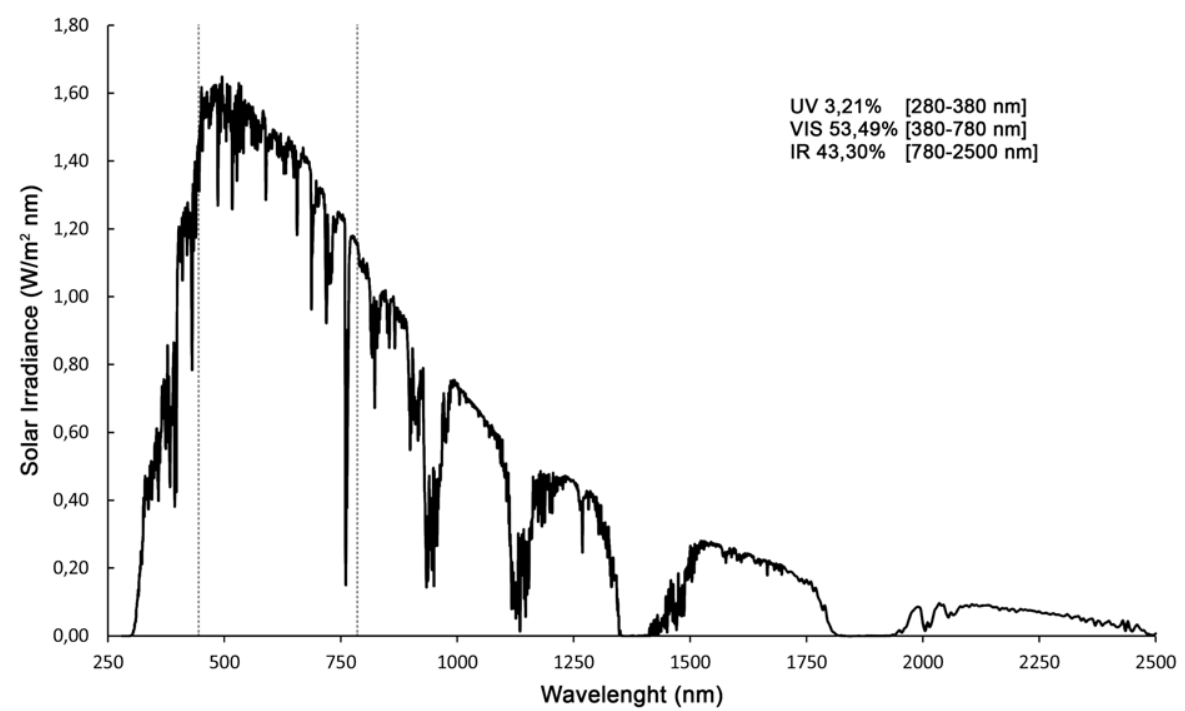

La luz solar es una fuente natural de fotones y su distribución espectral a nivel del mar se ilustra en la figura. La región UV del espectro electromagnético es necesaria para el fotocatalizador $\left(\mathrm{TiO}_{2}\right)$ y corresponde a longitudes de onda por debajo de $380 \mathrm{~nm}$, unicamente una pequeña parte de la energía de radiación total, alrededor de un $3 \%$, se encuentra en esta región, más de la mitad de toda la energía solar que se recibe es como radiación visible.

fotocatalizador $+h v \rightarrow$ fotocatalizador $+e^{-1}+h^{+}$

Reacción 2

La radiación electromagnética puede expresarse mediante una combinación de una función de onda y una partícula en forma de fotón, donde la energía de cada fotón se expresa mediante la ecuación de Planck:

$E=h \cdot v$

Ecuación 1

Donde h es la constante de Planck $\left(6,626 \times 10^{-34} \mathrm{~J} \cdot \mathrm{s}\right)$ y $v$ la frecuencia de la radiación expresada en $\left(\mathrm{s}^{-1}\right)$. 


\section{4 . 4 . REACCIONES HETEROGÉNEAS. FOTOCATÁLISIS.}

Las reacciones heterogéneas son sistemas de dos fases donde los reactivos están en una fase gaseosa o líquida y el catalizador en una fase sólida.. La aparición de la reacción fotocatalítica equivale, además de la activación por fotones, a la adsorción del reactivo sobre la superficie del catalizador. El proceso de reacción fotocatalítica se puede dividir en 5 etapas principales, en línea con la catálisis heterogénea clásica ${ }^{26}$ :

1. Transferencia de los reactivos en fase líquida a la superficie del catalizador

2. Adsorción de al menos uno de los reactivos

3. Reacción en la fase adsorbida

4. Desorción del (de los) producto (s)

5. Eliminación de los productos de la interfaz

Sin embargo, la única diferencia con la catálisis convencional es el modo de activación del catalizador, en el cual la activación térmica se sustituye por la activación producida por los fotones. El modo de activación no está relacionado con las etapas de reacción 1, 2, 4 y 5 , aunque exista fotoadsorción y fotodesorción de algunos reactivos, principalmente oxígeno ${ }^{27}$.

La etapa 3, de la reacción en fase adsorbida, se puede dividir en etapas intermedias:

3.1 Absorción por el sólido de los fotones y no, por los reactivos. No hay reaccion fotoquímica en la fase adsorbida.

3.2 Creación del par electron/hueco.

3.3 Reacción de transferencia de electrones, ionosorción en el caso de $\mathrm{O}_{2}, \mathrm{NO}$...), neutralizacion de la carga, formación de radicales y reacciones sobre la superficie.

Según Chen et al., los materiales catalíticos porosos, la difusión del reactivo sobre la superficie fotocatalítica podría tener cierta influencia en la reacción global ${ }^{28}$.

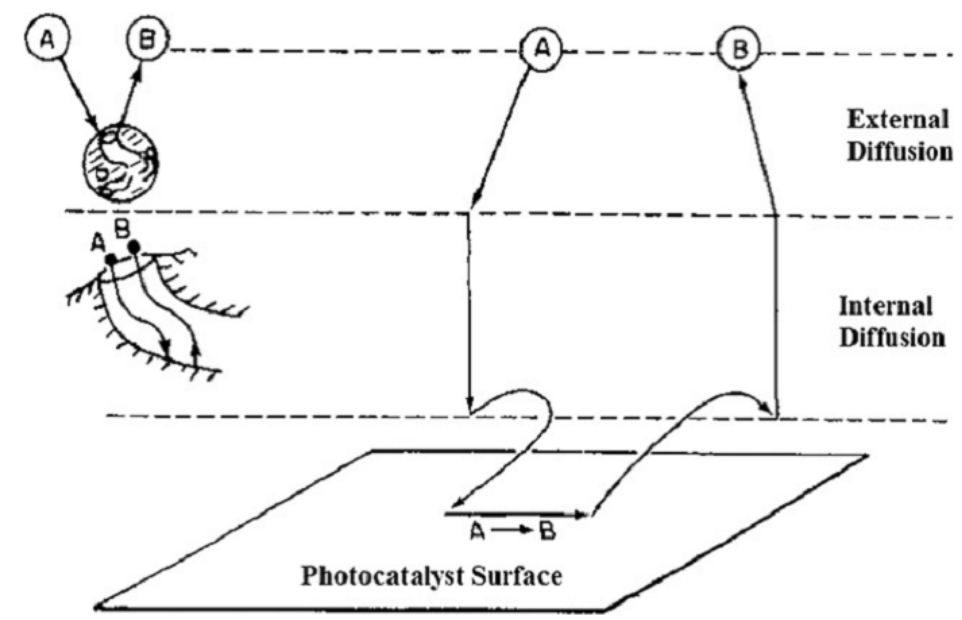

${ }^{26}$ Pichat, P., \& Herrmann, J. M. (1989). Photocatalysis: Fundamentals and Applications. Wiley \& Sons.

${ }^{27}$ Herrmann, J. M. (2005).

Heterogeneous photocatalysis: state of the art and present applications In honor of Pr. RL Burwell Jr.(1912-2003), Former Head of Ipatieff Laboratories, Northwestern University, Evanston (III). Topics in Catalysis, 34(1), 49-65.

28 Hsien, Y. H., Chang, C. F., Chen, Y. H., \& Cheng, S. (2001). Photodegradation of aromatic pollutants in water over $\mathrm{TiO} 2$ supported on molecular sieves. Applied Catalysis B: Environmental, 31(4), 241-249.

Fig 9. Representacion de los pasos en la reacción catalítica heterogénea ${ }^{24}$.

A esta figura se hace

referencia en la página 20.

Fuente. Fogler et a ${ }^{29}$.

${ }^{29}$ Fogler, H. S. (1999)

Elements of chemical reaction engineering. 
30 Guillard, C., Disdier, J., Herrmann, J. M., Lehaut, C., Chopin, T., Malato, S., \& Blanco, J. (1999). Comparison of various titania samples of industrial origin in the solar photocatalytic detoxification of water containing 4-chlorophenol. Catalysis Today, 54(2), 217-228.

31 Zeitner, W. A. \& Tompkins, D. T. (2005). Shedding Light on Photocatalysis. Ashrae Transactions, 111(2).

32 Linsebigler, A. L., Lu, G., \& Yates Jr, J. T. (1995).

Photocatalysis on $\mathrm{TiO} 2$ surfaces: principles, mechanisms, and selected results. Chemical reviews, 95(3), 735-758.

33 Pelizzetti, E., \& Serpone, N. (Eds.). (2012). Homogeneous and heterogeneous photocatalysis (Vol. 174). Springer Science \& Business Media.

Fig 10. Esquema de la promoción de un electrón y mecanismo de reducción-oxidación de las moléculas de oxigeno y agua. Fuente: Elaboracion propia.

Fig 11. Estructura electrónica del TiO Fuente: Sugrañez Pérez, R ${ }^{25}$.
De los procesos de oxidación avanzada, la fotocatálisis heterogénea ha generado un interés como herramienta eficaz para degradar contaminantes orgánicos tanto en medio acuoso como gaseoso ${ }^{30}$. La fotocatálisis heterogénea implica la aceleración de la fotorreacción en presencia de un fotocatalizador semiconductor. Una de las principales aplicaciones es la oxidación fotocatalítica, que produce la mineralización total o parcial de los contaminantes transformándolos en sustancias inocuas ${ }^{31}$. Aunque la degradación comienza con una degradación parcial, el término "degradación fotocatalítica" describe una oxidación fotocatalítica o fotomineralización completa, principalmente en $\mathrm{CO}_{2}, \mathrm{H}_{2} \mathrm{O}, \mathrm{NO}_{3}{ }^{-}, \mathrm{PO}_{4}{ }^{3-}$ e iones haluro.

Un fotocatalizador heterogéneo es un semiconductor que puede ser activado químicamente por radiación. Para explicarlo se reperesentan las estructuras electrónicas de los semiconductores de forma esquemática con un modelo de bandas. Los fundamentos de la fotocatálisis están bien documentados 32,33 .

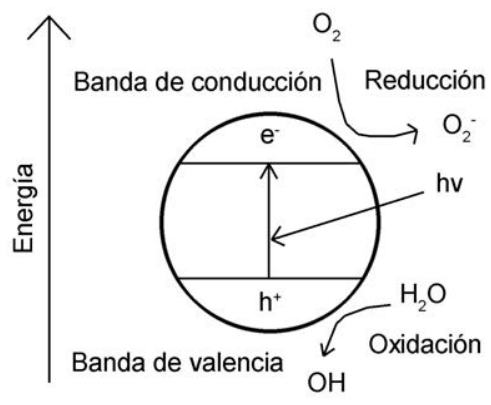

Los semiconductores que son estables, son típicamente óxidos metálicos, generalmente consisten en la parte superior de la banda de valencia situada a $+3 \mathrm{eV}$ o inferior. Desde el punto de vista de la utilización de la energía solar, el desarrollo de fotocatalizadores que pueden desencadenar reacciones re-dox bajo luz visible (> $400 \mathrm{~nm}$ ) es indispensable ${ }^{21}$.

Varios calcogenuros (óxidos y sulfuros) han mostrado propiedades fotocataliticas pero, generalmente, el mejor rendimiento fotocatalítico con el máximo rendimiento cuántico se ha obtenido siempre con el $\mathrm{TiO}_{2}{ }^{27}$. $\mathrm{El} \mathrm{TiO}_{2}$ es un semiconductor de tipo n. En su caso, esta propiedad se debe a pequeñas variaciones en la estequiometría y a un pequeño déficit de átomos de oxígeno.

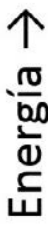

$\mathrm{BC}$

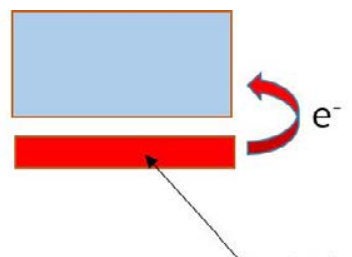

BV

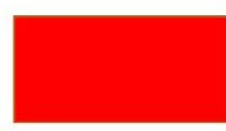

llena de electrones
$\mathrm{TiO}_{2}$ 
Fotosemiconductores como por ejemplo, $\mathrm{ZnO}, \mathrm{WO}_{3}, \mathrm{MoO}_{3}, \mathrm{ZrO}_{2}, \mathrm{SnO}_{2}$, $\mathrm{Fe}_{2} \mathrm{O}_{3}$, etc., han demostrado su eficacia en la degradación de una amplia gama de compuestos orgánicos en compuestos fácilmente biodegradables o mineralizandolos en dióxido de carbono y agua ${ }^{34}$.

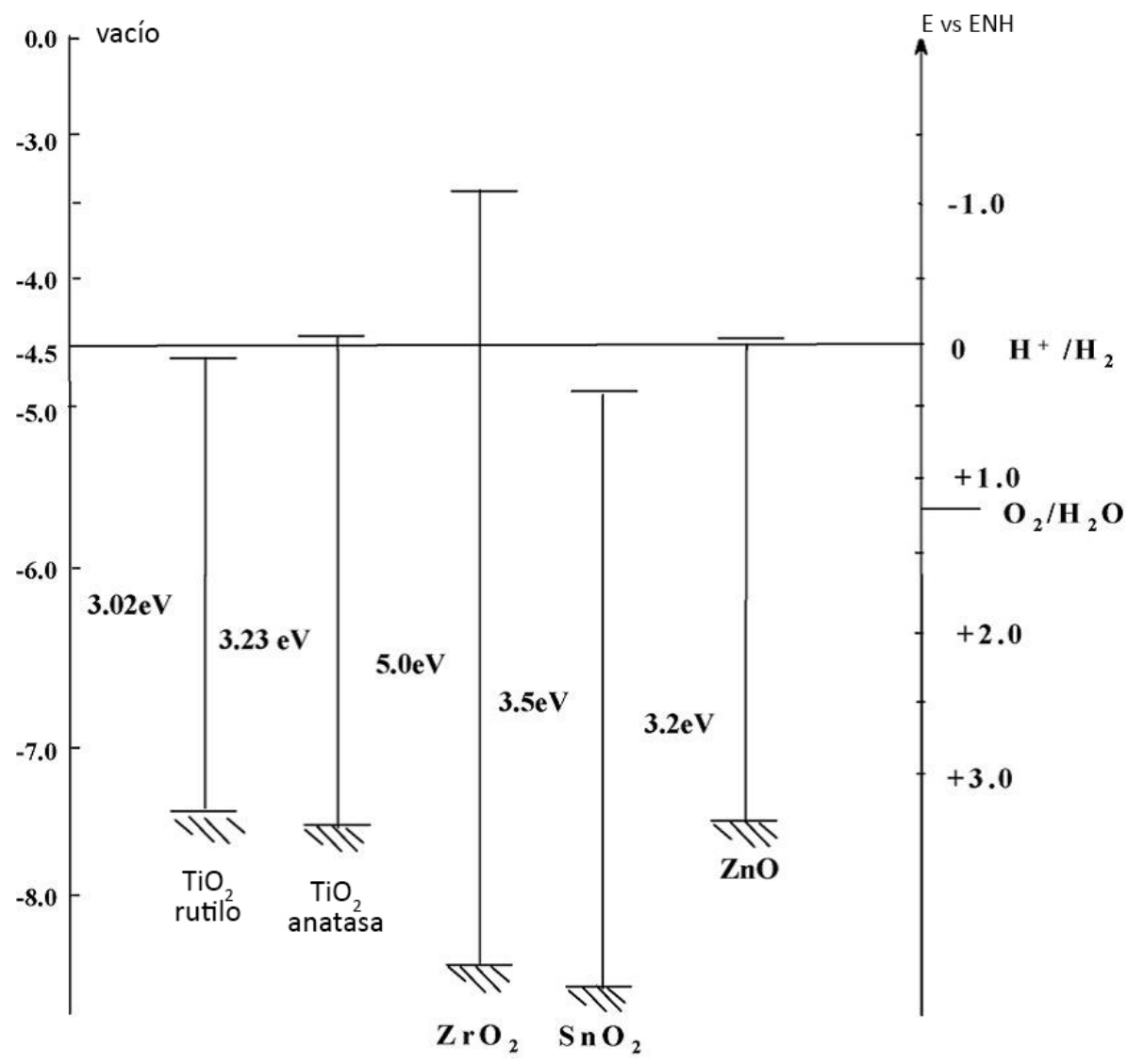

La reacción fotocatalítica se inicia cuando se promueve el electrón fotoexcitado desde la banda de valencia llena del semiconductor (SC), a la banda de conducción vacía por la energía del foton absorbido (hv), que iguala o supera el denominado "band gap" o salto entre las bandas, del semiconductor dejando un hueco en la banda de valencia. De esta en forma tenemos la pareja, electrón / hueco $\left(\mathrm{e}^{-} / \mathrm{h}^{+}\right)$. Las siguientes reacciones en cadena que se producen:

Foto excitación:

Reacción 3

$S C+h v \rightarrow e^{-}+h^{+}$

lonosorción del oxígeno:

Reacción 4

$$
\left(\mathrm{O}_{2}\right)_{a d s}+e^{-} \rightarrow \mathrm{O}_{2}^{-}
$$

lonización del agua:

Reacción 5

$\mathrm{H}_{2} \mathrm{O} \rightarrow \mathrm{OH}^{-}+\mathrm{H}^{+}$

Protonacion de los superoxidos:

$$
\mathrm{O}_{2}^{--}+\mathrm{H}^{+} \rightarrow \mathrm{HOO}^{\circ}
$$

${ }^{34}$ Vinu, R., \& Madras, G. (2012).

Environmental remediation by photocatalysis. Journal of the Indian Institute of Science, 90(2), 189-230.

Fig 12. Situacion de las bandas de conducción (BC) y valencia (BV) en óxidos metálicos semiconductores a pH $\mathrm{O}$. La escala de la izquierda representa las energías internas en el vacío. La escala de la derecha es la escala normal del electrodo del hidrógeno que permite valorar el potencial de reducción y oxidación de cada óxido ${ }^{35}$.

${ }^{35}$ Gaya, U. I., \& Abdullah, A. H. (2008). Heterogeneous photocatalytic degradation of organic contaminants over titanium dioxide: a review of fundamentals, progress and problems. Journal of Photochemistry and Photobiology C:

Photochemistry Reviews, 9(1), 1-12. 
${ }^{36}$ Zhao, J., \& Yang, X. (2003). Photocatalytic oxidation for indoor air purification: a literature review. Building and Environment, 38(5), 645-654.

${ }^{37}$ Serpone, N., \& Emeline, A. V. (2005). Modelling heterogeneous photocatalysis by metal-oxide nanostructured semiconductor and insulator materials:

factors that affect the activity and selectivity of photocatalysts. Research on chemical intermediates, 31(4), 391-432.

38 Litter, M. I., \& Navio, J. A. (1996). Photocatalytic properties of iron-doped titania semiconductors. Journal of Photochemistry and Photobiology A: Chemistry, 98(3), 171-181.

Tabla 2. Potenciales de oxidación de diversas especies.

39 Matsumoto, Y. (1996). Energy positions of oxide semiconductors and photocatalysis with iron complex oxides. Journal of Solid State Chemistry, 126(2), 227-234
El radical hidroperóxilo formado en (reacción 4) también puede capturar un electron como el $\mathrm{O}_{2}$ "- duplicando el tiempo del vida del hueco fotogenerado:

$$
\begin{aligned}
& S C+h v \rightarrow e^{-}+h^{+} \\
& \left(O_{2}\right)_{a d s}+e^{-} \rightarrow O_{2}^{\cdot-}
\end{aligned}
$$

Tanto la oxidación como la reducción pueden tener lugar en la superficie del fotocatalizador semiconductor fotoexcitado (Figura 1-salto de banda). La recombinación par electron/hueco se producirá si el oxígeno no esté disponible para incorporar los electrones y así formar los superóxidos $\left(\mathrm{O}_{2}{ }^{-}\right)$, la forma protonada del radical hidroperoxilo $\left(\mathrm{HO}_{2}{ }^{--}\right)$y como consecuencia $\mathrm{H}_{2} \mathrm{O}_{2}$. Estas especies altamente reactivas capaces de oxidar moléculas orgánicas tanto en fase líquida o en fase gaseosa ${ }^{36,37}$. Además, si hay oxigeno presente, este puede actuar como aceptor de electrones, y ser reducido para formar un ion superóxido, que es también un potente oxidante.

El radical hidroxilo tiene un potencial de oxidación muy alto y, después del ión fluoruro, es el agente oxidante más potente ${ }^{38}$. El potencial de oxidación de Oxidantes se resume en la Tabla XX donde se puede ver que el radical hidroxilo es aún más oxidante que el ozono. Cuanto mayor es el potencial de oxidación del compuesto, mayor es la capacidad de descomposición.

\begin{tabular}{|l|c|}
\hline Oxidante & Potencial de Oxidación (eV) \\
\hline $\mathrm{F}$ (Flúor) & 2,87 \\
\hline $\mathrm{OH} \cdot($ Radical hydroxylo) & 2,80 \\
\hline $\mathrm{O}($ Oxígeno atómico $)$ & 2,42 \\
\hline $\mathrm{O}_{3}($ Ozono $)$ & 2,07 \\
\hline $\mathrm{H}_{2} \mathrm{O}_{2}$ (Peróxido de hidrógeno) & 1,77 \\
\hline $\mathrm{Cl}($ Cloro $)$ & 1,36 \\
\hline $\mathrm{O}_{2}($ Oxigeno molecular) & 1,23 \\
\hline
\end{tabular}

Según Matsumoto et al, como la degradación de los contaminantes se debe a la capacidad de generar superóxidos $\left(\mathrm{O}_{2}{ }^{-}\right)$, y radical hidroperoxilo $\left(\mathrm{HO}_{2}{ }^{-}\right)$. El valor del band gap $(\mathrm{Eg})$ determina la banda del espectro que el semiconductor necesita absorber.

En el caso del $\mathrm{TiO}_{2}$ se conoce que, su banda de conducción y su banda de valencia se forman con orbitales $3 \mathrm{~d}$ del ( $\mathrm{Ti}$ ), y los orbitales $2 p$ del (O). De forma simplificada, la relación entre el potencial del electrodo normal de hidrogeno (ENH) y las energias de las bandas de conducción molecular (BCM) y de la banda de valencia molecular (BVM); (EPc, $E P v)$ respectivamente, con el band gap (Eg), se pueden calcular con las ecuaciones $^{39}$ propuestas por Matsumoto et al. 
$E P c(V v s . N H E)=1,23-E g(e V) / 2$

$E P C(V v s . N H E)=1,23+E g(e V) / 2$
Ecuación 2

Ecuación 3

El valor del band gap para el $\mathrm{TiO}_{2}$ es conocido, $(\mathrm{Eg}=3,2 \mathrm{eV})$, si se aplican las formulas, EPc y EPv son -0,37V y +2,83V frente al electrodo normal de hidrogeno $(E N H)$ respectivamente. A pesar de que el rutilo tiene un valor de band gap menor, $\mathrm{Eg}=3,0 \mathrm{eV}$ frente al de la anatasa $\mathrm{Eg}=3,2 \mathrm{eV}$, lo quel sería una ventaja, debido al potencial de su banda de conducción (EPv) el potencial redox hace que el $\mathrm{TiO}_{2}$-anatasa sea mas favorable. Ambas formas, anatasa y rutilo tienen un potencial de banda de valencia (EPv) suficientemente positivo para generar radicales hidroxilo, pero el potencial de la banda de conducción (EPc) del rutilo, no es lo suficientemente negativo como para reducir al oxígeno y generar radicales superóxido, mientras que en la anatasa sí lo es.

\section{E vs $E H N(V)$}

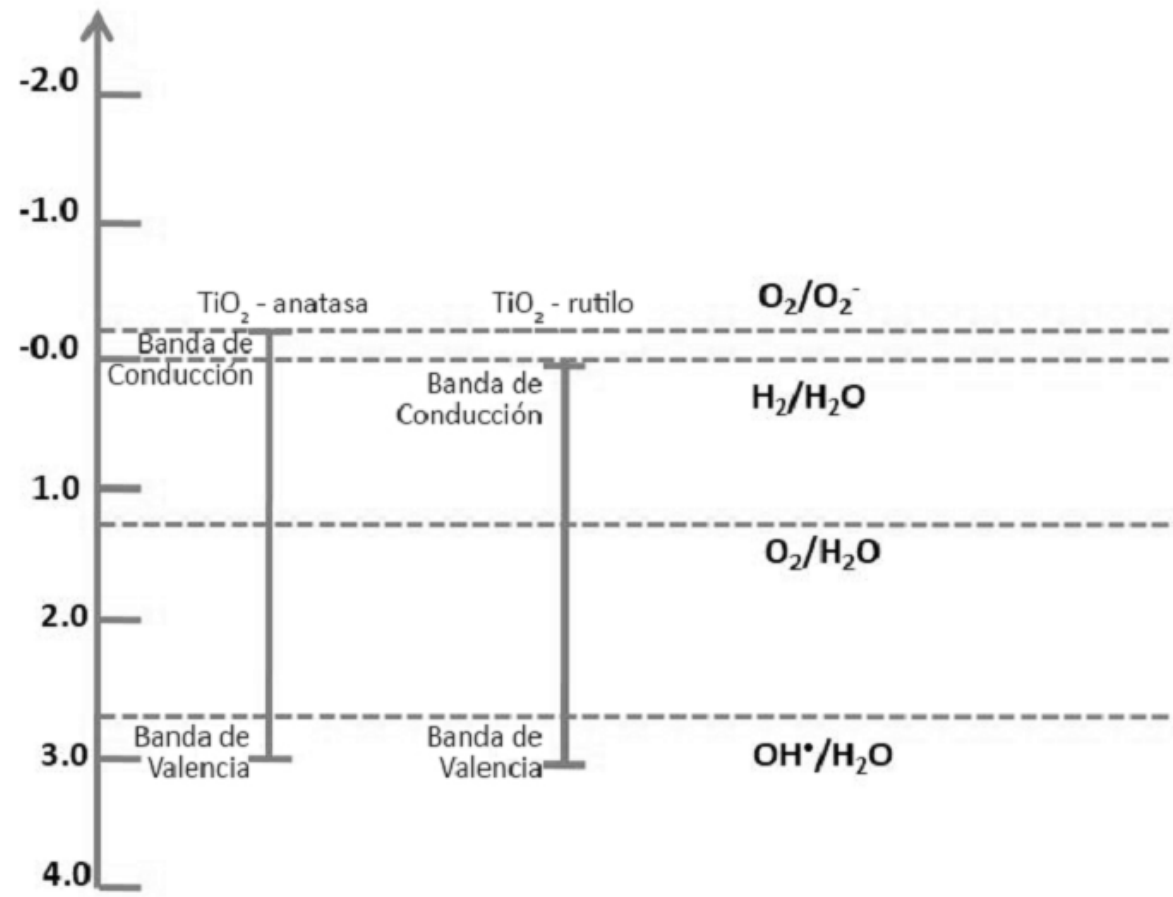

\subsubsection{MECANISMOS DE DEGRADACIÓN.}

El dióxido de Titanio se utiliza para generar el par electrón-hueco y producir las reacciones de reducción-oxidación ${ }^{41}$. Son reacciones fotocatalíticas aeróbicas, en presencia de oxigeno, frente a una reacción fotosintética favorable, $\Delta \mathrm{G}<0$. El ácido correspondiente $(H A)$ se forma con el sustituyente no metálico y se forma como un producto de reacción ${ }^{42}$ :

$$
\begin{array}{ll}
\text { contaminante } & \text { i) } \mathrm{TiO}_{2} \\
\text { orgánico } & \begin{array}{l}
\text { ii) } \mathrm{O}_{2} \\
\text { iii) } h v \geq \mathrm{E}_{\mathrm{g}}
\end{array}
\end{array}
$$

Fig 13. Potenciales redox respecto al ENH para las BC y BV de las fases anatasa $\left(\mathrm{TiO}_{2}-\mathrm{A}\right)$ y rutilo $\left(\mathrm{TiO}_{2}-\mathrm{R}\right)^{40}$

Fuente: Elaboración propia.

40 Yan, H., Wang, X., Yao, M., \& Yao, X. (2013)

Band structure design of semiconductors for enhanced photocatalytic activity: The case of $\mathrm{TiO}_{2}$

Progress in Natural Science:

Materials International, 23(4), 402-407.

${ }^{41}$ Kim, H., Lee, S., Han, Y., \& Park, J. (2006). Preparation of dip-coated $\mathrm{TiO} 2$ photocatalyst on ceramic foam pellets. Journal of materials science, 41(18), 6150 6153

${ }^{42}$ Carp, O., Huisman, C. L.,

\& Reller, A. (2004)

Photoinduced reactivity of titanium dioxide. Progress in solid state chemistry, 32(1), 33-177.

\section{Reacción.}

Reacción de reducción-oxidación. 
43 Yang, X., \& Tamai, N. (2001) How fast is interfacial hole transfer? In situ monitoring of carrier dynamics in anatase TiO 2 nanoparticles by femtosecond laser spectroscopy. Physical Chemistry Chemical Physics, 3(16), 3393-3398.

${ }^{44}$ Colombo, D. P. \& Bowman, R. M. (1996).

Does interfacial charge transfer compete with charge carrier recombination?

A femtosecond diffuse reflectance investigation of $\mathrm{TiO} 2$ nanoparticles. The Journal of Physical Chemistry, 100(47), 18445-18449

45 Domen, K., Naito, S. Onishi, T., \& Tamaru, K. (1982). Photocatalytic hydrogen production from a mixture of water and 2-propanol on some semiconductors. Chemistry Letters, 11(4), 555-558.

${ }^{46}$ Ballari, M. M., Yu, Q. L., \& Brouwers, H. J. H. (2011). Experimental study of the $\mathrm{NO}$ and $\mathrm{NO}$ 2 degradation by photocatalytically active concrete. Catalysis Today, 161(1), 175-180.

${ }^{47}$ Dylla, H., Hassan, M. M., Schmitt, M. Rupnow, T., \& Mohammad, L. N. (2010). Laboratory investigation of the effect of mixed nitrogen dioxide and nitrogen oxide gases on titanium dioxide photocatalytic efficiency in concrete pavements. Journal of Materials in civil engineering, 23(7), 1087-1093.

48 Dylla, H., Hassan, M., Schmitt, M., Rupnow, T., Mohammad, L., \& Wright, E. (2011)

Effects of roadway contaminants on titanium dioxide photodegradation of nitrogen oxides. Transportation Research

Record: Journal of the Transportation Research Board, (2240), 22-29

${ }^{49}$ Hüsken, G., Hunger, M., \& Brouwers, H. J. H. (2009). Experimental study of photocatalytic concrete products for air purification. Building and environment, 44(12), 2463-2474

Fig 14. Ilustración esquemática del mecanismo básico de un proceso de fotocatalisis heterogénea. Sistema TiO bajo irradiación de luz U.V.50

${ }^{50}$ Folli, A., Pade, C., Hansen, T. B., De Marco, T., \& Macphee, D. E. (2012). TiO, photocatalysis in cementitious systems: insights into self-cleaning and depollution chemistry. Cement and concrete research, 42(3), 539-548.

51 Fujishima, A., Rao, T. N., \& Tryk, D. A. (2000)

Titanium dioxide photocatalysis. Journal of Photochemistry and Photobiology C: Photochemistry Reviews, 1(1), 1-21.
En las últimas dos décadas, se han estudiado suspensiones acuosas de $\mathrm{TiO}_{2}$ utilizando espectroscopia de absorción con resolución de picosegundos y más recientemente de femtosegundo ${ }^{43}$. El estudio espectroscópico con resolución de femtosegundos del sistema acuoso $\mathrm{TiO}_{2} / \mathrm{SCN}$ - que llevaron a cabo Colombo y Bowman ${ }^{44}$ indicó un aumento subito de los portadores de carga en los primeros picosegundos. Los resultados también confirmaron que para las especies adsorbidas sobre el $\mathrm{TiO}_{2}$, la reacción de transferencia de hueco puede competir con éxito contra el proceso de recombinación de electrón/hueco que dura picosegundos.

Las reacciones fotoquímicas que se producen en la superficie son:

Foto excitación:

Reacción 9

$$
\mathrm{TiO}_{2}+h v \rightarrow e_{B C}^{-}+h_{b v}^{+}
$$

lonosorción del oxígeno:

Reacción 10

$$
e_{B C}^{-} \rightarrow e_{C T}^{-}
$$

lonización del agua:

Reacción 11

$$
h_{B V}^{+} \rightarrow h_{C T}^{+}
$$

Protonacion de los superoxidos:

Reacción 12

$$
e_{C T}^{-}+h_{B V}^{+}\left(h_{C T}^{+}\right) \rightarrow e_{B C}^{-}+\text {calor }
$$

En la mayoría de las aplicaciones, las reacciones de degradación fotocatalítica se dan en presencia de, agua, aire, el contaminante y el fotocatalizador. La presencia de agua es indispensable en la fotocatálisis con $\mathrm{TiO}_{2}$, trabajos anteriores sobre la fotooxidación de la molécula 2-propanol demuestra que la reacción no se da sin la presencia de agua $45,46,47,48,49$.

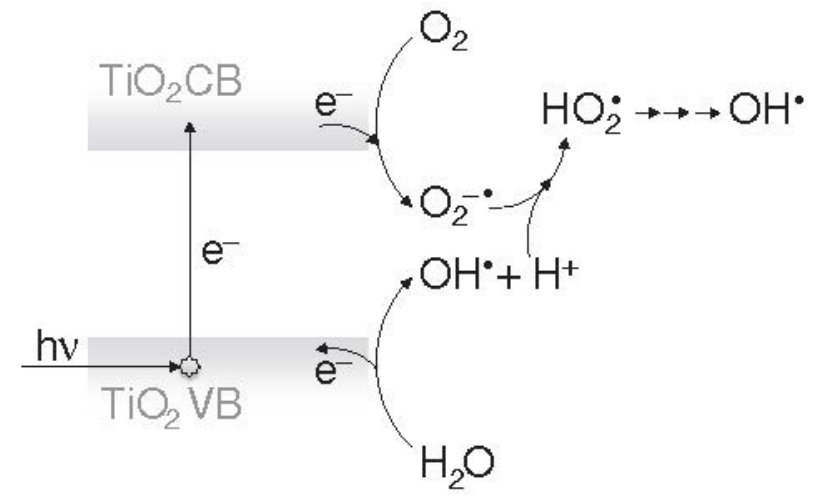

La figura, muestra las etapas en los procesos fotoinducidos de la fotomineralización de contaminante orgánico en presencia de $\mathrm{TiO}_{2}$. Los huecos fotogenerados poseen gran potencial de oxidación de sustancias orgánicas de forma directa o indirectamente a través de la combinación con $\mathrm{OH}^{\cdot}$ especie predominante en la solución acuosa ${ }^{36,51}$. 


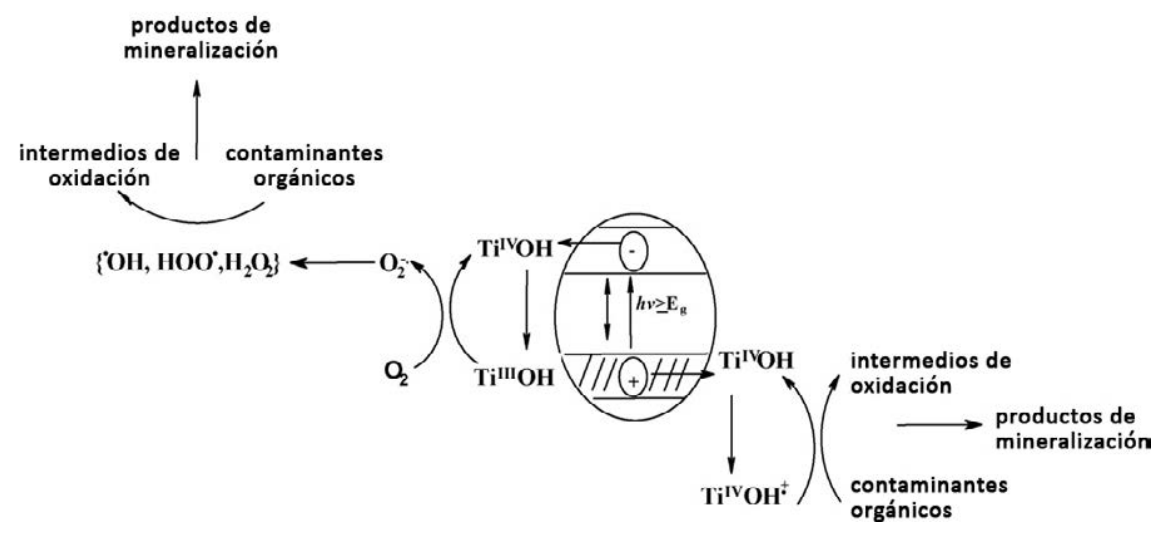

$\mathrm{H}_{2} \mathrm{O}+h^{+} \rightarrow \mathrm{OH}^{\cdot}+\mathrm{H}^{+}$

Reacción 13

$$
\mathrm{R}-\mathrm{H}+\mathrm{OH}^{\cdot} \rightarrow \mathrm{R}^{\prime}+\mathrm{H}_{2} \mathrm{O}
$$

Reacción 14
Fig 15. Diagrama de los procesos primarios implicados en la fotomineralización de compuestos orgánicos ${ }^{44}$.

${ }^{51}$ Fujishima, A., Rao, T. N., \&Tryk, D. A. (2000).

Titanium dioxide photocatalysis. Journal of Photochemistry and Photobiology C: Photochemistry Reviews, 1(1), 1-21.
52 Nakato, Y., Tsumura, A.,

\& Tsubomura, H. (1983).

Photo-and electroluminescence spectra from an $\mathrm{n}-\mathrm{TiO}_{2}$ semiconductor electrode as related to the intermediates of the photoxidation reaction of water. J. Phys. Chem.; (United States), 87(13).

53 Jacoby, W. A., Blake, D. M., Penned, J. A., Boulter, J. E., Vargo, L. M. George, M. C., \& Dolberg, S. K. (1996). Heterogeneous photocatalysis for control of volatile organic compounds in indoor air. Journal of the Air \& Waste Management Association, 46(9), 891-898.

${ }^{54}$ Sleiman, M., Conchon, P., Ferronato, C., \& Chovelon, J. M. (2007). lodosulfuron degradation by $\mathrm{TiO}_{2}$ photocatalysis: kinetic and reactional pathway investigations. Applied catalysis B: environmental, 71(3), 279-290.

${ }^{55}$ Ishibashi, K. I., Fujishima, A., Watanabe, T., \& Hashimoto, K. (2000). Quantum yields of active oxidative species formed on $\mathrm{TiO}_{2}$ photocatalyst. Journal of photochemistry and photobiology A: chemistry, 134(1), 139-142.

${ }^{56}$ Anpo, M., Shima, T., Kodama, S., \& Kubokawa, Y. (1987).

Photocatalytic hydrogen of $\mathrm{CH}_{3} \mathrm{CCH}$ with $\mathrm{H}_{2} \mathrm{O}$ on small - particle $\mathrm{TiO}_{2}$ : size quantization effects and reaction intermediates. J. Phys. Chem.; (United States), 91(16). 


\subsubsection{MECANISMOS DE ELIMINACIÓN DE LOS PRINCIPALES CONTAMINANTES}

\section{ÓXIDOS DE NITRÓGENO $\left(\mathrm{NO}_{x}\right)$}

La capacidad de generar radicales libres, (reacciones 8-11), hace del $\mathrm{TiO}_{2}$ una poderosa herramienta para la eliminación de contaminantes del aire. Las especies reactivas pueden reducir u oxidar los contaminantes en especies químicas inofensivas. El proceso fotocatalítico sobre la superficie del fotocatalizador es capaz de oxidar estos compuestos $\left(\mathrm{NO}_{x}\right)$ a ácido nítrico.

$$
\begin{aligned}
& \mathrm{NO}+\mathrm{OH}^{\cdot} \rightarrow \mathrm{HNO}_{2} \\
& \mathrm{HNO}_{2}+\mathrm{OH} \rightarrow \mathrm{NO}_{2}+\mathrm{H}_{2} \mathrm{O} \\
& \mathrm{NO}_{2}+\mathrm{OH} \rightarrow \mathrm{HNO}_{3}
\end{aligned}
$$$$
\text { Reacción } 17
$$

Reacción 18

${ }^{57}$ Mori, T., Suzuki, J., Fujimoto, K., Watanabe, M., \& Hasegawa, Y. (1999). Reductive decomposition of nitrate ion to nitrogen in water on a unique hollandite photocatalyst. Applied Catalysis B: Environmental, 23(4), 283-289.

58 Tseng, Y. H., \& Kuo, C. H. (2011) Photocatalytic degradation of dye and $\mathrm{NO} \times$ using visible-light-responsive carbon-containing $\mathrm{TiO}$

Catalysis today, 174(1), 114-120.

59 Yu, Y. H., Pan, Y. T., Wu, Y. T., Lasek, J., \& Wu, J. C. (2011). Photocatalytic $\mathrm{NO}$ reduction with $\mathrm{C}_{3} \mathrm{H}_{8}$ using a monolith photoreactor. Catalysis today, 174(1), 141-147.

${ }^{60}$ Zhaoliang, Z., Jun, M. \& Xiyao, Y. (2003).

Separate/simultaneous catalytic reduction of sulfur dioxide and/or nitric oxide by carbon monoxide over

titanium-tin solid solution catalysts. Chemical Engineering Journal, 95(1), 15-24.

${ }^{61}$ Zhaoliang, Z., Jun, M. \& Xiyao, Y. (2003)

Separate/simultaneous catalytic reduction of sulfur dioxide and/or nitric oxide by carbon monoxide over

$\mathrm{TiO}_{2}$ - promoted cobalt sulfides. Journal of Molecular Catalysis A: Chemical, 195(1), 189-200.15-24.

${ }^{62}$ Mills, A., Lee, S. K., \& Lepre, A. (2003).

Photodecomposition of ozone sensitised by a film of titanium dioxide on glass. Journal of Photochemistry and Photobiology A: Chemistry, 155(1), 199-205.
En los o experimentos realizados por Mori, Tseng y Yu con resultados exitosos. Los óxidos de nitrógeno se oxidaron a ácido nítrico como en el mecanismo propuesto ${ }^{57,58,59}$.

\section{ÓXIDO DE AZUFRE $\left(\mathrm{SO}_{2}\right)$}

El dióxido de azufre $\left(\mathrm{SO}_{2}\right)$ asi como el dióxido de nitrógeno pueden reducirse en presencia de monóxido de carbono como muestran las siguientes reacciones ${ }^{60,61}$ :

$$
\begin{array}{lr}
\mathrm{SO}_{2}+2 \mathrm{CO} \rightarrow \mathrm{S}+2 \mathrm{CO}_{2} & \text { Reacción } 19 \\
2 \mathrm{NO}+2 \mathrm{CO} \rightarrow \mathrm{N}_{2}+2 \mathrm{CO}_{2} & \text { Reacción 20 }
\end{array}
$$

\section{$\mathrm{OZONO}\left(\mathrm{O}_{3}\right)$}

El Ozono como consecuencia de su alta reactividad es un material muy tóxico con un gran poder oxidante. Se ha propuesto el siguiente esquema de reacción de degradación del ozono ${ }^{62}$ :

$$
\begin{aligned}
& e^{-}+\mathrm{O}_{3} \rightarrow \mathrm{O}_{3}^{-} \quad \text { Etapa limitante } \\
& h^{+}+\mathrm{OH}^{-} \rightarrow \mathrm{OH}^{\cdot} \\
& \mathrm{O}_{3}^{-}+\mathrm{O}_{3} \rightarrow \mathrm{O}_{4}^{-}+\mathrm{O}_{2}
\end{aligned}
$$




$$
\begin{array}{lr}
\mathrm{OH}^{\cdot}+\mathrm{O}_{3} \rightarrow \mathrm{O}_{4}^{-}+\mathrm{H}^{+} & \text {Reacción } 24 \\
\mathrm{O}_{4}^{-}+\mathrm{O}_{3} \rightarrow 2 \mathrm{O}_{2}+\mathrm{O}_{3}^{-} & \text {Reacción } 25 \\
\mathrm{H}^{+}+\mathrm{O}_{3}^{-}+\mathrm{O}_{4}^{-} \rightarrow 3 \mathrm{O}_{2}+\mathrm{OH}^{-} & \text {Reacción 26 }
\end{array}
$$

La etapa determinante de la velocidad de reacción es, la reducción inicial de una molécula de ozono adsorbida por un electrón fotogenerado. Se ha demostrado que en este caso, la actividad fotocatalítica es independiente del valor de la superficie específica, pero depende del polimorfo de $\mathrm{TiO}_{2}$, de su estructura cristalina, en el orden: anatasa $<<$ anatasa-rutilo $<$ rutilo ${ }^{63}$.

\section{4 . 5. DIÓXIDO DE TITANIO (TiO)}

El titanio es el cuarto metal más abundante del mundo, sólo superado por el aluminio, el hierro y el magnesio) y el noveno elemento más abundante, lo que significa aproximadamente el $0,63 \%$ de la corteza terrestre, fue descubierto en 1791 en Inglaterra.

Las fuentes del mineral son, el rutilo, la ilmenita y el leucoxeno, un producto de la meteorización de la ilmenita. Entre el 93 al 96\% del mineral de rutilo consiste en dióxido de titanio, la ilmenita puede contener entre el $44 \%$ y $70 \%$ de $\mathrm{TiO}_{2}$ y los concentrados de leucoxeno pueden contener hasta $90 \%$ de $\mathrm{TiO}_{2}$. A partir de la ilmenita se consiguen escorias de alto contenido en $\mathrm{TiO}_{2}$ que contienen entre un $75-85 \%$.

El destino principal de la producción de $\mathrm{TiO}_{2}$, alrededor del $98 \%$, se destina a su uso como pigmento blanco, y sólo el $2 \%$ restante se utiliza para obtenerlo como metal, revestimientos de electrodos para soldadura, fundentes y otros productos ${ }^{64}$.

La ilmenita es un mineral ligeramente magnético, negro o gris y se encuentra en rocas metamórficas y plutónicas. Se utiliza como fuente de titanio metálico. Kupffer lo descubrió en 1827 y lo nombró como la montaña llmen en los Urales (Rusia) donde fue encontrado por primera vez. Se encuentra en los grandes depósitos de minerales primarios o en depósitos aluviales secundarios que contienen minerales pesados. Manganeso, magnesio, calcio, cromo, silicio y vanadio están presentes como impurezas.

El rutilo es la forma más estable de dióxido de titanio y el principal mineral de titanio, fue descubierto en 1803 por Werner en España. Su nombre deriva del latín rutilus, rojo, en referencia al color rojo oscuro observado en algunas muestras. Normalmentes es de color marrón rojizo pero a veces tambien puede aparecer amarillento, azulado o violeta, pasando de transparente a opaco. El rutilo puede contener hasta un $10 \%$ de hierro, como impureza además de tántalo, niobio, cromo, vanadio y estaño. Se asocia con minerales como el cuarzo, la turmalina, la barita, la hematita y silicatos.
${ }^{63}$ Ohtani, B., Zhang, S. W., Nishimoto, S. I., \& Kagiya, T. (1992). Catalytic and photocatalytic decomposition of ozone at room temperature over titanium (IV) oxide. Journal of the Chemical Society, Faraday Transactions, 88(7), 1049-1053.

${ }^{64}$ Virta, R. L. (2002).

US Geological Survey Minerals Yearbook-2002. 
${ }^{65}$ Malato, S., Fernández-Ibáñez, P., Maldonado, M. I., Blanco, J., \& Gernjak, W. (2009).

Decontamination and disinfection of water by solar photocatalysis: recent overview and trends. Catalysis Today, 147(1), 1-59.

${ }^{66}$ Li, D., Huang, H., Chen, X., Chen, Z., Li, W., Ye, D., \& Fu, X. (2007). New synthesis of excellent visible- light $\mathrm{TiO}_{2}-x \mathrm{~N} x$ photocatalyst using a very simple method. Journal of Solid State Chemistry, 180(9), 2630-2634.

${ }^{67}$ Folli, A., Pochard, I., Nonat, A., Jakobsen, U. H., Shepherd, A. M., \& Macphee, D. E. (2010)

Engineering photocatalytic cements: understanding $\mathrm{TiO} 2$ surface chemistry to control and modulate photocatalytic performances. Journal of the American Ceramic Society, 93(10), 3360-3369.

${ }^{68}$ Meinhold, G. (2010)

Rutile and its applications in earth sciences. Earth-Science Reviews, 102(1), 1-28.

${ }^{69}$ Banfield, J. (1998)

Thermodynamic analysis of phase stability of nanocrystalline titania. Journal of Materials Chemistry, 8(9), 2073-2076.

70 Zhang, H., \& Banfield, J. F. (2000) Understanding polymorphic phase transformation behavior during growth of nanocrystalline aggregates: insights from TiO2. The Journal of Physical Chemistry B, 104(15), 3481-3487.

${ }^{71}$ Murakami, M., Matsumoto, Y., Nakajima, K., Makino, T., Segawa, Y., Chikyow, T., .. \& Koinuma, H. (2001) Anatase $\mathrm{TiO}_{2}$ thin films grown on latticematched $\mathrm{LaAlO}_{3}$ substrate by laser molecular-beam epitaxy. Applied Physics Letters, 78(18), 2664-2666.

72 Sekiya, T., Igarashi, M., Kurita, S., Takekawa, S., \& Fujisawa, M. (1998) Structure dependence of reflection spectra of TiO 2 single crystals. Journal of electron spectroscopy and related phenomena, 92(1), 247-250.
La brookita fue llamada así, en honor del geólogo inglés H.J. Brooke, y fue descubierta por A. Levy en 1825 en Snowen (Gales, Inglaterra). Sus cristales van de color marrón oscuro a negro verdoso opaco. Las formas cristalinas incluyen los típicos cristales planos con forma pseudohexagonal. Se presenta asociado a otros minerales como la anatasa, el rutilo, el cuarzo, feldespato, calcopirita, hematita y esfeno.

La anatasa, antes llamada octaedrita, fue denominada así por R.J. Hauy en 1801 proviene de la palabra griega 'anatasis' que significa 'extensión', debido a su eje vertical más largo comparado con el del rutilo. Se encuentra asociada con cristal de roca, feldespato y axinita en grietas en el granito, y mica ${ }^{42}$.

Entre los catalizadores semiconductores, el dióxido de titanio $\left(\mathrm{TiO}_{2}\right)$ es el que mas interés ha suscitado en fotocatálisis. $\mathrm{El} \mathrm{TiO}_{2}$ es el fotocatalizador más adecuado para la energía que suministra un fotón ( $h v$ ) de longitud de onda entre $300 \mathrm{~nm}<\lambda<390 \mathrm{~nm}$, frente a otros similares como el CdS o GaP que se degradan además de generar sustancias tóxicas, sigue estable después de varios ciclos de catálisis ${ }^{65}$. Junto a estas ventajas también tiene otras propiedades interesantes como su estabilidad térmica, resistencia a la descomposición química cuando se expone a ácidos y báses, su inercia química en ausencia de luz UV y unas buenas propiedades mecánicas le han hecho destacar en los estudios sobre fotocatálisis heterogénea. La reaccion fotoinducida en la superficie del $\mathrm{TiO}_{2}$, genera compuestos de oxigeno muy reactivos que destruyen la actividad microbiana y consiguen la mineralización completa de los contaminantes y compuestos intermedios generados sin contaminación secundaria, todo ello a unos costes operativos bajos.

Los principales inconvenientes que actualmente limitan una aplicación comercial más extendida son dos, que únicamente funciona cuando hay radiación en la región ultravioleta y la alta tasa recombinación de los pares electron/hueco. Actualmente se investiga en el desarrollo de fotocatalizadores de luz visible con $\mathrm{TiO}_{2}$ y asi aumentar la cantidad de luz solar visible que puede absorber ${ }^{66}$.

El tamaño de partícula del $\mathrm{TiO}_{2}$, junto con su gran relación superficie-volumen y la energía de superficie crea una fuerte tendencia a la aglomeración del catalizador durante su uso. Las aglomeraciones de partículas son perjudiciales por la reducción de la superficie que supone y su vida útill67.

\subsubsection{ESTRUCTURA CRISTALINA DEL TIO,}

El dióxido de titanio es el óxido natural de TilV $\left(\mathrm{TiO}_{2}\right)$. En la naturaleza se encuentra en tres estructuras cristalográficas diferentes: rutilo, anatasa y brookita; aunque también se han reportado otros polimorfos, a alta presión existen al menos seis estructuras cristalográficas diferentes ${ }^{68,69,70}$. Debido a las diferentes estructuras cristalinas, los polimorfos del dióxido de titanio muestran diferentes propiedades físicas y químicas.

Las propiedades ópticas de $\mathrm{TiO}_{2}$-Anatasa y $\mathrm{TiO}_{2}$-Rutilo están bien documentados en la literatura ${ }^{71,72}$. 
I NFLUENCIA DEL COLOR Y ELACABADO SUPERFICIALEN LASPROPIEDADES DE UN MORTEROFOTOCATALITICOCOMOSOLUCIÓN DE ENVOLVENTE
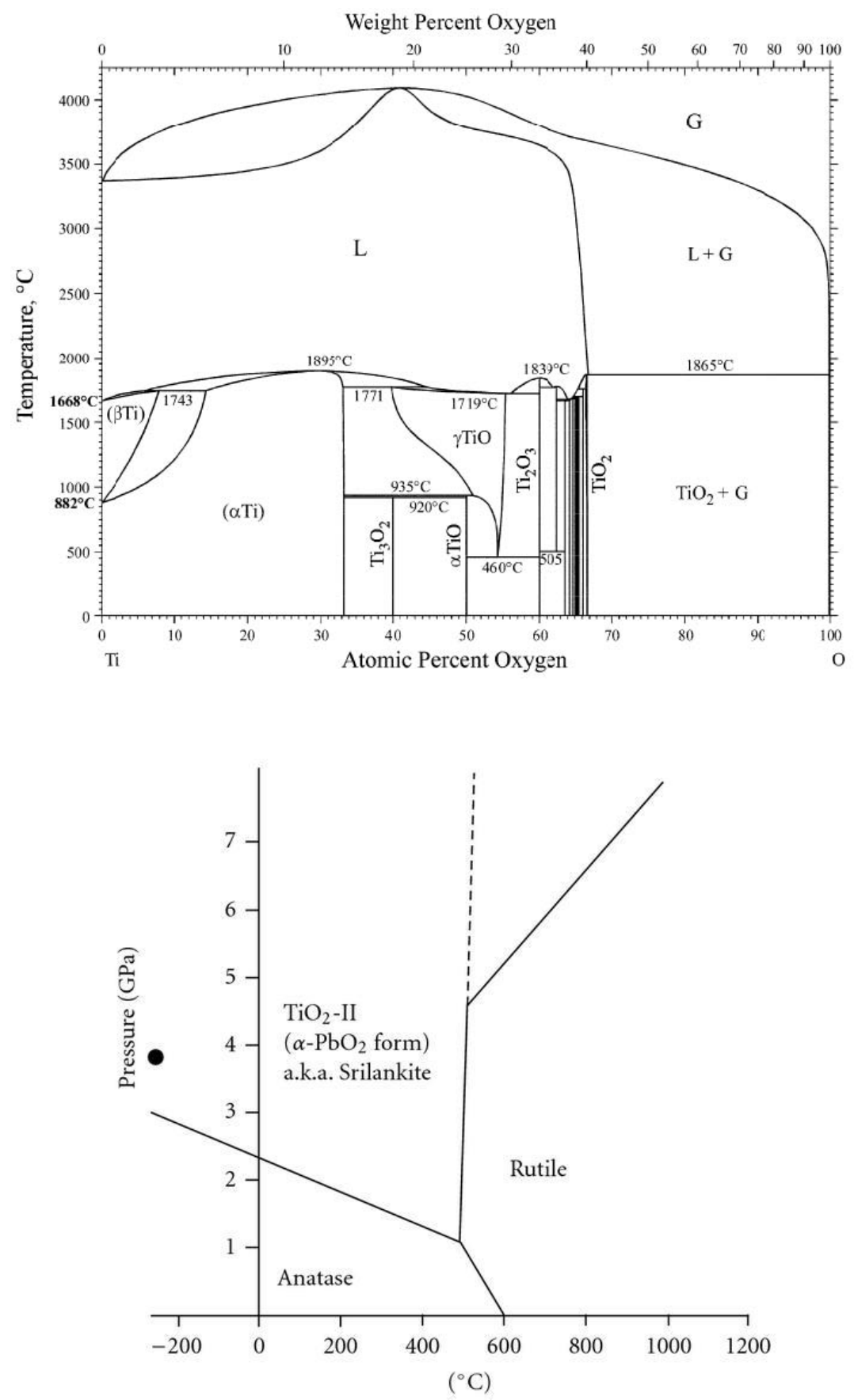

(a)

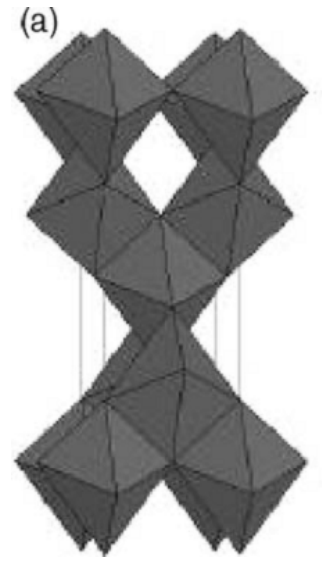

(b)

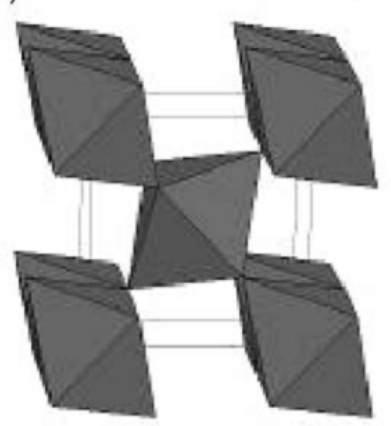

(c)

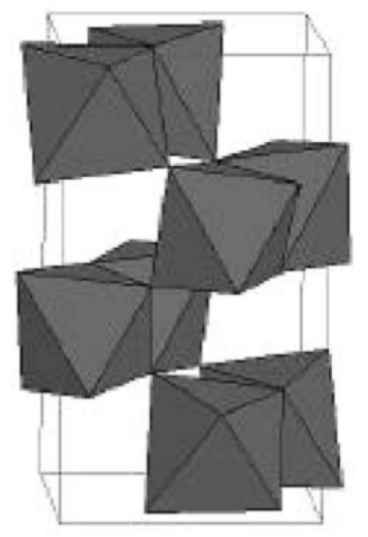

Fig 16. Diagrama de fases de $\mathrm{TiO}$ a diferentes temperaturas ${ }^{73}$.

${ }^{73}$ Diebold, U. (2003).

The surface science of titanium dioxide. Surface science reports, 48(5), 53-229.

Fig 17. Digrama de equilibrios de fase en el $\mathrm{TiO}_{2}$, entre la Anatasa, Rutilo y Srilankita ${ }^{74}$.

${ }^{74}$ Murray, J. L., \& Wriedt, H. A. (1987). The $\bigcirc-$ Ti (oxygen-titanium) system. Journal of Phase Equilibria, 8(2), 148-165.

Fig 18. Estructuras cristalinas de, Anatasa (a), Rutilo (b) y Brookita (c) ${ }^{42}$. Fuente: Carp et al. 


\section{Radio atómico $(\mathrm{nm})$}

$\mathrm{O}$

$\mathrm{Ti}$

0.066 (covalente)

0.146 (metálico)
Radio iónico $(\mathrm{nm})$
$\mathrm{O}(-2)$
$\mathrm{Ti}(+4)$
0.14
0.064

Estructura cristalina Sistema

\begin{tabular}{|c|c|c|c|c|c|c|}
\hline \multirow[t]{2}{*}{ (2) } & \multirow[t]{2}{*}{ - } & & \multicolumn{4}{|c|}{ Constantes de ted (nim) } \\
\hline & & & $a$ & $b$ & $c$ & $c / a$ \\
\hline rutilo & Tetragonal & $\mathrm{D}_{4 \mathrm{~h}}^{14}-\mathrm{P} 4_{2} / \mathrm{mnm}$ & 0.4584 & - & 0.2953 & 0.644 \\
\hline anatasa & Tetragonal & $D_{4 b}^{19}-14_{1} / a m d$ & 0.3733 & - & 0.937 & 2.51 \\
\hline brookita & Romboédrico & $\mathrm{D}_{2 \mathrm{~h}}^{15} \mathrm{-Pbca}$ & 0.5436 & 0.9166 & 0.5135 & 0.944 \\
\hline $\begin{array}{l}\text { Densidad }\left(\mathrm{kg} / \mathrm{m}^{3}\right) \\
\text { rutilo } \\
\text { anatasa } \\
\text { brookita }\end{array}$ & $\begin{array}{l}4240 \\
3830 \\
4170\end{array}$ & & & & & \\
\hline
\end{tabular}

Tabla 3. Parámetros físicos del $\mathrm{TiO}^{2}{ }^{42}$.

Fuente: Carp et al.

75 Navrotsky, A., Jamieson, J. C., \& Kleppa, O. J. (1967). Enthalpy of transformation of a high-pressure polymorph of titanium dioxide to the rutile modification.

Science, 158(3799), 388-389.

76 Jamieson, J. C., Olinger, B., Dachille, F., Simons, P. Y., \& Roy, R. (1969).

PRESSURE-TEMPERATURE STUDIES OF ANATASE, BROOKITE RUTILE AND TIO2 (II)-A DISCUSSION. American Mineralogist, 54(9-10), 1477.

77 Banfield, J. (1998). Thermodynamic analysis of phase stability of nanocrystalline titania. Journal of Materials Chemistry. 8(9), 2073-2076.

${ }^{78}$ Zhang, H., \& Banfield, J. F. (2000). Understanding polymorphic phase transformation behavior during growth of nanocrystalline aggregates: insights from TiO2. The Journal of Physical Chemistry B, 104(15), 3481-3487
Si nos centramos en los polimorfos de mayor interés, a saber, anatasa y rutilo, vemos que la estructura base es un átomo de titanio rodeado por seis átomos de oxígeno que, forman un octaedro más o menos distorsionado.

En ambas estructuras, los dos enlaces entre el titanio y los átomos de oxígeno en los vértices del octaedro son ligeramente más largos. Se observa una considerable desviación de los $90^{\circ}$ en el ángulo del enlace en la anatasa. En el rutilo, los octaedros vecinos comparten la arista a lo largo del plano (110) y se disponen a su eje más largo alternando a $90^{\circ}$ (véase la figura 18), en la anatasa el octaedro que comparte el vértice forma los planos (0 01 1), está conectado por la arista con el plano de octaedros inferior y en la brookita, se comparten los vértices y aristas.

Su termodinámica, basada en los datos calorimétricos indica que el rutilo es la fase más estable a las temperaturas y presiones hasta $60 \mathrm{kbar}$ donde el $\mathrm{TiO}_{2}$ (II) se convierte en la fase termodinámicamente más favorable ${ }^{75,76}$. Las pequeñas diferencias en la energía libre de Gibbs $(\Delta G)$ entre los tres, entre 4-20 kJ / mol sugieren que los polimorfos metastables, anatasa y brookita, son casi tan estables como el rutilo a presiones y temperaturas normales.

Los experimentos realizados en relacion a la influencia del tamaño de las partículas afirman que la relativa estabilidad de la fase podria cambiar cuando el tamaño de la partícula disminuye lo suficientemente debido a la energía superficial libre y a la tensión superficial, que dependen del tamaño de partícula ${ }^{77}$.

Si las tres fases cristalinas tienen el mismo tamaño de partícula, la anatasa es termodinámicamente más estable a tamaños inferiores a $11 \mathrm{~nm}$, la brookita es más estable entre 11 y $35 \mathrm{~nm}$ y el rutilo es más estable en tamaños superiores a $35 \mathrm{~nm}^{78}$. 
La entalpía para la transformación de la anatasa en rutilo es baja por lo que desde el punto de vista cinético la anatasa es estable, su transformación en rutilo es tan lenta a temperatura ambiente que prácticamente no se da. A escala macroscópica, la transformación alcanza una velocidad medible a $\mathrm{T}>600^{\circ} \mathrm{C}^{79}$.

La mayoría de los catalizadores comerciales de dióxido de titanio son una mezcla de la forma rutilo y anatasa, como por ejemplo el Degussa P-25, el más conocido, que está formado aproximadamente por una mezcla de 80-90\% de anatasa y el resto de rutilo ${ }^{80}$. Está comprobado que para ciertas reacciones fotocatalíticas y catálisis que no son fotoinducidas, funcionan mezclas de ambos polimorfos ${ }^{81}$.

Hay evidencias experimentales que parecen indicar que la anatasa es más activa que el rutilo para la fotooxidación de $\mathrm{O}_{2}$, aunque necesariamente no sea así para todos los procesos fotocatalíticos. La anatasa muestra un comportamiento distinto que el rutilo en los dispositivos para detección de gas y en la mayoría de las células fotovoltaicas que son en capa fina granular. Anatasa y rutilo tienen diferencias inherentes por el tamaño de partícula y esto podría ser la causa de algunas de las diferencias observadas en sus propiedades químicas ${ }^{73}$.
${ }^{79}$ Kumar, K. N. P., Keizer, K., Burggraaf, A. J., Okubo, T., Nagamoto, $H_{\text {., }}$ \& Morooka, S. (1992)

Densification of nanostructured titania assisted by a phase transformation. Nature, 358(6381), 48-51.

${ }^{80}$ Satterfield, C. N. (1991).

Heterogeneous catalysis in industrial practice.

81 Ohno, T., Sarukawa, K., \& Matsumura, M. (2001).

Photocatalytic activities of pure rutile particles isolated from $\mathrm{TiO} 2$ powder by dissolving the anatase component in HF solution. The Journal of Physical Chemistry B, 105(12), 2417-2420 
CAPÍTULO 4: ASPECTOS TEÓRICOS Y FUNDAMENTACIÓN 
INFLUENCIA DEL COLOR Y ELACABADO SUPERFICIALENLASPROPIEDADES DE UN MORTERO FOTOCATALITICO COMO SOLUCIÓN DE ENVOLVENTE 
En este capítulo se analiza el estado del marco de la investigación dentro del ámbito de la contaminación atmosférica, materiales base cemento y la fotocatálisis, lo que nos va a permitir contextualizar el material. 
INFLUENCIA DEL COLOR Y ELACABADO SUPERFICIALEN LAS PROPIEDADES DE UN MORTERO FOTOCATALITICO COMO SOLUCIÓN DE ENVOLVENTE 
${ }^{82}$ Van Broekhuizen, P. van Broekhuizen, F., Cornelissen, R. \& Reijnders, L. (2011) Use of nanomaterials in the European construction industry and some occupational health aspects thereof. Journal of Nanoparticle Research 13(2), 447-462

${ }^{83}$ Van Broekhuizen, F., \& Van Broekhuizen, P. (2009). Nano-products in the European construction industry. European Federation of Building and Wood Workers and European Construction Industry Federation.

${ }^{84}$ Cassar, L., \& Pepe, C. (1997) Paving tile comprising an hydraulic binder and photocatalyst particles.

Italcementi SpA, Bergamo, Italy, EP-Patent, (1600430A1).

${ }^{85}$ Cassar, L., Pepe, C., Pimpinelli, N., Amadelli, R., \& Antolini, L. (1999).

New Cement-Based Materials and Photocatalysis. In Rebuilding the City of Tomorrow, 3rd Eur. Conf. REBUILD

(Barcelona, Spain, 1999).

${ }^{86}$ M Oymak, M., \& Uner, D. (2013). Patents on Photocatalyst Incorporated Cement Based Materials. Recent Patents on Catalysis, 2(2), 116-129.

${ }^{87}$ Henderson, M. A. (2011).

A surface science perspective on photocatalysis. Surface Science Reports, 66(6), 185-297

${ }^{88}$ Cassar, L., Pepe, C., Pimpinelli, N. Amadelli, R., \& Bonato, T. (2000).

Materiali cementizi e fotocatalisi. Seminario FAST" Materiali: ricerca e prospettive tecnologiche aile soglie del.

89 Bonafous, L., Cassar, L., Cassat, P., Guillot, L., \& Colombet, P. (2007). U.S. Patent No. 7,300,514. Washington, DC: U.S. Patent and Trademark Office.

${ }^{90}$ Cassar, L., Pepe, C., Tognon, G., Guerrini, G. L., \& Amadelli, R. (2003, May)

White cement for architectural concrete, possessing photocatalytic properties. In Proceedings of the 11th International Congress on the Chemistry of Cement (Vol. 4, pp. 2012-2021)

91 Angelo, J., Andrade, L. \&Mendes, A. (2014)

Highly active photocatalytic paint for

$\mathrm{NO}$ x abatement under real-outdoor conditions. Applied Catalysis A: General, 484, 17-25.

92 Bengtsson, $\mathrm{N}$. \& Castellote, M. (2010) Photocatalytic Activity for $\mathrm{NO}$ Degradation by Construction Materials:

Parametric Study andMultivariable

Correlations. Journal of Advanced Oxidation Technologies, 13(3), 341-349

\section{I . NUEVOS MATERIALES}

En arquitectura, el uso de nuevos materiales en el diseño en la envolvente tienen un alto interés ya que contribuyen a disminuir la demanda energética, el consumo de materiales, la huella de carbono y el acondicionamiento interior de los edificios para mejorar el confort con lo que se contribuye a la sostenibilidad ambiental, mediante un uso racional de los recursos disponibles. Es indudable el interés que despierta la investigación para estudio de la incorporación de Nanomateriales que puedan mejorar las prestaciones a nivel estructural, durabilidad o simplemente en la resistencia de los materiales base cemento contribuyendo a mejorar la calidad y/o vida útil de las estructuras. Se plantea que la incorporación especifica de algunas sustancias que utilizados en tamaño de nanoescala reducirán las emisiones de dióxido de carbono asociadas con la producción de hormigón ${ }^{82,83}$.

\subsubsection{FOTOCATALISIS APLICADA A MATERIALES BASE CEMENTO}

La fotocatálisis en materiales a base de cemento es una cuestión reciente, mediados de los años 90, los primeros desarrollos fueron realizados por Italcementi Group y Mitsubishi Companies. La primera publicación oficial sobre estos productos fue presentada por Cassar et al. en 199784, 85 . Desde ese momento, el desarrollo de cementos fotocatalíticos se ha llevado a cabo con soluciones innovadoras crecientes habiendo presentado varias patentes ${ }^{86}$ hasta el momento actual, con un desarrollo progresivo de nuevos productos y aplicaciones que están disponibles comercialmente ${ }^{87}$. Un enfoque innovador de la ciencia de los materiales ha demostrado que la actividad fotocatalítica puede trasladarse a los materiales de construcción a base de cemento, como el hormigón, los morteros, las pinturas, etc. ${ }^{88,89,90,91 .}$

Los materiales de construcción tratados con $\mathrm{TiO}_{2}$ pueden mantener o recuperar su aspecto estético mediante la energía solar. La actividad fotocatalítica producida por los cementos que incorporan $\mathrm{TiO}_{2}$, dota de nuevas funcionalidades a los materiales utilizados como acabado en la envolvente, autolimpieza y descontaminación. Ofrecen la posibilidad de mejorar la calidad del aire degradando, contaminantes atmosféricos ${ }^{92,93,94,95}$, $\operatorname{COV}^{96,97}$, colorantes orgánicos ${ }^{50,98,99}$ y algas ${ }^{100}$. Incluso se ha demostrado que podria convertirse en una herramienta efectiva en el control de la contaminación atmosférica por altos niveles de pólenes según resultados obtenidos por Sapiña et al ${ }^{101}$.

Carp et al. ${ }^{42}$, concluyen que los fotocatalizadores unidos al cemento son especialmente atractivos para la aplicación a gran escala debido al coste relativamente bajo del cemento y la versatilidad de los materiales, los cuales pueden servir simultáneamente como componente estructural y como material fotocatalíticamente activo.

En la actualidad se comercializan nuevos materialesy soluciones en construcción con funcionalidades nuevas o mejoradas, propiedades desarrolladas a partir del 
uso de los nanomateriales, como las mejora de las prestaciones del cemento, el material de construcción más utilizado y por excelencia, si obviamos la piedra, el campo de las propiedades ópticas y en concreto de las fotocatalíticas, se han estado desarrollado estos últimos años ${ }^{18,102}$.

El aspecto de las superficies expuestas se deteriora paulatinamente con el tiempo. Las superficies, la envolvente se impregna con aceites y acumulan depósitos de grasa que como consecuencia facilitan la adherencia de las partículas que hay en el aire. El resultado, la suciedad se acumula en la superficie deteriorando su aspecto algo que $\sin$ un mantenimiento constante y adecuado es difícil evitar.

Devolver las propiedades estéticas de los edificios a través de la utilización de materiales de construcción fotocatalíticos autolimpiantes es una opción. La contaminación orgánica fijada en las superficies puede ser mineralizada, convirtiéndose en agua y $\mathrm{CO}_{2}$, mientras que otro tipo de residuos como el material particulado, hollín y polvo pueden ser retirados por la acción del agua de lluvia. Esta solución puede ahorrar mucho tiempo y dinero gastado en el mantenimiento y limpieza, especialmente en edificios altos donde ese mantenimiento es más difícil y costoso.

Con la luz solar, los contaminantes gaseosos pueden ser degradados en la superficie de los materiales de construcción que pueden ser finalmente lavados por la lluvia o el aire. El proceso de descontaminación es impulsado por una fuente de energía renovable y gratuita.
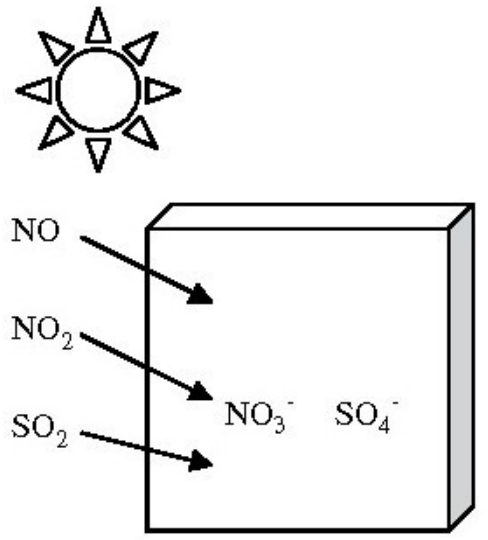

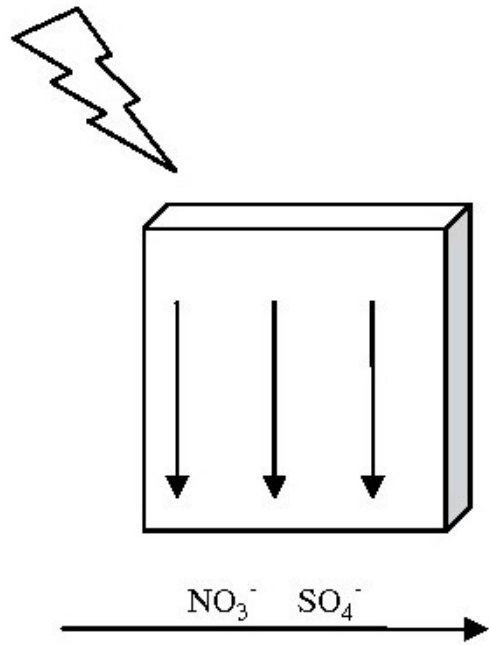

Otra propiedad interesante de los materiales fotocatalíticos es, la superhidrofilia. En exteriores existe una amplia gama de aplicaciones para esta propiedad, la mayoría de las envolventes de los edificios se ensucian debido a los gases de escape de los vehículos que contienen aceites. Si los materiales de construcción estuvieran recubiertos con un fotocatalizador superhidrofilia, la suciedad en las paredes se podria lavar con lluvia o lavar con agua.
93 Bengtsson, N.,

\& Castellote, M. (2014).

Heterogeneous photocatalysis on construction materials: effect of catalyst properties on the efficiency for degrading $\mathrm{NOx}$ and self cleaning. Materiales de Construcción, 64(314), 013.

94 Bengtsson, N., \& Castellote, M. (2010). Photocatalytic Activity for $\mathrm{NO}$ Degradation by Construction Materials: Parametric Study andMultivariable Correlations. Journal of Advanced Oxidation Technologies, 13(3), 341-349.

95 Guerrini, G. L. (2009).

Photo catalytic paving block surfaces. Some observations regarding in-service performance.

96 Aissa, A. H., Puzenat, E.,

Plassais, A., Herrmann, J. M.

Haehnel, C., \& Guillard, C. (2011).

Characterization and photocatalytic performance in air of cementitious materials containing TiO 2. Case study of formaldehyde removal. Applied Catalysis B: Environmental, 107(1), 1-8.

${ }_{97}$ Maury-Ramirez, A.,

Demeestere, K., \& De Belie, N. (2012).

Photocatalytic activity of titanium dioxide nanoparticle coatings applied on autoclaved aerated concrete: effect of weathering on coating physical characteristics and gaseous toluene removal. Journal of hazardous materials,211, 218-225.

98 Seabra, M. P., Pires, R. R.,

\& Labrincha, J. A. (2011)

Ceramic tiles for photodegradation of Orange II solutions. Chemical engineering journal, 171(2), 692-702.

99 Yuranova, T., Sarria, V., Jardim, W., Rengifo, J., Pulgarin, C.,

Trabesinger, G., \& Kiwi, J. (2007).

Photocatalytic discoloration of organic compounds on outdoor building cement panels modified by photoactive coatings. Journal of Photochemistry and

Photobiology A:

Chemistry, 188(2), 334-341.

Fig 19. Esquema de funcionamiento de las propiedades de autolimpieza y descontaminación sobre la envolvente de un edificio ${ }^{43}$.

100 Ramirez, A. M., \& De Belie, N. (2009). Evaluation of the algaecide activity of titanium dioxide on autoclaved aerated concrete. Journal of Advanced Oxidation Technologies, 12(1), 100-104.

101 Sapiña, M., Jimenez-Relinque, E., \& Castellote, M. (2013).

Controlling the levels of airborne pollen: can heterogeneous photocatalysis help? Environmental science \& technology, 47(20), 11711-11716. 
102 Bygott, C. E., Maltby, J. E., Stratton, J. L., \& Mclntyre, R. (2016).

Photocatalytic coatings for the construction industry. Newsletter.

${ }^{103}$ Hashimoto, K., Irie, $H_{\text {., }}$ \& Fujishima, A. (2005) $\mathrm{TiO}_{2}$ photocatalysis: a historical overview and future prospects. Japanese journal of applied physics, 44(12R), 8269

Fig 20. Esquema de un sistema de ahorro de energía con luz solar y agua de lluvia almacenada ${ }^{104}$.

104 Hashimoto, K., Irie, $\mathrm{H}$., \& Fujishima, A. (2005).

$\mathrm{TiO}_{2}$ photocatalysis: a historical overview and future prospects. Japanese journal of applied physics, 44(12R), 8269.

$105 \mathrm{He}, \mathrm{J} .$, \& Hoyano, A. (2008). A numerical simulation method for analyzing the thermal improvement effect of super-hydrophilic photocatalyst-coated building surfaces with water film on the urban/built environment. Energy and Buildings, 40(6), 968-978
Fig 21. Simulacion térmica del uso de un revestimiento superhidrófilo para disminuir la temperatura superficial de un edificio.
Las investigaciones de Fujishima et al. ${ }^{103}$, en el campo de la superhidrofilia fotoinducida han demostrado que en muros con revestimientos que contienen $\mathrm{TiO}_{2}$, el agua puede formar una película muy fina, de sólo $0,1 \mathrm{~mm}$ de espesor. Esto significa que con sólo $200 \mathrm{ml} / \mathrm{min}$ es posible cubrir una pared, una superficie de $5 \mathrm{~m}^{2}$. Según el autor, la sinergia entre esas propiedades, la fotocatálisis y la superhidrofilia, es la base de su capacidad de autolimpieza.

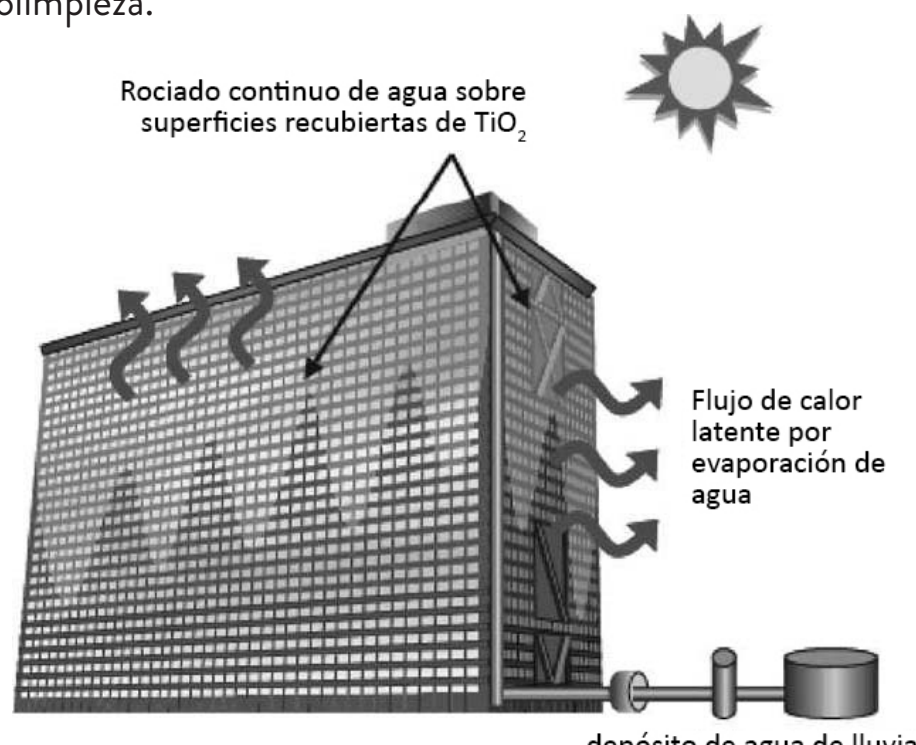

Las investigaciones de Fujishima et al., en el campo de la superhidrofilia fotoinducida han demostrado que en muros con revestimientos que contienen $\mathrm{TiO}_{2}$, el agua puede formar una película muy fina, de sólo $0,1 \mathrm{~mm}$ de espesor. Esto significa que con sólo $200 \mathrm{ml} / \mathrm{min}$ es posible cubrir una pared, una superficie de $5 \mathrm{~m}^{2}$. Según el autor, la sinergia entre esas propiedades, la fotocatálisis y la superhidrofilia, es la base de su capacidad de autolimpieza.

He et al. ${ }^{105}$, han desarrollado un modelo numérico para simular la mejora térmica que supondría un revestimiento superhidrofilia para enfriar con una película de agua superficies externas de un edificio que tenga un revestimiento en base $\mathrm{TiO}^{2}$.

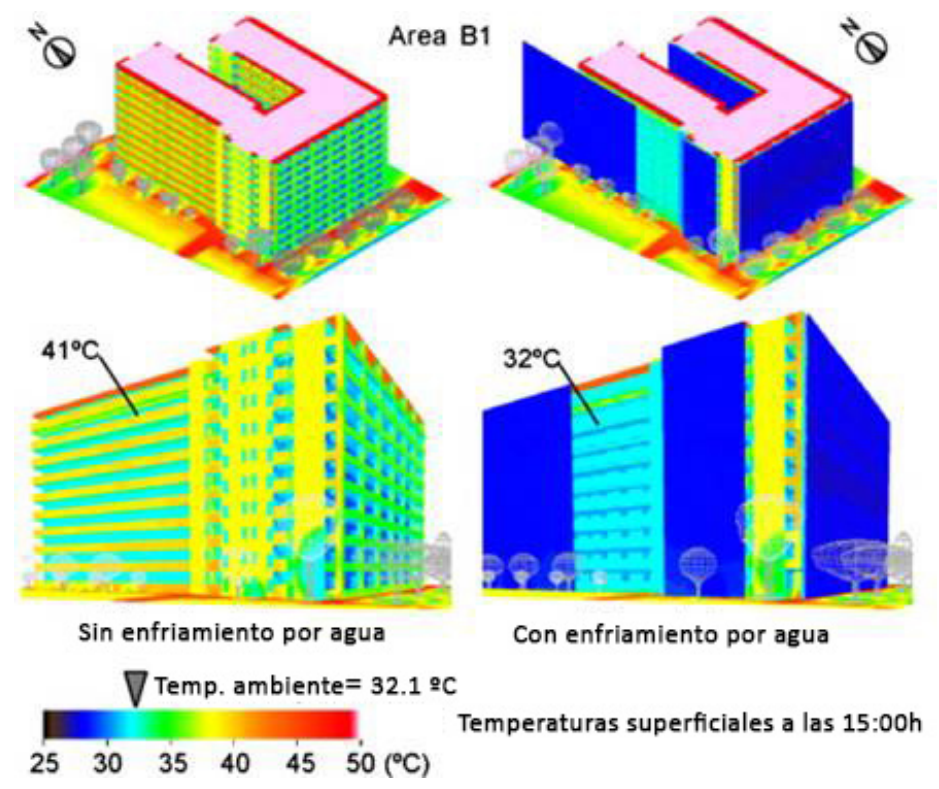


Un recubrimiento superhidrófilo, tiene un ángulo de contacto con el agua próxima a cero grados y por tanto, es mucho menos probable que se manche en relacion a cualquier otro material. En la siguiente imagen se muestra el resultado de un revestimiento superhidrófilo con el que se ha tratado unas baldosas, después de varios meses de exposición al exterior. Las muestras tratadas se colocaron junto con otros paneles de hormigón sin tratamiento, siguiendo el patrón de un tablero de ajedrez ${ }^{106}$.

El contraste es claro entre los que no tienen el tratamiento, en los que la suciedad era muy visible, y el material con recubrimiento superhidrofilia, que no se ha ensuciado. Fujishima señala en su artículo que se prevé que este tipo de revestimiento tenga una vida de por lo menos 10 años ${ }^{107}$.

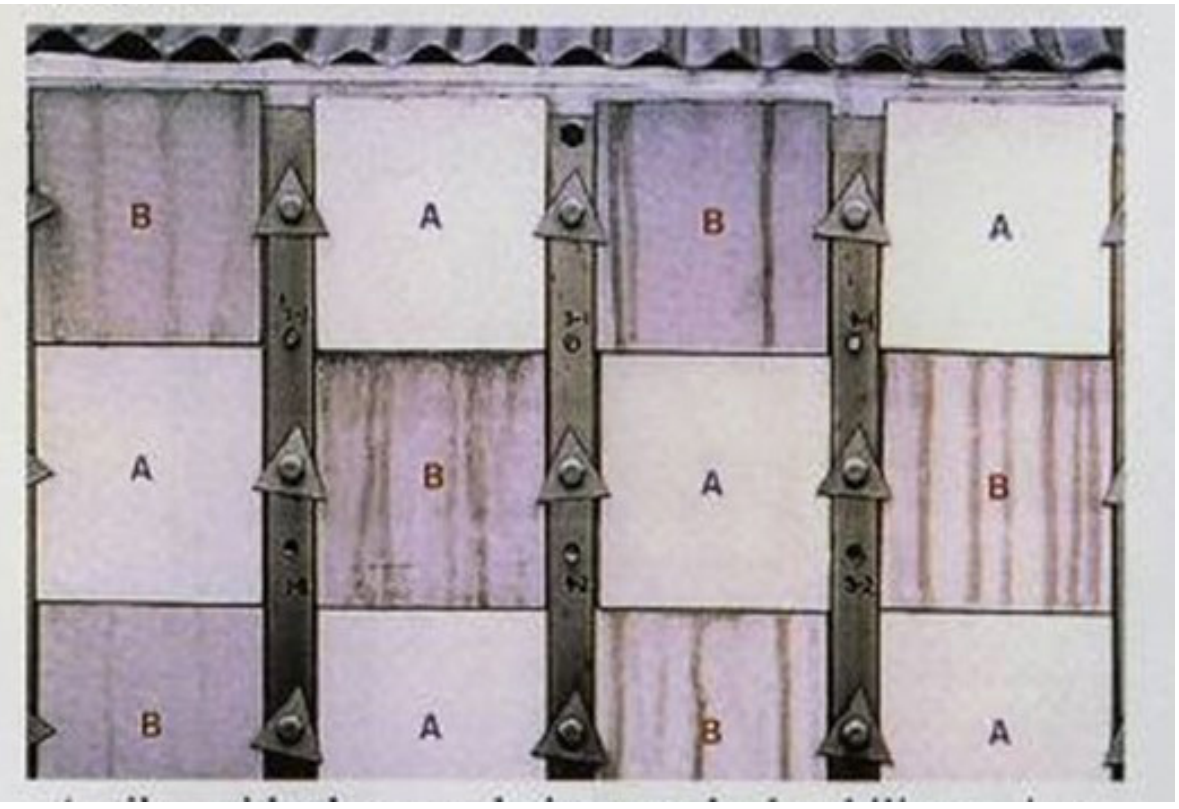

El efecto macro de la autolimpieza es, de hecho, un efecto combinado de superhidrofilia y degradación de depósitos orgánicos. Aunque la superhidrofilia y la degradación fotoinducidas de los contaminantes orgánicos son procesos diferentes, pueden tener efecto simultáneamente. Es difícil distinguir qué mecanismo es más importante para la autolimpieza. También vale la pena destacar el hecho interesante de que, en cierta medida, podría haber efecto sinérgico de la fotocatálisis y la superhidrofilia que favorece la autolimpieza. El radical hidroxilo juega un papel importante en la descomposición de compuestos orgánicos. Si pueden producirse más grupos hidroxilo en la superficie de $\mathrm{TiO}_{2}$ debido a la superhidrofilia, la eficiencia en la degradación de los compuestos orgánicos puede mejorar.

La absorción de compuestos orgánicos sobre la superficie puede producir que una superficie hidrófila, cambie a hidrófoba, por tanto, la descomposición fotocatalítica de contaminantes orgánica puede restaurar la superhidrofilia ${ }^{108}$. Por tanto, el efecto sinérgico entre la fotocatálisis y la superhidrofilia aseguran que pueda mantenerse permanentemente la autolimpieza de la superficie con $\mathrm{TiO}_{2}$.
106 Fujishima, A., Zhang, X.,

\& Tryk, D. A. (2008).

$\mathrm{TiO}_{2}$ photocatalysis and related surface phenomena. Surface Science Reports, 63(12), 515-582.

107 Wang, R., Hashimoto, K., Fujishima,

A., Chikuni, M., Kojima, E., Kitamura, A., \& Watanabe, T. (1998).

Photogeneration of highly amphiphilic $\mathrm{TiO}$, surfaces. Advanced Materials, $10(2), 135-138$

Fig 22. Prueba de campo con baldosas de hormigón resistentes a las manchas causadas por el aire urbano contaminado.

108 Guan, K. (2005)

Relationship between photocatalytic activity, hydrophilicity and self-cleaning effect of $\mathrm{TiO}_{2} / \mathrm{SiO}_{2}$ films. Surface and Coatings Technology, 191(2), 155-160. 
Fig 23. Esquema del proceso de descontaminación y de autolimpieza en una superficie fotocatalítica superhidrófila.

Fig 24. Ángulo de contacto para superficies hidrofóbicas, superhidrófobas, hidrofilicas y superhidrofilicas. hidrófila fotoinducida.
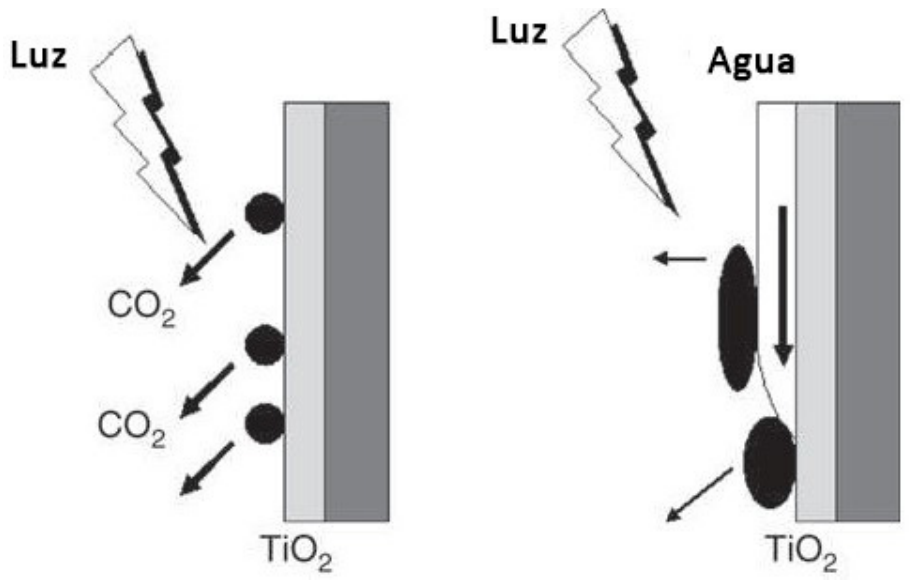

La superhidrofilia es un fenómeno que se produce cuando una película de $\mathrm{TiO}_{2}$ se somete a luz UV apareciendo con el agua un ángulo de contacto muy pequeño. En esta superficie, el agua tiende a extenderse sobre la superficie. Se ha demostrado que el ángulo de contacto está relacionado con la densidad en superficie de grupos hidroxilo producido por la radicación UV. Los enlaces entre los átomos de Titanio y Oxigeno se debilitan bajo la irradiación UV y las moléculas de agua adsorbidas pueden romper un enlace $\mathrm{Ti}-\mathrm{O}-\mathrm{Ti}$ para formar dos nuevos enlaces $\mathrm{Ti}-\mathrm{OH}$, produciendo el fenómeno de la superhidrofilia.
Hidrofóbico: $\theta>90^{\circ}$

\section{$\theta$}

Hidrotilico: $\theta<90$ g

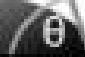

Súperhidrofóbico: $\theta>150^{\circ}$

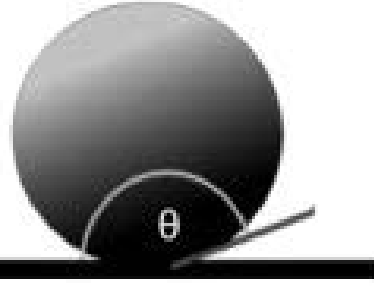

Súperhidrofilico: $\theta \sim 0$ ?

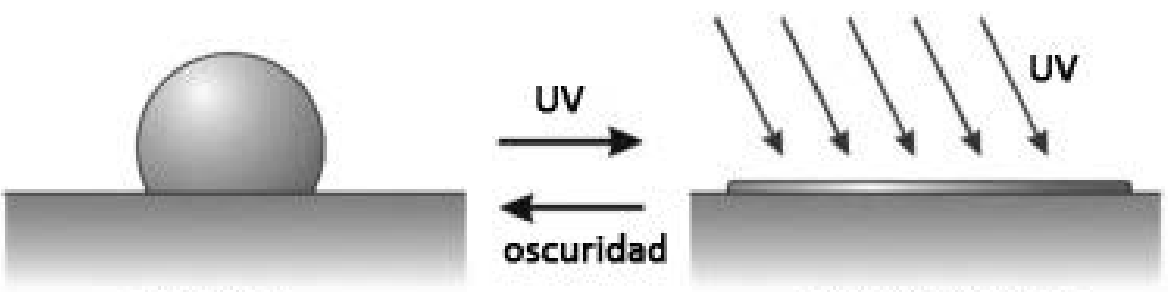

Hidrófobo

Súperhidrofilico

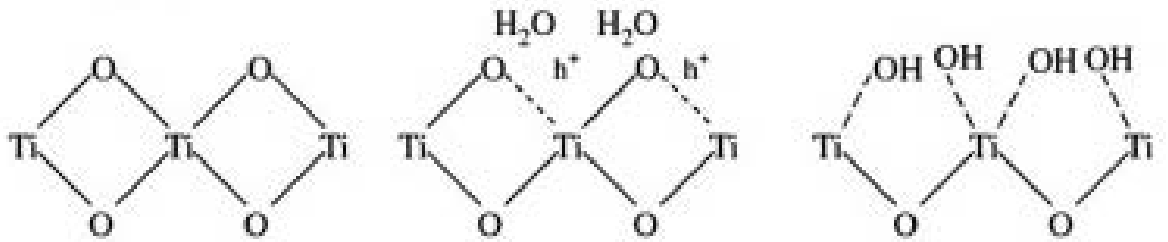

Oscuridad 
La superficie entonces puede adsorber líquidos tanto polares como no polares. Cuando el agua lave la superficie, sustancias como el aceite, pueden ser retiradas de la superficie ${ }^{109}$.

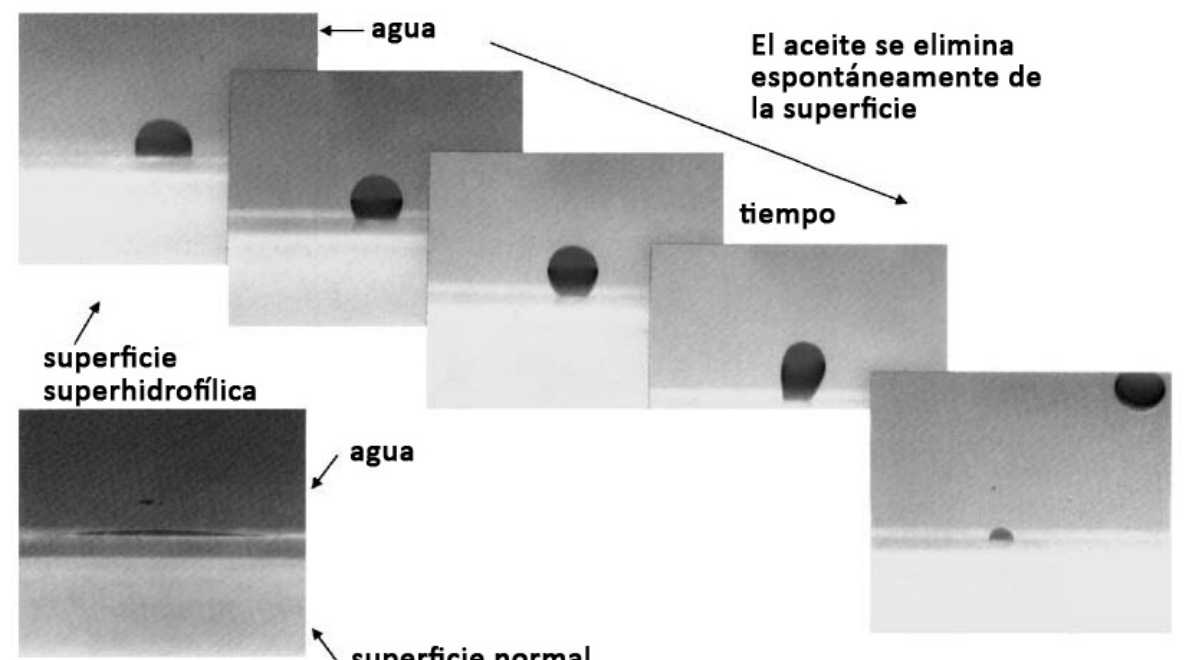

superficie normal

El acero de las estructuras de hormigón armado es vulnerable a la corrosión y degradación por los iones cloruro y los sulfatos iones presentes en el medioambiente y que pueden penetrar en la matriz de hormigón a más o menos velocidad dependiendo del tipo de hormigón. Hay investigadores que han trabajado en estudiar la capacidad de algunas nanopartículas de óxidos metálicos de reducir la permeabilidad a los iones y la resistencia del hormigón mejorando asi su durabilidad, como por ejemplo $\mathrm{TiO}_{2}{ }^{110,111,112}, \mathrm{Al}_{2} \mathrm{O}_{3}, \mathrm{ZrO}_{2}$, $\mathrm{Fe}_{2} \mathrm{O}_{3}, \mathrm{SiO}_{2}$, incluso nanoarcillas que contienen óxidos metálicos.

En general todas han demostrado que mejoran las propiedades del cemento y/o los morteros de cemento. La adición de nanopartículas de óxidos metálicos acelera las reacciones químicas durante la hidratación inicial, reforzando la matriz cemento. Las nanopartículas de óxidos metálicos reaccionan con el $\mathrm{Ca}(\mathrm{OH})_{2}$ presente, aumentando asi la cantidad de gel (C-S-H) producido, dando lugar a una microestructura más compacta que no sólo disminuye la permeabilidad, sino que también mejora las propiedades mecánicas ${ }^{113}$, tales como la resistencia a compresión, la resistencia a flexotracción y la resistencia a la abrasión.

Zhang y $\mathrm{Li}^{112}$ encontraron que la adición de $1 \%$ sobre peso de cemento de $\mathrm{TiO}_{2}$ con un tamaño de partícula de $15 \mathrm{~nm}$ de diámetro al hormigón tenía como consecuencia un refinamiento de la estructura de poros y aumentaba la resistencia a la penetración por cloruros en un $31 \%$. Shekari y Razzaghilit vieron que la adición de $1,5 \%$ sobre peso total de $\mathrm{Al}_{2} \mathrm{O}_{3}, \mathrm{ZrO}_{2}, \mathrm{TiO}_{2} \circ \mathrm{Fe}_{3} \mathrm{O}_{4}$ con un tamaño de partícula entre 10 y $25 \mathrm{~nm}$ aumentaba las resistencias a compresión y reducía la penetración de los cloruros en el hormigón entre un 20 y un $80 \%$.

Castellote et al. ${ }^{115}$, han estudiado la influencia del uso de $\mathrm{TiO}_{2}$ como adición al cemento sobre la corrosión de las armaduras embebidas en hormigón, ya que por un lado, la formación de $\mathrm{CO}_{2}$ por la oxidación de moléculas
109 Wang, R., Hashimoto, K., Fujishima, A., Chikuni, M., Kojima, E., Kitamura, A., ... \& Watanabe, T. (1997).

Light-induced amphiphilic surfaces. Nature, 388(6641), 431.

Fig 26. La imagen muestra cómo se limpia una superficie debido a la propiedad de la superhidrofilia.

110 Nazari, A., \& Riahi, S. (2011).

The effects of $\mathrm{TiO} 2$ nanoparticles on flexural damage of self-compacting concrete. International Journal of Damage Mechanics, 20(7), 1049-1072.

111 Nazari, A., \& Riahi, S. (2011)

$\mathrm{TiO}_{2}$ nanoparticles effects on physical, thermal and mechanical properties of self compacting concrete with ground granulated blast furnace slag as binder. Energy and Buildings, 43(4), 995-1002.

112 Zhang, M. H., \& Li, H. (2011).

Pore structure and chloride permeability of concrete containing nano-particles for pavement. Construction and Building Materials, 25(2), 608-616.

113 Senff, L., Hotza, D., Lucas, S.,

Ferreira, V. M., \& Labrincha, J. A. (2012). Effect of nano-SiO 2 and nano-TiO, addition on the rheological behavior and the hardened properties of cement mortars. Materials Science and Engineering: A, 532, 354-361.

114 Shekari, A. H., \& Razzaghi, M. S. (2011). Influence of nano particles on durability and mechanical properties of high performance concrete. Procedia Engineering, 14, 3036-3041.

${ }^{115}$ Castellote, M., Botija, S., \& Andrade, C. (2006)

Influencia del uso de material fotocatalítico como adición al cemento en la durabilidad de las armaduras embebidas en hormigón. 
${ }^{116}$ Chen, J., Kou, S. C., \& Poon, C. S. (2012). Hydration and properties of nano- $\mathrm{TiO}_{2}$ blended cement composites. Cement and Concrete Composites, 34(5), 642-649.

${ }^{117}$ Diamanti, M. V., Lollini, F., Pedeferri, M. P., \& Bertolini, L. (2013).

Mutual interactions between carbonation and titanium dioxide photoactivity in concrete. Building and Environment, 62, 174-181.

118 Lucas, S. S., Ferreira, V. M., \& de Aguiar, J. B. (2013) Incorporation of titanium dioxide nanoparticles in mortars-Influence of microstructure in the hardened state properties and photocatalytic activity.

Cement and concrete research, 43, 112-120.

119 Sugrañez, R., Álvarez, J. I., Cruz-Yusta, M., Mármol, I., Morales, J.,

Vila, J., \& Sánchez, L. (2013).

Enhanced photocatalytic degradation of $\mathrm{NO} \times$ gases by regulating the microstructure of mortar cement modified with titanium dioxide. Building and Environment, 69, 55-63.112-120.

${ }^{120}$ Ruot, B., Plassais, A., Olive, F., Guillot, L., \& Bonafous, L. (2009).

$\mathrm{TiO}_{2}$-containing cement pastes and mortars: measurements of the photocatalytic efficiency using a rhodamine B-based colourimetric test.

Solar Energy, 83(10), 1794-1801.

${ }^{121}$ Nazari, A., Riahi, S., Riahi, S., Shamekhi, S. F., \& Khademno, A. (2010). Improvement the mechanical properties of the cementitious composite by using $\mathrm{TiO} 2$ nanoparticles. Journal of American Science, 6(4), 98-101.

${ }^{122}$ Lackhoff, M., Prieto, X., Nestle, N., Dehn, F., \& Niessner, R. (2003). Photocatalytic activity of semiconductormodified cement-influence of semiconductor type and cement ageing. Applied Catalysis B: Environmental, 43(3), 205-216.

${ }^{123}$ Poon, C. S., \& Cheung, E. (2007). $\mathrm{NO}$ removal efficiency of photocatalytic paving blocks prepared with recycled materials. Construction and Building Materials, 21(8), 1746-1753.

124 Poon, C. S., \& Cheung, E. (2006, November).

Performance of photo-catalytic paving blocks made from waste. In Proceedings of the Institution of Civil Engineers-

Waste and Resource Management (Vol. 159, No. 4, pp. 165-171) Thomas Telford Ltd.

${ }^{125}$ Cassar, L., Beeldens, A., Pimpinelli, N., \& Guerrini, G. L. (2007, October). Photocatalysis of cementitious materials. In International RILEM Symposium on Photocatalysis, Environment and Construction Materials (pp. 131-145). orgánicas en su superficie podría llevar a la aceleración de la carbonatación de la matriz, y por otra parte, la oxidación de iones cloruro a cloro gaseoso evitaría la corrosión por picaduras inducida por aquellos. Concluye que no afectaba a los potenciales del acero en contacto con la matriz de cemento, ni a la velocidad de penetración del $\mathrm{CO}_{2}$ y con un efecto positivo ya que disminuía la penetración del frente de cloruros.

Se han llevado a cabo otras investigaciones donde se han estudiado las interacciones de las nanopartículas de $\mathrm{TiO}_{2}$ con el cemento fijándose en cómo influye en la hidratación ${ }^{116}$, la carbonatación ${ }^{117}$, la microestructura ${ }^{118,}{ }^{119}$, las

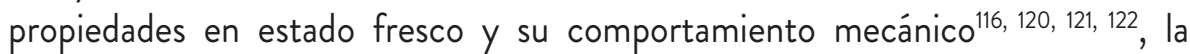
influencia de los diferentes tipos de áridos, incluso los $\mathrm{RCD}^{123,124}$ son algunos de los ejemplos estudiados, encontrando en algunos casos resultados contradictorios, principalmente en cuanto a la influencia en la porosidad y la resistencia mecánica resultante.

El interés por la aplicación de la fotocatálisis del $\mathrm{TiO}_{2}$ en materiales de construcción fue expuesta por el Comité Técnico RILEM 194-TDP125, 126, 127, 128 basado en un informe sobre estado del arte del año 2005 en relación los siguientes temas:

1. Fundamentos de la fotocatálisis $\mathrm{TiO}_{2}$ aplicable en la práctica en los campos de materiales de construcción.

2. Beneficios de la utilización de materiales de construcción $\mathrm{TiO}_{2}$ fotocatalítico.

3. Desarrollo de materiales de construcción autolimpiantes con $\mathrm{TiO}_{2}$ como fotocatalizador.

4. Desarrollo de materiales de construcción descontaminantes con $\mathrm{TiO}_{2}$ fotocatalizador.

5. Desarrollo de materiales de construcción antibacterianos con $\mathrm{TiO}_{2}$ como fotocatalizador.

6. Posibilidad de futuros desarrollos de materiales de construcción con $\mathrm{TiO}_{2}$ como fotocatalizador.

En las grandes ciudades con una densa población, la concentración de contaminantes a nivel del suelo puede ser bastante alta porque, la dispersión de los gases de escape generados por la circulación rodada se ve obstaculizada debido a los edificios circundantes. En estas ciudades la utilización de materiales base cemento que incorporan $\mathrm{TiO}_{2}$ como revestimiento exterior de los edificios o en los pavimentos podrían ser una estrategia complementaria a las tecnologías convencionales, como son los convertidores catalíticos que van instalados en los vehículos para reducir la emisión de gases de escape. 
Los pavimentos y las fachadas de los edificios son localizaciones óptimas para la aplicación de los materiales fotocatalíticos debido a la configuración relativamente plana que puede facilitar la exposición del fotocatalizador a la luz solar. Se ha comprobado que la naturaleza de la matriz de cemento es particularmente adecuada para incorporar las partículas de $\mathrm{TiO}_{2}{ }^{125,127}$.

Cassar et al. ${ }^{1}$, en el capítulo 4.3 Fotocatálisis añadió $\mathrm{TiO}_{2}$ en pastas de cemento blanco, con la idea de dotar al hormigón de actividad fotocatalítica, para verificar la propiedad de autolimpieza, utilizo testigos de cemento blanco que se mancharon con una solución de fenantroquinona en concentración 0,1 $\mathrm{mg} / \mathrm{cm} 3$, después de unas horas de irradiación UV consiguió restablecer el aspecto inicial de las muestras. Los ensayos comprobaron la capacidad de eliminación de $\mathrm{NO}_{x}$ en muestras que, contenían un $5 \%$ de $\mathrm{TiO}_{2}$ sobre peso de cemento. A escala de laboratorio, se obtuvieron eficiencias de eliminación de $\mathrm{NO}_{x}$ hasta un $92 \%$ después de una exposición de $7 \mathrm{~h}$ a una lámpara de $300 \mathrm{~W}$. El uso combinado de $\mathrm{TiO}_{2}$ y cemento mostró un efecto sinérgico hacia la eliminación de $\mathrm{NO}_{x}$.

Hunger et al. 129, 130, 131, compararon la aplicación de $\mathrm{TiO}_{2}$ sobre bloques de pavimento por pulverización de una suspensión de agua-catalizador ( $5 \%$ de $\mathrm{TiO}_{2}$ concentración) sin aglutinantes en la parte superior de un baldosa de hormigón que ya había fraguado y endurecido para compararla con otra en la que todavía no había fraguado. En este último caso, la superficie fresca ofrece un mejor anclaje del $\mathrm{TiO}_{2}$ pero, parte del catalizador queda cubierto y su actividad, determinada por la oxidación de $\mathrm{NO}_{x}$ fue inferior en comparación con las muestras en las que la solución se pulveriza sobre la superficie endurecida.

Según Chen et al. ${ }^{132}$, la versátil función del $\mathrm{TiO}_{2}$, que puede se puede utilizar para materiales fotocatalíticos tanto estructurales como no estructurales, ha facilitado su aplicación en materiales de construcción exterior y materiales de decoración interior, como mortero de cemento, baldosas exteriores, pavimentos, vidrio y PVC. Las ventajas de colocar $\mathrm{TiO}_{2}$ en materiales de construcción han atraído muchos intereses industriales.

En 2003, las ventas de materiales de construcción fotocatalíticos representaron el $60 \%$ de la cuota de mercado fotocatalítica total en Japón ${ }^{133}$.

Guerrini et al. ${ }^{134,135}$, en el artículo que presentó en el Congreso de Química del Cemento del año 2010 en Madrid expuso las cifras de consumo de cementos fotocatalíticos TX Active ${ }^{\circledR}$ fabricados por Italcementi Group en Italia, segmentados por solución constructiva durante el periodo 20062009. Guerrini señala que la tendencia en los consumos de volumen muestra un cambio de los pavimentos prefabricados, hacia las pinturas. Esto significa que ha habido un avance en los consumos que no corresponde a un aumento proporcional de las superficies cubiertas. De hecho, la superficie fotocatalítica en los pavimentos prefabricados de hormigón es sólo la capa superior. Las pinturas y revestimientos representan una pequeña cantidad de cemento debido al bajo espesor, pero en términos de
126 Hüsken, G., Hunger, M.,

\& Brouwers, H. J. (2007, October)

Comparative study on cementitious products containing titanium dioxide as photo-catalyst. In Proceedings of international RILEM symposium on photocatalysis, environment and construction materials (pp. 8-9).

127 Kawakami, M., Furumura, T., \& Tokushige, H. (2007).

$\mathrm{NO}$, removal effects and physical properties of cement mortar incorporating titanium dioxide powder

128 Ohama, Y., \& Van Gemert, D. (Eds.). (2011).

Application of titanium dioxide photocatalysis to construction materials: state-of-the-art report of the RILEM technical committee 194-TDP (Vol. 5). Springer Science \& Business Media.

129 Hunger, M., Hüsken, G. G., \& Brouwers, H. J. (2008).

Photocatalysis applied to concrete products-Part 1: Principles and test procedure. ZKG international, 61(8), 77.

130 Hunger, M., Hüsken, G.,

\& Brouwers, H. J. (2008).

Photocatalysis applied to concrete products. ZKG international, 61(10), 76-84

131 Hunger, M., Hüsken, G., \& Brouwers, H. J. (2009).

Photocatalysis applied to concrete products-Part 3: Practical relevance and modeling of the degradation process.

${ }^{132}$ Chen, J., \& Poon, C. S. (2009).

Photocatalytic construction and building materials: from fundamentals to applications. Building and Environment, 44(9), 1899-1906.

133 Fujishima, A., \& Zhang, X. (2006).

Titanium dioxide photocatalysis: present situation and future approaches. Comptes Rendus Chimie, 9(5), 750-760.

${ }^{134}$ Guerrini, G. L. (2010).

Photocatalytic Cementitious

Materials-Situation, Challenges, and

Perspectives. World Cement.[Online]

Available at:

http://www. worldcement. com/

documents/Italcementi\% 20proof. pdf

[Accessed Febrero 2015].

135 Hunger, M., Hüsken, G.,

\& Brouwers, H. J. (2008).

Photocatalysis applied

to concrete products.

ZKG international, 61(10), 76-84 
Fig 27. Segmentación del mercado Italiano, por productos fabricados con cemento fotocatalítico en el periodo 2006-2009.

${ }^{136}$ Allen, N. S., Edge, M., Verran, J., Stratton, J., Maltby, J., \& Bygott, C. (2008).

Photocatalytic titania based surfaces: environmental benefits.

Polymer degradation and stability, 93(9), 1632-1646.

${ }^{137}$ Hassan, M. M., Dylla, H., Mohammad, L. N., \& Rupnow, T. (2010). Evaluation of the durability of titanium dioxide photocatalyst coating for concrete pavement. Construction and building materials, 24(8), 1456-1461.

138 Panesar, D. K., \& Churchill, C. J. (2013). The influence of design variables and environmental factors on life-cycle cost assessment of concrete culverts. Structure and Infrastructure Engineering, 9(3), 201-213. superficies fotocatalíticas representan más del $50 \%$ del total. Según una estimación fiable, las superficies fotocatalíticas producidas en Europa con materiales a base de cemento hasta el año 2010 resultan ser próximas a los $2.000 .000 \mathrm{~m}^{2}$. Como se muestra más adelante, el hormigón fotocatalítico está aumentando en volumen de forma considerable
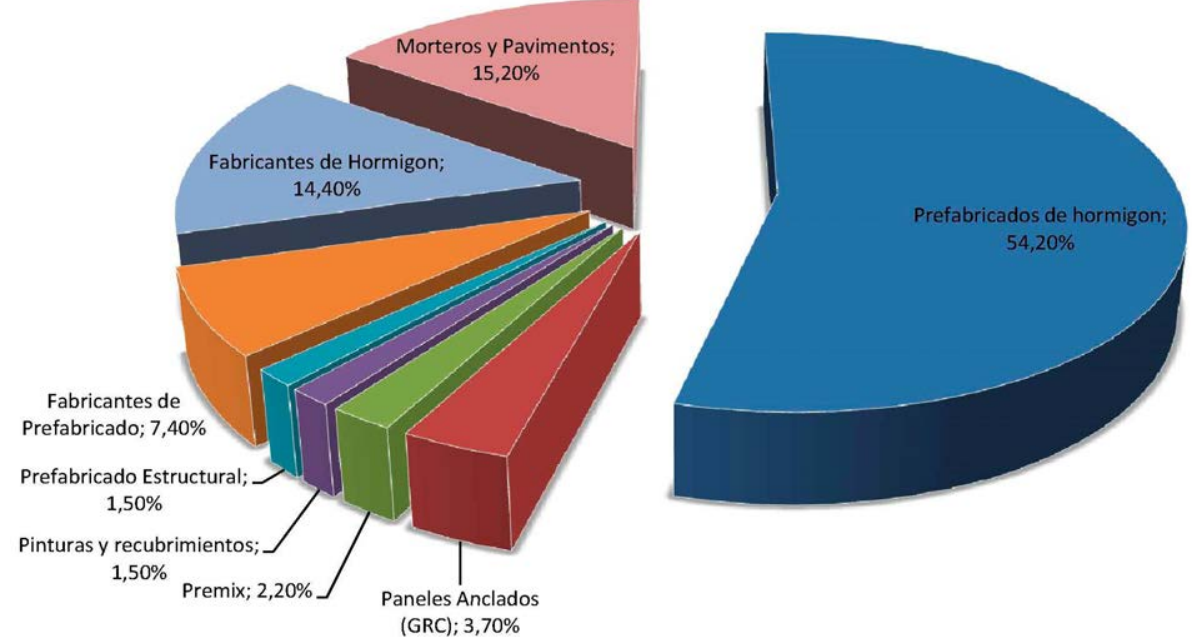

Un aspecto particularmente interesante de las mezclas de $\mathrm{TiO}_{2}$ y cemento es que existe una clara sinergia entre ellos que hace que el cemento sea un sustrato ideal para la fotocatálisis ambiental ${ }^{119,136}$. De hecho, muchos compuestos fotooxidantes como el $\mathrm{NO}_{x}$ y el $\mathrm{SO}_{x}$ tienen carácter ácido y la naturaleza básica de la matriz de cemento es particularmente adecuada para fijar en su superficie tanto los reactivos contaminantes, como los productos de la fotooxidación. Estos cementos llevan normalmente, hasta un $3 \%$ de $\mathrm{TiO}_{2}$ sobre peso de cemento para optimizar los costes. Esta contrastado también que los recubrimientos fotocatalíticos de $\mathrm{TiO}_{2}$ poseen una durabilidad y resistencia al desgaste aceptables ${ }^{137}$.

Aunque no se dispone de datos de costes por $\mathrm{m}^{3}$, es lógico pensar que sean más altos en el hormigón fotocatalítico, que en el hormigón convencional. En este sentido, un análisis de costes de ciclo de vida (ACV) realizado por Churchill y Panesar ${ }^{138}$ han calculado que en el caso de una barreras antiruido de una autovía, si se fabrica en bicapa, con la capa exterior de $25 \mathrm{~mm}$ de espesor fotocatalítica, suponiendo una vida útil de 40 años y asumiendo una tasa de degradación de $\mathrm{NOx}=6 \mathrm{mg}$ h- $1 \mathrm{~m}-2$, tendría un costo anual entre un $7 \%$ y $30 \%$ superior, frente a la solución no fotocatalítica, fabricada con cemento convencional y un 35\% de escorias (GGBFS).

Sin embargo económicamente, si se fabrica un hormigón fotocatalítico utilizando un cemento con contenido de entre un 35 y un $50 \%$ de escorias (GGBFS), es más favorable que si se hace utilizando un hormigón no fotocatalítico sin sustitución de parte del cemento por escorias, independientemente del tiempo de vida y la tasa de eliminación de $\mathrm{NO}_{x}$.

La eficacia de los materiales fotocatalíticos base cemento en la disminución de los compuestos orgánicos que contienen las partículas atmosféricas 
totales se demostró en un estudio realizado por el Departamento de Química de la Universidad de La Sapienza de Roma basado en una prueba respirométrica que ha cuantificado la velocidad de degradación de partículas PM10 orgánicas en contacto con pinturas a base de cemento fotocatalítico ${ }^{138}$.

Quagliarini et al. ${ }^{139}$, han valorado las propiedades fotocatalíticas del $\mathrm{TiO}_{2}$ para su aplicación en trabajos de restauración en el patrimonio histórico, en concreto sobre mármol travertino, una piedra caliza utilizada con frecuencia en edificios singulares. Estudiando el fenómeno de la superhidrofilia para obtener un efecto de autolimpieza. No afectaba a su aspecto original gracias a su bajo espesor, únicamente constato pequeñas modificaciones de la morfología del sustrato.

Según Smits et al. ${ }^{141}$, plantea en un trabajo de investigación que, debido a que las emisiones de los vehículos diésel deterioran los materiales de construcción utilizados en las envolventes de los edificios a través del ensuciamiento por el material particulado, lo cual afecta al valor estético del edificio y deteriora los materiales. Una solución puede será el uso de dióxido de titanio fotocatalítico en los materiales. $\mathrm{El} \mathrm{TiO}_{2}$ puede proporcionar propiedades descontaminantes y autolimpiantes debido a su actividad fotocatalítica a los materiales base cemento.
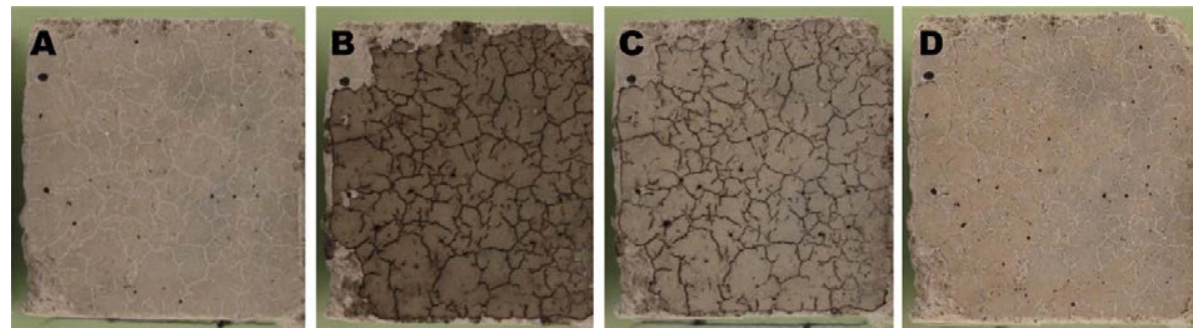

El resultado de su ensayos demostró que la eliminación de hollín en superficies base cemento recubiertas con $\mathrm{TiO}_{2}$-fotocatalitico es posible en la vida real, lo cual es un paso importante hacia la autolimpieza de los edificios. En general, debido a las mínimas influencias de los revestimientos sobre el aspecto visual, las aplicaciones en la vida real son posibles sin interferir con el valor estético del edificio. Se obtuvo la mineralización completa de aproximadamente el $60 \%$ del hollín en 24 horas, el único producto de oxidación observado fue $\mathrm{CO}_{2}$.

Hanus et al. ${ }^{142}$, propone una representación esquemática del mecanismo de los cementos fotocatalíticos por el cual, el $\mathrm{NO}_{x}$ se transforma en el $\mathrm{NO}_{3}$ - y este reacciona con las reservas de calcio que tiene el cemento para formar nitrato de calcio $\mathrm{CaNO}_{3}$, una sal soluble en agua e inocua que puede ser eliminada por el agua de lluvia
138 Campanella, L., Borzetti, F.,

\& Cassar, L. (2016).

Photocatalytic cement: a new approach to environmental protection. Newsletter.

139 Smits, M., kit Chan, C.,

Tytgat, T., Craeye, B., Costarramone, N., Lacombe, S., \& Lenaerts, S. (2013). Photocatalytic degradation of soot deposition: Self-cleaning effect on titanium dioxide coated cementitious materials. Chemical engineering journal, 222, 411-418.

141 Smits, M., kit Chan, C.,

Tytgat, T., Craeye, B., Costarramone, N., Lacombe, S., \& Lenaerts, S. (2013).

Photocatalytic degradation of soot deposition: Self-cleaning effect on titanium dioxide coated cementitious materials. Chemical engineering journal, 222, 411-418.

Fig 28. Fotos de las muestra de mortero gris revestida con $\mathrm{TiO}_{2}$-Degussa P25

(A) Muestra de mortero con $\mathrm{TiO}_{2}$

(B) después de la aplicación del hollín pero antes de la irradiación

(C) después de 42h de irradiación

(D) después de 420 h de irradiación.

Fuente: Smits et al. ${ }^{141}$
142 Hanus, M. J., \& Harris, A. T. (2013).

Nanotechnology innovations for the construction industry. Progress in materials science, 58(7), 1056-1102. 
Fig 29. Mecanismo de la fotocatálisis aplicada a los materiales de cemento que contienen $\mathrm{TiO}_{2}$ Fuente Hanus et al.
143 Jimenez-Relinque, E., Rodriguez-Garcia, J. R., Castillo, A., \& Castellote, M. (2015) Characteristics and efficiency of photocatalytic cementitious materials: Type of binder, roughness and microstructure. Cement and Concrete Research, 71, 124-131.

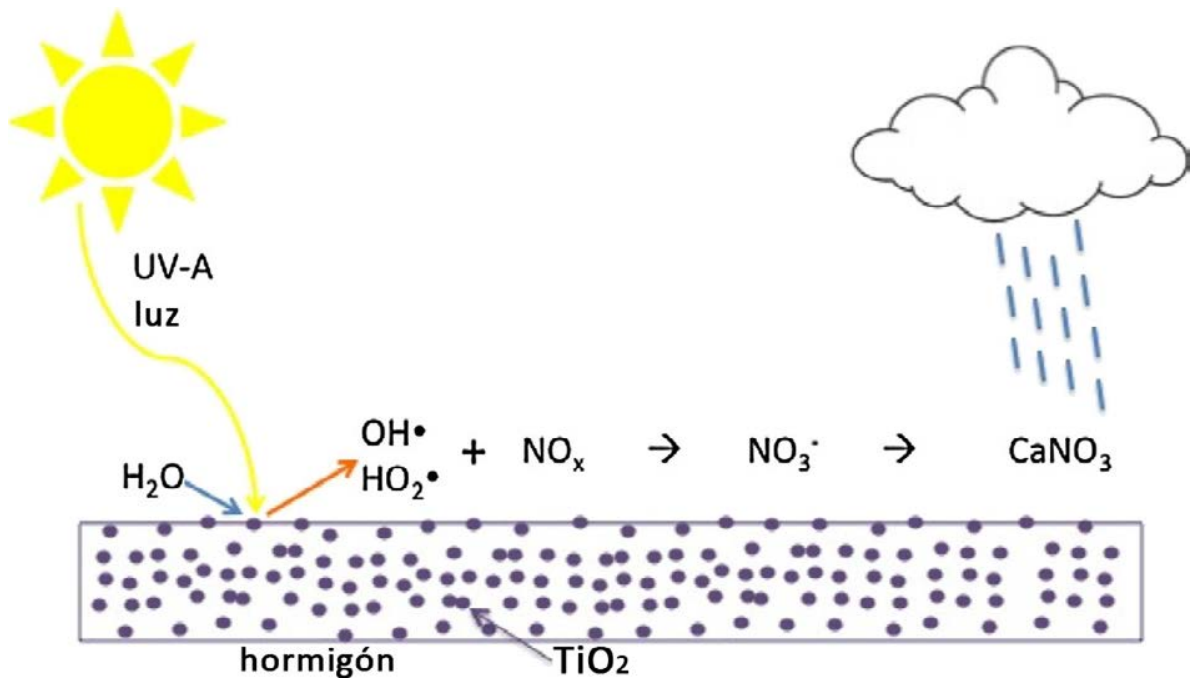

Según Fujishima et al. ${ }^{21}$, los contaminantes atmosféricos que se encuentran en concentraciones de 0,01 ppm a 10 ppm, ordinaria en los túneles de las autopistas, pueden ser eliminados eficientemente por tales materiales base cemento fotocatalítico

Dylla, et al. ${ }^{47,48}$, Han comparado tres técnicas en los pavimentos de hormigón 206]:

1. Aplicación de una fina capa de cemento que contiene fotocatalizador, donde el fotocatalizador se añade como polvo o suspensión durante el proceso de fabricación del cemento;

2. Aplicación de una disolución sobre el hormigón que contiene fotocatalizador;

3. Aplicación por aspersión del fotocatalizador sobre el hormigón fresco.

Relinque et al. ${ }^{143}$, han estudiado el efecto sobre las características de un mortero base cemento la adición de $\mathrm{TiO}_{2}$, en su investigación ha estudiado la influencia del tipo de conglomerante, la rugosidad superficial y la microestructura frente a la propiedades de autolimpieza y eliminación de $\mathrm{NO}_{\mathrm{x}}$. Obtuvo los siguientes resultados:

- La adición de $2 \%$ de $\mathrm{TiO}_{2}$ sobre el peso del cemento influye en las propiedades frescas y endurecidas de los morteros. Se identificó una disminución de la trabajabilidad y una ligera reducción de la resistencia a la compresión de los morteros. Con respecto a la microestructura, el diámetro medio de los poros disminuyó significativamente.

- Se estableció una correlación entre los rangos de poros y la actividad fotocatalítica. La condición más favorable representa un compromiso que permite a los contaminantes acceder a la estructura interna del mortero y también a la luz para alcanzar la parte más profunda de la misma, siendo para $\mathrm{NO}_{\mathrm{x}}$ (de 0,5 a 0,05 $\mu \mathrm{m}$ ) y para el azul de metileno (desde 1 a $0,05 \mu \mathrm{m}$ ). 
- La actividad fotocatalítica depende de la naturaleza química de los materiales de mezcla de los morteros, siendo el mortero OPC el mortero más activo junto con el CAC, seguido por ceniza volante y la escoria de alto horno siendo estos los menos activos.

Folli et al. ${ }^{43,60}$, realizaron un estudio de una matriz cemento endurecido que contenía $\mathrm{TiO}_{2}$ de tamaños nano y micrométrico y comprobó que, aunque las partículas de $\mathrm{TiO}_{2}$ a escala micrométrica y nanométrica tienden a aglomerarse, aunque las partículas $\mathrm{m}-\mathrm{TiO}_{2}$ de escala micrométrica se dispersan mejor, se aglomeran menos y generan poros de mayor tamaño, dispersándose mejor que las partículas de tamaño nanométrico $\mathrm{n}-\mathrm{TiO}_{2}$. El área superficial activa efectiva depende del tamaño de la molécula a degradarse, esto quiere decir que, como las moléculas de $\mathrm{NO}_{x}$, que tienen dimensiones relativamente pequeñas, del orden 100-200 pm pueden penetrar fácilmente tanto en las aglomeraciones de $\mathrm{n}-\mathrm{TiO}_{2}$ y de $\mathrm{m}-\mathrm{TiO}_{2}$ pero, como el $\mathrm{n}-\mathrm{TiO}_{2}$ tiene poros más pequeños su área superficial especifica disponible es mayor en el caso de las $\mathrm{m}_{-} \mathrm{TiO}_{2}$ y por tanto se consiguen mayores velocidades de descomposición.

Sin embargo la molécula de rodamina $B$, un contaminante orgánico de color rojo tiene un diámetro molecular de aprox. 1,6 nm, "no cabe", no puede acceder a la superficie del $\mathrm{n}-\mathrm{TiO}_{2}$, no le es posible de penetrar en los poros de $8 \mathrm{~nm}$ de las aglomeraciones del $\mathrm{n}-\mathrm{TiO}_{2}$. Las estructuras de $\mathrm{m}-\mathrm{TiO}_{2}$ son más grandes y permiten la degradación de esta molécula en particular.

(a)

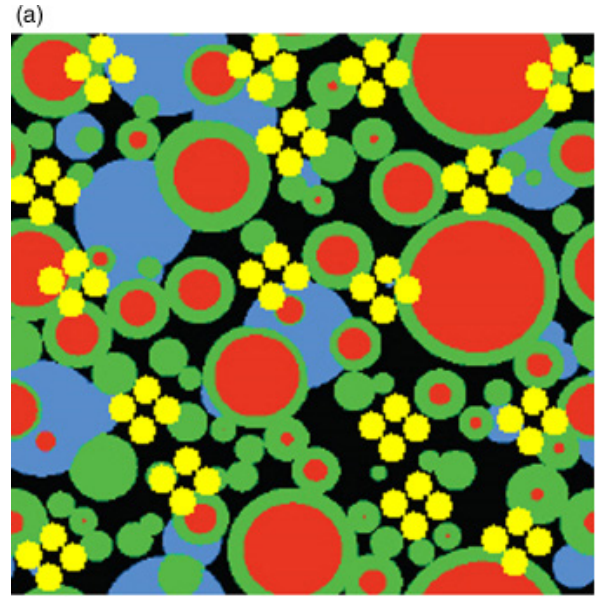

Grano de cemento sin reaccionar

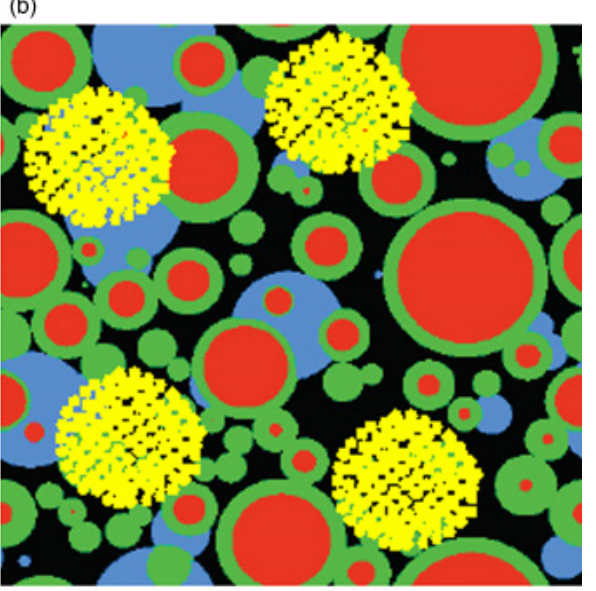

Hidróxido Cálcico (CH)

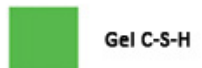

Porosidad

Comprobó como el $\mathrm{pH}$ e iones que están presentes en el poro de la matriz de cemento $\left(\mathrm{K}^{+}, \mathrm{Na}^{+}, \mathrm{Ca}^{2+}, \mathrm{SO}_{4}{ }^{2-}\right)$ pueden generar fenómenos de agregación y dispersiones inestables de las partículas de $\mathrm{n}-\mathrm{TiO}_{2}$ y $\mathrm{m}-\mathrm{TiO}_{2}$ debido adsorción específica de los iones en las superficie del $\mathrm{TiO}_{2}$.
Fig 30. La estructura del cemento endurecido que contiene

(a) partículas de $\mathrm{TiO}$, de tamaño micrométrico $\left(\mathrm{m}-\mathrm{TiO}_{2}\right)$ (b) nanopartículas de $\mathrm{TiO}_{2}\left(\mathrm{n}-\mathrm{TiO}_{2}\right)$. 
144 Hüsken, G., Hunger, M.,

\& Brouwers, H. J. H. (2009). Experimental study of photocatalytic concrete products for air purification.

Building and environment, 44(12), 2463-2474

${ }^{145}$ Guo, M. Z., Ling, T. C., \& Poon, C. S. (2013). Nano-TiO,-based architectural mortar for $\mathrm{NO}$ removal and bacteria inactivation: Influence of coating and weathering conditions. Cement and Concrete Composites, 36,

$101-108$

${ }^{146}$ Ramirez, A. M., Demeestere, K., De Belie, N., Mäntylä, T. \& Levänen, E. (2010).

Titanium dioxide coated cementitious materials for air purifying purposes: preparation, characterization and toluene removal potential. Building and Environment, 45(4), 832-838.

147 Strini, A., Cassese, S. \& Schiavi, L. (2005) Measurement of benzene, toluene, ethylbenzene and o-xylene gas phase photodegradation by titanium dioxide dispersed in cementitious materials using a mixed flow reactor. Applied Catalysis

B: Environmental, 61(1), 90-97.
Lucas et al. ${ }^{144}$, estudio el efecto en morteros de cemento, cemento-cal observo que mostraban una pérdida de resistencias mecánicas para adiciones de más del $1 \%$ en peso de $\mathrm{TiO}_{2}$, debido al aumento de la porosidad. Para el mortero de cal y yeso esa reducción de la resistencia mecánica, cuando el contenido de aditivo era superior al $1 \%$ en peso iba acompañada de un aumento de la porosidad total y del tamaño del poro. El mortero de yeso fue el que presento una mayor reducción de la resistencia mecánica, lo que indica un inconveniente para la incorporación de las nanopartículas.

Comparando los valores de eliminación de $\mathrm{NO}_{x}$ registrados, todas las muestras tuvieron una actividad fotocatalítica alta, incluso para los porcentajes de adición más bajos ( 0,5 y $1 \%$ en peso). Teniendo en cuenta la pérdida de resistencia mecánica, el ligero aumento de los valores de eliminación de $\mathrm{NO}_{x}$, al aumentar las cantidades de $\mathrm{TiO}_{2}$ (2,5 y $5 \%$ en peso) no los consideraban suficientes para que compensase su incorporación. Los morteros de cal y cal-cemento tuvieron los mayores valores de degradación de $\mathrm{NO}_{x}$ a $0,5 \%$ en peso y $1 \%$ en peso de $\mathrm{TiO}_{2}$ respectivamente, a porcentajes superiores a estos vieron que bajaba la velocidad de degradación. El resto de morteros de cemento, yeso y cal-yeso, tenían una mayor actividad fotocatalítica al aumentar el contenido de $\mathrm{TiO}_{2}$.

Hüsken et al. ${ }^{144}$, midió que la rugosidad de la superficie influía, cuanto más acentuada era, más favorable para la descontaminación del aire debido a la disponibilidad de mayor superficie activa. Otros autores estaban de acuerdo con estos resultados ${ }^{145,146}$, y reconocieron la ventaja de la superficie de rugosidad para la retención de las partículas de $\mathrm{TiO}_{2}$.

Poon y Cheung et al. ${ }^{123}$, comprobaron que la capacidad descontaminante (NO) de un pavimento prefabricado de hormigón fabricados por materiales reciclados que incorporaban $\mathrm{TiO}_{2}$. Encontraron que un diseño óptimo de la mezcla que incorporaba vidrio reciclado, arena, cemento y un $10 \%$ de $\mathrm{TiO}_{2}$ alcanzaba una tasa de eliminación de $\mathrm{NO}$ de $4,01 \mathrm{mg} \mathrm{h}^{-1} \mathrm{~m}^{2}$.

Hüsken et al. ${ }^{37}$, realizaron un estudio de análisis comparativo entre distintos productos fotocatalíticos base cemento en condiciones de laboratorio. Señalaron que la eficiencia con respecto a la degradación del $\mathrm{NO}_{\mathrm{x}}$ variaba significativamente de unas muestras a otras, algunos productos conseguían un $40 \%$ de degradación, mientras que otros prácticamente no mostraban casi ninguna actividad.

Respecto a la degradación de COVs, Strini et al. ${ }^{147}$, utilizaron un reactor de flujo agitado para medir la fotodegradación de compuestos orgánicos, sobre la superficie de materiales fotocatalíticos en concentraciones de ppb. Observaron que la actividad fotocatalítica de la muestra de $\mathrm{TiO}_{2}$ puro era de tres a diez veces mayor que la que tenía la muestra de cemento que se preparó con la incorporación de un 3\% de catalizador. La velocidad de descomposición de BTEX tiene una relacion lineal con la concentración del reactivo y de la intensidad de irradiación. Sin embargo, la actividad fotocatalítica no tenía una dependencia lineal en relacion al contenido 
de $\mathrm{TiO}_{2}$ de las muestras, ese hecho ellos lo achacaron, a la formación de aglomeraciones del catalizador en la pasta de cemento, influenciado por las diferentes viscosidades de la pasta.

Krishnan et al. ${ }^{148}$, compararon la actividad fotocatalítica con la degradación fotocatalítica de RhB (autolimpieza) en muestras de mortero con un $2 \%$ de $\mathrm{TiO}_{2}$ en masa, frente a muestras de mortero que tenían tres capas de un recubrimiento en base silicato, que tenía un $15 \%$ de $\mathrm{TiO}_{2}$ en masa, los resultados fueron comparables, aunque el mortero tenía 20 veces más $\mathrm{TiO}_{2}$, teniendo en cuenta que estas muestras de mortero eran de $12 \mathrm{~mm}$ de espesor. Las muestras recubiertas con silicato que contenía $\mathrm{TiO}_{2}$ al 15\% mostraba buenos resultados de degradación de la rodamina en ensayos de envejecimiento acelerado de hasta 2500 h de irradiación UV que simulaban 2,4 años en condiciones de calor y humedad tropicales, lo que indica su rendimiento duradero. El recubrimiento de silicato con un $15 \%$ de $\mathrm{TiO}_{2}$ puede ser una mejor opción en términos de costo y efectividad en aplicaciones donde no hay un proceso de abrasión.

Comprobaron también que en las muestras estudiadas que la carbonatación conlleva una disminución de la superficie específica $y$, por lo tanto, disminuyen el número de sitios activos disponibles para el proceso de la fotocatálisis. Señalan que esta puede ser la causa de la reducción de la eficiencia del $\mathrm{TiO}_{2}$ en la degradación de partículas contaminantes.

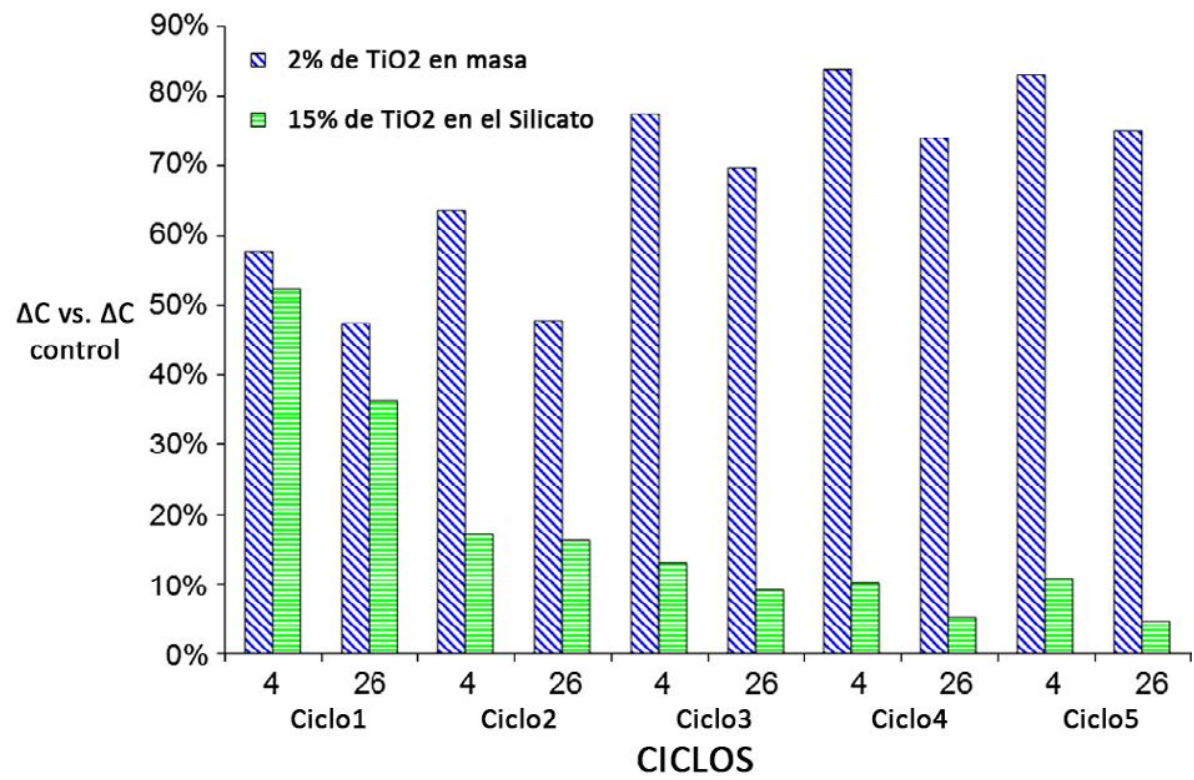

Lackhoff et al. ${ }^{33}$, investigaron la degradación fotocatalítica de una disolución de atrazina $(1 \mu \mathrm{g} \mathrm{I}-1)$, sobre muestras de cemento blanco modificadas con $\mathrm{TiO}_{2}$ y $\mathrm{ZnO}$, entre un 2-10\% en peso, como modelo de evaluación de la propiedad de autolimpieza en fachada. Se observó que la reacción seguía una cinética de primer orden para las muestras de cemento modificado con $\mathrm{TiO}_{2}$-Degussa P25. También comprobaron en su investigación que el proceso de carbonatación en los cementos modificados con $\mathrm{TiO}_{2}$, producía una pérdida de la eficiencia catalítica después de varios meses debido a los cambios producidos en la superficie del cemento.
148 Krishnan, P., Zhang, M. H.,

Yu, L., \& Feng, H. (2013). Photocatalytic degradation of particulate pollutants and self-cleaning performance of $\mathrm{TiO}_{2}$ containing silicate coating and mortar. Construction and Building Materials, 44, 309-316.

Fig 31. Variación de la medida de color de las muestras después de $4 \mathrm{~h}$ y $26 \mathrm{~h}$ de irradiación, la cantidad de rodamina utilizada es RhB $=4,2 \mu \mathrm{g} / \mathrm{cm}^{2}$. 
${ }^{149}$ Martínez, T., Bertron, A., Ringot, E., \& Escadeillas, G. (2011). Degradation of $\mathrm{NO}$ using photocatalytic coatings applied to different substrates. Building and Environment, 46(9), 1808-1816.
151 Maggos, T., Bartzis, J. G., Leva, P., \& Kotzias, D. (2007) Application of photocatalytic technology for NOx removal. Applied Physics A 89(1), 81-84
Martínezetal. ${ }^{149}$, estudiaron diversos parámetros que influyen en la eficiencia de la degradación del NO como son, la composición del revestimiento, la naturaleza del sustrato, la concentración inicial de $\mathrm{NO}$, el caudal de aire contaminado y la humedad. Se utilizaron substratos de mortero y vidrio. El primero era un material de construcción representativo, poroso y el segundo era un material no adsorbente utilizado a menudo como sustrato. En comparación con el vidrio, el uso de mortero como sustrato mejoró el rendimiento fotocatalítico de los recubrimientos al reducir la generación de $\mathrm{NO}_{2}$ gaseoso como subproducto de la reacción.

Los recubrimientos se formularon para el tratamiento superficial de materiales de construcción. Para identificar la posible influencia de la naturaleza del sustrato sobre la eficacia fotocatalítica, se ensayaron diversos tipos de sustratos. Los recubrimientos se aplicaron sobre un mortero, sobre una placa de vidrio y sobre una lámina de cartón no absorbente En los substratos de mortero y vidrio, la influencia del aumento de la humedad en las tasas de degradación dependía del sustrato y de la concentración inicial de NO.

No observó influencia significativa de la humedad, cuando se realizó la prueba a concentraciones iniciales de NO de 400 y 1000 ppb. Sin embargo, si se observó una disminución significativa de las tasas de degradación cuando la humedad disminuía a concentraciones iniciales más altas de NO (1500 y 2000 ppb).

La concentración inicial de NO influía mucho en el caso del vidrio, achacándolo a que el vidrio es un soporte sin absorción. Los investigadores achacan a que las moléculas de agua y las de los agentes contaminantes compiten por los sitios activos en la superficie del fotocatalizador y por tanto concluyen, que sólo en materiales con capacidad para absorber los contaminantes como los morteros a base de cemento, tendrán un mejor rendimiento fotocatalítico en descontaminación frente a soportes no absorbentes como el vidrio.

Maggos et al..$^{151}$, han comprobado que a una humedad relativa muy baja, la ausencia de moléculas de agua necesarias para la generación de radicales hidroxilo dificulta la oxidación fotocatalítica. Sin embargo como las concentraciones de los contaminantes atmosféricos a los que nos referimos son pequeñas, en el intervalo de ppb, únicamente es necesaria una muy pequeña concentración de radicales hidroxilo para la degradación, y por lo tanto humedad relativa muy baja.

Por el contrario, a humedades relativas altas lo que se ha comprobado que sucede es que, las moléculas de agua bloquean físicamente el contacto del contaminante con la superficie del $\mathrm{TiO}_{2}$ y por lo tanto la degradación del contaminante no se produce, compiten por los sitios activos el agua y las moléculas contaminantes que queremos degradar. De forma genérica, se ha demostrado que la eficiencia de la reducción de la concentración de $\mathrm{NO}_{\mathrm{x}}$ va disminuyendo cuando la humedad relativa aumenta del 10 al $80 \%{ }^{12,41}$. 
Dylla et al. ${ }^{47}$ especifican que la humedad relativa óptima es cercana al $25 \%$. El efecto de la humedad relativa sobre la actividad fotocatalítica podria ser una limitación de las zonas en las que se pueden utilizar los materiales de construcción fotocatalíticos en base cemento.

Boonen et al. ${ }^{151}$, también comprobaron en el proyecto $\mathrm{ECO}_{2} \mathrm{PROFIT}$, que la humedad relativa (HR) es un parámetro importante, que puede reducir la eficiencia en la ciudad. Si la HR es demasiado alta, el agua es adsorbida en la superficie y evita la reacción con los contaminantes.

\subsubsection{MEDICIONES A ESCALA REAL, DESCONTAMINACIÓN}

La capacidad descontaminante de materiales fotocatalíticos base cemento ha sido demostrado en estudios a escala real. En un proyecto en Antwerp ${ }^{152}$ (Bélgica), Beeldens et al., investigaron la viabilidad de utilizar el $\mathrm{TiO}_{2}$ en la superficie de las piezas de pavimento prefabricado de hormigón., se colocaron $10.000 \mathrm{~m} 2$ de bloques de pavimento fotocatalítico en un carril de estacionamiento. Las mediciones en el sitio indicaron una disminución evidente de la concentración de pico de $\mathrm{NO}_{x}$ debido a la presencia de los materiales fotocatalíticos. La actividad fotocatalítica de estos bloques se volvió a analizar en el laboratorio después de haber estado en servicio durante 2 años. Los resultados mostraron que no hubo reducción de la capacidad descontaminante después del lavado de los bloques de pavimentación con agua destilada.

Yu et al., el Departamento de Protección Ambiental de Hong Kong ${ }^{153}$ publicó un informe en el que afirmó que habían comprobado que la actividad fotocatalítica de los pavimentos revestidos de $\mathrm{TiO}_{2}$ disminuía significativamente después de 4 meses de exposición en el centro de la ciudad, debido a la acumulación de contaminantes en la superficie del bloque. Señalaban que es necesario un mantenimiento periódico, consistente en el lavado de los pavimentos prefabricados fotocatalíticos para mantener el efecto de descontaminación. Comprobaron que la retracción en los poros del mortero durante el curado, y la acumulación de contaminantes, como el aceite, polvo y sales de deshielo, reducen el rendimiento de las propiedades fotocatalíticas del hormigón con el tiempo ${ }^{154}$.

Agrios et al. ${ }^{155}$, comprobaron que, dado que las reacciones fotocatalíticas son en la superficie del catalizador están restringidas a los contaminantes adsorbidos, espacios confinados, como calles estrechas con edificios altos, en ciudades densamente pobladas o con altas tasas de contaminación por automóviles y/o actividad industrial, ofrecen condiciones más favorables que los espacios abiertos para conseguir altos valores de descontaminación con materiales que utilizan $\mathrm{TiO}_{2}$. En las grandes ciudades, estos fenómenos de altas concentraciones de contaminantes atmosféricos a nivel del suelo suelen ser debidos a que la dispersión de los gases de escape de los automóviles se ve obstaculizada por los altos circundantes edificios, es el denominado efecto calle cañón o "street canyon", concepto este que veremos cómo se repite en otras referencias.
151 Boonen, E., Beeldens, A., Dirkx, I., \& Bams, V. (2016) Durability of Cementitious Photocatalytic Building Materials. Catalysis Today.
152 Beeldens, A., Cassar, L., Pimpinelli, N., \& Guerrini, G. L. (2007). Air purification by road materials: results of the test project in AntwerpPhotocatalysis of cementitious materials.

153 Yu, C. (2003).

Deactivation and regeneration of environmentally exposed titanium dioxide $\left(\mathrm{TiO}_{2}\right)$ based products.

(No. E183413.).Environmental

Protection Department, HKSAR 2003.

154 Yu, C. M. (2003).

Deactivation and regeneration of environmentally exposed titanium dioxide $\left(\mathrm{TiO}_{2}\right)$ based products. Department of Chemistry, Chinese University of Hong Kong.

155 Agrios, A. G., \& Pichat, P. (2005)

State of the art and perspectives on materials and applications of photocatalysis over $\mathrm{TiO}_{2}$. Journal of Applied Electrochemistry, 35(7), 655-663. 
Fig 32. Distribución de la contaminación atmosférica como consecuencia de la acción conjunta del viento y el tráfico en una calle estrecha con edificios altos. Fuente Italcementi SpA ${ }^{156}$

156 Italcementi SpA. (2009). TX active. principio attivo fotocatalitico. Italia: Italcementi SpA.
Fig 33. Calle Borgo Palazzo con prefabricados fotocatalíticos en acera y calzada. Fuente. Italcementi SpA 156

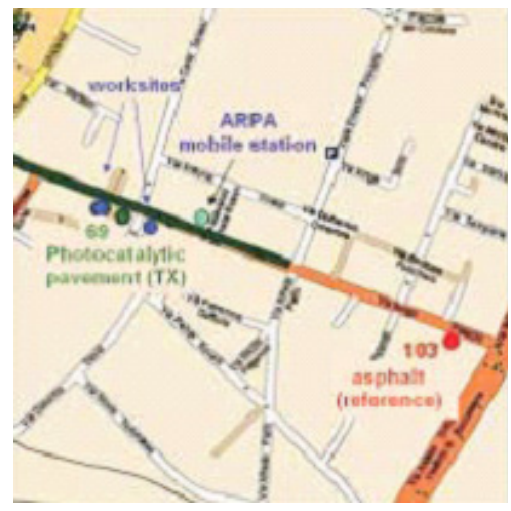

${ }^{157}$ GUERRINI, G. L. (2009). Some observations regarding in-service performance: Photocatalytic paving block surfaces. Betonwerk+ Fertigteil-Technik, 75(5).
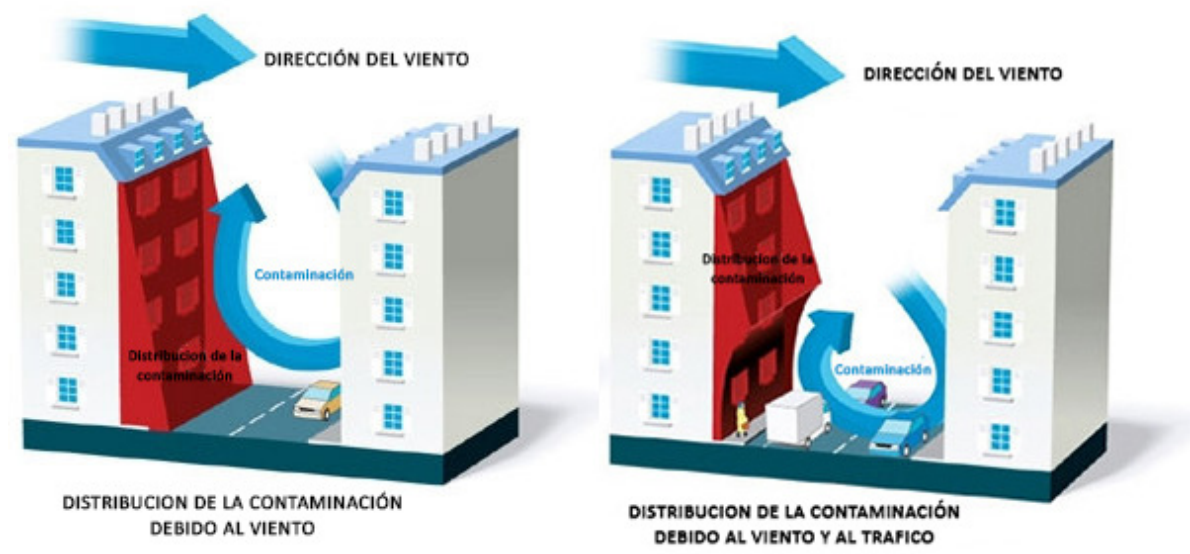

En Bérgamo (Italia), Italcementi obtuvo resultados prometedores de la investigación a escala real para verificar la eficacia de los materiales base cemento fotocatalítico. En la calle Borgo Palazzo, en el centro de la ciudad, fue pavimentada por los bloques de hormigón fotocatalíticos, un área de $7.400 \mathrm{~m} 2,500 \mathrm{~m}$ de longitud y una frecuencia de 400 vehículos/hora.

Se llevaron a cabo dos campañas de mediciones de óxidos de nitrógeno con una duración de dos semanas cada una, la primera en noviembre de 2006 y la segunda en enero de 2007 para monitorear el nivel de contaminación y compararla con la referencia de asfalto en la misma calle. Las medidas se realizaron en dos puntos simultáneamente. Uno se encontraba en la zona fotocatalítica y el otro en la zona de la calle pavimentada con asfalto convencional. Los resultados de las pruebas mostraron una disminución de la contaminación entre $30 \%$ y $40 \%$. La disminución de la contaminación fue comparable a una reducción del tráfico de 150 vehículos/hora.

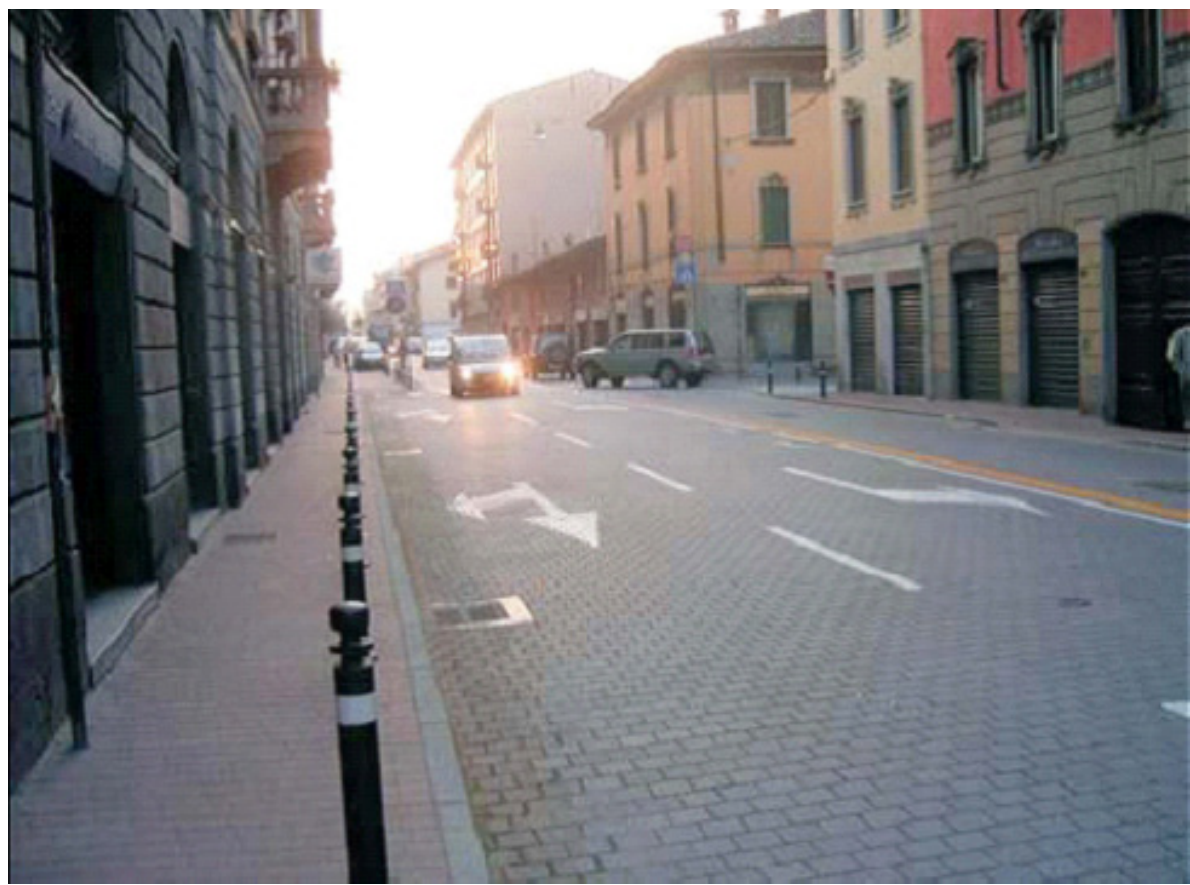

Guerrini et al. ${ }^{157}$, tambien comprobó posteriormente en 2009 que, después de 4 años en servicio el pavimento fotocatalítico de hormigón prefabricados, seguía activo como el primer día y recuperaba su capacidad descontaminante 
I NFLUENCIA DEL COLOR Y ELACABADOSUPERF|C|ALEN LAS PROPIEDADES DE UN MORTERO FOTOCATALITICO COMOSOLUCION DE ENVOLVENTE

después de un lavado superficial con la maquinaria de mantenimiento vial habitual en las ciudades.
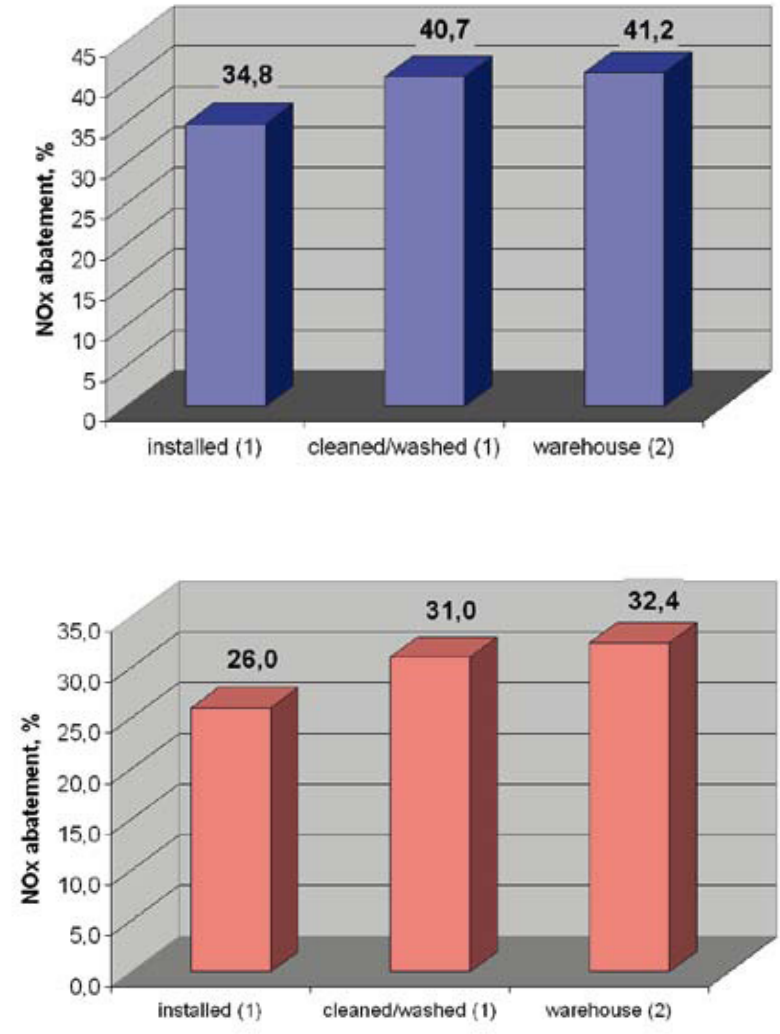

Fig 34. Resumen de los resultados de las pruebas según el color de la losa y condiciones de uso de la muestra.

Fig 35. Esquema de la distribución de los bloques extraídos para realizar las medidas.

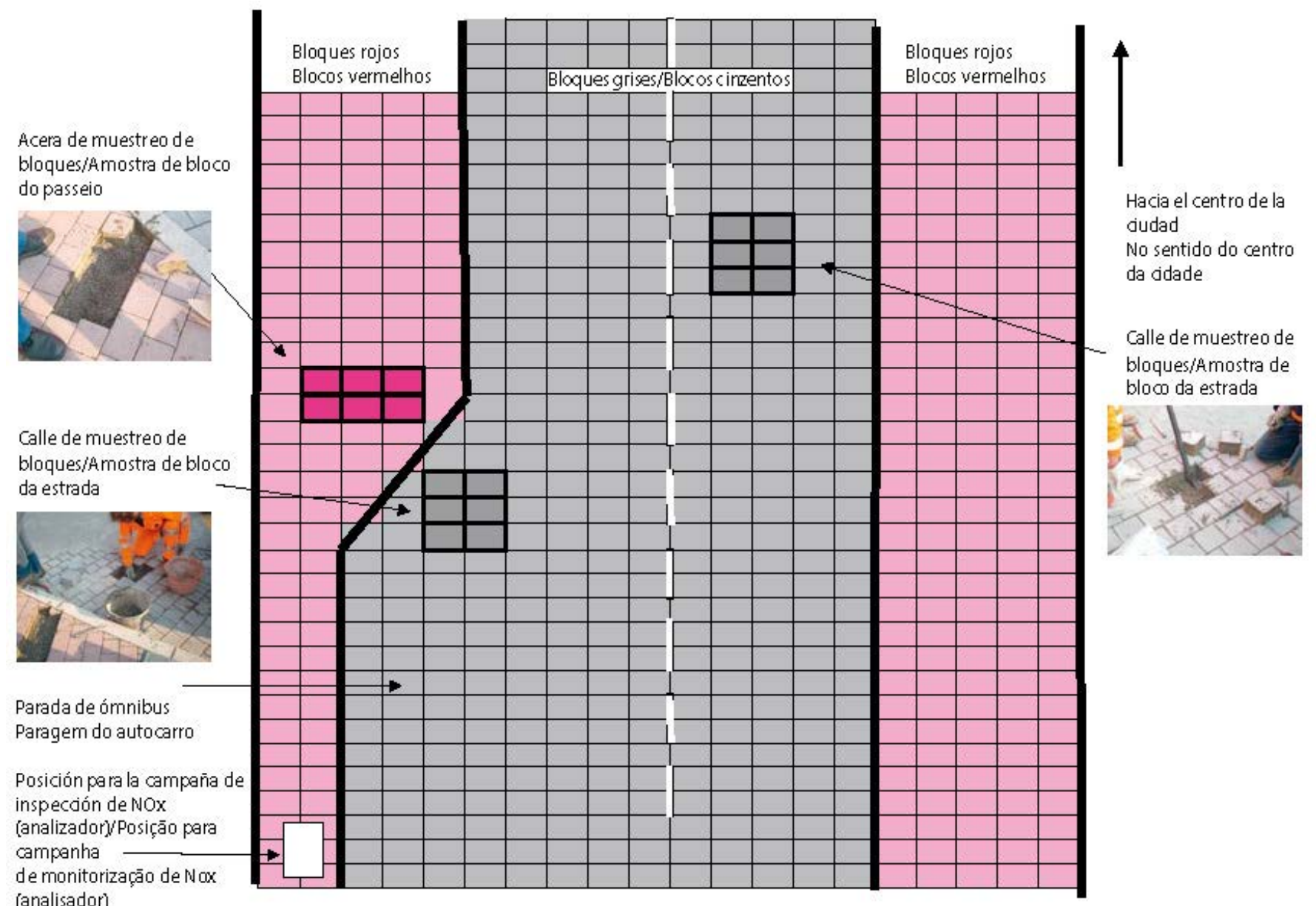


158 Picada. (2005).

Picada project. Retrieved from http:// www.picada-project.com/domino/ SitePicada/Picada.nsf? OpenDataBase. Consultado Febrero 2016
Fig 36. Configuración de las calles cañón, montaje en Guerville. Fuente. Italcementi.

Se realizó otro experimento a gran escala en Segrate (Italia) con un pavimento prefabricado de hormigón fotocatalítico, se colocaron a $6000 \mathrm{~m} 2$ en una calle con un volumen de tráfico de 1200 vehículos por hora. En un día soleado de verano, con una irradiación de $>90000$ lux, y una velocidad del viento $<0,7 \mathrm{~m} \mathrm{~s}-1$, se midió una reducción del $50 \%$ de NOx, con una estabilidad durante al menos un año de aplicación ${ }^{67}$.

Otro proyecto ${ }^{67}$ con materiales base cemento fotocatalítico fabricado por Italcementi, en los que se ha comprobado a escala real la capacidad descontaminante es, el situado en la calle Jean Bleuzen en Vanves (Francia), la actuación fue incluida en el plan de rehabilitación de red de autopistas. La calle tiene una longitud de $300 \mathrm{~m}$ con una configuración norte-sur y buena exposición solar, siendo perpendicular a los vientos dominantes. La intensidad de tráfico media es de más de 13.000 coches/día. El proyecto de remodelación consistió en la renovación del pavimento con un hormigón fotocatalítico. Los pavimentos de las aceras y bordillos terminados con baldosas prefabricadas de hormigón para una superficie total de $6000 \mathrm{~m}^{2}$. El resultado fue reducción de la contaminación de al menos un $20 \%$.

En el proyecto PICADA ${ }^{158}$, se construyeron tres street canyons o calles cañón con contenedores para poder evaluar el grado de descontaminación de un mortero base cemento fotocatalítico, que revestía las paredes, en las instalaciones de Calcia-Italcementi Group en Guerville (Francia).

\section{CONFIGURACIÓN 1 - Mortero Fotocatalítico $\left(\mathrm{TiO}_{2}\right)$}

Tubería perforada emitiendo contaminantes gaseosos
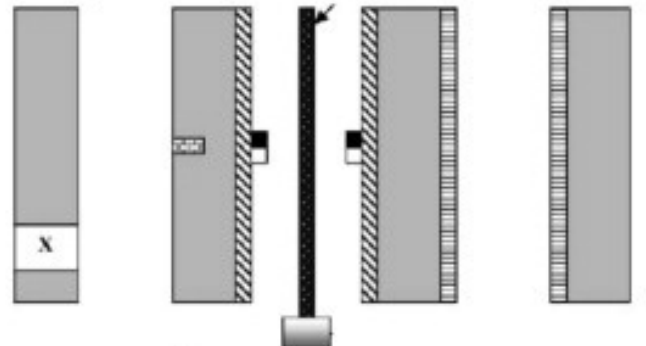

\section{CONFIGURACIÓN 1 - Mortero NO Fotocatalítico}

No medidor

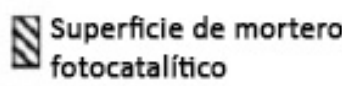

目 Superficie de mortero de referencia no fotocatalítico
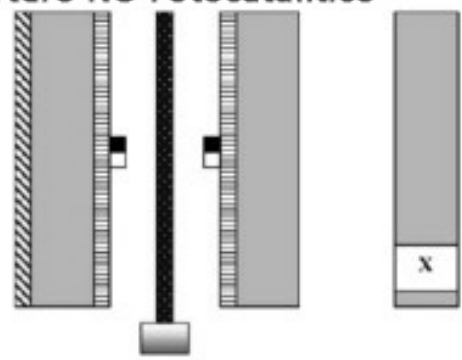

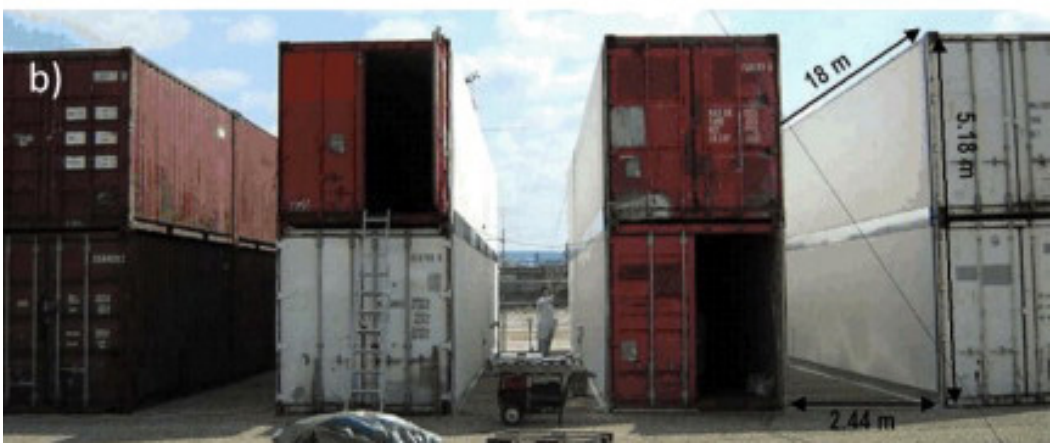




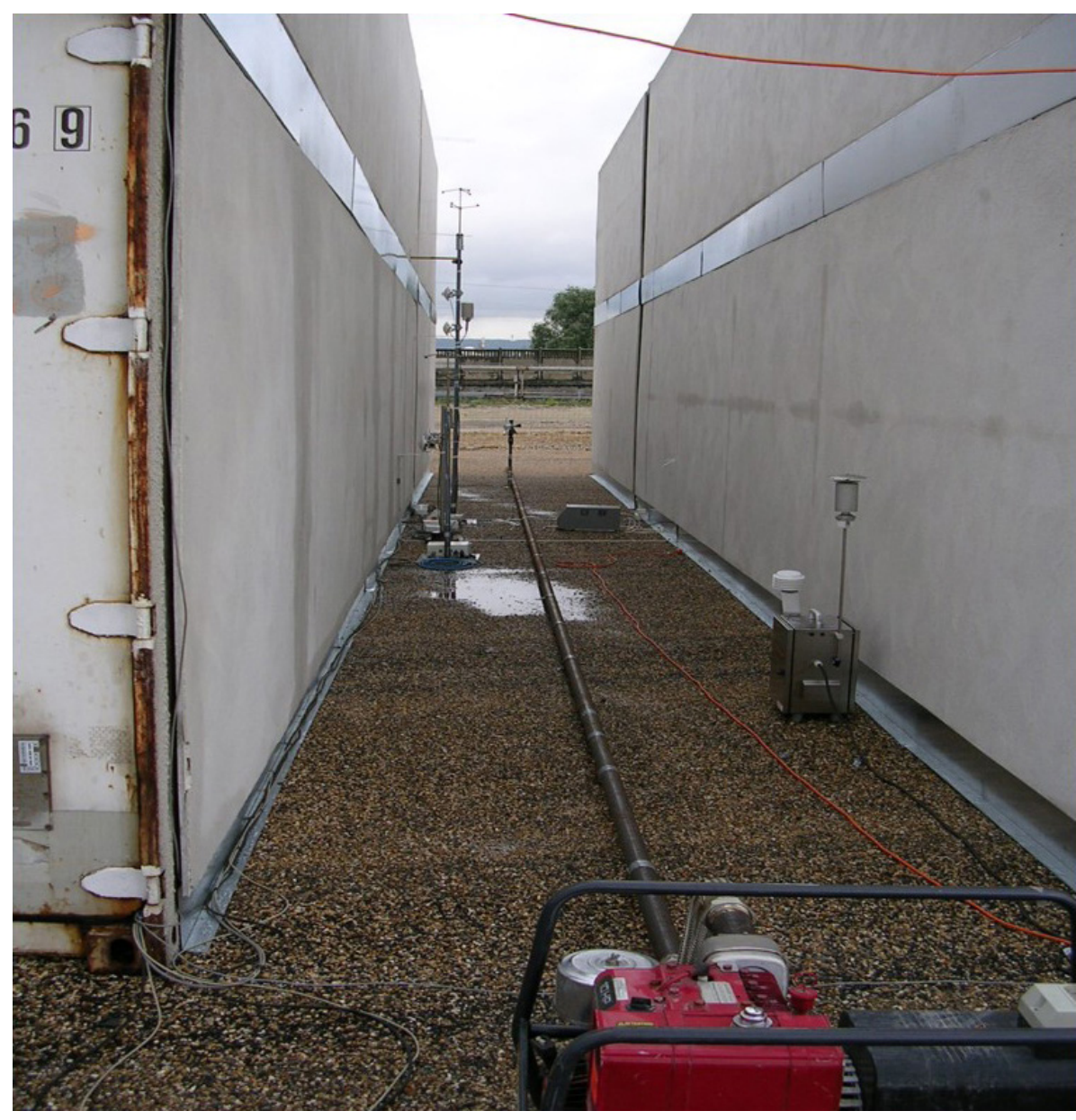

Las medidas de los valores de $\mathrm{NO}_{x}$ se tomaron en continuo de $\mathrm{NO}_{x}$ y de las condiciones meteorológicas. Las concentraciones de $\mathrm{NO}_{x}$ registradas en los corredores con mortero fotocatalítico fueron entre un 36,7 y un $82,0 \%$ inferiores a las observadas en la zona de referencia no fotocatalítica ${ }^{159}$.

Guerrini et al. ${ }^{160}$, midió después de la rehabilitación del túnel Umberto I en Roma que, se había conseguido una reducción significativa de las concentraciones de $\mathrm{NO}_{x}$. Se renovó el revestimiento de la bóveda con una pintura fotocatalítica base cemento, $9000 \mathrm{~m} 2$. La remodelación incluyó la sustitución del sistema de iluminación con lámparas que emitían radiación UV para maximizar la activación fotocatalizador. Estos cambios dieron lugar a reducciones de las concentraciones absolutas de $\mathrm{NO}_{x}$ en el túnel superiores al $20 \%$, al no ser posible hacer comparaciones simultáneas como en Bérgamo. Durante una segunda campaña de mediciones las concentraciones de $\mathrm{NO}_{x}$ corregidas utilizando las medidas de estaciones de medición de la agencia ARPA (Agencia de Medioambiente Italiana) fuera del túnel, demostraron que la reducción de la concentración de $\mathrm{NO}_{x}$ debido a la degradación fotocatalítica eran superiores al 50\%.
Fig 37. Disposición de los equipos de generación y medida de la contaminación. Fuente. Italcementi.

159 Maggos, T., Plassais, A., Bartzis, J. G., Vasilakos, C., Moussiopoulos, N., \& Bonafous, L. (2008).

Photocatalytic degradation of $\mathrm{NO}_{x}$ in a pilot street canyon configuration using $\mathrm{TiO} 2$-mortar panels.

Environmental monitoring and assessment, 136(1-3), 35-44.

160 Guerrini, G. L. (2012).

Photocatalytic performances in a city tunnel in Rome: $\mathrm{NO}_{x}$ monitoring results. Construction and Building Materials, 27(1), 165-175. 


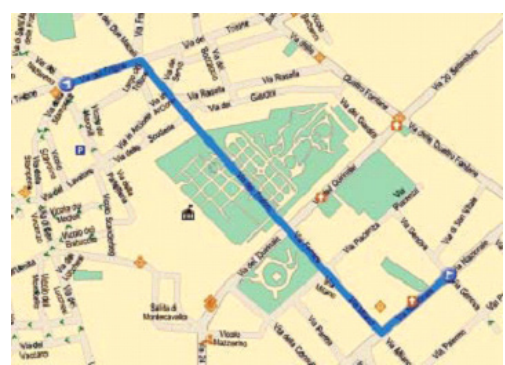

Fig 38. Situación del Túnel Umberto I. Fuente. Italcement

Fig 39. Túnel Umberto I después de la rehabilitación. Fuente. Italcementi.

161 Águia, C., Angelo, J., Madeira, L. M. \& Mendes, A. (2010)

Influence of photocatalytic paint components on the photoactivity of P25 towards $\mathrm{NO}$ abatement. Catalysis Today, 151(1), 77-83

162 Rachel, A., Subrahmanyam, M. \& Boule, P. (2002)

Comparison of photocatalytic efficiencies of $\mathrm{TiO} 2$ in suspended and immobilised form for the photocatalytic degradation of nitrobenzenesulfonic acids. Applied Catalysis B

Environmental, 37(4), 301-308.

163 Gallus, M., Ciuraru, R. Mothes, F., Akylas, V. Barmpas, F., Beeldens, A.

\& Charbonnel, N. (2015).

Photocatalytic abatement results from a model street canyon. Environmental Science and Pollution Research, 22(22), 18185-18196.

164 Boonen, E., \& Beeldens, A. (2014) Recent photocatalytic applications for air purification in Belgium. Coatings, $4(3), 553-573$

165 Gallus, M., Akylas, V., Barmpas, F., Beeldens, A., Boonen, E., Boréave, A.

\& Dupart, Y. (2015). Photocatalytic de-pollution in the Leopold II tunnel in Brussels: $\mathrm{NO} x$ abatement results. Building and Environment, 84, 125-133.

166 Photopaq. (2017)

PHOTOPaq demonstration of photocatalytic remediationprocesses on air quality Retrieved from http://photopaq.ircelyon.univ-lyon1.fr/

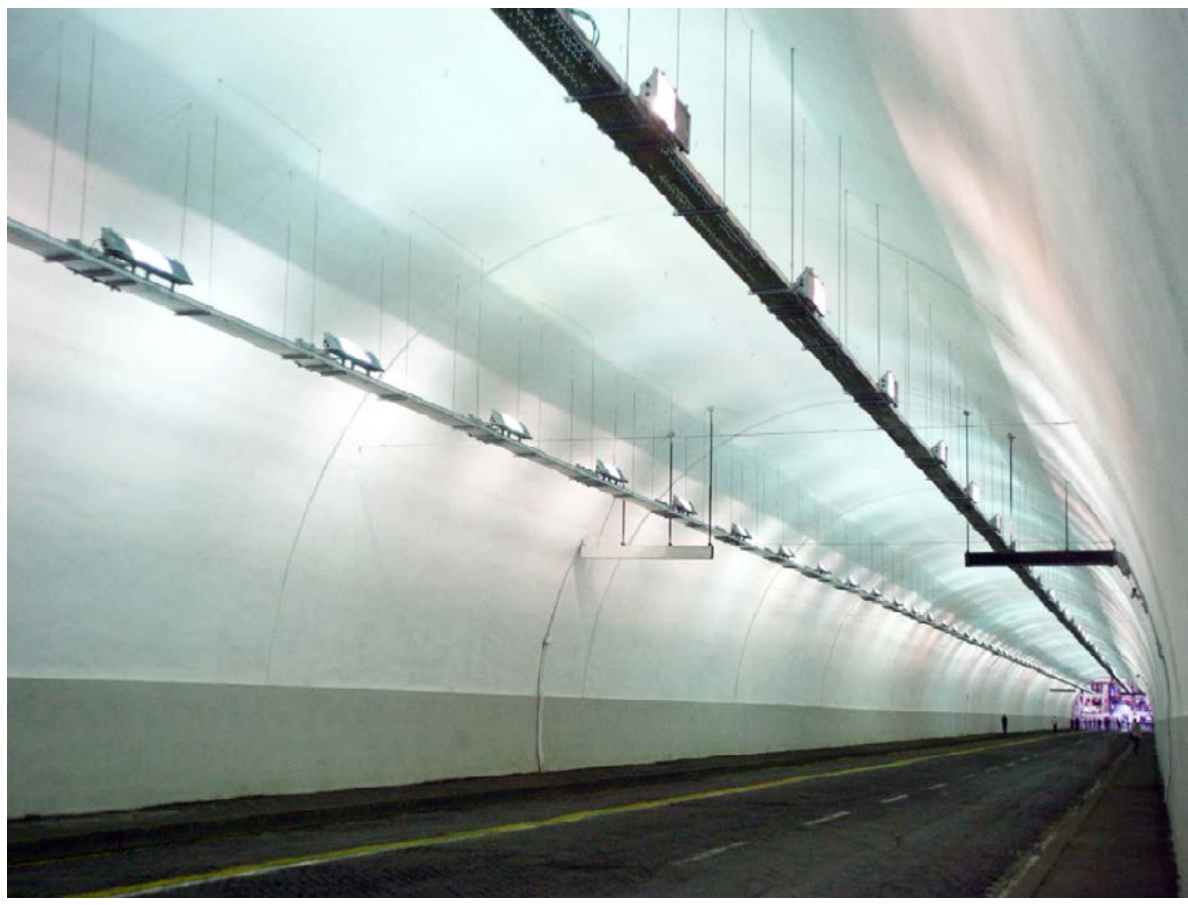

Ensayos similares a otra escala se han realizado por Águia et al. ${ }^{161}$, en una escuela de Londres, se pintó una pared de $300 \mathrm{~m} 2$ utilizando una pintura base de silicato que contenía $\mathrm{TiO}_{2}$ fotocatalítico al 7,5\% en peso, midieron una tasa de eliminación de aprox. 4,5 g de $\mathrm{NO}_{\mathrm{x}}$ diarios.

Aunque los efectos de los materiales de construcción fotocatalíticos se han medido por distintos investigadores y son evidentes, es reseñable que todavía existen problemas por resolver cuando estos materiales se utilizan en la vida real. La inmovilización de las partículas de $\mathrm{TiO}_{2}$ dentro de la matriz de los materiales puede dar como resultado una pérdida significativa de actividad fotocatalítica. Rachel et al. ${ }^{162}$, señalaron que las mezclas de cemento de $\mathrm{TiO}_{2}$ y ladrillo cerámico eran significativamente menos eficientes que un slurry de $\mathrm{TiO}_{2}$ en la descomposición del ácido 3-nitrobencenosulfónico. Se atribuye a una reducción de la superficie activa y a la presencia de especies iónicas que contribuyen a la recombinación del par electrón/hueco, como las razones de la pérdida de actividad catalítica.

El proyecto LIFE PHOTOPaq 163,164,165,166 (Demonstration of Photocatalytic Remediation Processes on Air Quality) entre 2011-2013, ha permitido demostrar que hay muchos factores implicados y hay que seguir investigando en el campo de los materiales fotocatalíticos. En contraste con las primeras estimaciones basadas en estudios de laboratorio, los resultados de campo en no mostraron reducciones significativas de $\mathrm{NO}_{x}$ en el túnel. Se midieron valores de reducción del $2 \%$ de $\mathrm{NO}_{\mathrm{x}}$, lo que corresponde con las incertidumbres experimentales. En experimentos de laboratorio posteriores a las mediciones de campo en el túnel, se observó la desactivación del catalizador en las superficies aplicadas. Las condiciones de humedad relativa elevada y la velocidad del viento dentro del túnel se han sumado, limitando aún más eliminación fotocatalítica de $\mathrm{NO}_{x}$. Concluyen los investigadores, con la recomendación de una caracterización cuidadosa de las condiciones del túnel, la cuantificación de la posible desactivación del material fotocatalítico 
en el túnel, cálculos previos de la reducción esperada de $\mathrm{NO}_{\mathrm{x}}$ y un análisis costo-beneficio antes de la aplicación de materiales fotocatalíticos y de los sistemas de iluminación en túneles de carretera (UV).
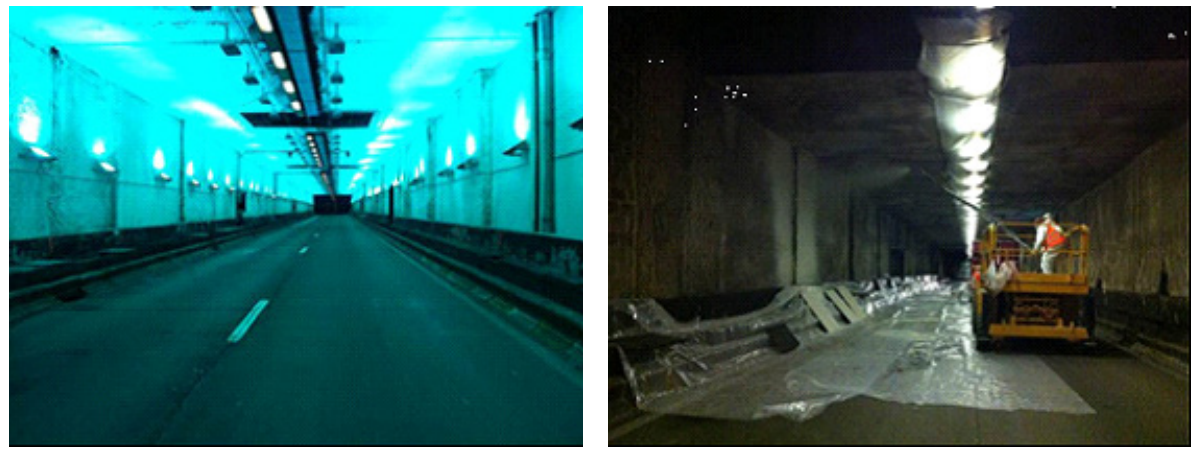

Boonen et al. ${ }^{164}$, describen los resultados del proyecto de sostenibilidad ambiental ECO2PROFIT, entre 2010-2102, de Belgian Road Researchs Center que se llevó a cabo en polígonos industriales en la frontera entre Flandes y Holanda, dos proyectos: "Den Hoek 3" en Wijnegem y "Duwijckpark" en Lier, ambos cerca de Amberes. La agencia de desarrollo regional POM Antwerp pretendía utilizar un hormigón realizado en dos capas fresco sobre fresco, para la construcción de carreteras, con áridos reciclados de hormigón para la capa inferior y en la capa superior un hormigón fotocatalítico $\left(\mathrm{TiO}_{2}\right)$, utilizando cementos y / o revestimientos fotoactivos. Se pretendía comprobar si es posible construir carreteras de hormigón que descontaminen, y con menor huella de $\mathrm{CO}_{2}$ al utilizar áridos reciclados, innovadoras y eficientes energéticamente

En Wijnegem (Den Hoek), se optó por utiliza áridos entre 0 y 6,3 mm en la capa superior por razones de reducción de ruido y confort del usuario de la carretera, para un acabado superficial de arido visto. En Lier (Duwijckpark) se eligió un acabado superficial cepillado para tener mayor cantidad de pasta en superficie. De hecho, se ha comprobado que el tipo de acabado superficial y / o tratamiento del pavimento puede tener efecto sobre la eficiencia fotocatalítica.

Los resultados muestran que la superficie con el arido visto funciona igual de bien que la superficie lisa, pero no tan bien como una superficie cepillada. Este es el resultado de la acción combinada de menos cemento fotocatalítico en la superficie y una mayor porosidad superficial, lo que da una superficie específica más alta.

La durabilidad de la acción fotocatalítica también permanece casi intacta, estando de acuerdo en que es necesaria una limpieza regular (por lluvia) de la superficie.

Las mediciones in situ durante dos años 2011-2013 del pavimento de hormigón fotocatalítico en dos capas, que se han hecho utilizando cemento fotocatalítico, se observan valores comparables entre las medidas obtenidas en el laboratorio y las de campo, aunque se registra cierta reducción en el tiempo debido a la acumulación de suciedad y otros depósitos en la superficie,
Fig 40. Aplicación del producto fotocatalítico e instalación de las lámparas UV en el túnel Leopold II en Bruselas, en el marco de PhotoPAQ. 
${ }^{167}$ Ballari, M. M. \& Brouwers, H. J. H. (2013). Full scale demonstration of air-purifying pavement. Journal of hazardous materials, 254, 406-414.

${ }^{168}$ Fraunhofer. (2010) Clean air by airclean. Retrieved from http://www.ime.fraunhofer.de/ content/dam/ime/de/documents/ AOe/2009_2010_Saubere\%20 Luft\%20durch \%20Pflastersteine_s.pdf. Consultado Febrero 2016

169 |PL. (2010).

Dutch air quality innovation programme concluded. (Technical). Netherlands: IPL.
La aplicación del curador para proteger al hormigón fresco contra la deshidratación después de la puesta en obra, produce una fuerte reducción inicial de la actividad fotocatalítica y también tiene un impacto a largo plazo. Por lo tanto, si fuese necesario se recomienda el uso de lámina de plástico para proteger el hormigón fresco. Otra conclusión ha sido que el acabado de arido visto no es el ideal para la actividad fotocatalítica, ya que en este caso el $\mathrm{TiO}_{2}$ sólo se encuentra presente en la pasta. La aplicación de un acabado superficial cepillado produce mejores resultados.

La utilización de superficial fotocatalítico en forma de dispersión liquida de $\mathrm{TiO}_{2}$ en la superficie del pavimento de hormigón, no aporta un valor añadido en relacion a la descontaminación comparado con la adición en la masa, a pesar de los resultados obtenidos en el laboratorio. Estiman que esto probablemente tiene que ver con la baja adherencia de este tipo de solución y a la que también contribuye la suciedad superficial que pudiera tener el pavimento en el momento de la aplicación. Posiblemente, este recubrimiento fotocatalítico se va junto con la suciedad al ser lavado. Los mejores resultados se obtuvieron en el hormigón fotocatalítico con arido de tamaño máximo más pequeño $\mathrm{D}=6.3 \mathrm{~mm}$, que en el hormigón de arido de tamaño máximo $D=20 \mathrm{~mm}$ en una sola capa, que podría ser porque el recubrimiento tenga una mejor adherencia sobre la superficie.

Otros experiencias con ensayos a escala real, mostraron altor porcentajes de eliminación de $\mathrm{NO}_{x}$, del orden del 19\% ${ }^{167}, 25-30 \%{ }^{168}$ y $26-66 \%{ }^{125}$ respectivamente. En otros proyectos, por el contrario, la reducción medida de $\mathrm{NO}_{x}$ estuvo por debajo de las expectativas en Putten, Holanda ${ }^{169}$ con barreras antiruido de hormigón fotocatalítico.

Estos resultados contradictorios pueden explicarse por la difusión de los contaminantes hasta la superficie fotocatalítica, las características geométricas de las diferentes ubicaciones elegidas, la representatividad de los puntos de muestreo, las condiciones climáticas locales predominantes como velocidad del viento, irradiancia, humedad relativa, etc.), tiempo de muestreo seleccionado (promedio del día o continuo) y reactividad, propiedades de los materiales fotocatalíticos utilizados. Por lo tanto, son necesarios más estudios en condiciones reales para tener en cuenta el impacto total de esta tecnología en la mejora de la calidad del aire ${ }^{165}$.

\subsubsection{MEDICIONES A ESCALA REAL: AUTOLIMPIEZA.}

A escala real también se ha demostrado la validez de los cementos fotocatalíticos con propiedades autolimpiantes, mediante un seguimiento colorimétrico de las superficies.

El primer edificio, fue un proyecto del arquitecto Richard Meier terminado en 2003, y realizado con cemento fotocatalítico TX Active de Italcementi S.p.A., multinacional fabricante de cemento. Ha tenido seguimiento colorimétrico periódico durante 9 años, sólo se han observado ligeras diferencia entre las paredes interiores y exteriores de la iglesia. Italcementi ha desarrollado 
I NFLUENCIA DEL COLOR Y ELACABADO SUPERF|C|ALEN LAS PROPIEDADES DE UN MORTEROFOTOCATALITICOCOMOSOLUCIÓNDE ENVOLVENTE

y patentado diferentes tipos de cemento fotocatalíticos y soluciones constructivas desarrolladas con los cementos de la gama TX Active ${ }^{170}$.
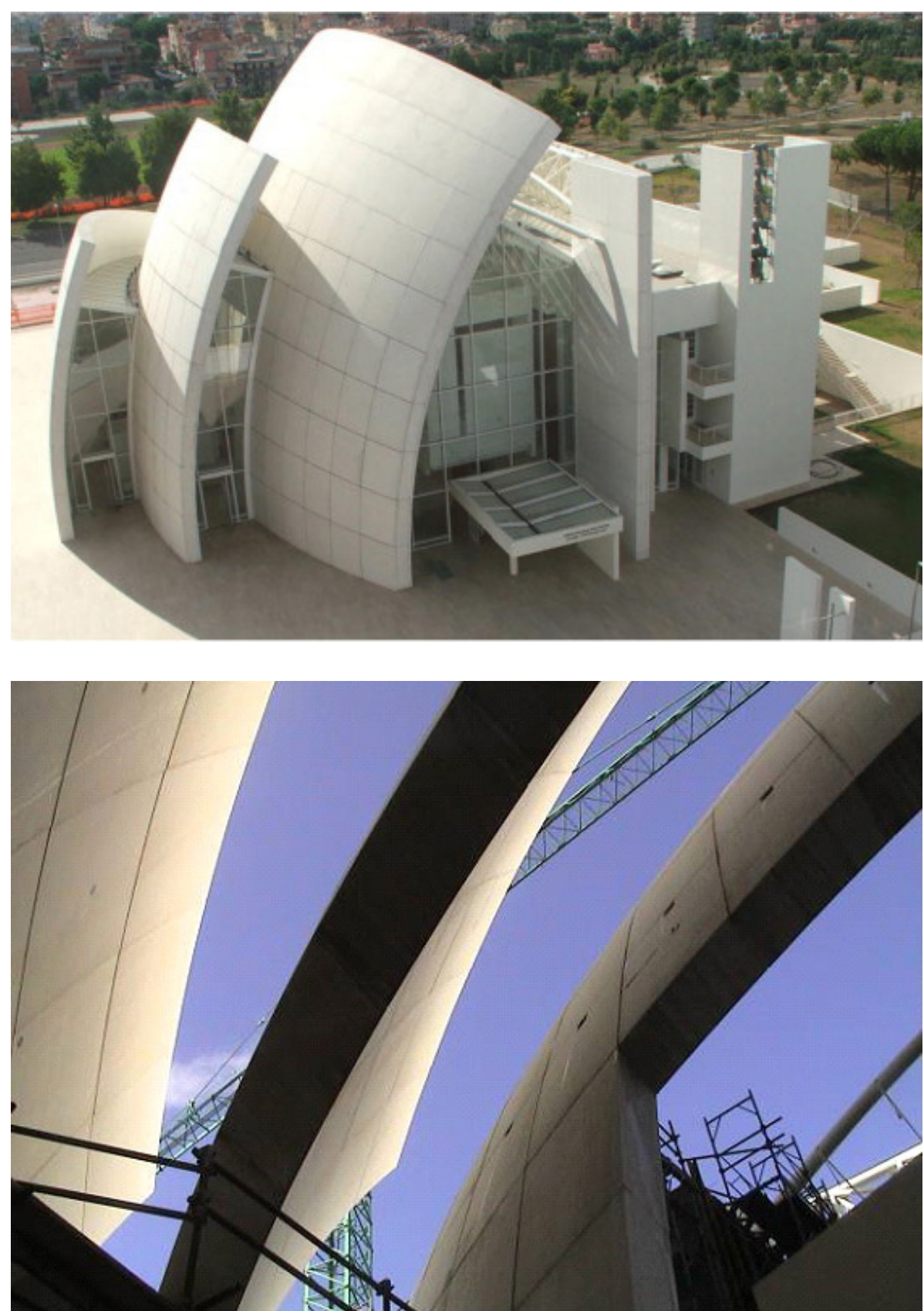

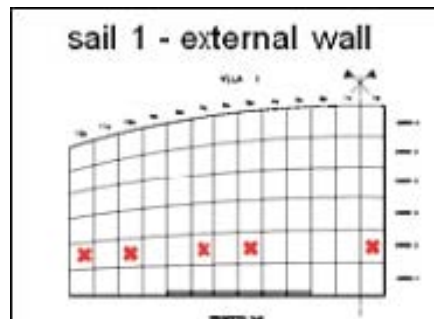

sail 1 - internal wall

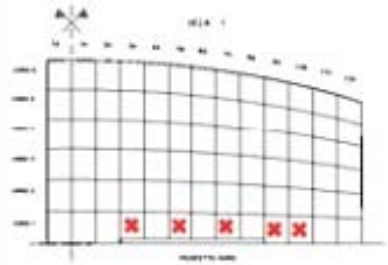

sail 2 - external wall

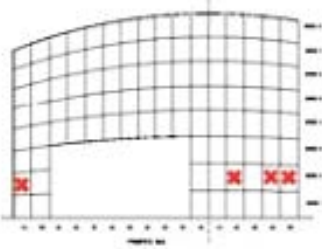

sail 2 - internal wall

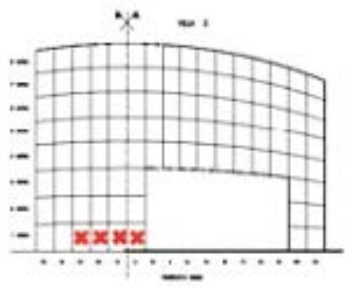

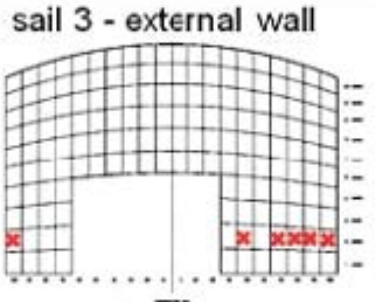

sail 3 - internal wall

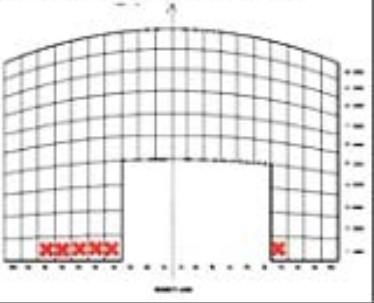

${ }^{170}$ Cassar, L., Pepe, C.,

Tognon, G., Guerrini, G. L., \& Amadelli, R. (2003, May).

White cement for architectural concrete, possessing photocatalytic properties. In Proceedings of the 11th International Congress on the Chemistry of Cement

(Vol. 4, pp. 2012-2021).

Fig 41. Iglesia Dives in Misericordia (Roma). Fuente. Italcementi

Fig 42. Iglesia Dives in Misericordia (Roma). Fuente. Italcementi

Fig 43. Esquema de los puntos de toma de medida colorimétrica en la estructura del edificio. 
Italcementi comprobó a través de medidas colorimétricas en el sistema $\mathrm{CIE}$ Lab, el mantenimiento del color de los elementos de hormigón fotocatalítico blanco después de 7 años de vida útil. Las últimas mediciones en 2007, en la pared norte (2007) mostraron los mismos valores durante la construcción de la iglesia en el año 2002.

Se detectaron variaciones en las medidas de la coordenada $\left(b^{*}\right)$, debidas a la presencia de sustancias inorgánicas en la superficie, un análisis químico confirmó que la razón de este efecto se debía al depósito de arena africana transportada por el viento sirocco (fenómeno típico en el área de Roma). Este fenómeno sin embargo no se ha registrado en la pared norte, construida con el mismo hormigón y menos expuesta. Aplicando un lavado superficial con agua a los paneles, el color original se recuperaba completamente, debido a la retirada de los depósitos de arena. Ref 67

Una de las primeras obras en Francia es la "Cité de la Musique et des BeauxArts" en Chambery (Francia). Construida con prefabricado de hormigón fotocatalítico se monitorea regularmente para medir el mantenimiento del color original a lo largo del tiempo. La luminancia $L^{*}$ - medida usando el método CIELAB - se muestra en la Figura

El proyecto de los arquitectos Yann Keromnès, Aurélio Galfetti y François Cusson, también ha permanecido sin cambios apreciables durante los aproximadamente 6 años que ha sido objeto de seguimiento en distintas posiciones de la fachada (Oeste / Norte / Este / Sur) [37] se construyó en Chambery, en el año 2000.

Fig 44. Cité de la Musique et des Beaux-Arts. Fuente. Italcementi

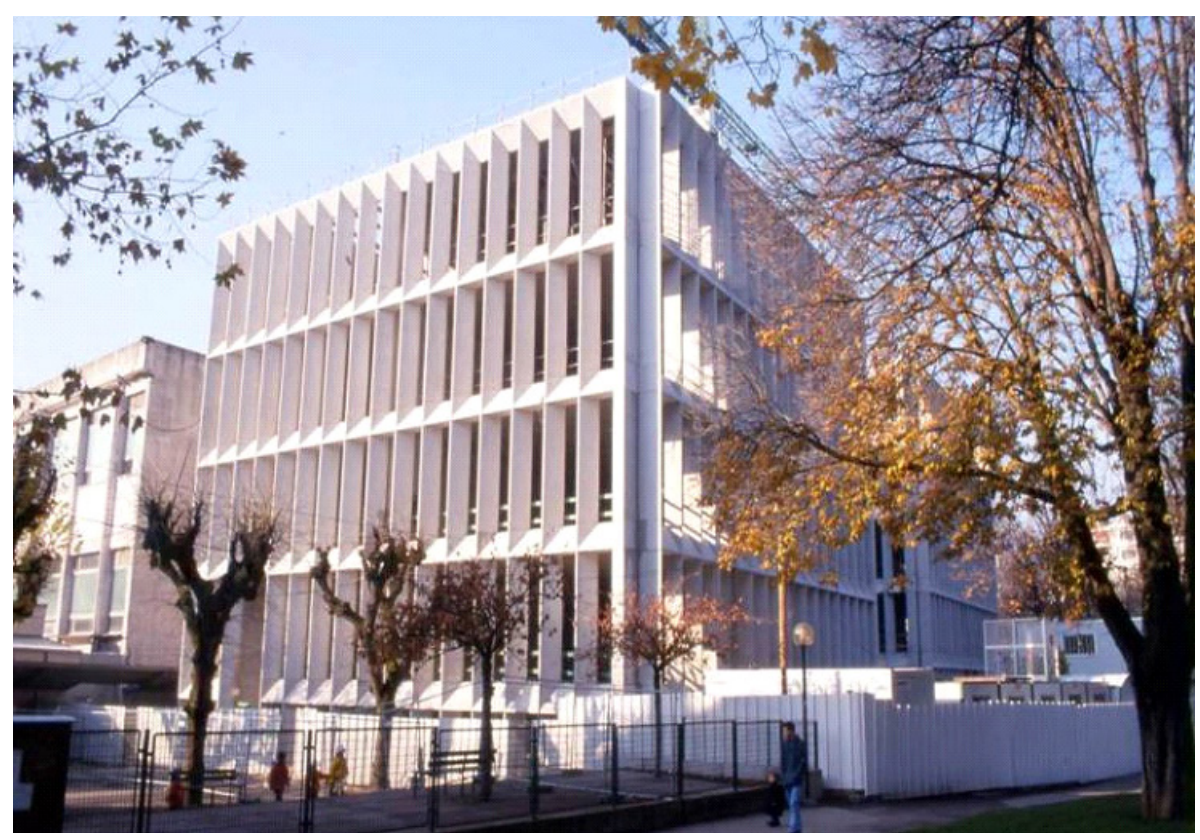


I NFLUENCIA DEL COLOR Y ELACABADOSUPERF|C|ALEN LAS PROPIEDADES DE UN MORTERO FOTOCATALITICO COMO SOLUCIÓN DE ENVOLVENTE
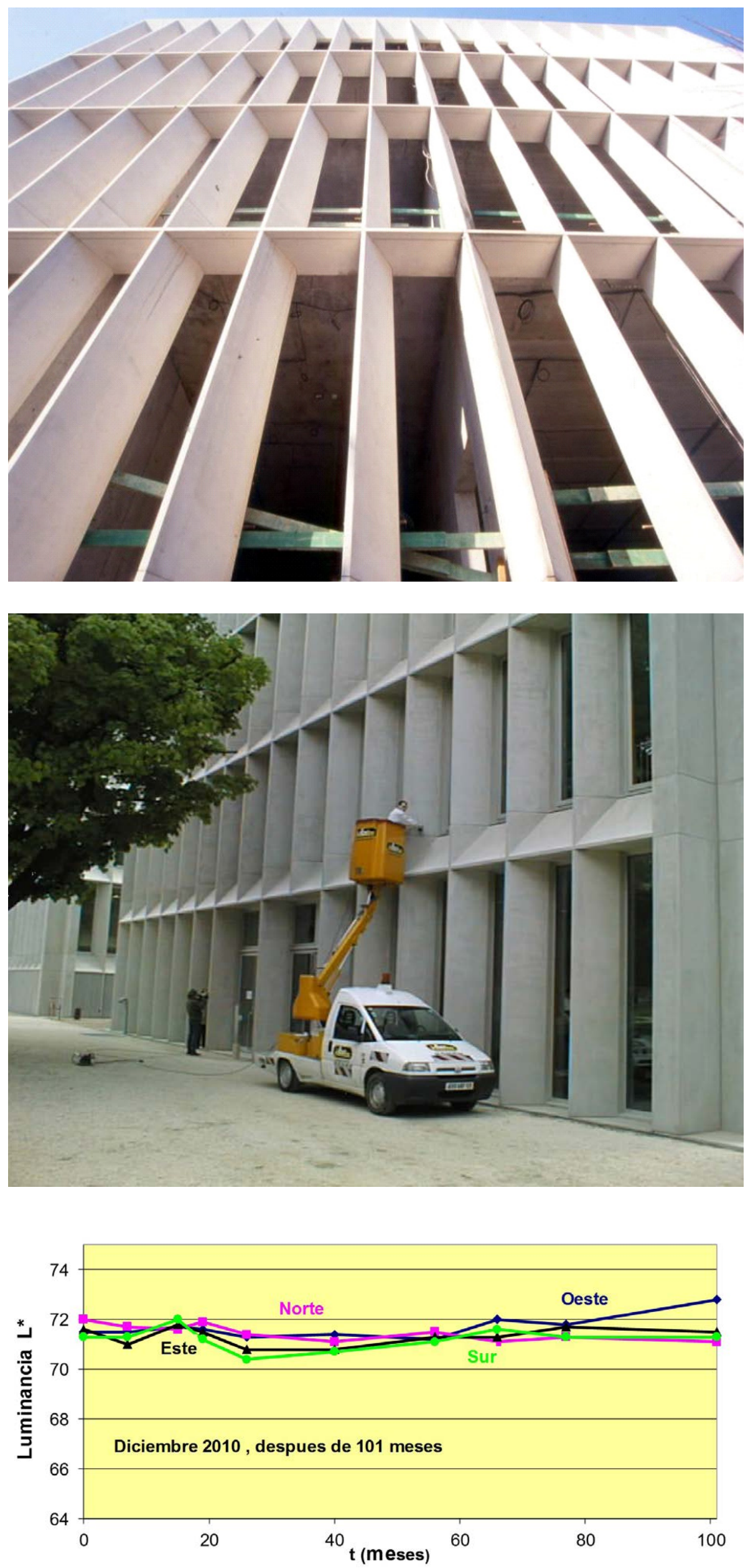

Fig 45. Cité de la Musique et des Beaux-Arts. Fuente. Italcementi

Fig 46. Toma de medidas sobre las superficies. Fuente. Italcementi.

Fig 47. Medidas de Luminancia L*, de las 4 fachadas del edificio principal después de 101 meses. 
171 Vallee, F., Ruot, B., Bonafous, L., Guillot, L., Pimpinelli, N., Cassar, L., ... \& Andre, H. (2004) Cementitious materials for self-cleaning and de-polluting facade surfaces. In RILEM International Symposium on Environment-Conscious Materials and Systems for Sustainable Development (pp. 337-346). RILEM Publications SARL.

172 Diamanti, M. V., Ormellese, $M$. \& Pedeferri, M. (2008) Characterization of photocatalytic and superhydrophilic properties of mortars containing titanium dioxide. Cement and Concrete Research, 38(11), 1349-1353.

${ }^{173}$ Enea, D., \& Guerrini, G. (2010). Photocatalytic properties of cementbased plasters and paints containing mineral pigments. Transportation Research Record: Journal of the Transportation Research Board, (2141), 52-60.

174 Milani, R., Bertani, R. Cona, A., Fiorentin, P., Garau, G., Maragno, C., \& Paparella, R. (2009).

Photocatalytic building products: Innovation and experimentations. Proc. Of: SASBE2009 PROCEEDINGS

DEN HAAG: CIP-data Koninklijke Bibliotheek.

175 Diamanti, M. V., Del Curto, B., Ormellese, M. A. R. C. O., \& Pedeferri, M. P. (2013)

Photocatalytic and self-cleaning activity of colored mortars containing $\mathrm{TiO}_{2}$. Construction and Building Materials, 46, 167-174
En el marco del proyecto LIFE europeo, PICADAref69 "Photocatalytic Innovative Coverings Application for Depollution Assessment", (20022005), se desarrollaron dos morteros base cemento, con un espesor de $10 \mathrm{~mm}$ (y una pintura para aplicar con $1 \mathrm{~mm}$ de espesor, ambos tenían TiO2 de tamaño nanométrico y también se comprobaron las propiedades de autolimpieza mediante la medida de la velocidad de descomposición fotocatalítica de un tinte orgánico, la rodamina $\mathrm{B}$, mediante mediciones colorimétricas en el sistema ClELab. Los resultados experimentales mostraron que las muestras recuperaron aproximadamente el $65 \%$ de los valores iniciales en menos de $24 \mathrm{~h}$ de exposición a luz solar artificial en condiciones controladas ${ }^{171}$.

Diamanti et al. ${ }^{172}$, caracterizaron 11 morteros diferentes, demostró que los morteros que contenían $\mathrm{TiO}_{2}$ mostraban propiedades fotocatalíticas. El objetivo final de la investigación era establecer una composición de mortero con fotoactividad óptima, pero al mismo tiempo comercialmente factible. Un contenido de $\mathrm{TiO}_{2}$ demasiado alto tendría un coste muy elevado. Obtuvo resultados de compromiso entre costes y propiedades fotocatalíticas, si el contenido de anatasa era de un $3 \%$ en polvo o una disolución al $2 \%$, observando efectos sinérgicos al utilizar ambas formas de presentación simultáneamente. La muestra permitió lograr tanto una buena conversión en pruebas fotocatalíticas como una notable variación de la interacción del agua con la superficie, que se volvió superhidrófila tras la irradiación UV. Estas dos propiedades condujeron a una pronunciada actitud de autolimpieza. Investigación futura al desarrollo de revestimientos superficiales fotoactivos con propiedades.

Hüsken et al., han estudiado como afectan los pigmentos a la degradación de $\mathrm{NO}_{x}$ en los materiales fotocatalíticos base cemento. Señalan que, el pigmentos de color rojo tiene una influencia despreciable en las capacidades de degradación de $\mathrm{NO}_{x}{ }^{144}$.

Enea et al., indican que los pigmentos rojos, amarillos y azules provocan una disminución de la degradación de $\mathrm{NO}_{x}{ }^{173}$. También hay informes de que la adición de óxidos metálicos $\left(\mathrm{Fe}_{2} \mathrm{O}_{3}, \mathrm{CO}_{3} \mathrm{O}_{4}\right.$ y $\left.\mathrm{NiO}\right)$ al $\mathrm{TiO}_{2}$ puede mejorar destrucción fotocatalítica del $\mathrm{NO}_{x}{ }^{174}$. Estos datos contradictorios hacen imposible sacar conclusiones sobre el efecto de los aditivos pigmentarios sobre la eficacia de los materiales fotocatalíticos cementosos.

Diamanti et al. ${ }^{175}$, estudiaron la influencia de los pigmentos en la propiedades de autolimpieza y descontaminación de un mortero base cemento, obteniendo como conclusión que los morteros que llevaban pigmentos de óxido de hierro mostraban menos actividad fotocatalítica en comparación con los morteros blancos.

Se investigaron la degradación fotocatalítica de tintes orgánicos y COV, la propiedad de la autolimpieza en muestras de morteros comerciales pigmentados, que contienen aproximadamente un $5 \%$ en peso de dióxido de titanio. En aquellos morteros que tenían pigmentos de óxido y/o 
hidróxido de hierro tenían menor actividad fotocatalítica, lo que significa una interacción negativa entre los pigmentos y $\mathrm{TiO}_{2}$.

\subsubsection{ACCION BACTERICIDA}

En comparación con las otras dos aplicaciones principales, se han realizado menos de investigaciones en materiales fotocatalíticos base cemento con capacidad bactericida.

Hanus et al..$^{53}$, hace referencia a las propiedades antimicrobianas de algunos metales y compuestos metálicos se conocen desde la antigüedad cuando, por ejemplo, se usaron compuestos basados en $\mathrm{Ag}$ para el tratamiento del agua. En los últimos tiempos, se ha encontrado que muchas nanopartículas de metal y óxido metálico son antimicrobianos particularmente eficaces, más que los correspondientes materiales a granel debido a su mayor área de superficie activa. Las nanopartículas de óxidos de metálicos que tienen propiedades antimicrobianas incluyen, $\mathrm{Ag}, \mathrm{Cu}, \mathrm{CuO}, \mathrm{ZnO}, \mathrm{MgO}_{\text {y }} \mathrm{TiO}_{2}$. La eficacia relativa de los agentes antimicrobianos varía, se ha demostrado su efectividad contra una amplia gama de bacterias, incluso con cepas resistentes a los antibióticos, virus, hongos y algas. Por ejemplo, la sensibilidad de los microbios a la destrucción funcional por nanopartículas fotocatalíticas como el $\mathrm{TiO}_{2}$ se ha comprobado que sigue un orden: virus $>$ bacterias gram-negativas $>$ bacterias gram-positivas $>$ endosporas $>$ levaduras $>$ hongos filamentosos ${ }^{176}$.

La actividad bactericida inducida por la luz de $\mathrm{TiO}_{2}$ también puede usarse para controlar el crecimiento biológico en superficies de hormigón. Las manchas superficiales que producen pueden causar la pérdida de las características estéticas particularmente en los lugares donde el diseño o la falta del mantenimiento. Esto también podría desencadenar cambios químicos de las superficies de hormigón y disminuir la durabilidad ${ }^{177}$.

Linkous et al. ${ }^{178}$, utilizaron $\mathrm{TiO}_{2}$ y $\mathrm{WO}_{3}$ para inhibir el crecimiento de Oedogonium, una alga filamentosa. Se demostró que el recubrimiento de sustratos de cemento con una dispersión de $10 \%$ en peso de polvo de $\mathrm{TiO}_{2}$ podría conseguir una reducción del $66 \%$ en el crecimiento de algas en comparación con una superficie de cemento no protegida. La adición de un 1,0\% en peso de $\mathrm{Pt}$ ó Ir al fotocatalizador, consiguió una reducción de hasta un $87 \%$.
176 Rajagopal, G., Maruthamuthu, S. Mohanan, S., \& Palaniswamy,N. (2006). Biocidal effects of photocatalytic semiconductor TiO 2. Colloids and Surfaces B: Biointerfaces, 51(2), 107-111.

\footnotetext{
177 Kurth, J. C. (2008).

Mitigating biofilm growth through the modification of concrete design and practice (Doctoral dissertation, Georgia Institute of Technology).

178 Linkous, C. A., Carter, G. J., Locuson, D. B., Ouellette, A. J., Slattery, D. K., \& Smitha, L. A. (2000). Photocatalytic inhibition of algae growth using $\mathrm{TiO} 2, \mathrm{WO} 3$, and cocatalyst modifications. Environmental Science \& Technology, 34(22), 4754-4758.
} 


\section{5 . 2 . ANTECEDENTES SECTORIALES}

\subsubsection{MATERIALES DE CONSTRUCCIÓN}

\section{ANTECEDENTES}

Los materiales son materia de diseño, ya lo largo de la historia han dictado su posibilidades y sus límites. La edad en la que ha vivido el hombre se conoce por el nombre de los materiales que utilizaba: piedra, bronce, hierro, plásticos, y hoy en día, silicio y nanomateriales.

Nunca ha habido una época en la que la evolución de los materiales fue más rápido y el barrido de sus propiedades más variado. En la gráfica se ilustra el aumento del ritmo de la evolución de los materiales. Los materiales de la prehistoria, (> $10.000 \mathrm{aC}$, la Edad de Piedra), eran la cerámica, vidrio, polímeros naturales y compuestos. Armas, siempre al frente de la tecnología, eran de madera y la piedra, edificios y puentes de piedra y de madera, ropa de la piel y de la piel. De origen natural, el oro y la plata estaban disponibles a nivel local pero, jugaron un papel menor en la tecnología.

Fig 48.La evolución de la ingeniería de los materiales con el tiempo ${ }^{179}$.

179 Ashby, M. F., \& Johnson, K. (2013). Materials and design: the art and science of material selection in product design. Butterworth-Heinemann.
El descubrimiento del cobre, el bronce y el hierro, (Edad del Bronce, 3000 aC a 1000 aC, y la Edad de Hierro del 1000 aC al 1620 dC), favoreció grandes avances, en armas y herramientas. La tecnología de fundición (1620 trajo el dominio de los metales y el desarrollo del acero, (1850 en adelante), las aleaciones ligeras en 1940 y otras aleaciones especiales, se han consolidado desde entonces. En la década de 1960, la ingeniería de materiales significaba, "metales".

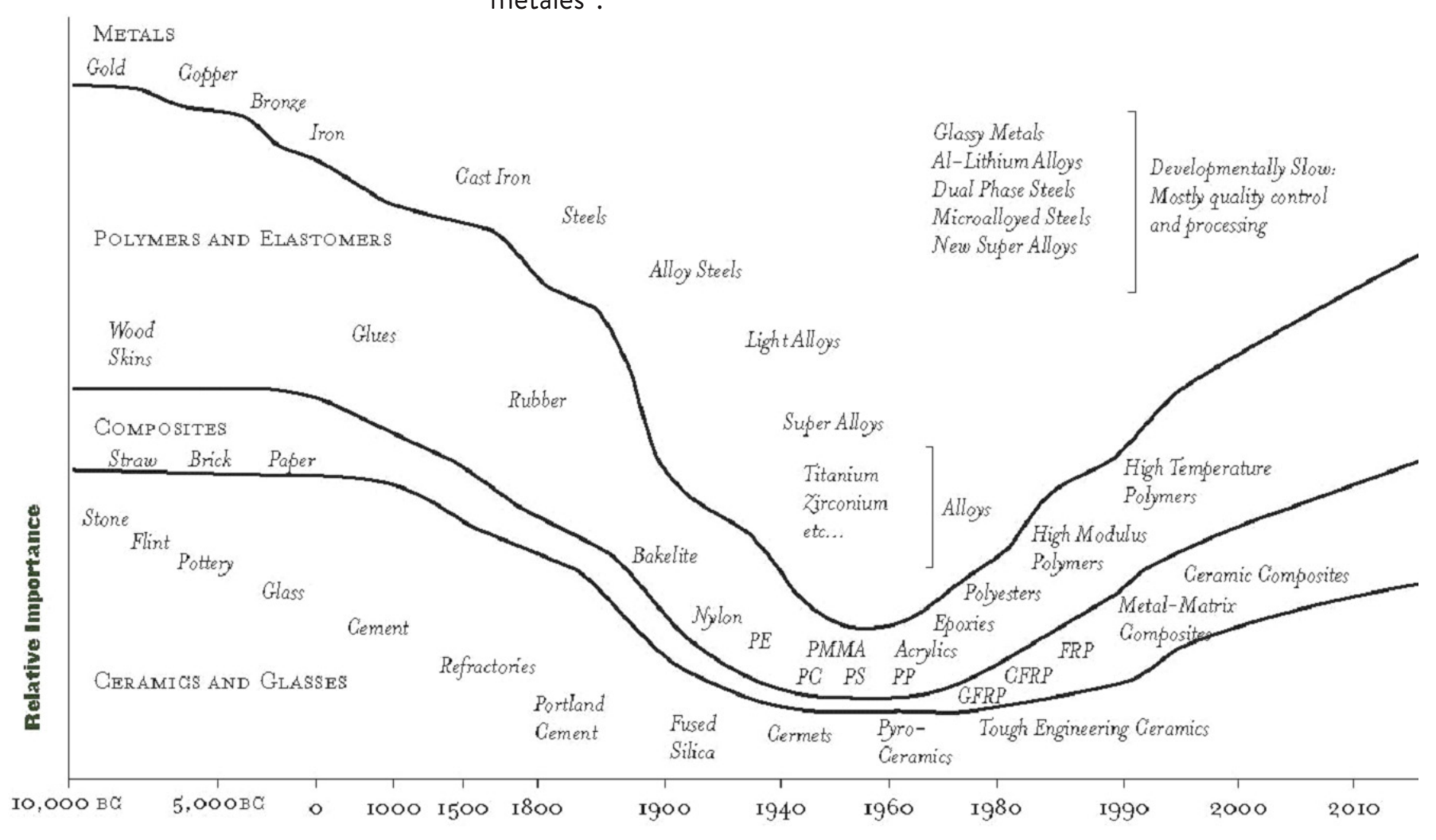

Date 
Desde la prehistoria la humanidad ha estado construyendo, la tecnología y la economía de la construcción ha ido cambiando a través del tiempo. Los primeros edificios eran simples cabañas, tiendas de campaña y refugios contra el viento, construido por los propios usuarios. Finales del siglo XX, el término sostenibilidad se asocia, casi de forma inmediata, a una serie de criterios medioambientales y no podemos olvidar la repercusión de todos los factores que caracterizan y aseguran un mayor grado de la sostenibilidad, por tanto, no sólo se deben tener en cuenta factores medioambientales, sino también sociales y económicos.

El campo de la ingeniería en la construcción se ha beneficiado desde siempre de las innovaciones de la tecnología de materiales. La invención del hormigón en la antigua Roma fue un descubrimiento importante, la producción masiva de acero y cristal a partir de mediados del siglo XIX

En la época actual, la nanotecnología está generando de nuevo grandes cambios, ejemplos de ello son habituales verlos en la producción de hormigón, en pinturas y recubrimientos o en materiales para el aislamiento térmico y la protección contra incendios.

\subsubsection{EL CEMENTO}

A pesar de que los materiales base cemento son los materiales más ampliamente utilizados en el mundo, su complejidad química y física hace que los mecanismos de su comportamiento sean aún poco conocidos hoy en día.

El hormigón junto con el acero, son la piedra angular en la industria de la construcción. Se ha estimado que en 2010 se produjeron 3.300 millones de toneladas de hormigón, lo que representa un aumento de casi $8 \%$ con respecto a 2009 , y la producción mundial de cemento continúa aumentando, impulsada por la creciente demanda de las economías emergentes, como China y la India ${ }^{180}$. Sin embargo, la fabricación de cemento es un proceso donde se produce un intensivo en energía, el proceso de calcinación se produce a temperaturas en torno a los $1300^{\circ} \mathrm{C}$ , lo cual representa el $7 \%$ del consumo mundial de energía y el $4 \%$ de las emisiones industriales de $\mathrm{CO}_{2}$ a nivel mundial ${ }^{181}$.

El volumen de consumo mundial de cemento se ha más que duplicado en los últimos 15 años, desde 1,8 bn tn en 2002 hasta las 4,4 bn tn en 2015. La tendencia es creciente, aunque el crecimiento se ha suavizado en este periodo.
180 Van Oss, H. G. (2009).

US Geological survey (USGS) mineral commodity summaries: Cement.

181 Lebental, B., Chainais, P., Chenevier, P., Chevalier, N., Delevoye, E., Fabbri, J. M., ... \& Ghis, A. (2011).

Aligned carbon nanotube based ultrasonic microtransducers for durability monitoring in civil engineering. Nanotechnology, 22(39), 395501. 
Fig 49. Consumo Mundial de Cemento en (MTns). Fuente: ICR research.

Fig 50. Evolución del consumo de cemento en Europa (MTn). Fuente: ICR research.

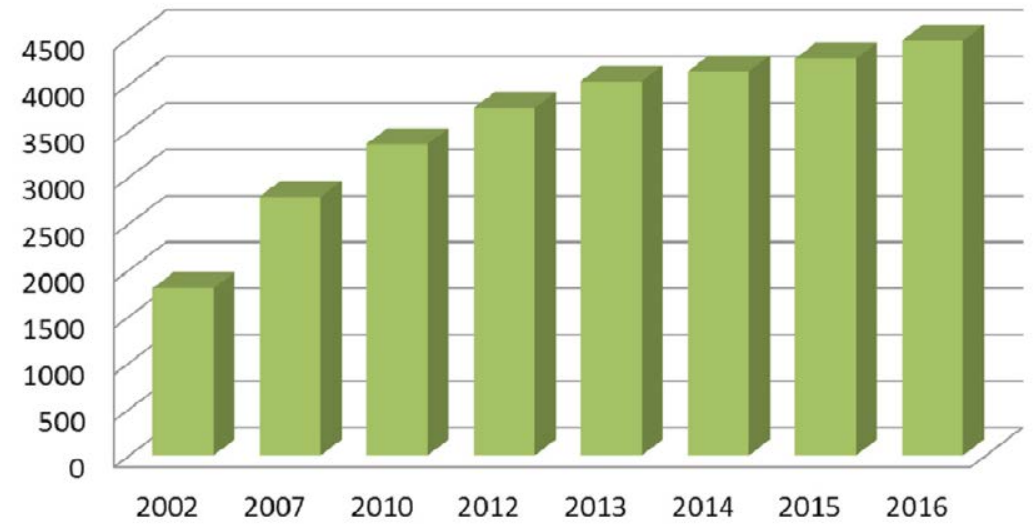

En Europa, tras la dramática caída del 40\% desde el año 2007, el mercado actual se ha estabilizado marcando un ligero crecimiento, a pesar de ello en Europa el consumo previsto en 2016, será un $40 \%$ más bajo que en 2007 , pasando de $266 \mathrm{M}$ tn a $162 \mathrm{M}$ tn

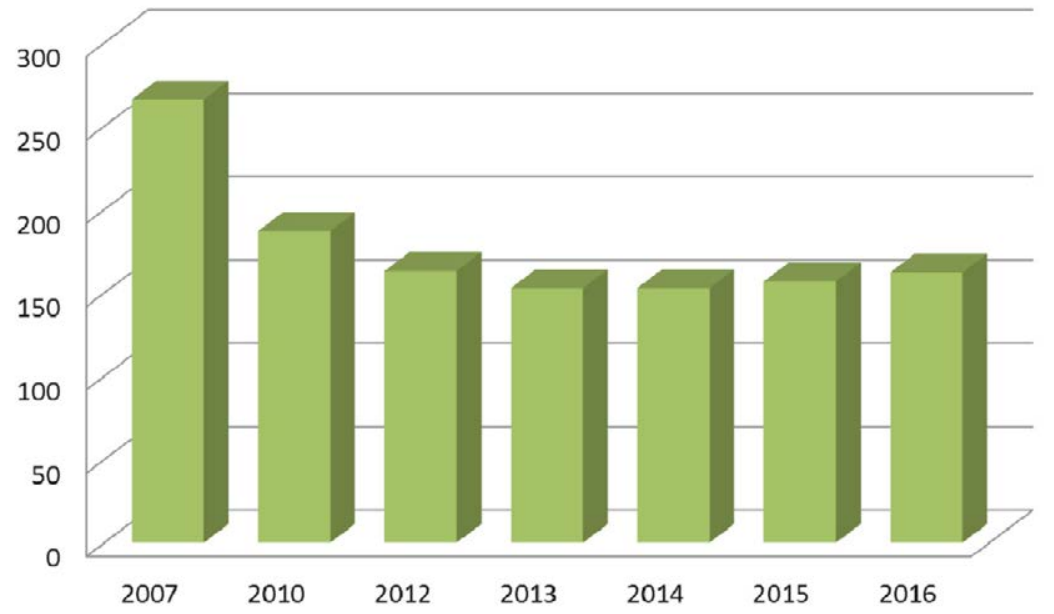

En el sentido más general de la palabra, el cemento es un conglomerante, una sustancia que fragua y endurece de forma sin necesidad de ayuda. Los granos de cemento se unen y crean un material similar a la piedra llamado, hormigón.

El cemento Portland es un conglomerante hidráulico, un material inorgánico finamente dividido que, amasado con agua forma una pasta que fragua y endurece a través de una serie de reacciones y procesos de hidratación que, una vez endurecido, conserva su resistencia y estabilidad incluso bajo el agua.

\section{$5 \cdot 2 \cdot 1.1 .1$. FABRICACIÓN Y COMPOSICIÓN}

El cemento Portland constituye actualmente más utilizado, se obtiene por molienda conjunta del clínker, las adiciones si las hay y de un regulador de fraguado, el sulfato cálcico (CŜ) cuya función es retardar la hidratación de los aluminatos, y así regular el tiempo de fraguado. 
Los materiales utilizables, que están recogidos en norma ${ }^{182}$ como adiciones posibles al cemento son, son las escorias vitreas de horno alto, los esquistos calcinados, el humo de sílice, las puzolanas naturales, las cenizas volantes y la caliza. El clínker es el componente base del cemento Portland y está formado por una mezcla de silicatos, aluminatos y ferrito aluminatos de calcio, que se obtiene por cocción de una mezcla homogénea y debidamente dosificada de calizas y arcillas denominada crudo, pasta o harina, en un horno a temperaturas entre $1300^{\circ} \mathrm{C}-1500^{\circ} \mathrm{C}^{183}$.

En el proceso de fabricación del clínker, las calizas son la fuente de óxido de calcio $(\mathrm{CaO})$ y las arcillas, de los óxidos de silicio $\left(\mathrm{SiO}_{2}\right)$, de aluminio $\left(\mathrm{Al}_{2} \mathrm{O}_{3}\right)$ y de hierro $\left(\mathrm{Fe}_{2} \mathrm{O}_{3}\right)$. En ocasiones se pueden utilizar otras materias primas como arena, pirita o caolín como correctores de las proporciones necesarias en el crudo de $\mathrm{SiO}_{2}, \mathrm{Fe}_{2} \mathrm{O}_{3}$ y $\mathrm{Al}_{2} \mathrm{O}_{3}$, respectivamente.En Europa, tras la dramática caída del $40 \%$ desde el año 2007, el mercado actual se ha estabilizado marcando un ligero crecimiento, a pesar de ello en Europa el consumo previsto en 2016, será un 40\% más bajo que en 2007 , pasando de $266 \mathrm{M}$ tn a $162 \mathrm{M}$ tn.

Composición química: $\mathrm{CaO}, \mathrm{SiO}_{2}, \mathrm{Al}_{2} \mathrm{O}_{3}, \mathrm{Fe}_{2} \mathrm{O}_{3}$ y otros compuestos

Especificaciones: $(\mathrm{CaO}) /(\mathrm{SiO} 2) \geq 2,0$

$$
\mathrm{MgO} \leq 5,0 \%
$$

$3 \mathrm{CaO} \cdot \mathrm{SiO}_{2}+2 \mathrm{CaO} \cdot \mathrm{SiO}_{2} \geq 2 / 3$

El proceso de clínkerización ocurre en varias etapas diferenciadas, en la primera etapa que comprende entre los 550 y $1.000{ }^{\circ} \mathrm{C}$ se produce la deshidratación de la arcilla y la descarbonatación de la caliza. La segunda etapa va de 1000 a $1250{ }^{\circ} \mathrm{C}$ y durante ella tienen lugar reacción en estado sólido que dan lugar a la formación de silicatos, aluminatos y ferrito aluminatos, ( $\mathrm{C}_{2} \mathrm{~S}, \mathrm{C}_{3} \mathrm{~A}, \mathrm{C}_{2} \mathrm{AS}, \mathrm{C}_{12} \mathrm{~A}_{7}$ y $\left.\mathrm{C}_{4} \mathrm{AF}\right)$

A temperaturas por encima de $1250{ }^{\circ} \mathrm{C}$ se forma, $\mathrm{C}_{3} \mathrm{~S}$ por reacción en estado sólido entre el $\mathrm{C}_{2} \mathrm{~S}$ y el $\mathrm{CaO}$ presente, por encima de $1.300{ }^{\circ} \mathrm{C}$ se genera en el horno una fase líquida que facilita la formación de $\mathrm{C}_{3} \mathrm{~S}$. De esta manera entre 1400 y $1450{ }^{\circ} \mathrm{C}$, una parte del $\mathrm{C}_{2} \mathrm{~S}$ formado reacciona con la cal restante. El proceso se considera acabado cuando no queda $\mathrm{CaO}$ libre ${ }^{184,185}$.

\section{Óxidos}

\section{$\mathrm{CaO}$}

$\mathrm{SiO} 2$

$\mathrm{Al} 2 \mathrm{O} 3$

$\mathrm{Fe} 2 \mathrm{O} 3$

$$
\mathrm{MgO}
$$

Minoritarios (Óxidos de Ti, Zn, Na, K, Mn...)

\section{Proporción de Clínker}

$60-69 \%$

$18-24 \%$

$4-8 \%$

$1-8 \%$

$1-5 \%$

$<8,5 \%$
182 UNE EN. 197-1: 2011.

Composition, specifications and conformity criteria for common cements.

${ }^{183}$ Mitsuda, T., \& Taylor, H. F. W. (1978). Normal and anomalous tobermorites. Mineral. Mag, 42(322), 229-35.

Tabla 4. Relaciones entre los óxidos en la composición química del clínker.

184 Skalny, J., Jawed, I.,

\& Taylor, H. F. W. (1978)

Hydration of

cement--recent developments.

World Cement Technology, 9(6), 183-86.

185 Taylor, H. F.,

Rossi, F. R., Martínez, J. A. F.,

\& Montemayor, M. A. (1978)

La química de los cementos.

Urmo, SA de Ediciones.

Tabla 5. Composición química del clínker de cemento Portland 
Tabla 6. Fases mineralógicas que componen el clínker de cemento Portland

\footnotetext{
${ }^{186}$ López, A., \& del Mar, M. (2011). Comportamiento y compatibilidad de cementos y aditivos superplastificantes basados en policarboxilatos. Efectos de la naturaleza de los cementos y estructura de los aditivos.
}

\begin{tabular}{|c|c|c|}
\hline Nombre & Composición & Proporción en Clínker \\
\hline $\begin{array}{l}\text { Silicato Tricálcico ó } \\
\mathrm{C}_{3} \mathrm{~S} \text { (alita) }\end{array}$ & $\begin{array}{l}3 \mathrm{CaO} \cdot \mathrm{SiO}_{2} 0 \\
\left(\mathrm{Ca}_{2} \mathrm{SiO}_{5}\right)\end{array}$ & $50-70 \%$ \\
\hline $\begin{array}{l}\text { Silicato Bicálcico ó } \\
\mathrm{C}_{2} \mathrm{~S} \text { (belita) }\end{array}$ & $\begin{array}{l}2 \mathrm{CaO} \cdot \mathrm{SiO}_{2} \text { ó } \\
\left(\mathrm{Ca}_{2} \mathrm{SiO}_{4}\right)^{-}\end{array}$ & $15-25 \%$ \\
\hline $\begin{array}{l}\text { Aluminato Tricálcico ó } \\
\mathrm{C}_{3} \mathrm{~A}\end{array}$ & $\begin{array}{l}3 \mathrm{CaO} \cdot \mathrm{Al}_{2} \mathrm{O}_{3} 0 \\
\left(\mathrm{Ca}_{3} \mathrm{Al}_{2} \mathrm{O}_{6}\right)\end{array}$ & $5-15 \%$ \\
\hline $\begin{array}{l}\text { Ferrito-aluminato ó } \\
\mathrm{C}_{4} \mathrm{AF}\end{array}$ & $\begin{array}{l}4 \mathrm{CaO} \cdot \mathrm{Al}_{2} \mathrm{O}_{3} \mathrm{Fe}_{2} \mathrm{O}_{3} \mathrm{o} \\
\left(\mathrm{Ca}_{4} \mathrm{Al}_{2} \mathrm{O}_{10} \mathrm{Fe}_{2}\right)\end{array}$ & $5-15 \%$ \\
\hline
\end{tabular}

Los componentes minerales principales del clínker se encuentran formando una masa de cristales microscópicos incluidos en una masa vítrea que varía entre el 8 y el $20 \%$. El porcentaje de fase amorfa es variable según la composición y velocidad de enfriamiento que haya sufrido el clinker ${ }^{186}$.

\subsection{TIPOS DE CEMENTOS Y COMPOSICIÓN}

Se consideran cementos comunes los definidos en la norma UNE-EN 197-1:2011 y se clasifican en cinco tipos:

CEM I o cemento Portland: Aquellos constituidos por al menos el $95 \%$ de clinker.

CEM II, con un contenido de adiciones entre el 6 y el $35 \%$. Las adiciones pueden ser escorias vítreas de horno alto, humo de sílice, puzolanas, cenizas volantes, esquistos calcinados o caliza. Poseen el sufijo A cuando el porcentaje de adición es del 6 al $20 \%$ y B cuando está comprendido entre el 21 y el $35 \%$.

CEM III, son los cementos con un porcentaje de escorias vítreas de horno alto entre el 36 y el $95 \%$. El sufijo $A$ indica una proporción de escoria entre el 36 y el $65 \%$, B si es del 66 al 80 \% y C si está entre el 81 y el $95 \%$.

CEM IV, son los cementos puzolánicos, con un contenido entre el 11 y el 55 $\%$ de humo de sílice, cenizas volantes o puzolanas. Los marcados como $\mathrm{A}$ tienen entre el 11 y el $35 \%$ de adición y los B entre el 36 y el $55 \%$.

CEM V, o cementos compuestos: Están constituidos por una mezcla de diferentes adiciones entre el 18 y el $50 \%$. Los marcados como $A$ tienen entre el 18 y el $30 \%$ de adición, y los B entre el 31 y el $50 \%$. 


\begin{tabular}{|c|c|c|c|c|c|c|c|c|c|c|c|c|c|}
\hline \multirow{4}{*}{ 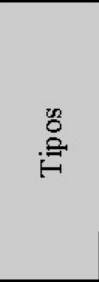 } & \multirow{4}{*}{ 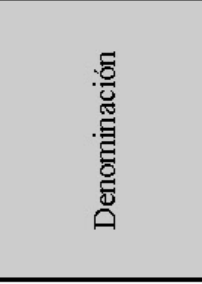 } & \multirow{4}{*}{ 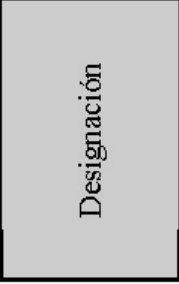 } & \multicolumn{11}{|c|}{ Composición (proporción en masa ) } \\
\hline & & & \multicolumn{10}{|c|}{ Componentes principales } & \multirow{3}{*}{$\begin{array}{l}\text { Constit. } \\
\text { Minorit } \\
\end{array}$} \\
\hline & & & \multirow[t]{2}{*}{$\mathrm{K}$} & \multirow[t]{2}{*}{$\mathrm{S}$} & \multirow[t]{2}{*}{ D } & \multicolumn{2}{|c|}{ Puzolana } & \multicolumn{2}{|c|}{$\begin{array}{c}\text { Cenizas } \\
\text { volantes } \\
\end{array}$} & \multirow[t]{2}{*}{$\mathrm{T}$} & \multicolumn{2}{|c|}{ Caliza } & \\
\hline & & & & & & $\mathrm{P}$ & $\mathrm{Q}$ & $\mathrm{V}$ & $\mathrm{W}$ & & $\mathrm{L}$ & $\mathrm{LL}$ & \\
\hline CEM I & $\begin{array}{l}\text { Cemento } \\
\text { Portland }\end{array}$ & CEM I & $95-100$ & - & - & - & - & - & - & - & - & - & $0-5$ \\
\hline \multirow{19}{*}{$\begin{array}{c}\text { CEM } \\
\text { II }\end{array}$} & \multirow{2}{*}{$\begin{array}{c}\text { Cemento } \\
\text { Portland } \\
\text { con escoria } \\
\end{array}$} & CEM II/A-S & $80-94$ & 6-20 & - & - & - & - & - & - & - & - & $0-5$ \\
\hline & & CEM II/B-S & $65-79$ & $21-35$ & - & - & - & - & - & - & - & - & $0-5$ \\
\hline & $\begin{array}{c}\text { Cemento } \\
\text { Portland con } \\
\text { humo de sílice }\end{array}$ & CEM II/A-D & $90-94$ & - & $6-10$ & - & - & - & - & - & - & - & $0-5$ \\
\hline & \multirow{4}{*}{$\begin{array}{c}\text { Cemento } \\
\text { Portland } \\
\text { con puzolana }\end{array}$} & CEM II/A-P & $80-94$ & - & - & $6-20$ & - & - & - & - & - & - & $0-5$ \\
\hline & & CEM II/B-P & 65-79 & - & - & $21-35$ & - & - & - & - & - & - & $0-5$ \\
\hline & & CEM II/AQ & \begin{tabular}{|l|}
$80-94$ \\
\end{tabular} & - & - & - & $6-20$ & - & - & - & - & - & $0-5$ \\
\hline & & CEM II/BQ & \begin{tabular}{|l|}
$65-79$ \\
\end{tabular} & - & - & - & $21-35$ & - & - & - & - & - & $0-5$ \\
\hline & \multirow{4}{*}{$\begin{array}{c}\text { Cemento } \\
\text { Portland con } \\
\text { ceniza volante }\end{array}$} & CEM II/AV & \begin{tabular}{|l|}
$80-94$ \\
\end{tabular} & - & - & - & - & $6-20$ & - & - & - & - & $0-5$ \\
\hline & & CEM II/BV & \begin{tabular}{|l|}
$65-79$ \\
\end{tabular} & - & - & - & - & $21-35$ & - & - & - & - & $0-5$ \\
\hline & & CEM II/AW & \begin{tabular}{|l|}
$80-94$ \\
\end{tabular} & - & - & - & - & - & $6-20$ & - & - & - & $0-5$ \\
\hline & & CEM II/BW & \begin{tabular}{|l|}
$65-79$ \\
\end{tabular} & - & - & - & - & - & $21-35$ & - & - & - & $0-5$ \\
\hline & \multirow{2}{*}{$\begin{array}{c}\text { Cemento } \\
\text { Portland } \\
\text { con esquistos } \\
\text { calcinados }\end{array}$} & CEM II/A-T & \begin{tabular}{|l|}
$80-94$ \\
\end{tabular} & - & - & - & - & - & - & $6-20$ & - & - & $0-5$ \\
\hline & & CEM II/B-T & $65-79$ & - & - & - & - & - & - & $21-35$ & - & - & $0-5$ \\
\hline & \multirow{4}{*}{$\begin{array}{l}\text { Cemento } \\
\text { Portland } \\
\text { con caliza }\end{array}$} & CEM II/A-L & \begin{tabular}{|l|}
$80-94$ \\
\end{tabular} & - & - & - & - & - & - & - & $6-20$ & - & $0-5$ \\
\hline & & CEM II/B-L & \begin{tabular}{|l|}
$65-79$ \\
\end{tabular} & - & - & - & - & - & - & - & $21-35$ & - & $0-5$ \\
\hline & & CEM I/A-LL & \begin{tabular}{|l|}
$80-94$ \\
\end{tabular} & - & - & - & - & - & - & - & - & $6-20$ & $0-5$ \\
\hline & & CEMI/B-LL & $65-79$ & - & - & - & - & - & - & - & - & $21-35$ & $0-5$ \\
\hline & \multirow{2}{*}{$\begin{array}{c}\text { Cemento } \\
\text { Portland mixto }\end{array}$} & CEM I/A-M & $80-94$ & \multicolumn{9}{|c|}{ 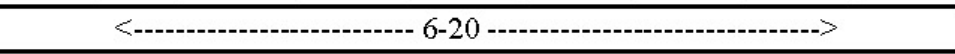 } & $0-5$ \\
\hline & & CEMП/B-M & $65-79$ & \multicolumn{9}{|c|}{ 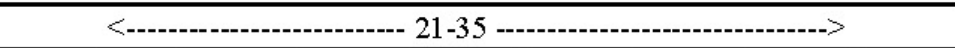 } & $0-5$ \\
\hline \multirow{3}{*}{$\begin{array}{c}\text { CEM } \\
\text { III }\end{array}$} & \multirow{3}{*}{$\begin{array}{c}\text { Cemento } \\
\text { con escorias } \\
\text { de horno alto }\end{array}$} & CEM III/A & $35-64$ & $36-65$ & - & - & - & - & - & - & - & - & $0-5$ \\
\hline & & CEM III/B & $20-34$ & $66-80$ & - & - & - & - & - & - & - & - & $0-5$ \\
\hline & & $\mathrm{CEM} \mathrm{III/C}$ & $5-19$ & $81-95$ & - & - & - & - & - & - & - & - & $0-5$ \\
\hline \multirow{2}{*}{$\begin{array}{c}\text { CEM } \\
\text { IV }\end{array}$} & \multirow{2}{*}{$\begin{array}{l}\text { Cemento } \\
\text { puzolánico }\end{array}$} & CEM IV/A & $65-89$ & - & \multicolumn{5}{|c|}{ <------------------ 11-35 -------------------> } & - & - & - & $0-5$ \\
\hline & & CEM IV/B & $45-64$ & - & $<--\cdot$ & ------- & $36-55$ & 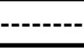 & $-\cdots>$ & - & - & - & $0-5$ \\
\hline $\mathrm{CEM}$ & Cemento & CEM V/A & $40-64$ & $18-30$ & - & & $18-30$ & & - & - & - & - & $0-5$ \\
\hline V & Compuesto & CEM V/B & \begin{tabular}{|l|}
$20-38$ \\
\end{tabular} & $31-50$ & - & $<------$ & $31-50-$ & $\cdots>$ & - & - & - & - & $0-5$ \\
\hline
\end{tabular}

K-Clínker; S-Escoria de horno alto; D-Humo de Sílice; P-Puzolana Natural; Q-Puzolana natural calcinada; V-Ceniza volante silícea; W-Ceniza volante calcárea; T-Esquistos calcinados; L-Calizas con un contenido en carbono orgánico total inferior al $0,5 \%$ en masa; LL-Calizas con un contenido en carbono orgánico total inferior al $0,2 \%$ en masa 


\subsection{CONTAMINACIÓN ATMOSFÉRICA}

\section{INTRODUCCIÓN.}

El aire es esencial para la vida, un requisito básico para la salud y el bienestar humanos y no sólo porque permite respirar a los organismos vivos, sino también porque su influencia en la Tierra hace que ésta sea habitable. Se dice de la atmósfera, que constituye el principal mecanismo de defensa de todas las formas de vida. El concepto "calidad del aire" da idea del grado de pureza del aire que respiramos. Una buena o mala calidad del aire depende de la cantidad y concentración de contaminantes presentes en el mismo, y aunque habitualmente pensamos en contaminación atmosférica como algo exterior, algo que se encuentra fuera de nuestra vivienda o del entorno de trabajo de hecho eso no es así. Las actividades de la vida diaria hacen que el individuo pase más del $80 \%$ de su tiempo en espacios interiores, oficinas, colegios, hospitales, guarderías, centros comerciales, viviendas particulares...; por ello, la calidad del aire que en ellos se respira puede afectar $y$ de hecho afecta, a la salud de sus habitantes.

La contaminación atmosférica es un fenómeno con un amplio y extenso impacto medioambiental y social, hoy supone un problema complejo que plantea múltiples desafíos, en términos de la gestión y la reducción o eliminación de contaminantes, no solo en las ciudades.

Esa contaminación atmosférica, genera un conjunto de efectos nocivos que alteran la biosfera, y que tienen múltiples impactos sobre los seres humanos. Dichos efectos nocivos dependen de la acción de agentes que, una vez liberados en el aire, principalmente como subproductos derivados de actividades humanas, modifican el equilibrio existente en la atmosfera. Por consiguiente, en la atmósfera están presentes sustancias que no se encuentran en la composición natural del aire o que, si se encuentran, presentan un nivel de concentración más bajo, en algunos de ellos por su mera presencia, tiene una serie de impactos en la salud, los ecosistemas, el entorno construido, el clima e incluso sobre el desarrollo económico.

A pesar de la acciones y planes adoptados a nivel mundial para reducir la contaminación atmosférica, continúa suponiendo una amenaza importante, debido a las concentraciones en las ciudades y a la larga exposición que soporta la población al vivir y/ o trabajar en las grandes áreas urbanas, focos de la actividad industrial y humana.

\subsubsection{CONSECUENCIAS A NIVEL MUNDIAL}

Hoy en día se vive en un mundo cada vez más global e interconectado. Como reflejo de este modelo de desarrollo, más de la mitad de la población mundial (54\%) vive en ecosistemas urbanos, alcanzando el $73 \%$ de la población en el caso de Europa, 3.900 millones en 2014. De esa población, el 92\% vivía en lugares donde no se respetaban las directrices de la Organización Mundial 
de la Salud (OMS) sobre la calidad del aire. Las previsiones realizadas por la Organización de las Naciones Unidas (ONU), estiman que el crecimiento de las áreas urbanas sume 2.500 millones de habitantes para el año 2050. Mientras que en el año 1950 solo el $30 \%$ de la población mundial vivía en zonas urbanas, en 2050 se proyecta que este porcentaje alcance el 66\% de la población mundial. De igual modo se prevé que cerca de una de cada ocho personas viva en alguna de las 28 mega-ciudades de 10 millones de habitantes El número de mega-ciudades casi se ha triplicado desde 1990; $Y$ para el 2030, se proyecta que 41 aglomeraciones urbanas alberguen al menos 10 millones de habitantes cada una ${ }^{186}$.

\author{
${ }^{186}$ DESA, U. (2016) \\ United nations department of economic \\ and social Affairs/Population division \\ (20014): World population prospects: \\ The 2014 revision, highlights \\ (ST/ESA/SER.A/352).
}
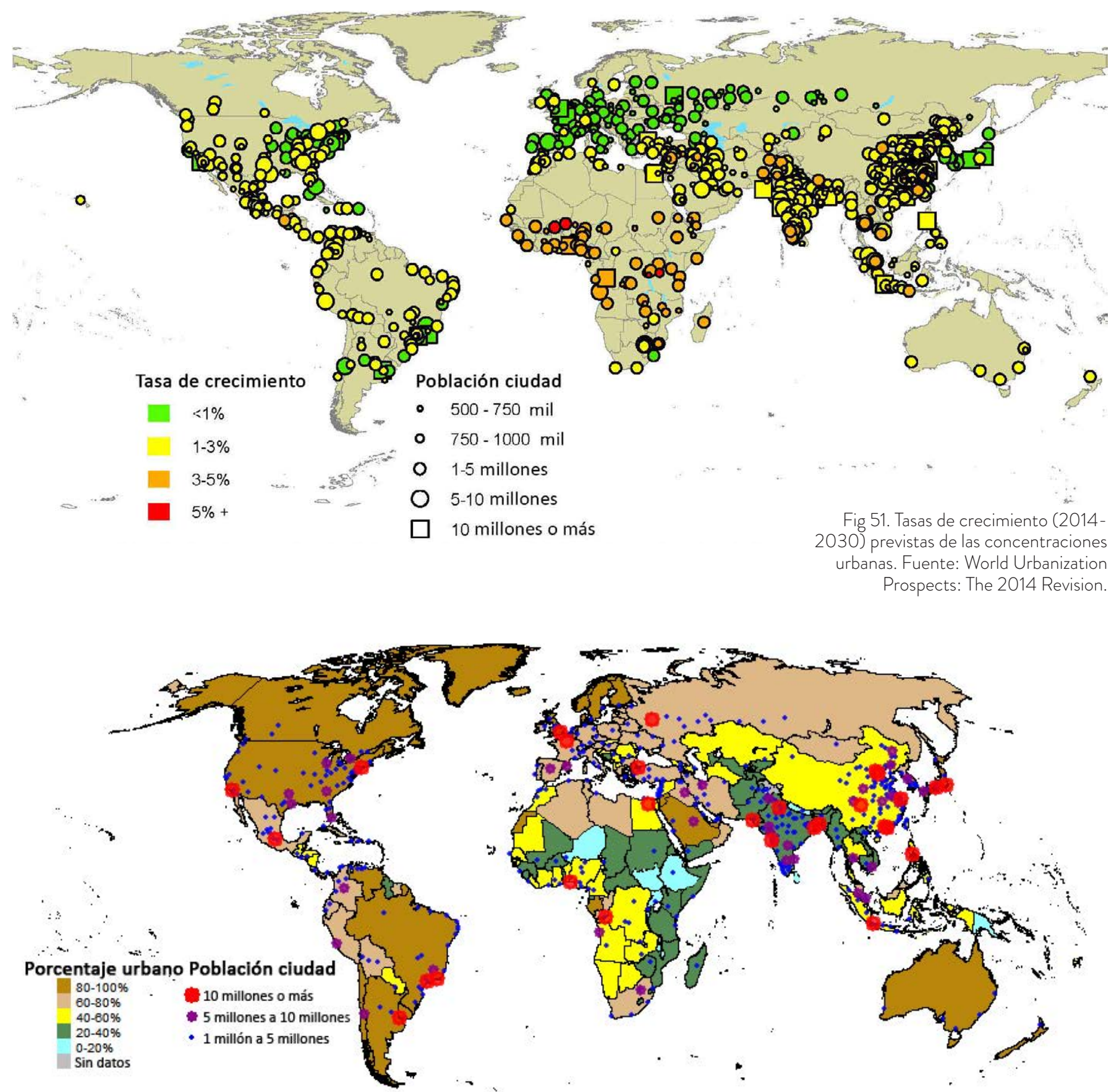

Fig 52. Porcentaje de concentración urbana y población urbana por clase y tamaño en 2014 
Fig 53. Efectos de la contaminación atmosférica para la salud. Los contaminantes atmosféricos pueden tener graves efectos para la salud de

las personas. Los niños los mayores son grupos especialmente vulnerables. Fuente. AEMA ${ }^{186}$

187 Agencia Europea del Medioambiente. (2013).

Cada vez que respiramos. mejorar la calidad del aire en europa.

( No. TH-AP-13-001-ES-C). Luxemburgo: Oficina de Publicaciones de la Unión Europea. doi:10.2800/83001

188 Pascal, M., Corso, M., Chanel, O., Declercq, C., Badaloni, C.,

Cesaroni, G., ... \& Medina, S. (2013)

Assessing the public health impacts of urban air pollution in 25 European cities: results of the Aphekom project. Science of the Total Environment, 449, 390-400.

189 World Health Organization. Air Quality Guidelines for Europe. Copenhagen: World Health Organization Regional Office for Europe.
Aunque la contaminación atmosférica afecta a todo el mundo, no daña a todos en la misma medida y de la misma forma. En las zonas urbanas hay más personas expuestas a la contaminación atmosférica debido a que alli las densidades de población son más elevadas. Algunos grupos son especialmente vulnerables: los que padecen enfermedades cardiovasculares y respiratorias, aquellos con vías respiratorias reactivas y alergias que afectan a las vías respiratorias, los ancianos y los bebés.

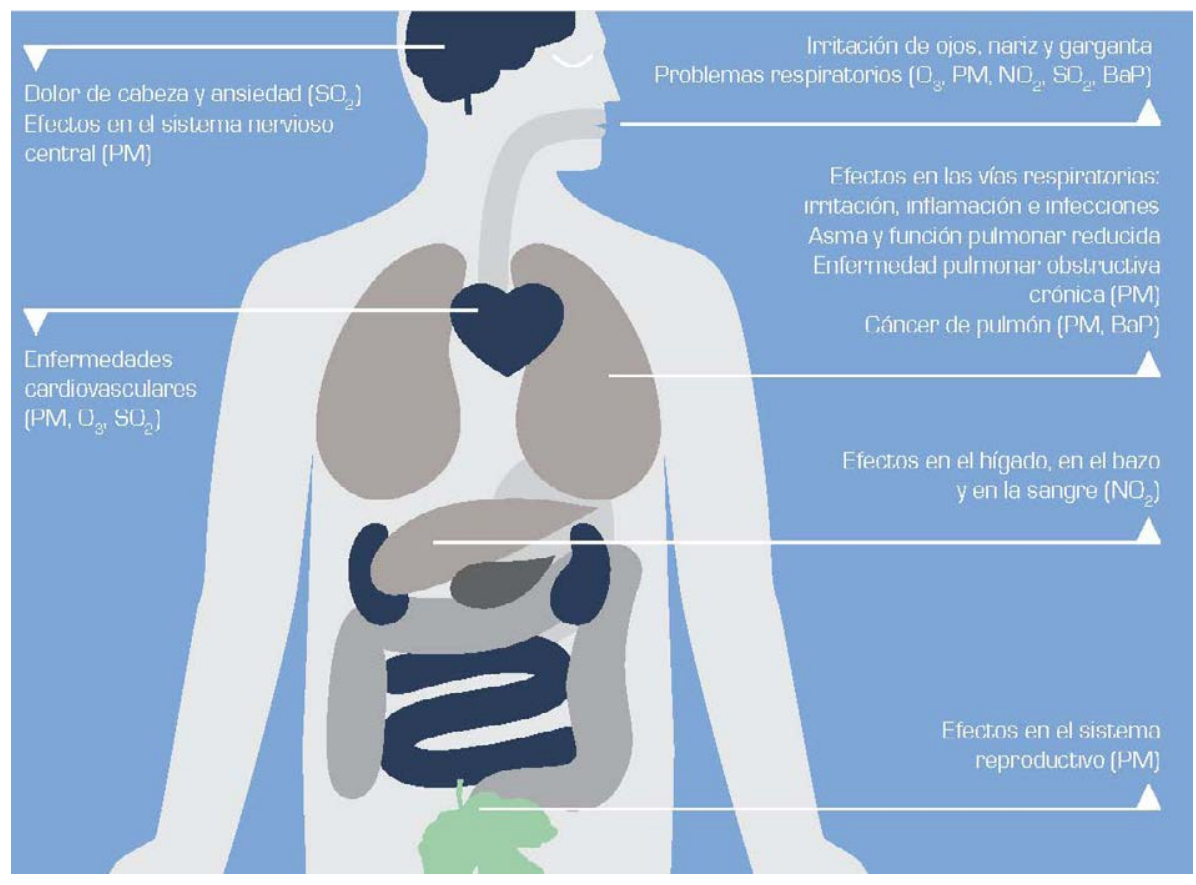

Según está recogido en las conclusiones del proyecto Aphekom ${ }^{187}$, cofinanciado por la Comisión Europea, la contaminación atmosférica en Europa causa una reducción de la esperanza de vida de alrededor de 8,6 meses por persona. El estudio señala que, la esperanza de vida aumentaría si los niveles anuales medios de $\mathrm{PM}_{2,5}$ se redujeran a los recomendados en las directrices de la Organización Mundial de la Salud de $20 \mu \mathrm{g} / \mathrm{m}^{3}$. Se calcula que solo logrando este objetivo podrían alcanzarse aumentos en la esperanza de vida por persona de, 22 meses en Bucarest , 19 meses en Budapest, 2 meses en Málaga y menos de medio mes en Dublín.

La OMS estima que, una reducción de los niveles del tipo de contaminante conocido como partículas finas (PM), podría reducir las muertes hasta en un $15 \%$ al año, que ha estimado que la contaminación ambiental debida a partículas es responsable de $1,4 \%$ de todas las muertes en el mundo ${ }^{189}$. 


\section{Concentraciones medias anuales de partículas finas (PM2.5) en las zonas urbanas $(\mu \mathrm{g} / \mathrm{m} 3), 2014$ *}

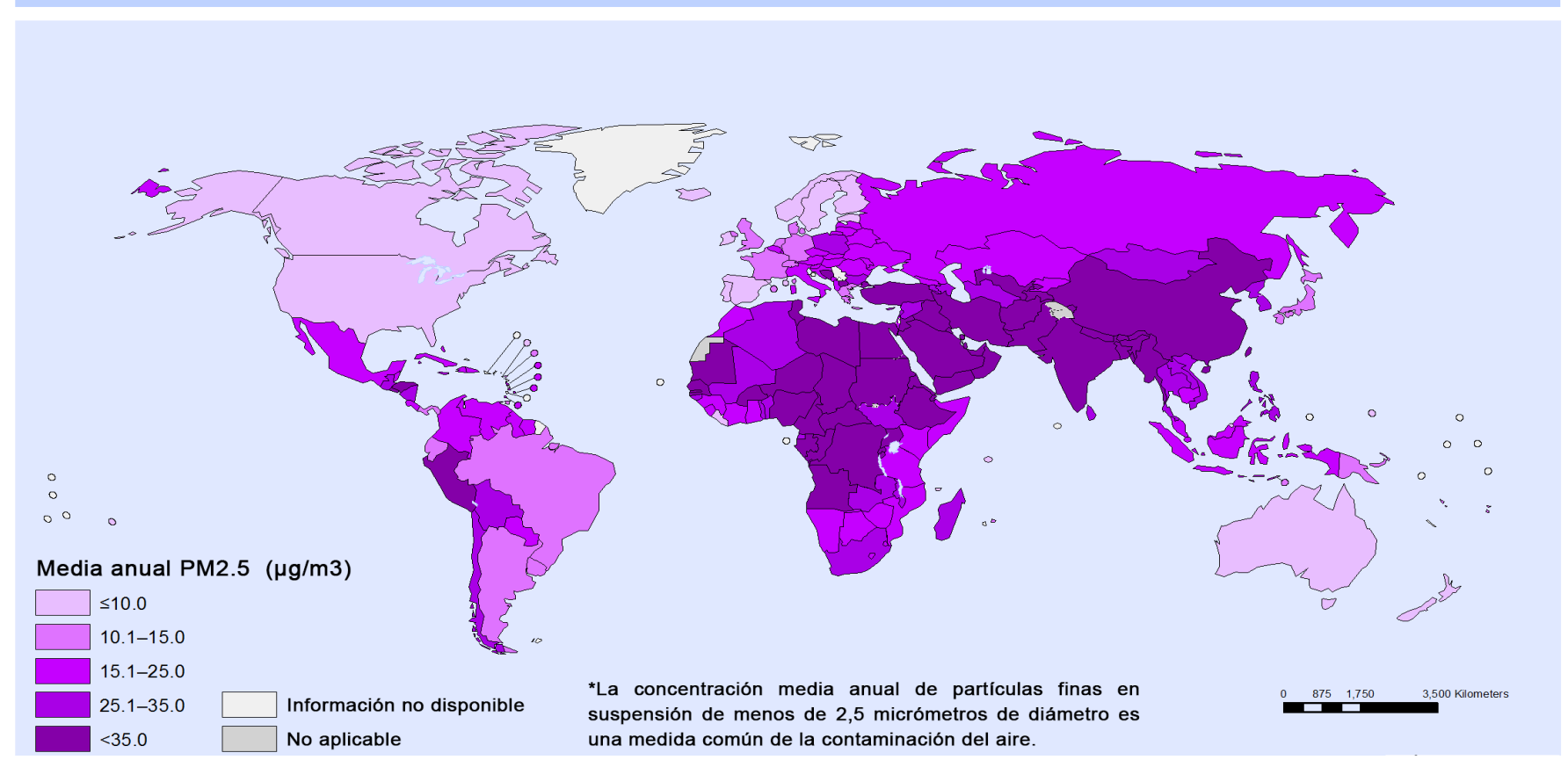

The Organisation for Economic Co-operation and Development (OECD) estima que, en ausencia de políticas adicionales y más estrictas, el aumento de la actividad económica y la demanda de energía producirá un aumento significativo de las emisiones globales de los contaminantes atmosféricos, de acuerdo con las proyecciones de la OCDE realizadas con sus modelos de estimación ENV-Linkages ${ }^{190}$.
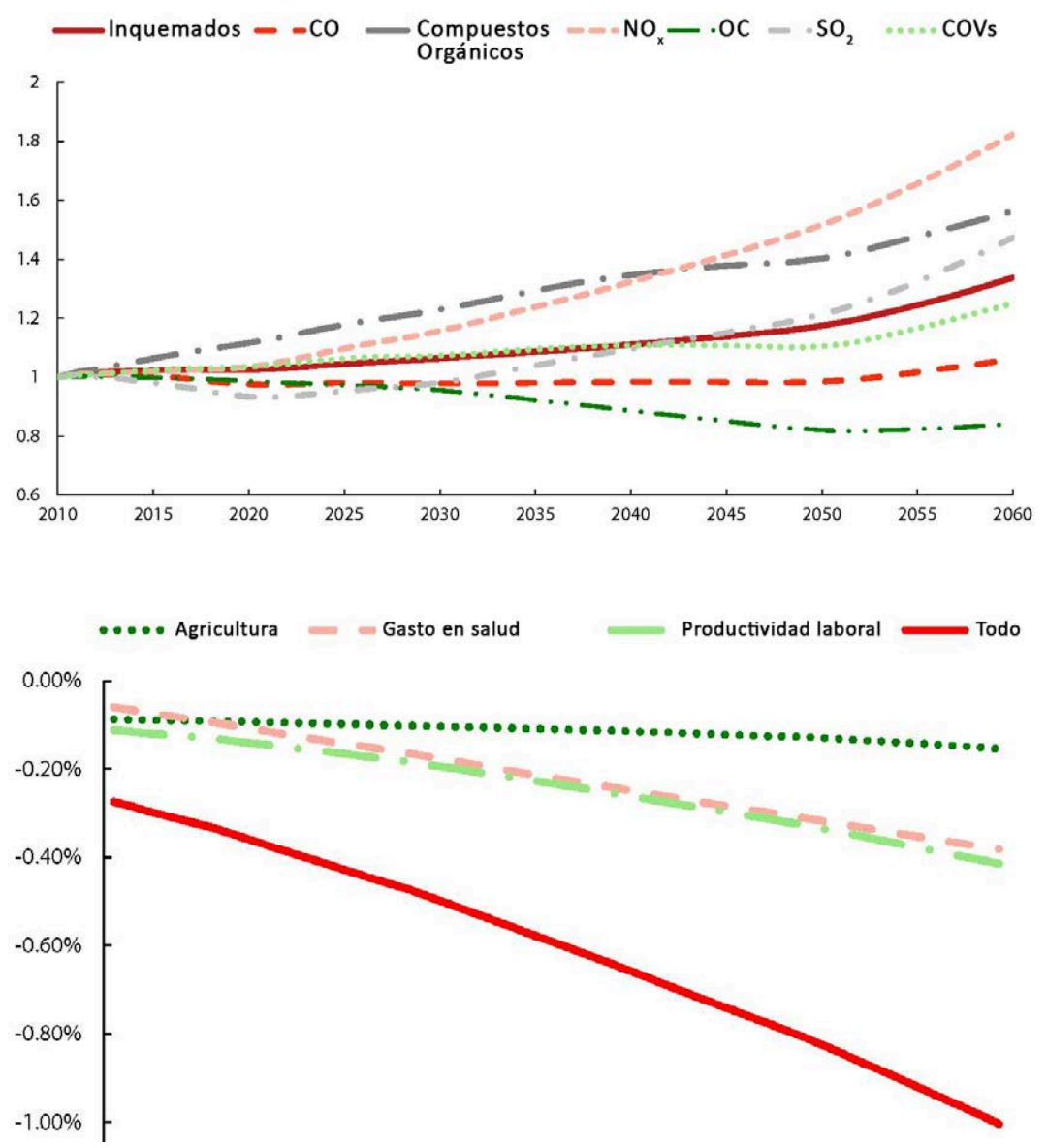

Fig 54. Concentraciones medias anuales de partículas fina PM Fuente: OM'S

190 OECD POLICY HIGHLIGHTS The economic consequences of outdoor air pollutionhttp://www.oecd.org/ environment/indicators-modellingoutlooks/Policy-Highlights-Economicconsequences-of-outdoor-airpollution-web.pdf

Fig 55. Proyección del aumento de las emisiones de contaminantes respecto a 2010. Fuente: OECD POLICY HIGHLIGHTS The economic consequences of outdoor air pollution.

Fig 56. Impacto macroeconómico previsto a determinados impactos de la contaminación atmosférica.

Fuente: OECD POLICY HIGHLIGHTS The economic consequences of outdoor air pollution. 
Se prevé que el aumento de las emisiones de contaminantes atmosféricos conduzca a concentraciones más elevadas de partículas $\left(P M_{2.5}\right)$ y Ozono. En varias zonas a nivel mundial las concentraciones medias de $\mathrm{PM}_{2,5}$ y ozono, ya se encuentran muy por encima de los valores recomendados por OMS para la calidad del aire.

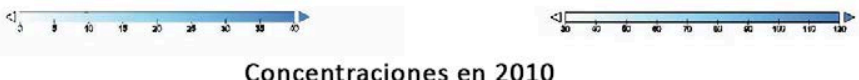

Concentraciones en 2010
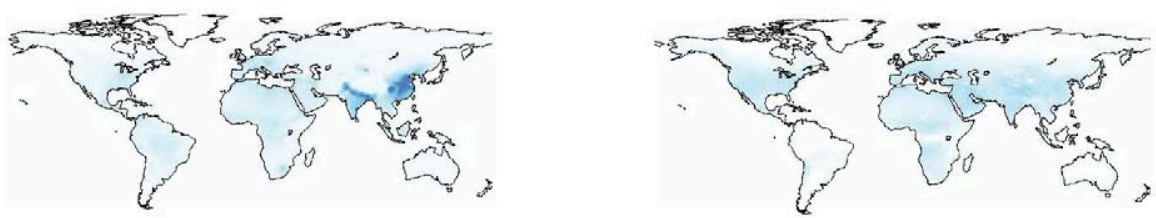

Concentraciones en 2030
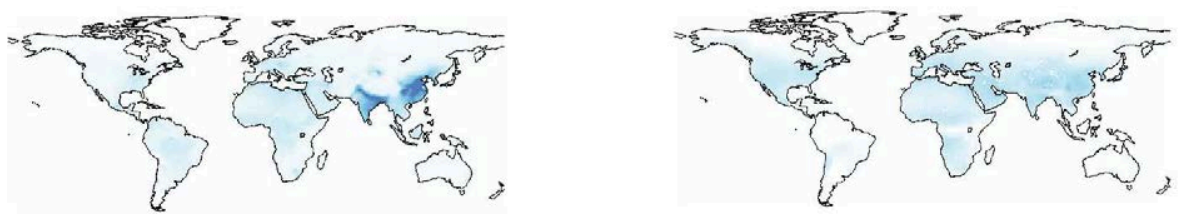

Fig 57. A la izquierda, predicciones de las concentraciones de $\mathrm{PM}_{2,5}$ de origen antropogénico, representadas en $\mu \mathrm{g} / \mathrm{m}^{3}$, a la derecha está representado el valor máximo de la media máxima horaria de 6 meses en la concentración de Ozono, valores en ppb. Fuente: OECD POLICY HIGHLIGHTS The economic consequences of outdoor air pollution.

191 OECD. (2016). Air pollution to cause 6-9 million premature deaths and cost $1 \%$ GDP by 2060 . Retrieved from https://www.oecd.org/environment/ air-pollution-to-cause-6-9-millionpremature-deaths-and-cost-1-gdpby-2060.htm. Consultado el 20 de Diciembre 2016.

Fig 58. Muertes atribuidas a la contaminación del aire ambiente en 2012

Fuente: OMS

\section{Concentraciones en 2060}
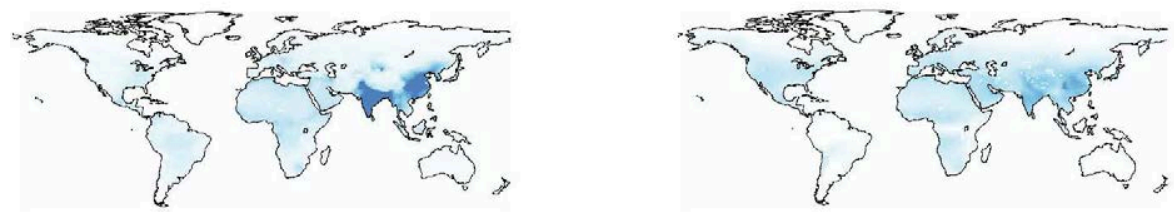

La contaminación atmosférica es uno de los riesgos ambientales más graves, los impactos son visibles ya en la salud y en la agricultura, investigaciones científicas han confirmado que la exposición a niveles altos de contaminación atmosférica se asocia a enfermedades respiratorias y cardiovasculares y, de acuerdo con la Organización Mundial de la Salud (OMS) y recogido por la OECD, anualmente se pueden atribuir más de 5,5 millones de muertes prematuras a los efectos de la contaminación atmosférica interior y exterior en el año 2013. En este informe se concluyó que La contaminación atmosférica mundial provoco el aumento sustancial de la mortalidad en el años 2013, datos de mortalidad que han ido aumentandodurante los últimos 23 años, (1990-2013) ${ }^{191}$.

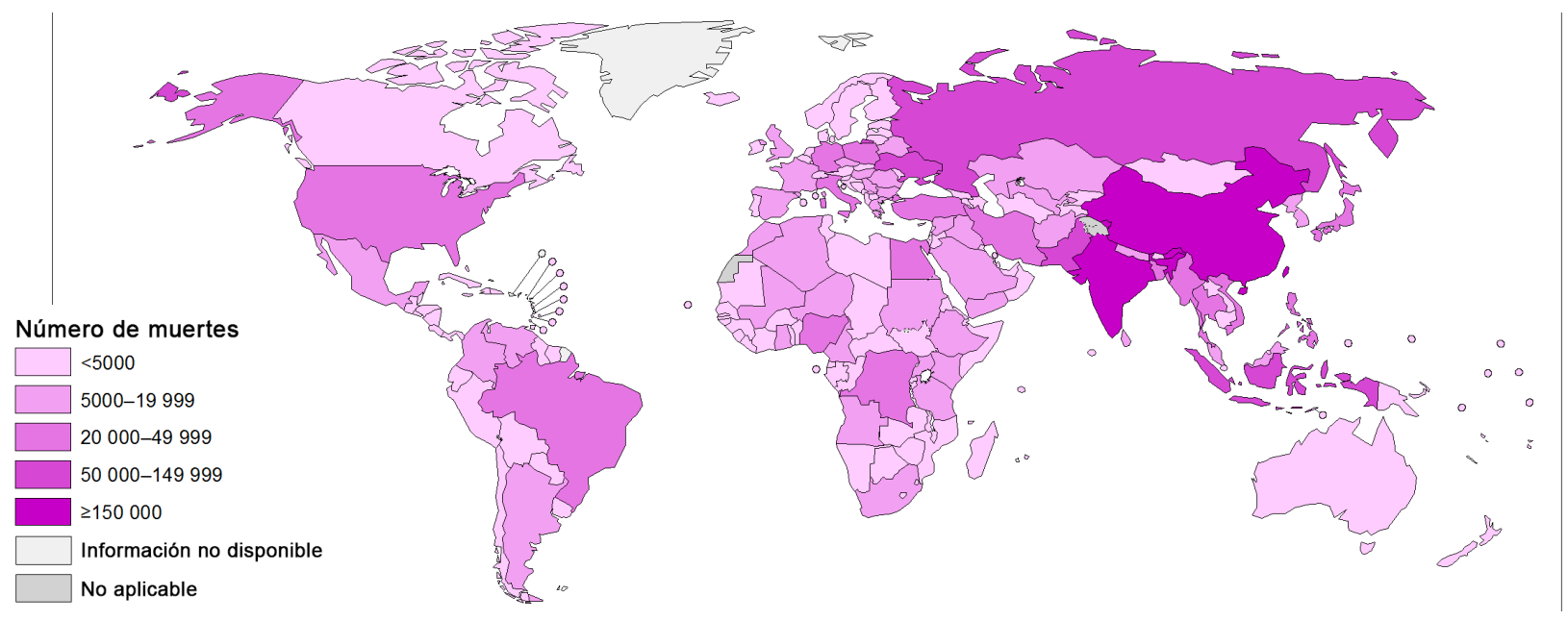


Según la misma OECD en ese mismo informe, la contaminación atmosférica al aire libre podría causar de 6 a 9 millones de muertes prematuras al año para 2060 y costar el $1 \%$ del PIB mundial - alrededor de 2.6 trillones de dólares anuales - como consecuencia de los costes asociados a enfermedades y la reducción de la producción agrícola ${ }^{192}$.

La reducción de la producción económica mundial en 2060 estará en torno a los 330 dólares por persona debido al incremento de los costos sanitarios anuales, relacionados con la contaminación atmosférica, que aumentarán hasta los 176 mil millones de dólares, 21 mil millones de dólares en 2015, mientras que el número de días de baja médica por enfermedades relacionadas con la contaminación atmosférica pasaría, de 1,2 mil millones de 3,7 mil millones ${ }^{193}$.
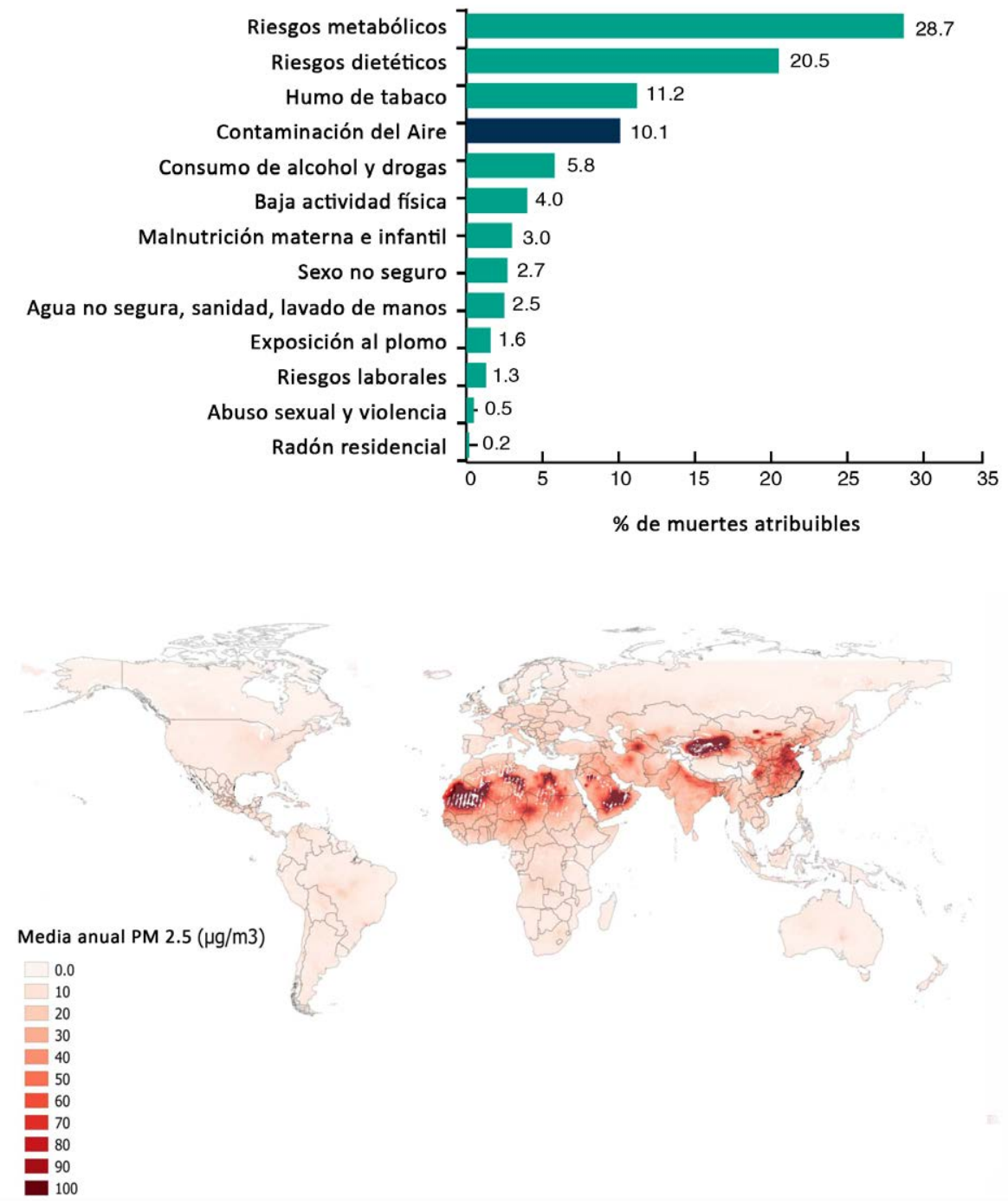

Brauer et al., en un estudio del "Aaron J. Cohen Health Effects Institute", recoge que un $87 \%$ de la población mundial se encuentra en áreas que exceden el valor límite establecido por la OMS en $10 \mu \mathrm{g} / \mathrm{m} 3 \mathrm{PM}_{2,5}$ de media anual para las $P M_{2,5}$. En ese mismo informe se dice que debido a que la respuesta a los ciclos exposición-respuesta frente a las $P_{2,5}$ no es lineal y por tanto la reducción de la mortalidad esperada en los paises más contaminados, serán pequeñas a menos que los niveles de $P M_{2,5}$ se reduzcan sustancialmente ${ }^{194}$.
192 OECD (2016),

The Economic Consequences of Outdoor Air Pollution, OECD

Publishing, Paris.

http://dx.doi.org/10.1787/9789264257474-en

193 World Bank and Institute for Health Metrics and Evaluation. 2016. The Cost of Air Pollution:

Strengthening the Economic Case for Action. Washington, DC: World Bank. License: Creative Commons Attribution CC BY 3.0 IGO.

Fig 59. Porcentaje de muertes atribuibles a nivel mundial en 2013 por factor de riesgo.

Fuente: World Bank and IHME, using data from IHME, GBD 2013.
Fig 60. Valores medios anuales en 2013 de PM

Fuente: Brauer et al.

\footnotetext{
194 Brauer, M., Freedman, G., Frostad, J., Van Donkelaar, A., Martin, R. V., Dentener, F., ... \& Balakrishnan, K. (2015). Ambient air pollution exposure estimation for the global burden of disease 2013. Environmental science \& technology, 50(1), 79-88
} 
195 Forouzanfar, M. H., Alexander, L. Anderson, H. R., Bachman, V. F., Biryukov, S., Brauer, M., ... \& Delwiche, K. (2015). Global, regional, and national comparative risk assessment of 79 behavioural, environmental and occupational, and metabolic risks

or clusters of risks in 188 countries, 1990 -2013: a systematic analysis for the

Global Burden of Disease Study 2013.

The Lancet, 386(10010), 2287-2323.

196 World Bank and Institute for Health Metrics and Evaluation. 2016. The Cost of Air Pollution: Strengthening the Economic Case for Action. Washington, DC: World Bank. License: Creative Commons Attribution CC BY 3.0 IGO

197 EEA. (2014). Air pollution fact sheet - Spain.

Fig 61. Relaciones entre impactos, calidad del aire y contaminantes. Fuente. Air pollution fact sheet - Spain
En 2013, los niveles de contaminación atmosférica tienen influencia en 4 de las 5 principales causas de enfermedad a nivel mundial ${ }^{195}$.

Según el Banco Mundial la contaminación es un factor que también se tiene en cuenta a la hora de elegir un puesto de trabajo y motiva lo que denomina "Loss of urban competitiveness". La habitabilidad de las ciudades afecta a la competitividad, ya que a medida que la mano de obra cualificada se vuelve más global, las mejores ciudades están compitiendo por atraer a los trabajadores más cualificados, aquellos que puede elegir vivir en lugares menos contaminados y más habitables. Hay evidencias sobre como la contaminación está perjudicando la capacidad de las empresas para atraer talento. En 2012, una encuesta de la Cámara de Comercio Americana en Hong Kong, concluyó que alrededor de un tercio de las empresas declararon que les estaba costando más tiempo y esfuerzo, atraer candidatos debido a la preocupación por la calidad del aire en Hong Kong ${ }^{196}$.

The European Environment Agency (EEA), señala que la contaminación atmosférica tiene repercusiones en la salud de los europeos especialmente de las zonas urbanas, así como impactos económicos considerables, reducción de la esperanza de vida, aumento de los costes médicos y reducción de la productividad a través de las bajas laborales perdidas. La contaminación es un problema complejo, los diferentes contaminantes interactúan en la atmósfera, afectando a nuestra salud, al medio ambiente y al clima ${ }^{197}$.

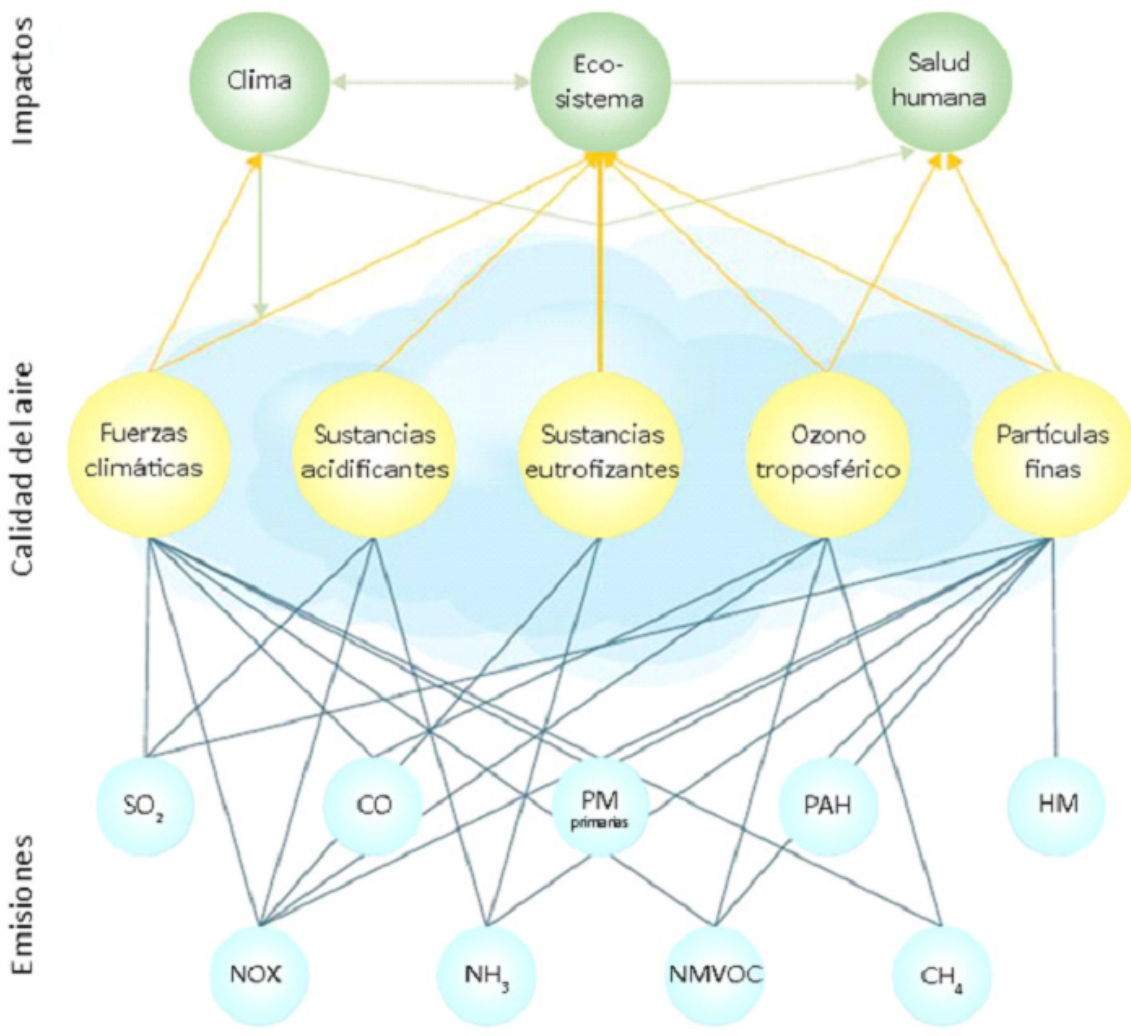


En la EU -28 según la EEA y referidas al año 2013, 430.000 muertes prematuras fueron debidas a exposición prolongada a las PM, 68.000 fueron debidas al $\mathrm{NO}_{2}$ y 17.000 por exposición al $\mathrm{O}_{3}$. En España las muertes prematuras fueron de $24.000,4.300$ y 1.800 , respectivamente. De igual manera la contaminación atmosférica continúa dañando la vegetación y los ecosistemas. En las últimas décadas, las estadísticas reflejan una reducción en las concentraciones de los principales contaminantes, mejorando en general la calidad del aire, esos logros han llegado fundamentalmente a través de la articulación de mecanismos legales orientados a reducir las emisiones. A pesar de todo, una proporción significativa de la población urbana europea sigue expuesta a niveles nocivos de contaminación del aire ${ }^{198,199}$.

\begin{tabular}{|c|c|c|c|c|}
\hline Contaminante & Valor de referencia UE ${ }^{(\mathbf{a})}$ & Exposicion estimada (\%) & OMS AQG * (a) & Exposicion estimada (\%) \\
\hline $\mathrm{PM}_{2.5}$ & Año $(25)$ & $8-12$ & Año $(10)$ & $85-91$ \\
\hline $\mathrm{PM}_{10}$ & Diario $(50)$ & $16-21$ & Año $(20)$ & $50-63$ \\
\hline $\mathrm{O}_{3}$ & 8 -horas (120) & $8-17$ & 8-horas $(100)$ & $96-98$ \\
\hline $\mathrm{NO}_{2}$ & Año $(40)$ & $7-9$ & Año $(40)$ & $7-9$ \\
\hline $\mathrm{BaP}$ & Año (1) & $20-24$ & Año $(0.12)(R L)$ & $88-91$ \\
\hline $\mathrm{SO}_{2}$ & Diario (125) & $<1$ & Diario (20) & $35-49$ \\
\hline
\end{tabular}

* OMS air-quality guidelines (AQGs) y valores de referencia estimados (RLs).

(a) Concentraciones en $\mu \mathrm{g} / \mathrm{m}^{3}$; excepto BaP, en $\mathrm{ng} / \mathrm{m}^{3}$.

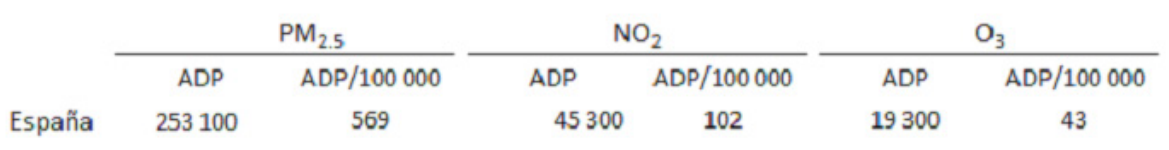

El Instituto Nacional de Investigación contra el cáncer de Milán (Italia), estima que un $50 \%$ de disminución de la contaminación atmosférica, sólo en la ciudad de Milán, evitaría 1.200 muertes y 10.000 casos de enfermedades respiratorias al año, así como un aumento de 1,5 años en la esperanza de vida de los ciudadanos ${ }^{200,201}$.

La OMS ha indicado que si se reducen los niveles de un tipo de contaminante - las partículas en suspensión de diámetro inferior a 10 micras $\left(P M_{10}\right)$-, la cifra anual de fallecidos en las ciudades contaminadas podría descender hasta un 15\%. La contaminación atmosférica por partículas en suspensión, dióxido de azufre, ozono o dióxido de nitrógeno tiene importantes repercusiones en la salud ${ }^{202}$.

En la Unión Europea se calcula que las partículas en suspensión más pequeñas $\left(P M_{2,5}\right)$ provocan por sí solas una reducción de 8,6 meses en la esperanza de vida del europeo medio siendo las partículas en suspensión el principal factor de riesgo de la contaminación atmosférica para la salud humana ${ }^{203,204 .}$
198 EEA. (2016). EEA air quality

in Europe-2016. (No. 28). doi:10.2800/413142.

199 Boldo, E., Medina, S., Le Tertre, A., Hurley, F., Mücke, H. G., Ballester, F., \& Aguilera, I. (2006). Apheis: Health impact assessment of long-term exposure to PM2,5 in 23 European cities. European journal of epidemiology, 21(6), 449-458.

Tabla 8. Porcentaje de la población de la UE-28 expuesta a concentraciones de contaminantes atmosféricos por encima de las concentración de referencia de la UE y de la OMS (2102-2014). Fuente: Tabla ES.1. EEA Report Air quality in Europe 2016 report.

200 Martuzzi, M., Galassi, C., Forastiere, F., \& Bertollini, R. (2002). Health impact assessment of air pollution in the eight major Italian cities. In Health impact assessment of air pollution in the eight major italian cities. OMS.

201 Organisation mondiale de la santé. Bureau régional de l'Europe,

\& Martuzzi, M. (2006).

Health impact of $P M_{10}$ and ozone in 13 Italian cities. WHO Regional Office for Europe.

202 Organización Mundial de la Salud. (2006). Guías de calidad del aire de la OMS relativas al material particulado, el ozono, el dióxido de nitrógeno y el dióxido de azufre: Actualización mundial 2005. Resumen de evaluación de los riesgos..

${ }^{203}$ La salud pulmonar en

Europa Hechos y cifras.

Libro Blanco Europeo del Pulmón, 2014.

http://www.ers-education.org/

Irmedia/2014/pdf/239351.pdf

Consultado el 10 enero 2017.

204 Guerreiro, C. B., Foltescu, V.,

\& De Leeuw, F. (2014).

Air quality status and trends in Europe.

Atmospheric Environment, 98, 376-384. 
Annual mean $\mathrm{PM}_{2.5}$ concentrations in 2014

$\mu g / \mathrm{m}^{3}$

$\bullet<10$

- $10-20$

- $20-25$

- $25-30$

- $>30$

\section{No data}

Countries/regions not included in the data exchange process
Fig 62. Valores medios anuales de las concentración de $\mathrm{PM}_{25}$ en UE en 2014 Fuente. EEA Report Air quality in Europe - 2016

205 Adams, M., van Aatdenne, J., Kampbel, E., Tista, M., \& Zuber, A. (2012).

European union emission inventory report 1990 -2010 under the UNECE convention on long-range transboundary air pollution (LRTAP). (No. 16).EEA. doi:10.2800/628267.

${ }^{206}$ Smits, M., Vanpachtenbeke,

F., Horemans, B., De Wael, K., Hauchecorne, B., Van Langenhove, H., ..

\& Lenaerts, S. (2012). Effect of operating and sampling conditions on the exhaust gas composition of small-scale power generators. PloS one, 7(3), e32825

207 Kennedy, I. M. (2007). The health effects of combustion-generated aerosols. Proceedings of the Combustion Institute, 31(2), 2757-2770.

208 Janssen, N. A., Hoek, G., SimicLawson, M., Fischer, P., Van Bree, L., Ten Brink, H., ... \& Cassee, F. R. (2011). Black

Carbon as an Additional Indicator of the Adverse Health Effects of Airborne Particles Compared with $\mathrm{PM}^{\wedge}$ sub 10^ and $\mathrm{PM}^{\wedge}$ sub $2.5^{\wedge}$. Environmental health perspectives, 119(12), 1691.

${ }^{209}$ Caillol, S. (2011). Fighting global warming: the potential of photocatalysis against $\mathrm{CO} 2, \mathrm{CH} 4, \mathrm{~N} 2 \mathrm{O}, \mathrm{CFCs}$, tropospheric $\bigcirc 3, \mathrm{BC}$ and other major contributors to climate change. Journal of Photochemistry and Photobiology C:

Photochemistry Reviews, 12(1), 1-19.

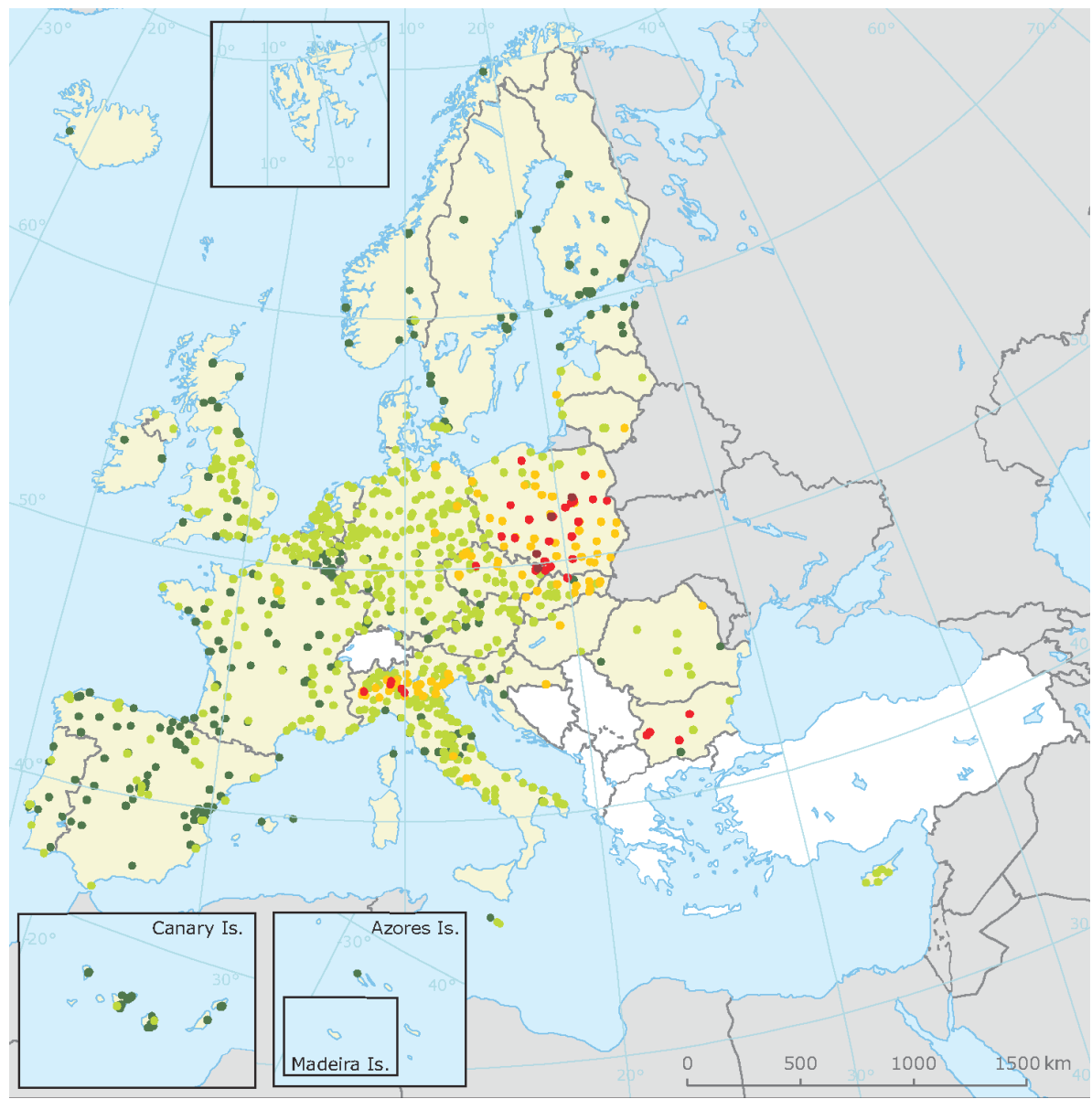

En Europa, se emiten anualmente aproximadamente 3000 kilotoneladas de partículas (PM), y 7300 kilotoneladas de $\mathrm{NO}_{x}$, de las cuales una gran contribución se obtiene por procesos de combustión ${ }^{205,206}$. La emisión de partículas de carbono a la atmósfera tiene una influencia negativa sobre la salud humana y el medio ambiente. La exposición crónica favorece el riesgo de desarrollar enfermedades cardiovasculares y respiratorias, así como el cáncer pulmonar ${ }^{207,208 .}$

DeRichter y Caillol, incluso afirman que los procesos fotocatalíticos de oxidación del hollín pueden contribuir a frenar el calentamiento global en un futuro cercano ${ }^{209}$.

Según Kunzli et al., en la ciudad de Barcelona y sus municipios limítrofes, los compuestos relacionados con las emisiones del tráfico son muy elevados. El alto nivel de partículas contaminantes (PM) en el aire de los 57 municipios del área metropolitana de Barcelona, muy por encima del volumen 1aconsejado por la OMS, provoca cada año 3.500 muertes, según un estudio del Centro de Investigación en Epidemiología Ambiental (CREAL). 


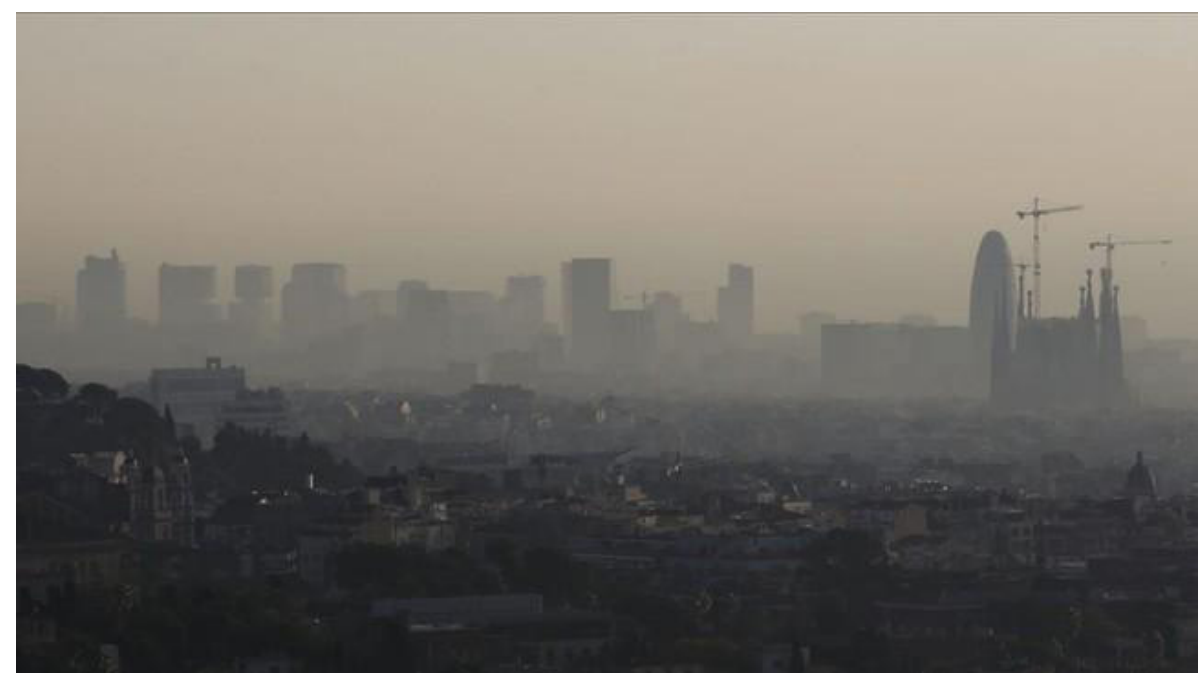

En el año 2009, se concluyó en un estudio publicado que, la reducción de la contaminación atmosférica (PM), en Barcelona al nivel que recomienda la OMS tendría como consecuencia un aumento medio de la esperanza de vida de 14 meses.

El estudio puso de manifiesto que cada año se podrían llegar a producir 3.500 muertes prematuras menos entre las personas mayores de 30 años (aproximadamente un $12 \%$ del total de muertes entre personas mayores de 30 años), un cálculo que incluye 520 muertes por exposición a corto plazo a la contaminación atmosférica. Además de una reducción de la tasa de mortalidad, se ha calculado que esta reducción podría representar anualmente:

- 1.800 ingresos hospitalarios menos por causas cardiorrespiratorias.

- 5.100 casos menos de bronquitis crónicas en adultos.

- 31.100 casos menos de bronquitis agudas en niños.

- 54.000 crisis asmáticas menos en niños y adultos.

Los beneficios para la salud derivados del cumplimiento del estándar actual de calidad del aire propuesto por la UE según el estudio, la reducción de los niveles actuales de contaminación atmosférica hasta los estándares comportaría beneficios sustanciales para la salud; de hecho, se conseguiría una tercera parte de los resultados mencionados por la OMS.

La valoración económica demuestra que los beneficios para la salud en el escenario de la OMS podrían representar un total 6.400 millones $€ / a n ̃ o$. En caso de una reducción de la contaminación atmosférica en el área metropolitana de Barcelona Centre de Recerca en Epidemiologia Ambiental las PM10 hasta el nivel que establece la UE, se calcula que el beneficio económico sería de 2.300 millones $€ /$ año, respectivamente ${ }^{210}$.

Los niveles actuales de contaminación atmosférica tienen una responsabilidad directa sobre el gasto médico, lo que implica un importante porcentaje de visitas hospitalarias, necesidad de medicación y bajas laborales.
Fig 63. Contaminación sobre Barcelona en el año 2013.

210 Pérez, L., Sunyer, J., \& Künzli, N (2009). Estimating the health and economic benefits associated with reducing air pollution in the Barcelona metropolitan area (Spain). Gaceta Sanitaria, 23(4), 287-294. 
${ }^{211}$ World Health Organization. (2015). Economic cost of the health impact of air pollution in Europe: Clean air, health and wealth. WHO Regional office for Europe, Copenhagen.

${ }^{212}$ Mills, G., \& Harmens, H. (2011). Ozone pollution: A hidden threat to food security. NERC/Centre for Ecology \& Hydrology.

${ }^{213}$ ESPAÑA, O. S. (2007). Calidad del aire en las ciudades: clave de sostenibilidad urbana.

214 Holland, M., Wagner, A., Davies, T., Spadaro, J., \& Adams, M. (2014). Costs of air pollution from european industrial facilities 2008-2012. (No. 20). EEA.
En la UE-25 se estima que, en el año 2000, el coste anual de los problemas derivados de impactos a la salud por ozono y partículas en suspensión en el año 2000 fue de entre 276.000 y 790.000 millones de euros, lo que supone entre el 3 y el $9 \%$ del PIB de la Europa de los 25. Además de estos efectos más o menos cuantificables sobre la salud, se produce un daño amplio y significativo al medio ambiente, a los cultivos -que ven mermado su rendimiento- y al patrimonio arquitectónico. La Comisión Europea (CE)en un "análisis del impacto" realizado que pretendía calcular el coste de la aplicación de políticas de mejora de la calidad del aire, llega a la conclusión de que incluso en el peor de los escenarios posibles, los beneficios superaban entre 1,4 y 4,5 veces a los costes.

Recientemente, la OMS y la OCDE han estimado en base a los fallecimientos prematuros ocasionados por las partículas finas (PM) que, los costes sanitarios derivados de la contaminación atmosférica representaron en 2010, un 2,8\% del Producto Interior Bruto (PIB) español, 42.951 millones de dólares en 2010, según el informe: Economic Cost of the Health Impact of Air Pollution In Europe ${ }^{211}$.

El coste económico de la morbilidad representa al menos el $10 \%$ del coste económico total de los impactos sanitarios de la contaminación atmosférica. Para el mismo año, la cifra se ampliaría hasta 63.532 millones de dólares (47.500 millones de euros), considerando el coste económico de la morbilidad generada, pero no el de los danos provocados sobre los cultivos y los ecosistemas naturales. En España, el Centro ICP ha estimado los costes económicos en España derivados de la menor producción de dos cultivos como el trigo y el tomate, por su exposición al ozono, en cerca de 800 millones de euros en el año 2000, lo que supone un 3,2\% del PIB agricola ${ }^{212}$.

Según el informe elaborado por el Observatorio de la Sostenibilidad en España en 2007, los costes económicos de la contaminación atmosférica en el Estado español referentes a la salud, eran de al menos 16.839 millones de euros aunque, según las estimaciones realizadas la cifra podria llegar a cerca de 46.000 millones. Ello supone que los costes derivados de la contaminación atmosférica representan entre un 1,7\% y un $4,7 \%$ del Producto Interior Bruto (PIB) español, lo que equivale a entre 413 y 1.125 euros por habitante y año. Al igual que en el resto de Europa, los mayores costes están relacionados con la mortalidad crónica asociada a la contaminación por partículas ${ }^{213}$.

La AEMA ha estimado el coste agregado entre 2008 y 2012 de los danos sanitarios ocasionados por la contaminación industrial en España entre 20.000 y 60.000 millones de euros, obedeciendo la incertidumbre a la falta de conocimiento de los impactos reales del cambio climático ${ }^{214}$. 


\subsubsection{CONTAMINANTES ATMOSFÉRICOS}

La Agencia Protección del Medioambiente Americana (EPA), en las enmiendas de 1990 a la Ley del Aire Limpio "Clean Air Act", cita 188 "contaminantes atmosféricos tóxicos» de origen tanto orgánico como inorgánico ${ }^{215}$.

Los contaminantes del aire son emitidos u originados por fuentes antropogénicas $\circ$ naturales, estos pueden emitirse directamente, contaminantes primarios, o pueden formarse en la atmósfera como productos de reacciones complejas a partir de los llamados precursores, constituyendo los denominados contaminantes secundarios, como por ejemplo el material particulado o partículas finas ( $P M)$, el ozono $\left(\mathrm{O}_{3}\right)$ y el dióxido de nitrógeno $\left(\mathrm{NO}_{2}\right)$. Estos pueden ser transportados o formados a largas distancias de su punto de emisión por dicha razón su influencia puede alcanzar a grandes áreas alejadas del punto de origen.

La contaminación atmosférica, también puede tener origen natural; por ejemplo, puede proceder de polvos producidos por los fuertes vientos que soplan en los desiertos, por la arena, las cenizas y el polvo procedentes de explosiones volcánicas y por núcleos de agua salada del mar llevados a la orilla por vientos fuertes. La contaminación procedente de gases naturales puede ser causada por explosiones volcánicas, fumarolas, marismas - materia en descomposición. Una vez las sustancias contaminantes son aerotransportadas por los vientos y las corrientes ascendentes, las partículas gruesas vuelven rápidamente a la superficie de la tierra por la acción de la gravedad (precipitación), mientras que las finas son eliminadas de la atmósfera por la precipitación de lluvia (arrastradas por el agua de la lluvia). Sin embargo, la contaminación atmosférica no se limita a las áreas metropolitanas, sino que es «migratoria» por naturaleza ${ }^{216}$.

Contaminantes primarios son, aquellos contaminantes que se emiten directamente. Los principales contaminantes primarios son producidos por procesos de combustión de cualquier tipo, es decir, hidrocarburos no quemados, monóxido de carbono, óxidos de nitrógeno (principalmente como monóxido) y partículas finas. En el caso de los combustibles que contienen azufre, puede producirse la emisión de dióxido de azufre.

Una vez se han emitido a la atmósfera, los contaminantes primarios experimentan procesos de difusión, transporte y deposición, asi como transformaciones físicas y químicas que pueden llevar a la formación de nuevas especies contaminantes, a veces más tóxicas y con un rango de acción mayor que los contaminantes originales.

Contaminantes secundarios, se definen como las especies contaminantes que resultan de la transformación fisicoquímica de los contaminantes primarios, es decir, de las especies químicas que liberan a la atmósfera directamente sus propias fuentes.
${ }^{215}$ Suh, H. H., Bahadori, T., Vallarino, J., \& Spengler, J. D. (2000).

Criteria air pollutants and toxic air pollutants. Environmental Health Perspectives, 108(Suppl 4), 625.

${ }^{216}$ EEA, E. (2013)

EEA air pollutant emission inventory guidebook 2013, technical guidance to prepare national emission inventories. European Environment Agency, EEA Technical Report, (12) 
Fig 64. Representación esquemática de las reacciones químicas implicadas en modelo fotoquímico de estado de equilibrio en el sistema $\mathrm{NO}_{x} / \mathrm{O}_{3}$ Fuente. Muilwijk, C., et al ${ }^{217}$

${ }^{217}$ Muilwijk, C., Schrijvers, P. J. C.,

Wuerz, S., \& Kenjereš, S. (2016).

Simulations of photochemical smog

formation in complex urban areas. Atmospheric Environment, 147, 470 -484.

${ }^{218}$ Atkinson, R., \& Arey, J. (2003).

Atmospheric degradation of volatile organic compounds. Chemical reviews, 103(12), 4605-4638.

${ }^{219}$ Azzi, M., Johnson, G. M., \& Cope, M. (1992, July).

An introduction to the generic reaction set photochemical smog mechanism. In Proceedings of the 11th International Clean Air and Environment Conference.

\footnotetext{
${ }^{220}$ Carpenter, L. J., Clemitshaw, K. C., Burgess, R. A., Penkett, S. A., Cape, J. N., \& McFadyen, G. G. (1998). Investigation and evaluation of the $\mathrm{NO} / \mathrm{O}_{3}$ photochemical steady state. Atmospheric Environment, 32(19), 3353-3365
}

Fig 65. Formación de smog fotoquímico. Fuente: Sugrañez $z^{25}$
Entre los procesos de formación de contaminantes secundarios, resulta de gran importancia la serie de reacciones que se producen entre los óxidos de nitrógeno y los hidrocarburos en presencia de la luz solar. Esta cadena de reacciones conlleva la oxidación del monóxido de nitrógeno (NO) en dióxido de nitrógeno $\left(\mathrm{NO}_{2}\right)$, la producción de ozono $\left(\mathrm{O}_{3}\right)$ y la oxidación de los hidrocarburos, y centenares de otras especies químicas menores.

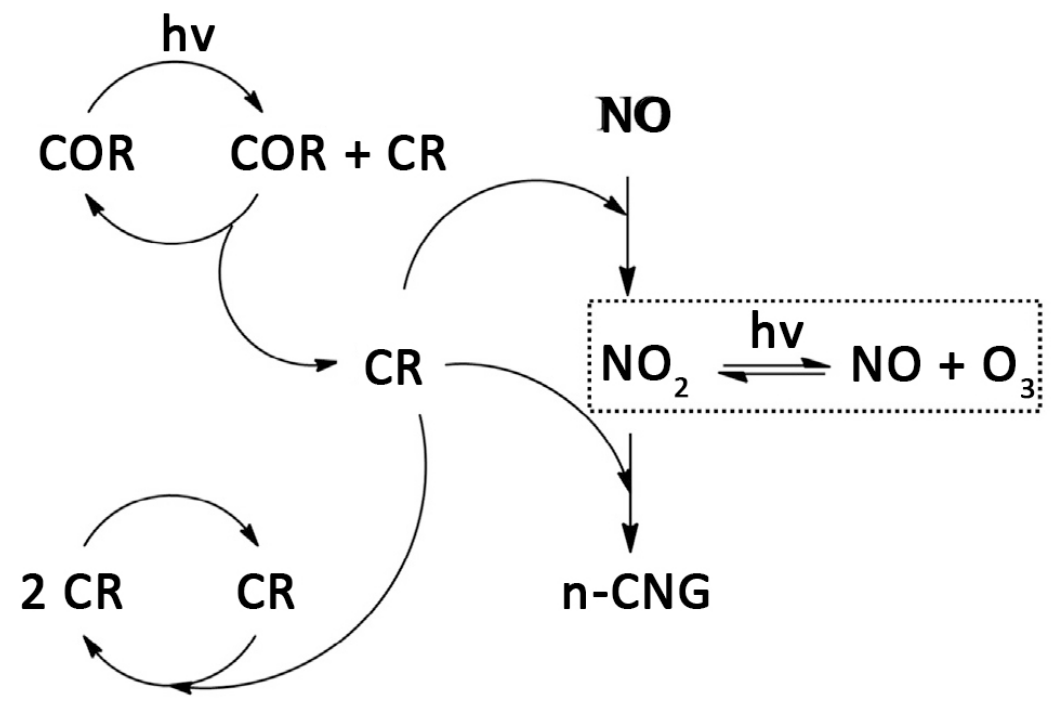

El conjunto de estos productos de reacciones se denomina niebla fotoquímica o SMOG, y representa una de las formas de contaminación más nocivas. El uso del término niebla contaminante o smog procede de la fuerte reducción de la visibilidad que se produce durante los episodios de contaminación fotoquímica causados por la formación de un gran número de partículas de tamaño considerable $218,219,220$.

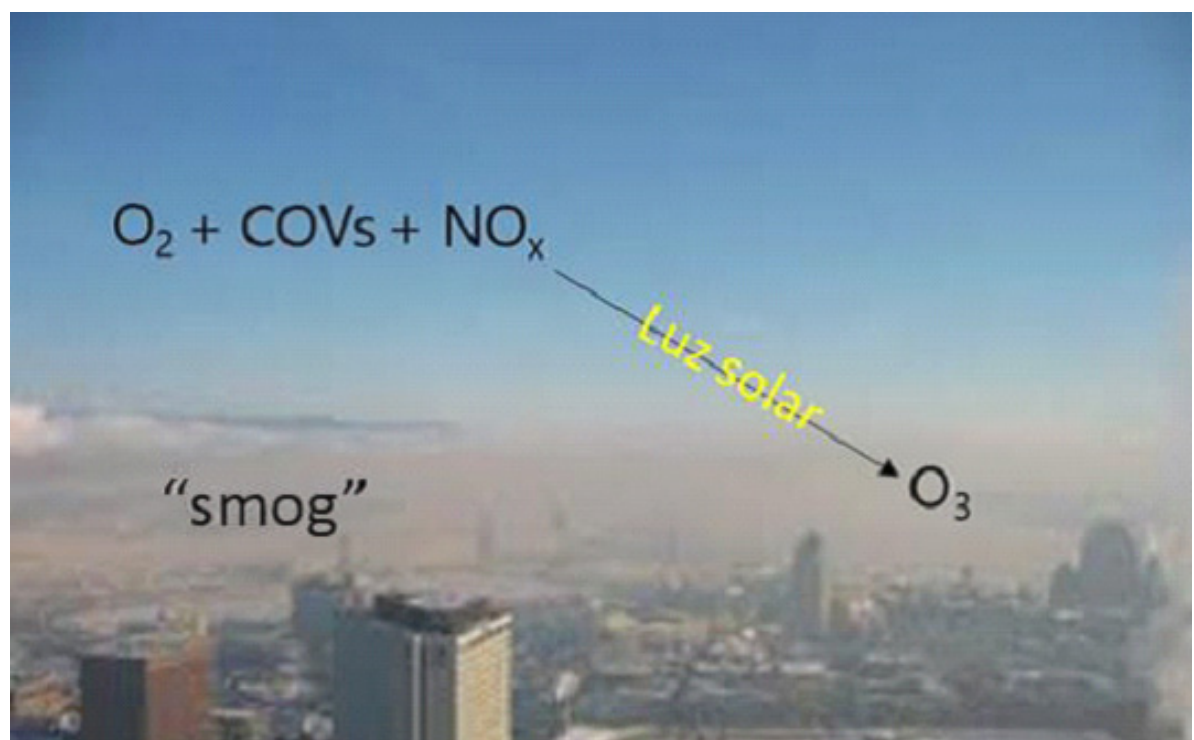


El origen de un episodio de niebla fotoquímica (SMOG), está formado por varias fases que se pueden resumir del modo siguiente ${ }^{221}$ :

1. Una atmósfera rica en contaminantes primarios, como los óxidos nítricos y los hidrocarburos volátiles, así como precursores de radicales $\mathrm{OH}$, como el ácido nitroso, el formaldehído y el ozono, es alcanzada por radiación solar (UV).

2. La radiación UV produce la fotólisis del ácido nitroso, el formaldehído y el ozono (de acuerdo con cada nivel propio en aumento de energía UV requerido), lo que conlleva la producción de radicales $\mathrm{OH}$.

3. Los radicales $\mathrm{OH}$ atacan varias especies de hidrocarburos volátiles reactivos, provocando una serie de reacciones en cadena que llevan a la degradación de las moléculas de hidrocarburo y la formación de radicales peróxidos.

4. Los radicales $\mathrm{RO}_{2}$ oxidan el monóxido de nitrógeno, lo que produce $\mathrm{NO}_{2}$. Cada radical toma parte en muchos ciclos de conversión de $\mathrm{NO}$ a $\mathrm{NO}_{2}$ antes de extinguirse.

5. Mediante la fotólisis, el $\mathrm{NO}_{2}$ produce ozono, regenerando una molécula de $\mathrm{NO}$ que queda disponible para un nuevo proceso de oxidación.

6. De modo alternativo, el $\mathrm{NO}_{2}$ reacciona bien con radicales $\mathrm{OH}$ - produce ácido nítrico- o con radicales de peroxiacetilo -forma nitrato de peroxiacetilo- (los productos finales que completan la serie de reacciones) $y$, en este caso, se elimina el $\mathrm{NO}_{2}$ del ciclo fotoquímico.

En el mapa atmosférico global de alta resolución del Envisat, que muestra la contaminación por dióxido de nitrógeno, es posible ver el impacto de las actividades humanas en la calidad del aire de todo el mundo: «las distribuciones altas en columna atmosférica de dióxido de nitrógeno se asocian a ciudades importantes de Norteamérica, Europa y el noreste de la China, junto con otros lugares como Ciudad de México en Centroamérica y las centrales de energía de carbón de Sudáfrica situadas próximas las unas a las otras cerca de la meseta de Highveld, al este del país. También por todo el sudeste asiático y gran parte de África se puede observar dióxido de nitrógeno producido por la quema de biomasa y se pueden ver rastros de barcos en algunos lugares (por ejemplo, el mar Rojo y el océano ĺndico entre el extremo meridional de India e Indonesia).

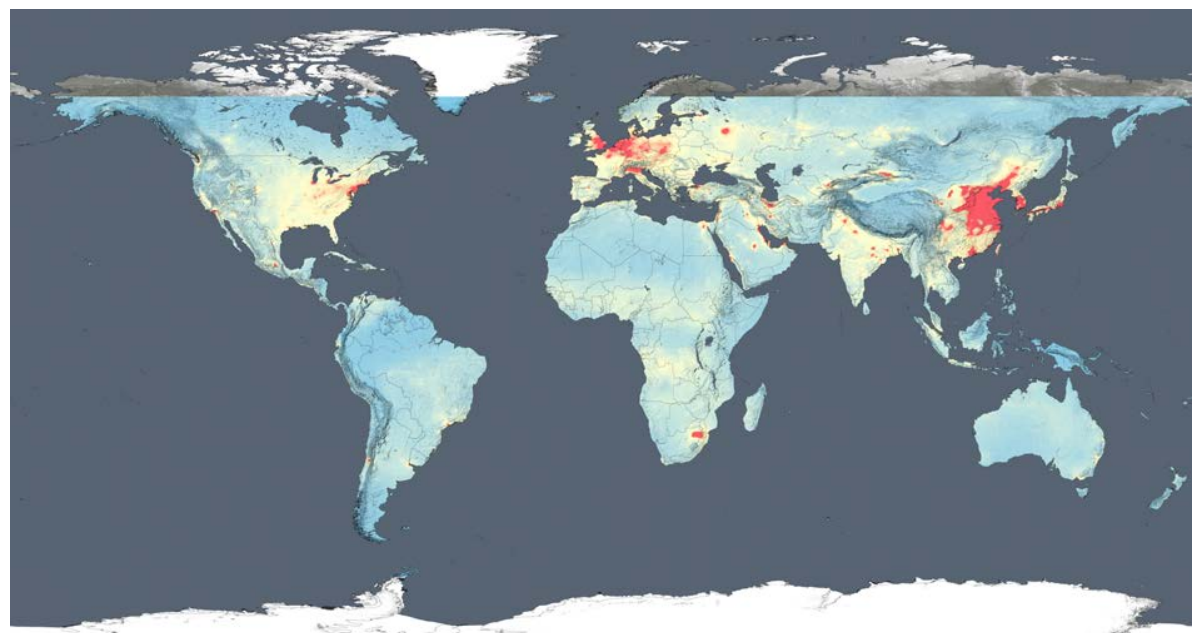

${ }^{221}$ dell'Ambiente, M. (2001).

Relazione sullo stato dell'ambiente. Ministero dell'Ambiente.
Fig 66. Este mapa global muestra la concentración promedio de dióxido de nitrógeno en 2014 medido en la troposfera por el Ozone Monitoring Instrument a bordo del satélite Aura, con un.

Fuente https://svs.gsfc.nasa.gov/12094. Consultado Febrero 2017 
222 Harrison, R. M., Brunekreef, B., Keuken, M., Denier Van Der Gon, H., \& Querol, X. (2014) New directions: cleaning the air-will the European Commission's clean air policy package of December 2013 deliver. Atmos Environ, 91, 172-174.

${ }^{223}$ NEC Directive status report 2015 http://www.eea.europa.eu/publications/ nec-directive-status-report-2015.

${ }^{224}$ Ortiz, A; Guerreiro, C; de Leeuw, F; Viana, M. (2016). Air quality in Europe (No 28). EEA Technical report

225 Holland, M., Wagner, A., Davies, T., Spadaro, J., \& Adams, M. (2011). Revealing the costs of air pollution from industrial facilities in Europe (No. 15) EEA Technical report.

Fig 67. El mapa muestra el cambio de tendencias de Europa en las concentraciones de dióxido de nitrógeno de 2005 a 2014 Fuente: https://svs.gsfc.nasa.gov/12094 Consultado Febrero 2017.

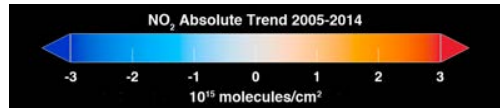

En Europa la reglamentación generada por la "Clean Air Policy" del consejo europeo, genero un paquete de directivas a finales de 2013, que tenían por objeto garantizar el pleno cumplimiento de la legislación vigente a más tardar en 2020 y mejorar aún más la calidad del aire europeo en 2030 de tal manera que las muertes prematuras se reduzcan más de la mitad de las atribuidas en $2005^{222}$.

La revisión de la Directiva NEC de 2001 la (2001/81 / CE), relativa a la reducción de las emisiones nacionales de determinados contaminantes atmosféricos, establece nuevos compromisos nacionales de reducción de emisiones aplicables a partir de 2020 y compromisos más estrictos a partir de 2030 para $\mathrm{SO}_{2}, \mathrm{NO}_{x}$, compuestos orgánicos volátiles no metálicos (COVNM), $\mathrm{NH}_{3}$ y $\mathrm{PM}$ con diámetro De 2,5 $\mu \mathrm{m}$ o menos, $\mathrm{PM}_{2,5}$. Con los nuevos compromisos, se estima que el impacto sanitario de la contaminación atmosférica se reducirá en un $50 \%$ en 2030 , comparadas con $2005^{210,223,224,225}$.

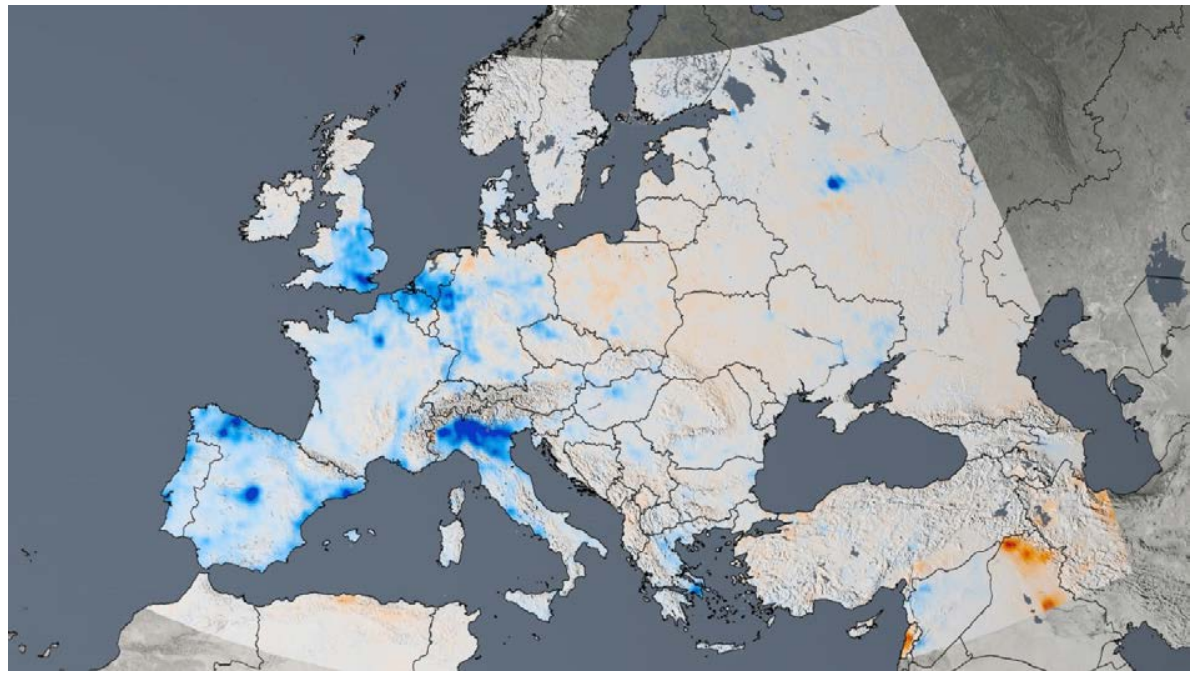

Los principales fuentes emisoras en Europa son, por este orden, el transporte, el comercio, el sector público, los hogares, la industria, la generación de energía, la agricultura y residuos. La Agencia Europea del Mediambiente (AEMA), ha calculado que la contaminación atmosférica de las 10.000 instalaciones más contaminantes de Europa costó a los europeos entre 102.000 millones y 169000 millones de euros en 2009. Solo 191 instalaciones resultaron ser causantes de la mitad del coste total de los daños ${ }^{187}$. 
I NFLUENCIA DEL COLOR Y ELACABADO SUPERFICIALEN LAS PROPIEDADES

DE UN MORTEROFOTOCATALITICO COMOSOLUCIÓN DE ENVOLVENTE

$-\mathrm{SO}_{\mathrm{x}}=\mathrm{NO}_{\mathrm{x}}-\mathrm{NH}_{3}-\mathrm{PM}_{10}-\mathrm{PM}_{2.5}=\mathrm{NMVOC}=\mathrm{CO}-\mathrm{CH}_{4}=\mathrm{BC}$

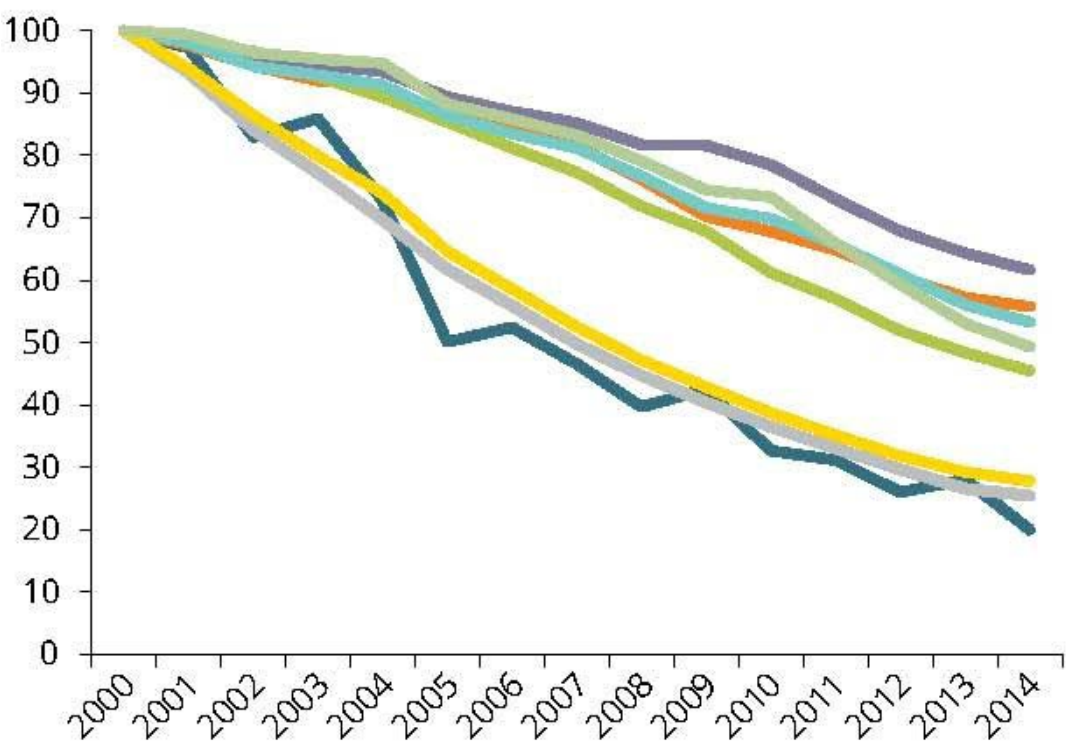

Fig 68. Emisiones en (\%)

del sector del Transporte.

Fuente: EEA Report. Air quality in

Europe $-2016^{198}$.

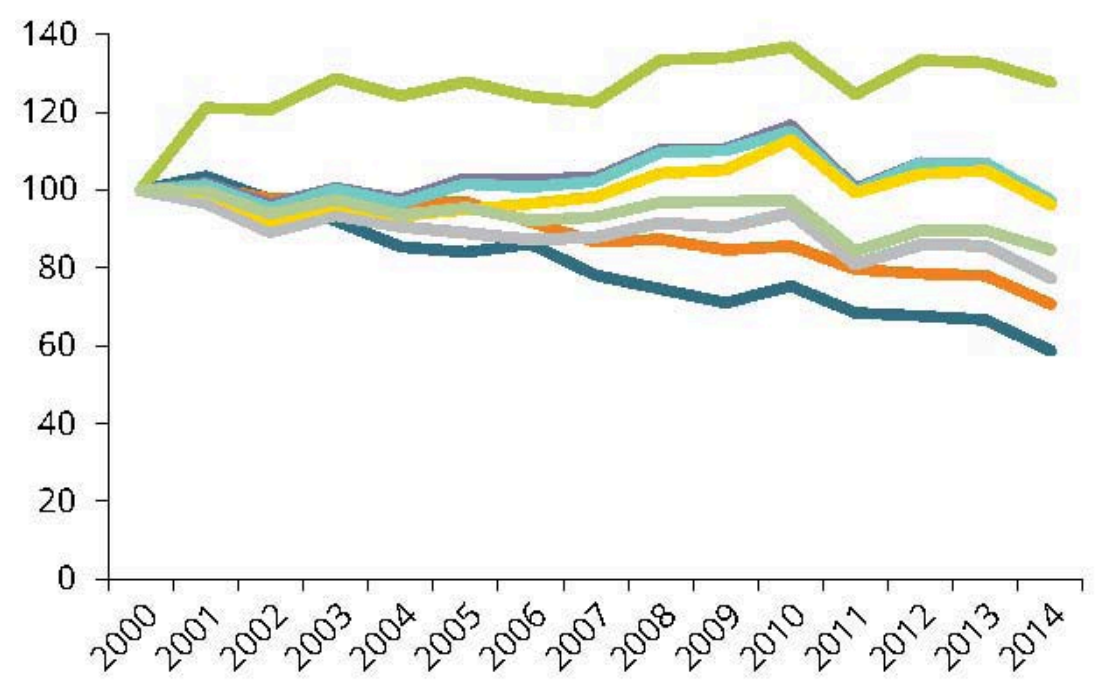

Fig 69. Emisiones en (\%) del sector del Comercial, Público y Particular.

Fuente: EEA Report. Air quality in Europe $-2016^{198}$.

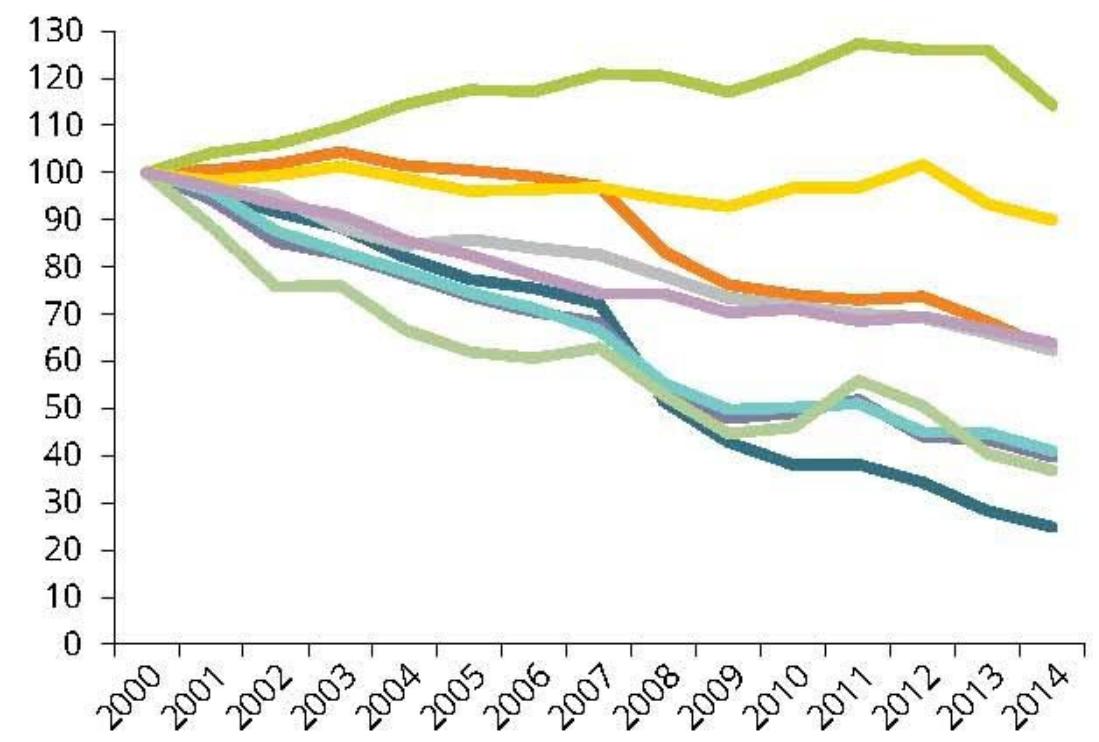

Fig 70. Emisiones en (\%) del sector de Producción y Distribución de energía. Fuente: EEA Report. Air quality in Europe $-2016^{198}$. 
Fig 71. Emisiones en (\%) del sector Industrial. Fuente: EEA Report. Air quality in Europe - 2016 198 .

Fig 72. Emisiones de EU-28 en 2000-2014 (\% de 2000)-SOX, NOX $\mathrm{NH} 3, \mathrm{PM} 10, \mathrm{PM} 2.5, \mathrm{COVNM}, \mathrm{CO}$ $\mathrm{CH} 4$ e inquemados.

Fuente: EEA Report. Air quality in Europe - 2016. No 28/2016 198
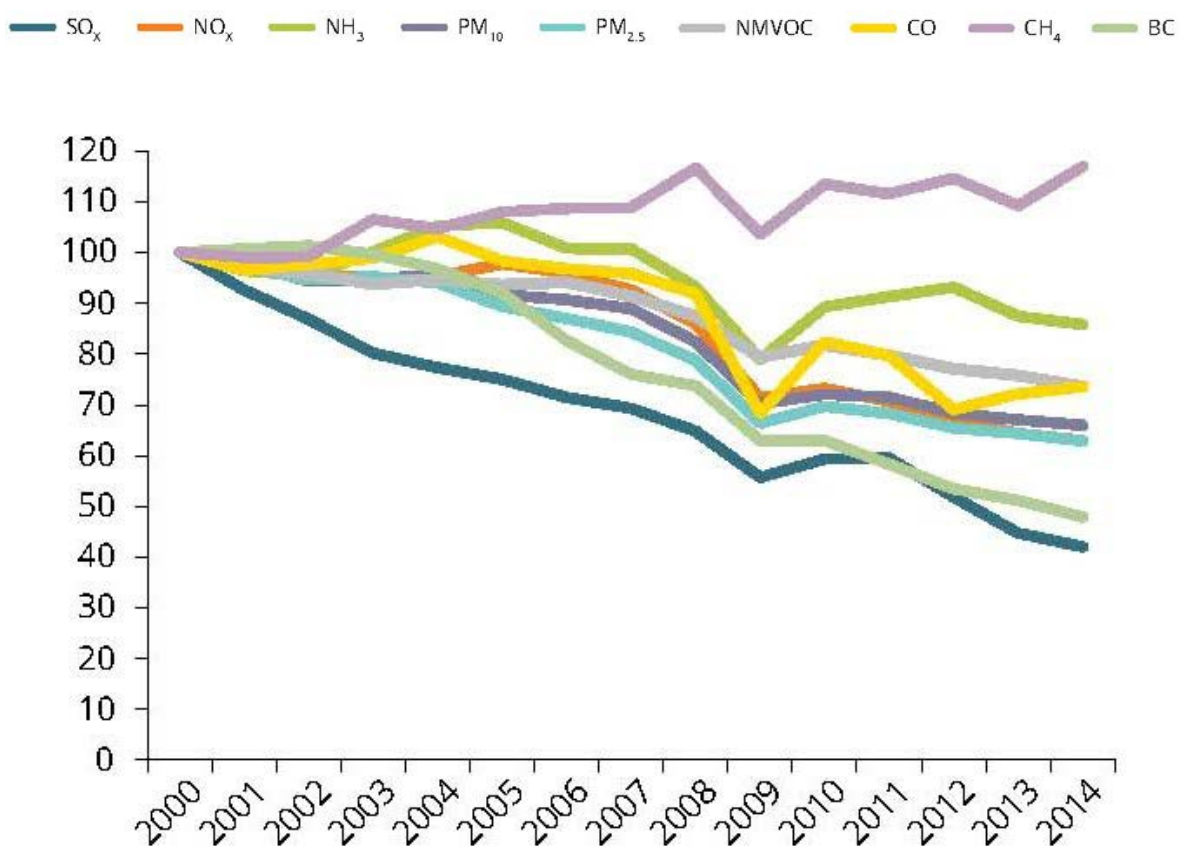

En Europa la situación general en cuanto al inventariado de emisiones se recoge en el informe de la EEA-2016, las emisiones de lo que antes hemos denominado contaminantes primarios y sustancias precursoras, que tienen relacion con el aumento de las concentraciones de las $\mathrm{PM}$, el $\mathrm{O}_{3}$ y el $\mathrm{NO}_{2}$, han disminuido entre 2000-2014 en el conjunto de la UE-28 según podemos observar en el gráfico.
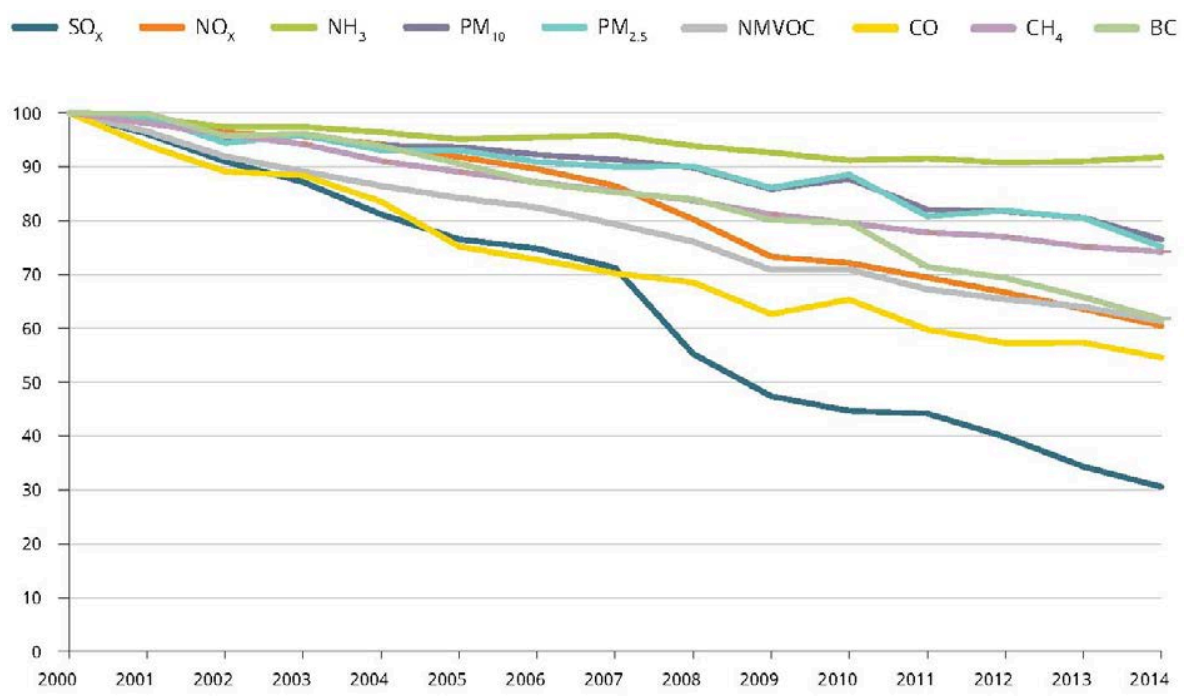

El contaminante que descendió en menor medida en la UE-28 fue el amoniaco $\left(\mathrm{NH}_{3}\right)$, con solo un $8 \%$, por el contrario el que sufrió una mayor reducción fue el $\mathrm{SO}_{\mathrm{x}}$ con un $69 \%$.

La figura muestra el desarrollo de las emisiones de $P M_{10}$ primaria ( $P M$ con un diámetro de $10 \mu \mathrm{m}$ o menos), $\mathrm{PM}_{2,5}$ primaria, $\mathrm{NO}_{x}, \mathrm{SO}_{x}, \mathrm{NH}_{3}$, COVNM, CO, inquemados y $\mathrm{CH}_{4}$ de estos sectores entre 2000 y 2014. 
Mención especial merece el auge en el uso de biomasa para la calefacción en algunos países europeos. Los incentivos gubernamentales, el aumento de los costes de otras fuentes de energía y la percepción que tiene la sociedad de su uso como una opción 'verde', han favorecido este auge. Sin embargo, el uso de biomasa genera emisiones de compuestos contaminantes en mayor medida que otras fuentes ${ }^{39}$.

\subsubsection{DESCRIPCION DE LOS PRINCIPALES CONTAMINANTES}

\section{ATMOSFÉRICOS}

\begin{tabular}{|c|c|c|}
\hline Contaminante & Formación & Estado físico \\
\hline $\begin{array}{c}\text { Partículas en suspensión } \\
\text { menores de } 10 \text { micras } \\
\left(P M_{10}\right) \text { y menores de } 2,5 \\
\text { micras }\left(P M_{2,5}\right) \text { y Humos } \\
\text { negros }\end{array}$ & $\begin{array}{l}\text { Primaria y } \\
\text { secundaria }\end{array}$ & Sólido / líquido \\
\hline Dióxido de Azufre $\left(\mathrm{SO}_{2}\right)$ & Primaria & Gas \\
\hline $\begin{array}{l}\text { Dióxido de Nitrógeno } \\
\qquad\left(\mathrm{NO}_{x}\right)\end{array}$ & Primaria & Gas \\
\hline $\begin{array}{c}\text { Monóxido de Carbono } \\
\text { (CO) }\end{array}$ & Primaria & Gas \\
\hline $\begin{array}{c}\text { Compuestos orgánicos } \\
\text { volátiles (COV) }\end{array}$ & $\begin{array}{l}\text { Primaria y } \\
\text { secundaria }\end{array}$ & Gas \\
\hline Ozono $\left(\mathrm{O}_{3}\right)$ & Secundaria & Gas \\
\hline
\end{tabular}
contaminantes atmosféricos más significativos para la calidad del aire urbano. Fuente Ballester et a $\left.\right|^{226}$

${ }^{226}$ Ballester, F. (2005). Contaminación atmosférica, cambio climático y salud. Revista española de salud pública, 79(2), 159-175. 


\subsubsection{PARTÍCULAS EN SUSPENSIÓN $\left(P_{10} Y P_{2,5}\right)$}

El término "partículas en suspensión" abarca un amplio espectro de sustancias orgánicas o inorgánicas, dispersas en el aire, procedentes de fuentes naturales y artificiales. Las partículas finas, material particulado o PM, es un contaminante de gran importancia tanto por su volumen como por sus efectos. Las PM se dividen en PM primarias, al emitirse directamente a la atmósfera y $P M$ secundarias, al formarse en la atmósfera. Los principales gases precursores de las $\mathrm{PM}$ secundarias son $\mathrm{SO}_{2}, \mathrm{NO}_{x}, \mathrm{NH}_{3}$ y $\mathrm{COV}$, al reaccionar en la atmosfera generando compuestos de amonio $\left(\mathrm{NH}_{4+}\right)$, sulfatos $\left(\mathrm{SO}_{4-2}\right)$ y nitratos $\left(\mathrm{NO}_{3}\right)$. Estos, a su vez, compuestos forman nuevos compuestos como consecuencia de reacciones en la atmosfera o por el contrario se condensan en forma de partículas finas, dando lugar a aerosoles inorgánicos secundarios.

Las PM primarias pueden tener un origen antropogénico y también, como un origen natural, por ejemplo, polvo en suspensión, polen y cenizas volcánicas. Las fuentes antropogénicas predominantes están en las áreas urbanas e incluirían, incluyendo la combustión en centrales térmicas, la incineración de residuos, calefacción doméstica y los vehículos de combustión, el desgaste de neumáticos, frenos o los pavimentos de las calzadas.

La combustión de carburantes fósiles generada por el tráfico, en especial los vehículos diésel (una de las principales fuentes de contaminación por partículas en las ciudades), puede producir diversos tipos de partículas: partículas grandes, por la liberación de materiales mal quemados (cenizas volátiles), partículas finas, formadas por la condensación de materiales vaporizados durante la combustión, y partículas secundarias, mediante reacciones atmosféricas de contaminantes desprendidos como gases.

Sus efectos sobre la salud, se suelen distinguir: las $\mathrm{PM}_{10}$ (partículas "torácicas" menores de $10 \mu \mathrm{m}$ que pueden penetrar hasta las vías respiratorias bajas), las $\mathrm{PM}_{2,5}$ (partículas "respirables" menores de $2,5 \mu \mathrm{m}$, que pueden penetrar hasta las zonas de intercambio de gases del pulmón), y las partículas ultrafinas (menores de $100 \mathrm{~nm}$, que pueden llegar al torrente circulatorio).

En el caso de las $P M_{2,5}$, su tamaño hace que sean $100 \%$ respirables, penetrando en el aparato respiratorio y depositándose en los alvéolos pulmonares, incluso pudiendo llegar al torrente sanguíneo. Estas partículas de menor tamaño están compuestas por elementos que son más tóxicos (como metales pesados y compuestos orgánicos) revelando las evidencias científicas que estas partículas $\mathrm{PM}_{2,5}$ tienen efectos más severos sobre la salud que las partículas más grandes, $\mathrm{PM}_{10}$.

Las partículas $P M_{2,5}$, se pueden acumular en el sistema respiratorio y están asociadas cada vez con mayor consistencia científica con numerosos efectos negativos sobre la salud, como el aumento de las enfermedades respiratorias y la disminución del funcionamiento pulmonar. 


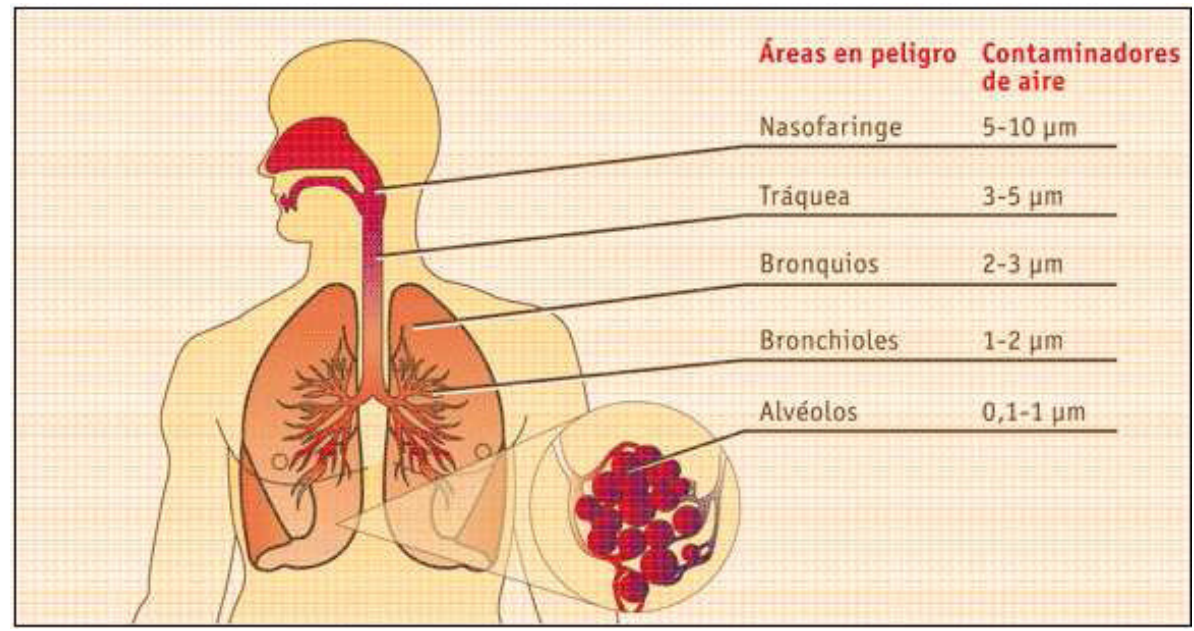

Los grupos más sensibles - niños, ancianos y personas con enfermedades respiratorias y cardiacas- corren más riesgos de padecer los efectos negativos de este contaminante. Asimismo, su tamaño hace que sean más ligeras por lo que generalmente, permanecen por más tiempo en el aire. Lo que no solo prolonga sus efectos, sino que facilita el que sean transportados por el viento a grandes distancias. Hoy día los científicos consideran que las partículas en suspensión son el problema de contaminación ambiental más severo, por sus graves afecciones al tracto respiratorio y al pulmón.

Según la OMS, existe una estrecha relación cuantitativa entre la exposición a altas concentraciones de pequeñas partículas $\left(P M_{10}\right.$ y $\left.P M_{2,5}\right)$ y el aumento de la mortalidad o morbilidad diaria y a largo plazo. A la inversa, cuando las concentraciones de partículas pequeñas y finas son reducidas, la mortalidad conexa también desciende, en el supuesto de que otros factores se mantengan sin cambios.

La contaminación con partículas conlleva patologías incluso en muy bajas concentraciones; de hecho, no se ha podido identificar ningún umbral por debajo del cual no se hayan observado daños para la salud y los límites de la directriz de 2005 de la OMS se orientan a lograr las concentraciones de partículas más bajas posibles ${ }^{198,227,228,229,230,231,232,233 .}$

\subsubsection{DIÓXIDO DE NITRÓGENO, $\left(\mathrm{NO}_{2}\right)$}

El $\mathrm{NO}_{2}$ presente en el aire de las ciudades proviene en su mayor parte de la oxidación del monóxido de nitrógeno, NO. En concentraciones de corta duración superiores a $200 \mathrm{mg} / \mathrm{m}^{3}$, es un gas tóxico que causa una importante inflamación de las vías respiratorias.

El $\mathrm{NO}_{2}$ constituye un buen indicador de contaminación debida al tráfico rodado. Por otro lado, el $\mathrm{NO}_{2}$ interviene en diversas reacciones químicas que tienen lugar en la atmósfera, dando lugar tanto a la producción de ozono troposférico como de partículas en suspensión secundarias menores de 2,5 micras $\left(P M_{2,5}\right)$, las más dañinas para la salud.
Fig 73. Capacidad de entrada de las partículas en el organismo en función de su tamaño.

Fuente. Calidad del aire interior. Ministerio de Trabajo y Asuntos Sociales.

227 World Health Organization. (2006). WHO Air quality guidelines for particulate matter, ozone, nitrogen dioxide and sulfur dioxide-Global update 2005-Summary of risk assessment, 2006. Geneva: WHO.

228 OMS. (Septiembre 2016).

Calidad del aire ambiente (exterior) y salud. nota descriptiva.

Retrieved from http://www.who.int/ mediacentre/factsheets/fs313/es/.

229 Pope III, C. A., \& Dockery, D. W. (2006). Health effects of fine particulate air pollution: lines that connect. Journal of the air \& waste management association, 56(6), 709-742.

230 SCHER-Scientific Committee on Health Environmental Risks. (2005). Opinion on "New evidence of air pollution effects on human health and the environment" european commission, health and consumer protection directorate, 1-15; 2005. European Commission.

231 Ballester, F., Medina, S., Boldo, E., Goodman, P., Neuberger, M., Iñiguez, C., \& Künzli, N. (2008). Reducing ambient levels of fine particulates could substantially improve health: a mortality impact assessment for 26 European cities. Journal of epidemiology and community health, 62(2), 98-105.

232 Boldo, E., Medina, S., Le Tertre, A., Hurley, F., Mücke, H. G., Ballester, F. \& Aguilera, I. (2006). Apheis: Health impact assessment of long-term exposure to PM2. 5 in 23 European cities. European journal of epidemiology, 21(6), 449-458

233 Boldo, E., Linares, C., Lumbreras, J., Borge, R., Narros, A., García-Pérez, J., \& Pollán, M. (2011).

Health impact assessment of a reduction in ambient PM 2.5 levels in Spain.

Environment International, 37(2), 342-348 
${ }^{234}$ Esplugues, A., Ballester, F., Estarlich, M., Llop, S., Fuentes, V., Mantilla, E., \& Iñiguez, C. (2010) Indoor and outdoor concentrations and determinants of $\mathrm{NO}_{2}$ in a cohort of 1 -year-old children in Valencia, Spain. Indoor air, 20(3), 213-223.

${ }^{235}$ World Health Organization. (2006). WHO Air quality guidelines for particulate matter, ozone, nitrogen dioxide and sulfur dioxide-Global update 2005-Summary of risk assessment, 2006. Geneva: WHO

${ }^{236}$ World Health Organization. (2005). Air quality guidelines for Europe, 2nd ed. Copenhagen, World Health Organization Regional Office for Europe, 2000

(WHO Regional Publications, European Series, No. 91). Global update 2005
De modo que a la hora de considerar los efectos del $\mathrm{NO}_{2}$ sobre la salud se deben tener en cuenta no solo los efectos directos que provoca, sino también su condición de marcador de la contaminación debida al tráfico y su condición de precursor de otros contaminantes. Los óxidos de nitrógeno son en general muy reactivos y al inhalarse afectan al tracto respiratorio. El $\mathrm{NO}_{2}$ afecta a los tramos más profundos de los pulmones, inhibiendo algunas funciones de los mismos, como la respuesta inmunológica, produciendo una merma de la resistencia a las infecciones. Los niños y asmáticos son los más afectados por exposición a concentraciones agudas de $\mathrm{NO}_{2}{ }^{49}$. Asimismo, la exposición crónica a bajas concentraciones de $\mathrm{NO}_{2}$ se ha asociado con un incremento en las enfermedades respiratorias crónicas, el envejecimiento prematuro del pulmón y con la disminución de su capacidad funcional.

Las principales fuentes de $\mathrm{NO}_{x}$ son los procesos de combustión, vehículos que utilizan combustibles fósiles y biocombustibles. La mayoría del $\mathrm{NO}_{2}$ se forma in situ por la oxidación de NO. NO representa la mayoría de las emisiones de $\mathrm{NO}_{x}$, Aunque parte de las emisiones de $\mathrm{NO}_{x}$ se emite directamente como $\mathrm{NO}_{2}$. La proporción de $\mathrm{NO}_{2}$, es decir el ratio $\mathrm{NO}_{2} / \mathrm{NO}_{x}$ que emiten los vehículos es sensiblemente superior en los vehículos que utilizan combustible diésel a los de gasolina, debido a la oxidación producida en los motores después de la combustión, lo que genera mayor cantidades de $\mathrm{NO}_{2}$.

Estudios epidemiológicos del OMS, han relacionado la exposición prolongada al $\mathrm{NO}_{2}$ con el aumento de los síntomas de bronquitis en niños asmáticos. La disminución del desarrollo de la función pulmonar también se asocia con las concentraciones de $\mathrm{NO}_{2}$ registradas (u observadas) actualmente en ciudades europeas y norteamericanas ${ }^{198,228,235,236 .}$

\section{$5 \cdot 3 \cdot 2 \cdot 3$. OZONO TROPOSFÉRICO $\left(\mathrm{O}_{3}\right)$}

El ozono troposférico $\left(\mathrm{O}_{3}\right)$, es un potente agente oxidante que se forma mediante una compleja serie de reacciones fotoquímicas en las que participa la radiación solar, es decir no es directamente emitido a la atmósfera, se forma en ella a partir de reacciones químicas en presencia de luz solar a partir de las emisiones de gases precursores, como los $\mathrm{NO}_{x}$ y los $\mathrm{COV}$ no metálicos, de origen natural o antropogénico y en escala continental el metano $\left(\mathrm{CH}_{4}\right)$ y el monóxido de carbono $(\mathrm{CO})$ también desempeñan un papel en la formación $\mathrm{O}_{3}$. Por lo tanto se trata de un contaminante secundario que se forma a partir de contaminantes precursores cuando se dan las condiciones meteorológicas adecuadas

Los episodios más agudos de ozono tienen lugar en las tardes de verano. Esta molécula, altamente reactiva, tiende a descomponerse en las zonas en las que existe una alta concentración de monóxido de nitrógeno (NO). Esto explica por qué su presencia en el centro de las grandes ciudades suele ser más baja que en los cinturones metropolitanos y en las áreas rurales circundantes. Por otro lado, el ozono se ve con frecuencia implicado en 
fenómenos de transporte atmosférico a grandes distancias, por lo que también origina problemas de contaminación transfronteriza.

Los efectos adversos sobre la salud tienen que ver con su potente carácter oxidante. A elevadas concentraciones causa irritación en los ojos, superficies mucosas y pulmones.

La respuesta a la exposición al ozono puede variar mucho entre individuos por razones genéticas, edad (afecta más a las personas mayores, cuyos mecanismos reparativos antioxidantes son menos activos), y por la presencia de afecciones respiratorias como alergias y asma, cuyos síntomas son exacerbados por el ozono. Un importante factor que condiciona los efectos de la exposición al ozono sobre los pulmones es la tasa de ventilación. Al aumentar el ritmo de la respiración aumenta el ozono que entra en los pulmones, por lo que sus efectos nocivos se incrementan con el ejercicio físico, y son por esta razón también mayores en los niños. Diversos estudios relacionan el ozono con inflamaciones de pulmón, síntomas respiratorios, e incrementos en la medicación, morbilidad y mortalidad.

Estudios recientes de la OMS, han descrito un número importante de efectos adversos del ozono, los más importantes relacionados con el sistema respiratorio, como disminución de la función pulmonar, agravamiento del asma, aumento de riesgo de visitas a urgencias, de ingresos hospitalarios $y$, probablemente, un aumento de riesgo de morir. Por otro lado, existen algunas evidencias de que los individuos, especialmente los más jóvenes, con hiperreactividad de vías aéreas, como los asmáticos, constituyen un grupo más sensible a los efectos del ozono. Actualmente se trata de uno de los contaminantes atmosféricos que más preocupan en Europa. Diversos estudios europeos han revelado que la mortalidad diaria y mortalidad por cardiopatías aumentan un $0,3 \%$ y un $0,4 \%$ respectivamente con un aumento de $10 \mu \mathrm{g} / \mathrm{m} 3$ en la concentración de ozono ${ }^{31,35,42,43}$.

\subsubsection{DIÓXIDO DE AZUFRE $\left(\mathrm{SO}_{2}\right)$}

El dióxido de azufre $\left(\mathrm{SO}_{2}\right)$ se emite principalmente combustión de combustibles que contienen azufre. Las derivadas de actividades humanas que generan la mayor cantidad son, la generación de energía, industrial, comercial, y doméstica. Por otro lado los volcanes son la mayor fuente natural de $\mathrm{SO}_{2}$. Este contaminante ocupó un lugar central en los años 80, pero su incidencia ha disminuido en los últimos años debida principalmente a la sustitución de los combustibles más contaminantes en las calderas de calefacción. El progresivo abandono del carbón y la prohibición del uso del fuelóleo, así como la limitación del contenido de azufre permitido en las calefacciones han reducido su presencia en la atmósfera de la mayoría las ciudades en general, aunque aún constituye un contaminante importante en determinados puntos de la geografía, especialmente en los aledaños de las centrales térmicas de carbón. 
${ }^{237}$ World Health Organization. (2016) Ambient air pollution: a global assessment of exposure and burden of disease. In Ambient air pollution: a global assessment of exposure and burden of disease.

${ }^{238}$ Franchi, M., Carrer, P., Kotzias, D., Rameckers, E. M. A. L., Seppänen, O., van Bronswijk, J. E. M. H., \& Viegi, G.

(2003). Towards healthy air in dwellings in Europe: The THADE report.

${ }^{239}$ European Lung Foundation. (2017) Retrieved from http://www.erswhitebook.org/.

${ }^{240}$ McGwin Jr, G., Lienert, J., \& Kennedy Jr, J. I. (2010). Formaldehyde exposure and asthma in children:

a systematic review. Environmental health perspectives, 118(3), 313.

241 World Health Organization. (2009). Global health risks: mortality and burden of disease attributable to selected major risks. World Health Organization.
La exposición crónica al $\mathrm{SO}_{2}$ y a partículas de sulfatos se ha correlacionado con un mayor número de muertes prematuras asociadas a enfermedades pulmonares y cardiovasculares. El efecto irritativo continuado puede causar una disminución de las funciones respiratorias y el desarrollo de enfermedades como la bronquitis.

$\mathrm{EISO}_{2}$ puede afectar al sistema respiratorio y las funciones pulmonares, y causa irritación ocular. La inflamación del sistema respiratorio provoca tos, secreción mucosa y agravamiento del asma y la bronquitis crónica; asimismo, aumenta la propensión de las personas a contraer infecciones del sistema respiratorio. Los ingresos hospitalarios por cardiopatías y la mortalidad aumentan en los días en que los niveles de $\mathrm{SO}_{2}$ son más elevados. En combinación con el agua, el $\mathrm{SO}_{2}$ se convierte en ácido sulfúrico, que es el principal componente de la lluvia ácida que causa la deforestación ${ }^{198,228,237,238}$.

\section{$5 \cdot 3 \cdot 2 \cdot 5 \cdot$ COMPUESTOS ORGANICOS VOLATILES (COV)}

Los compuestos orgánicos volátiles ( $C O V s$ ), son una amplia gama de compuestos químicos que contienen átomos de carbón y que pueden ser gases $o$, si bien son líquidos, tienden a evaporarse fácilmen te a temperatura ambiente. Los COV penetran fácilmente en la vía aérea por su capacidad para presentarse en forma de vapores o gases.

Su presencia es elevada en el entorno urbano, tanto en exteriores como en interiores de nuevas construcciones $y$ en edificios recientemente remodelados, ya que están presentes en la composición de resinas, barnices, pinturas, productos para el tratamiento de muebles, moquetas, alfombras... Los efectos son variables en función del tipo de compuesto pero, de manera general, se considera que el $80 \%$ de los COVs son potenciales irritantes de piel, ojos y tracto respiratorio, y el $25 \%$ podrian ser cancerígenos. Otros efectos característicos son: dolores de cabeza, irritación de mucosas, disfunciones neuropsicológicas, etc.

La European Lung Foundation, indica que la exposición a compuestos orgánicos volátiles está relacionada con un espectro de enfermedades que van, desde leve (irritaciones) a muy grave (cáncer). Incluso los niveles de exposición que se dan a nivel de la población general son relevantes. En lactantes y niños, la exposición a COV aumenta el riesgo de enfermedades respiratorias y alergias, tales como asma, sibilancias, bronquitis crónica, pérdida de la capacidad pulmonar, atopia y sensibilización a rinitis e infecciones respiratorias. Un análisis reciente ha estimado que en niños se da un aumento medio del $17 \%$ en el riesgo de padecer asma en niños por cada aumento en $10 \mu \mathrm{g} / \mathrm{m}^{3}$ de la concentración de formaldehído 238, 239, 240,241.

\subsubsection{BENZOPIRENO $\left(\mathrm{C}_{20} \mathrm{H}_{12}\right)$}

El benzopireno es otro contaminante de gran impacto que se genera a partir de la combustión incompleta o mala combustión de diversos combustibles fósiles. En Europa Las principales fuentes que generan esta sustancia son 
las calefacciones domésticas que utilizan como combustible madera o carbón, la quema de residuos y la producción de coque y acero. Aunque también hay otras fuentes significativas, naturales como los incendios o el tráfico por carretera, debido al desgaste de los neumáticos.

El $\mathrm{BaP}$ es un hidrocarburo aromático policíclico que se encuentra en partículas finas procedentes de una combustión incompleta. Una fuente principal de $\mathrm{BaP}$ en Europa es la calefacción doméstica, y en particular la quema de biomasa, la incineración de residuos, la producción de coque y acero y el transporte, así como la combustión al aire libre.

El BaP está clasificado en el Grupo 1 como cancerígeno seguro por la IARC, por lo que no existe una concentración máxima de seguridad por debajo de la cual no se produzcan efectos adversos para la salud ${ }^{31}$.

\subsubsection{MONÓXIDO DE CARBONO (CO)}

El monóxido de carbono $(\mathrm{CO})$ y el benceno $\left(\mathrm{C}_{6} \mathrm{H}_{6}\right)$ son compuestos emitidos en forma de gas como resultado de la combustión incompleta de combustibles fósiles y biocombustibles. El transporte por carretera era una fuente importante de emisiones de $\mathrm{CO}$, la introducción de la tecnología de los catalizadores en los sistemas de escape de los vehículos produjo como consecuencia una reducción significativa de estas emisiones ${ }^{198}$.

\subsubsection{BENCENO $\left(\mathrm{C}_{6} \mathrm{H}_{6}\right)$}

El benceno, es un compuesto cancerígeno y se utiliza como aditivo para la gasolina, en Europa la mayoría de sus emisiones provienen del tráfico. Estas emisiones de $\mathrm{C}_{6} \mathrm{H}_{6}$ han disminuido drásticamente a partir de la aprobación de la directiva comunitaria relativa a la calidad de los combustibles del año 2009. En general, las contribuciones producidas por la calefacción doméstica son pequeñas, en torno al $5 \%$ del total de las emisiones. Sin embargo, en áreas o países donde la madera se utiliza como combustible en las calefacción domestica supone una importante generadora ${ }^{198}$.

\subsubsection{AEROALÉRGENOS}

Según la European Lung Foundation en una publicación en diciembre de 2013 , los mohos son una fuente de alérgenos y pueden incrementar el riesgo de problemas relacionados con el asma en un 30-50 \% ${ }^{198}$.

En un número importante de estudios se ha descrito que las altas concentraciones de polen y esporas se asocian con epidemias de asma y de otras enfermedades alérgicas como la rinitis o la fiebre del heno. En un estudio realizado en Madrid se determinó una asociación significativa entre los incrementos del percentil 95 al 99 de polen de Poacea y Plantago con un incremento en el número de visitas por asma a las urgencias hospitalarias del $17 \%$ y del $16 \%$ respectivamente ${ }^{57}$. También se ha encontrado una asociación con el polen de urticáceas, con un $8,5 \%$ de incremento en el número de urgencias
242 Tobias, A., Galan, I., Banegas, J. R., \& Aranguez, E. (2003).

Short term effects of airborne pollen concentrations on asthma epidemic. Thorax, 58(8), 708-710. 
243 Suárez-Cervera, M., Castells, T., Vega-Maray, A., Civantos, E., del Pozo, V., Fernández-González, D., ...

\& Seoane-Camba, J. A. (2008) Effects of air pollution on Cup a 3 allergen in Cupressus arizonica pollen grains. Annals of Allergy, Asthma \& Immunology, 101(1), 57-66

244 EEA. (2013)

EEA air quality in europe-2013. (No. 9) doi:10.2800/92843

245 WHO. (2011).

New WHO database shows poor air quality in cities. Retrieved from

http://www.euro.who.int/en/data-andevidence/environment-and-healthinformation-system-enhis/news/ news/2011/09/ new-who-databaseshows-poor-air-quality-in-cities. Consultado Septiembre 2015

246 for Europe, W. R. O. (2013) Review of evidence on health aspects of air pollution-REVIHAAP Project.

247 Review of evidence on health aspects of air pollution - REVIHAAP" project. This project has been co-funded by the European Union under Contribution Agreement por asma. Hay que reseñar también la importancia de los pólenes. Estos provienen generalmente de plantas de exterior, y sus concentraciones en el aire suelen ser bajas; sin embargo, pueden elevar su concentración en edificios poco ventilados, y además se ha observado una interacción entre contaminantes ambientales y pólenes que potencian la alergenicidad de estos ${ }^{243}$.

\section{3 .3 . LA CALIDAD DE AIRE EN EUROPA}

El año 2013, fue declarado el "Año del Aire" por la Comisión Europea. Los datos del comisario de Medio Ambiente de la UE indican que, 420.000 personas en la UE en 2010 murieron de forma prematura debido a la contaminación del aire ${ }^{244}$.

En torno al $90 \%$ de la población urbana de la Unión Europea está expuesta a concentraciones de contaminantes atmosféricos que Organización Mundial de la Salud considera nocivas para la salud. Así lo demuestra el último estudio sobre la calidad del aire en Europa que ha publicado la Agencia Europea de Medio Ambiente.

Según los datos del Sistema de Información sobre el Medio Ambiente y la Salud (ENHIS), de la OMS, que abarcan 357 ciudades europeas de 33 paises, muestran que en 2009 casi el $83 \%$ de la población de estas ciudades estaba expuesta a niveles de $\mathrm{PM}_{10}$ que excedían las directrices de la OMS. Si bien esta proporción sigue siendo elevada, representa una mejora en comparación con años anteriores, ya que los niveles medios de $\mathrm{PM}_{10}$ disminuyeron lentamente en la mayoría de los países en la última década ${ }^{245}$.

Alrededor de 40 millones de personas en las 115 ciudades más grandes de la Unión Europea (UE) están expuestas a un aire que excede los valores recomendados por la OMS para la calidad del aire para al menos un contaminante. Los niños que viven cerca de carreteras con tráfico de vehículos pesados tienen el doble de riesgo de padecer de problemas respiratorios que los que viven cerca de las calles menos congestionadas. Un estudio reciente que utiliza datos de 25 ciudades de la Unión Europea ha estimado que la expectativa de vida podría aumentarse hasta aproximadamente 22 meses en las ciudades más contaminadas si la concentración de $\mathrm{PM}_{2,5}$ a largo plazo se redujera al nivel anual de la guía de la $\mathrm{OMS}^{198}$.

Entre 2009 y 2011, el $96 \%$ de la población urbana estuvo expuesta a concentraciones de partículas finas $\left(\mathrm{PM}_{2,5}\right)$ superiores a las indicadas en las directrices de la OMS y el $98 \%$ expuesto a concentraciones de ozono $\left(\mathrm{O}_{3}\right)$ también superiores a las indicadas por la OMS. Si se tiene en cuenta los límites de estas concentraciones de contaminantes permitidos por la UE, el número de ciudadanos expuestos a estos contaminantes será menor porque en algunos casos los límites permitidos son menos estrictos que los aconsejados por la OMS $246,247$. 


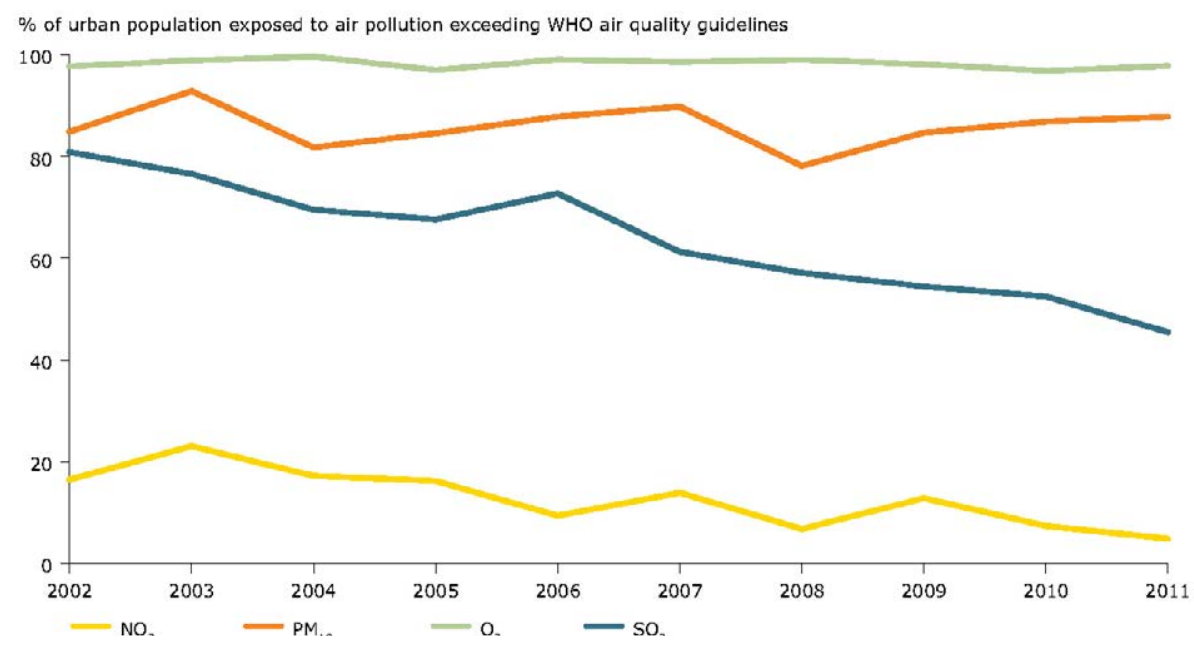

El Comisario de Medio Ambiente, Janez Potocnik, en un discurso titulado "Si crees que la economía es más importante que el medio ambiente, intenta aguantar la respiración mientras cuentas tu dinero" afirmó que, la calidad del aire es un problema esencial para muchas personas.

En España, el control se realiza por parte del Ministerio de Agricultura, Alimentación y Medio Ambiente, a partir de los datos que envían periódicamente las comunidades autónomas y determinadas entidades locales. Las evaluaciones que se realizan anualmente sirven para conocer la calidad del aire y para realizar el diagnóstico de situación en cuanto al cumplimiento de la normativa vigente en esta materia. Esta evaluación viene demostrando año tras año que el aire no entiende de fronteras administrativas puesto que la mayoría de los problemas existentes en nuestro país son comunes, independientemente de la comunidad autónoma o municipio ${ }^{248}$.

En 2015, se ha producido un aumento general de los niveles de contaminación de partículas en suspensión $\left(\mathrm{PM}_{10}\right.$ y $\left.\mathrm{PM}_{2,5}\right)$, dióxido de nitrógeno $\left(\mathrm{NO}_{2}\right)$, ozono troposférico $\left(\mathrm{O}_{3}\right)$ y dióxido de azufre $\left(\mathrm{SO}_{2}\right)$, el primero desde el inicio de la crisis económica en 2008.

El informe de Ecologistas en Acción toma como referencia los valores máximos de contaminación recomendados por la Organización Mundial de la Salud (OMS) y el objetivo a largo plazo para proteger la vegetación establecido por la Unión Europea. De acuerdo a esos niveles, el aire contaminado afectó en 2015 a 45,9 millones de personas en el Estado español, el $99 \%$ de su población, así como a 478.000 kilómetros cuadrados, el $95 \%$ del territorio 249 .

La principal fuente de contaminación en áreas urbanas, donde se concentra la mayor parte de la población, es el tráfico rodado. En determinadas áreas fabriles y en el entorno de las grandes centrales termoeléctricas de carbón y otros combustibles fósiles son estas fuentes industriales las que condicionan de manera decisiva la calidad del aire.
Fig 74. Porcentaje de población urbana expuesta a valores superiores a los indicados por la OMS. Fuente: EEA. (2014). Air pollution fact sheet - Spain ${ }^{197}$.

248 MAGRAMA (2013) Plan nacional de Calidad del aire y Protección de la Atmósfera 2013-2016. Plan AIRE. http://www.mapama.gob.es/es/calidad$y$-evaluacion-ambiental/participacionpublica/20130215_PLAN_AIRE_20132016_tcm7-262824.pdf.

${ }^{249}$ Ecologistas en Acción. (2016). La calidad del aire en el estado Español durante 2015. 
Fig 75. Mapa de estaciones de medición de contaminación atmosférica en España. Fuente. Plan nacional de calidad del aire y protección de la atmósfera 2013-2016.
Tabla 10. Incumplimientos frecuentes de los contaminantes atmosféricos. Fuente. Plan nacional de calidad del aire y protección de la atmósfera 2013-2016.

Tabla 11. Superficie afectada y población censada en zonas con incumplimientos. Fuente. Plan nacional de calidad del aire y protección de la atmósfera 2013-2016.
El ozono troposférico es el contaminante que presenta una mayor extensión y afección a la población, con unos niveles que se mantienen estacionarios o incluso al alza. Esto se debe al incremento de las temperaturas medias y de las situaciones meteorológicas extremas (olas de calor) durante el verano, como resultado del cambio climático. Durante el año 2015 los niveles de ozono aumentaron por el incremento del calor respecto a los de 2014, salvo en la cornisa cantábrica, de manera que la mayor parte de la población y el territorio españoles han seguido expuestos a concentraciones de ozono perjudiciales para la salud humana y vegetal.

Las partículas $\left(\mathrm{PM}_{10}\right.$ y $\left.\mathrm{PM} \mathrm{M}_{2,5}\right)$, el dióxido de nitrógeno $\left(\mathrm{NO}_{2}\right)$ y el dióxido de azufre $\left(\mathrm{SO}_{2}\right)$ en el aire afectan a más de cuatro quintas partes de la población durante el año 2015 se interrumpió la tendencia a la baja de estos contaminantes que se inició en 2008 , con la crisis económica.

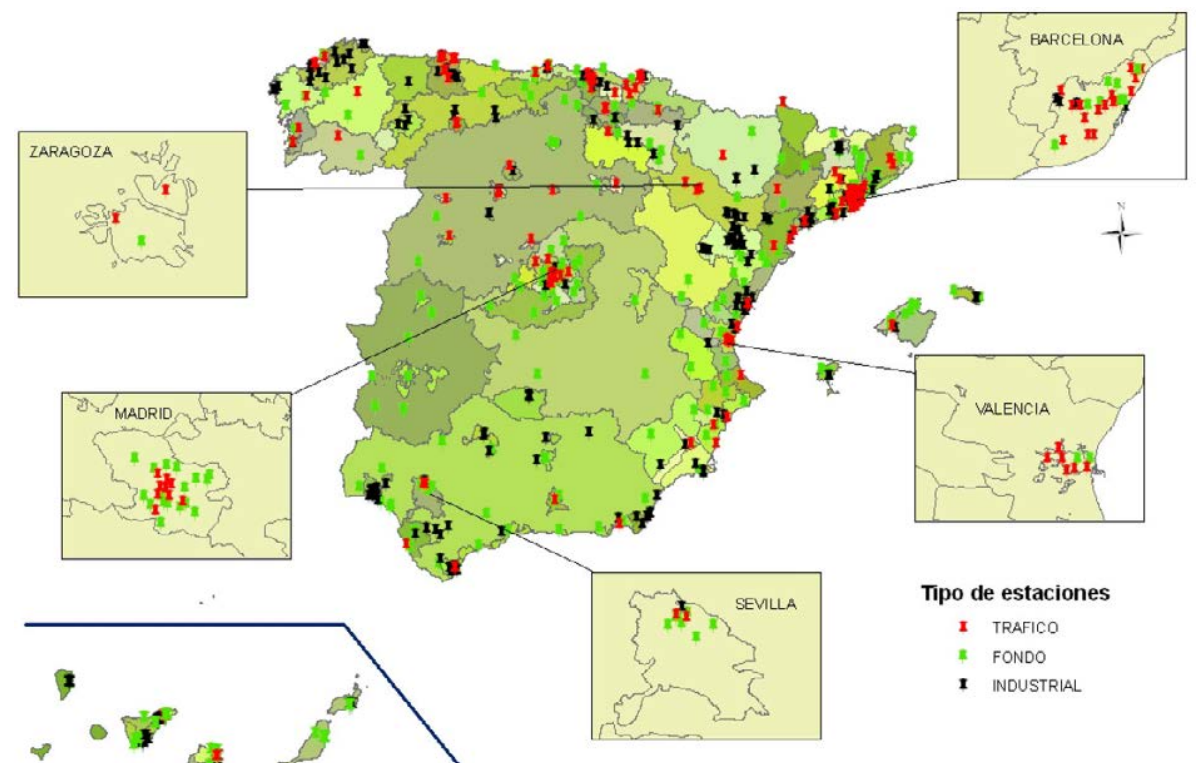


España es el país con más coches diésel de Europa. La contaminación del aire es responsable de más de 400.000 muertes prematuras en Europa cada año, aunque la situación ha mejorado, a lo largo de los años. En 2014, último año con datos oficiales reportados a la AEMA, y teniendo en cuenta los niveles europeos de calidad de aire, se superaron los valores límite de $\mathrm{NO}_{2}$ en estaciones de tráfico de las principales ciudades (como Madrid, Barcelona o Valencia), hubo pocas superaciones de $\mathrm{PM}_{10}$ (tres estaciones sobrepasaron el valor límite diario y una el valor límite anual) y el ozono presentó superaciones en todo el país, excepto algunas regiones en el norte y noreste del país ${ }^{248}$. 


\subsection{ARQUITECTURA}

\section{INTRODUCCIÓN.}

El cambio de las condiciones climáticas es otra vía para dañar estructuras y materiales. Estos impactos son de corta duración, agudos e intensos cuando se derivan de condiciones climáticas extremas por ejemplo, olas de calor y lluvias extremas más frecuentes y de larga duración. $\bigcirc$ bien puede ser de lento desarrollo cuando se derivan de cambios en las condiciones climáticas generales como por ejemplo, aumento de la temperatura media anual, veranos más secos e inviernos más húmedos.

La concentración y la naturaleza ácida u oxidante de algunos contaminantes atmosféricos es otro factor potencialmente dañino, porque la combinación de dichas sustancias y por ejemplo, un clima húmedo o de humedad relativa alta, favorece ciertos mecanismos de deterioro de los materiales.

Un ejemplo son, los procesos y mecanismos de deterioro y ennegrecimiento de la infraestructura construida, refiriéndonos tanto a edificios, incluido los históricos, como a infraestructuras (carreteras, vías férreas, puentes, túneles, puertos, aeropuertos. Fachadas de edificios, monumentos o infraestructuras que están expuestas a la contaminación urbana, cambian, mutan, se vuelven grises o incluso negras con el tiempo, debido a las partículas generadas por la contaminación que se depositan en su superficie debido a fenómenos físicos o químicos.

Los materiales que constituyen o están presentes en la mayoría de las fachadas como son, la piedra natural, el hormigón, los morteros de cal o morteros de cemento tienen porosidad, texturas, color y disposición que los hacen más o menos propensos al ensuciamiento por deposición debido la contaminación de tipo seco que, por ejemplo predomina en Madrid, o disueltos en el ataque por vía húmeda.

\subsubsection{CONTAMINACIÓN ATMOSFÉRICA. CÓMO AFECTA A LOS MATERIALES.}

250 Tidblad, J. and Kucera, V. (2007) Dose-response functions and tolerable levels for corrosion in the multi-pollutant situation. Pollut. Atmos. Numero Special "Effets de la pollution atmospherique sur les materiaux": 87-93

251 Tidblad, J. (2102)

Atmospheric corrosion of metals in 2010-2039 and 2070-2099.

J. Atmospheric Environment 55, 1-6.
Compuestos como el $\mathrm{SO}_{2}, \mathrm{O}_{3}$ y los $\mathrm{NO}_{x}$, hemos visto como son sustancias corrientes en los entornos urbanos, sustancias peligrosas para la salud humana pero, también para nuestros edificios deteriorándolos, principalmente por su carácter altamente oxidante, ácido y corrosivo a través de distintas rutas químicas ${ }^{250}$.

En las zonas alejadas de la costa se estima que la contaminación por $\mathrm{HNO}_{3}$ debido a la los niveles de emisión de $\mathrm{NO}_{x}$, contribuirá a la corrosión de metales expuestos a condiciones exteriores en el periodo (2070-2099) ${ }^{251}$.

Kumar et al., recogen en las conclusiones de su estudio que la naturaleza ácida de los contaminantes atmosféricos corrosivos y sus concentraciones 
ambientales son igualmente importantes para las áreas industriales geológicamente sensibles y para los parámetros climáticos, por ejemplo una combinación de humedad relativa alta compaginada con contaminantes pueden generar sustancias corrosivas que son capaces de deteriorar estructuras, interior o exteriormente, como podría ser un museo. $\mathrm{El}_{3}$ es un oxidante muy potente, actualmente uno de los contaminantes atmosféricos que mayor preocupación genera, debido a las concentraciones globales de fondo que se están midiendo y que están por encima de la tolerancia de los materiales.

En su artículo se revisan más de 150 trabajos de investigación relacionados con la contaminación del aire, cambio climático y estructuras de ingeniería civil con el objetivo de valorar el impacto, la huella que deja la contaminación atmosférica y los cambios climáticos en las estructuras y en los materiales de construcción. Los contaminantes atmosféricos como el $\mathrm{SO}_{2}$, el $\mathrm{O}_{3}$ y los $\mathrm{NO}_{x}$, son gases corrosivos que atacan y deterioran los materiales de construcción, también Las alteraciones en las concentraciones de $\mathrm{CO}_{2}$ juegan un papel clave a nivel del cambio climático y además, afecta directamente a las estructuras de hormigón a través del proceso de carbonatación.

\begin{tabular}{|c|c|c|c|c|c|c|c|c|}
\hline Material & $\mathrm{SO}_{2}$ & $\mathrm{O}_{3}$ & $\mathrm{NO}_{2}$ & $P M_{10}$ & $\mathrm{pH}$ & $\begin{array}{c}\text { Lluvia } \\
{\left[\mathrm{H}^{+}\right]}\end{array}$ & $\begin{array}{l}\text { Lluvia } \\
{\left[\mathrm{Cl}^{-}\right]}\end{array}$ & Temp \\
\hline \multicolumn{9}{|l|}{ Acero Inoxidable } \\
\hline \multicolumn{9}{|l|}{ Acero al carbono } \\
\hline \multicolumn{9}{|l|}{ Caliza } \\
\hline \multicolumn{9}{|l|}{ Arenisca } \\
\hline \multicolumn{9}{|l|}{ Zinc } \\
\hline \multicolumn{9}{|l|}{ Aluminio } \\
\hline \multicolumn{9}{|l|}{ Cobre } \\
\hline \multicolumn{9}{|l|}{ Bronce } \\
\hline \multicolumn{9}{|l|}{ Vidrio } \\
\hline \multicolumn{9}{|l|}{ Pintura / Galvanizado } \\
\hline \multicolumn{9}{|l|}{ Pintura / Acero } \\
\hline \multicolumn{9}{|l|}{ Níquel } \\
\hline \multicolumn{9}{|l|}{ Estaño } \\
\hline \multicolumn{9}{|l|}{ Caucho y plásticos } \\
\hline \multicolumn{9}{|l|}{ Plomo } \\
\hline \multicolumn{9}{|l|}{ Madera } \\
\hline Hormigón & & & & & & & & \\
\hline
\end{tabular}

El deterioro de la infraestructura construida se produce por el efecto

Tabla 12. Sensibilidad a la corrosión de diversos materiales hacia contaminantes atmosféricos y parámetros climáticos. combinado de agentes atmosféricos -vía física-y de sustancias contaminantes presentes en la atmósfera- vía química. Se puede ver globalmente ese proceso, en el siguiente esquema propuesto por Kumar et al. 
Fig 76. Impactos e interacciones de los contaminantes atmosféricos y parámetros climáticos en las infraestructuras.

252 Kumar, P., \& Imam, B. (2013). Footprints of air pollution and changing environment on the sustainability of built infrastructure. Science of the Total Environment, 444, 85-101

${ }^{253}$ Ghedini, N., Ozga, I., Bonazza, A., Dilillo, M., Cachier, H., \& Sabbioni, C. (2011). Atmospheric aerosol monitoring as a strategy for the preventive conservation of urban monumental heritage: The Florence Baptistery. Atmospheric environment, 45(33), 5979-5987.

254 Tidblad, J. (2014)

ICP mapping manual chapter 4 [http://www.corr-institute.se/icpmaterials/web/page. aspx? refid=19]. Consultado October 2015

255 Screpanti, A., \& De Marco, A. (2009). Corrosion on cultural heritage buildings in Italy: A role for ozone?.Environmental pollution, 157(5), 1513-1520.

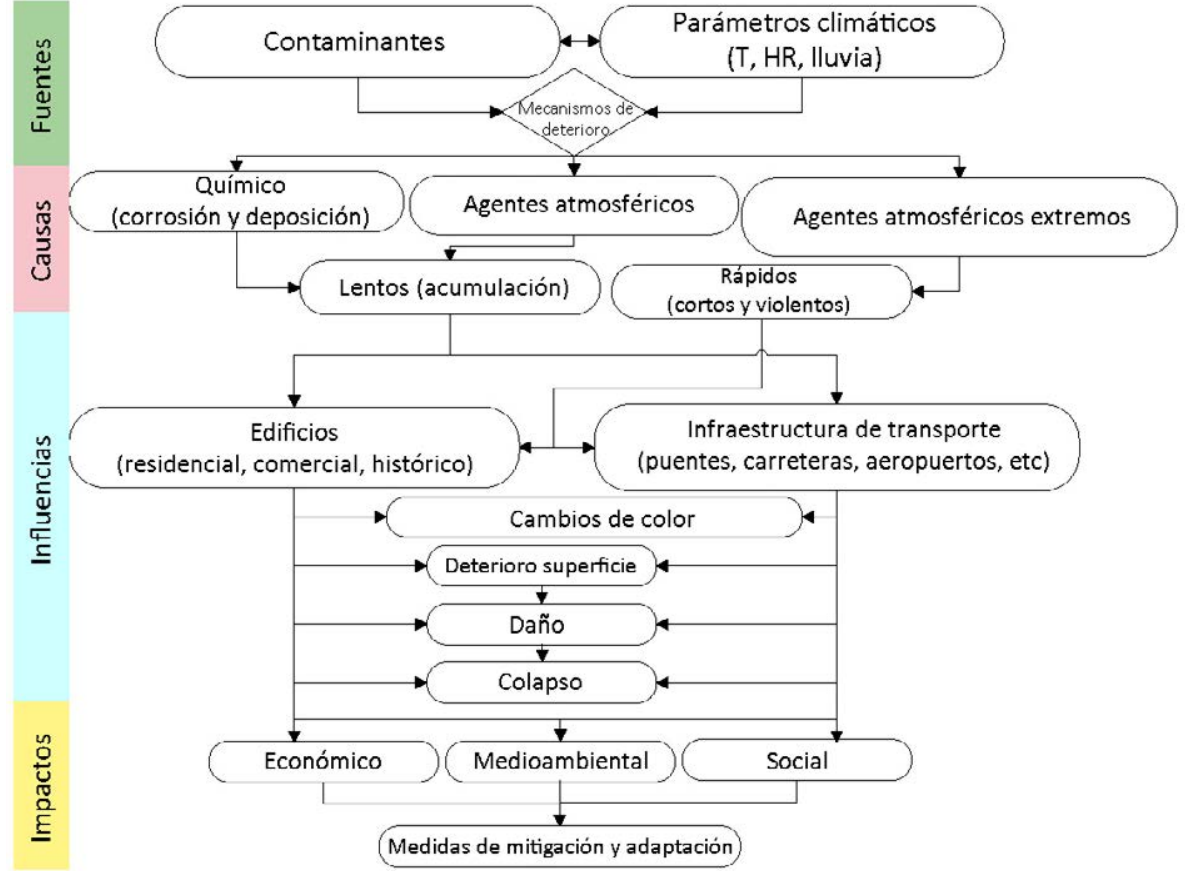

La literatura estudiada por este investigador, sugiere que la contaminación atmosférica y el cambio climático afectan a la durabilidad de los materiales y por tanto a la integridad de edificios e infraestructuras ${ }^{252}$.

Tidblad, y Ozga et al, señalan que tampoco hay que menospreciar el papel del $\mathrm{CO}_{2}$ en estos procesos de deterioro, dado el papel clave que se ha demostrado tienen las variaciones en las concentraciones de $\mathrm{CO}_{2}$ sobre el cambio de los parámetros climáticos. A través del llamado "cambio climático", además de afectar directamente a las estructuras de hormigón por medio del proceso de la carbonatación, han estudiado por separado, cómo la contaminación atmosférica induce la corrosión y el deterioro de metales y del hormigón expuesto en edificios ${ }^{253}$.

En Europa, la contaminación atmosférica sigue siendo mayor en las zonas urbanas e industriales europeas que en el medio rural. Un efecto indeseable de la contaminación del aire es que aumenta la tasa de degradación de los edificios y, por lo tanto, la necesidad y los costos de las actividades de conservación y restauración. A partir de las mediciones realizadas en el programa de materiales del ICP, se encontró que la tasa de degradación media en Europa de la piedra caliza era de $3.2 \mu \mathrm{m} / a$ ño. También se sugirió en ese estudio que los valores para la degradación producida por la contaminación para el periodo 2020-2050, deberían ser entre 2 y 2,5 veces más altos que los actuales ${ }^{254}$.

Se han hecho estimaciones de pérdidas en materiales, motivados por los cambios de los parámetros climáticos y las altas concentraciones atmosféricas de contaminantes. Por ejemplo, Screpanti y De Marco ${ }^{255}$, llevaron a cabo evaluaciones por corrosión en los edificios históricos en Italia. Encontraron que la velocidad en los procesos corrosivos sobre la piedra caliza y el cobre estaban muy por encima de los niveles tolerables y 
como medida para frenar el deterioro, sugirieron la necesidad de reducir las concentraciones de $\mathrm{O}_{3}$ ambiente.

Sobre el impacto en los edificios históricos se encuentran artículos publicados, estudios, que plantean serias preocupaciones sobre la respuesta a la rápida evolución de los parámetros climáticos y de la influencia de las concentraciones de contaminantes, como son los trabajos de Brimblecombe y Grossi ${ }^{256,257}$.

El ozono por ejemplo, es el oxidante más poderoso y actualmente unos de los contaminantes que genera mayor preocupación debido a sus concentraciones a nivel mundial que están en los límites de tolerancia, su efecto en materiales como el acero y la piedra se pueden medir incluso a muy baja concentración, 20 ppb.

Brimblecombe y Grossi, indican el siglo XXI parece proporcionar un entorno menos agresivo para la piedra y los metales tradicionales como zinc, aluminio o cobre, que en el siglo anterior, debido a la mejora en la calidad del aire en algunos compuestos como el $\mathrm{NO}_{x}$ o el $\mathrm{SO}_{x}$. Sin embargo, han observado que la degradación para los materiales poliméricos como plásticos, pintura y el caucho puede aumentar debido al aumento de las temperaturas y las concentraciones de contaminantes de carácter oxidante ${ }^{258}$. La composición de la atmósfera urbana ha cambiado mucho, y el predominio de oxidantes como el ozono o la presencia de material particulado producido por los vehículos diésel plantean un nuevo entorno más agresivo para algunos materiales. Estos contaminantes pueden ser perjudiciales para las pinturas y los polímeros ${ }^{259}$, o incluso causar decoloración de las fachadas ${ }^{260}$.

Materiales como el acero y la piedra están muy influenciados por los procesos de oxidación producidos por el $\mathrm{SO}_{2}, \mathrm{NO}_{\mathrm{x}} \mathrm{y}_{3}$.

Un estudio realizado por Lee et al. ${ }^{6}$, evaluó el daño potencial por $\mathrm{O}_{3}$ en los materiales en el Reino Unido en 170- 345 millones $€$ /año. Esto incluye, el deterioro causado a los revestimientos y elastómeros, así como el costo de la protección anti-ozono aplicado a los cauchos.

Los efectos de la concentración de $\mathrm{O}_{3}$ por el sobrecoste de volver a pintar se estimaron en el rango de:

- 0 - 60 millones $€$ /año para un cambio en la concentración de $\mathrm{O}_{3}$ de 15 a 20 ppb.

- 0 - 182 millones $E$ laño para un cambio en la concentración de $\mathrm{O}_{3}$ de 15 a 30 ppb.

Terje Grøntoft del NILU-Norwegian Institute for Air Research. Ha valorado los costes de conservación-restauración debidos a la degradación por la contaminación atmosférica en la ciudad de Cracovia sobre la piedra caliza de una fachada. Para hacerlo, tuvo en cuenta el nivel de contaminación atmosférica en el período 2013-2015, así como los valores estimados
${ }^{256}$ Brimblecombe, P. and Grossi, C.M. (2008)

Millennium - long recession of limestone facades in London. Environ.

Geol. 56, 463-471.

${ }^{257}$ Brimblecombe, P. (2000)

Air pollution and architecture: past present and future. J. Architect. Conserv. 5(2), $30-46$.

258 Brimblecombe, P. and Grossi, C.M. (2010)

Potential damage to modern building materials from 21st century air pollution. The Scientific World JOURNAL: TSW Environment 10, 116-125. DOI 10.1100/tsw.2010.17.

259 Holland, M. et al. (2007)

Ozone damage to paint and rubber goods in the UK. Pollut. Atmos. Numero Special "Effets de la pollution atmospherique sur les materiaux": 73-86.

${ }^{260}$ Grossi, C.M. and Brimblecombe, P. (2008)

Past and future colouring patterns of historic stone buildings. Rev. Mater. Construc. 58, 143-160. 
${ }^{261}$ Grentoft, T. (2016)

"Conservation-restoration costs for limestone façades due to air pollution in Krakow, Poland, meeting European target values and expected climate change," Sustainable Cities and Society 29 (2017) 169-177.

Fig 77. Ahorro de costes en conservaciónrestauración por cada $500 €$ de inversión, como porcentaje de un coste total estimado de $336 €$ por la contaminación atmosférica de Cracovia por contaminante y por el total de contaminantes, para una fachada de caliza a partir de los valores mediados en Cracovia. Comparado con

los niveles estimados para el periodo 2020 y 2050 en la directiva de la UE sobre la calidad del aire de 2008 y el aumento previsto de los costes debido al cambio climático hasta el período 2081-2100.

Fig 78. Ahorro de costes en conservaciónrestauración por cada $500 €$ de inversión en una fachada de piedra caliza debido a una reducción de $1 \mu \mathrm{g} / \mathrm{m}^{3}$ en la concentración de dióxido de azufre $\left(\mathrm{SO}_{2}\right)$ dióxido de nitrógeno $\left(\mathrm{NO}_{2}\right)$ y partículas finas $\left(P M_{10}\right)$

Los valores de contaminación en la ciudad de Cracovia, están representados por las líneas verticales de puntos. para 2020 y 2050 . Esa degradación es en la ciudad, entre 2 y 2,5 veces superior a la esperada en las zonas rurales que en las que la concentración de contaminantes es menor. Estima que podrían obtenerse ahorros del $27 \%$ y del $51 \%$ sobre los daños producidos por el deterioro de la piedra, basándose en una reducción de las concentraciones de $\mathrm{SO}_{2}, \mathrm{NO}_{2}$ y $\mathrm{PM}_{10}$, en un $36 \%$ y $67 \%$ respectivamente, sobre los niveles en 2013-15. Una reducción del $6 \%$ de los niveles de esos contaminantes compensaría las consecuencias previstas por el cambio climático en el período 2081-2100261.
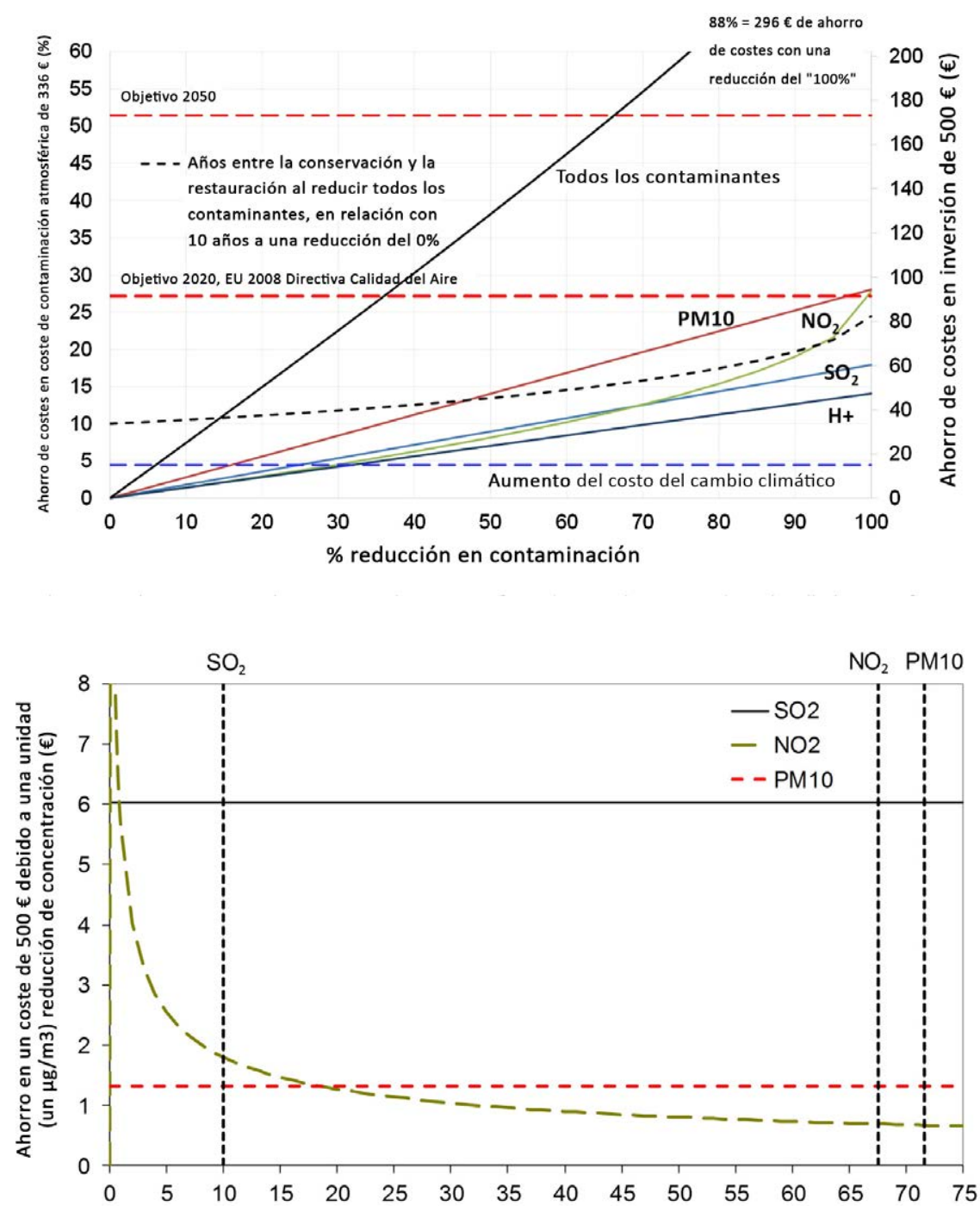

Doytchinov et al., han desarrollado una fórmula para valorar el coste económico como consecuencia del deterioro por la contaminación atmosférica en los edificios.

$$
K_{f}=M \cdot P \cdot\left(t_{p}^{-1}-t_{b}^{-1}\right)
$$

Donde $\left(K_{f}\right)$, son los costes en $€$ laño debidos a la degradación por los procesos de deterioro por la contaminación atmosférica a nivel nacional o local, $(M)$ en $\left(\mathrm{m}^{2}\right)$ es la superficie afectada de un tipo de material, $(P)$ en $\left(€ / \mathrm{m}^{2}\right)$ son los costes de mantenimiento por metro cuadrado del material, $\left(t_{p}\right)$ y $\left(t_{b}\right)$ expresados en años, son los periodos de tiempo entre 
intervenciones de conservación-restauración, en la situación actual o presente (p) y anterior (b).

El coste por la degradación de la fachada debido a la contaminación atmosférica es un costo adicional al del ciclo natural conservaciónrestauración, debido a que los intervalos entre las intervenciones para conservación o para restauración son más cortos en un entorno más contaminado, en comparación con la situación anterior en la que la contaminación no se daba $\left(t_{b}\right)^{262}$.
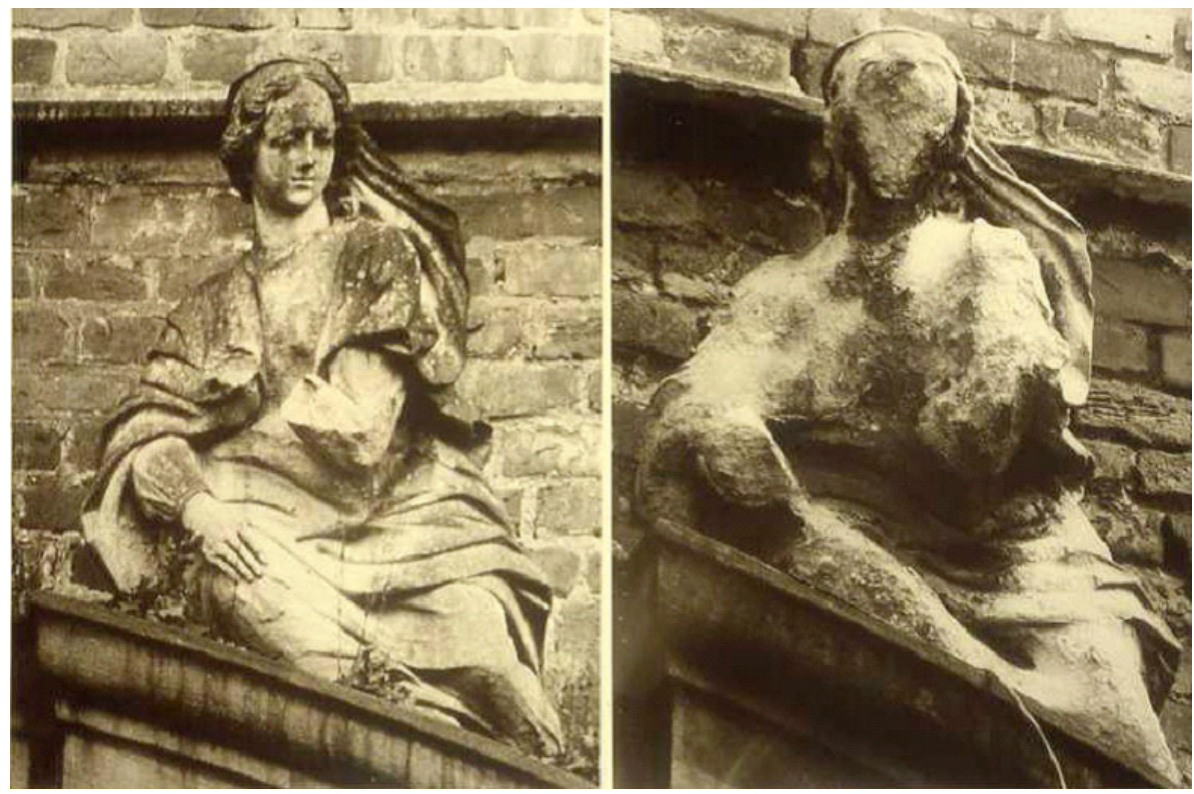

Comprobado el deterioro que los contaminantes atmosféricos producen en nuestro patrimonio histórico construido, causando un daño irreparable Di Turo et al, partiendo de la situación en 1980 realizan un trabajo de análisis para Europa, de la degradación y perdidas en la piedra caliza, el bronce y el cobre, como materiales representativos en el patrimonio cultural construido. En 1980 el número de lugares catalogados por la UNESCO en peligro era de un $94 \%$ para la piedra caliza y del $54 \%$ y $1 \%$ para el cobre y bronce respectivamente. En 2010 estos sitios no superaron el valor tolerable de la recesión superficial y la corrosión.

De sus análisis del impacto de la contaminación atmosférica en Europa desde 1980 hasta 2010, cabe destacar entre sus conclusiones que, en el periodo estudiado han observado una clara disminución de los niveles de corrosión en general para los materiales estudiados -caliza, cobre y bronce- pero, teniendo en cuenta el porcentaje de corrosión en el periodo de 2000 a 2010, se ha producido un pequeño incremento, que los autores relacionan con las concentraciones de $\mathrm{PM}_{10}$ en 2010 , que han aumentado desde el año $2000^{264}$.
262 Doytchinov, S., Spezzano, P., Screpanti, A., \& Leggeri, G. (2013). UNECE International co-operative programme on effects on materials, including historic and cultural monument. In Report No 73. Pilot study on inventory and condition of stock of materials at risk at United Nations Educational, Scientific and Cultural Organization (UNESCO) cultural heritage sites. Part III Economic evaluation. Italian National Agency for New Technologies. pp. 2013. Rome, Italy: Energy and sustainable economic development (ENEA)

Fig 79. Imagen sobre la entrada de un castillo en Westfalia, Alemania. Hecha en piedra arenisca en 1702. Imagen izquierda tomada en 1908, imagen derecha tomada en 1969263

263 http://www.biology-pages.info/A/ AcidRain.html Consultada Febrero 2017.

264 Di Turo, F., Proietti, C., Screpanti, A., Fornasier, M. F., Cionni, I., Favero, G., \& De Marco, A. (2016).

Impacts of air pollution on cultural heritage corrosion at European level: What has been achieved and what are the future scenarios.

Environmental Pollution, 218, 586-594. 


\subsubsection{EFECTO ISLA DE CALOR, INFLUENCIA DE LOS MATERIALES.}

Hoy en día las ciudades y el proceso de urbanización están asociados con importantes transformaciones económicas, sociales y del medio ambiente, los ya conocidos tres pilares del desarrollo sostenible. Ese papel de las ciudades, tiene un impacto global. Las decisiones sobre diseño, materiales y soluciones adoptadas por arquitectos, diseñadores, ingenieros en las envolventes, calles, superficies pavimentadas, tienen una influencia significativa. Por otro lado, la actividad económica también es generadora de contaminación. En consecuencia, una expansión urbana rápida, imprevista o inadecuadamente administrada, con patrones de producción, consumo y crecimiento insostenibles, lleva a un aumento de la contaminación y degradación ambiental.

En los años 70 del siglo XX, a raíz de la crisis energética origibnada por el "boom" de las fuentes renovables de energía, la arquitectura bioclimática, etc., se empezó a considerar el efecto que tiene el espacio construido con fines de reducción de la contaminación y eficiencia energética. Hoy en día. Los problemas que plantean el efecto invernadero, el efecto Isla de Calor Urbana, la sostenibilidad de los espacios, hacen que esta línea de investigación en el campo de la arquitectura, del urbanismo y los materiales sea importante en la acutalidad.

En el mundo global e interconectado en el que nos encontramos, más de la mitad de la población mundial, el $54 \%$ vive en ecosistemas urbanos, el $73 \%$ de la población europea y 3.900 millones en 2014 . Se prevé que el crecimiento y la urbanización añadan 2.500 millones a la población urbana mundial En 2050. En 1950, sólo el 30\% de la población mundial era urbana y, para 2050 , se proyecta que el $66 \%$ de la población mundial es urbana. Mientras que cerca de uno de cada ocho vive en las 28 mega-ciudades de 10 millones de habitantes o más. El número de mega-ciudades casi se ha triplicado desde 1990; Y para 2030 se proyecta que 41 aglomeraciones urbanas alberguen por lo menos 10 millones de habitantes cada una.

${ }^{265}$ Madlener R, Sunak Y. Impacts of urbanization on urban structures and energy demand: what can we learn for urban energy planning and urbanization management? Sustainable Cities and Society 2011; 1:45-53
Madlener et al., hacen referencia que las ciudades ocupan aproximadamente el $2 \%$ de la superficie terrestre. Hoy en día el tamaño de las ciudades están aumentando, cada vez más personas abandonan las zonas rurales para emigrar a las ciudades. Debido a ese aumento de la población, las ciudades necesitan de grandes cantidades de energía para funcionar, de hecho consumen más del $75 \%$ de los recursos energéticos totales ${ }^{265}$ y una parte de la energía se disipa al entorno en forma de calor, al que se suma la radiación solar.

La energía solar es absorbida por las superficies, lo que provoca que la temperatura superficial de las estructuras urbanas pase a ser varios grados más elevada que la temperatura del aire ambiente. Este fenómeno, denominado Isla de Calor Urbana (ICU), con un equilibrio térmico positivo en el centro de las ciudades, en comparación con las zonas suburbanas y rurales vecinas, da como resultado un importante aumento de las temperaturas ambientes urbanas $^{266,267}$. Si además hay una falta de espacios verdes en el entorno, 
este efecto es más acentuado como consecuencia de las emisiones de gases de efecto invernadero. El aumento de temperatura causado por este efecto de isla de calor, reduce la necesidad de calefacción en épocas frías, pero del mismo modo, aumenta la demanda de refrigeración en épocas cálidas.

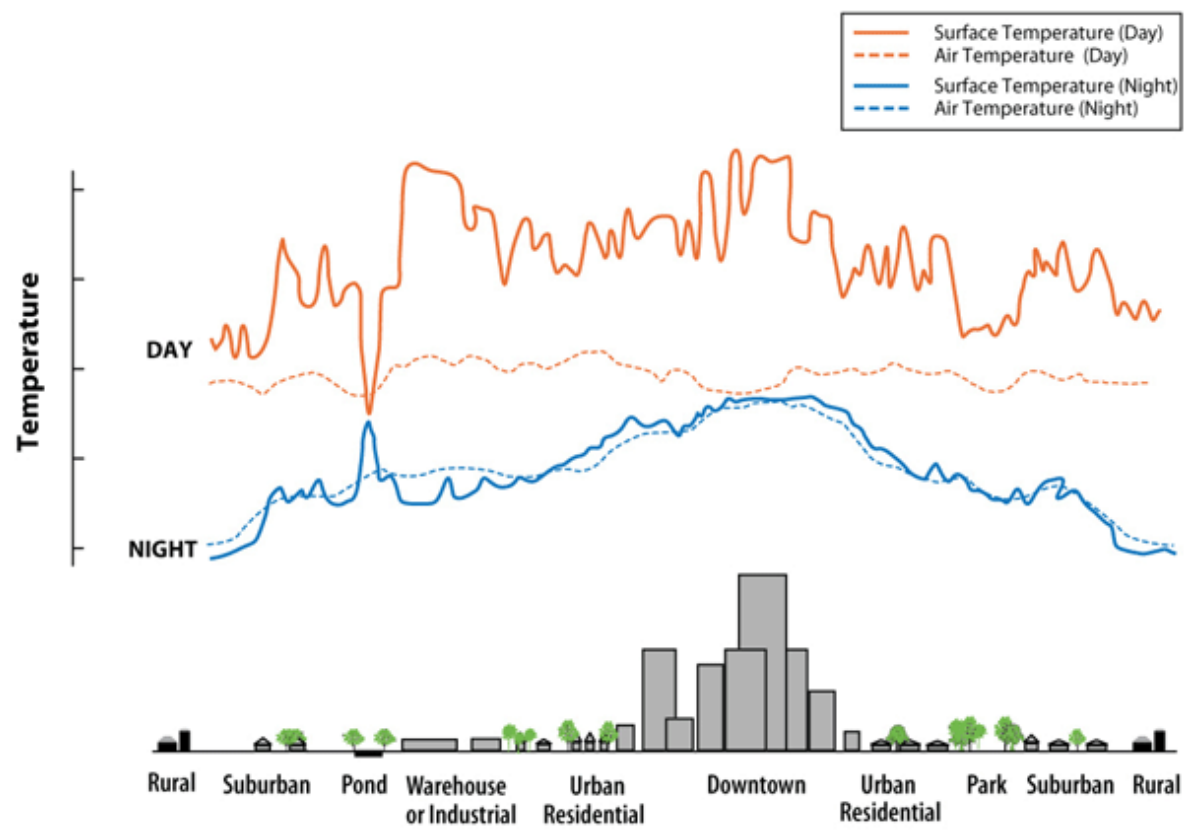

La diferencia de temperatura del aire entre las ciudades y las zonas rurales no es tan elevada como la de la temperatura superficial, quedándose en una diferencia alrededor de los $3^{\circ} \mathrm{C}$. Las zonas rurales o poco urbanizadas pueden enfriarse más fácilmente que las áreas densamente construidas, efecto muy evidente en las noches claras y poco ventiladas. El efecto de la isla de calor atmosférica no se manifiesta hasta el atardecer y es más importante por la noche que por el día. En algunos casos puede no alcanzar su pico máximo hasta el amanecer ${ }^{269}$.

El control de las condiciones micro climáticas urbanas es fundamental tanto para la eficiencia energética y la reducción de las emisiones, como para garantizar espacios de vida confortables para los ciudadanos. Esas condiciones pueden mejorar o empeorar la experiencia y el uso que se hace del mismo. El problema del enfriamiento de los edificios en los climas cálidos es muy importante, ya que puede suponer un consumo energético y unas emisiones superiores a los producidos por la calefacción.

Tumini, recoge varias referencias al confort en los espacios urbanos y el clima con la arquitectura, Jan Gehl (1987) afirma que el bienestar de los espacios depende de la protección ofrecida a las condiciones climáticas negativas y la exposición a las positivas. Asimismo, Ralph Erskine (1988) define los espacios sociales como el lugar para el desarrollo de las actividades espontáneas, fuertemente influenciado por las condiciones climáticas, y Finnish Reima Pietila (1988) habla de la arquitectura y el clima como una "pareja dinámica".
266 Oke, T. R. (1987)

Boundary layer climates. 2nd.

Methuen, 289p.

${ }^{267}$ Satterthwaite, D.

Cities contribution to global warming: Notes on the allocation

of green house gas emissions.

Environment and Urbanization 2008 20 (2): 539-49.
Fig 80. Isla de calor urbano. Variación de la temperatura superficial y atmosférica ${ }^{268}$

Fuente: Reducing Urban Heat Island: Compendium of Strategies, Eva Wong.

268 Wong, E., Akbari, H., Bell, R., \& Cole, D. (2011).

Reducing urban heat islands: compendium of strategies.

Environmental Protection Agency, retrieved May, 12, 2011.

269 Wong, E. (2002).

The US Environmental Protection Agency's Heat Island Reduction Initiative (HIRI):

Status and Future Directions. US Environmental Protection Agency, $1-11$. 
270 Tumini, I. (2010).

Estrategias para reducción del efecto isla de calor en los espacios urbanos.

Estudio aplicado al caso de Madrid.

Ponencia SB10 MAd, Edificación sostenible, Revitalización y Rehabilitación de Barrios. Madrid, España.

271 Perez-Lombard, L., Ortiz, J.,

Pout, C. (2008).

A review on buildings energy consumption information.

Energy Building, 40 (3): 394-398, doi: http://dx.doi.org/10.1016/j.enbuild. 2007.03.007.

${ }^{272}$ Santamouris, M. (2007). Heat island research in Europe The state of the art. Journal Advances Building Energy Research, 1 (1): 123-150, doi: http://dx.doi.org/10.1080/ 17512549.2007 .9687272

${ }^{273}$ Mirzaei, P., Haghighat, F. (2010). Approaches to study urban heat island Abilities and limitations. Building and Environment,45 (10): 2192-2201, doi: http://dx.doi.org/ 10.1016/ j.buildenv.2010.04.001.

${ }^{274}$ Akbari, H., Davis, S., Dorsano, S., Huang, J., \& Winnett, S. (1992).

Cooling our communities. US Environmental Protection Agency, Report\# PM-221/22p-200

275 Hassid, S., Santamouris, M., Papanikolaou, N., Linardi, A., Klitsikas, N., Georgakis, C.,

\& Assimakopoulos, D. N. (2000). The effect of the Athens heat island on air conditioning load. Energy and Buildings, 32(2), 131-141.

276 Kolokotroni, M., Zhang, Y., \& Watkins, R. (2007) The London Heat Island and building cooling design. Solar Energy, 81(1), 102-110.

277 Sobrino, J. A. DESIREX 2008 Urban heat island analysis in the City of Madrid. Revista de teledetección. ISSN: 1988-8740. 2009. 31: 80-92.

${ }^{278}$ Kondo, H., \& Kikegawa, Y. (2003)

Temperature variation in the urban canopy with anthropogenic energy use. In Air Quality (pp. 317-324).

Birkhäuser Basel
En las últimas décadas el consumo para la refrigeración se ha disparado, sobre todo en las ciudades europeas. Hay que tener en cuenta que los sistemas de aire acondicionado usan energía eléctrica, lo que crea importantes problemas en el suministro energético, además de traducirse en un aumento de las emisiones de gases de efecto invernadero, de los contaminantes como los óxidos de azufre $\left(\mathrm{SO}_{x}\right)$, el monóxido de carbono (CO), los óxidos de nitrógeno $\left(\mathrm{NO}_{x}\right)$ y las partículas volátiles (PM) producidas por la plantas de generación. En los veranos más calurosos hemos podido asistir a repetidos cortes de suministro energético, debido a la enorme demanda en las horas pico ${ }^{270}$.

La urbanización influye en la alteración antropogénica del clima en el que se desarrolla una ciudad, y genera un efecto isla de calor urbana (ICU). La ICU afecta, tanto directa como indirectamente, el consumo de energía, la habitabilidad y la calidad del aire de las ciudades $271,272,273$. Además de la incomodidad térmica, las islas de calor favorecen la formación del smog fotoquímico y aumentan la carga de uso del aire acondicionado, aumentando a su vez el consumo de energía. En el Lawrence Berkeley National Laboratory el grupo de estudio del efecto isla de calor comprobó que la producción de smog en la ciudad de Los Ángeles aumentaba un 5\% por cada grado de temperatura de aumento a partir de los $22^{\circ} \mathrm{C}^{274}$.

Hassid et al. ${ }^{275}$, indican que, enn la estimación del aumento de consumo debido a la ICU hay dos efectos importantes a tener en cuenta: el aumento de la potencia para alcanzar las condiciones de confort y el tiempo de uso de los sistemas de refrigeración. En presencia del efecto ICU, la dispersión diferida del calor acumulado en el día aumenta el tiempo de uso de los sistemas de aire acondicionado, pasando por ejemplo de 8 a 12 horas. El incremento de la temperatura, sobre todo en las horas pico, hace que sean necesarios equipos más potentes y en consecuencia de mayor coste ${ }^{275}$.

Kolokotroni et al., analizaron el efecto isla de calor en Londres. Se comprobó por un lado que la demanda energética en los sistemas de refrigeración fue un $25 \%$ mayor en la ciudad que en el campo y por otro lado que la demanda en sistemas de calefacción disminuyó en un $22 \%$. El resultado es un mayor uso de los sistemas de refrigeración, lo cual tiene un impacto negativo tanto a nivel económico, como en el medio ambiente. Las mediciones de temperaturas mostraron que las temperaturas del aire eran hasta 7 grados Kelvin más altas durante la noche en la ciudad, respecto de las de fuera de la ciudad ${ }^{276}$.

En Madrid, DESIREX 2008 mostró que ese aumento era de hasta de 5 grados Kelvin ${ }^{277}$.

Kondo y Kikegawa estimaron que la sensibilidad a la temperatura de la demanda máxima de electricidad sería de 6,6\% por cada grado centígrado para la zona más densamente urbanizada de Tokio ${ }^{278}$ (la ciudad más grande del mundo con una aglomeración de 38 millones de habitantes). 
En Atenas, Grecia, de acuerdo a las mediciones climáticas realizadas en 30 estaciones urbanas y suburbanas durante el verano de 1997, se encontró que la intensidad de la Isla de Calor estaba cerca de los $10^{\circ} \mathrm{C}^{279,280}$.

La temperatura en las áreas urbanas varía en función de la radiación solar incidente que es absorbida por las superficies de las ciudades. Cubiertas, fachadas de edificios, calles, plazas, etc. representan una importante masa de acumulación de calor, volviendo a emitirlo al ambiente en forma de radiación de onda larga y con un desfase en el tiempo. La intensidad de las ondas depende, entre otras cosas de las características de los materiales, así como el albedo, de la emisividad y de la inercia térmica ${ }^{281}$.

Bascon et al., señalan que, muchas áreas urbanas y suburbanas presentan temperaturas más elevadas que aquellas zonas rurales adyacentes. Esta diferencia de temperatura es lo que se conoce por isla de calor urbano. La media anual de las temperaturas de una ciudad de un millón de habitantes puede ser de 1 y $3^{\circ} \mathrm{C}$ más altas que las que se registrarían en sus alrededores. Sin embargo en una noche clara, con vientos en calmas esta diferencia de temperatura puede alcanzar los $12^{\circ} \mathrm{C}$. Incluso ciudades más pequeñas pueden experimentar estos fenómenos, si bien este efecto es proporcional al tamaño de la ciudad ${ }^{282}$.

Hoy en día, en la UE-28, el consumo de energía primaria en el entorno construido representa aproximadamente el $40 \%$ del consumo total de energía de la UE. La calefacción y la refrigeración representan el $40 \%$ de la demanda final de energía en el sector residencial. La demanda de electricidad se espera que aumente, debido al uso creciente de electrodomésticos, la demanda de refrigeración y el número de hogares. Los edificios comerciales son un entorno basado en la demanda de electricidad (que representa más del $33 \%$ del consumo de energía primaria). El calor es un factor menor aquí; Lo que se requiere es principalmente el enfriamiento. Por lo tanto, existe un gran potencial de ahorro energético al minimizar la demanda de energía para la calefacción y refrigeración de los edificios residenciales y comerciales ${ }^{283}$.

La demanda energética en refrigeración para los edificios ha aumentado de forma exponencial en las últimas dos décadas, pasando de 6 TJ en 1990 a $160 \mathrm{TJ}$ en $2010^{284}$.

Balaras et al., mencionan que dependiendo de la zona climática, es probable que la demanda energética de los sistemas de refrigeración aumente entre un 50 y un $90 \%$ de aquí a final de siglo ${ }^{285}$.

Diversos investigadores comenzaron a estudiar a mediados de la década de los 80 el impacto de los materiales con una alta reflectancia o albedo en las envolventes de los edificios, a fin de valorar su influencia para reducir el efecto isla de calor. Los "cool materials" o materiales fríos, se caracterizan por una alta reflectancia solar y alta emisividad. Debido a que reflejan la mayor parte de la radiación solar incidente al cielo, se calientan menos y por tanto trasmiten menos calor al interior de los edificios si forman la envolvente, reduciendo la demanda energética para el acondicionamiento interior de los edificios.
279 Santamouris, M. (2009).

Group Building Environmental Studies, Physics Department, University of Athens, Greece. Green Cities, 108

${ }^{280}$ Levinson, R., Berdahl, P.,

\& Akbari, H. (2005).

Solar spectral optical properties of pigments-Part l: model for deriving scattering and absorption coefficients from transmittance and reflectance measurements. Solar energy materials and solar cells, 89(4), 319-349..

${ }^{281}$ Gray, K. A., \& Finster, M. E. (1999).

The urban heat island,

photochemical smog, and Chicago: Local features of the problem and solution. Northwestern University, Department of Civil Engineering.

282 Bascón, P. D. (2002).

Clima regional y microclimas urbanos en la provincia de Córdoba. Universidad de Córdoba.

283 Buildings, E. E. (2009). PPP Research Priorities for the Definition of a Multi-annual Roadmap and Longer Term Strategy. Ad-hoc Industrial Advisory Group Energy-efficient Buildings PPP.

http://www.ectp.org/cws/params/ ectp/download_files/36D1191v1_EeB_

Roadmap.pdf

284 Balaras, C. A., Grossman, G., Henning, H. M., Ferreira, C. A. I., Podesser, E., Wang, L.,

\& Wiemken, E. (2007)

Solar air conditioning in Europe-an overview. Renewable and sustainable energy reviews, 11(2), 299-314.

284 Roetzel, A., \& Tsangrassoulis, A. (2012). Impact of climate change on comfort and energy performance in offices. Building and environment, 57, 349-361. 
${ }^{286}$ Taha, H., Sailor, D.,
\& Akbari, H. (1992).

High-albedo materials for reducing building cooling energy use (No. LBL-31721).

Lawrence Berkeley Lab., CA (United States).

${ }^{287}$ Berdahl, P. (1995).

Building energy efficiency and fire safety aspects of reflective coatings. Energy and buildings, 22(3), 187-191.

288 Simpson, J. R., \& McPherson, E. G. (1997). The effects of roof albedo modification on cooling loads of scale model residences in Tucson, Arizona. Energy and Buildings, 25(2), 127-137.

${ }^{289}$ Akbari, H., Bretz, S., Kurn, D. M., \& Hanford, J. (1997).

Peak power and cooling energy savings of high-albedo roofs. Energy and Buildings, 25(2), 117-126.

290 Synnefa, A., Santamouris, M., \& Akbari, H. (2007).

Estimating the effect of using cool coatings on energy loads and thermal

comfort in residential buildings in various climatic conditions. Energy and Buildings, 39(11), 1167-1174.

291 Santamouris, M., Synnefa, A., Kolokotsa, D., Dimitriou, V., \& Apostolakis, K. (2008).

Passive cooling of the built environment-use of innovative reflective materials to fight heat islands and decrease cooling needs. International Journal of Low-Carbon Technologies, 3(2), 71-82.

292 Levinson, R., \& Akbari, H. (2010). Potential benefits of cool roofs on commercial buildings: conserving energy, saving money, and reducing emission of greenhouse gases and air pollutants. Energy Efficiency, 3(1), 53.
La selección de materiales de gran albedo en las superficies urbanas es, una medida de bajo costo que puede reducir en verano la temperatura ambiente en las ciudades. El uso de estos materiales en el entorno urbano contribuye en cierta medida a que las temperaturas de las superficies que tienen los intercambios térmicos con el ambiente sean más bajas $286,287,288$.

En Sacramento, California, Akbari et al., confirmó que utilizando un material con un albedo alto como revestimiento para la cubierta, varios edificios tenían ahorros de la del $40-50 \%$ en demanda energética para refrigeración y reducción de un 30-40\% del pico de demanda ${ }^{289}$.

Synnefa et al., tuvieron resultados que muestran que el aumento de la reflectancia solar del techo reduce las cargas de refrigeración en un 18-93\% y el pico de demanda de refrigeración en edificios con aire acondicionado en un $11-27 \%$. Para el caso estudiado, la penalización por la pérdida que supone esa absorción de calor en la necesidad de calefacción se estimó en $\left(0,2-17 \mathrm{kWh} / \mathrm{m}^{2}\right.$ año), lo cual fue menos importante que la reducción de la carga de refrigeración $\left(9-48 \mathrm{kWh} / \mathrm{m}^{2} \text { año }\right)^{290}$.

De acuerdo con Santamouris et al., sus resultados arrojaron que la reducción de la demanda de energía por la disminución de las necesidades de refrigeración variaba entre $10-40 \mathrm{kWh} / \mathrm{m}^{2}$ año ${ }^{291}$.

Una de las aplicaciones en construcción de los "cool materials" en la envolvente, son los denominadas "cool roofs" o "cubiertas frías". Según Levinson et al., estos materiales reducen el flujo de energía que entra en un edificio a través de la cubierta. Son tres las propiedades del material utilizado como revestimiento de la cubierta que afectan a este flujo: la reflectancia solar, la emisividad infrarroja y el aislamiento térmico. La reflectancia solar es el porcentaje de la radiación solar que se refleja en la zona del espectro entre 300 y 2500 nm, reduciendo así la energía solar que absorbe la cubierta. Cuando una superficie absorbe la radiación solar esa energía se transforma en calor, y parte de este calor se emite de nuevo en forma de radiación infrarroja según la propiedad de emisividad del material entre 400 y 8000 $\mathrm{nm}$. Por lo tanto, una cubierta que tenga como revestimiento un material con una alta reflectancia solar y una alta emisión de infrarrojos absorberá menos energía y será más frío que una cubierta que no lo utilice ${ }^{292}$.

Si la superficie de la cubierta tiene una temperatura más baja, menos energía penetrará en el edificio en forma de calor, reduciéndose la demanda de energía para enfriar el espacio con equipos de aire acondicionado y ahorrando energía eléctrica. No todo el calor absorbido por el techo se transmitirá al edificio: el aislamiento es la propiedad que determina qué cantidad de esa energía puede, entrar o salir, a través de la envolvente. El aislamiento es la medida más eficaz para reducir la demanda de refrigeración y calefacción, aunque depende de la naturaleza del material. Normalmente es bastante costoso mejorarlo, ya que los cambios estructurales pueden ser por adición, por cambio del aislamiento o por la solución constructiva preexistente de la envolvente. La reflectancia solar puede ser controlada 
eligiendo el tipo de revestimiento, el material, generalmente cambiando el color de la superficie o utilizando materiales alta reflectancia.

Miller et al., concluyen que, en climas calurosos o suaves, la selección de materiales con una alta emisividad en la zona infrarroja del espectro es una manera eficaz para soltar la energía en forma de calor absorbido del sol, y evitar que se transmita al interior del edificio. Se consigue así reducir la demanda energética en edificios con instalaciones de aire acondicionado para refrigerar los espacios interiores, o condiciones térmicas más confortables si el edificio no tiene aire acondicionado. En zonas de climas fríos con veranos cálidos, también son aconsejables materiales de alta emisividad, ya que la penalización en calefacción durante el resto del año compensará el gasto en refrigeración durante la época cálida.

En climas fríos, las cubiertas o envolventes frías no están recomendadas porque no compensa el gasto extra en calefacción que el ahorro en refrigeración. En estos casos mejorar el aislamiento probablemente sea la mejor inversión ${ }^{46}$.

Según Gago et al., El criterio de selección de materiales en las ciudades puede realizarse en base a una serie de propiedades que contribuyen de forma positiva a la formación de la isla de calor urbano. Estas propiedades son: la capacidad que tienen los materiales para reflejar la la radiación solar, conocida como albedo/reflectancia, la emisividad térmica y la capacidad calorífica. Conociendo estas características se puede determinar cuanta energía procedente del sol es reflejada, emitida y absorbida en una ciudad, según Gago, et al. Si se aumenta el coeficiente de albedo, es posible lograr ahorros de consumo energético directo del $20-70 \% 294$.

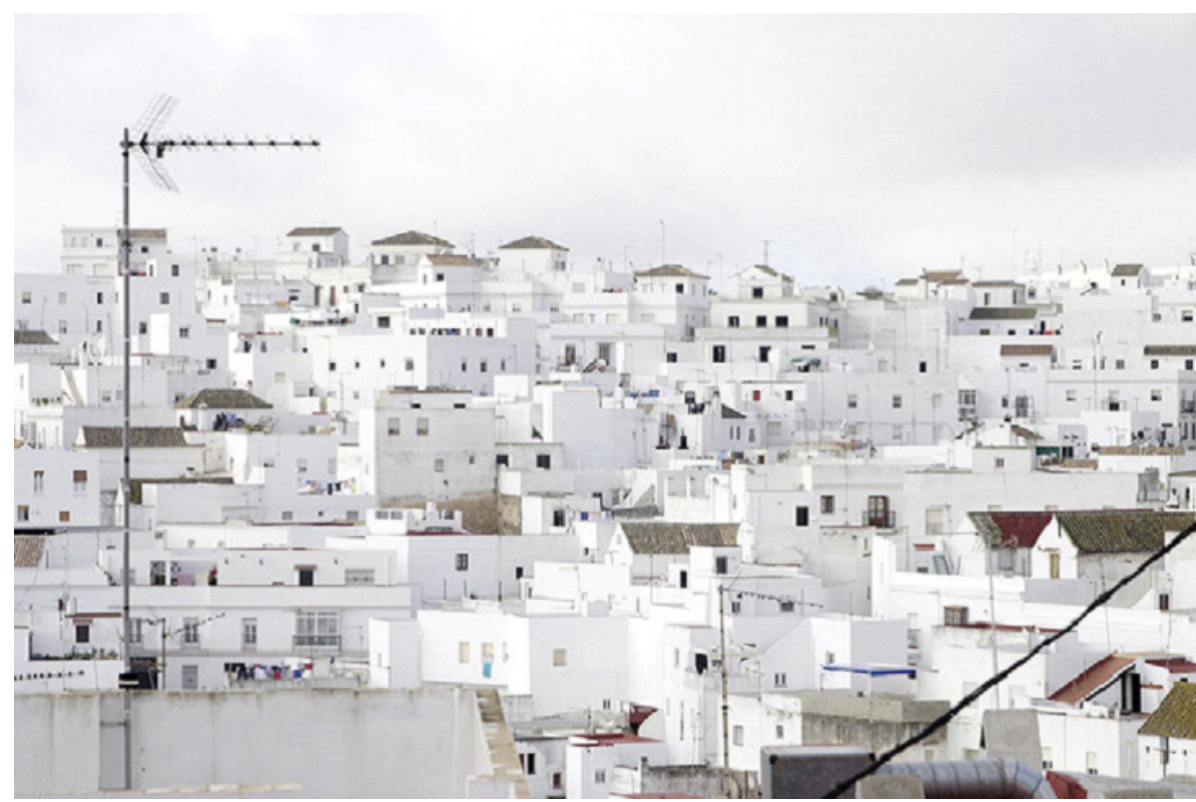

Boixo et al., recogen en sus conclusiones queel uso de materiales de alta reflectancia en las cubiertas es un método económico de ahorro de energía y de mejora del nivel de confort en el interior de los edificios en climas suaves y cálidos. Una aplicación a gran escala de esta técnica puede ayudar
${ }^{293}$ Miller, W. A., Parker, D. S., \& Akbari, H. (2004)

Painted metal roofs are energy-efficient, durable and sustainable. In Performance of Exterior Envelopes of Whole Buildings, IX International Conference, Clearwater, FL.

294 Gago, E. J., Roldan, J., Pacheco-Torres, R., \& Ordoñez, J. (2013).

The city and urban heat islands: A review of strategies to mitigate adverse effects. Renewable and Sustainable Energy Reviews, 25, 749-758.

Fig 81. Vista de las fachadas en Vejer de la Frontera horizontal. Fuente: Panoramio 
295 Boixo, S., Diaz-Vicente, M., Colmenar, A., \& Castro, M. A. (2012). Potential energy savings from cool roofs in Spain and Andalusia. Energy, 38(1), 425-438.758.

${ }^{296}$ Rosenfeld, A. H., Romm, J. J., Akbari, H., Pomerantz, M. \& Taha, H. (1996, August)

Policies to reduce heat islands: magnitudes of benefits and incentives to achieve them. In Proceedings of the 1996 ACEEE summer study on energy efficiency in buildings (Vol. 9, p. 177).

297 Santamouris, M., Papanikolaou, N., Livada, I., Koronakis, I., Georgakis, C., Argiriou, A., \& Assimakopoulos, D. N. (2001).

On the impact of urban climate on the energy consumption of buildings. Solar energy, 70(3), 201-216.

298 Rosenfeld, A. H., Akbari, H., Bretz, S., Fishman, B. L., Kurn, D. M., Sailor, D., \& Taha, H. (1995) Mitigation of urban heat islands: materials, utility programs, updates. Energy and buildings, 22(3), 255-265.

299 Rosenfeld, A. H., Akbari, H., Romm, J. J., \& Pomerantz, M. (1998). Cool communities: strategies for heat island mitigation and smog reduction. Energy and Buildings, 28(1), 51-62.

300 Taha, H. (1997).

Urban climates and heat islands: Albedo, evapotranspiration, and anthropogenic heat. Energy and buildings, 25(2), 99-103. a reducir la contaminación y reducir así como los picos de demanda de energía. La implantación a gran escala de techos fríos en Andalucía puede ahorrar $295.000 \mathrm{kWh}$ al año, un $2 \%$ del consumo total de electricidad en el sector residencial, considerando únicamente edificios residenciales con cubiertas planas. Lo cual se traduce en un ahorro de 2 euros $/ \mathrm{m}^{2}$. También se consiguen ahorros de entre 7,4 y $11 \%$ en Madrid. Con los precios actuales de la energía eléctrica, se podrían ahorrar 59 millones de euros al año y se evitaría la emisión de 136.000 toneladas de CO2 al año al no tener que producir esa electricidad ${ }^{295}$.

Akbari et al. ${ }^{296}$, continúan con esta línea de investigación, también Santamouris et al. ${ }^{297}$, señalando en sendas publicaciones que entre los factores que contribuyen al efecto de isla de calor urbana, las propiedades térmicas de los materiales utilizados en el tejido urbano juegan un papel muy importante. Las superficies de color, especialmente las cubiertas y los pavimentos, absorben la radiación solar durante el día y lo liberan en forma de calor durante la noche.

Rosenfeld et al., señalan que si la envolvente absorbe la energía solar recibida ese aumento, genera una demanda de refrigeración del edificio. Concluyen que, aumentando el albedo de las superficies de la envolvente se obtendría un ahorro directo en energía de un 20 a un 40\%. Para una vivienda unifamiliar, variando el albedo de los materiales de la envolvente, fachada y cubierta, obtuvieron ahorros de energía de hasta un $40-50 \%{ }^{298}$.

En otro trabajo Rosenfeld et al., relacionaron contaminación atmosféricatemperatura y determinaron que estos materiales también contribuyen a reducir la formación de smog, relacionándolo con el albedo y cómo por encima de los $22^{\circ} \mathrm{C}$ de temperatura se produce un aumento de la generación de ozono ${ }^{299}$.

Taha demostró que el uso de materiales de alto albedo, alta reflectancia, disminuye la radiación solar absorbida por la envolvente del edificio y las estructuras urbanas, consiguiendo que la temperatura del aire sea menor. Al mantener estas superficies más frías. La conclusión a la que se llega es que las temperaturas del aire en torno a la envolvente, en los días de verano pueden bajar hasta $4^{\circ} \mathrm{C}$, simplemente modificando el albedo de superficie de 0,25 a 0,40, en un clima cálido de latitud media ${ }^{300}$.

Alchapar et al., exponen que la mayoría de los materiales de construcción tienen baja reflectancia solar en comparación con los materiales naturales. Debido a que los materiales que componen las envolventes urbanas son responsables de la interacción entre el edificio y el medio ambiente, afectan tanto el consumo de energía para el acondicionamiento térmico de los edificios como las temperaturas de la ciudad. La selección adecuada de las envolventes contribuye a disminuir las temperaturas de la ciudad. A partir de los resultados obtenidos se podría inferir que en términos de intervención, mejorar la reflectancia solar (albedo) de los materiales ofrece mayores posibilidades de reducir las cargas térmicas en las envolventes de 
la ciudad. Los resultados de su investigación revelan que, aunque el color es una variable determinante de las prestaciones térmicas superficiales de un material su comportamiento puede ser mejorado o empeorado por otras características como son: el tipo de acabado, composición y envejecimiento. A igualdad de color, estas características pueden modificar la temperatura superficial de un material entre 20 y $29^{\circ} \mathrm{C}$. Una variable que debe ser considerada es la resistencia de los materiales al envejecimiento. La capacidad reflectiva de los materiales disminuye considerablemente con el paso del tiempo. Sólo el 30 \% de los materiales del estudio, consigue una SRI superior al $50 \%$ después de 3 años de exposición. A escala urbana, la aplicación de esta estrategia de enfriamiento permitiría reducir hasta $3^{\circ} \mathrm{C} \mathrm{la}$ temperatura del aire $12^{\circ} \mathrm{C}$ la temperatura de las superficies en la ciudad ${ }^{301}$.

Felipe Fernández, señala que las previsiones del IPCC (Intergovernmental Panel on Climate Change), indican un aumento térmico general que, en algunas zonas como el área mediterránea serán más acusadas durante el periodo cálido. Esto, unido al efecto de isla de calor urbano determina que en la ciudad las olas de calor sean más intensas y duraderas, aumenta el riesgo de mortalidad y morbilidad en esas áreas ${ }^{302}$.

El ejemplo de Madrid es bastante representativo, como se muestra en la figura, donde se han representado las temperaturas máximas registradas en una zona urbana y otra periurbana, durante la ola de calor de julio y agosto del año 2003. Las dos curvas que aparecen en el gráfico corresponden a la temperatura fisiológica, que no es más que un índice de estrés térmico resultante de la acción combinada de la temperatura del aire, la emitida por el asfalto y los edificios, la humedad y el viento ${ }^{303}$.

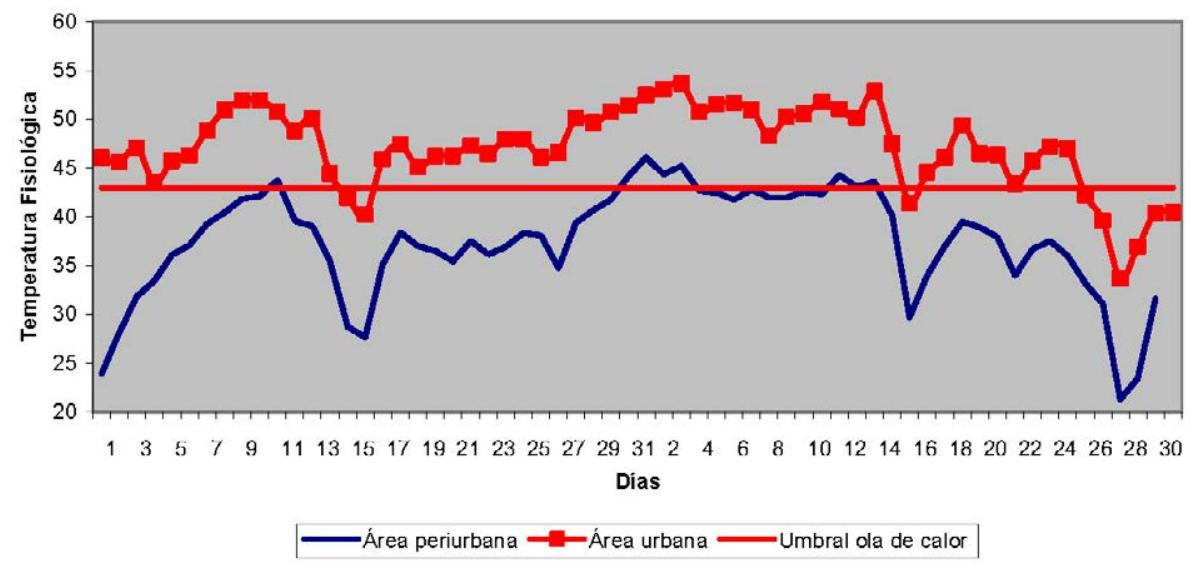

En las ciudades, las fachadas son el sistema constructivo con mayor incidencia en la demanda energética ${ }^{304}$. Por esta razón, desde la crisis energética de los años 70, se han implementado diferentes materiales y sistemas para mejorar la resistencia térmica de la fachada. Según Barbero et al., a pesar de que es posible reducir entre $24 \%$ y $89 \%$ el flujo de calor a través de las propiedades del revestimiento, apenas se han estudiado sus propiedades térmicas ${ }^{305}$.
${ }^{301}$ Alchapar, N., Correa, E. (2015)

Reflectancia solar de las envolventes opacas de la ciudad y su efecto sobre las temperaturas urbanas.

Informes de la Construcción, 67(540): e112. https://doi.org/10.3989/ic.14.131.

302 García, F. F. (2007).

Impactos del cambio climático en las áreas urbanas y rurales. Boletín de la Institución Libre de Enseñanza, (66-67).

${ }^{303}$ Fernández García, F.,

\& Rasilla Álvarez, D. (2008).

Olas de calor e influencia urbana en

Madrid y su área metropolitana.

Estudios Geográficos, LXIX(265),

495-518. doi:10.3989/estgeogr.0440.
Fig 82. Temperatura fisiológica en Madrid y su área metropolitana durante los meses de julio y agosto de 2003.

${ }^{304}$ Luxán García de Diego, M.,

Vázquez Espí, G., Gómez Muñoz, E., Román López, M.M., Barbero Barrera.

Actuaciones con criterios de sostenibilidad en la rehabilitación de viviendas en el centro de Madrid, Empresa Municipal de la Vivienda y Suelo, Madrid, 2009.

${ }^{305}$ Barbero-Barrera, M. M., Campos-Acosta, J., \& Neila-González, F. J. (2014).

Reflectance properties analysis of mineral based mortars for renders: Research of their energy performance. Energy and Buildings, 76, 615-621. 
306 Doulos, L., Santamouris, M., \& Livada, I. (2004) Passive cooling of outdoor urban spaces. The role of materials. Solar energy, 77(2), 231-249.

${ }^{307}$ Akbari H. Energy saving potentials and air quality benefits of urban heat island mitigation. Lawrence Berkeley National Laboratory; 2005 [LBNL- 58285].
Fig 83. Imágenes infrarroja (b) imágenes visibles de cuatro tejas de hormigón pintadas con recubrimientos blancos "fríos" (1 y 4), un recubrimiento negro (2) y una sin pintar (3).
Tumini et al., sostiene que los espacios los espacios demasiado soleados y calurosos son abandonados por los usuarios que buscarán en otros sitios, interiores y dotados de sistemas de refrigeración, ocio y descanso. Por su parte, las calles y plazas vacías, además de perjudicar la calidad urbana, crean problemas a la economía de los comercios que desarrollan sus actividades en la ciudad. Sin embargo, espacios acogedores con la justa proporción entre sombra y sol, temperatura confortable y ventilación adecuada, pueden atraer a los usuarios para volver a ocupar los espacios exteriores ${ }^{270}$.

Doulos et al., estudiaron muestras de pavimentos utilizados habitualmente en exteriores, en espacios urbanos con el objetivo de ver su influencia en la temperatura ambiente y combatir el efecto de isla de calor. Midieron las variaciones en la temperatura superficial que se atribuyen a los diferentes valores de albedo de cada muestra. Confirmando que las superficies rugosas y oscuras, tienden a absorber más radiación solar que las superficies lisas, y de color claro ${ }^{306}$.

El uso de estos materiales en el entorno urbano contribuye a que las temperaturas de la superficie sean más bajas disminuyendo el consumo energético necesario para refrigeración, ese ahorro energético se ha cifrado en ${ }^{307}$ :

\section{$12-25 \%$ en oficinas}

\section{$5-18 \%$ en locales comerciales}

\section{$7-17 \%$ en viviendas}

Synnefa et al. ${ }^{2}$, Comprobaron que un recubrimiento "frío" o cool material puede conseguir que la temperatura de la superficie de una pieza de hormigón blanco tratada sea en verano inferior en $4^{\circ} \mathrm{C}$ y en $2^{\circ} \mathrm{C}$ durante la noche. Durante el día tener una temperatura superior al ambiente solo $2^{\circ} \mathrm{C}$ y para tener durante la noche una temperatura inferior de hasta $5,9^{\circ} \mathrm{C}$ que la temperatura ambiente ${ }^{62,102}$. La diferencia en la reflectancia solar traduce en una diferencia significativa en la temperatura de la superficie.
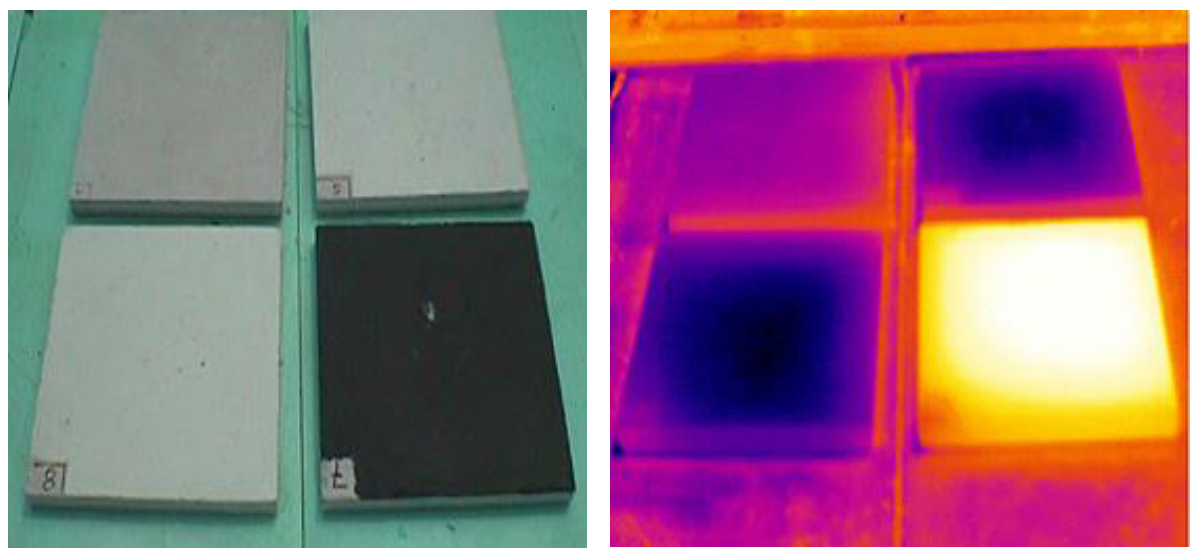


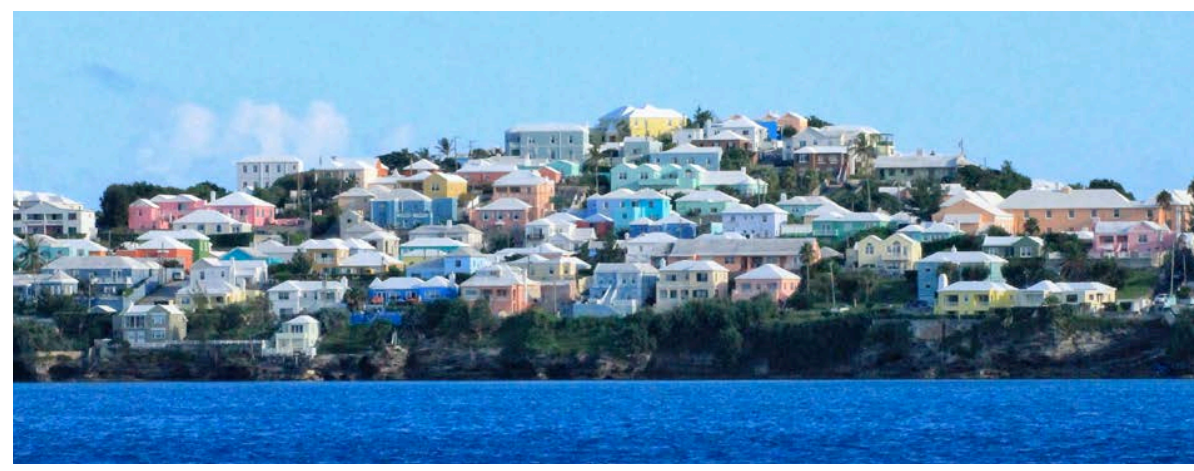

Que una cubierta esté acabada en color blanco puede no ser aceptado socialmente por razones estéticas. Sin embargo, en algunos lugares, como las Islas Bermudas, los tejados de color blanco dominan el paisaje.

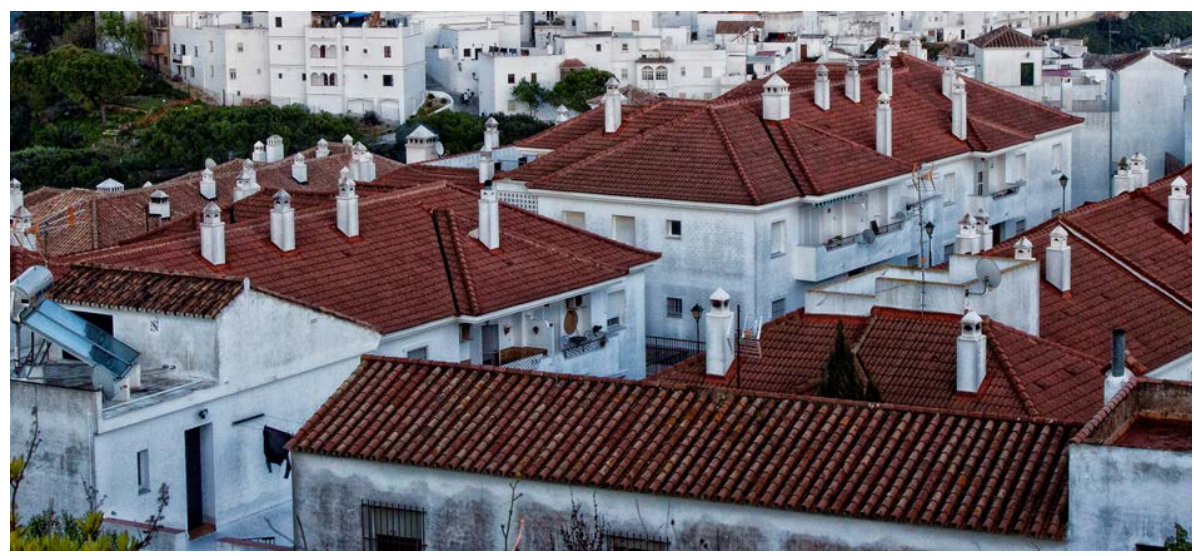

Levinson et al. ${ }^{308,309}$, han investigado en el desarrollo de nuevos revestimientos con el objetivo de aumentar la reflectancia solar. Otros autores ${ }^{310,311}$ han centrado sus investigaciones en materiales coloreados que utilizan pigmentos que reflejan la radiación infrarroja cercana o NIR, comprobando que también reducen significativamente las temperaturas superficiales.

La reflectancia solar disminuye debido a la exposición a la intemperie y al envejecimiento de los materiales. Brezt y Akbari, estimaron que el ahorro de energía de refrigeración a largo plazo sería un $20 \%$ menor que el ahorro del primer año, un $64 \%$ de ahorro de la demanda debida a necesidades de refrigeración, debido a un cambio en el albedo por la acumulación de suciedad $^{312}$. El desgaste no afecta a la emisión térmica ${ }^{313}$.

Esto supone un serio problema para estos materiales utilizados en envolventes y pavimentos reflectantes, ya que conlleva una pérdida del rendimiento esperado. Algunos autores han comprobado que las temperaturas de la superficie muestran ya una tendencia creciente 2,5 meses después estar colocadas. Los datos experimentales publicados sugieren que la perdida de reflectancia es debida al polvo, a la radiación UV, al crecimiento de hongos y líquenes, lluvia ácida, filtraciones de agua, condensaciones, viento y la acumulación de biomasa. Otras investigaciones demuestran que las partículas conocidas como partículas finas, inquemados, hollin y otros contaminantes, son una de las causas principales de pérdida de reflectancia ${ }^{314,315}$.
Fig 84. Viviendas en las Islas Bermudas 2010. Fuente: Flickr, Vadim Klochko.

${ }^{308}$ Levinson, R., Akbari, H., Berdahl, P., Wood, K., Skilton, W.

\& Petersheim, J. (2010)

A novel technique for the production of cool colored concrete tile and asphalt shingle roofing products.

Solar Energy Materials and Solar Cells, 94(6), 946-954.

${ }^{309}$ Levinson, R., Berdahl, P., Akbari, H., Miller, W., Joedicke, I., Reilly, J., ..

\& Vondran, M. (2007)

Methods of creating solar-reflective nonwhite surfaces and their application to residential roofing materials

Solar Energy Materials and Solar Cells, 91(4), 304-314.

Fig 85. Cubiertas en Vejer de la Frontera. Fuente: Flickr.

310 Synnefa, A., Santamouris, M., \& Apostolakis, K. (2007).

On the development, optical properties and thermal performance of cool colored coatings for the urban environment.

Solar Energy, 81(4), 488-497.

311 Synnefa, A., Saliari, M.

\& Santamouris, M. (2012)

Experimental and numerical assessment of the impact of increased roof reflectance on a school building in Athens. Energy and Buildings, 55, 7-15.

312 Bretz, S. E., \& Akbari, H. (1997) Long-term performance of high-albedo roof coatings. Energy and Buildings, 25(2), 159-167.

313 Petrie, T. W., Atchley, J. A.,

Childs, P. W., \& Desjarlais, A. O. (2001) Effect of Solar Radiation Control on Energy Costs-A Radiation Control Fact Sheet for Low-Slope Roofs.

Proceedings, Performance of the Exterior Envelopes of Whole Buildings VIII: Integration of Building Envelopes.

314 Synnefa, A., Santamouris, M.,

\& Livada, I. (2006)

A study of the thermal performance of reflective coatings for the urban environment. Solar Energy, 80(8), 968-981.VIII: Integration of Building Envelopes.

${ }^{315}$ Levinson, R., \& Akbari, H. (2002) Effects of composition and exposure on the solar reflectance of portland cement concrete. Cement and Concrete

Research, 32(11), 1679-1698. 
316 Berdahl, P., \& Bretz, S. E. (1997) Preliminary survey of the solar reflectance of cool roofing materials. Energy and Buildings, 25(2), 149-158.

${ }^{317}$ Bretz, S. E., \& Akbari, H. (1994) Durability of high-albedo roof coatings and implications for cooling energy savings. Final report (No. LBL--34974). Lawrence Berkeley Lab., CA (United States).
Berdahl et al., ha utilizado $\mathrm{TiO}_{2}$-rutilo, la forma sin propiedades fotocatalíticas, como pigmento blanco, comprobando en su estudio que las superficies que utilizan esos recubrimientos muestran buena capacidad reflectante como era esperar ${ }^{316}$.

Un adecuado mantenimiento en una cubierta convencional podria recuperar hasta un $90 \%$ de la reflectancia original, mostrando que la mayor parte de la degradación es causada principalmente por la acumulación de suciedad pero, los costes asociados a ese mantenimiento no son rentables si sólo se consideran los ahorros en refrigeración ${ }^{317}$. 


el conocimiento en relacion al campo del conocimiento estudiado.

El análisis nos permite situar esta tesis doctoral en esta parcela del conocimento 
INFLUENCIA DEL COLOR Y ELACABADO SUPERFICIALEN LAS PROPIEDADES DE UN MORTERO FOTOCATALITICO COMO SOLUCIÓN DE ENVOLVENTE 


\subsection{CONCLUSIONES}

Del estado del arte se puede concluir:

- La fotocatálisis es una solución efectiva para eliminar contaminantes orgánicos e inorgánicos.

- La fotocatálisis es un proceso que no se agota y que utiliza la luz del sol como fuente de energía.

-El cemento aporta una matriz resistente que aporta durabilidad al fotocatalizador

- Los materiales base cemento que incorporan $\mathrm{TiO}_{2}$, pueden adquirir propiedades fotocatalíticas como, la autolimpieza, eliminación de contaminantes atmosféricos, superhidrofilia y actividad antibacteriana.

- Es posible incorporar $\mathrm{TiO}_{2}$ como fotocatalizador a los materiales de construcción en base cemento, habiendo demostrado en ocasiones, ser capaz de producir, reducciones significativas en condiciones reales.

-El color y la textura influyen en las propiedades fotocatalíticas pero, se han encontrado comportamientos y explicaciones contradictorios.

- No se encontrado ningún estudio en relacion con los mecanismos del papel que juegan los pigmentos basados en óxidos de hierro en la capacidad fotocatalítica

- No se encontrado ningún estudio en el que se hayan estudiado como afectan los aditivos para morteros en las propiedades fotocatalíticas de un cemento fotocatalítico.

- La contaminación atmosférica es un fenómeno a nivel global con efectos sobre, la salud, el medioambiente y los materiales de construcción.

- Los principales y más peligrosos contaminantes atmosféricos son $\operatorname{los} \mathrm{NO}_{\mathrm{X}}, \mathrm{SO}_{\mathrm{X}}, \mathrm{O}_{3}, \mathrm{PM}_{2,5}, \mathrm{PM}_{10}$.

- Las previsiones son que la población mundial crecerá y tendera a concentrarse en las ciudades.

-En el fenómeno que se da en las ciudades, denominado Isla de Calor influyen la naturaleza y características de los materiales de construcción. 
-El uso de materiales con una alta reflectancia reduce el efecto isla de calor y disminuye la demanda energética para refrigeración.

-Los materiales utilizados como recubrimientos reflectantes, con el paso del tiempo pierden capacidad de reflectancia solar por ensuciamiento.

- La textura y color superficial influyen en las propiedades de reflectancia de los materiales.

En conclusión, hay una laguna en el conocimiento de aspectos que no se han determinado y explicado en el comportamiento de los materiales base cemento fotocatalitico. Esta investigación, nos permitira optimizar, conocer la composición de un mortero de acabado en la propiedad fotocatalítica que se le demanda al material, ya sea la autolimpieza o la eliminación de contaminantes atmosféricos, teniendo en cuenta el color y la textura superficial. Por ello de la necesidad y originalidad de esta Tesis Doctoral. 
CAPÍTULO 6: CONCLUSIONES ALESTADO DEL ARTE 
INFLUENCIA DEL COLOR Y ELACABADO SUPERFICIALENLASPROPIEDADES DE UN MORTERO FOTOCATALITICO COMO SOLUCIÓN DE ENVOLVENTE 


\section{CAPITULO 7: METODOLOGÍA}

En este capitulo se expone la estrategia metodologica que se ha seguido para conseguir los objetivos detallados a fin de demostrar la hipótesis de partida. 
INFLUENCIA DEL COLOR Y ELACABADO SUPERFICIALEN LAS PROPIEDADES DE UN MORTERO FOTOCATALITICOCOMOSOLUCIÓNDE ENVOLVENTE 


\subsection{METODOLOGÍA}

La metodología que se ha utilizado se basa en el método experimental y se desarrolla en tres etapas diferenciadas y consecutivas que tienen como objetivo llegar a la demostración de la hipótesis inicial y a la consecución de los objetivos fijados.

Una primera etapa, en la que la investigación detecta una posible laguna del conocimiento, lo que permite acotar el alcance. Una búsqueda documental de las investigaciones y experiencias llevadas a cabo en el campo de la fotocatálisis, los materiales de construcción, revestimientos base cemento en envolventes y contaminación atmosférica, que da una amplia base para la valoración de la situación actual. Con una perspectiva multidisciplinar que abarca la química, la construcción y la tecnología de materiales. No habiendo encontrado investigaciones similares al objeto de esta Tesis Doctoral, permite fijar la hipótesis de trabajo y la base para desarrollar en la siguiente etapa un plan de ensayos.

Una segunda etapa con la definición clara de las variables a medir y que habían quedado señaladas en el planteamiento de la hipótesis y objetivos. Esta etapa abarca el diseño experimental que se ha dividido en tres partes: diseño experimental, elección y caracterización de los materiales, y obtención de resultados.

Debido a que no es objeto de esta Tesis el desarrollo de un mortero fotocatalítico debido a su complejidad, y a que ya existen en el mercado, se decide fijar el punto de partida en un mortero fotocatalítico comercializado. Las variables que se eligen en la parte de diseño experimental, el tipo de mortero, el tipo de acabado superficial que se da al mortero, el color con la utilización de pigmentos, los aditivos ensayados y los métodos y normas que se aplicaron para la cuantificación de las propiedades medidas (físicas, químicas, fotocatalíticas y ópticas). Es necesario mencionar que aunque no es el objeto de esta tesis el desarrollo de una formulación, se ha creído necesario valorar el efecto individual sobre las propiedades fotocatalíticas de los aditivos utilizados en el desarrollo de este tipo de morteros.

Se seleccionaron con el objetivo de abarcar un rango suficiente de características, tomando como referencia las condiciones establecidas por la normativa para un mortero que pueda ser utilizado en como revestimiento de la envolvente.

Se ha llevado a cabo una exhaustiva caracterización tanto del mortero fotocatalítico y del mortero no fotocatalítico que sirven de base para comparar, de los morteros coloreados que se prepararon, pigmentos y aditivos, midiendo las propiedades que permiten en una posterior evaluación, obtener las conclusiones que den respuesta a la hipótesis de partida. 
I NFLUENCIA DEL COLOR Y EL ACABADO SUPERFICIALEN LASPROPIEDADES DE UN MORTERO FOTOCATALITIICO COMO SOLUCIÓN DE ENVOLVENTE

Una tercera etapa de análisis de los datos obtenidos, una evaluación critica de los resultados, que permita valorar e interpretar tanto cualitativa como cuantitativamente la influencia de las variables elegidas y estudiadas en las propiedades que se han medido. 
CAPITULO 7: METODOLOGÍA 
INFLUENCIA DEL COLOR Y ELACABADO SUPERFICIALENLASPROPIEDADES DE UN MORTERO FOTOCATALITICO COMO SOLUCIÓN DE ENVOLVENTE 


\section{CAPÍTULO 8:}

\section{PROCEDIMIENTO EXPERIMENTAL}

En este capítulo se enumeran las variables experimentales utilizadas, y las técnicas y materiales que se han empleado para la confección y análisis de los morteros.

En la segunda parte, se describe el procedimiento operativo que se ha seguido en cada caso y los resultados obtenidos. La campaña de ensayos se ha realizado en las instalaciones del Instituto Eduardo Torroja de Ciencias de las Construccion, únicamente las medidas de reflectancia se hicieron en el Instituto de Óptica "Daza de Valdés". 
I NFLUENCIA DEL COLOR Y EL ACABADO SUPERFICIALEN LAS PROPIEDADES DE UN MORTERO FOTOCATALÍTICO COMO SOLUCIÓN DE ENVOLVENTE 


\subsection{VARIABLES EXPERIMENTALES}

En este trabajo de investigación se han elegido como variables experimentales, el color y el acabado superficial. Al ser el punto de partida un mortero fotocatalítico, se ensaya también un mortero no fotocatalítico del mismo fabricante y tipología, para poder establecer el punto de partida y conocer cuáles son las mejoras cualitativas y cuantitativas, en relacion a un mortero no fotocatalítico

Al ser el color una variable, se parte de un mortero fotocatalítico de color blanco, actuando sobre el, con la adición de pigmentos inorgánicos para obtener los distintos colores objeto del estudio.

Se quieren valorar la influencia que tienen las variables relacionadas con las propiedades fotocatalíticas, así como con las ópticas (color y acabado superficial) de la envolvente.

La razón de elegir el color como variable fue debido a que el color de la envolvente forma parte fundamental del proceso de desarrollo del proyecto por parte del arquitecto, las propiedades de ópticas y energéticas del material cambian según el color del mortero, ya que la reflectancia cambia con el, y esto influye en las propiedades fotocatalíticas.

En la búsqueda documental desarrollada en la primera etapa de este trabajo, se pudo ver las nuevas propiedades, autolimpieza y descontaminación, de las que dota el mortero a la envolvente, se ven afectadas por la adición de pigmentos aunque, no se han encontrado resultados y criterios claros a la hora de predecir cómo y cuánto afectan, por esa razón se fija el color, como una variable. Las dosificaciones de los pigmentos se han elegido atendiendo a intensidad de color que se pueden ver en las fachadas de forma normal.

\begin{tabular}{c|c|c|c|c|c|c|}
$\begin{array}{c}\text { Estándar sin } \\
\text { pigmento }\end{array}$ & $\begin{array}{c}\text { Fotocatalítico } \\
\text { sin pigmento }\end{array}$ & $\begin{array}{c}\text { Pigmento } \\
\text { amarillo (\%) }\end{array}$ & $\begin{array}{c}\text { Pigmento } \\
\text { rojo (\%) }\end{array}$ & $\begin{array}{c}\text { Pigmento } \\
\text { marrón (\%) }\end{array}$ & \multicolumn{2}{|c|}{$\begin{array}{c}\text { Pigmento } \\
\text { negro (\%) }\end{array}$} \\
\hline M & MTX & MTX-A & MTX-R & MTX-M & MTX-G1 & MTX-G2 \\
\hline
\end{tabular}

La segunda variable, el acabado (rugoso o liso), se eligió por las mismas razones. El acabado forma parte también del proceso proyectual e influye en la propiedades ópticas al cambiar, la superficie del recubrimiento hace que varie la forma en la que refleja la luz incidente y por tanto la relacion y percepción del observador.

Las propiedades fotocatalíticas, se pueden ver alteradas ya que se utilizan distintas técnicas y herramientas para realizar cada acabado y por tanto se producen cambios en la morfología superficial del mortero, que es la que está en contacto con los contaminantes y sobre la que se desarrolla el proceso de fotocatálisis. 
Para la serie de ensayos con los aditivos, en primer lugar se realizó una selección previa de aditivos susceptibles de ser utilizados en morteros de revestimiento base cemento en exteriores, atendiendo a las propiedades que modifican. Las familias a las que pertenecen estos aditivos se incluyen en las formulaciones de morteros de revestimiento que se utilizan para envolventes, a saber: espesantes, aireantes, hidrofugante y polimero redispersable. Cada aditivo debido a su diferente naturaleza química pueden afectar a las propiedades fotocatalíticas del cemento.

En esta serie de ensayos la variable ha sido la cantidad del aditivo en relacion al peso de cemento.

\begin{tabular}{|c|c|}
\hline Familia & Referencia \\
\hline & 15000 \\
\hline Espesante de agua & 10012 \\
\hline Aireante & H 20 \\
\hline Hidrofugante & MH 200 \\
\hline & LS 14 \\
\hline Polimeros & Mas \\
\hline & Oleato \\
\hline & 554 \\
\hline
\end{tabular}


El plan experimental diseñado para realizar la investigación objetivo con las variables elegidas es el siguiente:

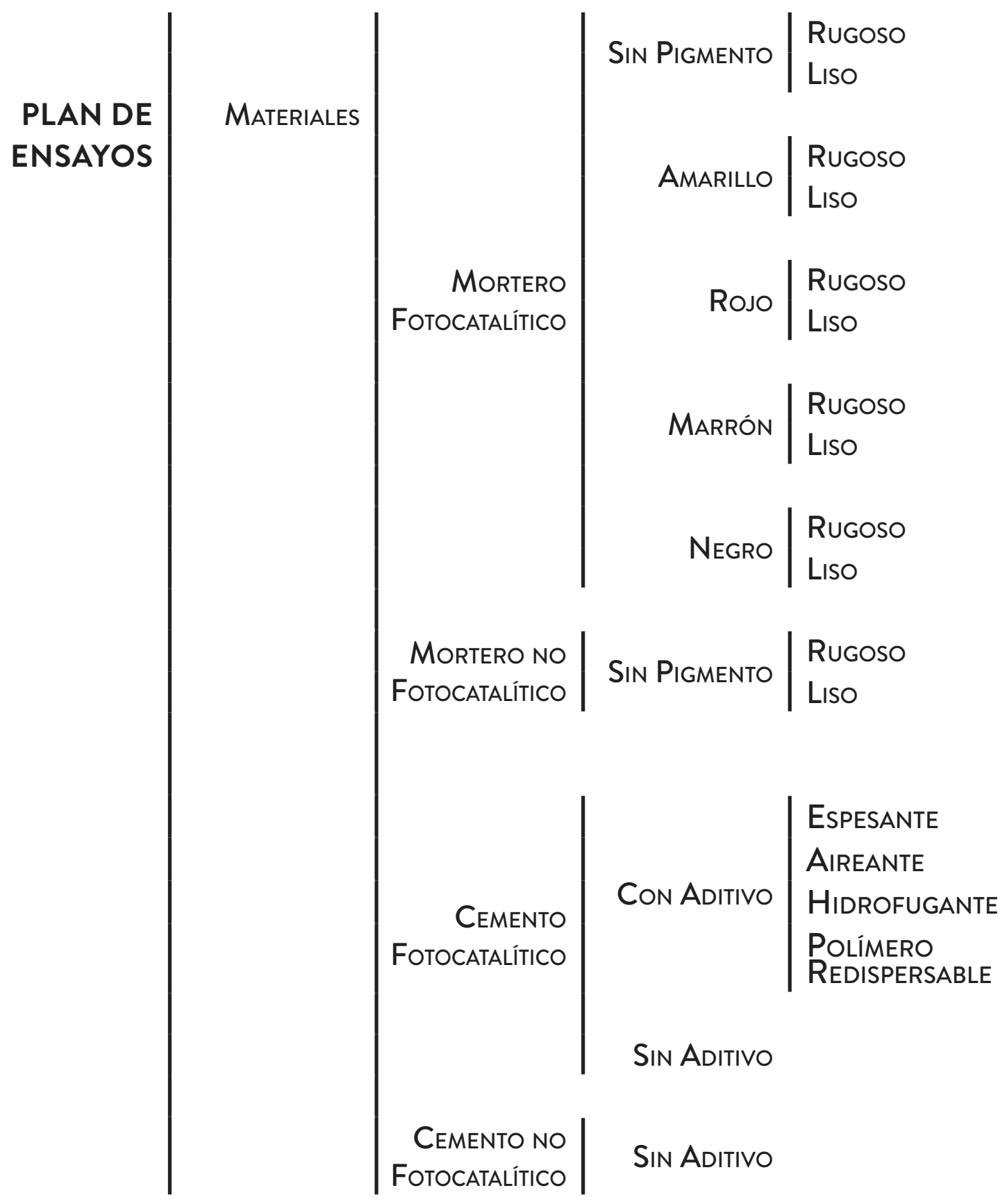




\section{2. TÉCNICAS DE ENSAYO UTILIZADAS}

\subsubsection{FLUORESCENCIA DE RAYOS X -FRX-}

La fluorescencia de rayos $X$ es una técnica de espectrometría de rayos $X$ no destructiva, en la que la fuente de excitación es una fuente de radiación de rayos $X$. Al irradiar la muestra, ésta emite rayos $X$ secundarios o de fluorescencia. El detector de rayos $X$ recoge los fotones emitidos y analiza sus energías.

La energía de los fotones es característica de cada tipo de átomo que compone la muestra, pues se generan a partir del mismo principio, es decir, transiciones entre los niveles electrónicos internos de los átomos, siendo su intensidad proporcional a la cantidad presente de cada uno de ellos. Mediante el uso de este tipo de técnica se puede hacer un análisis cuantitativo de elementos traza. Esa determinación es posible mediante relaciones de proporcionalidad entre la intensidad de señal emitida y con su concentración ${ }^{317,318}$.
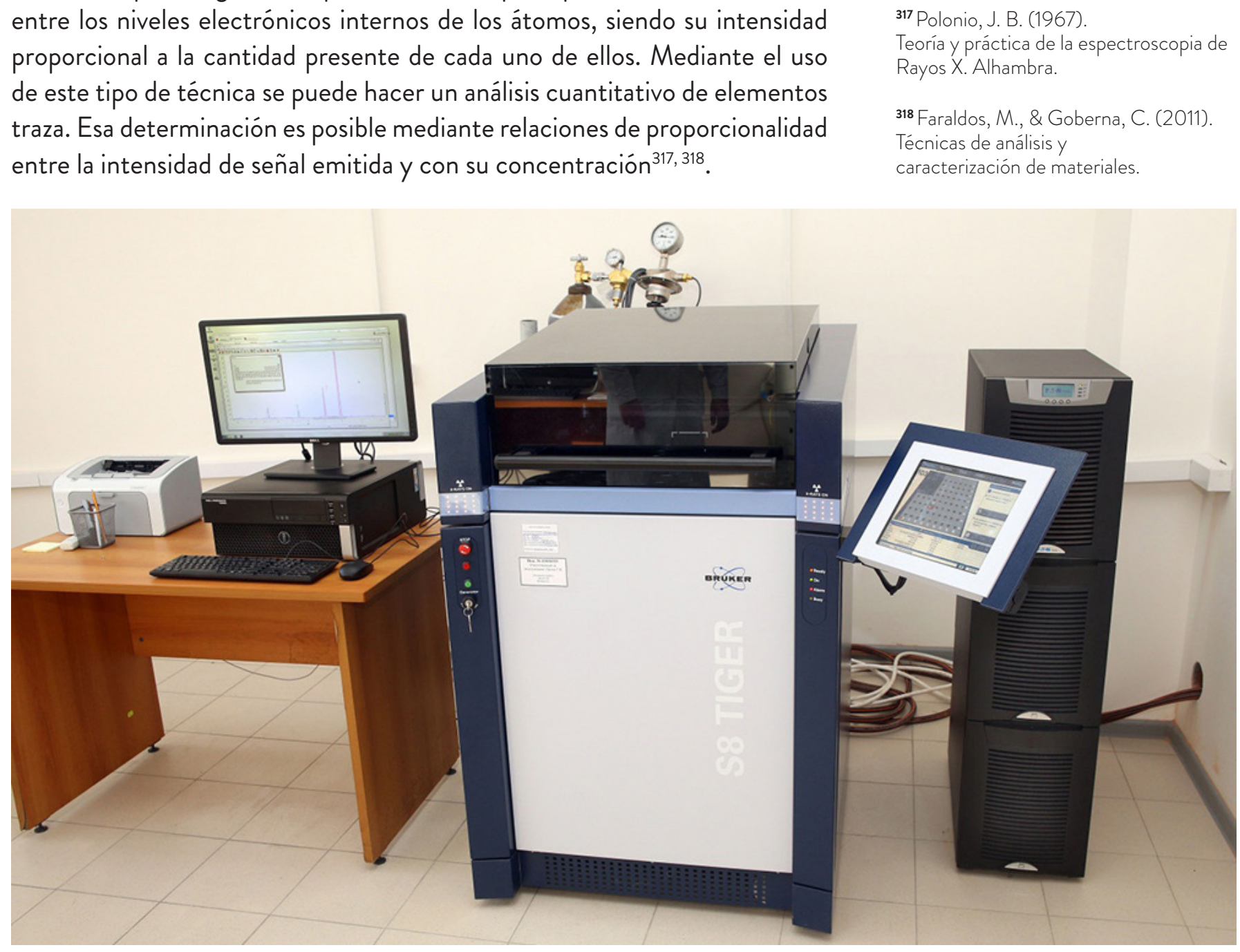

Las medidas fueron llevadas a cabo con un BRUKER S8 TIGER.

Fig 86. Equipo de Fluorescencia por Rayos X

\subsubsection{DIFRACCIÓN DE RAYOS X -DRX-}

La difracción de rayos $X$ es una técnica no destructiva ampliamente utilizada para la caracterización de materiales inorgánicos u orgánicos, tanto de origen natural como sintético. El patrón de DRX de una sustancia se considera como una suerte de "huella dactilar" de la sustancia. Entre sus principales usos se encuentra la identificación de fases, análisis cuantitativo y la determinación de imperfecciones estructurales. Se basa en el hecho 
de que cuando un haz de rayos $X$ incide sobre un material cristalino es difractado, produciendo fenómenos de interferencia destructiva en la mayor parte de las direcciones. Sin embargo, debido a la ordenación periódica de los átomos en el material, las ondas dispersadas se refuerzan en ciertas direcciones determinadas por la ley de Bragg, donde:

$$
n \lambda=2 d \cdot \operatorname{sen} \theta
$$

Donde:

$\lambda=$ longitud de onda de la radiación incidente

$d=$ espaciado de la red cristalina

$n=$ un número que toma siempre valor entero $(n=1,2 \ldots)$

$\theta=$ el ángulo que forma el haz incidente y el plano de reflexión.

Por tanto, cuando una radiación de rayos $X$ se hace incidir sobre una muestra cristalina en polvo y en ángulos diferentes, sólo para aquellas posiciones de dicha muestra en la que se cumpla la ley de Bragg ocurrirá el fenómeno de difracción.

Fig 87. Representación de la difracción de rayos $X$ por un sólido cristalino.

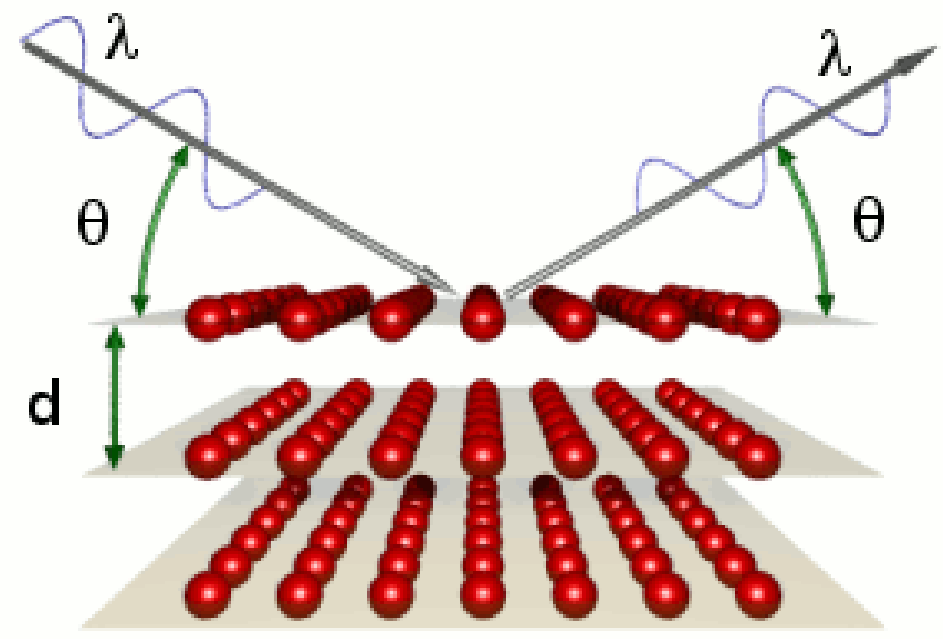

Como en un cristal hay diferentes familias de planos y con distintos espaciados, definidos por los parámetros reticulares de la red, existirán también varios ángulos para los que se cumple la ley de Bragg. Puesto Como en un cristal hay diferentes familias de planos y con distintos espaciados, definidos por los parámetros reticulares de la red, existirán también varios ángulos para los que se cumple la ley de Bragg. Puesto que la estructura cristalina es algo característico de cada material y no existen dos sustancias con la misma estructura cristalina, el conjunto de espaciados entre sus planos también será único para cada cristal. Así pues, se constata que no existen dos sustancias cristalinas con el mismo diagrama de difracción, de modo que, a partir de esta técnica pueden identificarse las fases que forman un material cristalino cualquiera. El diagrama de difracción de una sustancia puede realizarse con la cuantificación de las diferentes fases que la componen mediante el método de Rietveld ${ }^{4}$.

Los análisis realizados se realizaron con un difractómetro Bruker AXS D8 Advance. 


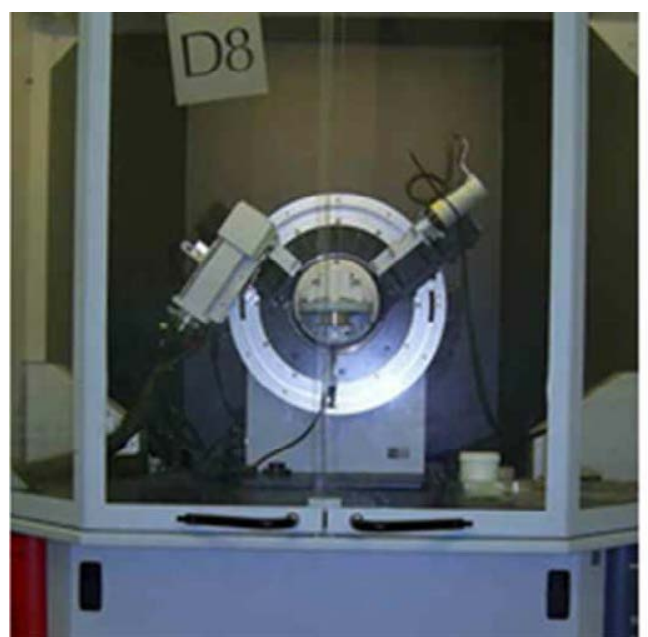

\subsubsection{MEDICIÓN DELACAPACIDADFOTOCATALÍTICADEAUTOLIMPIEZA}

Lacapacidad de autolimpieza de los morteros estudiados se basa en un método colorimétrico, el cual mide la capacidad de degradación de un contaminante orgánico llamado rodamina B. El método utilizado tiene como finalidad la determinación de la actividad fotocatalítica de los conglomerantes hidráulicos con base de cemento blanco y mide la evolución colorimétrica con el paso del tiempo de muestras cuya superficie ha sido tratada con rodamina $B$, se utiliza este compuesto por su baja fotosensibilidad a la luz UV, al entorno básico del cemento, su alta sensibilidad colorimétrica y por la amplia experiencia en su utilización en fotocatálisis.

La rodamina B se deposita sobre la superficie de las muestras en una concentración conocida. La prueba permitevalorarsi, através dela decoloración de la rodamina, la muestra de cemento se puede considerar fotocatalítica. El procedimiento experimental seguido ha sido el correspondiente a la norma UNI $11259^{319}$.

La fuente luminosa que se ha utilizado es una lámpara LED Philips ACTINIC, que proporciona una intensidad de radiación sobre la superficie de la muestra que en el espectro UV-A tenga una intensidad de $3,75 \pm 0,25 \mathrm{~W} / \mathrm{m}^{2}$.

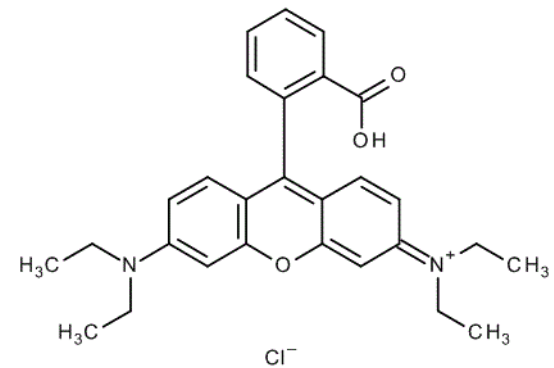

La degradación fotocatalítica de rodamina $B$ se produce por dos mecanismos propuestos. El primero es la activación del $\mathrm{TiO}_{2}$ donde los huecos generados atacan la molécula de rodamina $B$. La segunda alternativa es que, las moléculas de rodamina $\mathrm{B}$ reaccionan adicionalmente con el $\mathrm{TiO}_{2}$ o el $\mathrm{O}_{2}$. La rodamina $\mathrm{B}^{+}$ formada por las diferentes rutas se oxida formando rodamina como intermedio ${ }^{321}$.
Fig 88. Equipo de medida DRX BRUKER AXS D8 Advance.
319 UNI 11259:2008

Determination of the photocatalytic activity of hydraulic binders - rodammina test method. (2008).

Fig 89. Estructura molecular de rodamina $B$

Fuente. www.sigmaaldrich.com ${ }^{320}$

320 Sigma Aldrich. (2017). Rhodamine B base. Retrieved from http://www. sigmaaldrich.com/catalog/product/ aldrich/234141?lang=es\&region= ES\&gclid=CjwKEAjw3KDIBRCz OKvZIJ7k4TgSJABDqOK7Jz rCbyBkeO9Fcl31f6T1PViJ9Ja14 wvz9DlvP5QfRoCvKrw. Consultado 5 de octubre 2009.

${ }^{321}$ Ma, Y., \& Yao, J. N. (1999). Comparison of photodegradative rate of rhodamine $B$ assisted by two kinds of TIO 2 films.

Chemosphere, 38(10), 2407-2414. 
Rodamina $B+h^{+} \longrightarrow$ Rodamina $B^{+}$

Rodamina $B+h v \longrightarrow$ Rodamina $B^{*}$

Rodamina $\mathrm{B}^{*}+\mathrm{TiO}_{2} \longrightarrow$ Rodamin a $\mathrm{B}^{+}+\mathrm{TiO}_{2}^{-}$

Reacción 29

Rodamina $B^{*}+\mathrm{O}_{2} \longrightarrow$ Rodamina $\mathrm{B}^{+}+\mathrm{O}_{2}^{-}$

Reacción 30

Rodamina $B^{+} \rightarrow \rightarrow$ Producto

Para realizar las medidas se ha utilizado un espectrofotómetro Konika Minolta CM-2300d para medir el color en reflexión según el sistema CIELAB, con geometría d/8 $8^{\circ}$.

Dado que en el presente método se utiliza la rodamina $B$, que es de color rojo, se examina únicamente la coordenada colorimétrica a* sus variaciones a 4 h y $26 \mathrm{~h}$ horas de exposición bajo irradiación UV. En el análisis de la degradación el parámetro relevante que se considera es la variación porcentual de $a^{*}$, calculada según la ecuación:

$$
\begin{aligned}
& \Delta a_{\%}=\frac{\left(a_{t}^{*}-a_{0}^{*}\right)}{a_{0}^{*}} \cdot 100 \\
& R_{4}=\frac{a^{*}(0 h)-a^{*}(4 h)}{a^{*}(0 h)} \cdot 100 \\
& R_{26}=\frac{a^{*}(0 h)-a^{*}(26 h)}{a^{*}(0 h)} \cdot 100
\end{aligned}
$$

Donde:

$a^{*}{ }_{0}=$ valor de la coordenada cromática justo después manchar la muestra con la rodamina $B$.

$a^{*}{ }_{t}=$ valor después de un tiempo t de irradiación.

Las medidas se realizan a $22^{\circ} \mathrm{C} \pm 2{ }^{\circ} \mathrm{C}$. El material ensayado se considera fotocatalítico con respecto a la rodamina únicamente si se satisfacen los siguientes requisitos:

$$
R_{4}>20 \% \quad R_{26}>50 \%
$$


El sistema de medición está basado en el sistema CIE L*a*b* (CIELAB), el cual utiliza un modelo cromático, desarrollado específicamente con este propósito por la Commission Internationale d'Eclairage (CIE). El espacio de color CIELAB es un sistema coordenado cartesiano definido por tres coordenadas colorimétricas adimensionales $L^{*}, a^{*}, b^{*}$. Las coordenadas colorimétricas expresan:

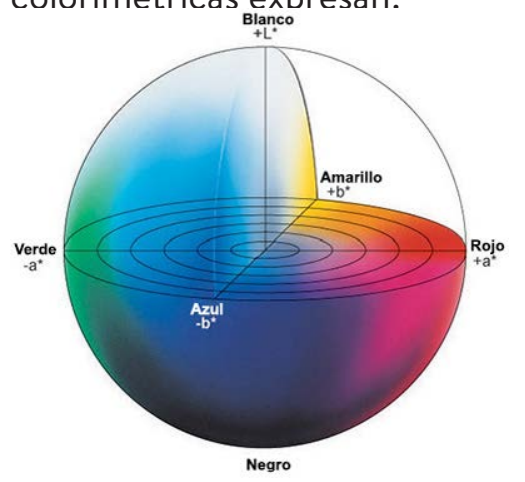

$L^{*}=$ Luminancia o claridad de un color. Los valores situados en el eje $L^{*}$ van de 0 (negro) a 100 (blanco).

$a^{*}=a^{*}$ define la desviación hacia el rojo si $\left(a^{*}>0\right)$ o hacia el verde si $\left(a^{*}<0\right)$.

$b^{*}=b^{*}$ define la desviación hacia amarillo si $\left(b^{*}>0\right)$ o hacia el azul si $\left(b^{*}<0\right)$.

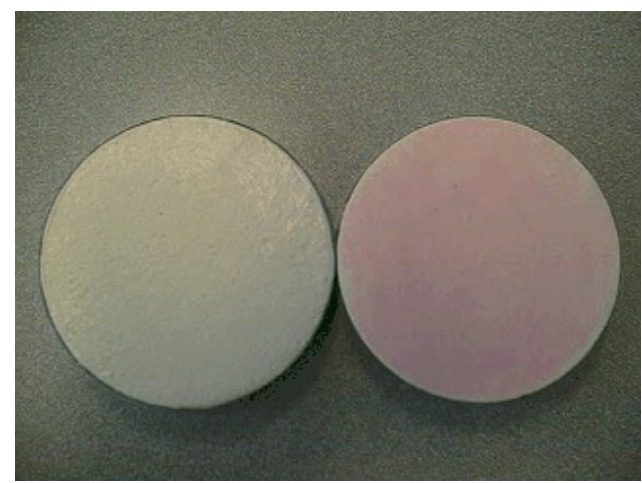

Cuando se encuentra en el sector positivo $(+)$, la coordenada $a^{*}$ indica una inclinación hacia el rojo, mientras que en la dirección negativa (-) indica una tendencia de desviación hacia la dirección del verde. En cambio, la coordenada $b^{*}$ en la dirección positiva (+) desvía al amarillo, mientras que en la negativa (-) va en la dirección del azul.

Dado que en el presente método se utiliza la rodamina $B$, que es de color rojo, se examinará únicamente la coordenada colorimétrica a* (crominancia).

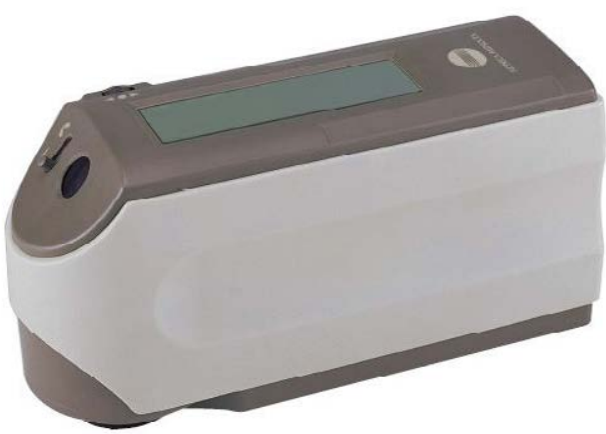

Fig 91. Muestra antes y después de manchar con Rodamina.

Fig 92. Equipo Konica Minolta CM2300d 
322 UNI 11247:2010.

Determination of the catalytic degradation of nitrogen oxides in the air by inorganic photocatalytic materials: Continuous flow test method. (2010).

\subsubsection{MEDICIÓN DE LA CAPACIDAD FOTOCATALÍTICA DE ELIMINACIÓN DE NO}

El método utilizado tiene como finalidad la determinación de la actividad fotocatalítica de materiales inorgánicos dispersos en matrices de cemento, en la reducción del monóxido de nitrógeno (NO) y del dióxido de nitrógeno $\left(\mathrm{NO}_{2}\right)$. Consiste en la medida de la actividad de materiales de base cemento y cerámicos en la degradación de óxidos de nitrógeno (NO, $\mathrm{NO}_{2}$ ) por vía fotocatalítica mediante metodología analítica basada en la quimiluminiscencia. Las pruebas de fotoactividad se llevan a cabo con aire con $\mathrm{NO}_{x}$, a partir de una mezcla de $\mathrm{NO}_{\text {y }} \mathrm{NO}_{2}$ de manera que, simula un grado de contaminación atmosférica plausible. El procedimiento experimental $\mathrm{NO}_{\mathrm{x}}$ seguido ha sido el correspondiente a la norma, UNI $11247^{322}$.

La degradación de $\mathrm{NO}_{\text {y }} \mathrm{NO}_{2}$ se lleva a cabo sobre un flujo continuo del gas conteniendo los óxidos de nitrógeno, con iluminación ultravioleta de la muestra que se ensaya.

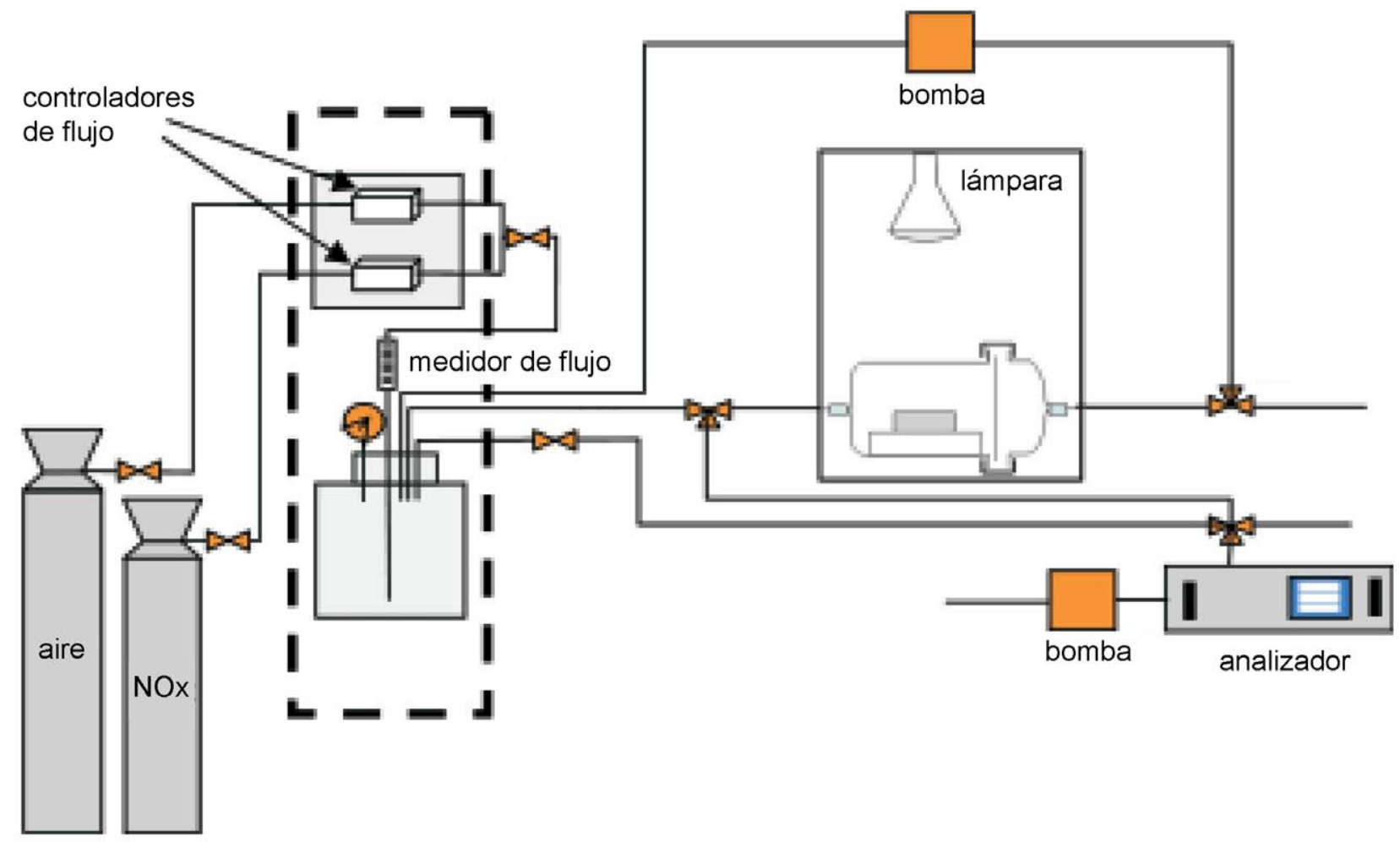

Fig 93. Montaje experimental para ensayo eliminación fotocatalítica de óxidos de nitrógeno $\left(\mathrm{NO}_{x}\right)$.
Para la circulación del gas se utilizan tubos de politetrafluoretileno que no alteren la concentración de los óxidos de nitrógeno. El equipo experimental está formado por los siguientes componentes principales:

1. Mezcla de óxidos de nitrógeno $\left(\mathrm{NO}_{x}\right)$

2. Aire como fuente de aire

3. Controladores másicos de flujo

4. Cámara de premezcla

5. Humidificador

6. Cámara de reacción

7. Analizador de $\mathrm{NO} / \mathrm{NO}_{2}$ 
S Fuentes de gas

$\mathrm{S} 1$ = Botella de $\mathrm{NO}$ en nitrógeno. Valor certificado de 4,6 ppmv con incertidumbre de medida (\% relativa) de $\pm 5 \%$.

$\mathrm{S} 2$ = Botella de $\mathrm{NO}_{2}$ en nitrógeno. Valor certificado de 15,7 ppmv con incertidumbre de medida (\% relativa) de $\pm 5 \%$.

S3 = Gas de calibración; botella de NO en nitrógeno. Valor certificado de 449,1 ppbm incertidumbre 4,9 ppbm, para la calibración del equipo de quimiluminiscencia.

S4 = Botella de aire Alphagas 1 para gas-cromatografía.

F Calibrador de flujo

El flujo de gas y la concentración de los óxidos de nitrógeno se mantiene constante mediante dos caudalímetros másicos Brooks, modelo 5850 S.

C Cámara de control de humedad

El grado de humedad del flujo gaseoso está fijado en $40 \% \pm 2 \%$. Éste se consigue haciendo pasar el aire por frascos lavadores que contienen agua y controlando el grado de humedad con un higrómetro PCE-HT-110.

R Sistema de irradiación de las muestras.

La fuente de iluminación consiste en una lámpara de y emisión de luz ultravioleta, visible e infrarrojo. La distancia de la lámpara a la superficie del reactor se regula de tal forma que el flujo radiante integrado entre 315 y $400 \mathrm{~nm}$, resulte ser de $20 \mathrm{~W} / \mathrm{m}^{2} \pm 1 \mathrm{~W} / \mathrm{m}^{2}$. El flujo radiante está medido por un radiómetro Delta Ohm HD2102.1 colocado en el interior del reactor sobre la superficie de la probeta.

Características del reactor.

El reactor utilizado es de vidrio Pyrex con un volumen vacío total de 2,81 litros y una altura de $13,5 \mathrm{~cm}$.

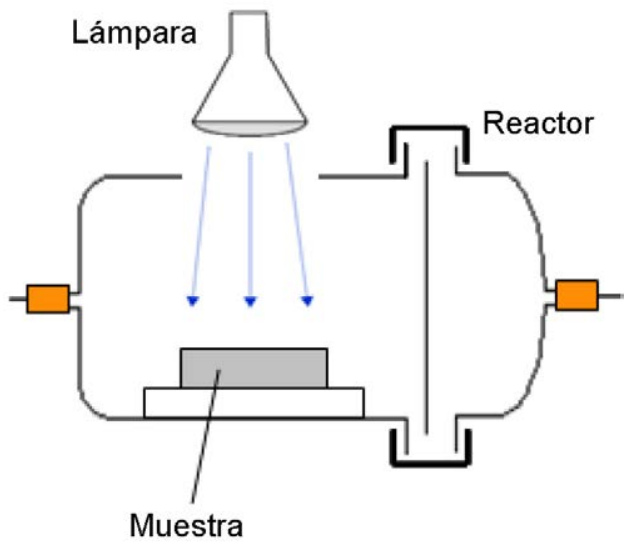

Fig 94. Reactor y sistema de irradiación de la muestra. 


\section{CARACTERÍSTICAS DE LAS MUESTRAS}

Se utilizan las muestras confeccionadas en las placas de petri de plástico, $8,8 \mathrm{~cm}$ de diámetro y $15 \mathrm{~mm}$ de altura. El área de ensayo es de $64 \mathrm{~cm}^{2}$.

\section{A Analizador de $\mathrm{NO} / \mathrm{NO}_{2}$}

El análisis de la concentración de $\mathrm{NO}_{\text {y }} \mathrm{NO}_{2}$ se lleva a cabo por quimiluminiscencia por el equipo $A C 32 M$ de Environnment S.A en la salida del reactor, donde se mide simultáneamente la concentración de ambos compuestos.

El análisis de la concentración de $\mathrm{NO}_{\text {y }} \mathrm{NO}_{2}$ se lleva a cabo por quimiluminiscencia por el equipo $\mathrm{AC} 32 \mathrm{M}$ de Environnment $\mathrm{S}$.A en la salida del reactor, donde se mide simultáneamente la concentración de ambos compuestos.

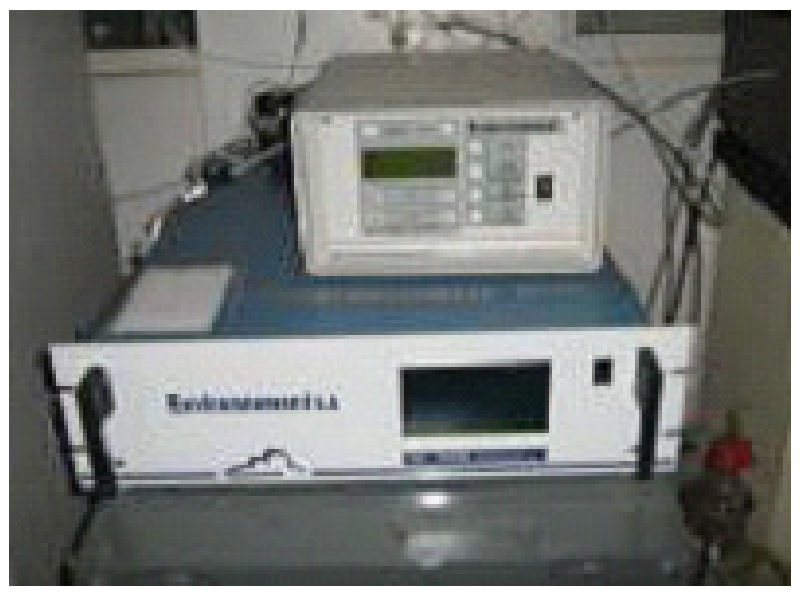

La actividad fotocatalítica de reducción de óxidos de nitrógeno, $A_{C}$, para distintos tiempos de reacción se calcula con la siguiente fórmula:

$$
A_{c}=100 \frac{\left(C_{B}-C_{L}\right)}{C_{B}} \cdot \frac{I_{N}}{I} \cdot \frac{S_{N}}{S}
$$

Donde:

$A_{C}=$ Índice adimensional de eliminación de $\mathrm{NO}_{x}$ bajo las condiciones de ensayo expresado en porcentaje.

$C_{B}$ y $C_{L}=$ concentraciones $\left(\mathrm{NO}_{X}, \mathrm{NO}_{2}, \mathrm{NO}\right)$ anteriormente definidas.

$\mathrm{S}_{\mathrm{N}}$ = área nominal de la muestra a examen $\left(64 \mathrm{~cm}^{2}\right)$.

$\mathrm{S}=$ área de la muestra sometida a ensayo expresada en $\mathrm{cm}^{2}$.

$\mathrm{I}_{\mathrm{N}}=$ irradiancia nominal $\left(20 \mathrm{~W} / \mathrm{m}^{2}\right)$.

$\mathrm{I}=$ irradiancia media expresada en $\mathrm{W} / \mathrm{m}^{2}$. 


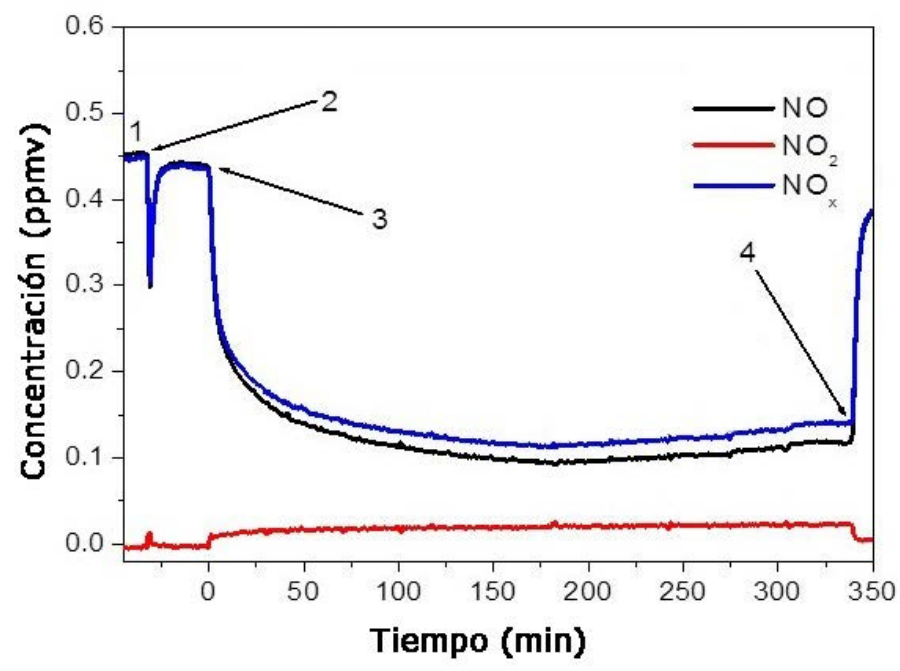

Donde:

$\mathrm{t}=$ Tiempo (en minutos)

C = Concentración (en ppmv)

$1=$ Reactor sin flujo

2 = Inyección de gas al reactor

$3=$ Comienzo iluminación

4 = Fin iluminación
Fig 96. Gráfica típica de evolución de concentraciones de $\mathrm{NO}, \mathrm{NO}_{2}$ Y $\mathrm{NO}_{x}$ durante un ensayo

El momento del inicio de iluminación a la muestra se considera como el valor 0 en la escala de tiempo.

\subsection{5 . ESPECTROMETRÍA DE FLUORESCENCIA CON ÁCIDO TERFTÁLICO}

La espectrometría de fluorescencia es un tipo de espectroscopia electromagnética que analiza la fluorescencia de una muestra. La fluorescencia es un proceso de emisión en el cual las moléculas son excitadas por la absorción de radiación electromagnética y al relajarse al estado basal liberan el exceso de energía en forma de fotones.

Las moléculas tienen diferentes estados llamados niveles de energía. La espectrometría de fluorescencia se refiere principalmente a estados vibracionales y electrónicos. Las especies objeto de examen tendrán un estado electrónico basal (un estado de baja energía) de interés, y un estado electrónico excitado de mayor energía. Dentro de cada uno de estos estados electrónicos hay diferentes estados vibracionales.

En la espectroscopia de fluorescencia, primero se excita la muestra mediante la absorción de un fotón de luz, desde su estado electrónico basal a uno de los distintos estados vibracionales del estado electrónico excitado. Las colisiones con otras moléculas causan que la molécula excitada pierda energía vibracional hasta que alcanza el estado vibracional más bajo del estado electrónico excitado. 
${ }^{323}$ Xiang, Q., Yu, J., \& Wong, P. K. (2011).

Quantitative characterization of hydroxyl radicals produced by various photocatalysts. Journal of Colloid and Interface Science, 357(1), 163-167.

324 Hirakawa, T., \& Nosaka, Y. (2002).

Properties of $\mathrm{O} 2 \cdot-$ and $\mathrm{OH}$. formed in $\mathrm{TiO} 2$ aqueous suspensions by photocatalytic reaction and the influence of $\mathrm{H} 2 \mathrm{O} 2$ and some ions. Langmuir, 18(8), 3247-3254.

${ }^{325}$ Bubacz, K., Kusiak-Nejman, E., Tryba, B., \& Morawski, A. W. (2013). Investigation of $\mathrm{OH}$ radicals formation on the surface of $\mathrm{TiO} 2 / \mathrm{N}$ photocatalyst at the presence of terephthalic

acid solution. Estimation of optimal conditions. Journal of Photochemistry and Photobiology A: Chemistry, 261, 7-11.

326 Ishibashi, K. I., Fujishima, A., Watanabe, T., \& Hashimoto, K. (2000). Detection of active oxidative species in $\mathrm{TiO} 2$ photocatalysis using the fluorescence technique. Electrochemistry Communications, 2(3), 207-210

327 Jimenez-Relinque, E., \& Castellote,

M. (2015). Quantification of hydroxy radicals on cementitious materials by fluorescence spectrophotometry as a method to assess the photocatalytic activity. Cementand Concrete Research, 74 ,

108-115.

${ }^{328}$ Kubelka, P., \& Munk, F. (1931). An article on optics of paint layers. Z. Tech. Phys, 12(593-601).
La molécula desciende luego a uno de los distintos niveles de vibración del estado electrónico basal, emitiendo un fotón en el proceso. Como las moléculas pueden caer a cualquiera de los diferentes niveles de vibración en el estado basal, los fotones emitidos tendrán diferentes energías y, por lo tanto, frecuencias. Así pues, mediante el análisis de las diferentes frecuencias de luz emitida por espectrometría de fluorescencia, junto con sus intensidades relativas, se puede determinar la estructura de los diferentes niveles de vibración. La mayoría de los compuestos que contienen anillos aromáticos proporcionan emisión fluorescente.

Este método, cuantitativo se basan en la medición de la velocidad del radical hidroxilo $\mathrm{OH}$ - generado por las superficies excitadas fotocatalíticas ${ }^{323,324,325}$. Se conoce que esta especie es un reactivo muy importante presente en las reacciones fotocatalíticas, de hecho es la principal especie responsable de la oxidación fotocatalítica y por ese motivo, presenta algunas características que dificultan su detección directa como son, una vida muy corta y una alta reactividad

Se ha desarrollado una técnica simplificada de fotoluminiscencia para detectar fácilmente el $\mathrm{OH}$ ' formado. En este método, se utiliza el ácido benceno-1,4-dicarboxilico o ácido terftálico, $\left(\mathrm{C}_{8} \mathrm{H}_{6} \mathrm{O}_{4}\right)$, captura el radical hidroxilo y producen compuestos muy fluorescentes que pueden ser detectados por espectrometría de fluorescencia ${ }^{326}$.

La intensidad de fluorescencia de los compuestos fluorescentes es proporcional a la cantidad de $\mathrm{OH}$. generada. Por ejemplo, Xiang et al. ${ }^{10}$ propusieron el concepto "indice $\mathrm{OH}$ " para cuantificar la producción de $\mathrm{OH}$ ' de fotocatalizadores semiconductores en polvo y poder comparar la tasa de formación de $\mathrm{OH}^{\cdot}$ en sistemas fotocatalíticos.

En el presente estudio se ha utilizado este método con ácido terftálico como sonda para analizar cuantitativamente las cantidades de radical hidroxilo $\left(\mathrm{OH}^{\cdot}\right)$, formado sobre las muestras de mortero fotocatalítico y no fotocatalítico. La actividad fotocatalítica para cada muestra también se midió por la capacidad de degradación de $\mathrm{NO}_{x}$. La tecnica consiste en irradiar con una fuente luminoso que emita radiación a $\lambda=315 \mathrm{~nm}$ sobre una disolución de acido terftálico, el cual reaccióna con $\mathrm{OH} \cdot$ para producir un producto altamente fluorescente, que emite a $\lambda=425 \mathrm{~nm}$. La intensidad recogida sera proporcional a la cantidad de $\mathrm{OH}^{\cdot}$ generados y para determinarlos de forma cuantitativa se hace una curva de calibración del $\mathrm{TaOH}$ a pH alcalino ${ }^{327}$.

\subsubsection{ESPECTROSCOPIA DE REFLECTANCIA DIFUSA UV-VISIBLE}

A fin de poder determinar el salto de banda o band gap de los semiconductores, se determina usando la espectroscopia de reflectancia difusa UV-Vis, junto con la ecuacion Kubelka-Munk ${ }^{328}$, convirtiendo la reflectancia en el coeficiente de absorción ' $F(R)$ '. $F(R)$ es proporcional al coeficiente de absorción. 


$$
F(R)=\frac{(1-R)^{2}}{2 R}
$$

En la ecuación de Tauc, el coeficiente de absorción se puede sustituir por $F_{(R)}$ quedando:

$$
F(R) h=\left(h-E_{g}\right)^{n}
$$

$(h v F(R))^{n}=A\left(h-E_{g}\right)^{n}$

Donde:

$\mathrm{n}=2$ para transición directa permitida.

$A=$ constante.

$\mathrm{h}=$ constante de Planck.

$v=$ frecuencia.

La energía de fotoabsorción o band gap, se obtiene representando la ecuación de Tauc, $(F(R) h v)^{1 / n}$ frente a la energía absorbida ${ }^{329}$. El valor del band gap se determina por el punto de intersección entre la línea que trazamos tangente a la pendiente en los puntos de inflexión de la curva de absorción y el eje $X^{330,331}$.

Con estos valores es posible calcular la posición de las bandas de valencia y de conducción para cada mortero (BV) (BC), se utilizan las siguientes ecuaciones $^{34}$.

$$
\begin{aligned}
& B C(V \text { vs. } E N H)=1,23-P E \frac{e V}{2} \\
& B V(V \text { vs. } E N H)=1,23+P E \frac{e V}{2}
\end{aligned}
$$

Ecuación 2

Las mediciones se llevaron a cabo sobre las muestras de mortero con un espectrómetro Agilent Cary 5000.

\subsubsection{ESPECTROSCOPIA DE REFLECTANCIA DIFUSA UV-VIS-NIR}

Las propiedades de reflexión y transmisión de la luz de los materiales en el intervalo de longitudes de onda de la radiación óptica, particularmente la luz, son importantes en muchos campos. Estas propiedades se caracterizan por la reflectancia y transmitancia en sus componentes regulares y difusos.

Según se recoge en el documento CIE 130-1998332, de la Commission internationale de l'éclairage, la reflexión se define como el proceso por el cual la radiación es devuelta por una superficie o un medio, sin cambio de frecuencia de sus componentes monocromáticos. La absorción, como el proceso mediante el cual la energía radiante se convierte en una forma diferente de energía al interaccionar con la materia. La reflectancia es la magnitud que caracteriza la
329 Jimenez-Relinque, E., Llorente, I.,

\& Castellote, M. (2017).

TiO, cement-based materials:

Understanding optical properties

and electronic band structure

of complex matrices.

Catalysis Today, 287, 203-209.

330 Augugliaro, V., Kisch, H.,

Loddo, V., López-Muñoz, M. J.,

Márquez-Álvarez, C., Palmisano, G., ... \& Yurdakal, S. (2008).

Photocatalytic oxidation of aromatic alcohols to aldehydes in aqueous suspension of home prepared titanium dioxide: 2. Intrinsic and surface features of catalysts. Applied Catalysis A: General, 349(1), 189-197.

${ }^{331} \mathrm{CIE}$. (1979). Absolute methods for reflection measurements (No 44-1979).

${ }^{332}$ CIE. (1998).

Absolute methods for reflection measurements. practical methods for the measurement of reflectance and transmittance. (No. 130-1998). 
reflexión y se define como el cociente entre el flujo reflejado y el flujo incidente. Generalmente, la reflexión puede tener una parte regular o especular y una parte difusa $(\rho d)$ que se produce en múltiples direcciones.

Las mediciones de reflectancia difusa se llevan a cabo habitualmente con la ayuda de un patrón y, por consiguiente, se clasifican como un método relativo. La reflectancia total de la muestra se obtiene como suma de las componentes difusa y regular.

$$
\rho=\left(\rho_{r}+\rho_{d}\right)
$$

Donde:

$$
\begin{aligned}
& \rho=\text { reflectancia } \\
& \rho_{d}=\text { reflectancia difusa } . \\
& \rho_{r}=\text { reflectancia regular } .
\end{aligned}
$$

${ }^{333} \mathrm{CIE}$. (1979) Absolute methods for reflection measurements (No 44-1979).

${ }^{334} \mathrm{CIE} .(2016)$ Geometric tolerances for colour measurements. (No. 176-2016)
Aunque no se indica explícitamente, el valor de la reflectancia depende de la longitud de onda de la radiación incidente.

Existen métodos absolutos de medida de reflectancia difusa ${ }^{333}$, que se utilizan para realizar calibraciones de los patrones. En el método que se ha utilizado en esta tesis, la radiación reflejada en todas las direcciones por la muestra es recogida por una esfera integradora. Esto es una esfera hueca, cuya superficie interior es un reflector difuso no selectivo, que se consigue recubriéndola con una pintura de alta reflectancia, espectralmente neutra, con lo que se produce una irradiancia uniforme sobre la pared interior a partir del haz luminoso que entra.

La reflectancia es la potencia óptica o flujo radiante, reflejada por un objeto y depende de varios factores, entre ellos el ángulo de incidencia sobre el objeto. Por ese motivo, cuando se refiere un valor para la reflectancia, hay que indicar el ángulo de incidencia. Dependiendo de la rugosidad de la superficie, la luz se reflejará de forma más o menos difusa, variando la relación entre la potencia óptica reflejada en la dirección especular y la reflejada en las demás direcciones. Este procedimiento trata sobre la medida de la reflectancia difusa y especular para un ángulo de incidencia de $0^{\circ}$ y eso se denota como $\rho\left(0^{\circ}: d\right)$, de acuerdo con la convención internacional recomendada por la Comisión Internacional de lluminación.

En situaciones como la evaluación de la apariencia de color de objetos, es necesario distinguir entre la reflectancia total del objeto y la reflectancia regular. Esto se puede llevar a cabo midiendo la reflectancia difusa incluyendo o excluyendo la componente especular, lo que implica que la luz reflejada en la dirección especular incida, o no, respectivamente, sobre la superficie de la esfera integradora. Para poder incluir la componente especular, es necesario que la luz incida sobre la muestra con un ángulo ligeramente diferente a 0 grados. Se admite como incidencia normal cualquier ángulo comprendido entre 0 y 10 grados. 


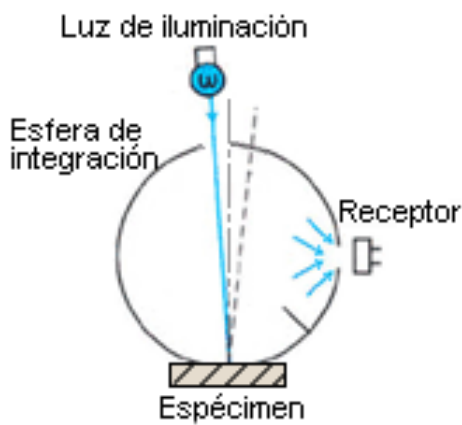

La geometría de medición que se utilizara en los ensayos es de $8^{0}: \mathrm{d}$, lo que significa que la luz incidente es casi normal a la muestra, mientras que la reflectancia se mide en todo el hemisferio. Esta geometría fue elegida porque es la configuración recomendada por CIE para medidas de reflectancia en estos materiales

El equipo para este ensayo se compone de una fuente de irradiación, un equipo de detección y los componentes mecánicos y / u ópticos adicionales necesarios, incluyendo un monocromador porque las medidas se realizan espectralmente entre $280 \mathrm{~nm}$ y $2500 \mathrm{~nm}^{335}$.

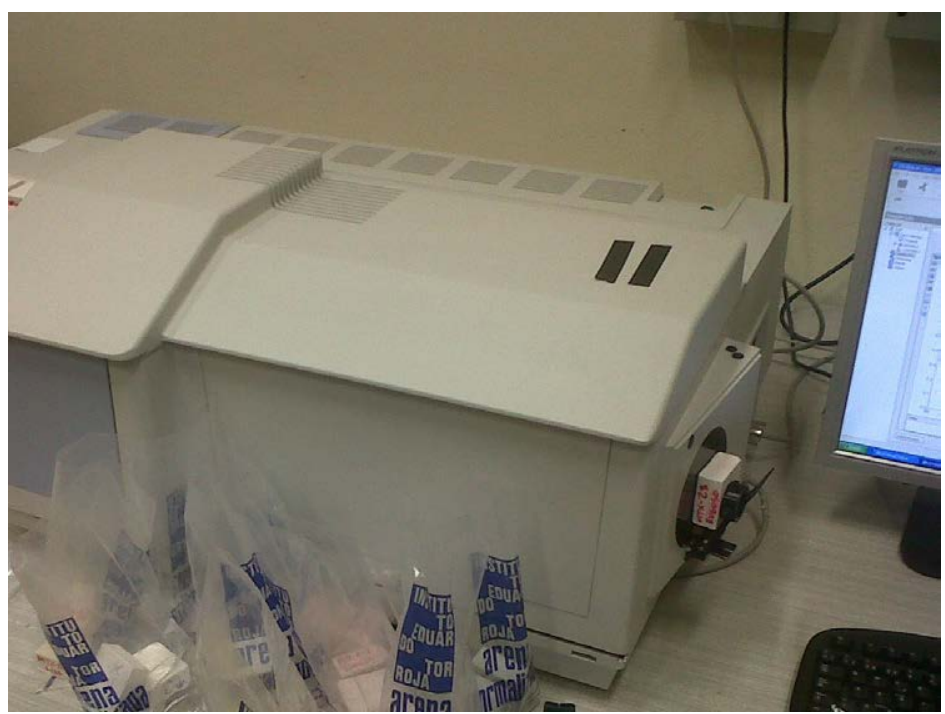

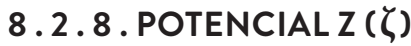

Esta es una medida de la estabilidad de una partícula e indica el potencial que se requiere para penetrar la capa de iones circundante a la partícula para desestabilizarla. El potencial zeta es una propiedad física que tiene cualquier partícula que se encuentra en una suspensión. Es el potencial existente en el plano de deslizamiento entre la superficie cargada y la disolución de electrolito, o más concretamente es la diferencia de potencial que existe entre la superficie de separación de las partes fija y móvil y el seno del líquido.

El potencial zeta es una característica que influye en la desestabilización de una partícula en una disolución y puede ser una manera efectiva de
Fig 97. Diagrama de medida de la reflectancia con una esfera integradora, con geometría de medición $8^{\circ}:$ d.

335 Taylor, J., Hanson, A. R., Clarke, P. J., Campos, J., Pons, A., Czepluch, W., \& Costa, J. L. C. (2000)

Good Practice guide to surface colour measurement. Publicación Europea SMT4-CT96-2140 EUR 19552EN.

Fig 98. Equipo con una muestra de mortero colocada en el puerto durante una medida. 
controlar el comportamiento del coloide ya que señala los cambios en el potencial de la superficie y en las fuerzas de repulsión entre los coloides. La mayoría de los sólidos adquieren una carga eléctrica superficial cuando se dispersan en un disolvente polar. Los posibles mecanismos por los que se puede generar dicha carga son:

1. Disolución de algunos iones presentes en la superficie del sólido.

2. Disociación o ionización de grupos superficiales.

3. Adsorción específica de iones presentes en la disolución.

4. Sustitución de iones en la red cristalina.

La superficie del sólido presentará un exceso de carga por unidad de área, que deberá estar compensada por otra carga equivalente pero de signo contrario en la fase acuosa en torno a la partícula sólida de tal forma que se mantenga la electroneutralidad del sistema. Ambas distribuciones de carga constituyen la llamada doble capa eléctrica. El término "doble capa" suele utilizarse para describir la ordenación de cargas y dipolos orientados que constituyen la región de la interfase en los límites de un electrolito.

Fig 99. Distribución de iones positivos y negativos alrededor del coloide Fuente. Zeta Potential: A Complete Course in 5 Minutes, Zeta-Meter $\operatorname{lnc}^{336}$

${ }^{336}$ Zeta-Meter, I. (1997) Zeta-Potential: A Complete Course in 5 Minutes. Zeta-Meter Inc, 1-8.

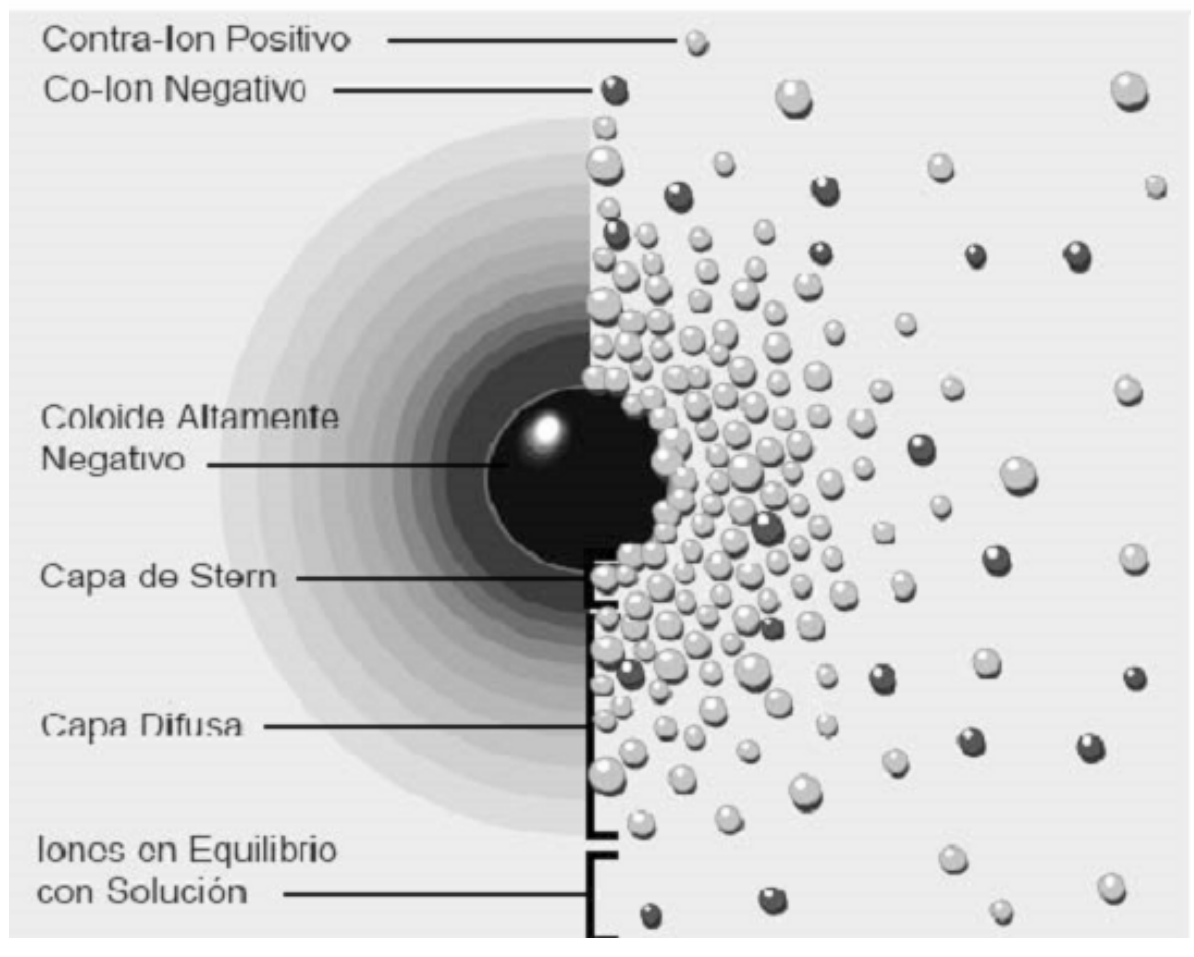

Para un mortero durante su fase plástica es útil conocer la magnitud de esta propiedad para producir suspensiones estables. El potencial zeta está relacionada con la estructura química de los pigmentos, el $\mathrm{TiO}_{2}{ }^{50}$, concentración, y $\mathrm{pH}$, proporcionan información sobre los cambios en las propiedades superficiales y la estabilidad de la dispersión. Las repulsiones mutuas entre partículas adyacentes no permite la sedimentación. En otros casos, se deben minimizar las fuerzas de repulsión entre las partículas que las enturbian, para formar grandes aglomerados que se sedimenten y sean filtrados fácilmente. 
La relación entre el potencial zeta y el potencial de superficie depende del nivel de iones en la solución. Así, en el agua, la doble capa hace que el potencial zeta sea una buena aproximación del potencial de superficie.

El equipo utilizado mide en primera instancia la llamada movilidad electroforética de las partículas, que se expresa en $(\mu / \mathrm{s} \cdot \mathrm{v} \cdot \mathrm{cm})$. El primer término es simplemente una medida de la velocidad, mientras que el segundo se refiere al campo eléctrico aplicado. De la movilidad obtenida se calcula el potencial zeta, mediante la ecuación de Smoluchowski:

$$
\zeta=\frac{4 \pi}{D} \cdot E M
$$

Donde:

$\zeta=$ potencial zeta.

$\eta=$ viscosidad de la suspensión líquida, en poisses.

$\mathrm{D}=$ constante dieléctrica.

$E M=$ Movilidad electroforética.

Las medidas se han llevado a cabo con un equipo Zeta Meter 3,0+337, 338 .

\section{2 . 10. DETERMINACION DE LAS PROPIEDADES DEL MORTERO EN ESTADO FRESCO Y ENDURECIDO}

Para caracterizar a nivel macroestructural las propiedades de ambos morteros y sus diferencias con la adición de los pigmentos.

\subsubsection{DETERMINACIÓN DEL MÓDULO DE ELASTICIDAD DINÁMICO DE LAS MUESTRAS.}

La determinación del módulo de elasticidad dinámico del hormigón, se determinado en probetas cilíndricas $7,5 \times 15 \mathrm{~cm}$, a partir de la velocidad de propagación de pulsos ultrasónicos.

La velocidad de propagación de los impulsos ultrasónicos se ha determinado de acuerdo a la norma UNE-EN 12504-4339. Para las determinaciones se ha empleado un equipo de medida de la propagación de impulsos ultrasónicos modelo PUNDIT de la casa CNS FARNELL con resolución de $0,1 \mu \mathrm{s}$.

El valor del módulo de elasticidad dinámico se obtiene a partir de la ecuación de propagación de los impulsos de las vibraciones longitudinales en un sólido elástico:
337 Hunter, R. J. (2013).

Zeta potential in colloid science: principles and applications (Vol. 2).

Academic press.

338 Nägele, E. (1985).

The zeta-potential of cement. Cement and Concrete Research, 15(3), 453-462.
339 UNE-EN 12504-4:2006

Ensayos de hormigón en estructuras. parte 4: Determinación de la velocidad de los impulsos ultrasónicos. 


$$
V=\sqrt{\frac{E}{\rho}}\left(\frac{(1-v)}{(1+v)(1-2 v)}\right)
$$

Donde:

$V$ = velocidad de propagación de los impulsos ultrasónicos.

$\rho=$ densidad de la muestra.

$v=$ coeficiente de Poisson de la muestra.

$\mathrm{E}=$ módulo de elasticidad dinámico de la muestra

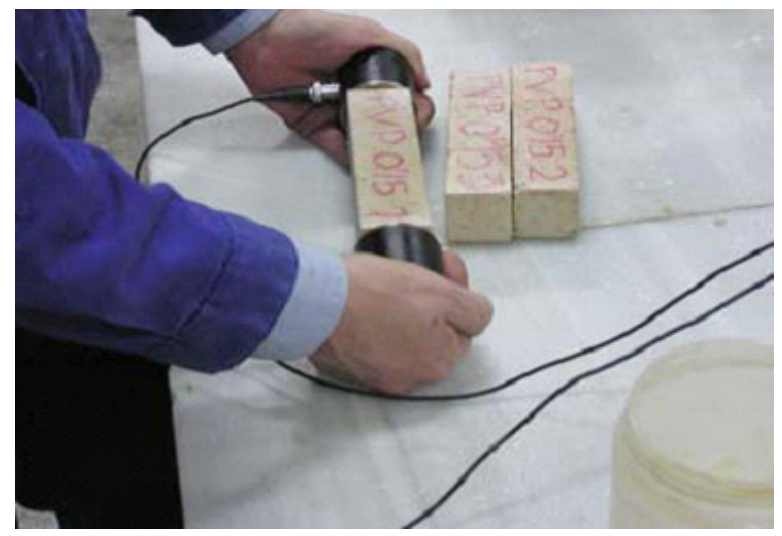

Para la determinación de la densidad de la muestra se recurrió a la pesada previa de las muestras en una balanza electrónica modelo Adam Equipment QW15 con precisión de $10 \mathrm{~g}$. Dicha densidad se obtiene dividiendo el peso aparente por el volumen de la probeta. El coeficiente de Poisson de las muestras se ha supuesto de acuerdo a la Instrucción EHE de hormigón estructural, igual a 0,2 .

\subsubsection{AMASADO DE LOS MORTEROS}

340 UNE-EN.1015-2:1999/A1:2007. Métodos de ensayo de los morteros para albañilería. parte 2:

Toma de muestra total de morteros y preparación de los morteros para ensayo.
${ }^{341}$ UNE-EN.1015-3:2000. Métodos de ensayo para morteros de albañilería. parte 3: Determinación de la consistencia del mortero fresco (por la mesa de sacudidas.
El amasado del mortero tendrá lugar de acuerdo con la UNE EN 1015-2 340 , el procedimiento de amasado para morteros de revoco, enlucido, y albañilería.

\subsubsection{DETERMINACIÓN DE LA CONSISTENCIA DE LOS MORTEROS}

Esta es una medida de la fluidez y/o humedad del mortero fresco que nos proporciona una medida de la deformabilidad del mortero cuando se somete a un esfuerzo determinado. Se ajusta a un intervalo de consistencia predefinido para evaluar sus propiedades. La magnitud se determina midiendo el diámetro de la muestra de mortero fresco después de su amasado y tiempo de reposo, en este caso 5 minutos. Se realiza segun la norma UNE EN 1015-3241. 


\subsubsection{0 . 4. DETERMINACIÓN DE LA DENSIDAD EN ESTADO FRESCO}

La densidad de un mortero fresco se determina dividiendo su masa por el volumen que ocupa cuando se introduce y se compacta en un recipiente que tiene una capacidad conocida (V). Se recomienda en la norma de referencia se ha utilizado en la medida el recipiente del dispositivo que se utiliza para medir la cantidad de aire ocluido en el mortero.

Se calcula la densidad aparente del mortero $\left(\rho_{m}\right)$ por medio de la siguiente expresión:

Se realiza segun la norma UNE EN 1015-6 $6^{342}$.

342 UNE-EN.1015-6:1999/A1:2007. métodos de ensayo de los morteros para albañilería. parte 6: Determinación de la densidad aparente del mortero fresco.

\subsubsection{DETERMINACIÓN DEL AIRE OCLUIDO}

Se aplica el método de medida recogido en la norma como método de presión, porque el contenido de aire ocluido declarado por el fabricante es inferior al $20 \%$. El principio consiste en colocar un volumen de mortero en un recipiente de medida conocido y aplicando una presión de aire se fuerza la introducción de agua en el mortero que desplaza el volumen de aire ocluido en su masa. Se realiza según el método de presión recogido en la norma UNE EN 1015-7343.

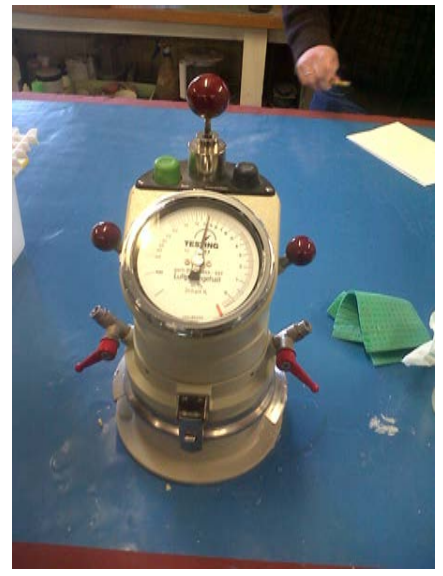

343 UNE-EN.1015-7:1999.métodos de ensayo de los morteros para albañilería. parte 7: Determinación del contenido en aire en el mortero fresco.

Fig 101. Equipo de medida de aire ocluido para morteros.

\subsubsection{DETERMINACIÓN DE LA RESISTENCIA A FLEXIÓN Y COMPRESIÓN DEL MORTERO}

El ensayo se realiza según UNE EN 1015-11344.

344 UNE-EN.1015-11:2000/A1:2007. métodos de ensayo de los morteros para albañilería. parte 11: Determinación de la resistencia a flexión y a compresión del mortero endurecido. 


\subsection{ENSAYO DE FLEXOTRACCIÓN}

Fig 102. Dispositivo de carga para la determinación de la resistencia a flexión Fuente UNE EN 1015-11.
Se realiza mediante el método de carga en tres puntos, este consiste en la rotura de las probetas prismáticas de $4 \times 4 \times 16 \mathrm{~cm}$ de tamaño mediante el apoyo de la probeta sobre dos rodillos de acero de longitud entre 45 y $50 \mathrm{~mm}$ y un diámetro de $10 \mathrm{~mm} \pm 0,5 \mathrm{~mm}$, y de un tercer rodillo de carga de la misma longitud y diámetro instalado centralmente entre los rodillos de apoyo. Los tres planos verticales que pasan por los ejes de los tres rodillos deben de ser paralelos y permanecer durante el ensayo, además de equidistantes y perpendiculares a la dirección de la probeta. Uno de los rodillos de apoyo y el rodillo de carga deben poder oscilar ligeramente para permitir una distribución uniforme de la carga sobre el total del ancho del prisma sin someterlo a esfuerzo de torsión.

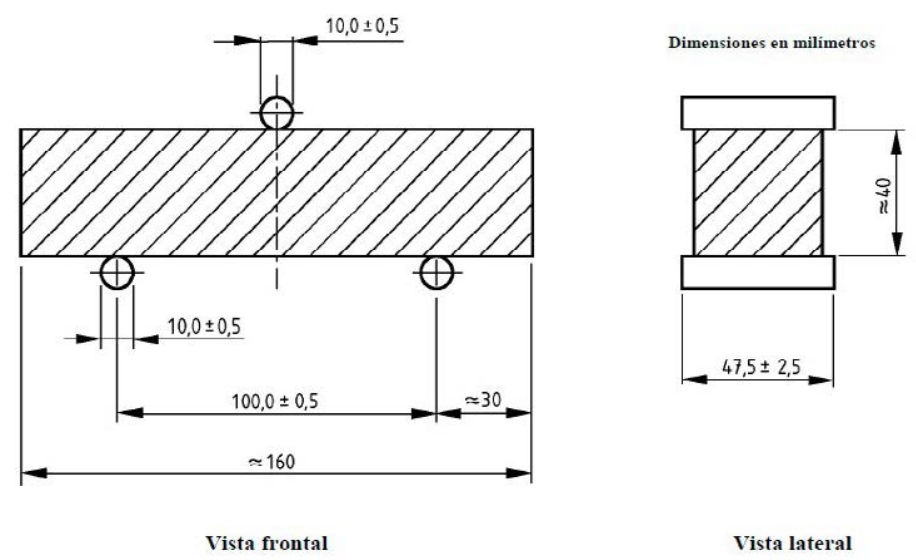

La carga se aplica sin aceleraciones bruscas a una velocidad uniforme comprendida entre los $10 \mathrm{~N} / \mathrm{s}$ y los $50 \mathrm{~N} / \mathrm{s}$. la carga máxima se registra en Newtons. Las dos mitades de la probeta partida se utilizan para determinar la resistencia a compresión.

La resistencia a flexión ( $f$ ) se expresa en $\mathrm{N} / \mathrm{mm}^{2}$ y se calcula con la siguiente ecuación:

$$
f=1,5 \frac{F l}{b d^{2}}
$$

Donde:

$F=$ carga aplicada expresada en Newtons.

I = la distancia entre apoyos expresada en milimetros

b y $d=$ las dimensiones interiores del molde 


\subsection{ENSAYO DE COMPRESIÓN}

El ensayo consiste en determinar la resistencia a compresión que presenta a el material mediante la aplicación la aplicación gradual de una fuerza axial que se aplica progresivamente a un ritmo entre $50 \mathrm{~N} / \mathrm{s}$ y $500 \mathrm{~N} / \mathrm{s}$ la probeta se instala en el dispositivo de ensayo, entre los pilares, con su eje longitudinal perpendicular a la aplicación dela carga y se coloca la otra placa de carga sobre la probeta.

La resistencia se calcula dividiendo la carga máxima soportada por la probeta por su seccion transversal, (c) se expresa en $\mathrm{N} / \mathrm{mm}^{2}$ y se calcula con la siguiente ecuación:

$$
c=\frac{F}{1600}
$$

Donde:

$F=$ carga aplicada expresada en Newtons.

$A=$ área de contacto de las placas de carga $1600 \mathrm{~mm}^{2}$. 


\subsection{MATERIALES}

La selección de materiales se realiza en el desarrollo de la segunda etapa de la metodología, en el diseño experimental y en base a la definición de las variables que habían sido señaladas durante el planteamiento de la hipótesis y objetivos.

Los criterios que se han seguido en su selección son, que sean materiales ya comercializados, de marcas reconocidas y accesibles.

\subsubsection{MORTERO FOTOCATALÍTICO}

Se utilizó un mortero fotocatalítico Morcemsec Active Capa Fina, fabricado

345 UNE-EN 998-1: 2010 Especificaciones de los morteros para albañilería.parte 1 : Morteros para revoco y enlucido.

${ }^{346}$ UNE EN 80305:2012 Cementos blancos. en color blanco por la empresa Grupo Puma en su fábrica de Málaga con marcado CE CR CSIV W2, según UNE EN 998-1345. Este mortero según la ficha técnica contiene cemento fotocatalítico blanco i active Tecno 42.5 $\mathrm{R}$ fabricado por Italcementi con $\mathrm{TiO}_{2}$ como fotocatalizador. Los ensayos de actividad fotocatalítica, autolimpieza y descontaminación se han realizado por parte del fabricante en el Instituto Eduardo Torroja de la Construcción (IETcc-CSIC).

El cemento blanco i active TECNO 42,5 R de Italcementi corresponde a un cemento BL II/B-LL 42,5 R según UNE $80305^{346}$.

\subsubsection{MORTERO NO FOTOCATALÍTICO}

Se utilizó un mortero no fotocatalítico Morcemsec Capa Fina, fabricado en color blanco por la empresa Grupo Puma en su fábrica de Málaga con marcado CE CR CSIV W2, según UNE EN 998-11.

\subsubsection{CEMENTO FOTOCATALÍTICO}

Se ha utilizado, cemento blanco i active TECNO 42,5 R de Italcementi para hacer los ensayos con los aditivos, corresponde a un cemento BL II/BLL 42,5 R según UNE 80305:2012².

\subsubsection{CEMENTO NO FOTOCATALÍTICO}

Se ha utilizado, cemento blanco para hacer los ensayos con los aditivos, corresponde a un cemento BL II/A-LL 52,5 N según UNE 80305:20122.

\subsubsection{AGUA}

Para la realización de las distintas amasadas y probetas se ha utilizado agua potable del sistema de suministro del Canal de Isabel II de Madrid. 


\subsection{6.ÁRIDO}

El arido empleado para la fabricación de las probetas para ensayar los aditivos, es una arena normalizada CEN, que cumple los requisitos impuestos por la normativa UNE EN 196-1. De acuerdo a esta normativa, la arena será natural, silícea, de granos redondeados, y cuyo contenido en sílice es al menos del 98\%. La arena normalizada CEN esta envasada en bolsas de plástico de $1350 \pm 5 \mathrm{~g}$

\subsubsection{PIGMENTOS}

Se probaron cuatro tipos diferentes de pigmentos:

- Bayferrox 330. Rojo. Num CAS. 3309-37-1. Óxido de hierro sintético $\mathrm{Fe}_{2} \mathrm{O}_{3}$. Fabricado por Lanxess

- Bayferrox 330. Color negro. Num CAS. 1317-61-9. Óxido de hierro sintético $\mathrm{Fe}_{3} \mathrm{O}_{4}$. Fabricado por Lanxess

- Bayferrox 920. Color amarillo. Num CAS. 20344-49-4. Óxido de hierro sintético arpa FeOOH. Fabricado por Lanxess

- Oxined CUERO 7025. Color marrón. Mezcla de óxidos sintéticos. Fabricado por Europigments

\subsubsection{ADITIVOS}

Los aditivos para mortero seleccionados son:

\begin{tabular}{|c|c|}
\hline Familia & Referencia \\
\hline & 15000 \\
\hline Espesante de agua & 10012 \\
\hline Aireante & H 20 \\
\hline Hidrofugante & MH 200 \\
\hline & LS 14 \\
\hline Polimeros & Oleato \\
\hline & 554 \\
\hline
\end{tabular}

Tabla 15. Listado de las referencias de aditivo ensayadas. 


\subsection{PLAN DE ENSAYOS}

\subsubsection{CONFECCION DE LA SERIE DE MORTEROS DE REVESTIMIENTO}

Para la campaña experimental se llevaron a cabo siete amasadas de mortero, seis correspondieron al mortero fotocatalítico y una al mortero no fotocatalítico, según el siguiente esquema:

\begin{tabular}{c|c|c|c|c|c|c|}
\hline $\begin{array}{c}\text { Estándar sin } \\
\text { pigmento }\end{array}$ & $\begin{array}{c}\text { Fotocatalítico } \\
\text { sin pigmento }\end{array}$ & $\begin{array}{c}\text { Pigmento } \\
\text { amarillo }(\%)\end{array}$ & $\begin{array}{c}\text { Pigmento } \\
\text { rojo }(\%)\end{array}$ & $\begin{array}{c}\text { Pigmento } \\
\text { marrón (\%) }\end{array}$ & \multicolumn{2}{|c|}{$\begin{array}{c}\text { Pigmento } \\
\text { negro (\%) }\end{array}$} \\
\hline M & MTX & MTX-A & MTX-R & MTX-M & MTX-G1 & MTX-G2 \\
\hline- & - & 0,05 & 0,04 & 0,1 & 0,015 & 0,03 \\
\hline
\end{tabular}

\section{4.1.1. DETERMINACION DEL AGUA DE AMASADO PARA} CADA MORTERO

Para cada mortero se determina la cantidad disponible en cada saco y se prepara la mezcla en seco con la cantidad de pigmento fijada siguiendo los siguientes pasos:

1. Se abre el saco y se pesa el contenido de mortero.

2. Se calcula la cantidad de pigmento necesario en cada caso para la cantidad conocida de mortero y se pesa el pigmento correspondiente.

3. Se mezclan en seco durante 2 minutos en una bolsa de plástico, el pigmento y el mortero con el fin de realizar un pre dispersión.

A partir de fijar la consistencia objetivo se determina el agua de amasado de cada mortero, como se señala en la norma UNE EN 1015-2, se sigue para ello el siguiente esquema en cada mortero:

1. Se realizan amasadas de dos kg del mortero, según UNE EN 1015-2 partiendo del agua indicada por el fabricante en la ficha técnica con el objetivo de encontrar la dosificación de agua de amasado. Según la ficha técnica de ambos morteros, MORCEMSEC CAPA FINA ACTIVE y MORCEMSEC CAPA FINA la densidad aparente en fresco es mayor de $1200 \mathrm{~kg} / \mathrm{m} 3$, por lo tanto según la tabla 2 de la norma UNE EN 1015-2 el valor de escurrimiento para estos morteros debe de ser de $175 \pm 10 \mathrm{~mm}$, medido según UNE EN 1015-3. Dado que el intervalo contemplado por la norma es tan amplio (165-185mm), fijamos como valor objetivo $169 \pm 3 \mathrm{~mm}$.

A. El amasado del mortero tendrá lugar de acuerdo con la UNE EN 1015-2, el procedimiento operatorio de amasado de morteros de revoco y enlucido, y albañilería. 


\begin{tabular}{|c|c|c|}
\hline & Rotación $\left(\mathrm{min}^{-1}\right)$ & $\begin{array}{c}\text { Movimiento } \\
\text { Planetario }\left(\mathrm{min}^{-1}\right)\end{array}$ \\
\hline Velocidad baja & $140 \pm 5$ & $62 \pm 5$ \\
\hline Velocidad alta & $285 \pm 10$ & $125 \pm 10$ \\
\hline
\end{tabular}

PROCEDIMIENTO OPERATIVO

1. Se introduce la cantidad de agua predeterminada en el recipiente de la amasadora.

2. Se coloca en su posición para el amasado.

3. Se añade el mortero seco y se amasa durante 15 s en velocidad lenta.

4. Se baja de la amasadora se retira de las paredes del recipiente y se continua el amasado a la misma velocidad durante 75 s suplementarios.

Dejar reposar durante 5 min y volver a reamasar manualmente durante 15s.

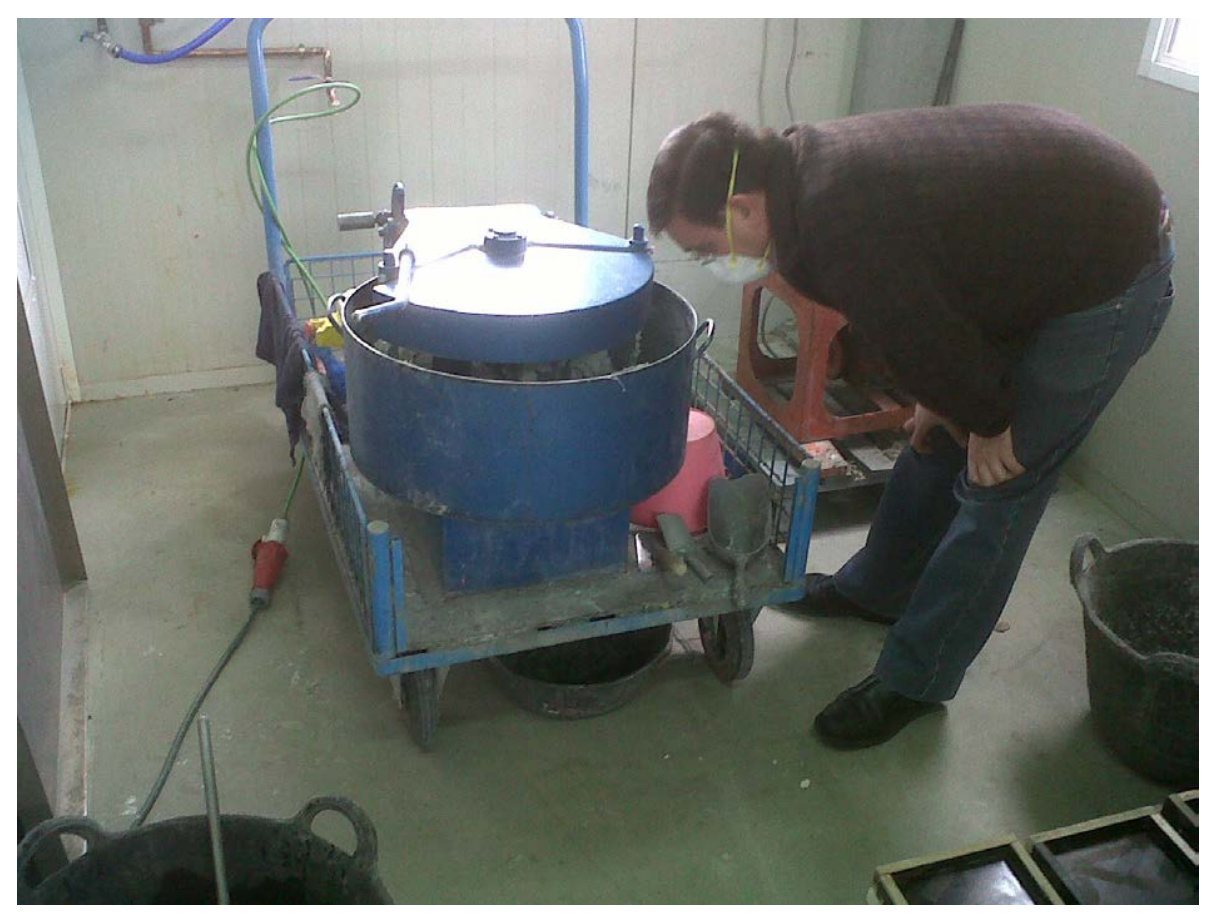

A continuación se mide la consistencia según UNE EN 1015-3.

\section{PROCEDIMIENTO OPERATIVO}

1. Se asegura que la superficie de la mesas de sacudidas está limpia, asi como la superficie interior y los bordes del molde.

2. A continuación se lubrican ligeramente con un pincel impregnado en aceite mineral de baja viscosidad.

3. Se coloca el molde troncocónico en el centro de la mesa de sacudidas apoyado por su base mayor, y se llena en dos capas con mortero fresco, cada una de las cuales se compacta con 10 golpes de pisón y se enrasa la superficie. Después se separa el molde
Tabla 17. Velocidades de la amasadora indicadas en la norma UNE-EN 196-1. 
verticalmente con precaución y se deja caer el tablero 15 veces en otros tantos segundos.

4. Se miden los dos diámetros perpendiculares de la masa extendida y se calcula la media. La consistencia del mortero se expresa en milimetros.

5. Se realizan los tanteos sucesivos necesarios para ello.

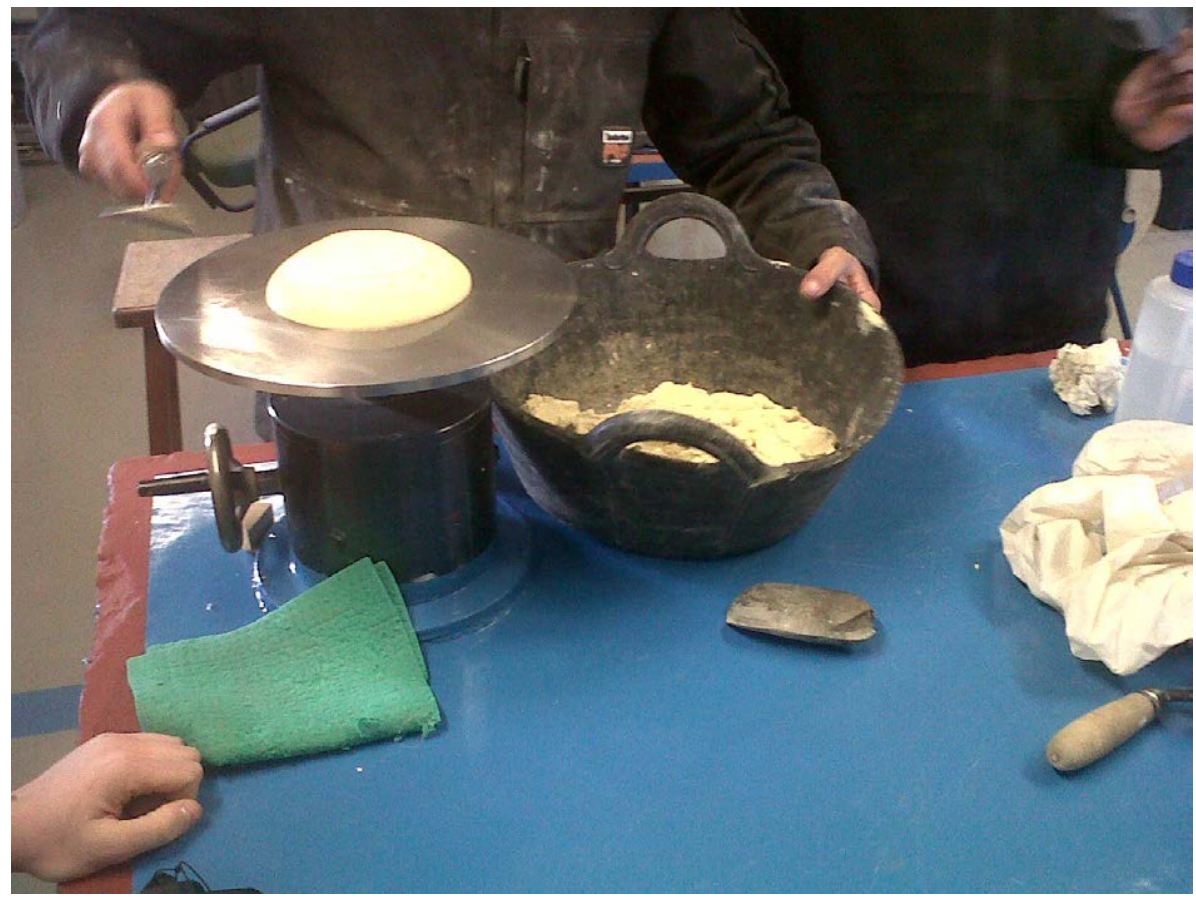

Resultados:

\begin{tabular}{|l|c|c|c|c|c|c|c|}
\hline & M & MTX & MTX-A & MTX-R & MTX-M & MTX-G1 & MTX-G2 \\
\hline Mortero (kg) & 24 & 25 & 23,9 & 23,9 & 25 & 25 & 24 \\
\hline Agua (kg) & 4,0 & 4,3 & 4,2 & 4,2 & 4,2 & 4,2 & 4,2 \\
\hline Pigmento (\%) & - & - & 0,05 & 0,04 & 0,1 & 0,015 & 0,03 \\
\hline Rel. a/mortero & 0,16 & 0,17 & 0,17 & 0,17 & 0,18 & 0,18 & 0,18 \\
\hline
\end{tabular}

\subsubsection{DETERMINACIÓN DE LAS PROPIEDADES EN ESTADO FRESCO DE CADA UNO}

\subsection{AMASADO DE LOS MORTEROS}

Una vez fijados los ratios agua/polvo para cada mortero se procede de la siguiente manera al amasado de cada mortero para poder confeccionar todas las probetas necesarias. 


\section{PROCEDIMIENTO OPERATIVO}

1. Si el mortero es coloreado, se mezcla en seco durante 2 minutos en una bolsa de plástico, el pigmento y el mortero con el fin de realizar un pre dispersión.

2. Se pesa la cantidad de agua potable tomada de la red en la mezcladora.

3. Se pone en marcha y comienza el vertido, se realiza en un tiempo entre 15-20 segundos.

4. A continuación durante 2 minutos, se amasa el mortero en una mezcladora de eje vertical IBERTEST, detenemos la amasadora y se retira el mortero que se haya podido pegar en las paredes del recipiente o en la palas y no se esté mezclando de forma homogénea con la masa durante 15 segundos, y se continua el amasado a la misma velocidad durante 1 minuto más, detenemos la amasadora y se dejar reposar 5 minutos el mortero para que los aditivos desarrollen su función.

5. Se comprueba que la masa tiene un aspecto y color homogéneo, sin exudación.

6. Se saca la masa a una cubeta de plástico y a continuación, determinamos las propiedades del mortero en estado fresco (consistencia, densidad en fresco y aire ocluido), rellenamos los moldes de las probetas.

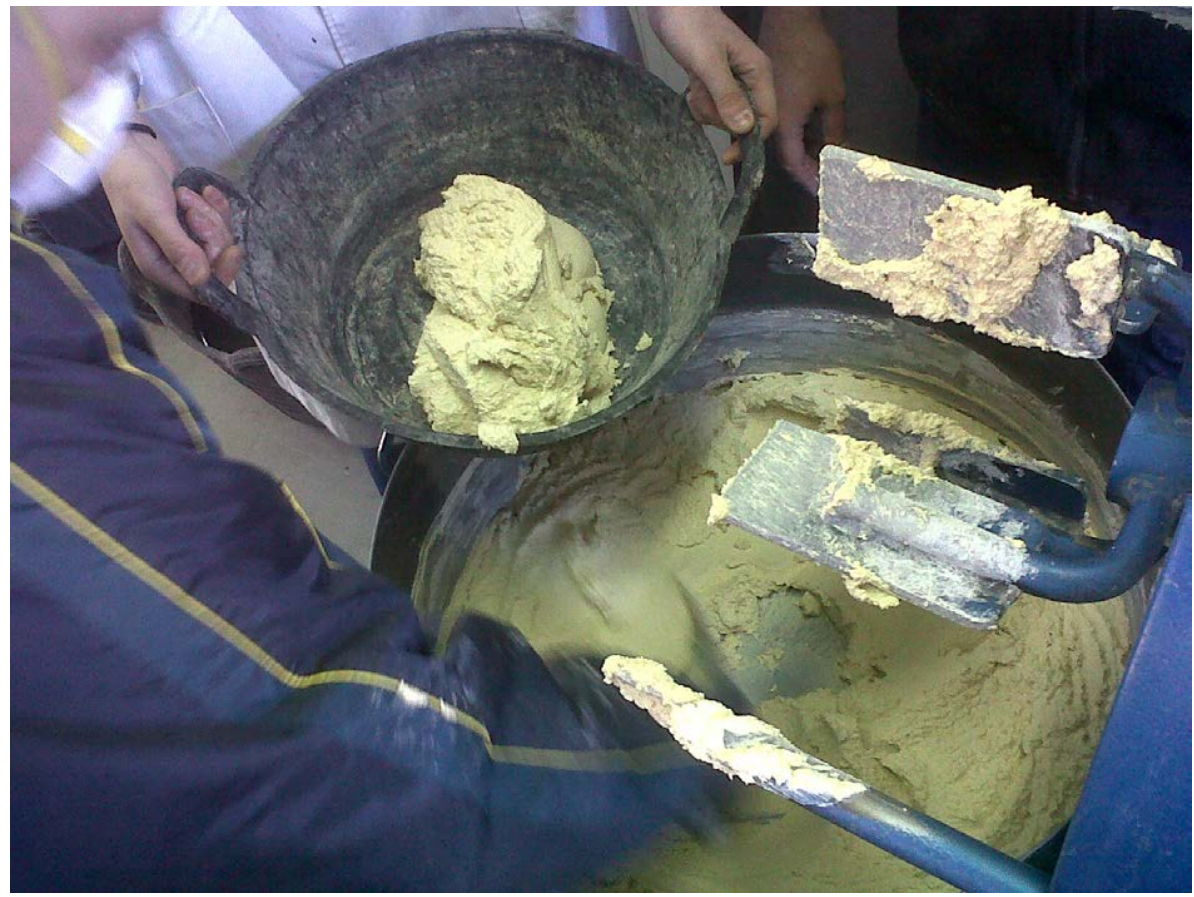




\subsection{MEDIDA DE LA CONSISTENCIA}

Esta es una medida de la fluidez y/o humedad del mortero fresco que nos proporciona una medida de la deformabilidad del mortero cuando se somete a un esfuerzo determinado. Se ajusta a un intervalo de consistencia predefinido para evaluar sus propiedades. La magnitud se determina midiendo el diámetro de la muestra de mortero fresco después de su amasado y tiempo de reposo, en este caso 5 minutos.

\section{PROCEDIMIENTO OPERATIVO}

1. Se asegura que la superficie de la mesas de sacudidas está limpia, así como la superficie interior y los bordes del molde.

2. A continuación se lubrican ligeramente con un pincel impregnado en aceite mineral de baja viscosidad.

3. Se coloca el molde troncocónico en el centro de la mesa de sacudidas apoyado por su base mayor, y se llena en dos capas con mortero fresco, cada una de las cuales se compacta con 10 golpes de pisón y se enrasa la superficie. Después se separa el molde verticalmente con precaución y se deja caer el tablero 15 veces en otros tantos segundos.

4. Se miden los dos diámetros perpendiculares de la masa extendida de dos piezas de madera colocadas en el borde y se calcula la media. La consistencia del mortero se expresa en milimetros.

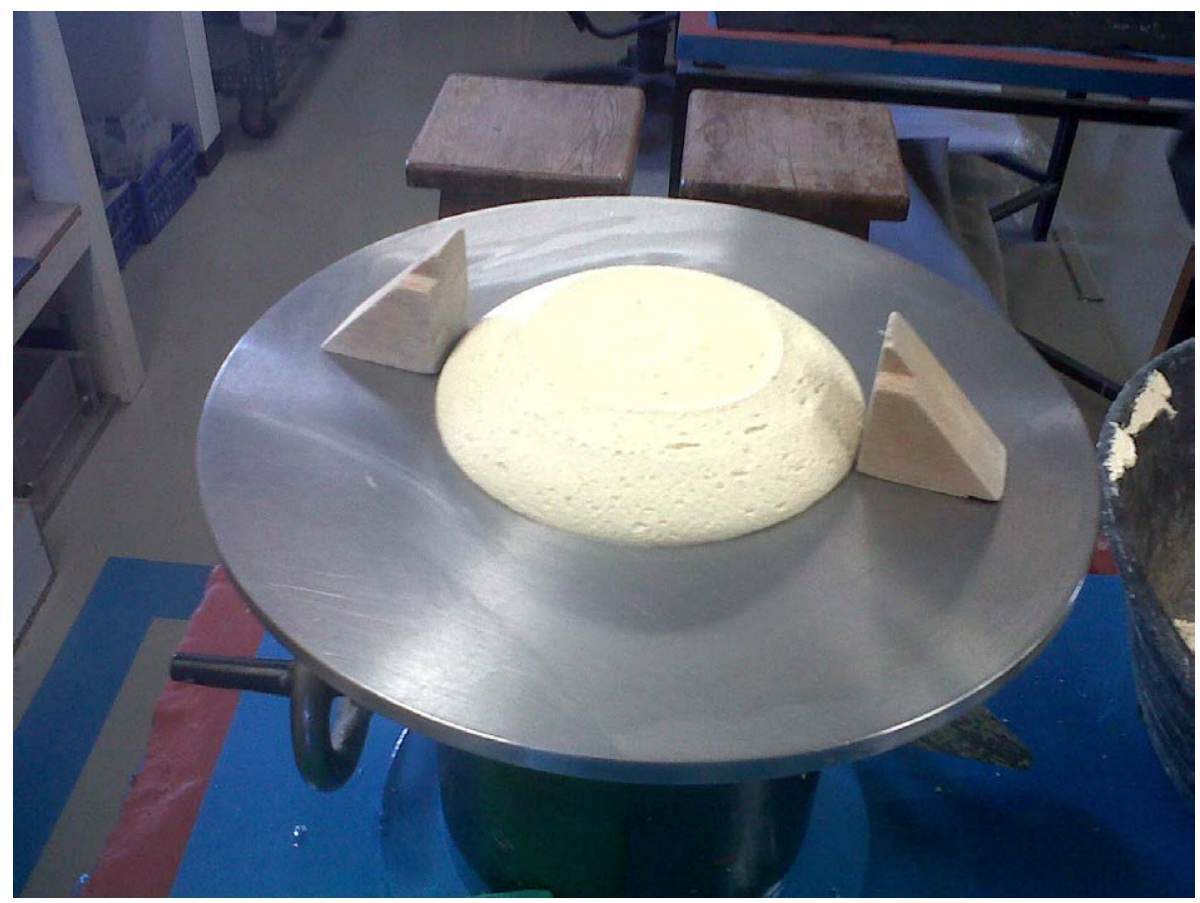




\subsection{MEDIDA DE LA DENSIDAD EN ESTADO FRESCO}

La densidad de un mortero fresco se determina dividiendo su masa por el volumen que ocupa cuando se introduce y se compacta en un recipiente que tiene una capacidad conocida (V). Como se recomienda en la norma de referencia se ha utilizado en la medida el recipiente del dispositivo que se utiliza para medir la cantidad de aire ocluido en el mortero.

\section{PROCEDIMIENTO OPERATIVO}

1. Pesar el recipiente vacío y anotar su peso, $\mathrm{m}_{1}$.

2. Se llena el recipiente hasta la mitad con mortero hasta, aproximadamente, la mitad de su altura. Se compacta el mortero, para ello basculamos el recipiente de un lado a otro, desde una altura aproximadamente de $30 \mathrm{~mm}$ y lo dejamos caer 5 veces sobre la mesa del laboratorio, una superficie rígida y sólida. A continuación del mismo modo, rellenar con mortero el recipiente hasta nivelarlo con el borde superior y compactar el mortero del mismo modo.

3. Eliminar el exceso de mortero con una regla metálica rígida de manera que quede la superficie del mortero plana y nivelada con el borde.

4. Limpiar el borde con un paño húmedo.

5. Pesar el recipiente y anotar su valor, $\mathrm{m}_{2}$, con exactitud de $1 \mathrm{~g}$.

6. Calcular la densidad aparente del mortero $\left(\rho_{\mathrm{m}}\right)$ por medio de la siguiente expresión:

$$
\rho_{m}=\frac{m_{2}-m_{1}}{V}
$$

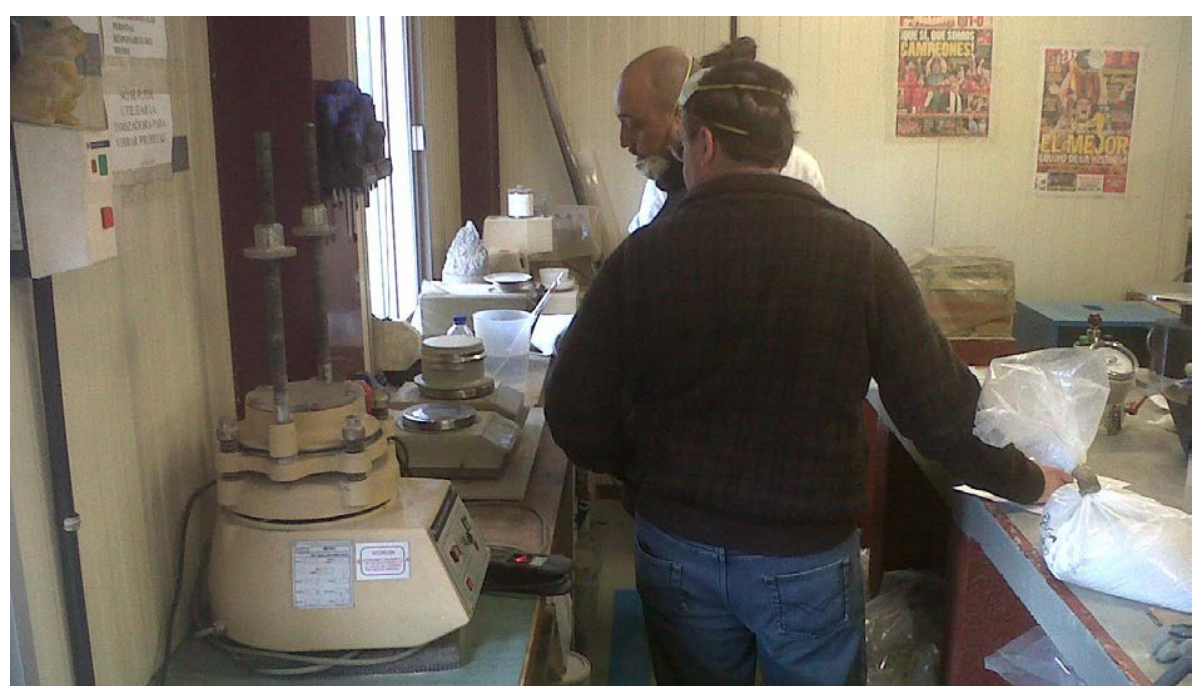

Fig 107. Determinación de la densidad en fresco, medida del peso del mortero a un volumen conocido según UNE EN 1015-6. 


\subsection{MEDIDA DEL AIRE OCLUIDO}

Se aplica el método de medida recogido en la norma como método de presión, porque el contenido de aire ocluido declarado por el fabricante es inferior al $20 \%$. El principio consiste en colocar un volumen de mortero en un recipiente de medida conocido y aplicando una presión de aire se fuerza la introducción de agua en el mortero que desplaza el volumen de aire ocluido en su masa.

\section{PROCEDIMIENTO OPERATIVO}

1. Se procede al llenado completo del recipiente con el mortero, en cuatro capas, aproximadamente iguales, compactar cada capa con 10 golpes cortos de pisón, regularmente distribuidos de manera que se obtenga una superficie del mortero plana.

2. Eliminar el exceso de mortero, con la regla para enrasar, de manera que se obtenga una superficie del mortero plana y nivelada con el borde superior del recipiente.

3. Limpiar el exterior del recipiente de tal modo que esté, además de limpio y seco, permita fijar la tapa firmemente en el recipiente.

4. Cerrar la válvula principal, llenar el espacio de aire que se encuentra debajo de la cubierta y encima del mortero con agua hasta que esta salga por los orificios laterales, cerrar las válvulas laterales e inyectar aire en la cámara de aire hasta que se haya alcanzado una presión estable. Enrasar a cero y pulsar válvula de aire. Leer el contenido de aire en el manómetro, y anotar este valor con una exactitud de, aproximadamente $0,1 \%$.

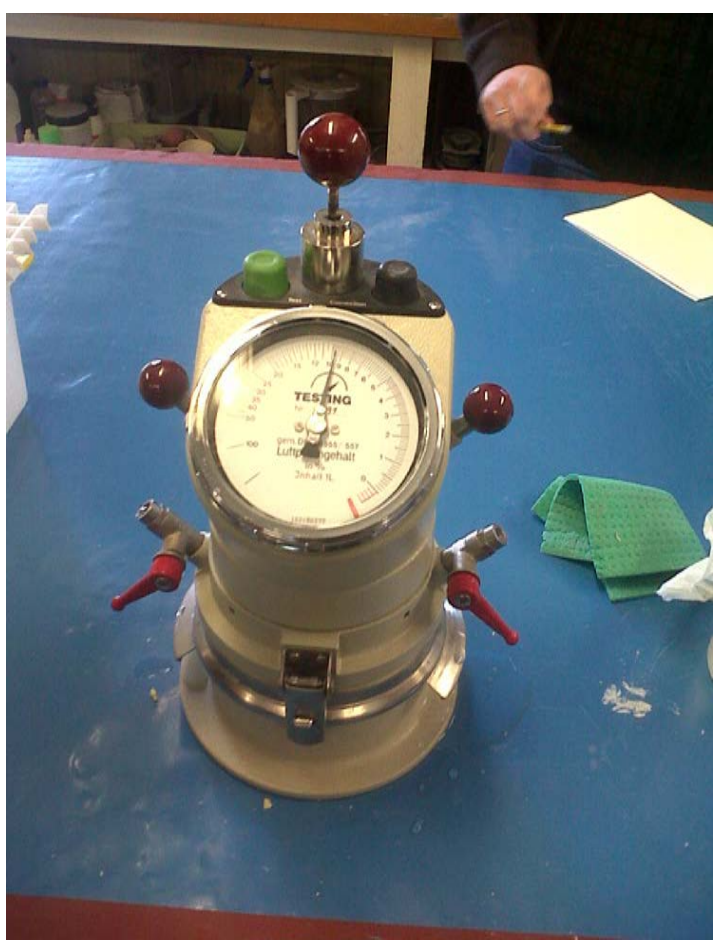



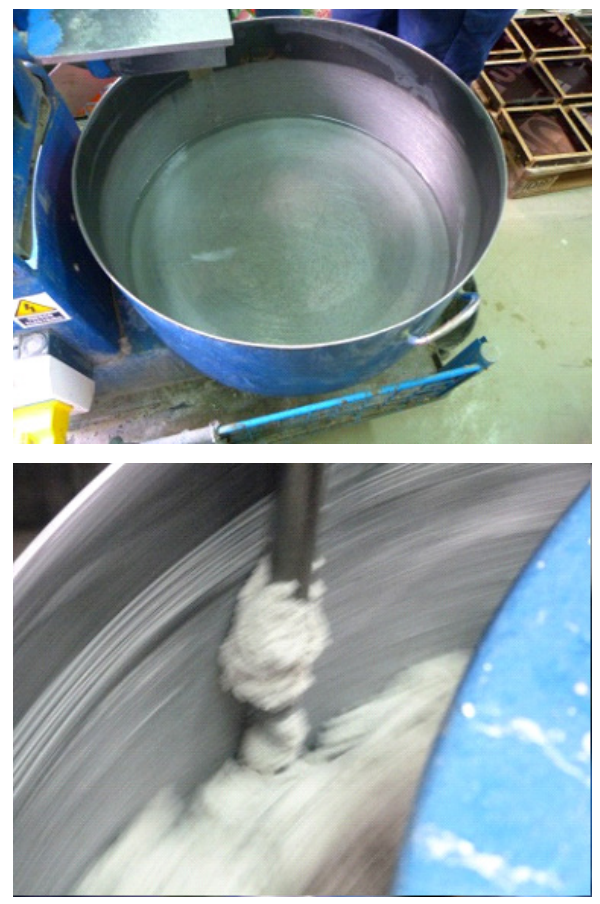

Resultados:
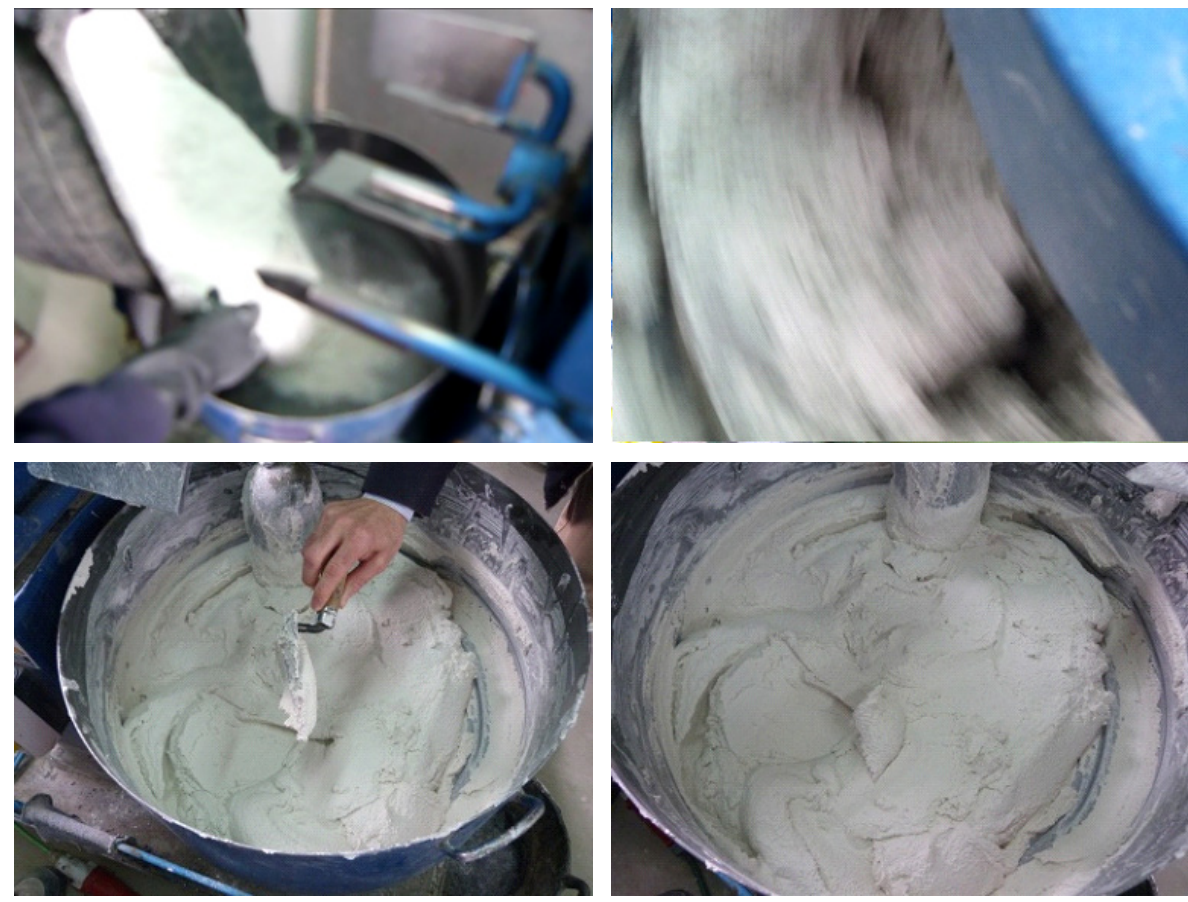

Fig 109. Proceso de amasado del mortero.

\begin{tabular}{|c|c|c|c|}
\hline Mortero & $\begin{array}{c}\text { Consistencia } \\
(\mathrm{mm})\end{array}$ & $\begin{array}{c}\text { Densidad } \\
(\mathrm{Kg} / \mathrm{l})\end{array}$ & $\begin{array}{c}\text { Aire ocluido } \\
(\%)\end{array}$ \\
\hline M & 170 & 2,00 & 7,2 \\
\hline MT-X & 170 & 2,00 & 11,0 \\
\hline MTX-A & 169 & 2,01 & 9,8 \\
\hline MTX-R & 166 & 1,99 & 10,4 \\
\hline MTX-M & 166 & 1,96 & 12,0 \\
\hline MTX-G1 & 168 & 1,94 & 12,0 \\
\hline MTX-G2 & 167 & 2,03 & 10,0 \\
\hline
\end{tabular}

Tabla 19. Características de los morteros en estado fresco.

\subsubsection{FABRICACION DE LAS PROBETAS DE MORTERO}

Con el mortero restante de cada amasada, se fabrica el mismo número de probetas:

1. 6 losas de $20 \times 20 \times 2 \mathrm{~cm}$. ( 3 acabado rugoso y 3 acabado liso)

2. 3 probetas prismáticas de $4 \times 4 \times 16 \mathrm{~cm}$

3. 6 probetas cilindricas de $7,5 \times 15 \mathrm{~cm}$

4. 16 placas Petri de $8,8 \mathrm{~cm}$ de diámetro ( 8 acabado rugoso y 8 acabado liso) 
Fig 110

(lzq) Llana metálica para el acabado fino;

(Der) Fratás de esponja para acabado rugoso.
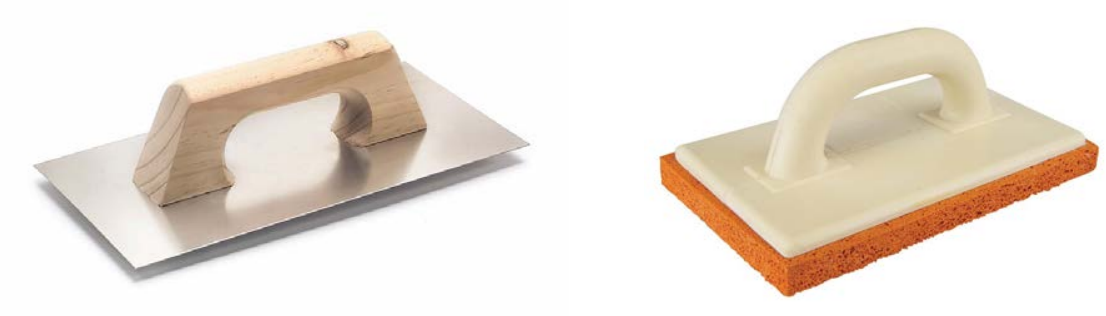

PROCEDIMIENTO OPERATIVO

Placas Petri de $\varnothing=8,8 \mathrm{~cm}$ y $\mathrm{h}=15 \mathrm{~mm}$.

1. Se etiquetan las placas para identificarlas previamente al llenado.

2. Se rellena uniformente, en una o varias veces el mortero con una cuchara de forma que sobre algo de mortero.

3. A continuación se compacta con 10 golpes.

4. Se retira el exceso de mortero con la regla plana, manteniéndose casi vertical pero inclinada en la dirección del movimiento, con lentos movimientos transversales de sierra, una vez en cada dirección.

5. Se quita el mortero que quede en el perímetro del molde como consecuencia del enrasado.

6. El acabado fino se realiza con el borde una llana metálica al cabo de 1 hora, pasando la llana con una inclinación de 30 grados respecto a la superficie de la probeta.

7. El acabado rugoso, se consigue pasando un fratás de esponja humedecido ligeramente con movimiento circular al cabo de 4 horas después del amasado.

8. Se coloca cada placa sobre una superficie horizontal en la cámara húmeda. El aire húmedo debe tener acceso a todos los lados del molde 
1. Se introduce, en una o varias veces, con una cuchara adecuada, la primera de las dos capas de mortero en cada compartimento del molde.

2. Se extiende la capa uniformemente. A continuación se compacta la primera capa de mortero con 15 golpes. Se introduce la segunda capa de mortero, asegurándose de que hay excedente de mortero, y se compacta con otros 15 golpes.

3. Se retira el exceso de mortero con la regla plana, manteniéndose casi vertical pero inclinada en la dirección del movimiento, con lentos movimientos transversales de sierra, una vez en cada dirección. Se repite este procedimiento con la regla plana mantenida a un ángulo más agudo para alisar la superficie.

4. Se quita el mortero que quede en el perímetro del molde como consecuencia del enrasado.

5. Se etiquetan los moldes para identificar las probetas.

6. El desmoldado se realiza a los dos días del enmoldado, y se lleva a cabo sin dañar las probetas utilizando un martillo de plástico. Las probetas se marcan adecuadamente para su identificación posterior.

7. El acabado fino se realiza con el borde una llana metálica al cabo de 1 hora, pasando la llana con una inclinación de 30 grados respecto a la superficie de la probeta.

8. El acabado rugoso, se consigue pasando un fratás de esponja humedecido ligeramente con movimiento circular al cabo de 4 horas después del amasado.

9. Se coloca cada molde sobre una superficie horizontal en la cámara húmeda. El aire húmedo debe tener acceso a todos los lados del molde. 
El procedimiento operativo es de acuerdo a la UNE EN 1015-11.

1. Se enmoldan las probetas inmediatamente después de la preparación del mortero. Con el molde perfectamente unido a la mesa de la compactadora, se impregna ligeramente con una fina capa de aceite mineral de baja viscosidad las caras del molde.

2. Se introduce, en una o varias veces, con una cuchara adecuada, la primera de las dos capas de mortero en cada compartimento del molde.

3. Se extiende la capa uniformemente, utilizando la espátula, mantenida verticalmente y pasándola a lo largo de cada compartimento del molde, hacia delante y hacia atrás. A continuación se compacta la primera capa de mortero con 25 golpes con la compactadora. Se introduce la segunda capa de mortero, asegurándose de que hay excedente de mortero, y se compacta con otros 25 golpes.

4. Se retira con precaución el molde de la mesa de sacudidas e inmediatamente, se quita el exceso de mortero con la regla plana, manteniéndose casi vertical pero inclinada en la dirección del movimiento, con lentos movimientos transversales de sierra, una vez en cada dirección. Se repite este procedimiento con la regla plana mantenida a un ángulo más agudo para alisar la superficie.

5. Se quita el mortero que quede en el perímetro del molde como consecuencia del enrasado.

6. Se etiquetan los moldes para identificar las probetas.

7. Se coloca cada molde sobre una superficie horizontal en la cámara húmeda. El aire húmedo debe tener acceso a todos los lados del molde.

8. El desmoldado se realiza a los dos días del enmoldado según se indica en la UNE EN 1015-11 para morteros de revoco y enlucido, y se lleva a cabo sin dañar las probetas utilizando un martillo de plástico. Las probetas se marcan adecuadamente para su identificación posterior. Se mantienen durante 5 días en cámara húmeda a $20^{\circ} \mathrm{C} \pm 2{ }^{\circ} \mathrm{C}$ y humedad relativa del $95 \% \pm 5 \%$ y 21 en cámara climática a $20^{\circ} \mathrm{C} \pm 2{ }^{\circ} \mathrm{C}$ y humedad relativa del $65 \% \pm 5 \%$ 


\section{PROBETAS CILÍNDRICAS 7,5X15 CM}

El procedimiento operativo es de acuerdo a la UNE EN 1015-11.

1. Se impregna ligeramente con una fina capa de aceite mineral de baja viscosidad las caras del molde.

2. Se introduce, en una o varias veces, con una cuchara adecuada, la primera de las dos capas de mortero en cada compartimento del molde.

3. Se compacta la primera capa de mortero con 25 golpes con barra. Se introduce la segunda capa de mortero, asegurándose de que hay excedente de mortero, y se compacta con otros 25 golpes.

4. Se quita el exceso de mortero con la regla plana, manteniéndose casi vertical pero inclinada en la dirección del movimiento, con lentos movimientos transversales de sierra, una vez en cada dirección. Se repite este procedimiento con la regla plana mantenida a un ángulo más agudo para alisar la superficie.

5. Se quita el mortero que quede en el perímetro del molde como consecuencia del enrasado.

6. Se etiquetan los moldes para identificar las probetas.

7. Se coloca cada molde sobre una superficie horizontal en la cámara húmeda. El aire húmedo debe tener acceso a todos los lados del molde.

8. El desmoldado se realiza a los dos días del enmoldado, y se lleva a cabo sin dañar las probetas utilizando un martillo de plástico. Las probetas se marcan adecuadamente para su identificación posterior.

Las probetas se han curado en cámara durante 28 días, en cámara húmeda a $20{ }^{\circ} \mathrm{C} \pm 2{ }^{\circ} \mathrm{C}$ y humedad relativa del $95 \% \pm 5 \%$, a continuación se han almacenado en cámara climática $20{ }^{\circ} \mathrm{C} \pm 2{ }^{\circ} \mathrm{C}$ y humedad relativa del $6 \% \pm 5 \%$. 


\begin{tabular}{|c|c|c|c|c|c|c|c|}
\hline $\begin{array}{l}\text { Tipo de } \\
\text { Muestra }\end{array}$ & MTX & MTX-A & MTX-R & MTX-M & MTX-G1 & MTX-G2 & $M$ \\
\hline \multirow{8}{*}{$\begin{array}{c}\text { Placas } \\
\text { Petri } \\
\text { RUGOSO }\end{array}$} & MTX-1 & MTXA-56 & MTXR-24 & MTXM-16 & MTXG1-16 & MTXG2-1 & $M-17$ \\
\hline & MTX-2 & MTXA-57 & MTXR-25 & MTXM-17 & MTXG1-17 & MTXG2-2 & $M-18$ \\
\hline & MTX-3 & MTXA-58 & MTXR-26 & MTXM-18 & MTXG1-18 & MTXG2-3 & $M-19$ \\
\hline & MTX-4 & MTXA-59 & MTXR-27 & MTXM-19 & MTXG1-19 & MTXG2-4 & $M-20$ \\
\hline & MTX-5 & MTXA-60 & MTXR-28 & MTXM-20 & MTXG1-20 & MTXG2-5 & $M-21$ \\
\hline & MTX-6 & MTXA-61 & MTXR-29 & MTXM-21 & MTXG1-21 & MTXG2-6 & $M-22$ \\
\hline & MTX-7 & MTXA-62 & MTXR-30 & MTXM-22 & MTXG1-22 & MTXG2-7 & $M-23$ \\
\hline & MTX-8 & MTXA-63 & MTXR-31 & MTXM-23 & MTXG1-23 & MTXG2-8 & $M-24$ \\
\hline \multirow{8}{*}{$\begin{array}{l}\text { Placas } \\
\text { Petri } \\
\text { LISO }\end{array}$} & MTX-9 & MTXA-48 & MTXR-16 & MTXM-24 & MTXG1-24 & MTXG2-9 & $M-25$ \\
\hline & MTX-10 & MTXA-49 & MTXR-17 & MTXM-25 & MTXG1-25 & MTXG2-10 & $M-26$ \\
\hline & MTX-11 & MTXA-50 & MTXR-18 & MTXM-26 & MTXG1-26 & MTXG2-11 & $M-27$ \\
\hline & MTX-12 & MTXA-51 & MTXR-19 & MTXM-27 & MTXG1-27 & MTXG2-12 & $M-28$ \\
\hline & MTX-13 & MTXA-52 & MTXR-20 & MTXM-28 & MTXG1-28 & MTXG2-13 & $M-29$ \\
\hline & MTX-14 & MTXA-53 & MTXR-21 & MTXM-29 & MTXG1-29 & MTXG2-14 & $M-30$ \\
\hline & MTX-15 & MTXA-54 & MTXR-22 & MTXM-30 & MTXG1-30 & MTXG2-15 & $M-31$ \\
\hline & MTX-16 & MTXA-55 & MTXR-23 & MTXM-31 & MTXG1-31 & MTXG2-16 & $M-32$ \\
\hline \multirow{6}{*}{$\begin{array}{c}\text { Probetas } \\
7,5 \times 15\end{array}$} & MTX-17 & MTXA-42 & MTXR-10 & MTXM-7 & MTXG1-7 & MTXG2-20 & $M-1$ \\
\hline & MTX-18 & MTXA-43 & MTXR-11 & MTXM-8 & MTXG1-8 & MTXG2-21 & $M-2$ \\
\hline & MTX-19 & MTXA-44 & MTXR-12 & MTXM-9 & MTXG1-9 & MTXG2-22 & $M-3$ \\
\hline & MTX-20 & MTXA-45 & MTXR-13 & MTXM-10 & MTXG1-10 & MTXG2-23 & $M-4$ \\
\hline & MTX-21 & MTXA-46 & MTXR-14 & MTXM-11 & MTXG1-11 & MTXG2-24 & $M-5$ \\
\hline & MTX-22 & MTXA-47 & MTXR-15 & MTXM-12 & MTXG1-12 & MTXG2-25 & $M-6$ \\
\hline \multirow{3}{*}{$\begin{array}{l}\text { Losa } 2 \mathrm{cms} \\
\text { RUGOSO }\end{array}$} & MTX-23 & MTXA-33 & MTXR-1 & MTXM-1 & MTXG1-1 & MTXG2-26 & $M-11$ \\
\hline & MTX-24 & MTXA-34 & MTXR-2 & MTXM-2 & MTXG1-2 & MTXG2-27 & $M-12$ \\
\hline & MTX-25 & MTXA-34 & MTXR-3 & MTXM-3 & MTXG1-3 & MTXG2-28 & $M-13$ \\
\hline \multirow{3}{*}{$\begin{array}{c}\text { Losa } 2 \mathrm{cms} \\
\text { LISO }\end{array}$} & MTX-26 & MTXA-36 & MTXR-4 & MTXM-4 & MTXG1-4 & MTXG2-29 & $M-14$ \\
\hline & MTX-27 & MTXA-37 & MTXR-5 & MTXM-5 & MTXG1-5 & MTXG2-30 & $M-15$ \\
\hline & MTX-28 & MTXA-38 & MTXR-6 & MTXM-6 & MTXG1-6 & MTXG2-31 & $M-16$ \\
\hline \multirow{3}{*}{$\begin{array}{l}\text { Probetas } \\
4 \times 4 \times 16\end{array}$} & MTX-29 & MTXA-39 & MTXR-7 & MTXM-13 & MTXG1-13 & MTXG2-17 & $M-7$ \\
\hline & MTX-30 & MTXA-40 & MTXR-8 & MTXM-14 & MTXG1-14 & MTXG2-18 & $M-8$ \\
\hline & MTX-31 & MTXA-41 & MTXR-9 & MTXM-15 & MTXG1-15 & MTXG2-19 & $M-9$ \\
\hline
\end{tabular}


INFLUENCIA DEL COLOR Y ELACABADOSUPERFICIALEN LAS PROPIEDADES

DE UN MORTEROFOTOCATALITICO COMOSOLUCIÓNDE ENVOLVENTE

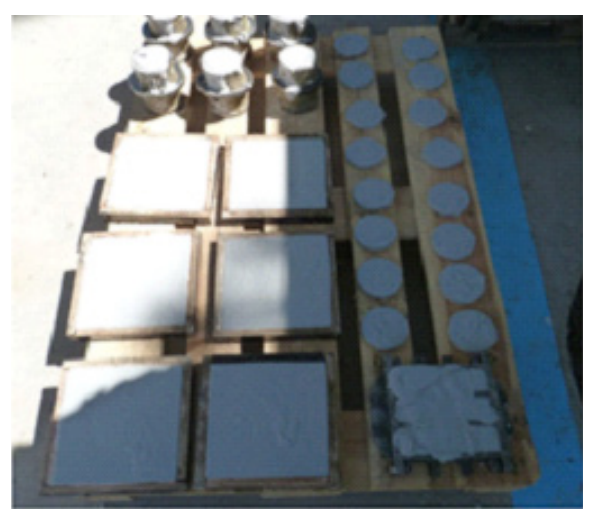

MTX-G1

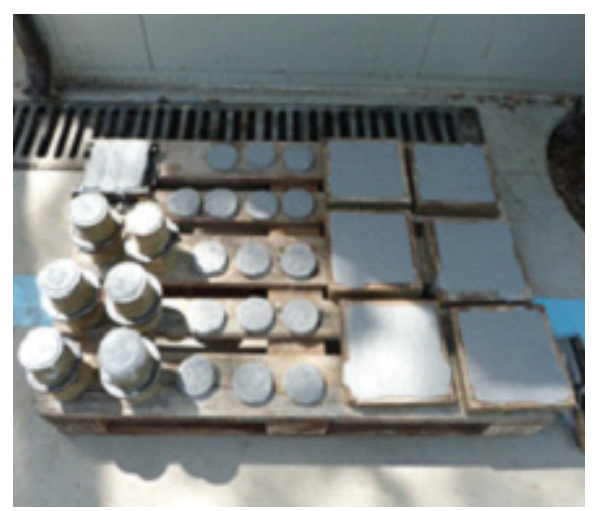

MTX-G2

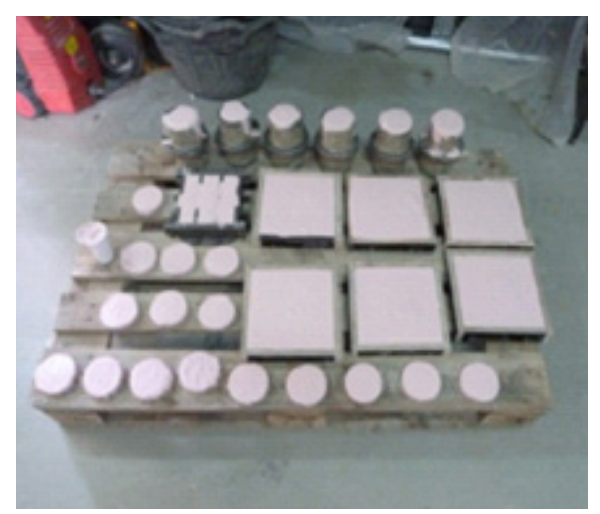

MTX-R

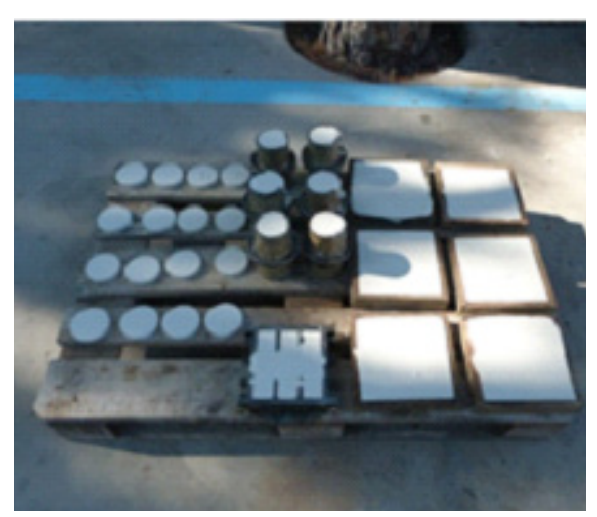

$M$

Fig 111. Probetas fabricadas en cada amasada.

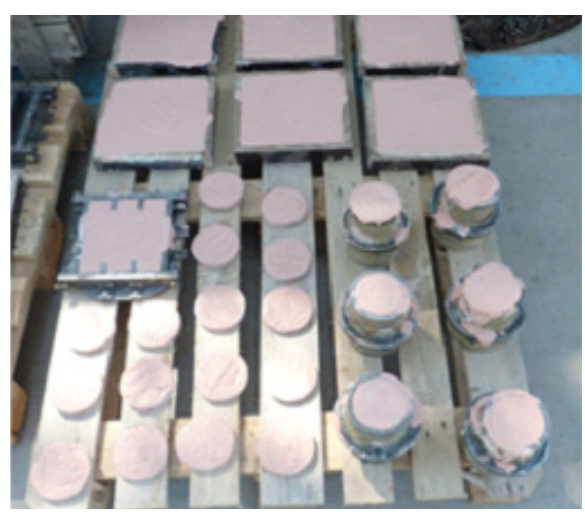

MTX-M

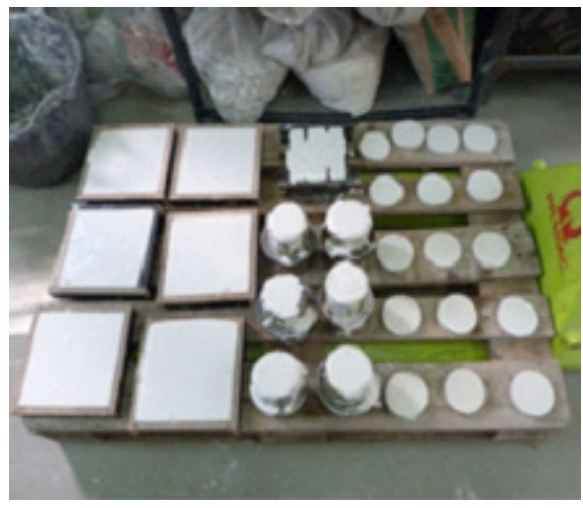

MTX

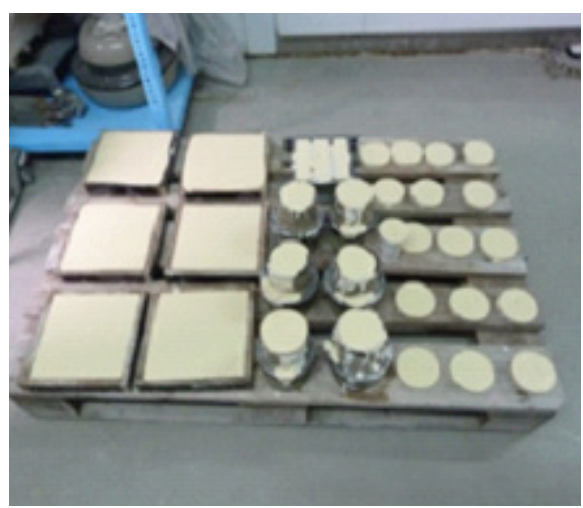

MTX-A 


\subsubsection{DETERMINACIÓN DE LA RESISTENCIA A FLEXOTRACCIÓN Y COMPRESIÓN DEL MORTERO.}

El ensayo está de acuerdo a UNE EN 1015-11 y se realiza a los 28 días de la confección de la probeta. El primer módulo de la máquina, rompe la probeta por la mitad y determina la resistencia a flexión, y con el siguiente módulo de ensayo, cada mitad es sometida a ensayo para determinar su resistencia a compresión, obteniéndose así un dato de carga y tensión por flexión y dos datos de carga y tensión por compresión.

\subsection{ENSAYO DE RESISTENCIA A FLEXOTRACCIÓN}

El ensayo se realiza mediante el método de carga en tres puntos, este consiste en la rotura de las probetas prismáticas de $4 \times 4 \times 16 \mathrm{~cm}$ de tamaño mediante el apoyo de la probeta sobre los rodillos del dispositivo en la prensa separados $10 \mathrm{~cm}$ y la aplicación de una carga superior centrada que se va incrementando gradualmente hasta llegar a la rotura.

\section{PROCEDIMIENTO OPERATIVO}

1. Se coge la probeta y se observa si tiene algún desperfecto y en su caso se anota, se limpia de partículas adheridas de mortero que pudiera tener.

2. Nos aseguramos de que la superficie del dispositivo de ensayo y los platos de apoyo estén limpios.

3. Se coloca la probeta de tal forma que se apoye en los rodillos sea sobre una de las caras que estaba colocada contra el molde.

4. Se da comienzo al ensayo y se anota el valor en rotura. Se reservan las dos mitades en que se rompe la probeta para la determinar la resistencia a compresión.

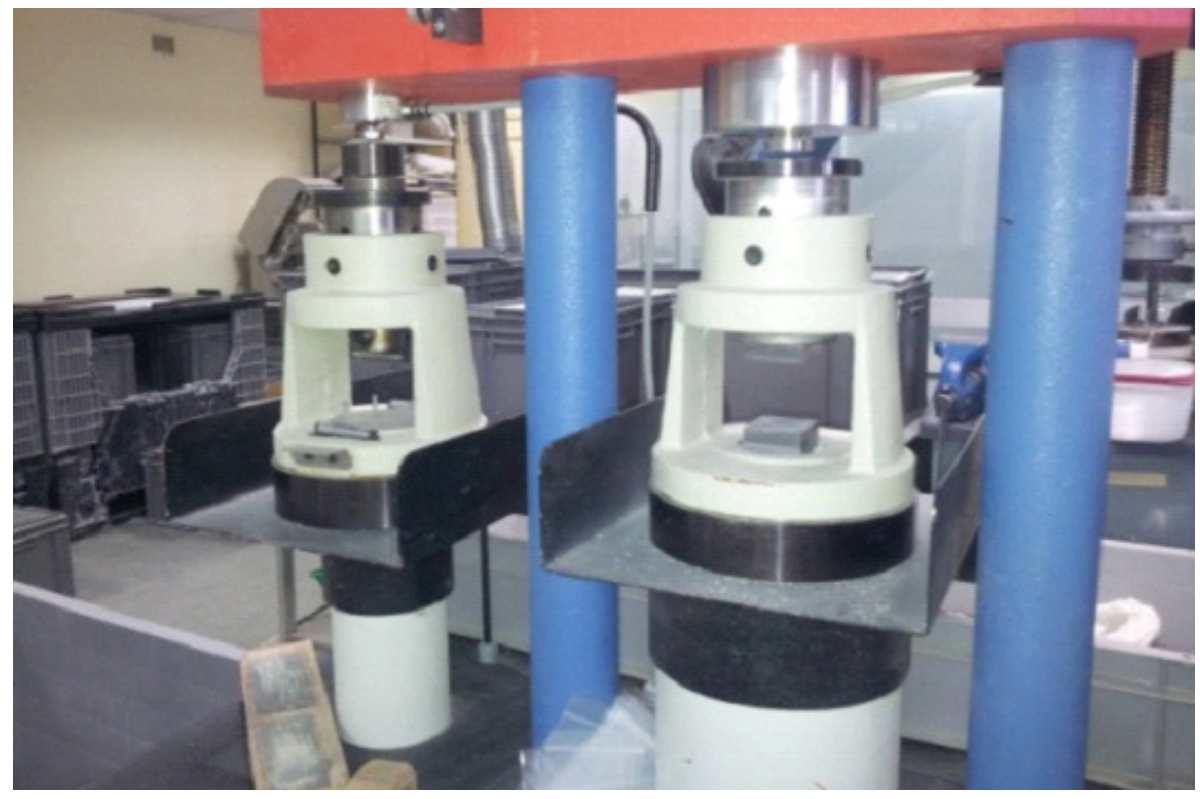




\subsection{ENSAYO DE RESISTENCIA A COMPRESIÓN}

El ensayo se realiza mediante el método de carga en tres puntos, este consiste en la rotura de las probetas prismáticas de $4 \times 4 \times 16 \mathrm{~cm}$ de tamaño mediante el apoyo de la probeta sobre los rodillos del dispositivo en la prensa separados $10 \mathrm{~cm}$ y la aplicación de una carga superior centrada que se va incrementando gradualmente hasta llegar a la rotura.

\section{PROCEDIMIENTO OPERATIVO}

1. Se coge la probeta y se observa por si tiene algún desperfecto y en su caso se anota, se limpia de partículas adheridas de mortero que pudiera tener.

2. Nos aseguramos de que la superficie del dispositivo de ensayo y los platos de apoyo estén limpios.

3. Se coloca la probeta de tal forma que las caras de apoyo contra los platos de carga sean dos caras que estaban en contacto con el molde, alineamos la probeta de tal modo que la carga se aplique en todo el ancho de las caras en contacto con las platos.

4. Se da comienzo al ensayo y se anota el valor en rotura para cada una de las dos mitades de la probeta prismática rota a flexión.

Resultados:

\section{Fabricación \\ $31 / 05 / 2013$}

Roturas $28 / 06 / 2013$

\begin{tabular}{|l|c|c|c|}
\hline & Flexión & \multicolumn{3}{|c|}{ Compresión } \\
\hline M7 & 3,21 & 5,42 & 9,26 \\
\hline M8 & 3,02 & 8,72 & 10,17 \\
\hline M9 & 3,58 & 8,69 & 9,34 \\
\hline Media (MPa) & 3,27 & & 8,60 \\
\hline Desviac. & 0,28 & \multicolumn{3}{|c|}{1,65} \\
\hline CoV. & 8,62 & \multicolumn{3}{|c|}{19,17} \\
\hline
\end{tabular}

Tabla 21. Valores de las resistencias mecánicas a 28 días de los morteros. 


\begin{tabular}{|c|c|c|c|}
\hline Fabricación & $26 / 02 / 2013$ & & \\
\hline \multirow[t]{2}{*}{ Roturas } & $26 / 03 / 2013$ & & \\
\hline & Flexión & \multicolumn{2}{|c|}{ Compresión } \\
\hline MTX-29 & 1,82 & 3,34 & 4,23 \\
\hline MTX-30 & 2,57 & 3,73 & 3,92 \\
\hline MTX-31 & 2,18 & 3,45 & 4,17 \\
\hline Media (MPa) & 2,19 & \multicolumn{2}{|c|}{3,81} \\
\hline Desviac. & 0,37 & \multicolumn{2}{|c|}{0,37} \\
\hline CoV. & 17,00 & \multicolumn{2}{|c|}{9,65} \\
\hline
\end{tabular}

\begin{tabular}{|l|l|}
\hline Fabricación & $14 / 03 / 2013$ \\
\hline Roturas & $04 / 04 / 2013$ \\
\hline
\end{tabular}

\begin{tabular}{|l|c|c|c|}
\hline & Flexión & \multicolumn{3}{|c|}{ Compresión } \\
\hline MTX-A 39 & 2,85 & 7,11 & 7,24 \\
\hline MTX-A 40 & 2,93 & 6,01 & 7,51 \\
\hline MTX-A 41 & 2,90 & 6,24 & 7,67 \\
\hline Media (MPa) & 2,89 & & 6,96 \\
\hline Desviac. & 0,04 & & 0,68 \\
\hline CoV. & 1,33 & & 9,80 \\
\hline
\end{tabular}

\begin{tabular}{|l|l|}
\hline Fabricación & $14 / 03 / 2013$ \\
\hline Roturas & $04 / 04 / 2013$ \\
\hline
\end{tabular}

Flexión

MTX-R 7

MTX-R 8

MTX-R 9

Media (MPa)

Desviac.

CoV.

3,68

4,08

3,87

3,88

0,20

5,11

\section{Compresión}

\begin{tabular}{l|r}
7,59 & 7,72 \\
\hline
\end{tabular}

7,77

7,85

7,60

7,85

7,73

0,12

1,50 


\section{Fabricación 24/04/2013 \\ Roturas 22/05/2013}

\begin{tabular}{|l|c|c|c|}
\hline & Flexión & \multicolumn{3}{|c}{ Compresión } \\
\hline MTX-M 13 & 2,89 & 7,29 & 7,49 \\
\hline MTX-M 14 & 3,08 & 7,24 & 7,31 \\
\hline MTX-M 15 & 2,74 & 7,50 & 7,49 \\
\hline Media (MPa) & 2,90 & \multicolumn{3}{|c|}{7,39} \\
\hline Desviac. & 0,17 & \multicolumn{3}{|c|}{0,12} \\
\hline CoV. & 5,76 & \multicolumn{3}{|c|}{1,61} \\
\hline
\end{tabular}

\begin{tabular}{l|l}
\hline Fabricación & $24 / 04 / 2013$ \\
\hline Roturas & $22 / 05 / 2013$
\end{tabular}

\begin{tabular}{|l|c|c|c|}
\hline & Flexión & \multicolumn{2}{|c}{ Compresión } \\
\hline M7 & 2,66 & 7,62 & 6,71 \\
\hline M8 & 2,75 & 6,50 & 7,01 \\
\hline M9 & 2,85 & 6,69 & 6,23 \\
\hline Media (MPa) & 2,75 & & 6,79 \\
\hline Desviac. & 0,10 & & \\
\hline CoV. & 3,50 & & 0,48 \\
\hline
\end{tabular}

\begin{tabular}{l|l} 
Fabricación & $22 / 05 / 2013$ \\
\hline Roturas & $19 / 06 / 2013$
\end{tabular}

\begin{tabular}{|l|c|c|c|}
\hline & Flexión & \multicolumn{3}{|c|}{ Compresión } \\
\hline MTX-G2 17 & 2,84 & 6,14 & 6,90 \\
\hline MTX-G2 18 & 2,92 & 6,84 & 6,94 \\
\hline MTX-G2 19 & 3,07 & 6,29 & 6,37 \\
\hline Media (MPa) & 2,94 & & 6,58 \\
\hline Desviac. & 0,12 & & 0,35 \\
\hline CoV. & 4,05 & \multicolumn{3}{|c|}{5,36} \\
\hline
\end{tabular}

\subsubsection{DETERMINACIÓN DEL MÓDULO DE LA ELASTICIDAD DINÁMICO}

Este es un ensayo no destructivo que se ha realizado a partir de unos elementos simples y económicos. La simplicidad del método aplicado y la correlación de los resultados obtenidos permiten valorar la rigidez del material. En el ámbito de los morteros de revestimiento, resulta de especial 
interés conocer la capacidad de deformación bajo tensión de los morteros que van a ser colocados en fachada.

\section{PROCEDIMIENTO OPERATIVO}

Previamente al ensayo se pesan las probetas de 7,5 ×15 cm para tener la densidad del mortero en estado endurecido con el volumen conocido de la probeta.

Se realiza la medida de velocidad de ultrasonido para calcular el módulo de elasticidad dinámico, coincidiendo con el ensayo de resistencias mecánicas a compresión y flexo tracción.

\begin{tabular}{|c|c|c|c|c|}
\hline Mortero & $\begin{array}{l}\text { Velocidad } \\
\text { (V) }(\mathrm{km} / \mathrm{s})\end{array}$ & $\begin{array}{c}\text { Coef. de } \\
\text { Poisson (v) }\end{array}$ & $\begin{array}{c}\text { Densidad } \\
\text { endurecido }(\mathrm{kg} / \mathrm{l})\end{array}$ & $\begin{array}{l}\text { Mod de elasticidad } \\
\text { dinámico (E) (GPa) }\end{array}$ \\
\hline M1 & 2,75 & 0,2 & 2,04 & 13,88 \\
\hline M2 & 2,56 & 0,2 & 2,02 & 11,91 \\
\hline M3 & 2,49 & 0,2 & 2,04 & 11,38 \\
\hline M4 & 2,47 & 0,2 & 2,03 & 11,15 \\
\hline M5 & 2,56 & 0,2 & 2,06 & 12,15 \\
\hline M6 & 2,50 & 0,2 & 2,04 & 11,48 \\
\hline MTX-17 & 2,68 & 0,2 & 2,00 & 12,97 \\
\hline MTX-18 & 2,67 & 0,2 & 2,01 & 12,84 \\
\hline MTX-19 & 2,71 & 0,2 & 2,05 & 13,52 \\
\hline MTXA-42 & 2,43 & 0,2 & 2,03 & 10,74 \\
\hline MTXA-43 & 2,41 & 0,2 & 2,00 & 10,45 \\
\hline MTXA-44 & 2,36 & 0,2 & 2,04 & 10,24 \\
\hline MTXA-45 & 2,36 & 0,2 & 2,01 & 10,08 \\
\hline MTXA-46 & 2,36 & 0,2 & 2,01 & 10,03 \\
\hline MTXA-47 & 2,36 & 0,2 & 2,01 & 10,06 \\
\hline MTXR-10 & 2,28 & 0,2 & 2,01 & 9,41 \\
\hline MTXR-11 & 2,26 & 0,2 & 2,00 & 9,16 \\
\hline MTXR-12 & 2,33 & 0,2 & 2,01 & 9,84 \\
\hline MTXR-13 & 2,26 & 0,2 & 2,02 & 9,29 \\
\hline MTXR-14 & 2,30 & 0,2 & 2,00 & 9,52 \\
\hline MTXR-15 & 2,32 & 0,2 & 1,98 & 9,57 \\
\hline MTXM-7 & 2,75 & 0,2 & 1,78 & 12,08 \\
\hline MTXM-8 & 2,69 & 0,2 & 1,77 & 11,51 \\
\hline MTXM-9 & 2,71 & 0,2 & 1,75 & 11,57 \\
\hline MTXM-10 & 2,71 & 0,2 & 1,82 & 12,03 \\
\hline MTXM-11 & 2,69 & 0,2 & 1,79 & 11,66 \\
\hline MTXM-12 & 2,65 & 0,2 & 1,78 & 11,25 \\
\hline MTXG1-7 & 2,75 & 0,2 & 1,74 & 11,83 \\
\hline MTXG1-8 & 2,69 & 0,2 & 1,77 & 11,50 \\
\hline MTXG1-9 & 2,71 & 0,2 & 1,75 & 11,57 \\
\hline MTXG1-10 & 2,71 & 0,2 & 1,76 & 11,67 \\
\hline MTXG1-11 & 2,69 & 0,2 & 1,74 & 11,34 \\
\hline MTXG1-12 & 2,65 & 0,2 & 1,76 & 11,13 \\
\hline MTXG2-20 & 2,61 & 0,2 & 1,96 & 11,98 \\
\hline MTXG2-21 & 2,58 & 0,2 & 1,96 & 11,74 \\
\hline MTXG2-22 & 2,65 & 0,2 & 1,97 & 12,45 \\
\hline MTXG2-23 & 2,62 & 0,2 & 1,98 & 12,23 \\
\hline MTXG2-24 & 2,61 & 0,2 & 1,92 & 11,77 \\
\hline MTXG2-25 & 2,63 & 0,2 & 1,97 & 12,26 \\
\hline
\end{tabular}




\begin{tabular}{|r|c|}
\hline Mortero & $\begin{array}{c}\text { Mod. de Elasticidad } \\
\text { dinámico }-\mathrm{E}_{\mathrm{D}} \\
(\mathrm{GPa})\end{array}$ \\
\hline M & 11,99 \\
\hline MTX & 13,11 \\
\hline MTX-A & 10,27 \\
\hline MTX-R & 9,46 \\
\hline MTX-M & 11,68 \\
\hline MTX-G1 & 11,51 \\
\hline MTX-G2 & 12,07 \\
\hline
\end{tabular}

Tabla 23. Valores de las resistencias mecánicas a 28 días de los morteros.

\subsubsection{DETERMINACIÓN DEL POTENCIAL $\zeta$ DE LOS PIGMENTOS.}

Esta es una medida de la estabilidad de una partícula en disolución y se ha utilizado para comparar y predecir el grado de estabilidad de cada pigmento en la matriz del mortero.

\section{PROCEDIMIENTO OPERATIVO}

El dispositivo consta de una cámara o celda electroforética de cuarzo y de un microscopio de alta calidad para observar las partículas coloidales que se encuentran en su interior. La cámara contiene la suspensión que va a ser analizada. Una vez llena la cámara se cierra con los tapones de plástico correspondientes. En los extremos se colocan dos electrodos de titanio y de molibdeno conectados a una fuente de tensión, creándose asi un campo eléctrico que cruza el sistema.

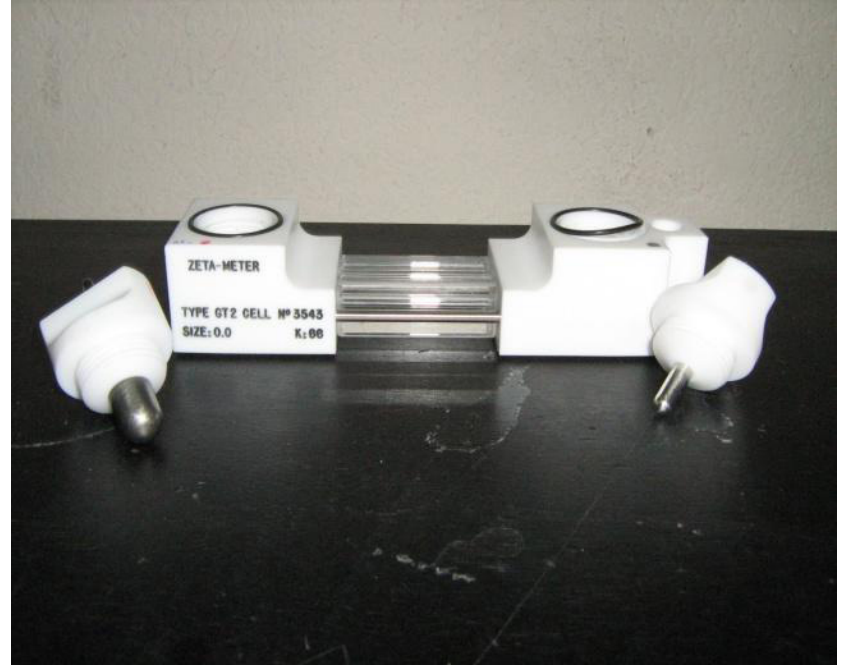

Fig 114. Equipo utilizado en las medidas, Zeta Meter 3.0+ con el microscopio y la celda micro-electroforética y electrodos utilizados en las medidas de potencial zeta.

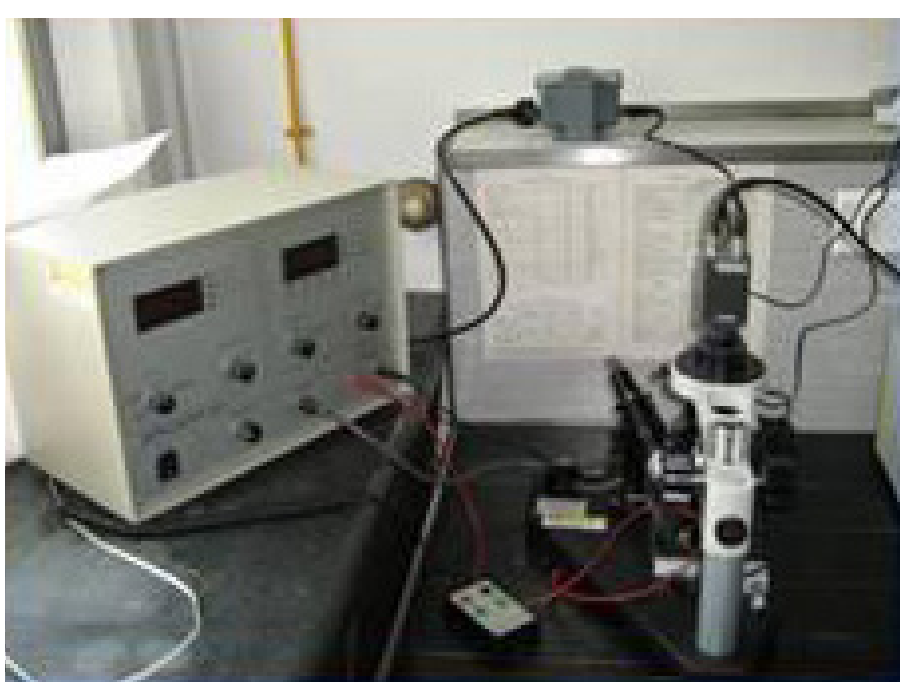

Fig 113. Equipo utilizado en las medidas, Zeta Meter 3.0+ con el microscopio y la celda micro-electroforética y electrodos utilizados en las medidas de potencial zeta. 
El equipo utilizados para aplicar la diferencia de potencial ha sido una fuente de tensión Hewlett Packard modelo HP E3611A, con regulación de línea a voltaje continuo de menos de $0.01 \%$ más $2 \mathrm{mV}$ para cualquier cambio en la tensión de línea dentro de la entrada nominal, y menos de $200 \mathrm{~V}$ y 2 $\mathrm{mV}$ pico a pico de rizado y ruido. Las medidas de $\mathrm{pH}$ se han efectuado con un $\mathrm{pH}$-metro CRISON, modelo 501 y un electrodo combinado de vidrio marca ORION, de rango de $\mathrm{pH}$ comprendido entre 0 y 14 .

Se realizan pruebas preliminares con el objetivo de determinar la cantidad de pigmento a disolver óptima, para cada material existe un rango de relaciones sólido/líquido en la que los coloides que se desplazaban hasta el campo eléctrico se distinguen claramente y se puede efectuar la medida con el mínimo error. Específicamente fueron, 0,03 g de pigmento amarillo y negro en $100 \mathrm{ml}$ de agua destilada, en $200 \mathrm{ml}$ para pigmento rojo y en $150 \mathrm{ml}$ para pigmento marrón.

1. Se prepararan las disoluciones de los pigmentos en agua destilada con las siguientes proporciones para cada uno.

2. Se aplica una diferencia de potencial de baja intensidad a través de los electrodos. En este sistema las especies cargadas se comportarán como si estuvieran en disolución, migrando hacia uno de los polos en función de su signo.

3. Los coloides cargados migran bajo la acción del campo eléctrico estando su velocidad y dirección relacionadas con el potencial zeta. Este aparato, además de una medida directa del potencial zeta, recoge la medida de la conductividad de la disolución ensayada.

4. Las imágenes captadas por el microscopio del dispositivo son reproducidas en una pantalla, siendo posible seleccionar la escala de medida más apropiada en función del número y del tamaño de los coloides, de esta forma es posible seguir el movimiento de coloides de pequeño tamaño aumentando el zoom del microscopio.

Tabla 24. Datos experimentales para las medida del pH y conductividad específica, con los datos de potencial Z, su desviación estándar y coeficiente de variación para $n=10$.

\section{Pigmento}

\begin{tabular}{|r|c|c|c|c|}
\hline & Amarillo & Negro & Marrón & Rojo \\
\hline Cantidad (g) & 0,03 & 0,03 & 0,03 & 0,03 \\
\hline Agua (ml) & 100 & 100 & 150 & 200 \\
\hline pH & 8,61 & 9,25 & 9,27 & 9,22 \\
\hline Conductividad $(\mu \mathrm{S} / \mathrm{cm})$ & 9,1 & 8,3 & 31,1 & 36,6 \\
\hline Potencial Zeta medio $(\mathrm{mV})$ & $-6,74$ & $-22,46$ & $-15,49$ & $-17,96$ \\
\hline Desviación estándar & 2,49 & 7,97 & 5,56 & 6,46 \\
\hline Coeficiente de variación & 36,99 & 35,46 & 35,88 & 35,98 \\
\hline
\end{tabular}




\subsubsection{DETERMINACIÓN POR DRX DE LA COMPOSICIÓN DE LOS PIGMENTOS.}

La difracción de rayos $\mathrm{X}$ es una técnica no destructiva que se ha utilizado para el análisis e identificación de las fases principales de los pigmentos.

Fig 115. Difractogramas del pigmento
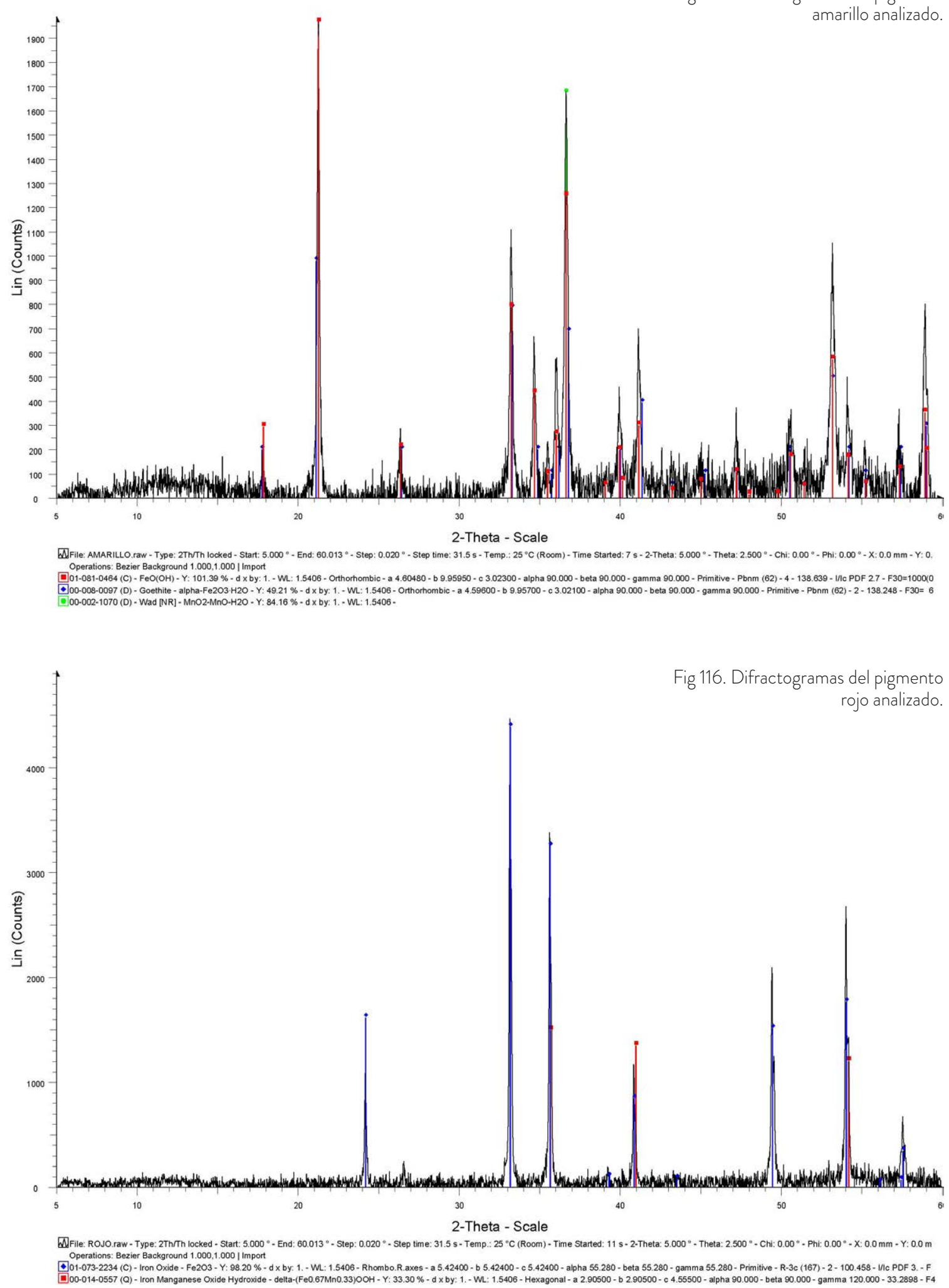

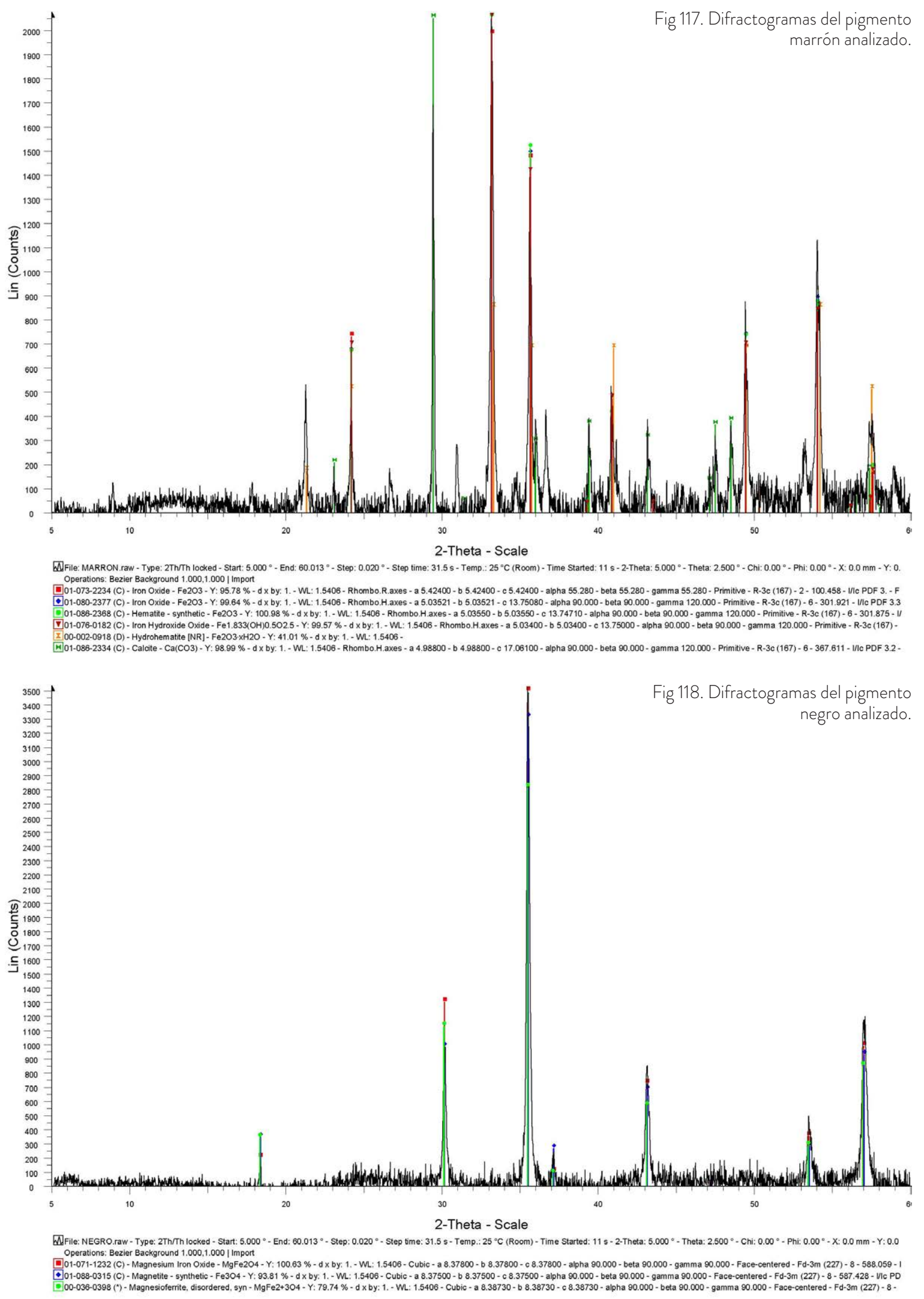


\subsubsection{DETERMINACIÓN POR FLUORESCENCIA DE RAYOS X DE LA COMPOSICIÓN DE LOS PIGMENTOS Y MORTEROS.}

La fluorescencia de rayos $X$ es una técnica no destructiva, se ha utilizado para el análisis químico elemental cuantitativo de la composición de los morteros y pigmentos. La determinación es posible mediante relaciones de proporcionalidad entre la intensidad de señal emitida y con su concentración.

El equipo empleado en este trabajo fue un espectrómetro de fluorescencia de rayos X PHILIPS PW 1404/00/01, que trabaja con un ángulo $2 \theta$ desde $O$ hasta $147,6^{\circ}$. La intensidad de corriente y voltaje aplicados al tubo generador de rayos $X$ fueron $80 \mathrm{~mA}$ y $100 \mathrm{kV}$ respectivamente, con un anticátodo de rodio de $4 \mathrm{~kW}$ de potencia. Las mezclas, una vez homogeneizadas, se depositaban en cápsulas portamuestras de aluminio sobre una capa de ácido bórico y se les aplicaba, en una prensa, una carga de 25 toneladas durante un tiempo de 9 segundos para su caracterización cuantitativa por FRX.

Resultados:

\begin{tabular}{|c|c|c|c|c|}
\hline & \multicolumn{4}{|c|}{ Pigmentos } \\
\hline & Amarillo (\%) & Rojo (\%) & Marrón (\%) & Negro (\%) \\
\hline $\mathrm{Fe}_{2} \mathrm{O}_{3}$ & 86,35 & 96,47 & 65,66 & 60,95 \\
\hline $\mathrm{CO}_{2}$ & 12,30 & 0,52 & 13,30 & 33,30 \\
\hline $\mathrm{SO}_{3}$ & 0,926 & 0,089 & 0,184 & 1,950 \\
\hline $\mathrm{SiO}_{2}$ & 0,145 & 2,020 & 3,990 & 0,819 \\
\hline $\mathrm{CaO}$ & 0,083 & 0,071 & 13,700 & 0,216 \\
\hline $\mathrm{MgO}$ & 0,063 & 0,000 & 0,837 & 0,067 \\
\hline $\mathrm{ZnO}$ & 0,049 & 0,018 & 0,025 & 0,118 \\
\hline $\mathrm{Cr}_{2} \mathrm{O}_{3}$ & 0,024 & 0,156 & 0,034 & 0,026 \\
\hline $\mathrm{MnO}$ & 0,018 & 0,090 & 0,086 & 0,589 \\
\hline $\mathrm{TiO}_{2}$ & 0,017 & 0,018 & 0,080 & 0,989 \\
\hline $\mathrm{Cl}$ & 0,015 & 0,017 & 0,015 & 0,028 \\
\hline $\mathrm{CuO}$ & 0,014 & 0,218 & 0,021 & 0,000 \\
\hline $\mathrm{K}_{2} \mathrm{O}$ & 0,005 & 0 & 0,446 & 0,019 \\
\hline $\mathrm{MoO}_{3}$ & 0 & 0,033 & 0,006 & 0,008 \\
\hline $\mathrm{Al}_{2} \mathrm{O}_{3}$ & 0 & 0,129 & 1,510 & 0,072 \\
\hline $\mathrm{NiO}$ & 0 & 0,061 & 0,011 & 0,029 \\
\hline $\mathrm{P}_{2} \mathrm{O}_{5}$ & 0 & 0,049 & 0,063 & 0,332 \\
\hline $\mathrm{Na}_{2} \mathrm{O}$ & 0 & 0,047 & 0 & 0,530 \\
\hline $\mathrm{Gd}_{2} \mathrm{O}_{3}$ & 0 & 0 & 0,045 & 0 \\
\hline $\mathrm{Nb}_{2} \mathrm{O}_{5}$ & 0 & 0,003 & 0 & 0 \\
\hline Total & 100 & 100 & 100 & 100 \\
\hline
\end{tabular}

Tabla 25. Composición elemental de los pigmentos referida a su óxido correspondiente. 


\begin{tabular}{|c|c|c|c|c|c|c|c|c|c|}
\hline & \multicolumn{9}{|c|}{ Mortero } \\
\hline & $\begin{array}{l}M \\
(\%)\end{array}$ & $\begin{array}{c}M \sin \\
\text { árido (\%) }\end{array}$ & $\begin{array}{l}\text { MTX } \\
(\%)\end{array}$ & $\begin{array}{l}\text { MTX sin } \\
\text { árido (\%) }\end{array}$ & $\begin{array}{c}\text { MTX-A } \\
(\%)\end{array}$ & $\begin{array}{c}\text { MTX-R } \\
(\%)\end{array}$ & $\begin{array}{c}M T X-M \\
(\%)\end{array}$ & $\begin{array}{c}\text { MTX-G1 } \\
(\%)\end{array}$ & $\begin{array}{c}\text { MTX-G2 } \\
(\%)\end{array}$ \\
\hline $\mathrm{CO}_{2}$ & 43,40 & 28,00 & 45,10 & 28,70 & 44,10 & 43,70 & 43,90 & 43,90 & 42,10 \\
\hline $\mathrm{CaO}$ & 42,10 & 61,78 & 40,70 & 61,75 & 40,70 & 40,14 & 41,10 & 41,02 & 42,57 \\
\hline $\mathrm{MgO}$ & 10,28 & 0,44 & 9,82 & 0,64 & 10,47 & 12,00 & 10,59 & 10,53 & 11,07 \\
\hline $\mathrm{SiO}_{2}$ & 2,750 & 6,073 & 2,820 & 4,920 & 2,880 & 2,550 & 2,850 & 3,0 & 2,910 \\
\hline $\mathrm{Al}_{2} \mathrm{O}_{3}$ & 0,662 & 1,350 & 0,534 & 0,891 & 0,624 & 0,506 & 0,558 & 0,602 & 0,516 \\
\hline $\mathrm{SO}_{3}$ & 0,452 & 1,588 & 0,450 & 1,447 & 0,465 & 0,379 & 0,460 & 0,470 & 0,445 \\
\hline $\mathrm{TiO}_{2}$ & 0 & 0,129 & 0,252 & 0,902 & 0,291 & 0,406 & 0,240 & 0,222 & 0,239 \\
\hline $\mathrm{K}_{2} \mathrm{O}$ & 0,1450 & 0,248 & 0,026 & 0,069 & 0,035 & 0,033 & 0,024 & 0,025 & 0,026 \\
\hline $\mathrm{Fe}_{2} \mathrm{O}_{3}$ & 0,1040 & 0,124 & 0,060 & 0,103 & 0,116 & 0,106 & 0,134 & 0,077 & 0,092 \\
\hline $\mathrm{Na}_{2} \mathrm{O}$ & 0,093 & 0,143 & 0,171 & 0,442 & 0,262 & 0,120 & 0,140 & 0,092 & 0 \\
\hline $\mathrm{Cl}$ & 0,0335 & 0,028 & 0,014 & 0,013 & 0,012 & 0,013 & 0,015 & 0,016 & 0,016 \\
\hline $\mathrm{P}_{2} \mathrm{O}_{3}$ & 0,022 & 0,039 & 0 & 0,048 & 0,023 & 0,026 & 0 & 0 & 0,022 \\
\hline $\mathrm{SrO}$ & 0,0143 & 0,018 & 0,014 & 0,025 & 0,013 & 0,014 & 0,014 & 0,014 & 0,014 \\
\hline $\mathrm{Cr}_{2} \mathrm{O}_{3}$ & 0 & 0 & 0 & 0 & 0 & 0 & 0 & 0 & 0,013 \\
\hline $\mathrm{ZrO}_{2}$ & 0 & 0,003 & 0 & 0,017 & 0 & 0 & 0 & 0 & \\
\hline Total & 100 & 100 & 100 & 100 & 100 & 100 & 100 & 100 & 100 \\
\hline
\end{tabular}

Tabla 26. Composición elemental de los morteros referida a su óxido correspondiente.

\subsubsection{MEDICIÓN DE LA CAPACIDAD FOTOCATALÍTICA DE AUTOLIMPIEZA}

Es un ensayo normalizado, que permite valorar si, a través de la decoloración de la rodamina en un intervalo de tiempo determinado, la muestra de cemento se puede considerar fotocatalítica. El colorante orgánico utilizado es la rodamina $B$, debido a su baja fotosensibilidad a la luz UV, a su baja sensibilidad al entorno básico, alta sensibilidad colorimétrica y a la amplia experiencia en su utilización en fotocatálisis. La rodamina $B$ se deposita sobre la superficie de las muestras en una concentración conocida. La prueba

El colorante orgánico utilizado es la rodamina $B$, debido a su baja fotosensibilidad a la luz UV, a su baja sensibilidad al entorno básico, alta sensibilidad colorimétrica y a la amplia experiencia en su utilización en fotocatálisis. La rodamina B se deposita sobre la superficie de las muestras en una concentración conocida. La prueba permite valorar si, a través de la decoloración de la rodamina, la muestra de cemento se puede considerar fotocatalítica.

Dado que en el presente método se utiliza la rodamina $B$, que es de color rojo, se examinará únicamente la coordenada colorimétrica a* (crominancia). Se utilizan las muestras confeccionadas en las placas de petri de plástico, $8,8 \mathrm{~cm}$ de diámetro y $15 \mathrm{~mm}$ de altura 
Se sigue el método descrito en la norma UNI 11259, con las siguientes diferencias en el procedimiento:

1. Medida del rango de luz ultravioleta. El equipo disponible mide en el rango 315-400 nm en vez de 300-400 nm estipulado por la norma.

2. Se utiliza un volumen de rodamina añadida a las probetas superior a la estipulada por la norma, $6 \mathrm{ml}$ en vez de $0,5 \mathrm{ml}$ para obtener volumen suficiente para extender el líquido de forma homogénea sobre toda la superficie delimitada. Se ajusta la concentración de la disolución para que la cantidad total de rodamina en la superficie de la probeta sea igual a $0.0083 \mathrm{~g} / \mathrm{l}$.

3. La balanza para pesar el cemento tiene una precisión igual a 0,1 g, inferior a la estipulada por la norma de 0,0005 g.

4. El curado de las probetas ha sido en cámara húmeda en vez de bajo agua, que es lo estipulado por la norma.

\section{PROCEDIMIENTO OPERATIVO}

El dispositivo está formado por, la muestra y la lámpara UV. La fuente luminosa que se ha utilizado es una lámpara Philips ACTINIC BL, que proporciona una intensidad de radiación sobre la superficie de la muestra que en el espectro UV-A tenga una intensidad de 3,75 $\pm 0,25 \mathrm{~W} / \mathrm{m}^{2}$.

Se utiliza un medidor Delta Ohm 2102.1 con sensor LP471 UVA para medir la intensidad de UV-A en el rango de 315 hasta $400 \mathrm{~nm}$. La medida se toma colocando el sensor encima y en el centro de la superficie de la probeta.

Las condiciones ambientales durante el ensayo son, temperatura de $20^{\circ} \mathrm{C} \pm 2^{\circ} \mathrm{C}$ y humedad relativa de $50 \pm 5 \%$. La humedad y la temperatura se controlan mediante humidificadores y aire acondicionado portátil.

1. Se extiende el producto hidrofóbico CimcurePro en todas las probetas para delimitar una zona de aproximadamente $22 \pm 2 \mathrm{~cm}^{2}$ sobre la superficie de la probeta.

2. Tras un secado completo, se aplica en la zona delimitada $6 \mathrm{ml}$ de solución de rodamina $B\left(C A S n^{0} 81-88-9\right)$ solubilizada en agua potable, de concentración 0,0083 g/l, en dos manos, cada una de $3 \mathrm{ml}$. Como resultado una concentración de rodamina en superficie igual a $2,25 \mu \mathrm{g} / \mathrm{cm}^{2}$.

3. Se introduce la probeta en un ambiente oscuro (a $20^{\circ} \mathrm{C} \pm 2^{\circ} \mathrm{C}$ y H.R. $60 \pm 10 \%$ ) durante 24 h.

4. Se efectúa la primera medición del parámetro a*(Oh), justo antes de la exposición de la probeta a la lámpara. Se toma la medida en tres puntos distintos de la muestra y se hace el promedio. 
5. Se efectúa la segunda medición tras $4 \mathrm{~h}$ de exposición: $a^{*}(4 \mathrm{~h})$. Se toma la medida en tres puntos distintos de la muestra y se hace el promedio.

6. Se efectúa la última medición tras 26 h de exposición: a*(26h). Se toma la medida en tres puntos distintos de la muestra y se hace el promedio.

7. Se repite la misma operación para las probetas asignadas para los ensayos de rodamina, siguiendo exactamente el procedimiento descrito en los puntos 1 a 6 .

Resultados:

Se tomaron medidas de las coordenadas colorimétricas $\left(a^{*}, b^{*}\right.$ y $\left.L^{*}\right)$ para todos los colores y acabados para poder definir cada color. Se considera la media de las probetas ensayadas

Para medir la actividad fotocatalítica en el ensayo de la norma UNI 11259, solo es necesario medir la coordenada $a^{*}$ en los distintos tiempos de exposición estandarizados en la norma, se recogieron también los valores para las coordenadas $b^{*}$ y L* a Oh, $4 h$ y $26 h$.

\begin{tabular}{|r|c|c|c|}
\hline & $a^{*}$ inicial & $b^{*}$ inicial & $L^{*}$ inicial \\
\hline M-R21 & 0,70 & 1,46 & 93,70 \\
\hline M-L30 & 0,50 & 0,94 & 94,20 \\
\hline MTX-R2 & 0,36 & 1,76 & 90,92 \\
\hline MTX-L9 & 0,30 & 0,97 & 94,15 \\
\hline MTXA-L48 & 2,11 & 10,13 & 89,98 \\
\hline MTXR-R56 & 1,94 & 9,49 & 89,98 \\
\hline MTXR-L22 & 4,86 & 2,59 & 87,62 \\
\hline MTXM-R22 & 6,83 & 3,72 & 87,22 \\
\hline MTXM-L27 & 9,56 & 6,74 & 83,97 \\
\hline MTXG1-R21 & 0,10 & 9,17 & 82,09 \\
\hline MTXG1-L27 & $-0,02$ & 0,22 & 84,49 \\
\hline MTXG2-R6 & $-0,07$ & $-1,02$ & 82,42 \\
\hline MTXG2-L12 & $-0,16$ & $-0,88$ & 82,79 \\
\hline
\end{tabular}




\begin{tabular}{|c|c|c|c|c|c|c|c|c|c|}
\hline & $a^{*} O h$ & $a^{*} 4 h$ & $a^{*} 26 h$ & $\mathrm{~b}^{*} \mathrm{Oh}$ & $b^{*} 4 h$ & $b^{*} 26 h$ & $\mathrm{~L}^{*} \mathrm{Oh}$ & $L^{*} 4 h$ & $L^{*} 26 h$ \\
\hline M-R21 & 14,75 & 12,48 & 11,91 & $-2,35$ & $-1,71$ & $-1,39$ & 86,93 & 88,29 & 88,74 \\
\hline$M-R 20$ & 18,16 & 14,06 & 14,14 & $-5,30$ & $-3,52$ & $-2,63$ & 85,94 & 88,23 & 88,85 \\
\hline M-L30 & 21,79 & 20,76 & 10,59 & $-5,17$ & $-3,08$ & 1,37 & 83,31 & 84,38 & 88,34 \\
\hline M-L31 & 22,00 & 21,29 & 15,29 & $-8,61$ & $-5,95$ & $-3,01$ & 85,25 & 86,33 & 88,60 \\
\hline MTX-R2 & 21,38 & 21,26 & 11,21 & $-5,17$ & $-3,08$ & 1,37 & 83,31 & 84,38 & 88,34 \\
\hline MTX-R3 & 19,03 & 16,38 & 12,29 & $-5,75$ & $-3,37$ & $-0,44$ & 85,70 & 87,14 & 89,37 \\
\hline MTX-L9 & 22,47 & 19,98 & 15,35 & $-8,61$ & $-5,95$ & $-3,01$ & 85,25 & 86,33 & 88,60 \\
\hline MTX-L10 & 22,00 & 21,29 & 14,34 & $-6,09$ & $-7,04$ & $-3,51$ & 85,99 & 84,94 & 88,49 \\
\hline MTXA-L48 & 18,23 & 18,90 & 17,33 & 2,23 & 2,25 & 2,43 & 84,73 & 85,72 & 86,51 \\
\hline MTXA-L49 & 17,77 & 15,38 & 10,74 & 0,19 & 0,53 & 1,98 & 82,55 & 85,03 & 83,96 \\
\hline MTXA-R56 & 10,96 & 11,04 & 9,94 & 7,86 & 6,62 & 6,29 & 85,06 & 87,63 & 88,07 \\
\hline MTXA-R59 & 18,41 & 17,43 & 12,60 & 2,65 & 4,84 & 7,65 & ,8375 & 85,61 & 87,85 \\
\hline MTXR-R24 & 17,77 & 15,38 & 10,77 & 0,19 & 1,06 & 1,98 & 82,55 & 85,03 & 83,96 \\
\hline MTXR-R25 & 16,03 & 14,86 & 11,29 & $-0,86$ & 1,53 & 2,20 & 83,12 & 84,24 & 82,87 \\
\hline MTXR-L22 & 18,68 & 16,43 & 13,36 & $-1,56$ & 0,32 & 0,96 & 83,22 & 83,84 & 84,36 \\
\hline MTXR-L23 & 16,56 & 14,73 & 11,15 & $-1,04$ & 0,22 & 1,53 & 83,80 & 84,99 & 85,02 \\
\hline MTXM-R18 & 13,58 & 12,42 & 11,89 & 4,82 & 4,81 & 4,77 & 88,55 & 82,49 & 82,87 \\
\hline MTXM-R22 & 16,34 & 14,98 & 14,09 & 4,45 & 5,74 & 6,65 & 80,03 & 79,37 & 80,71 \\
\hline MTXM-L27 & 21,44 & 20,17 & 18,50 & 3,05 & 2,83 & 5,69 & 83,56 & 77,97 & 79,06 \\
\hline MTXM-L29 & 30,50 & 29,57 & 27,35 & $-6,17$ & $-3,08$ & $-1,26$ & 72,31 & 72,39 & 73,61 \\
\hline MTXG1-R19 & 5,06 & 3,87 & 1,92 & $-0,92$ & $-0,71$ & 0,07 & 83,78 & 83,80 & 87,74 \\
\hline MTXG1-R21 & 3,87 & 3,21 & 2,11 & $-1,09$ & $-0,82$ & $-0,27$ & 83,35 & 84,51 & 84,35 \\
\hline MTXG1-L27 & 4,02 & 3,48 & 2,13 & $-1,73$ & $-1,49$ & $-0,80$ & 83,24 & 73,07 & 83,49 \\
\hline MTXG1-L31 & 4,60 & 3,90 & 2,31 & $-2,23$ & $-1,64$ & $-0,62$ & 82,26 & 82,49 & 83,33 \\
\hline MTXG2-R4 & 4,15 & 4,18 & 3,07 & $-3,54$ & $-2,83$ & $-2,32$ & 78,51 & 77,29 & 78,26 \\
\hline MTXG2-R6 & 10,95 & 12,05 & 8,61 & $-8,49$ & $-8,52$ & $-5,79$ & 67,41 & 67,15 & 68,14 \\
\hline MTXG2-L12 & 5,58 & 6,11 & 5,28 & $-3,77$ & $-4,28$ & $-4,01$ & 74,73 & 73,81 & 74,42 \\
\hline MTXG2-L9 & 2,83 & 2,59 & 1,83 & $-3,59$ & $-3,24$ & $-2,78$ & 79,46 & 79,01 & 79,63 \\
\hline
\end{tabular}




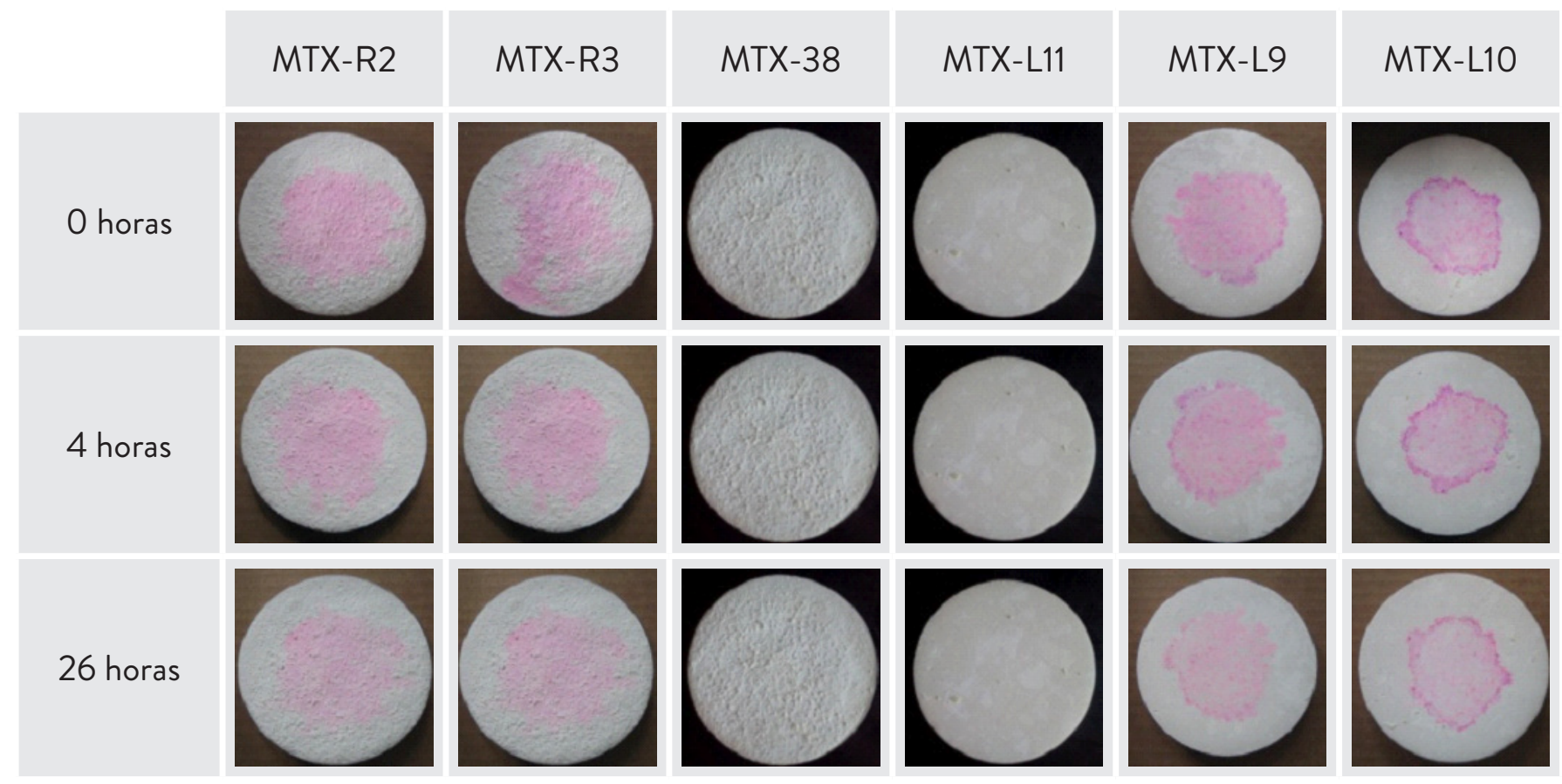

Fig 119. Aspecto de las probetas ensayadas de mortero fotocatalítico blanco a los

distintos tiempos de irradiación,

MTX (L10, L9) y MTX (R2, R3).

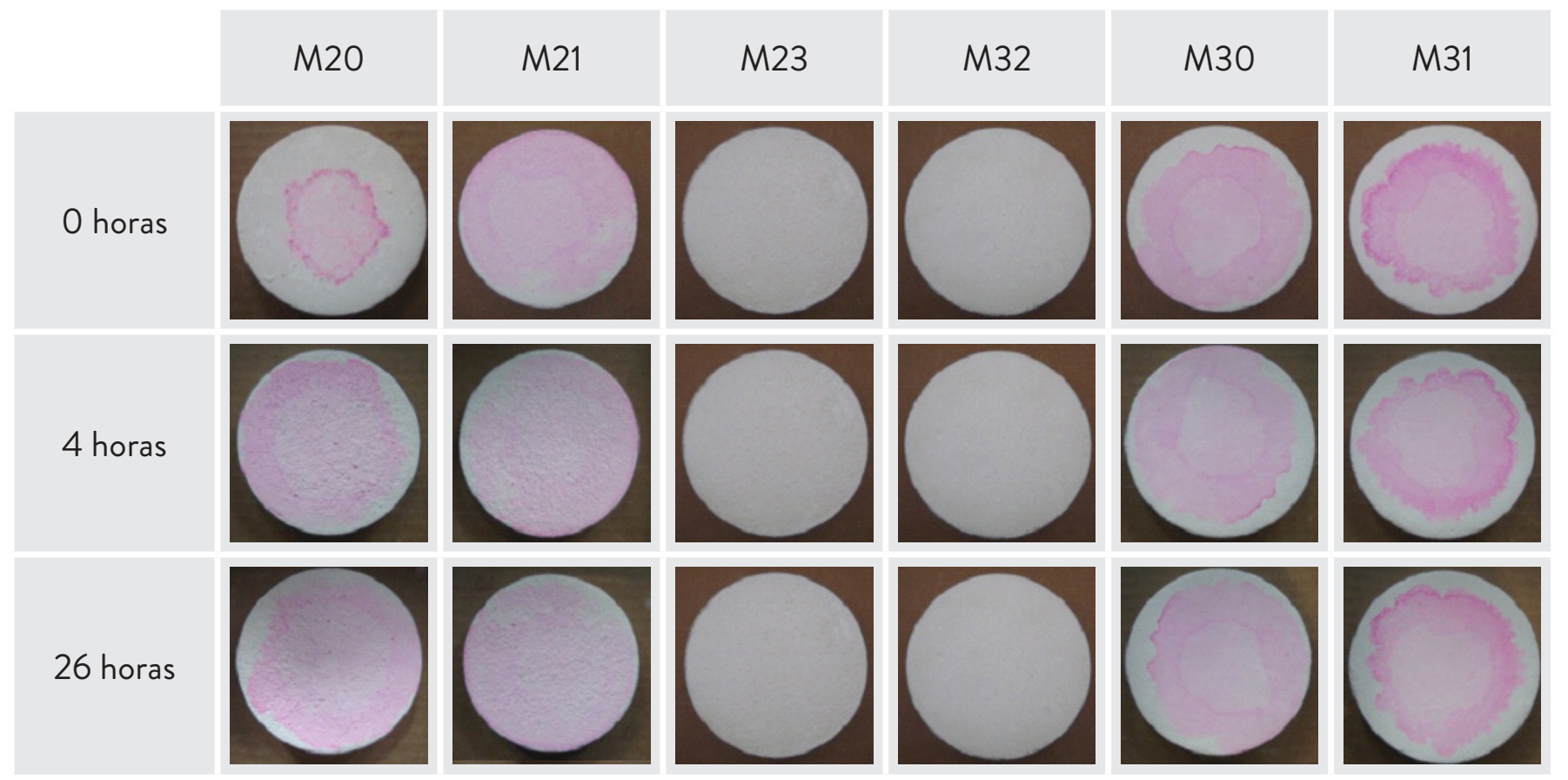

Fig 120. Aspecto de las probetas

ensayadas de mortero no fotocatalítico

blanco a los distintos tiempos de

irradiación,

$M(L 30, L 31)$ y $M(R 20, R 21)$. 


\subsubsection{MEDICIÓN DE LA CAPACIDAD FOTOCATALÍTICA DE ELIMINACIÓN DE NO}

Es un ensayo normalizado, que se utiliza para medir la capacidad de degradación del óxido de nitrógeno de un material fotocatalítico en un intervalo de tiempo determinado.

\section{PROCEDIMIENTO OPERATIVO}

Las muestras son preacondicionadas $24 \mathrm{~h}$ antes del ensayo en las condiciones de humedad y temperatura del laboratorio durante el ensayo, temperatura de $22^{\circ} \mathrm{C} \pm 2^{\circ} \mathrm{C}$ y humedad relativa de $40 \pm 2 \%$. La humedad y la temperatura se controlan mediante humidificadores y aire acondicionado portátil. Para la circulación del gas se utilizan tubos de politetrafluoretileno que no alteren la concentración de los óxidos de nitrógeno.

El $\mathrm{NO}$ se diluye con mezcla con aire puro a una concentración inicial de $400 \pm 50$ ppb, de $\mathrm{NO}$, se incluye una pequeña cantidad de $\mathrm{NO}_{2}$ de $20 \pm 5$ ppb. El procedimiento experimental $\mathrm{NO}_{x}$ seguido ha sido el correspondiente a la norma, UNI 11247.

El dispositivo está formado por, la muestra y la lámpara UV. La fuente luminosa que se ha utilizado es una lámpara LED a $365 \mathrm{~nm}$, que proporciona una intensidad de radiación sobre la superficie de la muestra con intensidad nominal de $20 \pm 1 \mathrm{~W} / \mathrm{m}^{2}$.

Se utiliza un medidor Delta Ohm 2102.1 con sensor LP471 UVA para medir la intensidad de UV-A en el rango de $315 \mathrm{~nm}$ hasta $400 \mathrm{~nm}$. La medida se toma con el sensor colocado en el interior del reactor en la superficie de la probeta. El flujo de alimentación es de 1,5litros/min. La temperatura del gas se mide antes que entre en el reactor.

El flujo de alimentación es de 1,5litros/min. La temperatura del gas se mide antes que entre en el reactor.

Se llevan a cabo las siguientes medidas:

1. La concentración inicial de los óxidos de nitrógeno antes de entrar en el reactor fotoquímico $\left(C_{A}\right)$.

2. La concentración en la salida del reactor fotoquímico en la oscuridad $\left(\mathrm{C}_{\mathrm{B}}\right)$.

3. La concentración en la salida del reactor fotoquímico con iluminación $\left(C_{L}\right)$. 
La actividad fotocatalítica de reducción de óxidos de nitrógeno, $A_{C}$, para distintos tiempos de reacción se ha calculado con la siguiente fórmula:

$$
A_{C}=100 \frac{\left(C_{B}-C_{L}\right)}{C_{B}} \cdot \frac{I_{N}}{I} \cdot \frac{S_{N}}{S}
$$

donde:

$\mathrm{A}_{C}=$ Índice adimensional de eliminación de $\mathrm{NO}_{x}$ bajo las condiciones de ensayo expresado en porcentaje.

$C_{B}$ y $C_{L}=$ concentraciones $\left(\mathrm{NO}_{X}, \mathrm{NO}_{2}, \mathrm{NO}\right)$ anteriormente definidas.

$\mathrm{S}_{\mathrm{N}}$ = área nominal de la muestra a examen $\left(64 \mathrm{~cm}^{2}\right)$.

$\mathrm{S}=$ área de la muestra sometida a ensayo expresada en $\mathrm{cm}^{2}$.

$\mathrm{I}_{\mathrm{N}}=$ irradiancia nominal $\left(20 \mathrm{~W} / \mathrm{m}^{2}\right)$.

$\mathrm{I}=$ irradiancia media expresada en $\mathrm{W} / \mathrm{m}^{2}$.

Resultados:

Tabla 29. Parámetros de ensayo del procedimiento experimental de las probetas ensayadas

\begin{tabular}{|c|c|c|c|}
\hline $\begin{array}{c}\text { Flujo } \\
(1 / \mathrm{min})\end{array}$ & $\begin{array}{c}\mathrm{I}_{\mathrm{N}} \\
\left(\mathrm{W} / \mathrm{m}^{2}\right)\end{array}$ & $\begin{array}{c}\mathrm{S}_{\mathrm{N}} \\
\left(\mathrm{cm}^{2}\right)\end{array}$ & $\begin{array}{c}\text { Temperatura } \\
\left({ }^{\circ} \mathrm{C}\right)\end{array}$ \\
\hline 1,50 & 20,00 & 64,00 & 25,00 \\
\hline
\end{tabular}

\begin{tabular}{|c|c|c|c|c|c|c|c|c|c|c|c|c|c|}
\hline \multirow[b]{2}{*}{ Probeta } & \multirow{2}{*}{$\begin{array}{c}\text { Tiempo de } \\
\text { Iluminación } \\
\text { (min) }\end{array}$} & \multicolumn{3}{|c|}{$C_{A}(p p b)$} & \multicolumn{3}{|c|}{$C_{B}(p p b)$} & \multicolumn{3}{|c|}{$C_{L}(p p b)$} & \multicolumn{3}{|c|}{$A_{C}(\%)$} \\
\hline & & NO & $\mathrm{NO}_{2}$ & $\mathrm{NO}_{x}$ & NO & $\mathrm{NO}_{2}$ & $\mathrm{NO}_{x}$ & NO & $\mathrm{NO}_{2}$ & $\mathrm{NO}_{x}$ & $\mathrm{NO}$ & $\mathrm{NO}_{2}$ & $\mathrm{NO}_{x}$ \\
\hline M-L1 & 30 & 439,55 & 29,78 & 469,33 & 418,03 & 27,69 & 445,72 & 417,87 & 28,56 & 446,43 & 0 & -3 & 0 \\
\hline$M-L 2$ & 30 & 439,60 & 29,75 & 469,35 & 421,90 & 27,73 & 449,63 & 418,50 & 28,88 & 447,38 & 1 & -4 & 1 \\
\hline MTX-L" & 30 & 419,95 & 27,86 & 447,81 & 412,83 & 29,57 & 442,40 & 368,08 & 28,99 & 397,07 & 11 & 2 & 10 \\
\hline MTX-L! & 30 & 417,60 & 28,24 & 448,84 & 402,80 & 25,82 & 428,62 & 346,50 & 27,41 & 373,91 & 14 & -6 & 13 \\
\hline MTX-A-L2 & 30 & 414,63 & 28,16 & 442,79 & 377,24 & 38,93 & 416,17 & 350,80 & 33,28 & 384,08 & 7 & 15 & 8 \\
\hline MTX-A-L1 & 30 & 438,30 & 27,16 & 465,46 & 410,90 & 27,16 & 438,06 & 361,50 & 26,46 & 387,96 & 12 & 3 & 11 \\
\hline MTX-R-L2 & 30 & 430,28 & 27,25 & 457,53 & 395,65 & 41,30 & 436,95 & 297,65 & 40,51 & 338,16 & 25 & 2 & 23 \\
\hline MTX-R-L3 & 30 & 448,80 & 30,12 & 478,92 & 446,60 & 28,90 & 475,50 & 352,20 & 29,67 & 381,87 & 21 & -3 & 20 \\
\hline MTX-M-L1 & 30 & 444,35 & 31,04 & 475,39 & 447,80 & 31,99 & 479,79 & 409.70 & 31,73 & 441,43 & 9 & 1 & 8 \\
\hline MTX-M-L2 & 30 & 442,80 & 29,72 & 472,52 & 425,10 & 28,01 & 453,11 & 388,60 & 28,05 & 416,65 & 9 & 0 & 8 \\
\hline MTX-G1-L1 & 30 & 428,93 & 31,18 & 460,11 & 399,19 & 29,59 & 428,78 & 321,82 & 31,70 & 353,52 & 19 & -7 & 18 \\
\hline MTX-G1-L2 & 30 & 445,30 & 27,62 & 472,92 & 421,56 & 27,68 & 449,24 & 324,42 & 25,43 & 349,85 & 23 & 8 & 22 \\
\hline MTX-G2-L1 & 30 & 420,99 & 29,12 & 450,11 & 416,77 & 30,38 & 447,15 & 368,59 & 30,27 & 398,86 & 12 & 0 & 11 \\
\hline MTX-G2-L2 & 30 & 414,92 & 26,99 & 441,91 & 397,34 & 28,46 & 425,80 & 342,96 & 28,96 & 371,92 & 14 & -2 & 13 \\
\hline
\end{tabular}

Tabla 30. Resultados obtenidos, 
I NFLUENCIA DEL COLOR Y ELACABADOSUPERFICIAL EN LAS PROPIEDADES DE UN MORTEROFOTOCATALITICOCOMOSOLUCIÓNDEENVOLVENTE

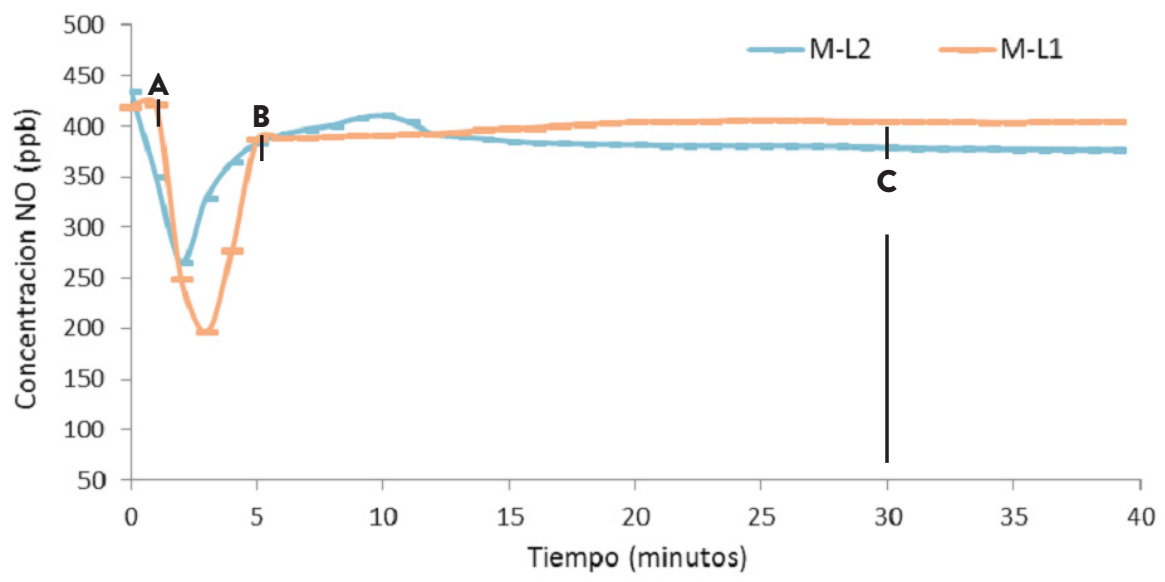

Fig 121. Gráfica con la evolución de concentraciones de $\mathrm{NO}$ durante el ensayo de la muestra de mortero no fotocatalítico liso $(M-L)$

A) Inyección de gas al reactor.

B) Comienzo de la iluminación

C) Fin de la iluminación)

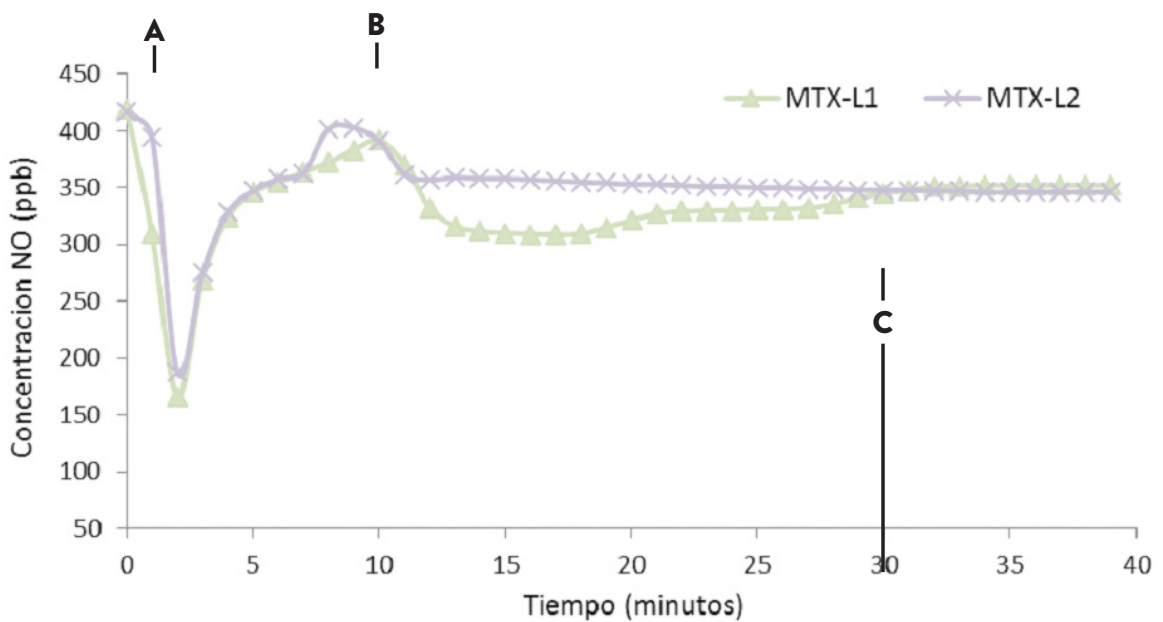

Fig 122. Gráfica con la evolución de concentraciones de $\mathrm{NO}$ durante el ensayo de la muestra de mortero fotocatalítico liso (MTX-L).

A) Inyección de gas al reactor.

B) Comienzo de la iluminación.

C) Fin de la iluminación)

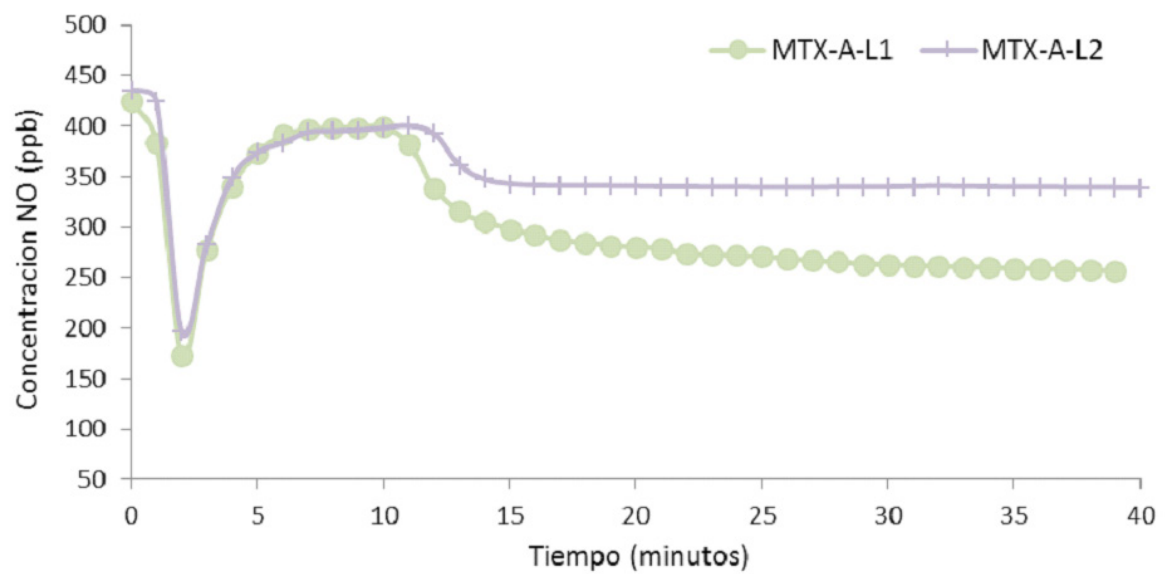

Fig 123. Gráfica con la evolución de concentraciones de NO durante el ensayo de la muestra de mortero fotocatalítico amarillo liso (MTX-A-L). 
Fig 124. Gráfica con la evolución de concentraciones de $\mathrm{NO}$ durante el ensayo de la muestra de mortero fotocatalítico rojo liso (MTX-R-L).

Fig 125. Gráfica con la evolución de concentraciones de NO durante el ensayo de la muestra de mortero fotocatalítico marrón liso (MTX-M-L).

Fig 126. Gráfica con la evolución de concentraciones de $\mathrm{NO}$ durante el ensayo de la muestra de mortero fotocatalítico G1 liso (MTX-G1-L).
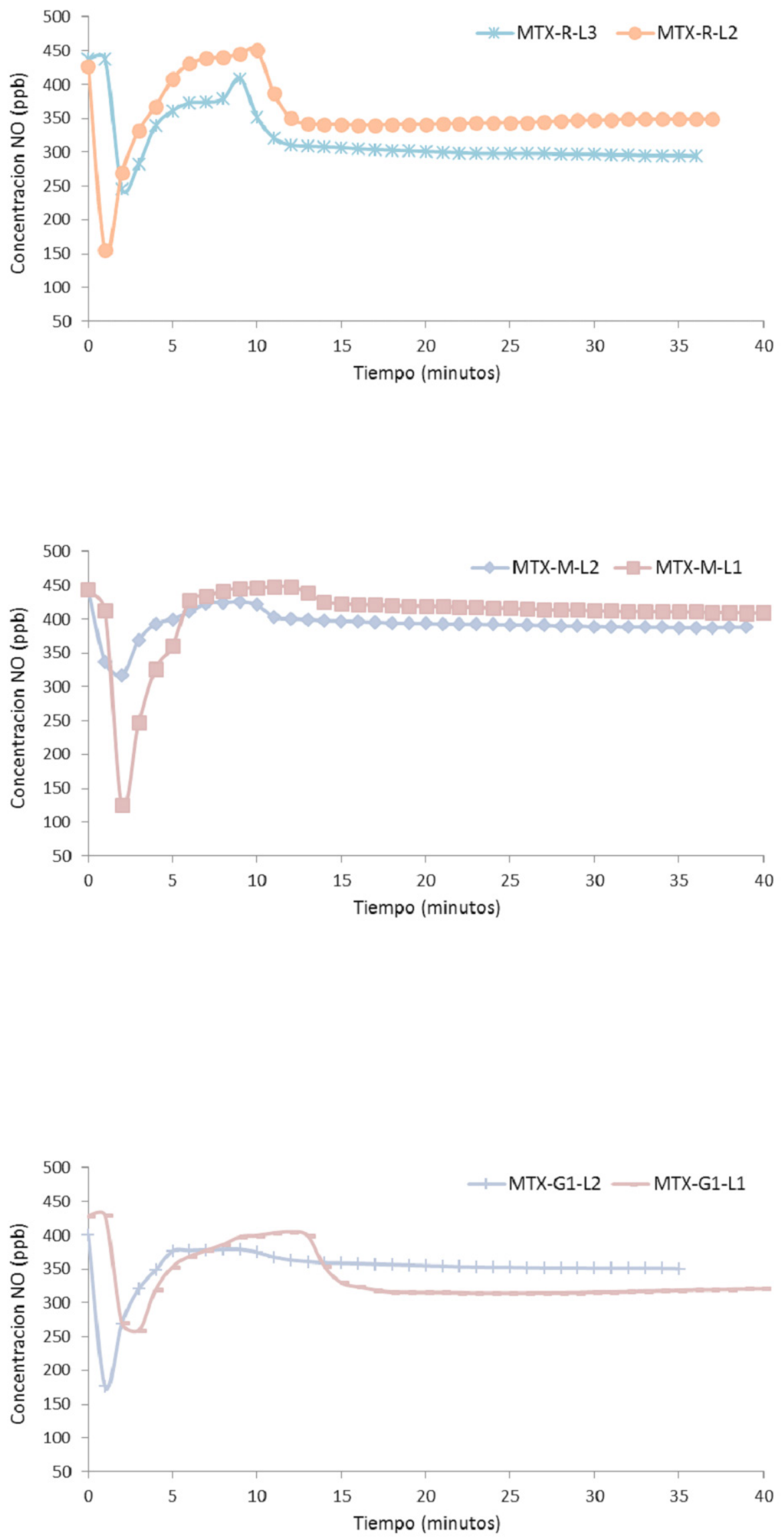


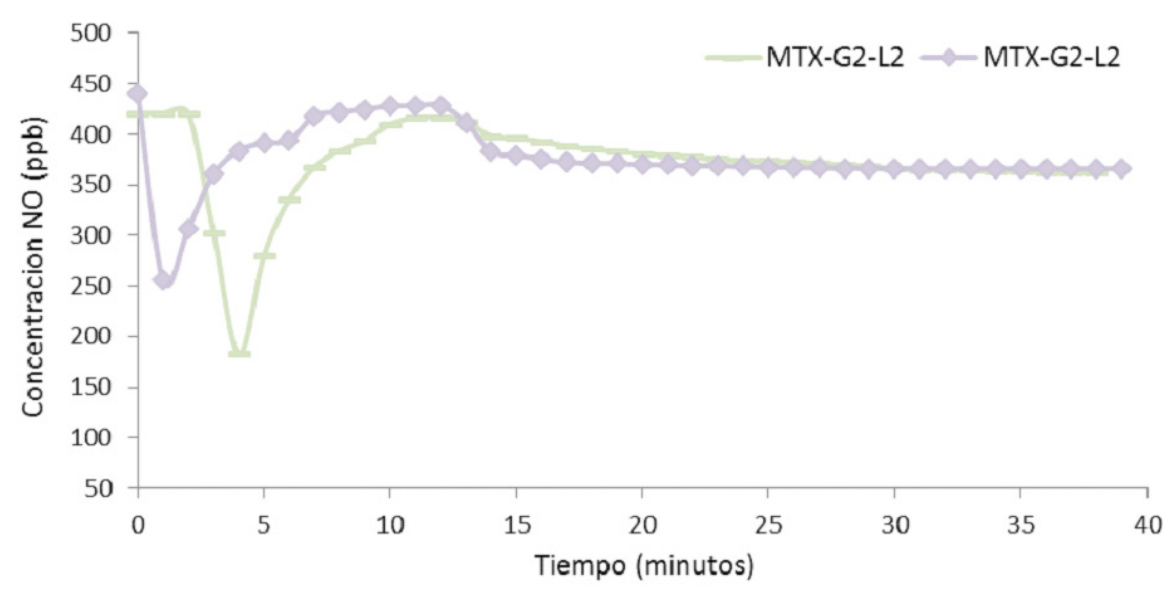

Fig 127. Gráfica con la evolución de concentraciones de NO durante el ensayo de la muestra de mortero fotocatalítico G2 liso (MTX-G2-L).

\begin{tabular}{|c|c|c|c|c|c|c|c|c|c|c|c|c|c|}
\hline \multirow[b]{2}{*}{ Probeta } & \multirow{2}{*}{$\begin{array}{c}\text { Tiempo } \\
\text { iluminación } \\
\text { (min) }\end{array}$} & \multicolumn{3}{|c|}{$C_{A}(p p b)$} & \multicolumn{3}{|c|}{$C_{B}(p p b)$} & \multicolumn{3}{|c|}{$C_{L}(p p b)$} & \multicolumn{3}{|c|}{$A_{C}(\%)$} \\
\hline & & NO & $\mathrm{NO}_{2}$ & $\mathrm{NO}_{\mathrm{x}}$ & NO & $\mathrm{NO}_{2}$ & $\mathrm{NO}_{x}$ & NO & $\mathrm{NO}_{2}$ & $\mathrm{NO}_{x}$ & NO & $\mathrm{NO}_{2}$ & $\mathrm{NO}_{\mathrm{x}}$ \\
\hline M-R1 & 30 & 412,00 & 30,22 & 442,22 & 402,99 & 28,57 & 431,56 & 400,10 & 29,68 & 429,78 & 1 & -4 & 0 \\
\hline M-R2 & 30 & 457,50 & 30,35 & 487,85 & 422,50 & 27,39 & 449,89 & 409,79 & 27,92 & 437,71 & 3 & -2 & 3 \\
\hline MTX-R1 & 30 & 417,80 & 29,75 & 447,55 & 391,64 & 27,78 & 419,42 & 327,81 & 30,54 & 358,35 & 16 & -10 & 15 \\
\hline MTX-R2 & 30 & 412,74 & 27,08 & 439,82 & 390,08 & 27,89 & 417,97 & 301,03 & 37,88 & 338,91 & 23 & -36 & 19 \\
\hline MTX-A-R1 & 30 & 435,19 & 30,85 & 466,04 & 451,84 & 31,95 & 483,79 & 386,49 & 33,51 & 420,00 & 14 & -5 & 13 \\
\hline MTX-A-R2 & 30 & 440,10 & 27,30 & 467,40 & 433,10 & 33,60 & 466,70 & 359,20 & 35,25 & 384,45 & 17 & -5 & 15 \\
\hline MTX-R-R1 & 30 & 419,70 & 28,67 & 448,37 & 403,26 & 28,91 & 432,17 & 252,60 & 24,76 & 277,36 & 37 & 14 & 36 \\
\hline MTX-R-R2 & 30 & 443,30 & 30,14 & 473,44 & 446,41 & 30,34 & 746,75 & 324,60 & 29,24 & 353,84 & 27 & 4 & 26 \\
\hline MTX-M-R1 & 30 & 411,40 & 28,80 & 440,20 & 399,58 & 28,69 & 428,27 & 336,04 & 28,33 & 364,37 & 16 & 1 & 15 \\
\hline MTX-M-R2 & 30 & 444,14 & 27,39 & 471,53 & 420,84 & 27,66 & 448,50 & 369,77 & 27,42 & 397,19 & 12 & 1 & 11 \\
\hline MTX-G1-R1 & 30 & 443,99 & 30,08 & 474,07 & 420,57 & 28,54 & 449,11 & 303,65 & 28,49 & 332,14 & 28 & 0 & 26 \\
\hline MTX-G1-R3 & 30 & 430,21 & 27,84 & 458,05 & 419,71 & 27,37 & 447,08 & 351,75 & 26,10 & 277,85 & 16 & 5 & 15 \\
\hline MTX-G2-R1 & 30 & 436,23 & 29,92 & 466,15 & 394,34 & 29,60 & 423,94 & 340,61 & 28,97 & 369,58 & 14 & 2 & 13 \\
\hline MTX-G2-R2 & 30 & 450,50 & 27,64 & 478,14 & 427,35 & 27,77 & 455,12 & 363,34 & 26,52 & 389,86 & 15 & 5 & 14 \\
\hline
\end{tabular}


Fig 128. Gráfica con la evolución de concentraciones de $\mathrm{NO}$ durante el ensayo de la muestra de mortero no fotocatalítico rugoso (M-R).

Fig 129. Gráfica con la evolución de concentraciones de $\mathrm{NO}$ durante el ensayo de la muestra de mortero fotocatalítico blanco rugoso (MTX-R),

Fig 130. Gráfica con la evolución de concentraciones de NO durante el ensayo de la muestra de mortero fotocatalítico amarillo rugoso (MTX-A-R).
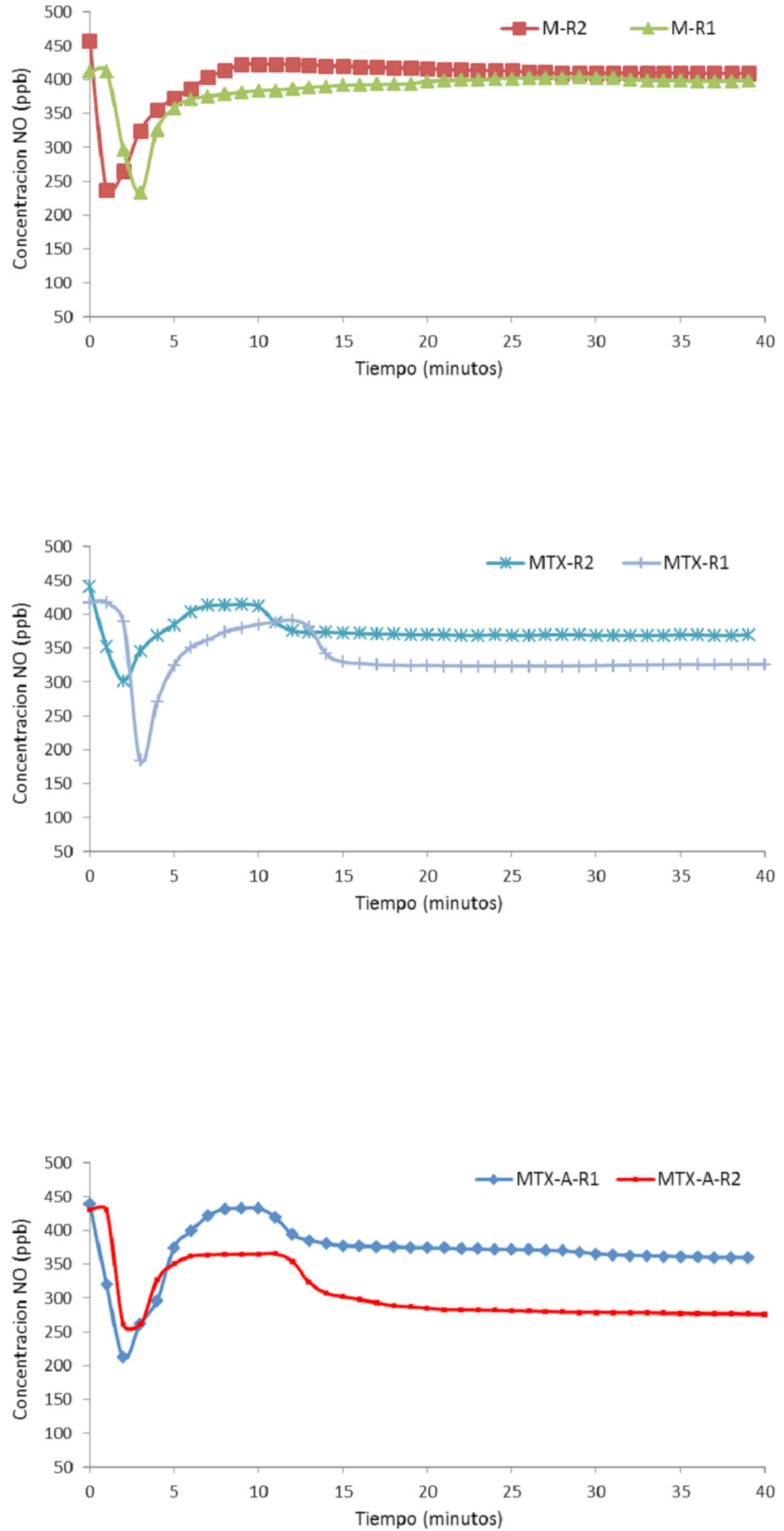
I NFLUENCIA DEL COLOR Y ELACABADOSUPERFICIALEN LAS PROPIEDADES DE UN MORTEROFOTOCATALITICOCOMOSOLUCIÓNDEENVOLVENTE
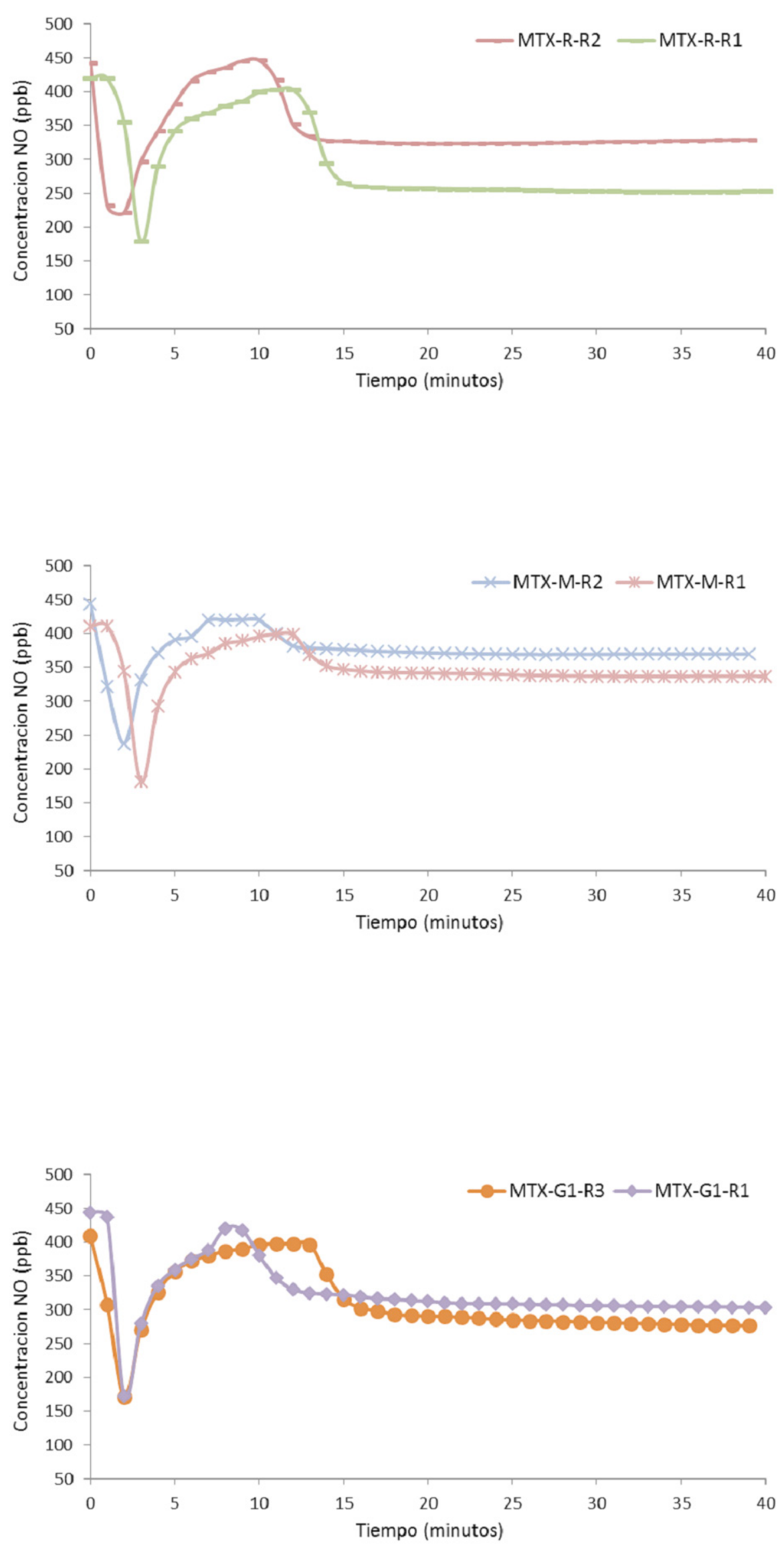

Fig 131. Gráfica con la evolución de concentraciones de NO durante el ensayo de la muestra de mortero fotocatalítico rojo rugoso (MTX-R-R).

Fig 132. Gráfica con la evolución de concentraciones de NO durante el ensayo de la muestra de mortero fotocatalítico marrón rugoso (MTX-M-R).

Fig 133. Gráfica con la evolución de concentraciones de NO durante el ensayo de la muestra de mortero fotocatalítico G1 rugoso (MTX-G1-R). 
Fig 134. Gráfica con la evolución de concentraciones de NO durante el ensayo de la muestra de mortero fotocatalítico G2 rugoso (MTX-G2-R).

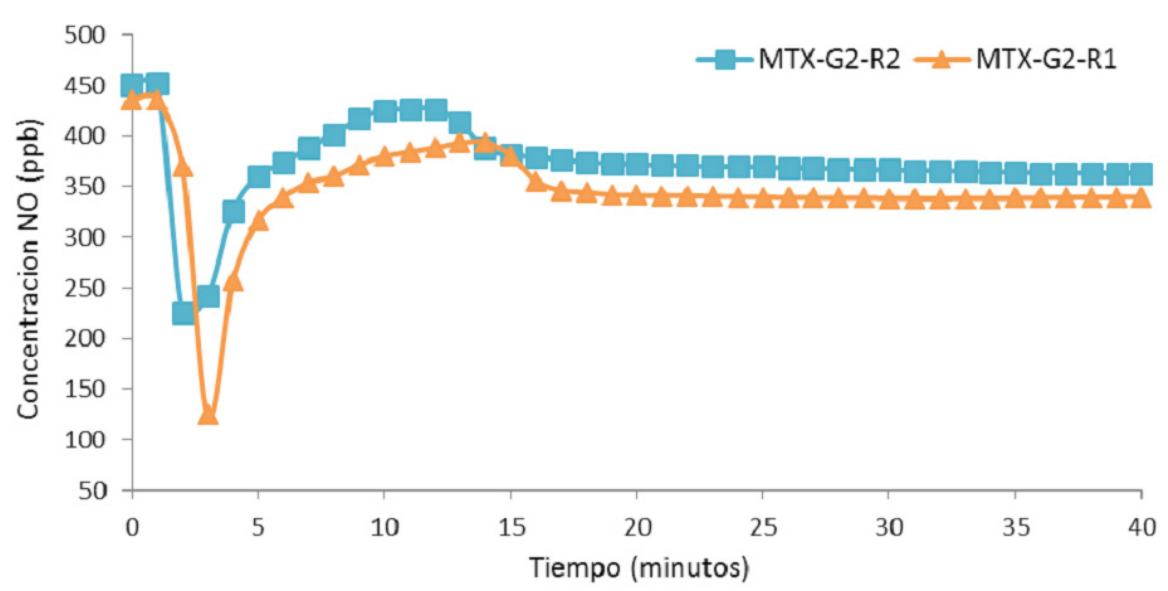

\subsubsection{DETERMINACION DE LA REFLECTANCIA DIFUSA UV-VIS-NIR}

Las mediciones de reflectancia se realizaron en muestras endurecidas utilizando un espectrofotómetro PerkinElmer UV / VIS / NIR, modelo Lambda 900. La reflectancia se determinó espectralmente dentro del intervalo de longitudes de onda $(\lambda)$ de $380 \mathrm{~nm}$ a $2500 \mathrm{~nm}$ con un paso espectral de $10 \mathrm{~nm}$ en el rango UV, visible y NIR.

Es una técnica no destructiva que se ha utilizado para medir y comparar las propiedades de reflexión de los materiales en la gama de longitudes de onda de la radiación UV-VIS-NIR para cada color y acabado. En los materiales utilizados como revestimiento de fachada es importante conocer la reflectancia espectral difusa. El color de las sustancias se debe a que absorben ciertas longitudes de onda de la luz blanca que incide sobre ellas.

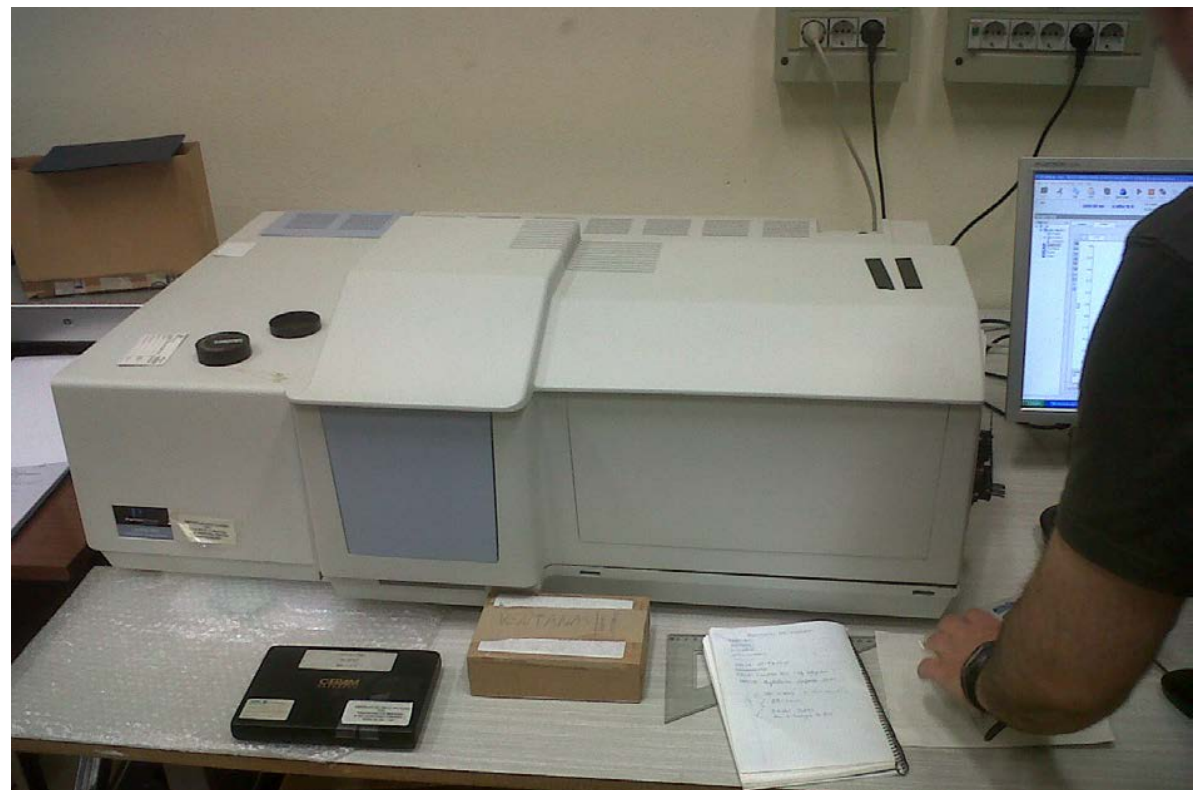




\section{PROCEDIMIENTO OPERATIVO}

Las condiciones ambientales durante las medidas son $25^{\circ} \mathrm{C} \pm 3^{\circ} \mathrm{C}$. Utiliza una lámpara de deuterio para la zona ultravioleta del espectro hasta $319 \mathrm{~nm}$ y otra de tungsteno para el resto del intervalo espectral. El espectrofotómetro utilizado es de doble haz, pero en nuestro caso las muestras y el patrón de referencia se midieron en el mismo puerto de la esfera a fin de evitar los errores asociados a las inhomogeneidades de la esfera y la diferencia entre los puertos.

La geometría de medición utilizada es de $8^{\circ}: \mathrm{d}$, lo que significa que la luz incidente es casi normal a la muestra, mientras que la reflectancia se mide en todo el hemisferio. Esta geometría fue elegida porque es la configuración recomendada por CIE para medidas de reflectancia en estos materiales.

El patrón de referencia es una baldosa cerámica blanca de la serie CCS-II, identificada como BK97, que se encuentra atemperada en el laboratorio antes de la realización de la calibración.

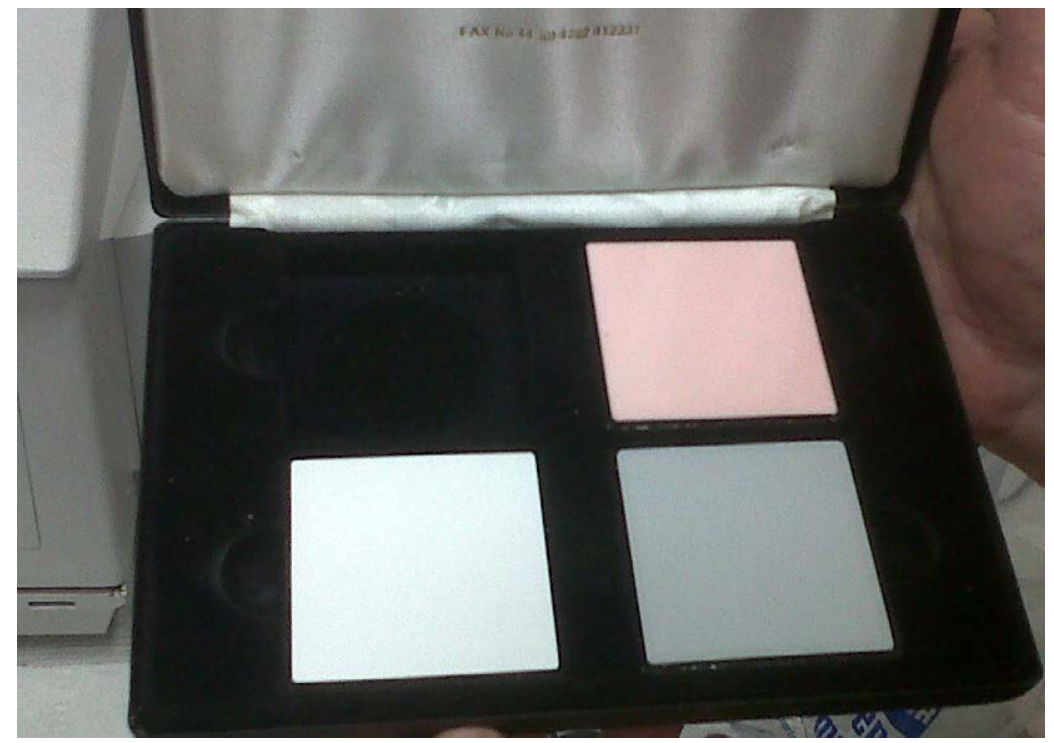

El instrumento ejecuta una rutina automática de encendido $y$, una vez acabada, se deja un periodo de 30 minutos para que se alcance el equilibrio térmico del mismo.

Parámetros de medida:

1. Intervalo de longitud de onda en que se quiere realizar la medida, se introduce $(380 \mathrm{~nm}$ a $2500 \mathrm{~nm})$.

2. Ancho de banda en $\mathrm{nm}$, se introduce el valor (2) en ultravioleta y visible y variable en infrarrojo.

3. Intervalo de muestreo de la longitud de onda, se introduce el valor $(1 \mathrm{~nm})$.
Fig 136. Cerámica blanca serie CCS-II, utilizada como patrón. 
Fig 137. (lzq) Detalle del puerto de medida (Der) Detalle de la posición de la muestra MTX-R23 para una medida.
4. Tiempo de integración, se introduce un valor que de un nivel de ruido admisible con lo querido (alrededor de $1 \mathrm{~s}$ para el fotomultiplicador $y$ de $2 \mathrm{~s}$ para el detector de sulfuro de plomo).

5. La ganancia de los detectores se fija en automática para el fotomultiplicador y fija para el de sulfuro de plomo, con un valor tal que la anchura de banda no exceda el valor de 4 al cambiar de detector.
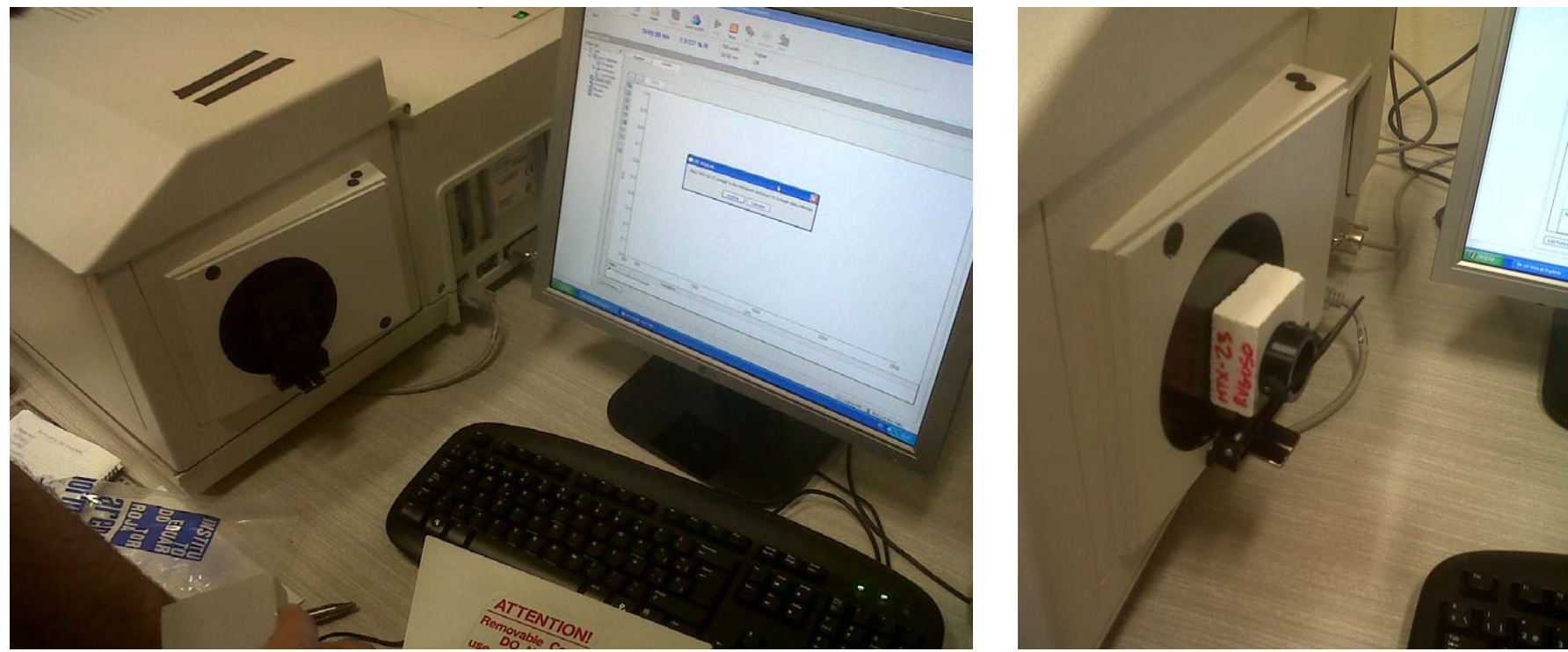

Secuencia de medida:

1. Tras la selección de los parámetros anteriores, se rellenan los campos apropiados en el programa de control del espectrofotómetro y se ejecuta la rutina correspondiente.

2. Se coloca una tapadera blanca en la boca de la esfera correspondiente a la componente especular, para incluir la componente especular de la reflectancia.

3. Se sitúa el patrón blanco de referencia, BK97, en la boca de la esfera para la muestra y se ejecuta el procedimiento para ajustar la línea de base.

4. Se sitúa un dispositivo de reflectancia nula en lugar del patrón y se ejecuta el procedimiento de barrido espectral. Este registro se denomina lectura del cero.

5. Se coloca la muestra en el mismo puerto de la esfera y se ejecuta el procedimiento de barrido espectral. Este registro se denomina lectura de la muestra. Se realizan dos barridos de cada muestra y se calcula un promedio de ambos.

6. Se guardan los registros en formato ASCII, seleccionando ese formato en el programa de control. 
I NFLUENCIA DEL COLOR Y ELACABADO SUPERFICIALEN LASPROPIEDADES DE UN MORTERO FOTOCATALITICO COMO SOLUCIÓN DE ENVOLVENTE

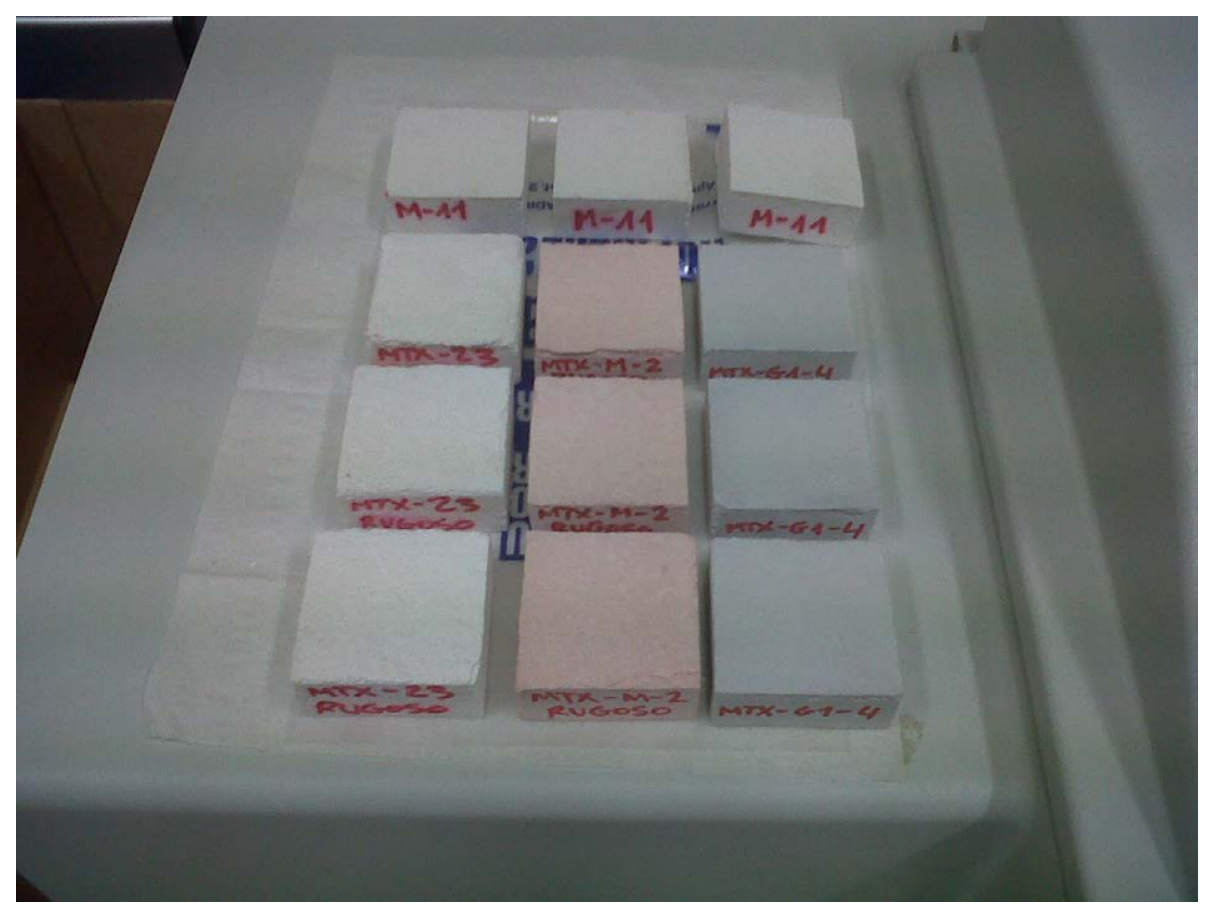

Fig 138. Muestras de mortero ensayadas.

\section{Resultados:}

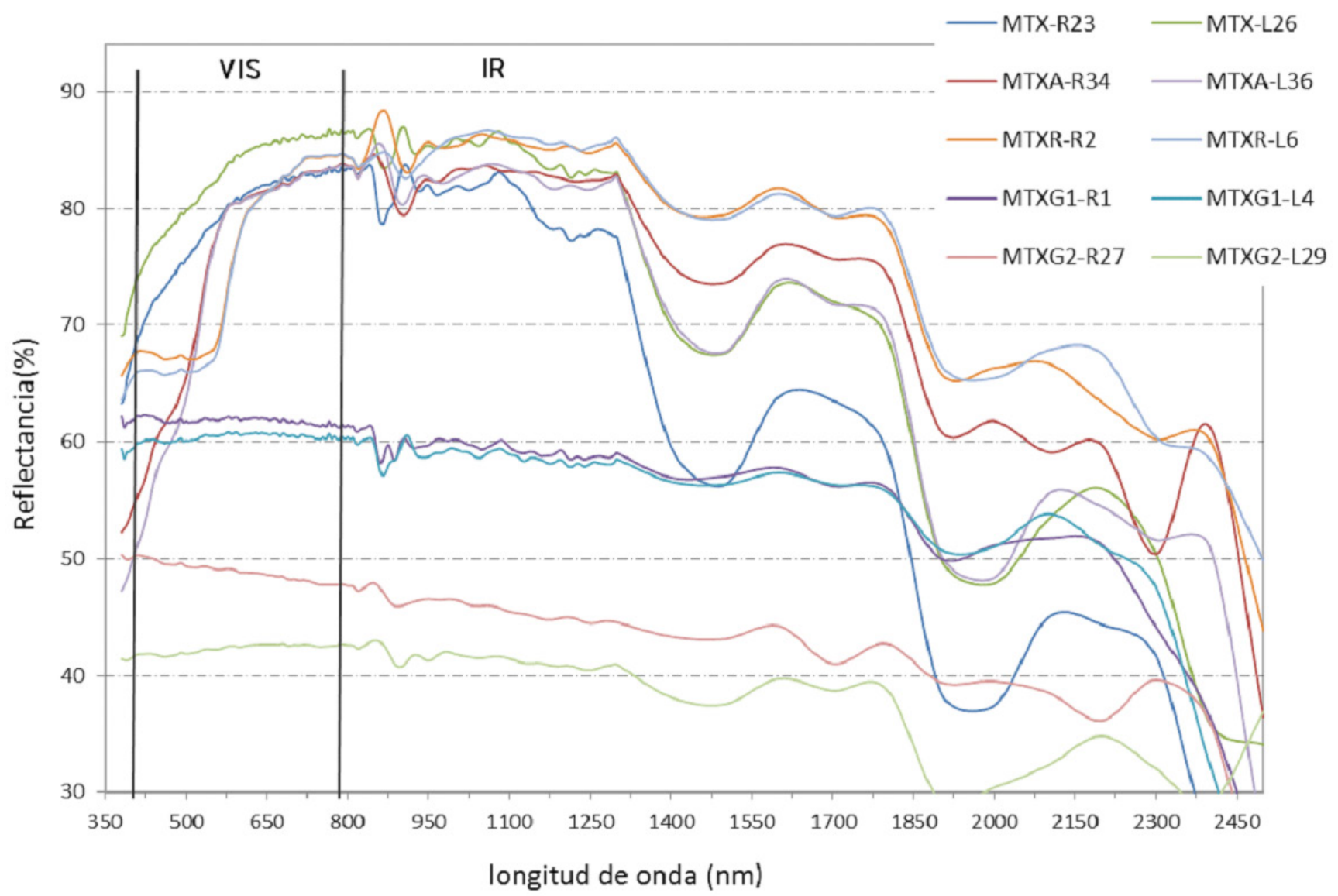

Fig 139. Espectros de reflectancia para los morteros fotocatalíticos según acabado superficial y color. 


\subsubsection{DETERMINACION DE LA REFLECTANCIA DIFUSA UV-VIS. ENERGIA DE FOTOABSORCION (EG)}

Es una técnica no destructiva que se ha utilizado para medir y comparar la radiación absorbida UV-Vis de cada mortero y medir los cambios en las bandas de conducción y valencia a causa de los pigmentos.

\section{PROCEDIMIENTO OPERATIVO}

La energía de fotoabsorción o band gap, se obtiene representando la ecuación de Tauc, frente a la energía absorbida (eV)

El valor del band gap se determina por el punto de intersección entre la línea que trazamos tangente a la pendiente en los puntos de inflexión de la curva de absorción y el eje X. Las mediciones se llevaron a cabo sobre las muestras de mortero no fotocatalítico blanco, mortero fotocatalítico y los fotocatalíticos pigmentados en masa.

Resultados:

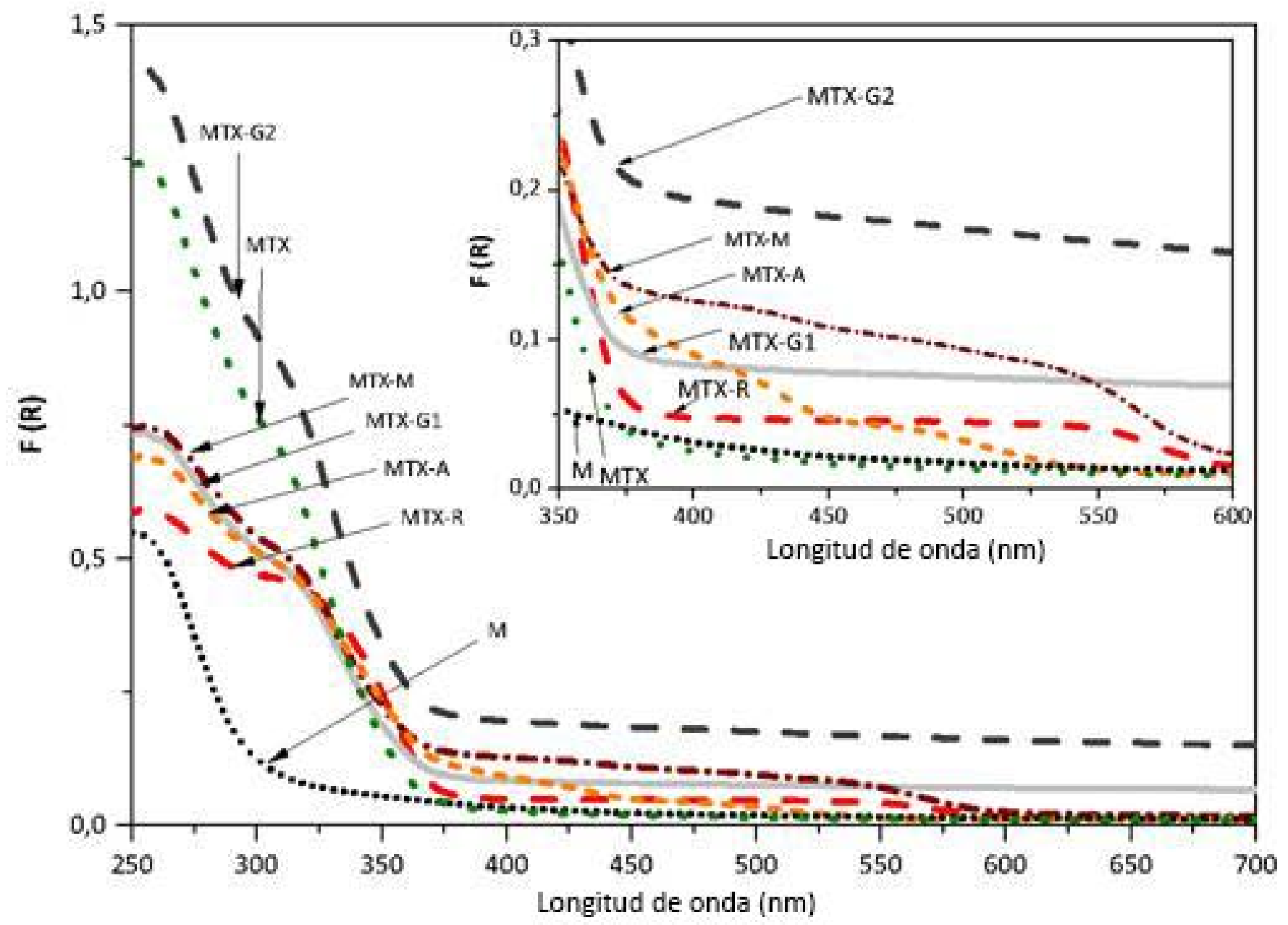

Fig 140. Curvas de absorción KubelkaMunk, detalle ampliado con los espectros de absorción entre 350 y 600 nm. 


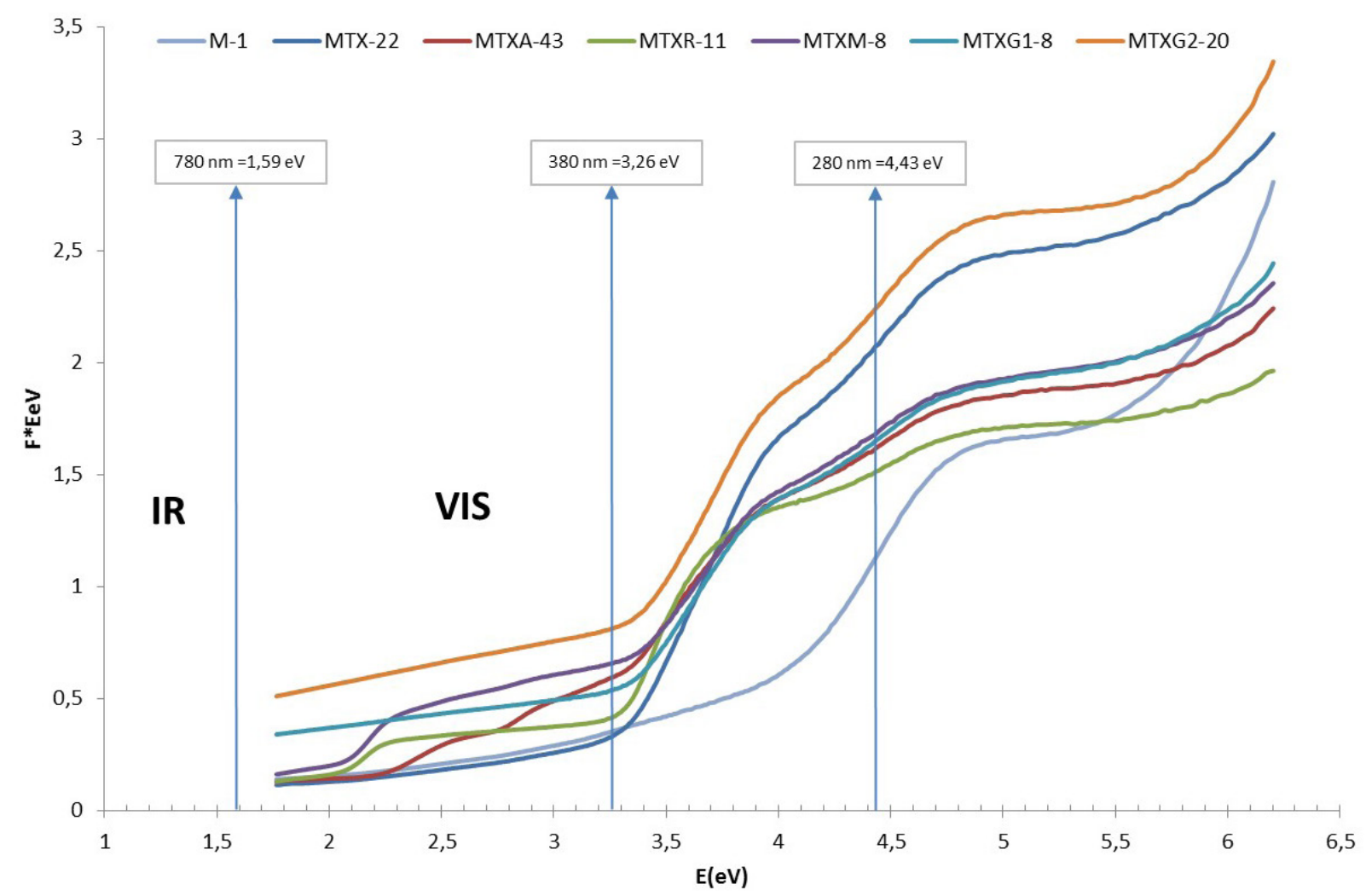

\subsubsection{DETERMINACIÓN POR ESPECTROMETRÍA DE FLUORESCENCIA CON ÁCIDO TERFTÁLICO}

Fig 141. Curvas de todos los morteros al representar la ecuación de Tauc, $(F(R) h v) 1 / n$ frente a la energía absorbida hu(eV)

Es una técnica de análisis que detecta y cuantifica especies reactivas del oxígeno, en concreto el radical hidroxilo. Es una técnica muy indicada debido a su alta sensibilidad $y$, a la respuesta lineal a un rango de concentraciones de especies reactivas del oxígeno. Se ha utilizado el método con ácido terftálico para determinar la actividad fotocatalítica de las muestras de mortero fotocatalítico y no fotocatalítico y generar la especie reactiva.

Se ha utilizado el método con ácido terftálico como sonda para analizar cuantitativamente las cantidades de radical hidroxilo $(\mathrm{OH} \cdot)$, formado sobre las muestras de mortero fotocatalítico y no fotocatalítico y con ello determinar la actividad fotocatalítica de cada muestra para generar la especie reactiva.

La fuente de luz utilizada tiene picos, en $365 \mathrm{~nm}$ zona del espectro UVA y a $404 \mathrm{~nm}$ y $436 \mathrm{~nm}$ en el espectro de luz visible. La intensidad se ajustó a $10 \pm 0,2 \mathrm{~W} / \mathrm{m}^{2}$. La evaporación de las soluciones se controla cubriendo la célula de ensayo con filtros de control de calor transparentes (KG1 Heat Absorbing Glass). Los espectros de fluorescencia de las disoluciones se midieron con un espectrofotómetro de fluorescencia (Perkin-Elmer, LS-55).

Se reacondicionan las muestras durante 3 días, a una temperatura de $23 \pm 5^{\circ} \mathrm{C}$ y humedad relativa del $60 \pm 10 \%$. La celda de prueba tiene un diámetro $\varnothing=67,53 \mathrm{~mm}$ y $\mathrm{h}=40 \mathrm{~mm}$, se coloca sobre la superficie de los morteros con silicona. 


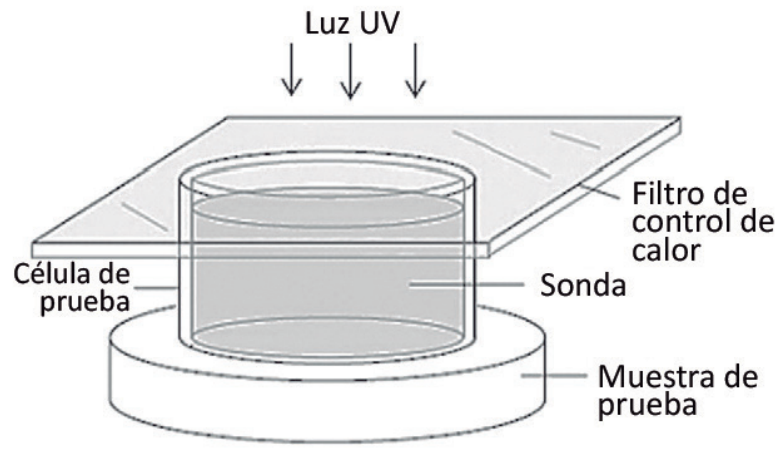

Fig 142. Esquema de la célula de ensayo.

\section{PROCEDIMIENTO OPERATIVO}

1. Se coloca en la célula de ensayo la muestra de mortero y se añade 25 $\mathrm{ml}$ de TA, una disolución de ácido terftálico comercial $(2 \mathrm{mM})$, diluido con una disolución acuosa de $\mathrm{NaOH}(0,02 \mathrm{M})$ hasta neutralización.

2. A continuación la disolución se irradia con la fuente luminosa durante 15 min bajo agitación continua.

3. Se mide la intensidad de fluorescencia de la disolución a $425 \mathrm{~nm}$ en diferentes tiempos de irradiación.

Resultados:

\begin{tabular}{|c|c|c|c|c|c|}
\hline \multicolumn{3}{|c|}{ MTX } & \multicolumn{3}{|c|}{ MTX-M } \\
\hline $\begin{array}{c}\text { Tiempo } \\
\text { (min) }\end{array}$ & $\begin{array}{l}\text { Media I.F } \\
\text { (u.a) }\end{array}$ & $\mathrm{DeV}$ & $\begin{array}{c}\text { Tiempo } \\
\text { (min) }\end{array}$ & $\begin{array}{l}\text { Media I.F } \\
\text { (u.a) }\end{array}$ & $\mathrm{DeV}$ \\
\hline 0 & 2,04 & 0,00 & 0 & 2,04 & 0,00 \\
\hline 5 & 5,85 & 0,85 & 5 & 4,74 & 0,35 \\
\hline 10 & 12,53 & 0,76 & 10 & 8,31 & 0,32 \\
\hline 15 & 19,21 & 0,15 & 15 & 11,50 & 0,25 \\
\hline \multicolumn{3}{|c|}{ MTX-A } & \multicolumn{3}{|c|}{ MTX-G1 } \\
\hline $\begin{array}{l}\text { Tiempo } \\
\text { (min) }\end{array}$ & $\begin{array}{l}\text { Media I.F } \\
\text { (u.a) }\end{array}$ & $\mathrm{DeV}$ & $\begin{array}{c}\text { Tiempo } \\
\text { (min) }\end{array}$ & $\begin{array}{l}\text { Media I.F } \\
\text { (u.a) }\end{array}$ & $\mathrm{DeV}$ \\
\hline 0 & 2,04 & 0,00 & 0 & 2,04 & 0,00 \\
\hline 5 & 5,34 & 0,83 & 5 & 7,78 & 0,49 \\
\hline 10 & 11,20 & 0,18 & 10 & 14,67 & 0,65 \\
\hline 15 & 16,30 & 1,17 & 15 & 20,67 & 0,25 \\
\hline \multicolumn{3}{|c|}{ MTX-R } & \multicolumn{3}{|c|}{ MTX-G2 } \\
\hline $\begin{array}{l}\text { Tiempo } \\
\text { (min) }\end{array}$ & $\begin{array}{l}\text { Media I.F } \\
\text { (u.a) }\end{array}$ & $\mathrm{DeV}$ & $\begin{array}{l}\text { Tiempo } \\
\text { (min) }\end{array}$ & $\begin{array}{l}\text { Media I.F } \\
\text { (u.a) }\end{array}$ & $\mathrm{DeV}$ \\
\hline 0 & 2,04 & 0,00 & 0 & 2,04 & 0,00 \\
\hline 5 & 17,65 & 0,78 & 5 & 7,08 & 3,14 \\
\hline 10 & 28,02 & 3,70 & 10 & 10,58 & 2,04 \\
\hline 15 & 45,02 & 0,83 & 15 & 14,10 & 2,66 \\
\hline
\end{tabular}




\begin{tabular}{|c|c|c|}
\hline & $\begin{array}{c}\text { Ratio } \\
\left(\mathrm{Fe} / \mathrm{TiO}_{2}\right)\end{array}$ & $\begin{array}{c}\text { Producción de } \mathrm{OH} \\
\left(\mu \mathrm{mol} / \mathrm{min}_{\mathrm{cm}} \mathrm{cm}^{2}\right)\end{array}$ \\
\hline MTX & 0,24 & 0,16 \\
\hline MTX-A & 0,40 & 0,39 \\
\hline MTX-R & 0,26 & 0,14 \\
\hline MTX-M & 0,56 & 0,09 \\
\hline MTX-G1 & 0,35 & 0,17 \\
\hline MTX-G2 & 0,39 & 0,11 \\
\hline
\end{tabular}

\subsubsection{CONFECCIÓN DE LA SERIE DE MORTERO CON ADITIVOS}

Para la campaña experimental en el IETcc se utilizó, cemento fotocatalítico blanco TX Active (TX Aria) BL II/B LL 42,5R y cemento blanco no fotocatalítico (BL II/A-LL 52,5 N) segun UNE 80305 y 10 aditivos diferentes para la fabricación de morteros especiales. Se fabricaron 2 probetas para ensayo de eliminación de $\mathrm{NO}_{x}$ y 4 probetas para el ensayo de autolimpieza con rodamina $B$, cada serie con 6 probetas en total, para cada aditivo añadido en una concentración, también se fabricó una serie de probetas con cemento fotocatalítico sin aditivos y otra de mortero blanco no fotocatalítico también sin aditivos.

Se identificaron cada serie de probetas, diferenciadas por tipo y contenido de aditivo. Las probetas de cada serie se denominan 1, 2, 3 y 4 para el ensayo de autolimpieza (rodamina) y 5 y 6 para ensayo de descontaminación $\left(\mathrm{NO}_{x}\right)$.
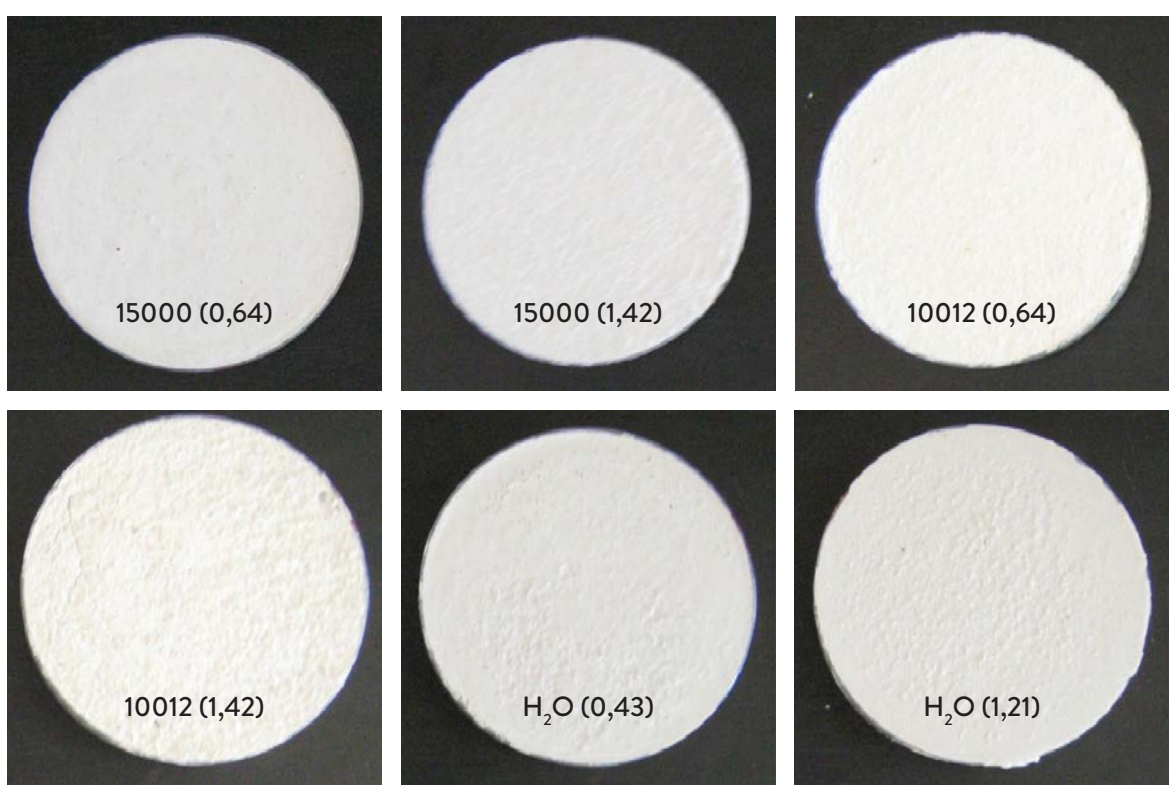

Tabla 33. Valores de calculados del ratio $\mathrm{Fe} / \mathrm{TiO}_{2}$ y de la generación de $(\mathrm{OH} \cdot)$ para cada mortero fotocatalítico coloreado.

Fig 143. Aspecto de las probetas fabricadas y curadas en el IETcc. Cada imagen es una muestra de cada una de las series de probetas con distinto aditivo añadido. Su porcentaje en peso sobre cemento se indica entre paréntesis. 
Fig 143. Aspecto de las probetas fabricadas y curadas en el IETcc. Cada imagen es una muestra de cada una de las series de probetas con distinto aditivo añadido. Su porcentaje en peso sobre cemento se indica entre paréntesis.
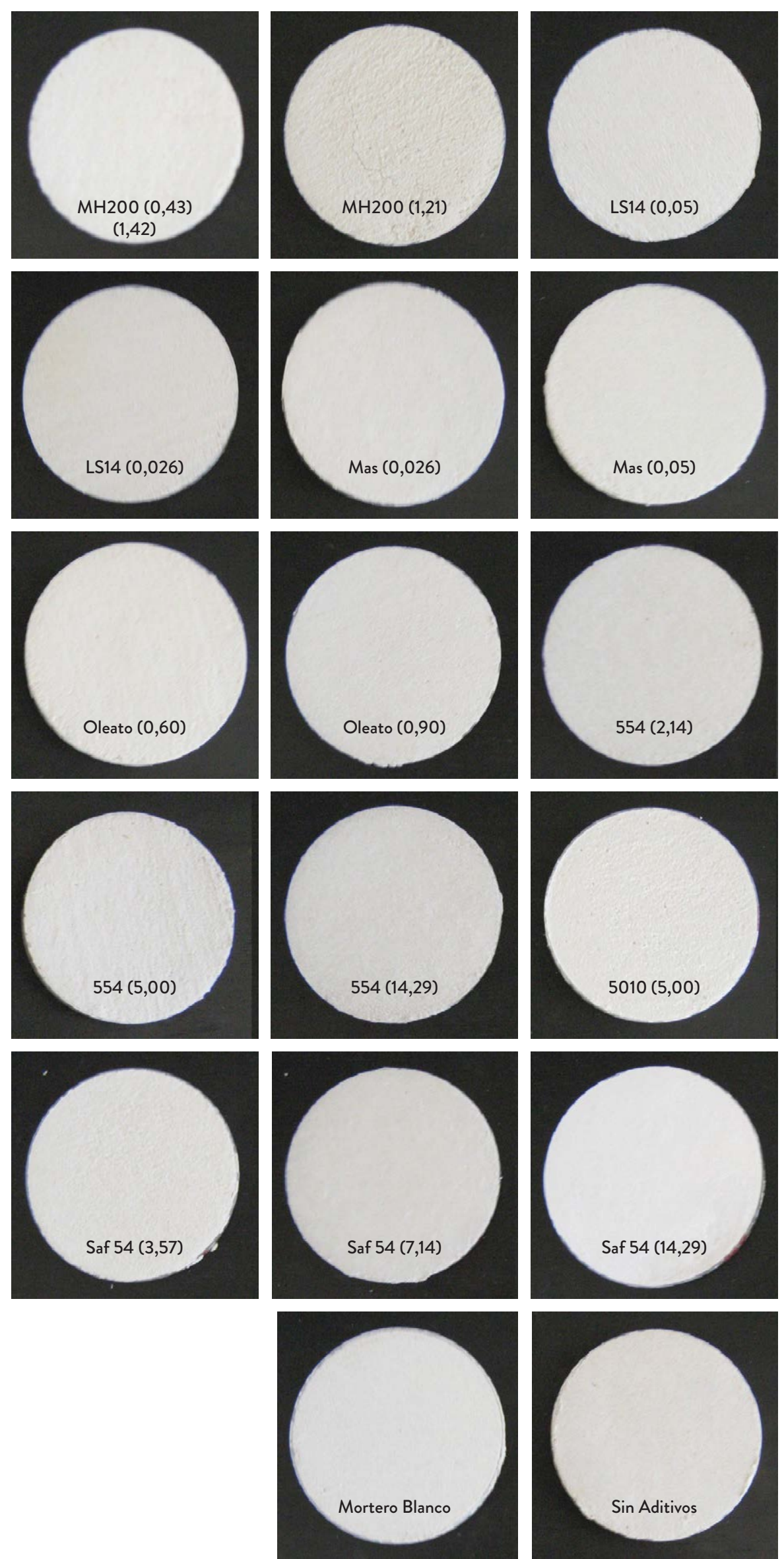

Se utilizan placas de petri en poliestireno de $8,8 \mathrm{~mm}$ de diámetro y $15 \mathrm{~mm}$ de altura como molde. Los moldes se marcan y se llenan sin tratamiento previo con el mortero para cada serie de probetas 


\begin{tabular}{|c|c|c|c|c|c|}
\hline Ref. Aditivo & $\begin{array}{c}\text { Dos. aditivo } \\
\text { (\% spc) }\end{array}$ & $\begin{array}{l}\text { Probetas } \\
\text { en la serie }\end{array}$ & $\begin{array}{l}\text { Forma } \\
\text { probeta }\end{array}$ & $\begin{array}{c}\text { Diámetro / } \\
\text { altura }\end{array}$ & Color \\
\hline Mortero No fotocatalítico & - & $4+2=6$ & Cilindrica & $8,8 / 1,5$ & Blanco \\
\hline Mortero fotocatalítico sin aditivo & - & $4+2=6$ & Cilindrica & $8,8 / 1,5$ & Blanco \\
\hline 15000 & 0,64 & $4+2=6$ & Cilindrica & $8,8 / 1,5$ & Blanco \\
\hline 15000 & 1,42 & $4+2=6$ & Cilindrica & $8,8 / 1,5$ & Blanco \\
\hline 10012 & 0,64 & $4+2=6$ & Cilindrica & $8,8 / 1,5$ & Blanco \\
\hline 10012 & 1,42 & $4+2=6$ & Cilindrica & $8,8 / 1,5$ & Blanco \\
\hline $\mathrm{H} 20$ & 0,43 & $4+2=6$ & Cilindrica & $8,8 / 1,5$ & Blanco \\
\hline H 20 & 1,21 & $4+2=6$ & Cilindrica & $8,8 / 1,5$ & Blanco \\
\hline MH 200 & 0,43 & $4+2=6$ & Cilindrica & $8,8 / 1,5$ & Blanco \\
\hline MH 200 & 1,21 & $4+2=6$ & Cilindrica & $8,8 / 1,5$ & Blanco \\
\hline LS 14 & 0,03 & $4+2=6$ & Cilindrica & $8,8 / 1,5$ & Blanco \\
\hline LS 14 & 0,05 & $4+2=6$ & Cilindrica & $8,8 / 1,5$ & Blanco \\
\hline Mas & 0,03 & $4+2=6$ & Cilindrica & $8,8 / 1,5$ & Blanco \\
\hline Mas & 0,05 & $4+2=6$ & Cilindrica & $8,8 / 1,5$ & Blanco \\
\hline Oleato & 0,60 & $4+2=6$ & Cilindrica & $8,8 / 1,5$ & Blanco \\
\hline Oleato & 0,90 & $4+2=6$ & Cilindrica & $8,8 / 1,5$ & Blanco \\
\hline 554 & 2,14 & $4+2=6$ & Cilindrica & $8,8 / 1,5$ & Blanco \\
\hline 554 & 5,00 & $4+2=6$ & Cilindrica & $8,8 / 1,5$ & Blanco \\
\hline 554 & 14,29 & $4+2=6$ & Cilindrica & $8,8 / 1,5$ & Blanco \\
\hline 5010 & 2,14 & $4+2=6$ & Cilindrica & $8,8 / 1,5$ & Blanco \\
\hline 5010 & 5,00 & $4+2=6$ & Cilíndrica & $8,8 / 1,5$ & Blanco \\
\hline Saf 54 & 3,57 & $4+2=6$ & Cilindrica & $8,8 / 1,5$ & Blanco \\
\hline Saf 54 & 7,14 & $4+2=6$ & Cilindrica & $8,8 / 1,5$ & Blanco \\
\hline Saf 54 & 14,29 & $4+2=6$ & Cilindrica & $8,8 / 1,5$ & Blanco \\
\hline
\end{tabular}

\section{PROCEDIMIENTO OPERATIVO}

Consideraciones previas:
Tabla 34. Referencias y características de las probetas por tipo y cantidad de aditivo en porcentaje sobre el peso de cemento.
1. Se pesa el cemento con una balanza analítica capaz de pesar con una precisión de $\pm 0,1 \mathrm{~g}$. Los aditivos y las probetas después del curado en la camera húmeda se pesa con una balanza analítica con una precisión de $\pm 0,0001 \mathrm{~g}$.

2. Se identifica cada serie de probetas, anotando la referencia y contenido de aditivo. El llenado y compactación de las muestras se realiza en una mesa de vibración para compactar y distribuir el mortero homogéneamente en el molde.

3. Se determina la consistencia del mortero fresco para cada una de las amasadas según UNE-EN 1015-3.

4. Las muestras de mortero normalizado se han preparado según norma UNE-EN 196-1. Las proporciones del mortero en peso es 1:3, la relación agua/cemento utilizada es de 0,50. La cantidad preparada para cada serie de mortero ha sido de $450 \pm 2 \mathrm{~g}$ de cemento, $1350 \pm 5 \mathrm{~g}$ de arena y $225 \pm 1 \mathrm{~g}$ de agua, a esta mezcla se añaden las cantidades de aditivo, en algunas de las mezclas, hay variaciones respecto a las proporciones del mortero. 


\begin{tabular}{|c|c|c|c|c|}
\hline Aditivo & $\begin{array}{c}\text { Aditivo } \\
\text { (g) }\end{array}$ & $\begin{array}{l}\text { Agua } \\
(\mathrm{ml})\end{array}$ & $\begin{array}{c}\text { Cemento } \\
\text { (g) }\end{array}$ & $\begin{array}{c}\text { Arena } \\
\text { (g) }\end{array}$ \\
\hline Mortero No fotocatalítico & - & 225 & 450 & 1350 \\
\hline Mortero fotocalítico sin aditivo & - & 225 & 450 & 1350 \\
\hline 15000 & 2,88 & 315 & 450 & 1350 \\
\hline 15000 & 6,39 & 315 & 450 & 1350 \\
\hline 10012 & 2,88 & 315 & 450 & 1350 \\
\hline 10012 & 6,39 & 315 & 450 & 1350 \\
\hline $\mathrm{H} 20$ & 1,94 & 225 & 450 & 1350 \\
\hline H 20 & 5,45 & 225 & 450 & 1350 \\
\hline MH 200 & 1,94 & 225 & 450 & 1350 \\
\hline MH 200 & 5,45 & 225 & 450 & 1350 \\
\hline LS 14 & 0,12 & 225 & 450 & 1350 \\
\hline LS 14 & 0,23 & 225 & 450 & 1350 \\
\hline Mas & 0,12 & 225 & 450 & 1350 \\
\hline Mas & 0,23 & 225 & 450 & 1350 \\
\hline Oleato & 2,70 & 225 & 450 & 1350 \\
\hline Oleato & 4,05 & 225 & 450 & 1350 \\
\hline 554 & 9,63 & 225 & 450 & 1350 \\
\hline 554 & 22,50 & 225 & 450 & 1350 \\
\hline 554 & 64,31 & 225 & 450 & 1350 \\
\hline 5010 & 9,63 & 225 & 450 & 1350 \\
\hline 5010 & 22,50 & 225 & 450 & 1350 \\
\hline Saf 54 & 16,07 & 311 & 450 & 1350 \\
\hline Saf 54 & 32,13 & 308 & 450 & 1350 \\
\hline Saf 54 & 64,31 & 301 & 450 & 1350 \\
\hline
\end{tabular}

Todos los aditivos en el estudio salvo el aditivo Saf-54 se han mezclado con la arena antes de la preparación del mortero. El aditivo Saf-54 se ha mezclado previamente con el agua utilizada para la fabricación del mortero.

El amasado, preparación, curado y acondicionamiento de las muestras se realiza de la siguiente manera:

Se añade el cemento mezclado con el aditivo en su caso, sobre el agua y se arranca el mezclador a baja velocidad.

Después de 30 s de amasado se añade la arena con un flujo constante durante $30 \mathrm{~s}$.

Se cambia a velocidad alta de mezclado durante otros $30 \mathrm{~s}$, después de los cuales se detiene el amasado durante 1 min y $30 \mathrm{~s}$. Durante los primeros $15 \mathrm{~s}$, se retira todo el mortero adherido a las paredes y al fondo de la cubeta con una rasqueta de goma y se colocar en el centro de la misma.

Al terminar el ciclo de amasado, se preparan series de seis probetas para el estudio de cada aditivo añadido en su proporción especificada. 
Se compacta la probeta mediante vibración y se marca el molde para identificar la probeta.

La superficie de la probeta se repasa con una espátula para quitar exceso de mortero y dejar la superficie lisa.

Se curan dentro del molde en cámara húmeda a temperatura $20 \pm 1$ ${ }^{\circ} \mathrm{C}$ con humedad relativa superior al $90 \%$ durante 28 días, después se almacenan en cámara climática con humedad relativa $50 \%$ y 20 ${ }^{\circ} \mathrm{C}$.

Antes del ensayo, las probetas deben haber estado al menos 2 días en cámara climática con humedad relativa $50 \%$ y $20{ }^{\circ} \mathrm{C}$.

Antes del ensayo se pesan de las probetas dentro de su propio molde, de forma que se pueda establecer una comparación entre la compactación de cada material y entre las probetas de la misma serie en caso necesario.

\section{8 . 4 . 2.1. MEDICIÓN DE LA CAPACIDAD FOTOCATALÍTICA DE AUTOLIMPIEZA}

El colorante orgánico utilizado es la rodamina B, debido a su baja fotosensibilidad a la luz UV, a su baja sensibilidad al entorno básico, alta sensibilidad colorimétrica y a la amplia experiencia en su utilización en fotocatálisis. La rodamina B se deposita sobre la superficie de las muestras en una concentración conocida. La prueba permite valorar si, a través de la decoloración de la rodamina, la muestra de cemento se puede considerar fotocatalítica.

Dado que en el presente método se utiliza la rodamina $B$, que es de color rojo, se examinará únicamente la coordenada colorimétrica a* (crominancia).

Se sigue el método descrito en la norma UNI 11259, con las siguientes diferencias en el procedimiento:

1. Medida del rango de luz ultravioleta. El equipo disponible mide en el rango $315 n m-400 n m$ en vez de $300 n m-400 n m$ estipulado por la norma.

2. Se utiliza un volumen de rodamina añadida a las probetas superiores a la estipulada por la norma, $3 \mathrm{ml}$ en vez de $0,5 \mathrm{ml}$ para obtener volumen suficiente para extender el líquido de forma homogénea sobre toda la superficie delimitada. Se ajusta la concentración de la disolución para que la cantidad total de rodamina en la superficie de la probeta sea igual a $2,25 \mu \mathrm{g} / \mathrm{cm}^{2}$.

3. La balanza para pesar el cemento tiene una precisión igual a 0,1g, inferior a la estipulada por la norma de 0,0005g. 
4. El curado de las probetas ha sido en cámara húmeda en vez de bajo agua, que es lo estipulado por la norma.

\section{PROCEDIMIENTO OPERATIVO}

El banco de trabajo está formado por la muestra y la lámpara UV. La fuente de iluminación consiste en una lámpara de Osram Ultravitalux de $300 \mathrm{~W}$ de potencia, que proporciona una intensidad de radiación sobre la superficie de la muestra que en el espectro UV-A tenga una intensidad de $3,75 \pm 0,25 \mathrm{~W} / \mathrm{m}^{2}$. Las condiciones ambientales de ensayo son $20^{\circ} \mathrm{C} \pm 2^{\circ} \mathrm{C}$ y humedad relativa del $70 \pm 10 \%$.

Se utiliza un medidor Delta Ohm 2102.1 con censor LP471 UVA para medir la intensidad de UV-A en el rango de $315 \mathrm{~nm}$ hasta $400 \mathrm{~nm}$. La medida se toma colocando el sensor encima y en el centro de la superficie de la probeta.

1. Se extiende el producto hidrofóbico CimcurePro en todas las probetas para delimitar una zona de aproximadamente $22 \pm 2 \mathrm{~cm}^{2}$ sobre la superficie de la probeta.

2. Tras un secado completo, se aplica en la zona delimitada $3 \mathrm{ml}$ de solución de rodamina B (CAS $n^{0}$ 81-88-9) solubilizada en agua potable, de concentración $0,0165 \mathrm{~g} / \mathrm{l}$, en dos manos, cada una de 1,5 $\mathrm{ml}$. Como resultado una concentración de rodamina en superficie igual a $2,25 \mu \mathrm{g} / \mathrm{cm}^{2}$.

3. Se introduce la probeta en un ambiente oscuro (a $20^{\circ} \mathrm{C} \pm 2^{\circ} \mathrm{C}$ y HR. $70 \pm 10 \%$ ) durante $24 \mathrm{~h}$.

4. Se efectúa la primera medición del parámetro a*(Oh), justo antes de la exposición de la probeta a la lámpara. Se toma la medida en tres puntos distintos de la muestra y se hace el promedio.

5. Se efectúa la segunda medición tras 4 h de exposición: a*(4h). Se toma la medida en tres puntos distintos de la muestra y se hace el promedio.

6. Se efectúa la última medición tras $26 \mathrm{~h}$ de exposición: a*(26h). Se toma la medida en tres puntos distintos de la muestra y se hace el promedio.

7. Se repite la misma operación para las probetas asignadas para los ensayos de rodamina, siguiendo exactamente el procedimiento descrito en los puntos 1 a 6 .

No se han podido colorear uniformemente la muestra con el aditivo Saf $54(14,29 \%$ spc).

Resultados en la Tabla 36 (Resultados de las series de autolimpieza), desarrollada en las siguientes páginas. 


\begin{tabular}{|c|c|c|c|c|c|c|}
\hline$N^{0}$ Serie & Aditivo (\% spc) & $\mathrm{N}^{0}$ & $\mathrm{R}_{4}$ & $\begin{array}{c}\text { Promedio } \mathrm{R}_{4} \\
\text { de la serie }\end{array}$ & $\mathrm{R}_{26}$ & $\begin{array}{c}\text { Promedio } \mathrm{R}_{26} \\
\text { de la serie }\end{array}$ \\
\hline \multirow{4}{*}{1} & Mortero NO Fotocatalítico & 1 & 4 & \multirow{4}{*}{3} & 17 & \multirow{4}{*}{16} \\
\hline & Mortero NO Fotocatalítico & 2 & 4 & & 16 & \\
\hline & Mortero NO Fotocatalítico & 3 & 1 & & 12 & \\
\hline & Mortero NO Fotocatalítico & 4 & 2 & & 15 & \\
\hline \multirow{4}{*}{2} & Mortero Fotocataítico SIN Aditivo & 1 & 46 & \multirow{4}{*}{46} & 74 & \multirow{4}{*}{75} \\
\hline & Mortero Fotocataítico SIN Aditivo & 2 & 47 & & 75 & \\
\hline & Mortero Fotocataítico SIN Aditivo & 3 & 55 & & 79 & \\
\hline & Mortero Fotocataítico SIN Aditivo & 4 & 44 & & 72 & \\
\hline \multirow{4}{*}{3} & $15000(0,64)$ & 1 & 44 & \multirow{4}{*}{59} & 85 & \multirow{4}{*}{84} \\
\hline & $15000(0,64)$ & 2 & 51 & & 86 & \\
\hline & $15000(0,64)$ & 3 & 55 & & 84 & \\
\hline & $15000(0,64)$ & 4 & 59 & & 82 & \\
\hline \multirow{4}{*}{4} & $15000(1,42)$ & 1 & 40 & \multirow{4}{*}{27} & 63 & \multirow{4}{*}{61} \\
\hline & W15000 $(1,42)$ & 2 & 36 & & 68 & \\
\hline & $15000(1,42)$ & 3 & 19 & & 53 & \\
\hline & $15000(1,42)$ & 4 & 47 & & 73 & \\
\hline \multirow{4}{*}{5} & $10012(0,64)$ & 1 & 41 & \multirow{4}{*}{40} & 68 & \multirow{4}{*}{65} \\
\hline & $10012(0,64)$ & 2 & 38 & & 65 & \\
\hline & $10012(0,64)$ & 3 & 40 & & 65 & \\
\hline & $10012(0,64)$ & 4 & 27 & & 64 & \\
\hline \multirow{4}{*}{6} & $10012(1,42)$ & 1 & 50 & \multirow{4}{*}{49} & 79 & \multirow{4}{*}{74} \\
\hline & $10012(1,42)$ & 2 & 26 & & 58 & \\
\hline & $10012(1,42)$ & 3 & 46 & & 70 & \\
\hline & $10012(1,42)$ & 4 & 50 & & 74 & \\
\hline \multirow{4}{*}{7} & $\mathrm{H} 2 \mathrm{O}(0,43)$ & 1 & 46 & \multirow{4}{*}{36} & 74 & \multirow{4}{*}{70} \\
\hline & H2O $(0,43)$ & 2 & 32 & & 66 & \\
\hline & $\mathrm{H} 2 \mathrm{O}(0,43)$ & 3 & 30 & & 73 & \\
\hline & $\mathrm{H} 2 \mathrm{O}(0,43)$ & 4 & 50 & & 67 & \\
\hline \multirow{4}{*}{8} & $\mathrm{H} 2 \mathrm{O}(1,21)$ & 1 & 54 & \multirow{4}{*}{59} & 83 & \multirow{4}{*}{85} \\
\hline & $\mathrm{H} 2 \mathrm{O}(1,21)$ & 2 & 63 & & 83 & \\
\hline & $\mathrm{H} 2 \mathrm{O}(1,21)$ & 3 & 68 & & 88 & \\
\hline & H2O (1,21) & 4 & 56 & & 89 & \\
\hline \multirow{4}{*}{9} & $\mathrm{MH} 2 \mathrm{OO}(0,43)$ & 1 & 33 & \multirow{4}{*}{37} & 69 & \multirow{4}{*}{73} \\
\hline & $\mathrm{MH} 200(0,43)$ & 2 & 41 & & 73 & \\
\hline & MH2OO $(0,43)$ & 3 & 39 & & 72 & \\
\hline & $\mathrm{MH} 200(0,43)$ & 4 & 53 & & 78 & \\
\hline
\end{tabular}




\section{¿Descartada?}

Sí
Sí
Sí
Sí
No
No
No
No
No
No
No
No
No
Sí
Sí
Sí

No

No

No

No

No

Sí

No

No

Sí

No

Sí

Sí

No

No

No

No

No

No

No

No

\section{¿Descartada como serie?}

Sí

No

No

No

No

No

No

Si

No

Sí

Sí
Sí
Sí
Sí

Sí

Sí

Sí

Sí

Sí

No

Si
Si
Si
Si

Sí

Sí

No
¿Fotocatalítico como serie?

No

Sí

Sí

Sí

Sí

Sí

Sí

Sí

Sí

Sí

Sí 


\begin{tabular}{|c|c|c|c|c|c|c|}
\hline$N^{0}$ Serie & Aditivo (\% spc) & $N^{0}$ & $\mathrm{R}_{4}$ & $\begin{array}{c}\text { Promedio } \mathrm{R}_{4} \\
\text { de la serie }\end{array}$ & $\mathrm{R}_{26}$ & $\begin{array}{c}\text { Promedio } \mathrm{R}_{26} \\
\text { de la serie }\end{array}$ \\
\hline \multirow{4}{*}{10} & $\mathrm{MH} 2 \mathrm{OO}(1,21)$ & 1 & 34 & \multirow{4}{*}{31} & 69 & \multirow{4}{*}{65} \\
\hline & $\mathrm{MH} 2 \mathrm{OO}(1,21)$ & 2 & 33 & & 69 & \\
\hline & $\mathrm{MH} 2 \mathrm{OO}(1,21)$ & 3 & 20 & & 53 & \\
\hline & $\mathrm{MH} 2 \mathrm{OO}(1,21)$ & 4 & 28 & & 58 & \\
\hline \multirow{4}{*}{11} & LS $14(0,026)$ & 1 & 64 & \multirow{4}{*}{66} & 86 & \multirow{4}{*}{87} \\
\hline & LS $14(0,026)$ & 2 & 65 & & 87 & \\
\hline & LS $14(0,026)$ & 3 & 67 & & 88 & \\
\hline & LS $14(0,026)$ & 4 & 68 & & 85 & \\
\hline \multirow{4}{*}{12} & LS $14(0,05)$ & 1 & 60 & \multirow{4}{*}{60} & 85 & \multirow{4}{*}{87} \\
\hline & LS $14(0,05)$ & 2 & 63 & & 88 & \\
\hline & LS $14(0,05)$ & 3 & 56 & & 85 & \\
\hline & LS $14(0,05)$ & 4 & 60 & & 88 & \\
\hline \multirow{4}{*}{13} & Mas $(0,026)$ & 1 & 59 & \multirow{4}{*}{57} & 84 & \multirow{4}{*}{85} \\
\hline & Mas $(0,026)$ & 2 & 56 & & 85 & \\
\hline & Mas $(0,026)$ & 3 & 53 & & 85 & \\
\hline & Mas $(0,026)$ & 4 & 60 & & 86 & \\
\hline \multirow{4}{*}{14} & Mas $(0,05)$ & 1 & 66 & \multirow{4}{*}{65} & 89 & \multirow{4}{*}{89} \\
\hline & Mas $(0,05)$ & 2 & 60 & & 91 & \\
\hline & Mas $(0,05)$ & 3 & 39 & & 87 & \\
\hline & Mas $(0,05)$ & 4 & 69 & & 90 & \\
\hline \multirow{4}{*}{15} & oleato $(0,60)$ & 1 & 54 & \multirow{4}{*}{54} & 82 & \multirow{4}{*}{80} \\
\hline & oleato $(0,60)$ & 2 & 46 & & 47 & \\
\hline & oleato $(0,60)$ & 3 & 53 & & 83 & \\
\hline & oleato $(0,60)$ & 4 & 54 & & 79 & \\
\hline \multirow{4}{*}{16} & oleato $(0,90)$ & 1 & 33 & \multirow{4}{*}{38} & 77 & \multirow{4}{*}{77} \\
\hline & oleato $(0,90)$ & 2 & 37 & & 76 & \\
\hline & oleato $(0,90)$ & 3 & 45 & & 79 & \\
\hline & oleato $(0,90)$ & 4 & 52 & & 77 & \\
\hline \multirow{4}{*}{17} & $554(2,14)$ & 1 & 7 & \multirow{4}{*}{10} & 48 & \multirow{4}{*}{48} \\
\hline & $554(2,14)$ & 2 & 9 & & 44 & \\
\hline & $554(2,14)$ & 3 & 13 & & 47 & \\
\hline & $554(2,14)$ & 4 & 16 & & 53 & \\
\hline \multirow{4}{*}{18} & $554(5)$ & 1 & 28 & \multirow{4}{*}{36} & 65 & \multirow{4}{*}{66} \\
\hline & $554(5)$ & 2 & 19 & & 66 & \\
\hline & $554(5)$ & 3 & 40 & & 65 & \\
\hline & $554(5)$ & 4 & 42 & & 70 & \\
\hline
\end{tabular}


¿Descartada?

No
No
Sí

No

No

No

No

No

No

No

No

No

No

No

No

No

No

No

No

No

No

Sí

No

No

Sí

No

Si

Sí

Sí

No

Sí

Sí

Sí

Sí

No

Sí
¿Descartada como serie?

¿Material Fotocatalítico?

¿Fotocatalítico como serie?

\begin{tabular}{c|c|}
\hline & Sí \\
\hline & Si \\
\hline & Sí \\
\hline & Sí \\
\hline
\end{tabular}

Sí

Sí

Sí

Sí

Sí

Si

No

No

\begin{tabular}{|l|}
\hline Sí \\
\hline Sí \\
\hline Sí \\
\hline Si \\
\hline
\end{tabular}

Sí

Sí

Sí

Sí

\begin{tabular}{|l|}
\hline Sí \\
\hline Sí \\
\hline Sí \\
\hline Sí
\end{tabular}

Sí

No

No

No

No

\begin{tabular}{|c|}
\hline Sí \\
\hline No \\
\hline Sí \\
\hline Sí \\
\hline
\end{tabular}

\section{Sí}

(1)

\section{Sí}

si

(1)




\subsubsection{MEDICIÓN DE LA CAPACIDAD FOTOCATALÍTICA DE ELIMINACIÓN DE NO${ }_{x}$.}

\section{PROCEDIMIENTO OPERATIVO}

El procedimiento experimental NOx seguido ha sido el correspondiente a la norma, UNI 11247. Las muestras son preacondicionadas $24 \mathrm{~h}$ antes del ensayo en las condiciones de humedad y temperatura del laboratorio durante el ensayo, temperatura de $22^{\circ} \mathrm{C} \pm 2{ }^{\circ} \mathrm{C}$ y humedad relativa de $50 \% \pm 10 \%$. La humedad y la temperatura se controlan mediante humidificadores y aire acondicionado portátil. Para la circulación del gas se utilizan tubos de politetrafluoretileno que no alteren la concentración de los óxidos de nitrógeno.

La cantidad de $\mathrm{NO}_{x}$ se fija en el valor de 0,55 $\pm 0,05 \mathrm{ppm}$, de las cuales $0,15 \pm 0,05 \mathrm{ppm}$ son de $\mathrm{NO}^{2}$ y 0,4 $\pm 0,05 \mathrm{ppm}$, de $\mathrm{NO}$. La degradación de $\mathrm{NO}$ y $\mathrm{NO}^{2}$ se lleva a cabo sobre un flujo continuo del gas conteniendo los óxidos de nitrógeno, con iluminación ultravioleta de la muestra que se ensaya.

La fuente de iluminación consiste en una lámpara de Osram Ultravitalux de $300 \mathrm{~W}$ de potencia, que proporciona una intensidad de radiación sobre la superficie de la muestra que en el espectro UV-A tenga una intensidad de $20 \pm 1 \mathrm{~W} / \mathrm{m}^{2}$. Las condiciones ambientales de ensayo son $20^{\circ} \mathrm{C} \pm 2^{\circ} \mathrm{C}$ y humedad relativa del $70 \pm 10 \%$.

Se utiliza un medidor Delta Ohm 2102.1 con sensor LP471 UVA para medir la intensidad de UV-A en el rango de $315 \mathrm{~nm}$ hasta $400 \mathrm{~nm}$. La medida se toma con el sensor colocado en el interior del reactor en la superficie de la probeta. El flujo de alimentación es de 1,5 litros/min. La temperatura del gas se mide antes que entre en el reactor.

Se llevan a cabo las siguientes medidas:

1. La concentración inicial de los óxidos de nitrógeno antes de entrar en el reactor fotoquímico $\left(C_{A}\right)$.

2. La concentración en la salida del reactor fotoquímico en la oscuridad $\left(\mathrm{C}_{\mathrm{B}}\right)$.

3. La concentración en la salida del reactor fotoquímico con iluminación $\left(C_{L}\right)$. 
La actividad fotocatalítica de reducción de óxidos de nitrógeno, $A_{C}$, para distintos tiempos de reacción se ha calculado con la siguiente fórmula:

$$
A_{C}=100 \frac{\left(C_{B}-C_{L}\right)}{C_{B}} \cdot \frac{I_{N}}{I} \cdot \frac{S_{N}}{S}
$$

Donde:

$\mathrm{A}_{C}=$ Índice adimensional de eliminación de $\mathrm{NO}_{x}$ bajo las condiciones de ensayo expresado en porcentaje.

$C_{B}$ y $C_{L}=$ concentraciones $\left(\mathrm{NO}_{X}, \mathrm{NO}_{2}, \mathrm{NO}\right)$ anteriormente definidas.

$\mathrm{S}_{\mathrm{N}}=$ área nominal de la muestra a examen $\left(64 \mathrm{~cm}^{2}\right)$.

$\mathrm{S}=$ área de la muestra sometida a ensayo expresada en $\mathrm{cm}^{2}$.

$\mathrm{I}_{\mathrm{N}}=$ irradiancia nominal $\left(20 \mathrm{~W} / \mathrm{m}^{2}\right)$.

$\mathrm{I}=$ irradiancia media expresada en $\mathrm{W} / \mathrm{m}^{2}$.

La actividad fotocatalítica de reducción de óxidos de nitrógeno, AF , (en unidad de $\mathrm{m} / \mathrm{h}$ ), para distintos tiempos de reacción se ha calculado con la siguiente formula:

$$
A_{F}=\frac{\left(C_{B}-C_{L}\right)}{C_{B}} \cdot \frac{F}{S} \cdot I
$$

Donde:

$C_{B}$ y $C_{L}$ son las concentraciones $\left(\mathrm{NO}_{X}, \mathrm{NO}_{2}, \mathrm{NO}\right)$ anteriormente definidas;

$\mathrm{S}=$ área geométrica de la muestra a examen en $\mathrm{m}^{2}$

$\mathrm{F}=$ flujo del gas expresado en $\mathrm{m}^{3} / \mathrm{h}$

I = intensidad adimensional del flujo luminoso, obtenida indicando la intensidad medida experimentalmente I' (expresada en $\mathrm{W} / \mathrm{m}^{2}$ ) a $1.000 \mathrm{~W} / \mathrm{m}^{2}$, correspondiente a aproximadamente 100.000 lux, es decir, al valor medio que la luz solar alcanza a medio día un día de julio, según la formula

$$
I=\frac{1000}{I}
$$

$A_{F}$ hace referencia a los $\mathrm{NO}_{x}, \mathrm{NO}_{\text {y }} \mathrm{NO}_{2}$ y se calculan para cada probeta. 


\begin{tabular}{|c|c|c|c|c|c|c|c|}
\hline \multirow{2}{*}{ Serie } & \multirow{2}{*}{ Aditivo (\% spc) } & \multicolumn{3}{|c|}{$A C(\%)$} & \multicolumn{3}{|c|}{ Promedio serie (AF) } \\
\hline & & & $\mathrm{NO}_{2}$ & $\mathrm{NO}_{x}$ & NO & $\mathrm{NO}_{2}$ & $\mathrm{NO}_{\mathrm{x}}$ \\
\hline 1 & Mortero no fotocatalítico & 1 & 0,2 & $-2,7$ & 7 & 1 & -20 \\
\hline 2 & Mortero fotocatalítico & 7 & 6 & 5 & 53 & 47 & 33 \\
\hline 3 & $15000(0,64)$ & 14 & 12 & 8 & 100 & 90 & 60 \\
\hline 4 & $15000(1,42)$ & 12 & 8 & -3 & 87 & 57 & -21 \\
\hline 5 & $10012(0,64)$ & 18 & 13 & -1 & 128 & 93 & -6 \\
\hline 6 & $10012(1,42)$ & 16 & 13 & 5 & 113 & 90 & 34 \\
\hline 7 & $\mathrm{H} 2 \mathrm{O}(0,43)$ & 19 & 15 & 6 & 138 & 111 & 46 \\
\hline 8 & $\mathrm{H} 2 \mathrm{O}(1,21)$ & 5 & 9 & 17 & 35 & 60 & 125 \\
\hline 9 & $\mathrm{MH} 200(0,43)$ & 8 & 10 & 14 & 57 & 68 & 98 \\
\hline 10 & $\mathrm{MH} 200(1,21)$ & 7 & 5 & 1 & 48 & 37 & 8 \\
\hline 11 & LS $14(0,026)$ & 21 & 16 & 1 & 155 & 112 & 8 \\
\hline 12 & LS $14(0,05)$ & 11 & 12 & 17 & 77 & 90 & 122 \\
\hline 13 & Mas $(0,026)$ & 15 & 11 & 3 & 109 & 82 & 18 \\
\hline 14 & Mas $(0,05)$ & 28 & 23 & 8 & 207 & 163 & 58 \\
\hline 15 & Oleato $(0,60)$ & 20 & 16 & 4 & 147 & 114 & 31 \\
\hline 16 & Oleato $(0,90)$ & 21 & 19 & 13 & 156 & 139 & 96 \\
\hline 17 & $554(2,14)$ & 12 & 9 & 2 & 84 & 66 & 17 \\
\hline 18 & $554(5)$ & 23 & 18 & 5 & 170 & 131 & 37 \\
\hline 19 & $554(14,29)$ & 1 & 1 & 1 & 4 & 5 & 7 \\
\hline 20 & $5010(2,14)$ & 10 & 12 & 15 & 76 & 87 & 113 \\
\hline 21 & $5010(5)$ & 4 & 3 & -2 & 32 & 19 & -15 \\
\hline 22 & saf $54(3,75)$ & 20 & 14 & -1 & 147 & 105 & -7 \\
\hline 23 & saf $54(7,14)$ & 19 & 14 & 4 & 140 & 104 & 24 \\
\hline 24 & saf $54(14,29)$ & 6 & 6 & 5 & 44 & 41 & 34 \\
\hline
\end{tabular}




\begin{tabular}{|c|c|c|c|c|c|c|c|}
\hline \multicolumn{3}{|c|}{ Coeficiente de variación (\%) } & \multicolumn{3}{|c|}{ Resultado Válido } & \multirow{2}{*}{ Serie } & \multirow{2}{*}{ Aditivo (\% spc) } \\
\hline NO & $\mathrm{NO}_{2}$ & $\mathrm{NO}_{x}$ & NO & $\mathrm{NO}_{2}$ & $\mathrm{NO}_{\mathrm{x}}$ & & \\
\hline 67 & 50 & 74 & No & No & No & 1 & Mortero no fotocatalítico \\
\hline 5 & 3 & 31 & Sí & Si & No & 2 & Mortero fotocatalítico \\
\hline 17 & 2 & 71 & No & Si & No & 3 & $15000(0,64)$ \\
\hline 1 & 1 & 21 & Sí & Sí & No & 4 & $15000(1,42)$ \\
\hline 7 & 18 & 703 & Si & No & No & 5 & $10012(0,64)$ \\
\hline 10 & 11 & 31 & No & No & No & 6 & $10012(1,42)$ \\
\hline 6 & 11 & 50 & Sí & No & No & 7 & $\mathrm{H} 2 \mathrm{O}(0,43)$ \\
\hline 13 & 7 & 18 & No & Si & No & 8 & $\mathrm{H} 2 \mathrm{O}(1,21)$ \\
\hline 29 & 25 & 19 & No & No & No & 9 & $\mathrm{MH} 200(0,43)$ \\
\hline 8 & 5 & 50 & Si & Si & No & 10 & $\mathrm{MH} 200(1,21)$ \\
\hline 5 & 3 & 88 & Sí & Sí & No & 11 & LS $14(0,026)$ \\
\hline 13 & 11 & 7 & No & No & Si & 12 & LS $14(0,05)$ \\
\hline 12 & 10 & 21 & No & Si & No & 13 & Mas $(0,026)$ \\
\hline 3 & 2 & 10 & Sí & Si & Si & 14 & Mas $(0,05)$ \\
\hline 3 & 2 & 8 & Si & Sí & Si & 15 & Oleato $(0,60)$ \\
\hline 15 & 24 & 54 & No & No & No & 16 & Oleato $(0,90)$ \\
\hline 5 & 11 & 101 & Si & No & No & 20 & $554(2,14)$ \\
\hline 43 & 37 & 26 & No & No & No & 21 & $554(5)$ \\
\hline 75 & 17 & 156 & No & No & No & 22 & $554(14,29)$ \\
\hline 31 & 30 & 28 & No & No & No & 23 & $5010(2,14)$ \\
\hline 5 & 1 & 51 & Sí & Si & No & 24 & $5010(5)$ \\
\hline 1 & 0 & 86 & Si & Si & No & 25 & saf $54(3,75)$ \\
\hline 6 & 2 & 104 & Si & Si & No & 26 & saf $54(7,14)$ \\
\hline 15 & 17 & 20 & No & No & No & 27 & saf $54(14,29)$ \\
\hline
\end{tabular}


INFLUENCIA DEL COLOR Y ELACABADO SUPERFICIALENLASPROPIEDADES DE UN MORTERO FOTOCATALITICO COMO SOLUCIÓN DE ENVOLVENTE 
En la primera parte de este capitulo se realiza el análisis de datos obtenidos para evaluar la reflectancia y los aspectos de las propiedades fotocatalíticas a través de las capacidades autolimpiantes, descontaminantes y como el color y el acabado superficial las condicionan

En la segunda parte se realiza el analisis de los datos obtenidos para evaluar la influencia de los aditivos en las propiedades fotocataliticas del cemento. 
INFLUENCIA DEL COLOR Y ELACABADO SUPERFICIALEN LAS PROPIEDADES DE UN MORTERO FOTOCATALITICO COMO SOLUCIÓN DE ENVOLVENTE 


\section{I . ANÁLISIS DE LOS RESULTADOS Y DISCUSIÓN DE LOS ENSAYOS A LOS MORTEROS.}

\subsubsection{PROPIEDADES FÍSICAS DE LA SERIE DE MORTERO}

Las tablas siguientes resumen los resultados obtenidos de consistencia, aire ocluido, resistencias a la compresión y flexotraccion para los distintos morteros.

Los resultados de relacion a/mortero y consistencia, indican que la demanda de agua varia poco con la adición de los pigmentos respecto al mortero fotocatalítico blanco. La disminución de la consistencia en los morteros pigmentados se ha debido probablemente, al tamaño extremadamente

348 Fernandes, V., Silva, L., Ferreira, V. M., \& Labrincha, J. A. (2005) Influence of the kneading water content in the behaviour of single-coat mortars. Cement and concrete research, 35(10), 1900-1908.

Tabla 38. Parámetros físicos de los pigmentos fino de los pigmentos, lo que causa una mayor demanda de agua.

El módulo de elasticidad es similar en todos los morteros ensayados y asimilable a los de un mortero de revestimiento ${ }^{348}$, varían entre un $-27,8 \%$ a $-7,9 \%$. Entre los valores individuales se observa que el mortero fotocatalítico sin pigmentos es el que tiene el valor más alto, y el mortero fotocatalítico con pigmento rojo (MTX-R) el más bajo.

\begin{tabular}{|c|c|c|c|}
\hline Pigmento & Forma de la Partícula & $\begin{array}{c}\text { Residuo (\%) en Tamiz } \\
\mathbf{7 4 5} \boldsymbol{\mu m}\end{array}$ & $\begin{array}{c}\text { Tamaño medio de la } \\
\text { Partícula }(\boldsymbol{\mu m})\end{array}$ \\
\hline Bayferrox 130-Rojo & Esférica & 0,06 & 0,17 \\
\hline Bayferrox 330-Negro & Esférica & 0,1 & 0,15 \\
\hline Bayferrox 920-Amarillo & Acicular & 0,04 & $0,1-0,6$ \\
\hline Oxined 7025-Marrón & $\begin{array}{c}\text { Mezcla Pigmentos + Filler } \\
\text { Calizo }\end{array}$ & 0,04 & 1,2 \\
\hline
\end{tabular}

\begin{tabular}{|c|c|c|c|c|c|c|c|}
\hline & M & MTX & MTX-A & MTX-R & MTX-M & MTX-G1 & MTX-G2 \\
\hline Dosificación Pigmento (\%) & - & - & 0,05 & 0,04 & 0,1 & 0,015 & 0,03 \\
\hline Relación Agua/Mortero & 0,16 & 0,17 & 0,17 & 0,17 & 0,18 & 0,18 & 0,18 \\
\hline \multicolumn{8}{|c|}{ Resultados en estado fresco } \\
\hline Consistencia (mm) & 168 & 168 & 165 & 163 & 160 & 164 & 162 \\
\hline Aire ocluido & 7,2 & 11 & 9,8 & 10,4 & 12 & 12 & 10 \\
\hline Densidad (kg/l) & 2 & 2 & 2,01 & 1,99 & 1,96 & 1,94 & 2,03 \\
\hline \multicolumn{8}{|c|}{ Resultados en estado endurecido } \\
\hline Densidad (kg/l) & 2,04 & 2,02 & 2,02 & 2 & 1,78 & 1,76 & 1,76 \\
\hline $\mathrm{Rc}(\mathrm{MPa})$ & 8,6 & 3,81 & 5,57 & 6,19 & 7,39 & 6,79 & 6,58 \\
\hline $\operatorname{Rf}(M P a)$ & 3,27 & 2,19 & 2,89 & 3,88 & 2,9 & 2,75 & 2,94 \\
\hline$E_{D}(G P a)$ & 11,99 & 13,11 & 10,27 & 9,46 & 11,68 & 11,51 & 12,07 \\
\hline
\end{tabular}


En cuanto al aire ocluido, los resultados no muestran una clara tendencia, siendo insignificante la diferencia entre el mortero fotocatalítico blanco y coloreados, del mismo modo la diferencia con el mortero no fotocatalítico es del (4-5\%). No podemos establecer comparaciones en estas propiedades con el mortero no fotocatalítico al desconocer el tipo de cemento blanco que se ha utilizado para fabricarlo.

Con respecto a las resistencias mecánicas en los morteros fotocatalíticos, se observan diferencias en la resistencia a la flexotraccion con la adición de los pigmentos, el mortero con pigmento rojo consigue una mejora del $77 \%$, estando el intervalo entre 25 y el $77 \%$. La resistencia a compresión también experimenta mejoras con la presencia del pigmento, parece que en el grado de dosificación tan bajo en el que hemos trabajado, lo pigmentos podrían desempeñar como filler un efecto positivo de relleno ${ }^{349}$, tanto en los morteros coloreados en los que aumenta la demanda de agua respecto al mortero fotocatalítico blanco sin pigmentos, como en los que la mantienen, se observan aumentos en la resistencia mecánica a compresión entre el 46 al $93 \%$.

El módulo de elasticidad es similar en todos los morteros ensayados y asimilable a los de un mortero de revestimiento, varían entre un $-27,8 \%$ a $-7,9 \%$. Entre los valores individuales se observa que el mortero fotocatalítico sin pigmentos es el que tiene el valor más alto, y el mortero fotocatalítico con pigmento rojo (MTX-R) el más bajo.

\subsubsection{DIFRACCIÓN DE RAYOS X (DRX)}

Los difractogramas de los pigmentos indican que el pigmento rojo está compuesto principalmente por hematita $\left(\mathrm{Fe}_{2} \mathrm{O}_{3}\right)$, la goethita $(\mathrm{FeOOH})$ es el principal componente del pigmento amarillo y la magnetita $\left(\mathrm{Fe}_{3} \mathrm{O}_{4}\right)$, es el componente principal del pigmento negro. El pigmento marrón, es una mezcla de pigmento rojo y amarillo (hematita y goethita), e incluye también calcita $\left(\mathrm{CaCO}_{3}\right)$ en su composición, esto es debido a su uso en el proceso de fabricación como carga mineral inerte que ayuda a la mezcla de los pigmentos entre sí.
349 Lee, H. S., Lee, J. Y., $\& Y u, M . Y .(2003)$.

Influence of iron oxide pigments on the properties of concrete interlocking blocks. Cement and concrete research, 33(11), 1889-1896. 


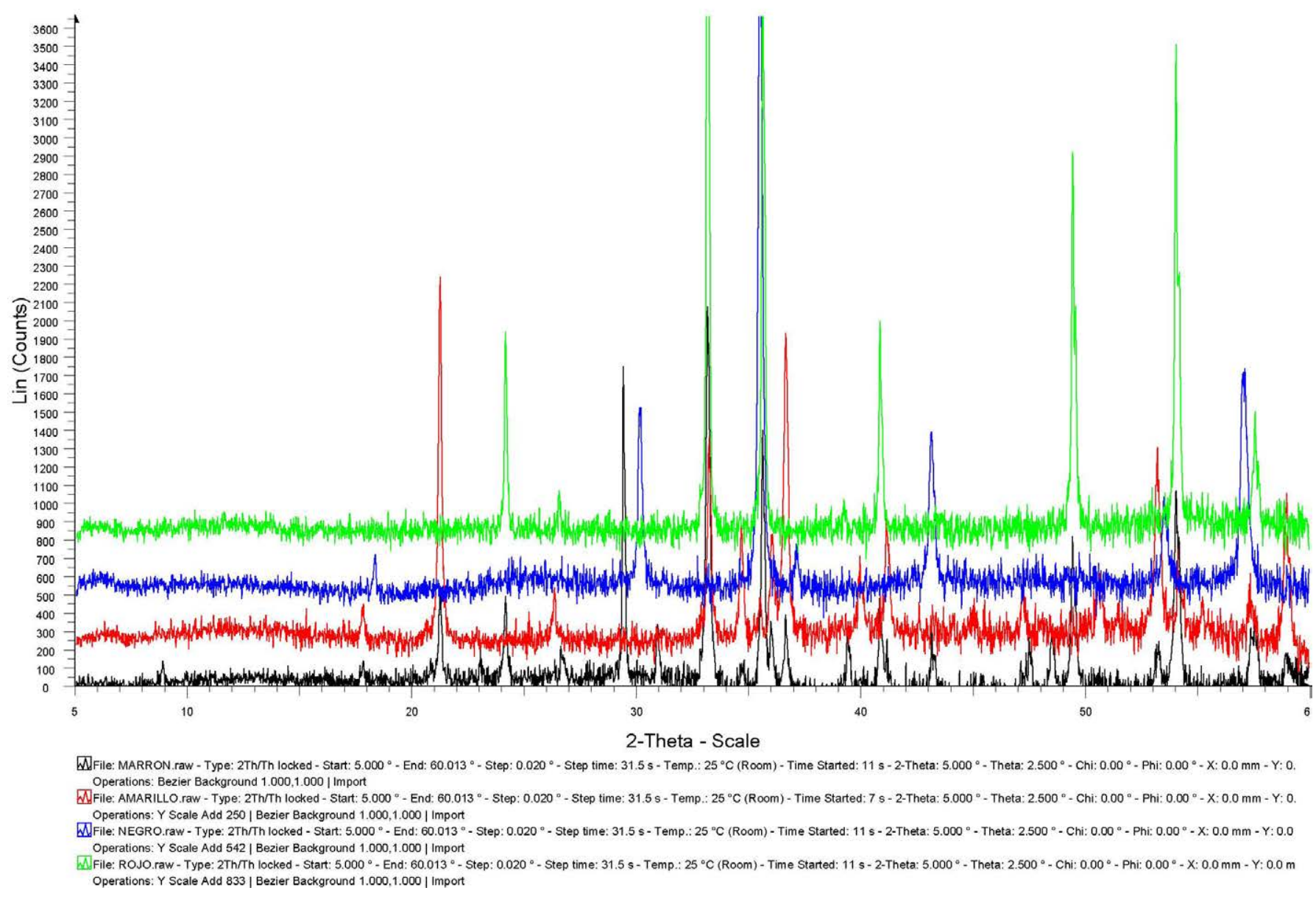

Fig 144. Superposición de los difractogramas de los pigmentos analizados.

\subsubsection{FLUORESCENCIA DE RAYOS X (FRX).}

El análisis de los resultados de la composición elemental por fluorescencia de rayos $\mathrm{X}(\mathrm{FRX})$ ha revelado que el hierro $(\mathrm{Fe})$, se encuentra presente en mayor porcentaje en el pigmento rojo $(96,47 \%)$, seguido por el amarillo $(86,35 \%)$, el marrón $(65,66 \%)$ y el pigmento negro que tiene una cantidad similar al marrón (60,95\%). La pérdida al fuego que se realiza a los pigmentos, corrobora la presencia del carbonato cálcico en las muestras analizadas, el pigmento que contiene menor cantidad es el pigmento rojo $(0,5 \%)$, mientras que las más alta es la del pigmento negro (33\%), el pigmento amarillo y el marrón presentan porcentajes similares un (12\%) y un (13\%) respectivamente. Cabe destacar la presencia de un, $1 \%$ de $\mathrm{TiO}_{2}$ equivalente en el pigmento negro.

De los datos de los morteros analizados, morteros no fotocatalítico, mortero fotocatalítico, morteros fotocatalíticos coloreados y las muestra sin arido de mortero no fotocatalítico (M-sin arido) y mortero fotocatalítico blanco (MTX-sin arido), corroboran los datos en relacion con las conclusiones del análisis de los pigmentos. Las dos muestras sin arido nos indican la diferencia esperadas en el contenido de $\mathrm{TiO}_{2}$, presente únicamente en los morteros fotocatalíticos (MTX) en cantidades similares. 
I NFLUENCIA DEL COLOR Y ELACABADOSUPERFICIALEN LAS PROPIEDADES DE UN MORTEROFOTOCATALITICO COMOSOLUCIÓN DE ENVOLVENTE

Fig 145. Página Izquierda Composición elemental de los pigmentos referida a su óxido correspondiente.

Tabla 40. Datos de pH, conductividad y Potencial Z (valor medio, con su desviación estándar, $n=10$ ).

350 Levinson, R., Berdahl, P., \& Akbari, H. (2005).

Solar spectral optical properties of pigments - Part II: survey of common colorants. Solar Energy Materials and Solar Cells, 89(4), 351-389.

Fig 146. Página Izquierda Composición elemental de los morteros referida a su óxido correspondiente

\subsubsection{POTENCIAL ZETA (५)}

Del análisis de los datos, vemos que todos los pigmentos tienen un $\mathrm{pH}$ similar, siendo el que presentaba la disolución de pigmento amarillo un poco más bajo que el resto.

No es posible generalizar o reducir la influencia de los pigmentos, aparentemente iguales, se han comprobado diferencias de composición y naturaleza través de los datos de difracción y fluorescencia de rayos $X$, de las diferencias medidas en la conductividad de cada disolución vemos que hay grandes diferencias en el número de especies móviles que cada uno de los pigmentos pone en el medio.

En relacion al potencial zeta $(\zeta)$ taly como era esperable, todos los pigmentos exhiben valores negativos. En valor absoluto, el pigmento amarillo tiene el menor valor $(-6,74 \mathrm{mV})$, mientras que el pigmento negro, tiene el mayor $(-22,46 \mathrm{mV})$. En términos absolutos, un valor mayor del potencial zeta lo que indica, es una menor tendencia a la aglomeración de las partículas que lo componen, dando como resultado una mejor distribución del pigmento en la matriz de mortero.

\begin{tabular}{|c|c|c|c|}
\hline Pigmento & $\mathrm{pH}$ & $\begin{array}{c}\text { Conductividad } \\
(\mu \mathrm{S} / \mathrm{cm})\end{array}$ & $\begin{array}{c}\text { Potencial Zeta } \\
(\mathrm{mV})\end{array}$ \\
\hline Amarillo & 8,61 & 9,1 & $-6,74 \pm 2,49$ \\
\hline Rojo & 9,22 & 36,6 & $-17,96 \pm 6,46$ \\
\hline Marrón & 9,27 & 31,1 & $-15,49 \pm 5,56$ \\
\hline Negro & 9,25 & 8,3 & $-22,46 \pm 7,97$ \\
\hline
\end{tabular}

\subsubsection{ESPECTROSCOPIA DE REFLECTANCIA DIFUSA UV-VIS-NIR}

Del análisis de los espectros obtenidos para los morteros según el color y acabado, podemos observar que los pigmentos producen cambios en la reflectancia espectral del mortero base, no sólo en la zona del espectro visible (VIS), como sería esperable, sino también en la zona del infrarrojo cercano (NIR).

La reflectancia relativa en el visible de las muestras del mortero blanco con fotocatalizador (MTX) ha sido ligeramente superior a las muestras de mortero blanco no fotocatalítico $(M)$, en torno al $3 \%$,.exceptuando la zona aproximadamente entre 1800 y $2000 \mathrm{~nm}$ del NIR.

El mortero fotocatalítico contiene $\mathrm{TiO}_{2}$, que se utiliza también como pigmento blanco, con una absorción débil a las longitudes de onda del VIS-NIR y por tanto contribuye a aumentar la reflectancia en el rango VIS-NIR $280,315,350$. 
Desde el punto de vista del balance energético, una característica interesante es la reflectancia solar, en la siguiente figura se muestra la distribución de irradiancia solar estándar definida por ASTM G173-03. Sobre la base de este espectro estándar, la energía radiante solar se distribuye $3,21 \%$ en el rango ultravioleta (UV), $53,49 \%$ en el visible (VIS) y $43,30 \%$ en el infrarrojo cercano (NIR). El espectro de referencia empleado es el indicado por la ASTM G 173-03. Para estos cálculos, el intervalo ultravioleta (UV) oscila entre $280 \mathrm{~nm}$ y $380 \mathrm{~nm}$, el visible (VIS) de $380 \mathrm{~nm}$ a $780 \mathrm{~nm}$ y el NIR oscila entre $780 \mathrm{~nm}$ y $2500 \mathrm{~nm}$.

A fin de resaltarlo la figura 2 muestra la reflectancia del mortero fotocatalítico blanco y acabado liso (MTX-L) de mortero superpuesta con la irradiancia solar de 280 a $2500 \mathrm{~nm}$.

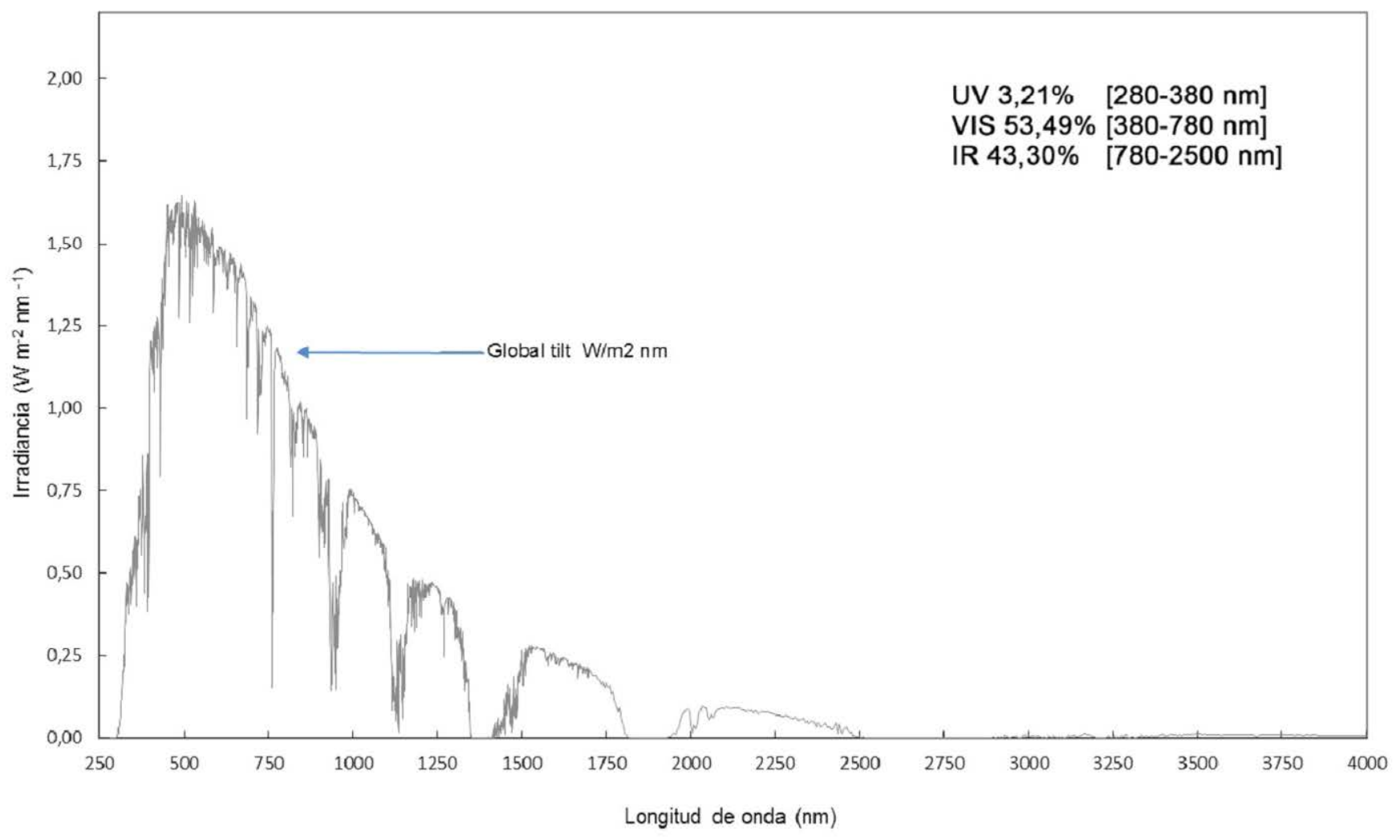

Fig 147. Irradiancia solar y porcentaje de la cantidad de radiación electromagnética en las zonas UV, Vis y NIR del espectro. 


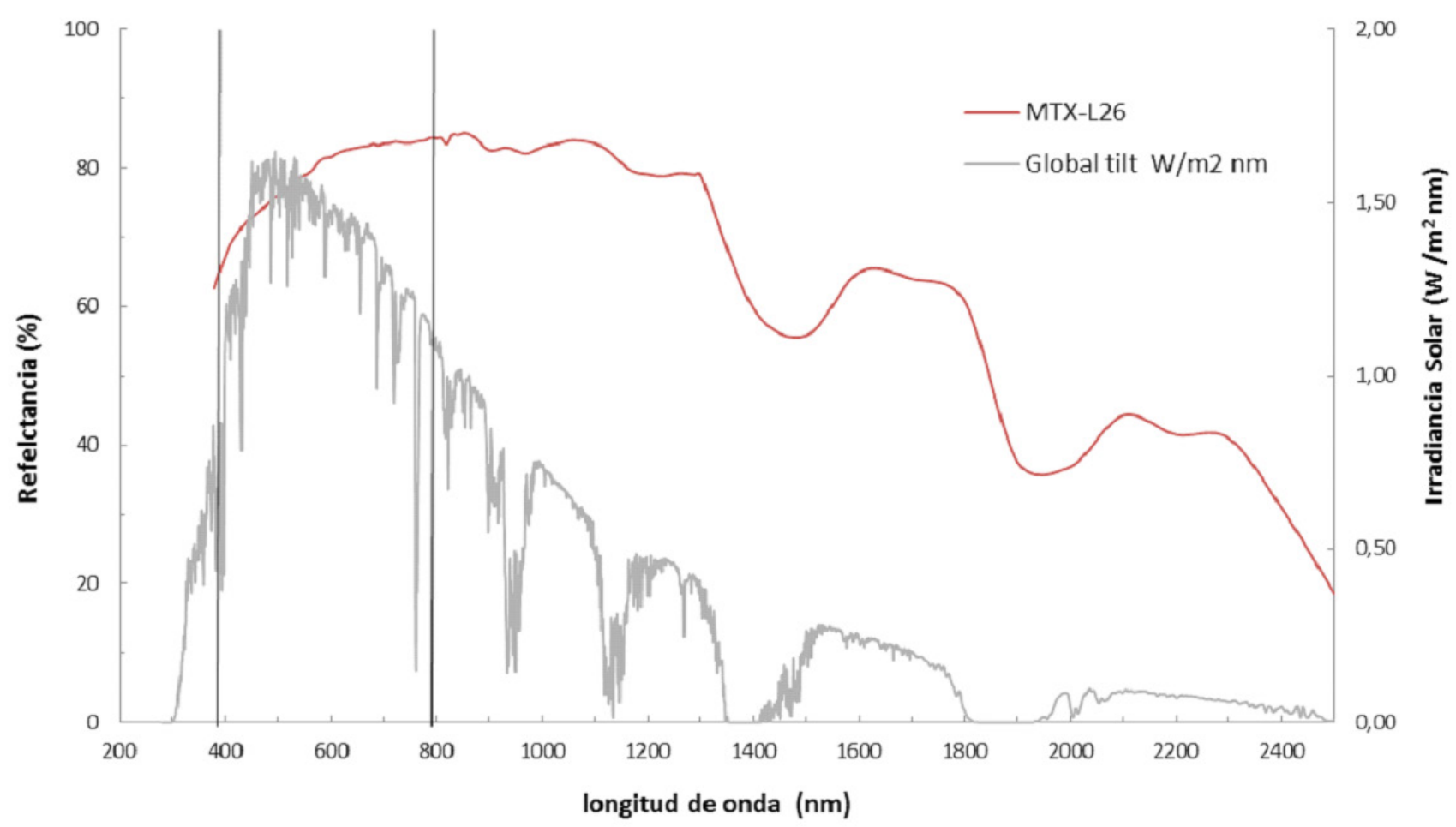

Fig 148. Reflectancia del mortero fotocatalítico blanco acabado liso, superpuesto al espectro de irradiancia solar.

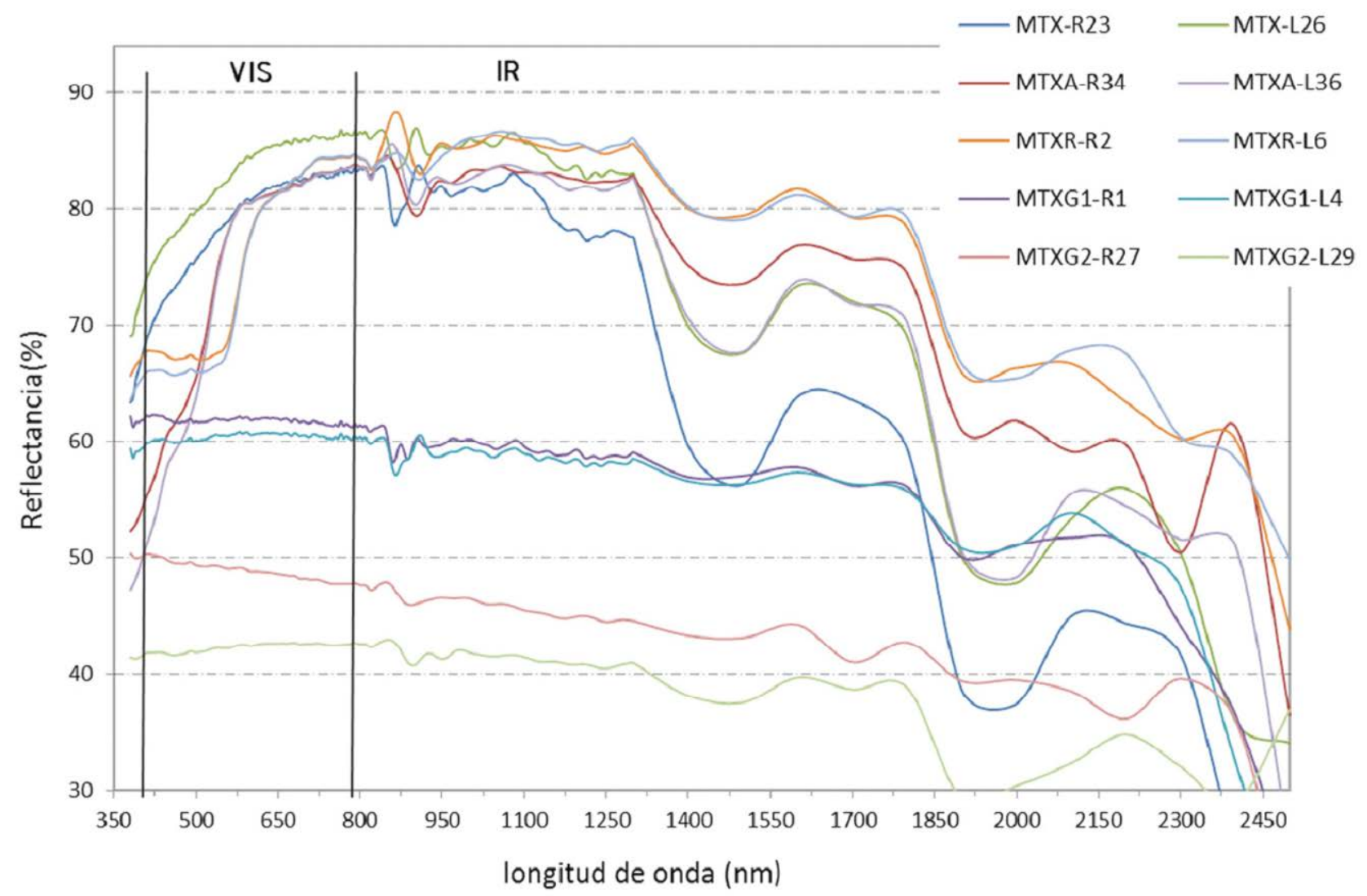

Fig 149. Reflectancia de todas las muestras de morteros fotocatalítico en los dos acabados. 


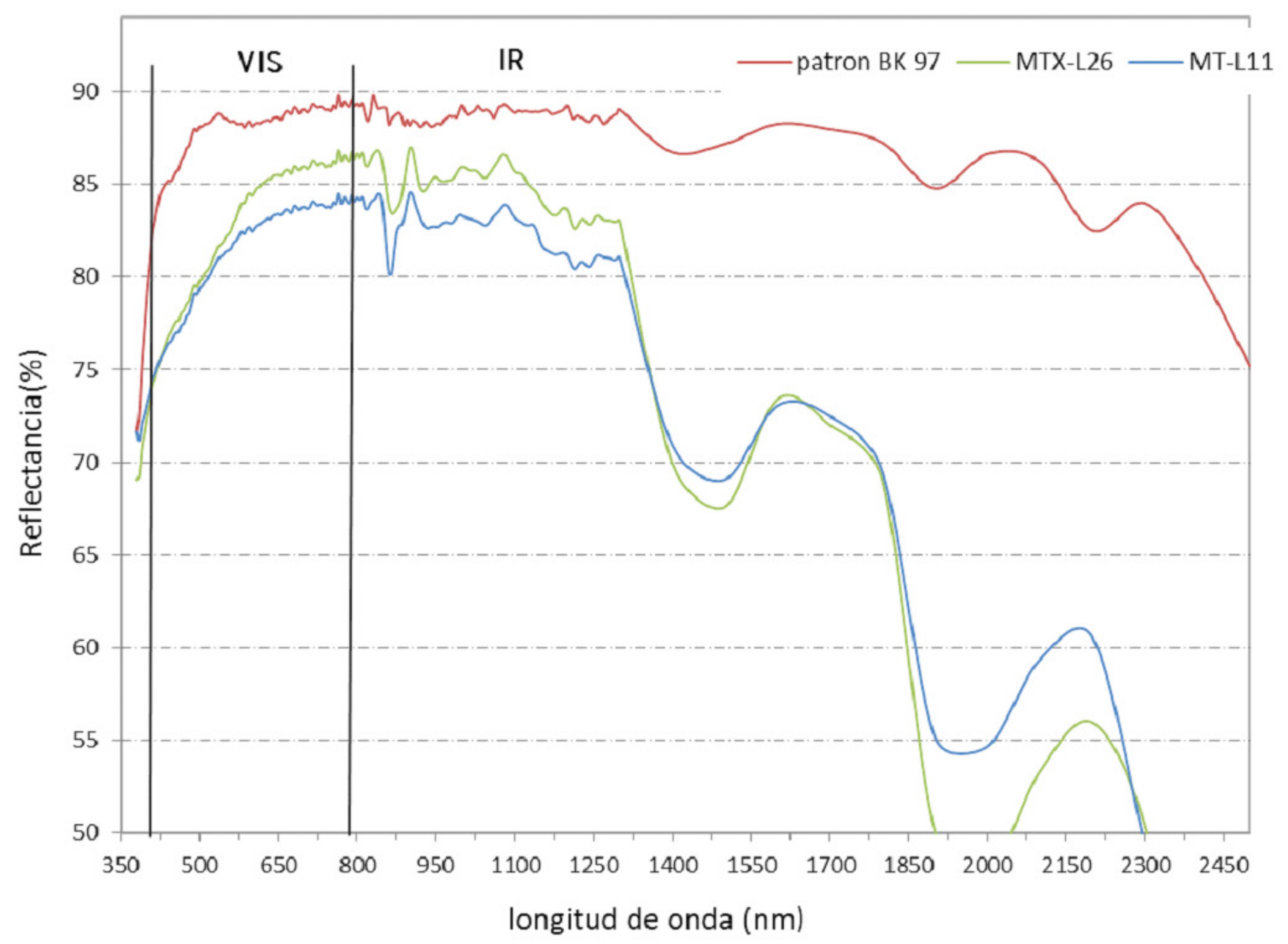

Fig 150. Reflectancia de las muestras lisas blancas de mortero fotocatalítico blanco, (MTX-26) el mortero no fotocatalítico (M-L11) comparadas con el patrón BK 97.

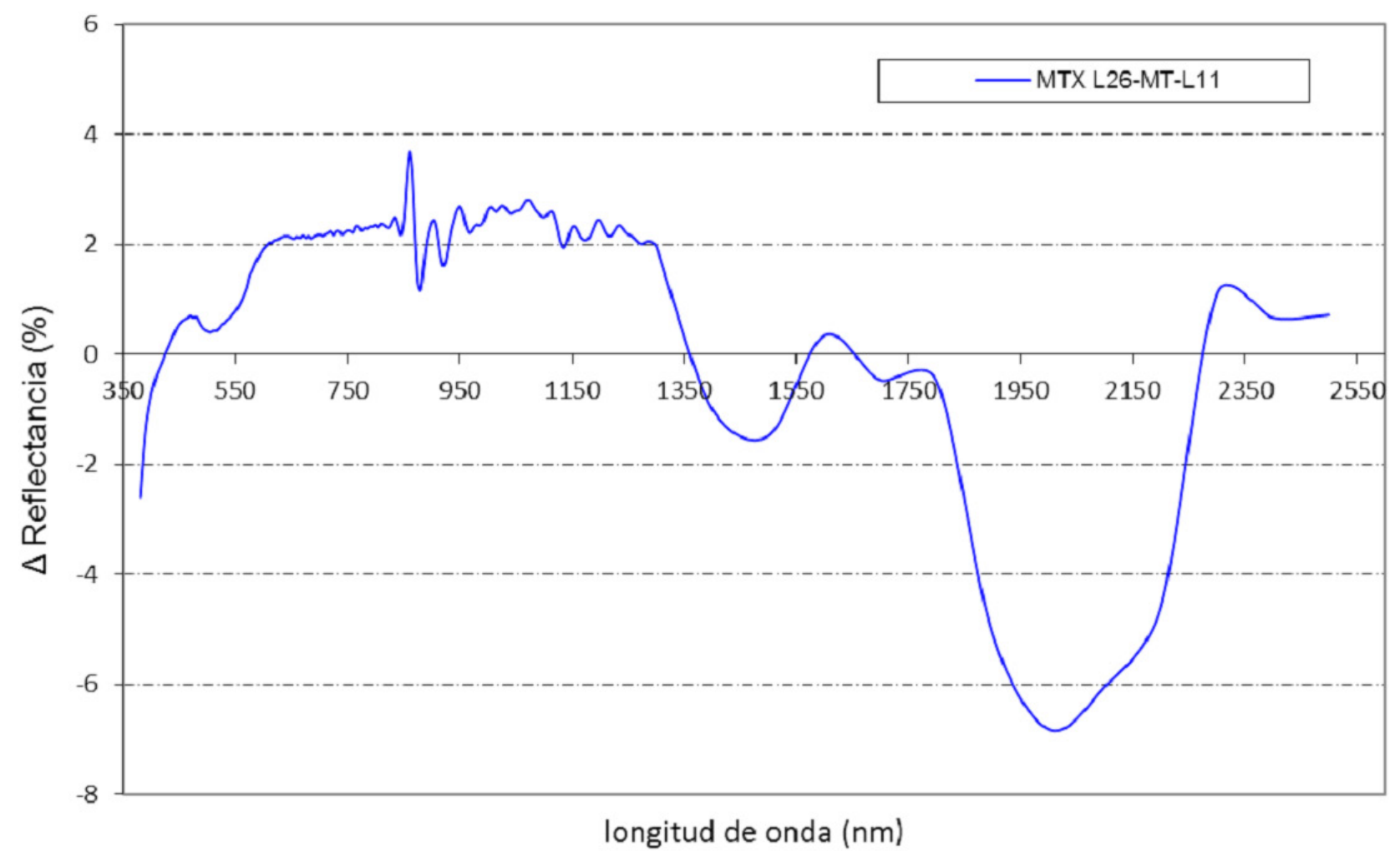

Fig 151. Diferencia de reflectancia entre las muestras lisas de mortero fotocatalítico blanco (MTX-L26) y mortero no fotocatalítico (M-L11) 


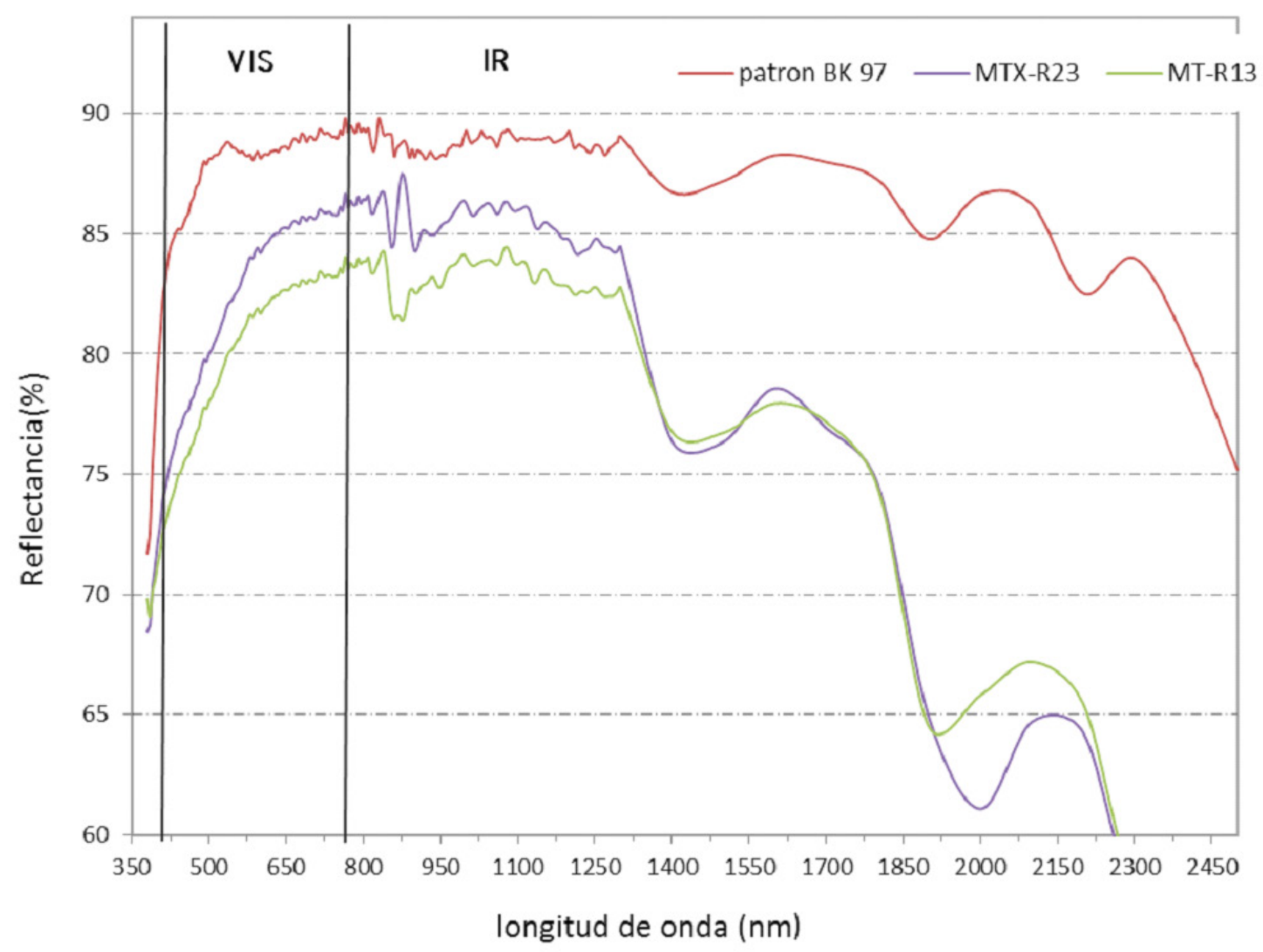

Fig 152. Reflectancia de las muestras rugosas blancas de mortero fotocatalítico blanco, (MTX23) y el mortero no fotocatalítico (M-R13) comparadas con el patrón BK 97.

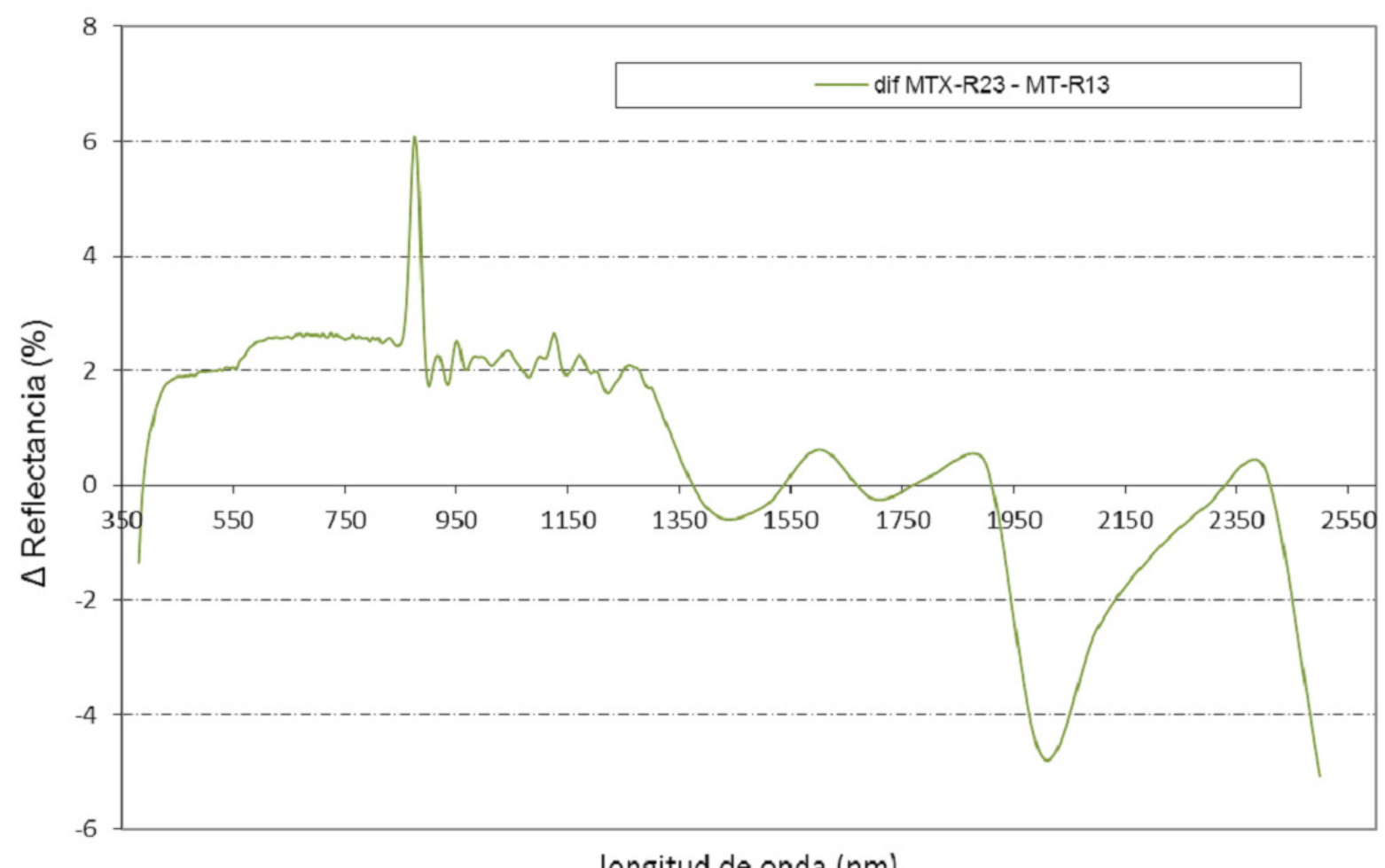

Fig 153. Diferencia de reflectancia entre las muestras rugosas de mortero fotocatalítico blanco (MTX-R23) y mortero no fotocatalítico (M-R13). 
I NFLUENCIA DEL COLOR Y ELACABADOSUPERFICIALEN LAS PROPIEDADES DE UN MORTEROFOTOCATALITICOCOMOSOLUCIÓNDEENVOLVENTE

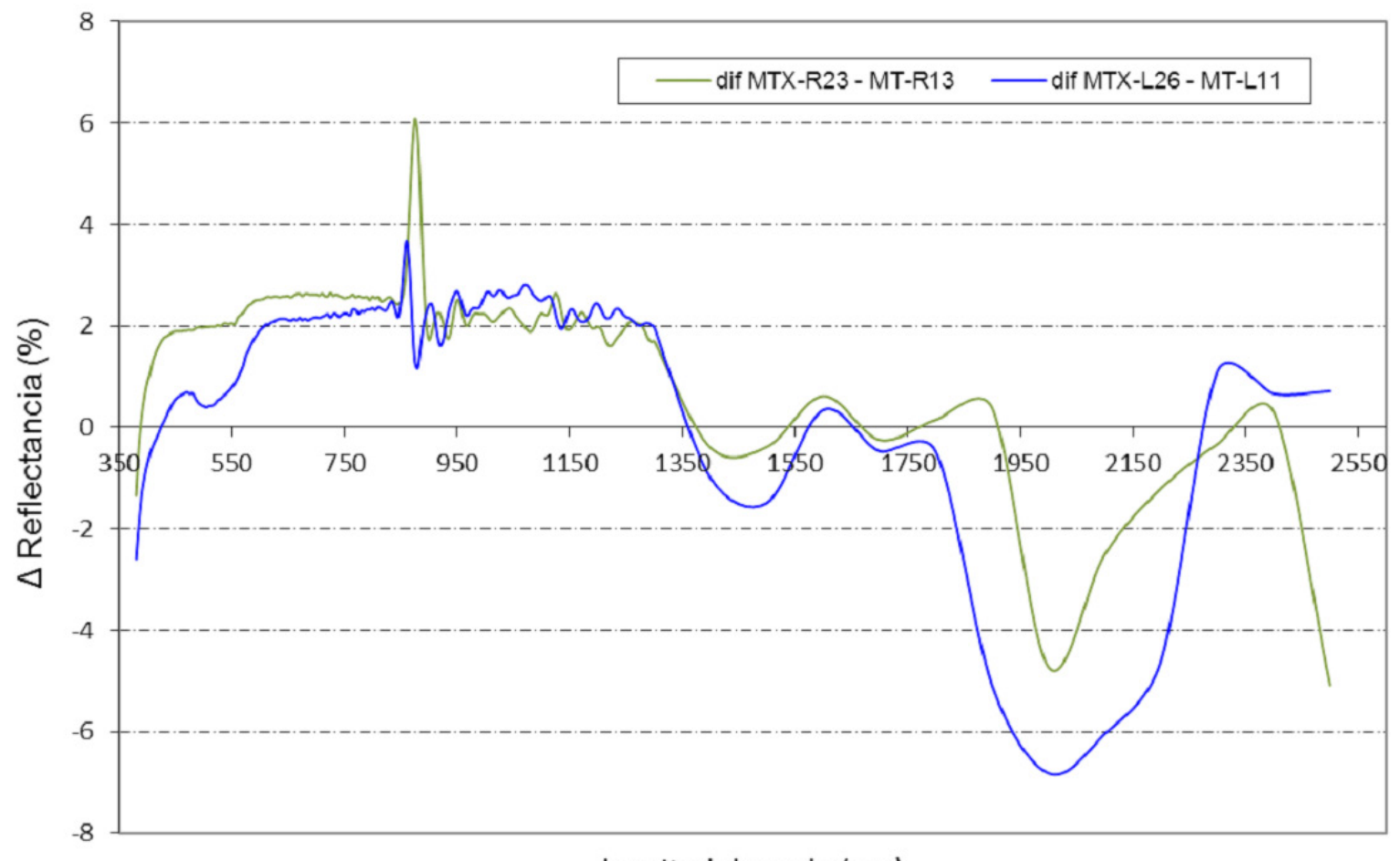

longitud de onda $(\mathrm{nm})$

Fig 154. Diferencias entre $\triangle$ Reflectancia (MTX-L26 y MT-L11) y $\triangle$ Reflectancia (MTX-R23 y MT-R13).

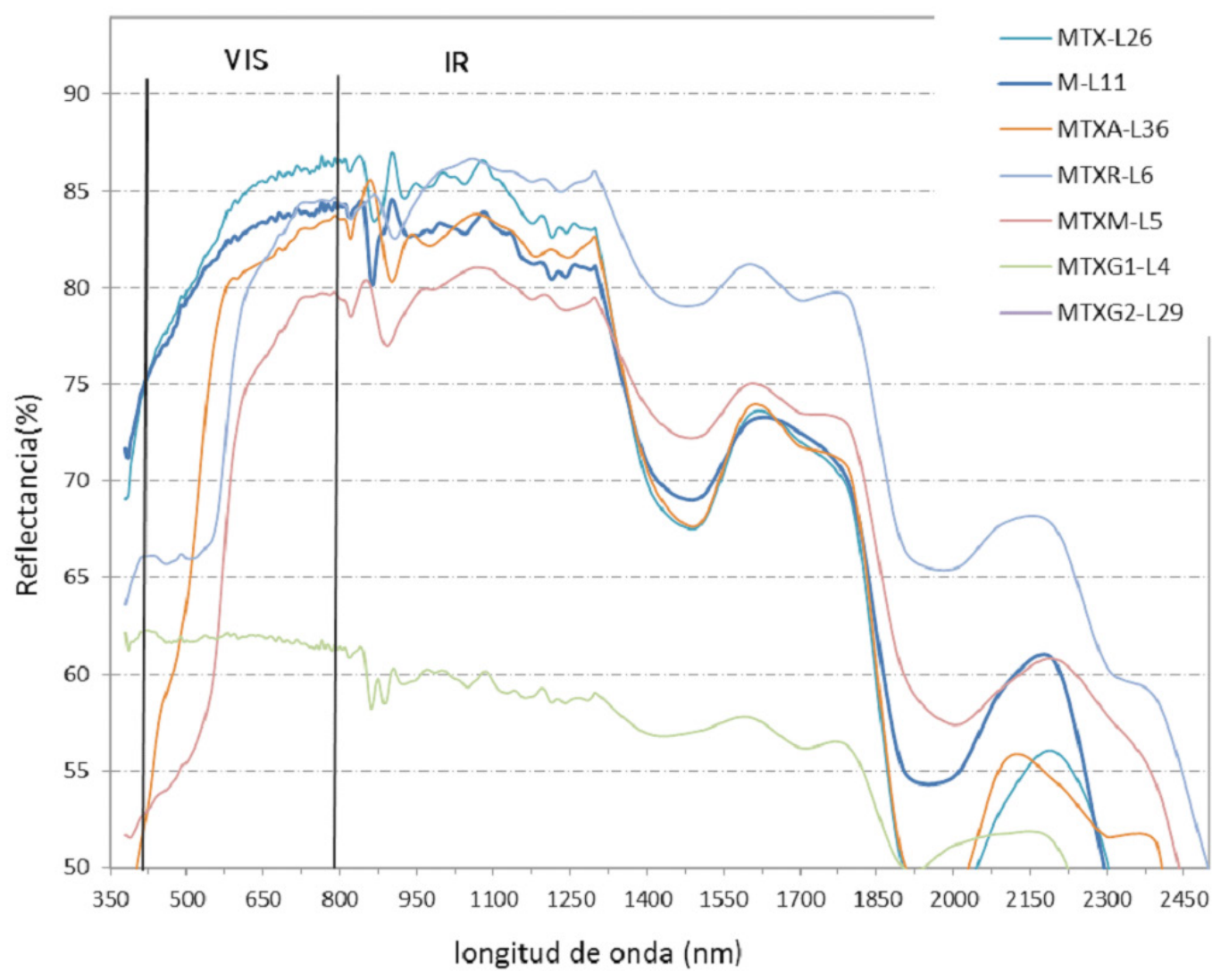

Fig 155. Reflectancia de las muestras de morteros con acabado LISO. 


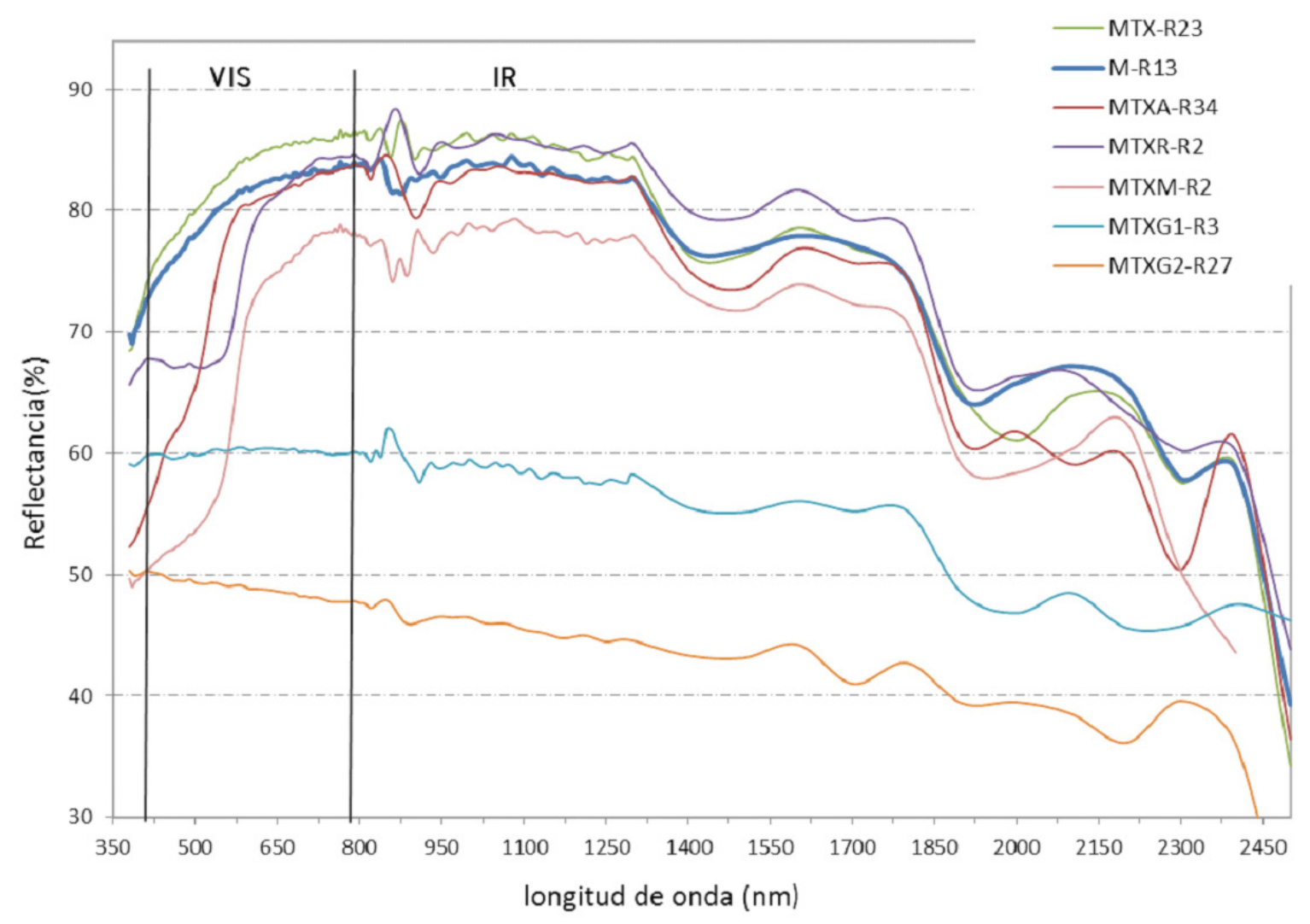

Fig 156. Reflectancia de las muestras de morteros con acabado RUGOSO.

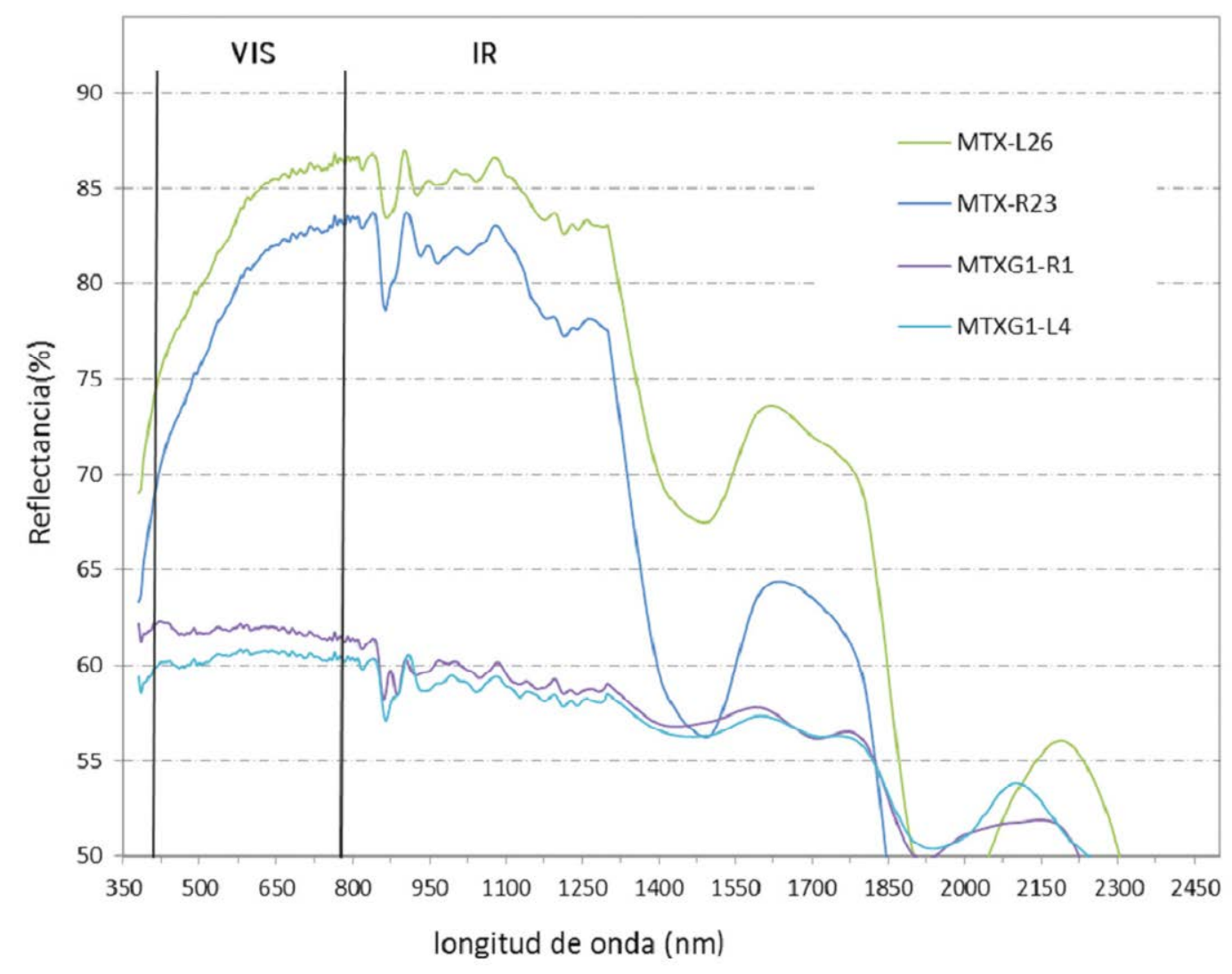

Fig 157. Reflectancia de las muestras de morteros fotocatalíticos blancos (MTX) y gris claro (MTX-G1). 
En los espectros observamos grandes bandas de absorción en el infrarrojo cercano, se deben a la vibracion de los enlace de los átomos. La fuerte absorción hasta $2300 \mathrm{~nm}$ se debe a los enlaces $\mathrm{C}-\mathrm{H}$ de los aditivos organicos que utilizan los morteros. Las bandas entre $1400 \mathrm{~nm}$ y $1600 \mathrm{~nm}$ son bandas de absorción características, que se deben a los enlaces $\mathrm{C}-\mathrm{C}$, $\mathrm{C}-\mathrm{O}, \mathrm{CH}_{2}-\mathrm{CH}_{3}-, \mathrm{C}=\mathrm{O}$, y a los átomos de hidrógeno de los grupos $\mathrm{OH}$.La baja reflectancia del pigmento negro, la corroboramos también viendo las diferencias entre ambas muestras grises, ya que MTX-G2 muestra una reducción sustancial por el mayor porcentaje de pigmento. La marcada diferencia en reflectancia total y aspecto de las curvas de reflectancia, especialmente entre $1100 \mathrm{~nm}$ and $2100 \mathrm{~nm}$, achacable a la naturaleza del pigmento, ya señalada por otros investigadores ${ }^{315}$.

En las muestras coloreadas, el espectro de reflectancia depende del tipo de pigmento utilizado en la formulación, el pigmento rojo compuesto principalmente de hematita $\left(\mathrm{Fe}_{2} \mathrm{O}_{3}\right)$, tiene una reflectancia relativa alta para las longitudes de onda VIS y NIR. El pigmento negro por el contrario, compuesto principalmente por magnetita $\left(\mathrm{Fe}_{3} \mathrm{O}_{4}\right)$ tiene una reflectancia débil en las zonas del espectro VIS y NIR. El resultado obtenido de las medidas es una mayor reflectancia de las muestras coloreadas en el siguiente orden, MTX-R > MTX-A> MTX-M, frente a las muestras de grises (MTX-G1 > MTX-G2).

La textura superficial, el acabado (fino o rugoso) no implica una diferencia significativa de la reflectancia, aunque hay que señalar que se encontraron las mayores diferencias a longitudes de onda más altas, estudiar el motivo no está en el objetivo de esta tesis.

La rugosidad a una escala mayor, que la longitud de onda de la irradiación incidente no afecta. La reflectancia es la probabilidad de que la radiación incidente se refleje cuando se encuentra una superficie. Si la superficie en cuestión es rugosa, la radiación que se refleja, es probable que sufra una o más reflexiones adicionales con diferentes distribuciones espaciales antes de escaparse, por lo que dependiendo de la rugosidad final, la probabilidad de absorción se incrementa. El tamaño máximo del árido en el mortero es de $1 \mathrm{~m} \mathrm{~m}$, lo que reduce las diferencias entre los acabados liso y rugoso.

Si integramos el área de la grafica para cada mortero en el visible (380$780 \mathrm{~nm}$ ), en la zona del infrarrojo cercano (790-1400) y sobre el espectro total (380-2500 nm), tenemos los siguientes resultados: 
Tabla 41. Cantidad de la radiación electromagnética reflejada ordenada de mayor a menor, para todos los morteros, por color y acabado.

Fig 158. Cantidad de la radiación electromagnética reflejada ordenada de mayor a menor, para todos los morteros, por color y acabado. Intervalo visible (380-780nm) y NIR (790-1400nm).

\begin{tabular}{|r|c|c|c|c|}
\hline Muestra & $\begin{array}{c}\text { Reflec VIS (\%) } \\
\text { 380-780 nm }\end{array}$ & $\begin{array}{c}\text { Reflec VIS (\%) } \\
790-1400 \mathbf{n m}\end{array}$ & $\begin{array}{l}\text { Reflec VIS (\%) } \\
790-2500 \mathbf{n m}\end{array}$ & $\begin{array}{c}\text { Reflec VIS (\%) } \\
380-2500 \mathrm{~nm}\end{array}$ \\
\hline MTX-L & 82,03 & 84,47 & 65,18 & 68,35 \\
\hline MTX-R & 81,95 & 84,02 & 71,70 & 73,63 \\
\hline M-L & 80,79 & 80,68 & 65,82 & 68,64 \\
\hline M-R & 79,78 & 82,15 & 71,78 & 73,29 \\
\hline MTXR-R & 75,05 & 84,48 & 73,79 & 74,03 \\
\hline MTXR-L & 74,43 & 84,40 & 74,33 & 74,35 \\
\hline MTXA-L & 73,86 & 81,51 & 69,18 & 70,34 \\
\hline MTXM-R & 72,78 & 80,76 & 65,18 & 66,61 \\
\hline MTXM-L & 66,77 & 78,66 & 67,83 & 67,95 \\
\hline MTXG1-R & 65,02 & 77,03 & 66,30 & 66,06 \\
\hline MTXG1-L & 60,33 & 59,15 & 52,40 & 54,18 \\
\hline MTXG2-R & 48,95 & 45,48 & 40,91 & 53,50 \\
\hline MTXG2-L & 42,25 & 40,92 & 36,81 & 42,29 \\
\hline
\end{tabular}

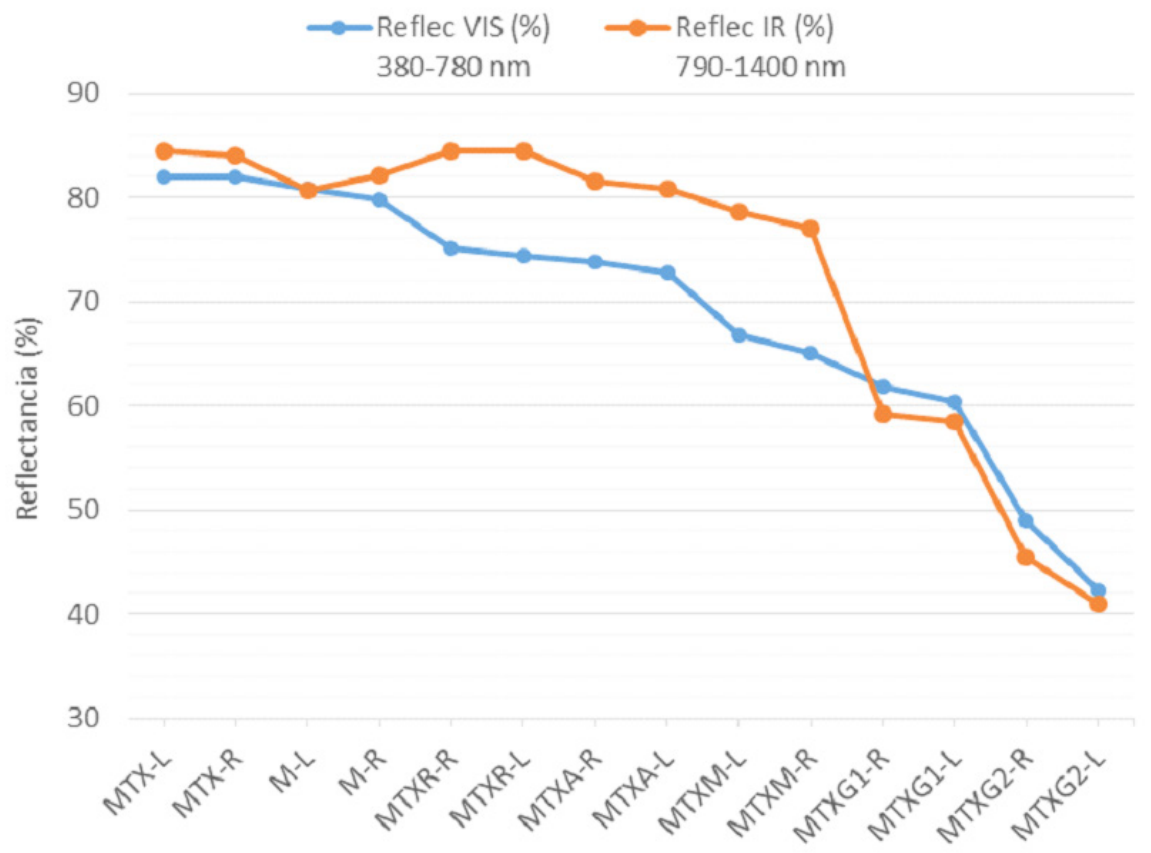

Ordenado de mayor a menor reflectancia a la irradiación visible (380$780 \mathrm{~nm}$ ), teniendo en cuenta el color y el acabado, la serie es:

MTX-L > MTX-R > M-L > M-R > MTXR-R > MTXR-L > MTXA-R > MTXA-L > MTXM-L > MTXM-R > MTXG1-R > MTXG1-L > MTXG2-R> MTXG2-L

Ordenado de mayor a menor reflectancia a la irradiación infrarrojo en la zona (790-1500 nm), teniendo en cuenta el color y el acabado, la serie es:

MTXR-R > MTX-L > MTXR-L > MTX-R > M-R > MTXA-R > MTXA-L > $M-L>M T X M-L>M T X M-R>M T X G 1-R>M T X G 1-L>M T X G 2-R>$ MTXG2-L 
Para poder evaluarlo se calcula la reflectancia en cada zona para cada mortero, diferenciando también, entre los acabados. Se puede ver que el acabado superficial no afecta a todos por igual. Las muestras sin pigmento, las blancas, con acabado rugoso tiene una mayor reflectancia en la zona NIR, que las finas, esta situación se invierte en la zona visible. Las muestras rugosas marrones, muestran una reflectancia más baja que las finas en las dos zonas. Las demás muestras fotocatalíticas rugosas, tienen mas reflectancias que las lisas en ambas zonas.
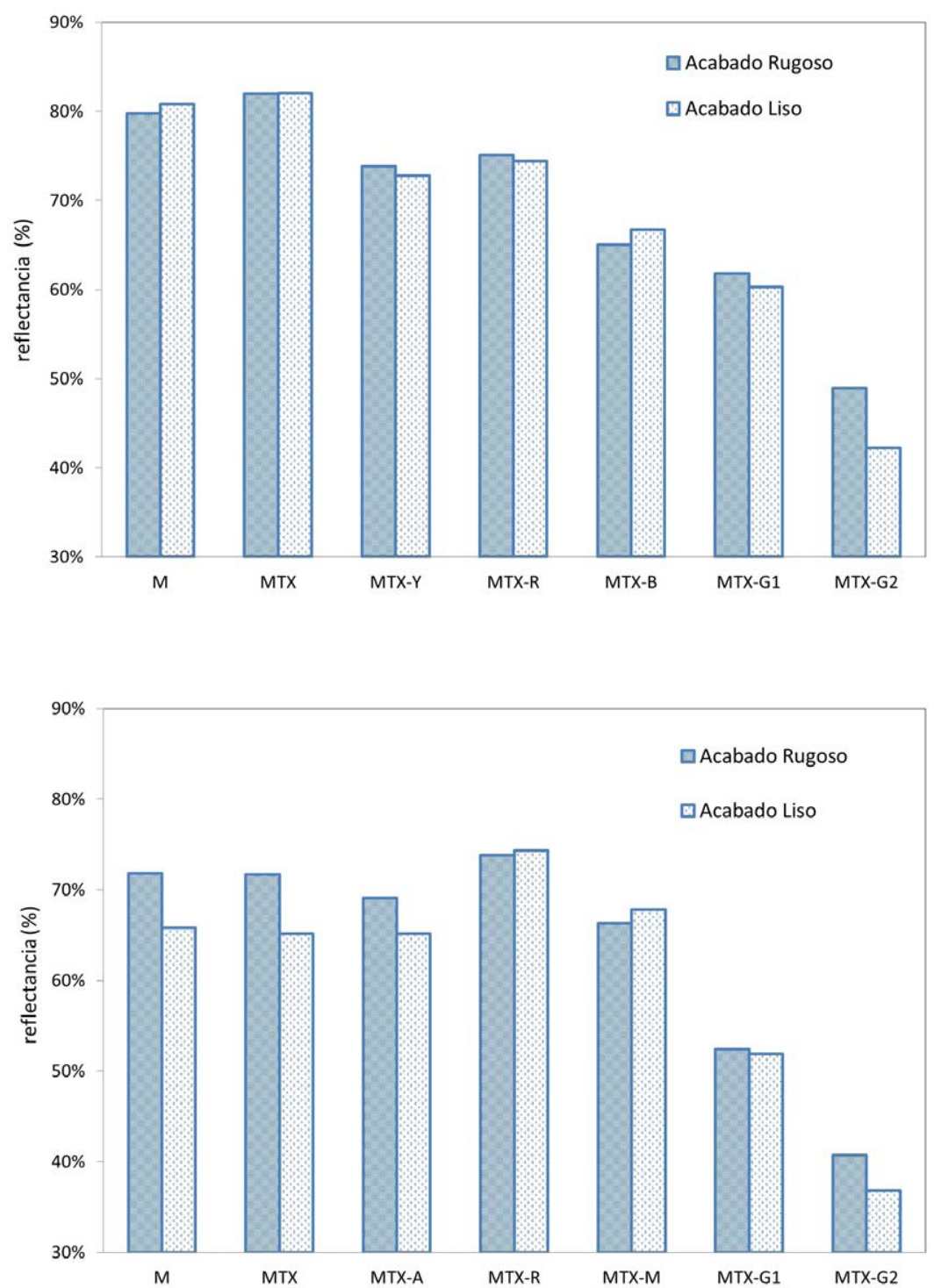

Fig 159. Reflectancia en la banda del espectro (380-780 nm) para cada mortero según el acabado superficial.

Fig 160. Reflectancia en la banda del espectro (790-1400nm) para cada mortero según el acabado superficial. 
Fig 161. Representación de la ecuación de Tauc frente a la energía absorbida, detalle de lectura de la energía de band gap en la curva de absorción del mortero fotocatalítico de color rojo (MTX-R)

\subsubsection{REFLECTANCIA DIFUSA UV-VIS. ENERGIA DE FOTOABSORCION (E G}

Partiendo de los espectros obtenidos para cada mortero mediante la ecuación de Kubelka-Munk hemos obtenido los valores de reflectancia para la zona del espectro estudiada la ultravioleta y visible. La energía de fotoabsorción o band gap, se obtiene representando la ecuación de Tauc, frente a la energía absorbida. El valor del band gap se determina por el punto de intersección entre la línea que trazamos tangente a la pendiente en los puntos de inflexión de la curva de absorción y el eje $X$, como se puede ver en las figuras.
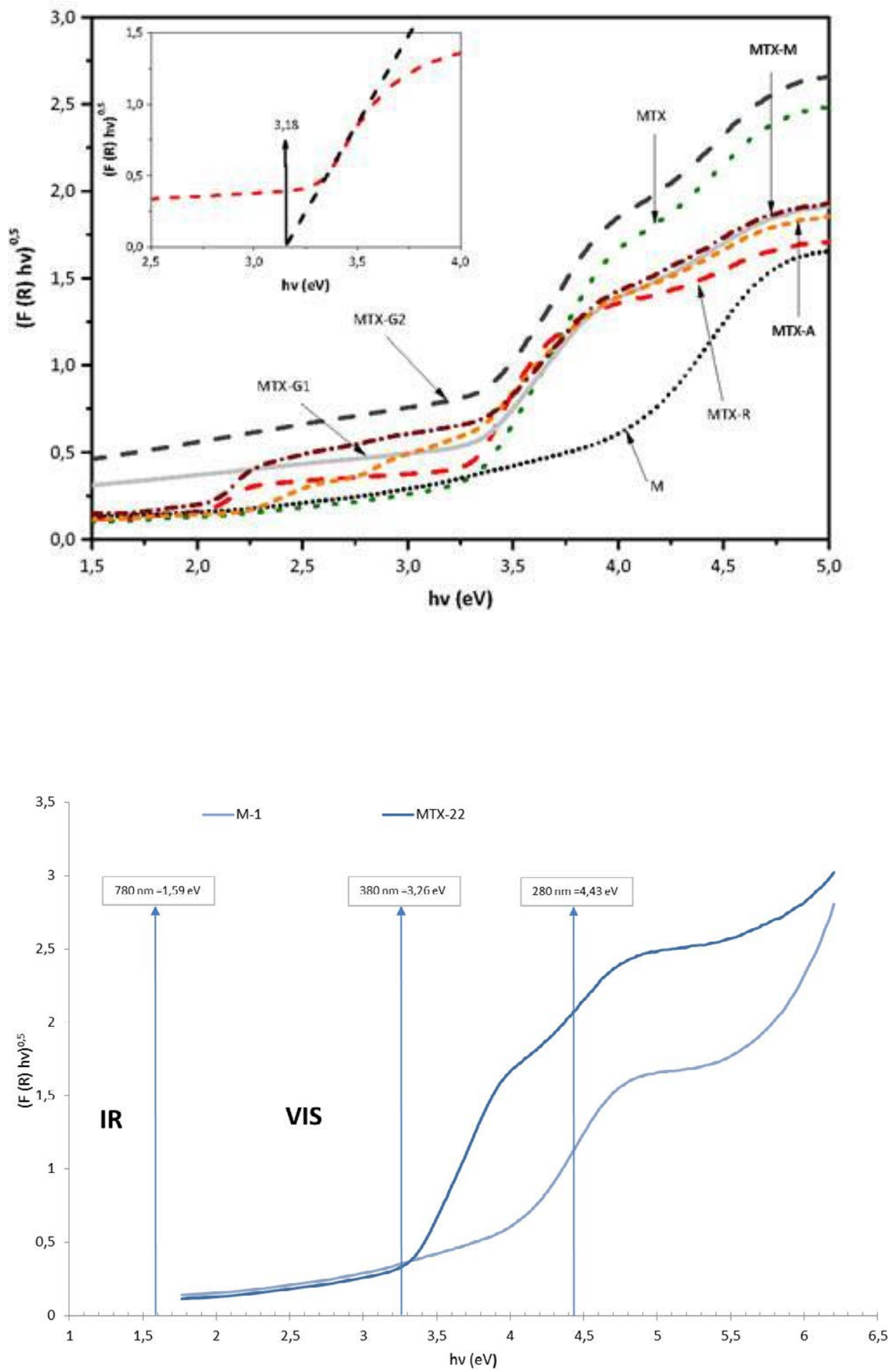

Fig 162. Espectros de absorción del mortero no fotocatalítico blanco (M) y del mortero fotocatalítico blanco (MTX). 
I NFLUENCIA DEL COLOR Y ELACABADO SUPERFICIALEN LASPROPIEDADES DE UN MORTEROFOTOCATALITICO COMOSOLUCIÓN DE ENVOLVENTE
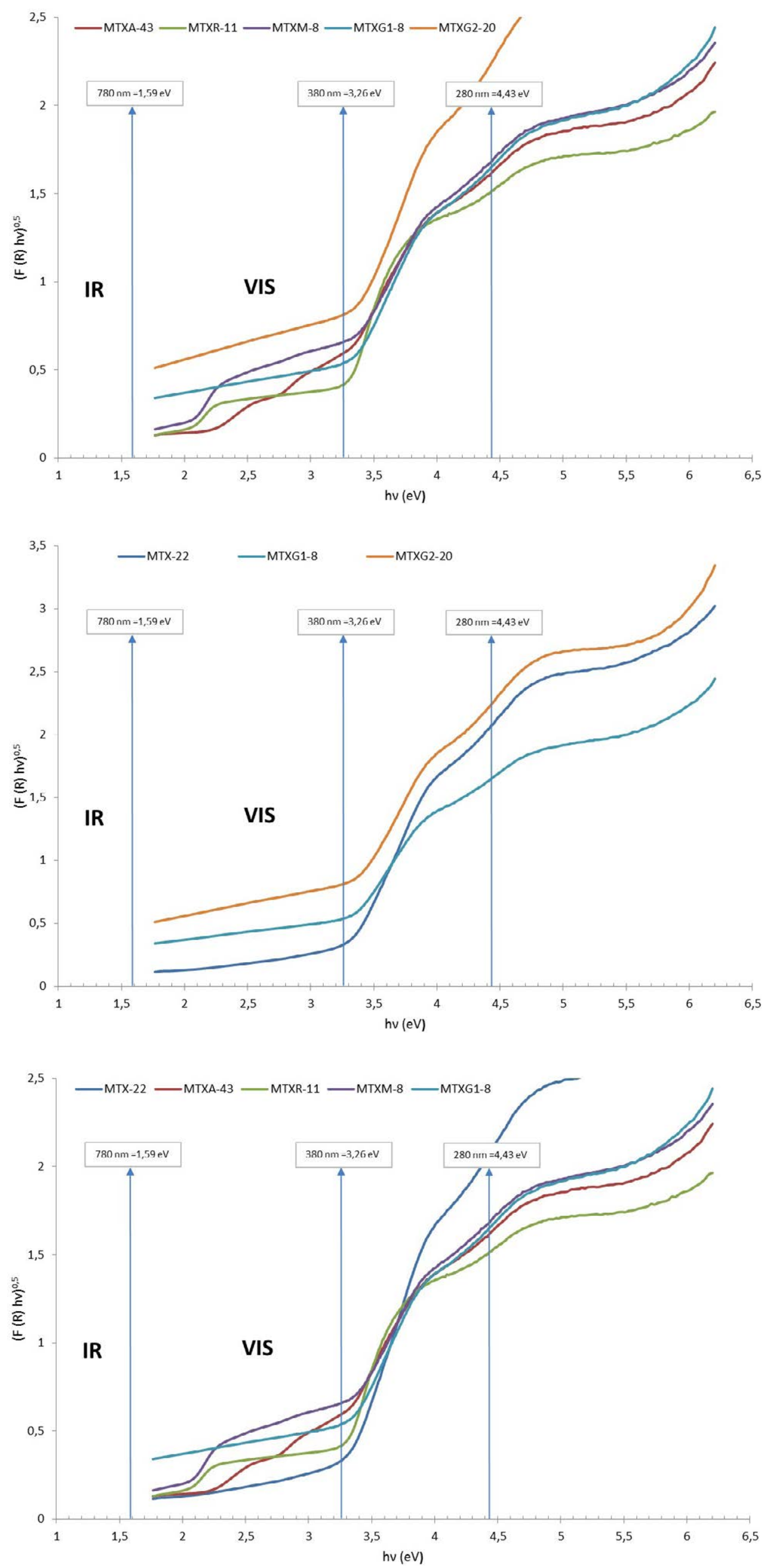

Fig 163. Espectros de absorción de los morteros fotocatalíticos pigmentados.

Fig 164. Espectros de absorción de los morteros fotocatalíticos pigmentados grises (MTXG1 y MTXG2) y el mortero fotocatalítico blanco (MTX).

Fig 165. Espectros de absorción de los morteros fotocatalíticos coloreados amarillo, rojo, marrón y gris claro, con el mortero fotocatalítico blanco (MTX). 
Fig 166. Espectros de absorción de los morteros fotocatalíticos coloreados amarillo, rojo, marrón, blanco y el mortero no fotocatalítico $(M)$

Fig 167. Energía de absorción (eV) para el mortero no fotocatalítico blanco $(M-1)$

Fig 168. Energía de absorción (eV) para el mortero fotocatalítico blanco (MTX-22).
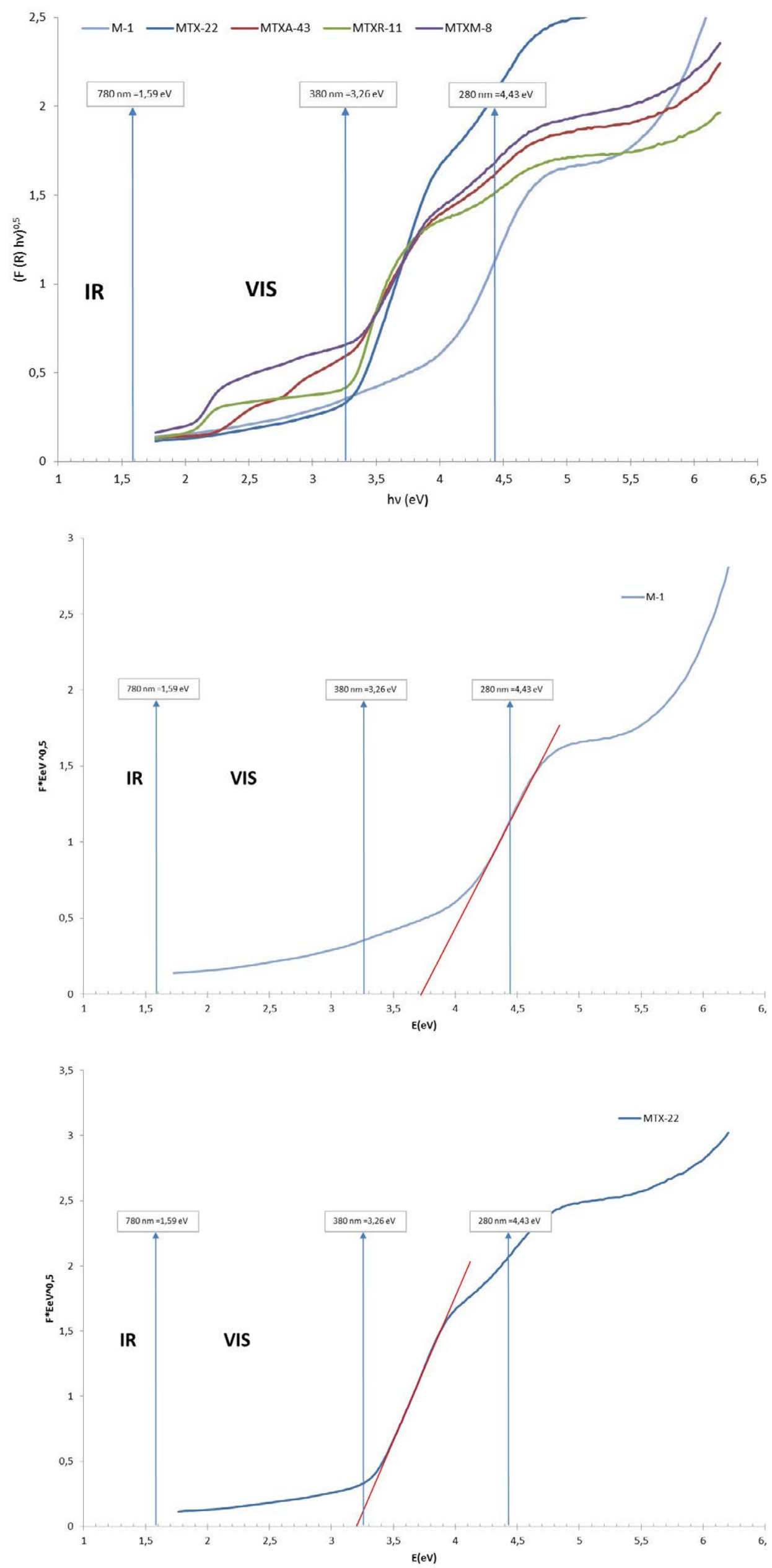
I NFLUENCIA DEL COLOR Y EL ACABADO SUPERFICIALEN LASPROPIEDADES DE UN MORTERO FOTOCATALITICO COMO SOLUCIÓN DE ENVOLVENTE
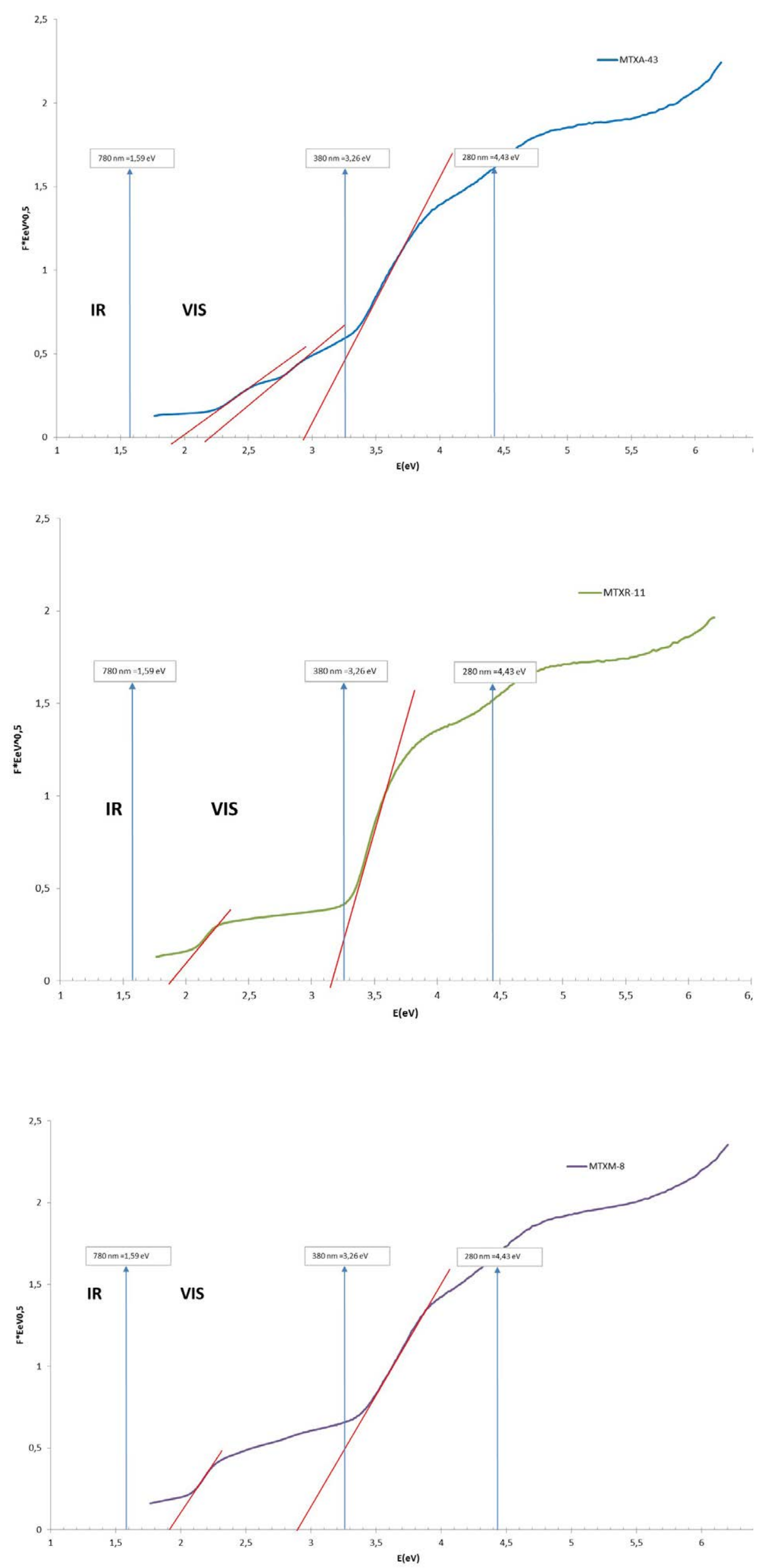

Fig 169. Energías de absorción (eV) para el mortero fotocatalítico amarillo (MTXA-43).
Fig 170. Energías de absorción (eV) para el mortero fotocatalítico rojo (MTXR-11).

Fig 171. Energías de absorción (eV) para el mortero fotocatalítico marrón (MTXM-8) 
Fig 172. Energía de absorción (eV) para el mortero fotocatalítico gris claro (MTXG1-8).

Fig 173. Energía de absorción (eV) para el mortero fotocatalítico gris oscuro (MTXG2-20).

Tabla 42. Valores de la energía de absorción necesaria para promocionar un electrón a la banda de conducción para cada mortero.

Tabla 43. Energía de la radiación de longitud de onda indicada, en el limite UV-Vis y Vis-IR.
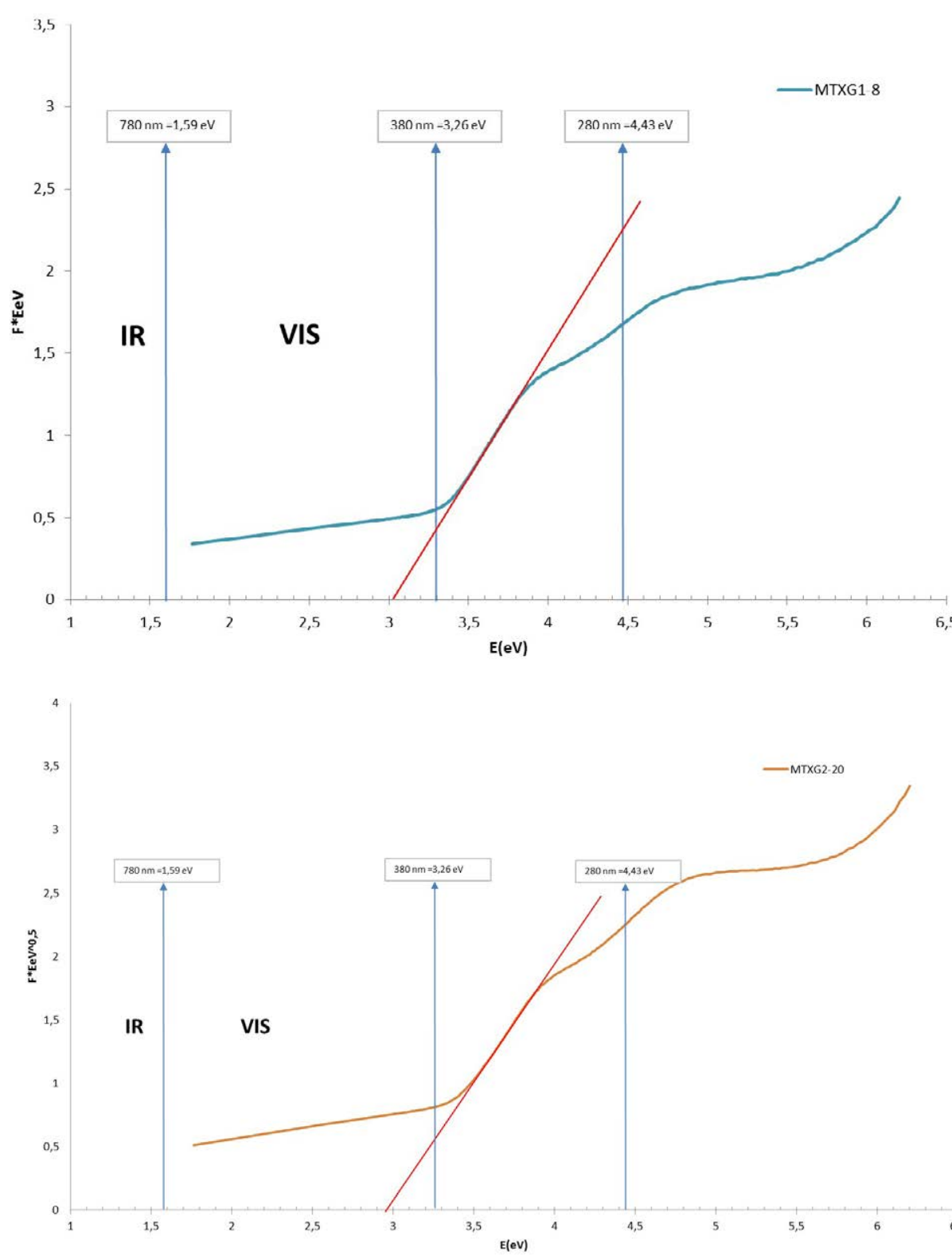

Valores de $\mathrm{E}_{\mathrm{g}}$ de las graficas:

\begin{tabular}{|c|c|c|c|c|c|c|c|}
\hline \multicolumn{7}{|c|}{ Energía de absorción (eV) } \\
\hline $\mathbf{1}$ & M & MTX & MTXA & MTXR & MTXB & MTXG1 & MTXG2 \\
\hline $\mathbf{1}$ & $3,75^{*}$ & $3,20^{*}$ & 1,98 & 1,87 & 1,93 & $3,03^{*}$ & $2,975^{*}$ \\
\hline 3 & & & 2,20 & $3,18^{*}$ & $2,93^{*}$ & & \\
\hline & & & $2,96^{*}$ & & & \\
\hline
\end{tabular}

\begin{tabular}{c|c|c|} 
& $\begin{array}{c}\mathrm{UV}>\mathrm{Vis} \\
\lambda=380 \mathrm{~mm}\end{array}$ & $\begin{array}{c}\text { Vis }>\mathrm{IR} \\
\lambda=780 \mathrm{~mm}\end{array}$ \\
\hline $\mathrm{E}(\mathrm{eV})$ & 3,26 & 1,59 \\
\hline
\end{tabular}


De los datos se puede deducir que, existen tres patrones diferenciados, el primero es el del mortero no fotocatalítico $(M)$ cuya curva no presenta ningún punto de inflexión en los intervalos correspondientes a las zonas del espectro UV-VIS. Un segundo grupo está compuesto por los morteros fotocatalíticos blanco y gris que sólo tienen un punto de inflexión en la zona UV del espectro (MTX, MTX-G1 y MTX-G2). El tercer grupo corresponde a los morteros que presentan puntos de inflexión en los rangos correspondientes a luz VIS y UV (MTX-A, MTX-R y MTX-M). El punto de inflexión en la zona visible se corresponde con la zona de absorción del color propio del mortero.

A partir de estos datos podemos decir que, la introducción de pigmentos modifica las características de la energía de absorción del mortero. Se observa que la zona de absorción se desplaza hacia valores energéticos más bajos en todas las muestras de mortero coloreado fotocatalítico respecto a la formulación de mortero fotocatalítico blanco.

Con estos valores experimentales, según Matsumoto et al. ${ }^{39}$, se puede hacer un cálculo aproximado de la posición de las bandas de valencia y de conducción para cada mortero EPv y EPc.

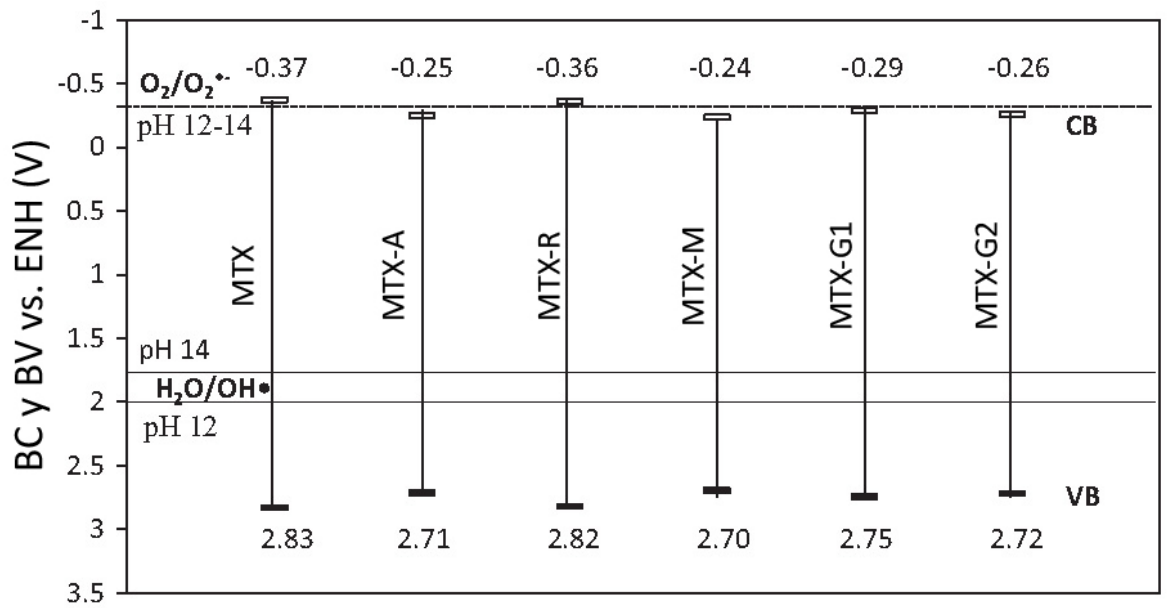

Una vez calculadas la posición de las bandas de conducción BC y de valencia BV representadas en la Fig. en el $\mathrm{pH}$ típico de un mortero ( $\mathrm{pH} 12-14)$, todas las muestras pueden oxidar el par $\mathrm{H}_{2} \mathrm{O} / \mathrm{OH}^{\cdot}$ y producir radicales $\mathrm{OH} \cdot$, al tener $E P v>2 \bigvee$. Sin embargo, como vemos en el diagrama, sólo los morteros MTX y MTX-R pueden reducir el $\mathrm{O}_{2}$ y producir $\mathrm{O}_{2}$; por tener EPv $>-0,33 \mathrm{~V}$
$\mathrm{BC}(\mathrm{eV}) \quad \mathrm{BV}(\mathrm{eV})$

\begin{tabular}{|r|r|r|}
\hline MTX & $-0,37$ & 2,83 \\
\hline MTX-A & $-0,25$ & 2,71 \\
\hline MTX-R & $-0,36$ & 2,82 \\
\hline MTX-M & $-0,24$ & 2,70 \\
\hline MTX-G1 & $-0,29$ & 2,75 \\
\hline MTX-G2 & $-0,26$ & 2,72 \\
\hline
\end{tabular}

Tabla 44. Valores calculados de las bandas de conducción (BC) y de la banda de valencia (BV) para cada mortero fotocatalítico coloreado.

Fig 174. Diagrama con las bandas de valencia (BV) y bandas de conducción (BC) de los morteros fotocatalíticos y líneas de equilibrio correspondientes a $\mathrm{OH} / \mathrm{OH}^{\prime}$ y $\mathrm{O}_{2} / \mathrm{O}_{2} \cdot{ }^{\prime-}$ a $\mathrm{pH} 12-14$. 
Tabla 45. Valores de la actividad fotocatalítica de reducción de óxidos de nitrógeno Ac (\%) y desviación estándar para los morteros según el color y su acabado superficial.

Fig 175. Valores de eliminación de $\mathrm{NO}$ para todos los morteros por colory acabado con intervalos de error.

\subsubsection{MEDICIÓN DE LA CAPACIDAD FOTOCATALÍTICA DE ELIMINACIÓN DE NO}

Debido a la dispersión de los datos experimentales por la heterogeneidad intrínseca de las muestras, se realizaron múltiples ensayos para cada mortero y textura superficial. La figura muestra el efecto de los diferentes pigmentos en la capacidad de eliminación de $\mathrm{NO}_{x}$ en comparación con las muestras de mortero fotocatalítico de referencia sin pigmento (MTX). Los morteros de referencia que no contenían $\mathrm{TiO}_{2}(M)$ no dieron ninguna reducción de $\mathrm{NO}_{x}$ en comparación con el mortero fotocatalítico, tal y como como se esperaba.

\begin{tabular}{|r|c|c|c|}
\hline & $A_{C}(\%)$ & $A_{C}(\%)$ \\
\hline M-R & 0,00 & M-L & 0,17 \\
\hline DeV & 0,00 & DeV & 0,47 \\
\hline DeV & 3,08 & MTX-L & 11,51 \\
\hline MTXA-R & 14,33 & DeV & 1,78 \\
\hline DeV & 1,62 & MTXA-L & 11,21 \\
\hline MTXR-R & 30,80 & DeV & 3,39 \\
\hline DeV & 7,10 & MTXR-L & 24,22 \\
\hline MTXM-R & 13,18 & DeV & 3,75 \\
\hline DeV & 2,46 & MTXM-L & 8,02 \\
\hline MTXG1-R & 20,76 & DeV & 0,04 \\
\hline DeV & 7,47 & MTXG1-L & 19,84 \\
\hline MTXG2-R & 13,58 & DeV & 3,23 \\
\hline DeV & 1,07 & DeV & 1,47 \\
\hline
\end{tabular}

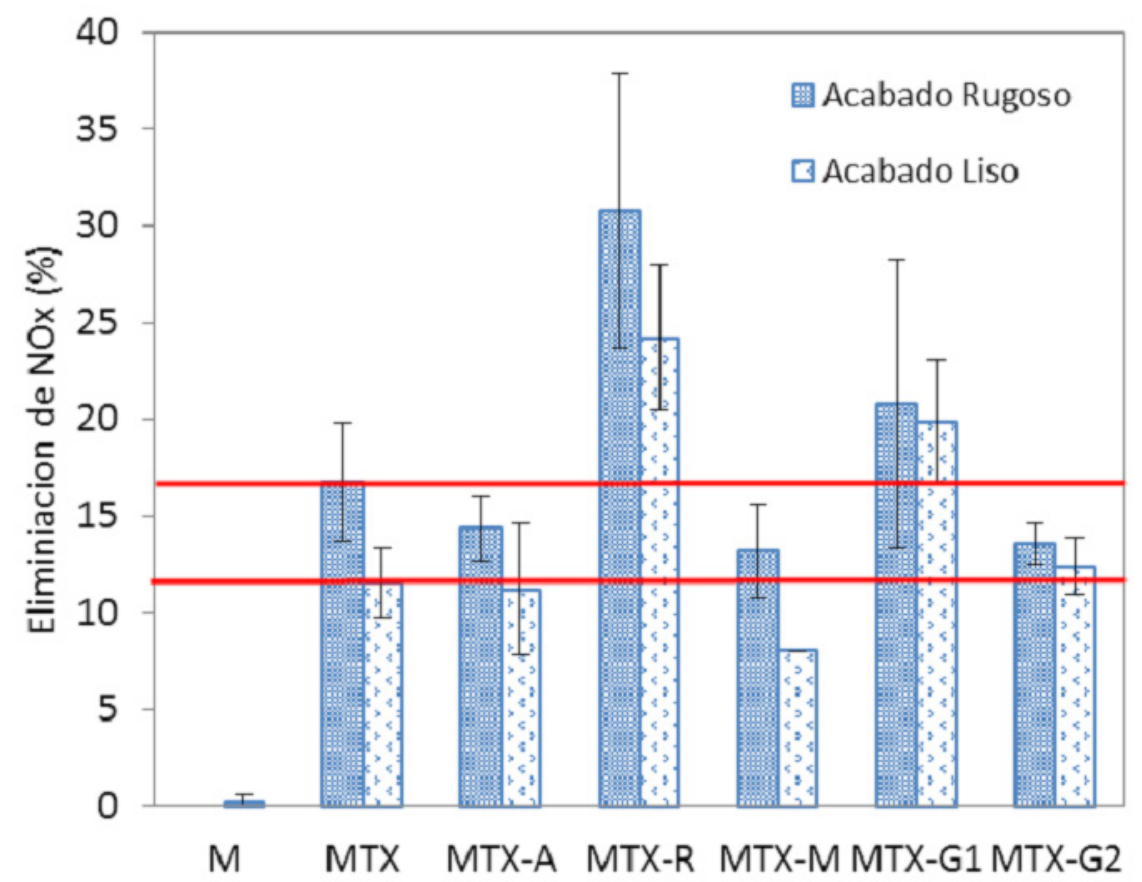


En general las muestras de acabado rugoso para un mismo color daban mejor tasas de eliminación de $\mathrm{NO}_{x}$. Se puede observar que las muestras de mortero rojo (MTX-R) y de mortero gris claro (MTX-G1) dieron mayor tasa de eliminación de NO que las otras muestras, incluyendo al mortero fotocatalítico blanco de referencia sin pigmento (MTX).

Las otras muestras coloreadas (MTX-A, MTX-M y MTX-G2) mostraron una menor eficiencia de degradación en comparación con el mortero fotocatalítico sin pigmento (MTX). La clasificación de las muestras para la eliminación de $\mathrm{NO}_{x}$ fue la siguiente:

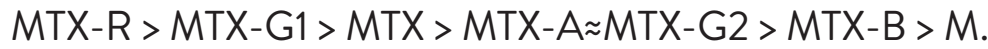

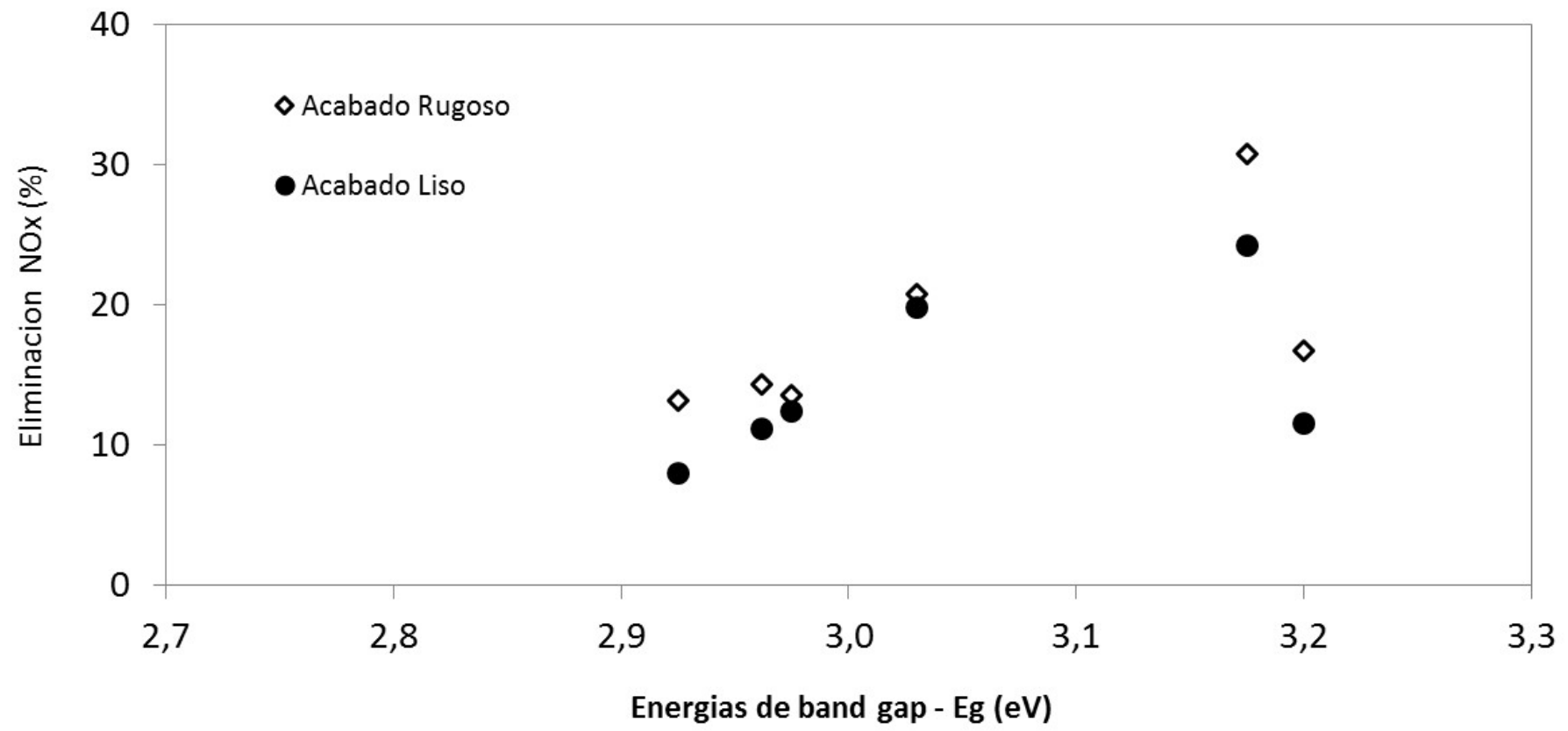

Hemos visto que los resultados de energías de fotoabsorción para los morteros fotocatalíticos demuestran que, la adición de pigmentos de muestras fotocatalíticas según el acabado en función de la energía de absorción o band gap $\left(E_{g}\right)$. óxido de hierro cambia hacia valores de energía más bajos con respecto a la formulación de mortero fotocatalítico sin pigmentos. En la gráfica podemos ver que, ese cambio a menores valores, esa reducción de la energía de fotoabsorción (Eg), no produce una mayor actividad fotocatalítica. Este comportamiento de los morteros podría ser debido que se produce una mayor de recombinación del par electrón/hueco, que depende principalmente de las posiciones de las bandas de energía de la estructura del acoplamiento óxido de hierro-semiconductor. 
351 Lopes, O. F., de Mendonça, V. R. Umar, A., Chuahan, M. S., Kumar, R., Chauhan, S., \& Ribeiro, C. (2015) Zinc hydroxide/oxide and zinc hydroxy stannate photocatalysts as potential scaffolds for environmental remediation. New Journal of Chemistry, 39(6), 4624-46301
Tabla 46. Cálculo de los valores para $\mathrm{R}_{4}$ y $R_{26}$ y desviación estándar, a partir de las medias para cada mortero y acabado en cada coordenada colorimétrica.

\subsubsection{MEDICIÓN DE LACAPACIDAD FOTOCATALÍTICA DEAUTOLIMPIEZA}

En la prueba de autolimpieza de $\mathrm{RhB}$, debido a la rugosidad y heterogeneidad de la superficie de la muestra, fue difícil conseguir una absorción homogénea de la disolución de la rodamina y no se obtuvo por tanto, una degradación uniforme del colorante, dando lugar a resultados con un sesgo sustancial. Para amortiguar estos, la prueba se realizó en 3-5 diferentes muestras. Los valores en cada mortero son la media de al menos 3 medidas en partes diferentes del área ensayada de las muestras $\left(22 \pm 2 \mathrm{~cm}^{2}\right)$. Los resultados experimentales se presentan en la Fig., junto con las barras de error de las medidas. Los morteros de referencia que no contienen $\mathrm{TiO}_{2}(M)$ muestran una ligera conversión RhB debido al proceso fotocatalítico UV 351 .

\begin{tabular}{|c|c|c|c|c|c|c|}
\hline & \multicolumn{2}{|c|}{$a$} & \multicolumn{2}{|c|}{ b } & \multicolumn{2}{|c|}{ L } \\
\hline & $\mathrm{R}_{4}(\%)$ & $\mathrm{R}_{26}(\%)$ & $\mathrm{R}_{4}(\%)$ & $\mathrm{R}_{26}(\%)$ & $\mathrm{R}_{4}(\%)$ & $\mathrm{R}_{26}(\%)$ \\
\hline$M-R$ & 9,36 & 15,38 & 13,37 & 28,66 & 9,34 & 15,76 \\
\hline $\mathrm{DeV}$ & 6,51 & 3,58 & 19,45 & 17,54 & 6,99 & 3,77 \\
\hline MTX-R & 7,26 & 41,49 & 40,93 & 109,37 & 9,12 & 43,39 \\
\hline $\mathrm{DeV}$ & 9,48 & 8,59 & 0,58 & 24,08 & 9,60 & 7,45 \\
\hline MTXA-R & 2,29 & 20,44 & $-33,35$ & $-84,36$ & 3,65 & 16,77 \\
\hline $\mathrm{DeV}$ & 4,27 & 15,72 & 69,53 & 147,53 & 1,30 & 5,62 \\
\hline MTXR-R & 10,34 & 34,47 & $-97,82$ & $-307,52$ & 10,07 & 33,36 \\
\hline $\mathrm{DeV}$ & 4,34 & 6,93 & 530,54 & 937,27 & 4,44 & 7,08 \\
\hline MTXM-R & 8,43 & 13,20 & $-14,35$ & $-24,25$ & 6,42 & 9,62 \\
\hline $\mathrm{DeV}$ & 0,19 & 1,02 & 20,59 & 35,61 & 1,65 & 2,11 \\
\hline MTXG1-R & 20,38 & 53,88 & 23,91 & 91,46 & 20,64 & 54,98 \\
\hline $\mathrm{DeV}$ & 4,51 & 11,69 & 1,54 & 22,84 & 4,11 & 10,96 \\
\hline MTXG2-R & $-5,35$ & 23,69 & 9,83 & 33,10 & 0,49 & 27,27 \\
\hline $\mathrm{DeV}$ & 6,65 & 3,29 & 14,46 & 1,79 & 9,92 & 3,04 \\
\hline$M-L$ & 8,70 & 6,17 & 7,35 & 19,10 & 8,90 & 7,17 \\
\hline $\mathrm{DeV}$ & 13,83 & 16,70 & 37,15 & 44,16 & 15,22 & 18,49 \\
\hline MTX-L & 7,13 & 33,26 & 7,70 & 53,74 & 7,55 & 35,17 \\
\hline $\mathrm{DeV}$ & 5,54 & 2,21 & 32,89 & 16,09 & 8,19 & 0,23 \\
\hline MTXA-L & 4,85 & 22,24 & $-93,81$ & $-489,74$ & 4,84 & 21,62 \\
\hline $\mathrm{DeV}$ & 12,11 & 24,49 & 131,07 & 679,57 & 12,05 & 23,93 \\
\hline MTXR-L & 11,51 & 30,55 & 120,71 & 204,10 & 11,73 & 30,33 \\
\hline $\mathrm{DeV}$ & 0,71 & 2,95 & 0,63 & 60,37 & 0,79 & 2,56 \\
\hline MTXM-L & 4,48 & 12,02 & 28,62 & $-3,39$ & 5,20 & 11,33 \\
\hline $\mathrm{DeV}$ & 1,79 & 3,12 & 32,71 & 53,10 & 0,18 & 4,77 \\
\hline MTXG1-L & 14,42 & 48,43 & 20,23 & 63,21 & 15,46 & 50,67 \\
\hline $\mathrm{DeV}$ & 1,23 & 2,07 & 8,48 & 12,98 & 2,55 & 3,76 \\
\hline MTXG2-L & $-0,63$ & 20,24 & $-1,94$ & 8,09 & $-0,82$ & 14,32 \\
\hline $\mathrm{DeV}$ & 27,48 & 3,24 & 5,55 & 34,16 & 4,37 & 36,30 \\
\hline
\end{tabular}



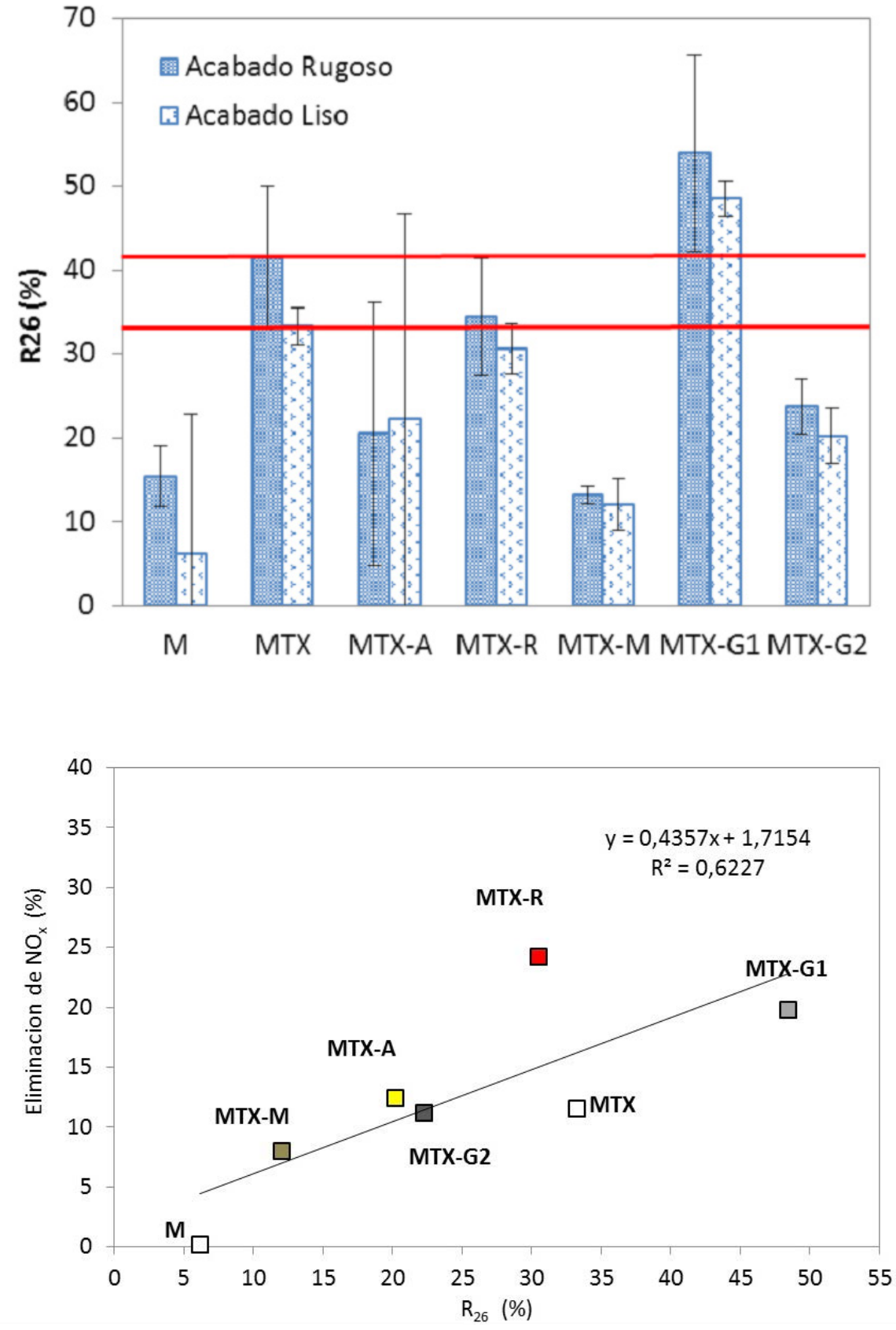

A pesar de los márgenes de error, se puede observar que hay algunas diferencias entre la decoloración de $\mathrm{RhB}$ y la degradación de $\mathrm{NO}_{\mathrm{x}}$ producida por los morteros de diferente color.

Sólo el MTX-G1 mostró una mayor eficiencia para ambas pruebas que el mortero fotocatalítico blanco de referencia (MTX). En contraste con las pruebas de $\mathrm{NO}_{x}$, las muestras de MTX-R mostraron una menor eficiencia de degradación en comparación con el mortero sin pigmento (MTX). Lo esperable sería una variación de la actividad fotocatalítica en muestras coloreadas, vinculado principalmente a la capacidad de absorción de la radiación de los pigmentos.

Las diferencias en los resultados en ambas pruebas fotocatalíticas está, necesariamente relacionada con el tipo de fotoactivación utilizada, ya que es la única fuente de heterogeneidad entre las muestras ensayadas en
Fig 177. Valores de autolimpieza, a las 26 h de exposición $-\mathrm{R}_{26}(\%)$, para todos los morteros por color y acabado, con intervalos de error.

Fig 178. Relación de los datos de eliminación de $\mathrm{NO}_{x}, \mathrm{~A}_{c}(\%)$ y los de autolimpieza $\mathrm{R}_{26}(\%)$ en relacion al color. 
352 Zhang, M. H., Tanadi, D., \& Li, W.

(2010, August).

Effect on Photocatalyst $\mathrm{TiO}_{2}$ on workability, strength and self-cleaning efficiency of mortars for applications in tropical environment.

In 35th Conference on our world in concrete \& structures.
Fig 179. Curvas de intensidad de fluorescencia medidas a $\boldsymbol{\lambda}=425 \mathrm{~nm}$, a distintos tiempos de irradiación a $\boldsymbol{\lambda}=315$ $\mathrm{nm}$, de la solución de $\mathrm{TaOH}$ sobre la muestra de mortero fotocatalítico amarillo (MTX-A). ambas pruebas (RhB sólo se realiza bajo luz UV y NO , bajo luz UV-Vis). Por otra parte, como la mineralización o degradación de la RhB se calcula a partir de la medida de la disminución en la intensidad de la coordenada a* (rojo), hay necesariamente una subestimación del resultado en las muestras MTX-R y MTX-M debido al hecho de que la pérdida del color de RhB implica la aparición del color original del sustrato, del mortero. Esto reduce la fiabilidad de este procedimiento experimental para la comparación del rendimiento fotocatalítico entre los distintos colores, en comparación con la medida de la degradación de $\mathrm{NO}_{x}$, cuyos resultados son independientes de la medida del color del sustrato.

El rendimiento de las muestras con superficie lisa en general, es más baja que en las muestras rugosas, como hemos visto en el apartado anterior. Esto puede ser debido a la disponibilidad de mayor superficie activa para reacción por la alta rugosidad del sustrato. Esta conclusión coincide con el resultado de estudios anteriores $144,145,146,352$.

\subsubsection{ESPECTROMETRÍA DE FLUORESCENCIA CON ÁCIDO TERFTÁLICO}

Del análisis de los datos recogidos de las medidas del espectro de la emisión de fluorescencia a $\lambda=425 \mathrm{~nm}$, de la solución de TA cada $5 \mathrm{~min}$ hemos estudiado la actividad fotocatalítica de cada muestra a través de la generación de especies reactivas, el radical hidroxilo.

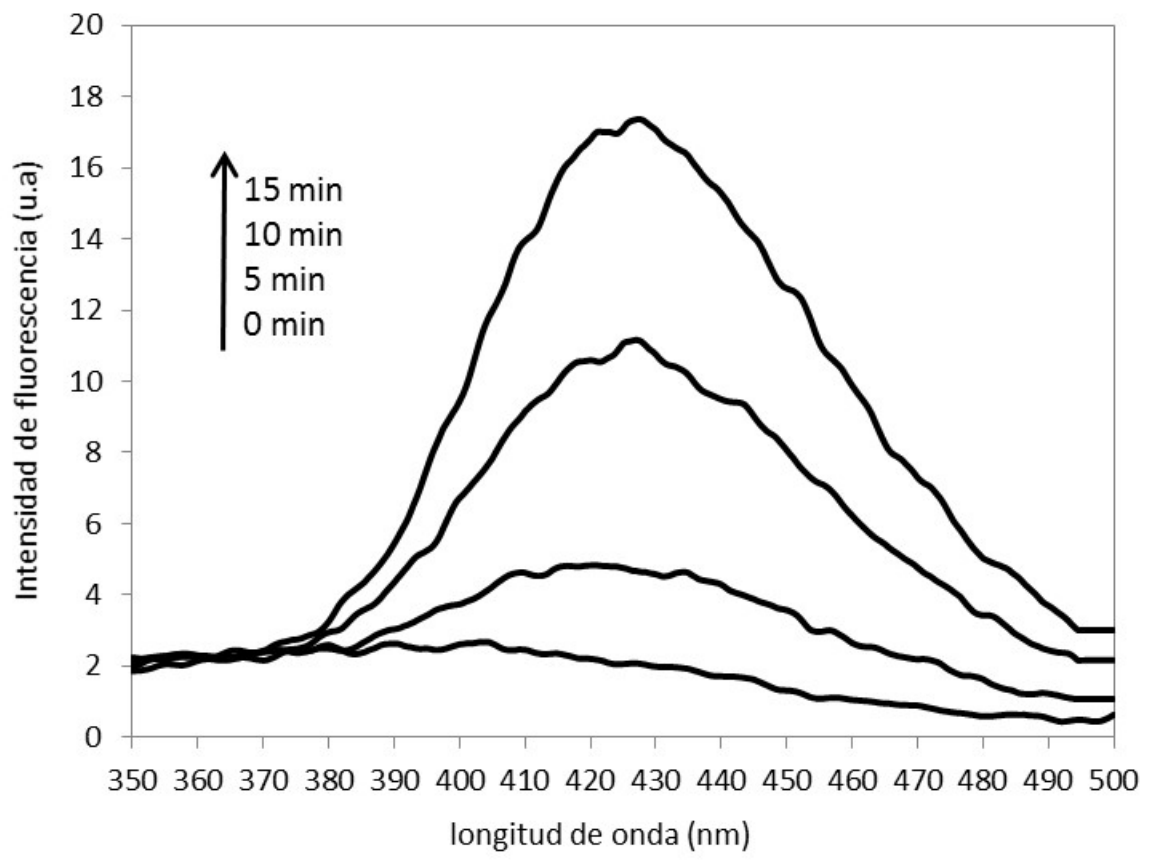




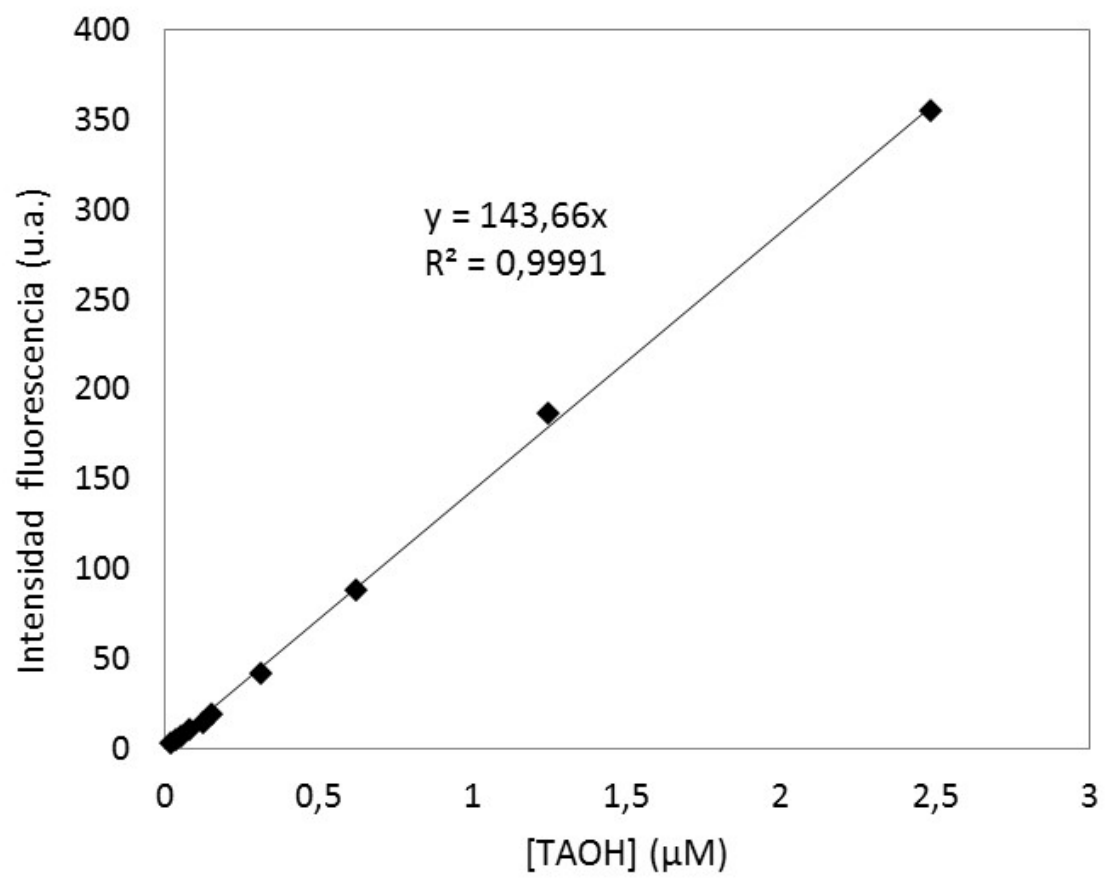

El mortero blanco no fotocatalítico $(\mathrm{M})$, que no contiene $\mathrm{TiO}_{2}$, tal y como se esperaba no tuvo ningún aumento de la fluorescencia durante el tiempo de medida. Todos los morteros fotocatalíticos (con adición de pigmento o no), mostraron un aumento lineal de la intensidad de fluorescencia frente al tiempo de irradiación, es decir que la cinética de la reacción de generación de radicales hidroxilo generados en la superficie de las muestras es de orden cero, al ser lineal la relacion.

De la curva de calibración de $\mathrm{TAOH}^{327}$ y suponiendo un rendimiento del $35 \%$ de la reacción del TA para producir $\mathrm{TAOH}^{353}$, la tasa de generación de los $\mathrm{OH}$ ' de los morteros se puede obtener de las pendientes de las rectas, intensidad de fluorescencia vs Tiempo representadas, en la Fig:

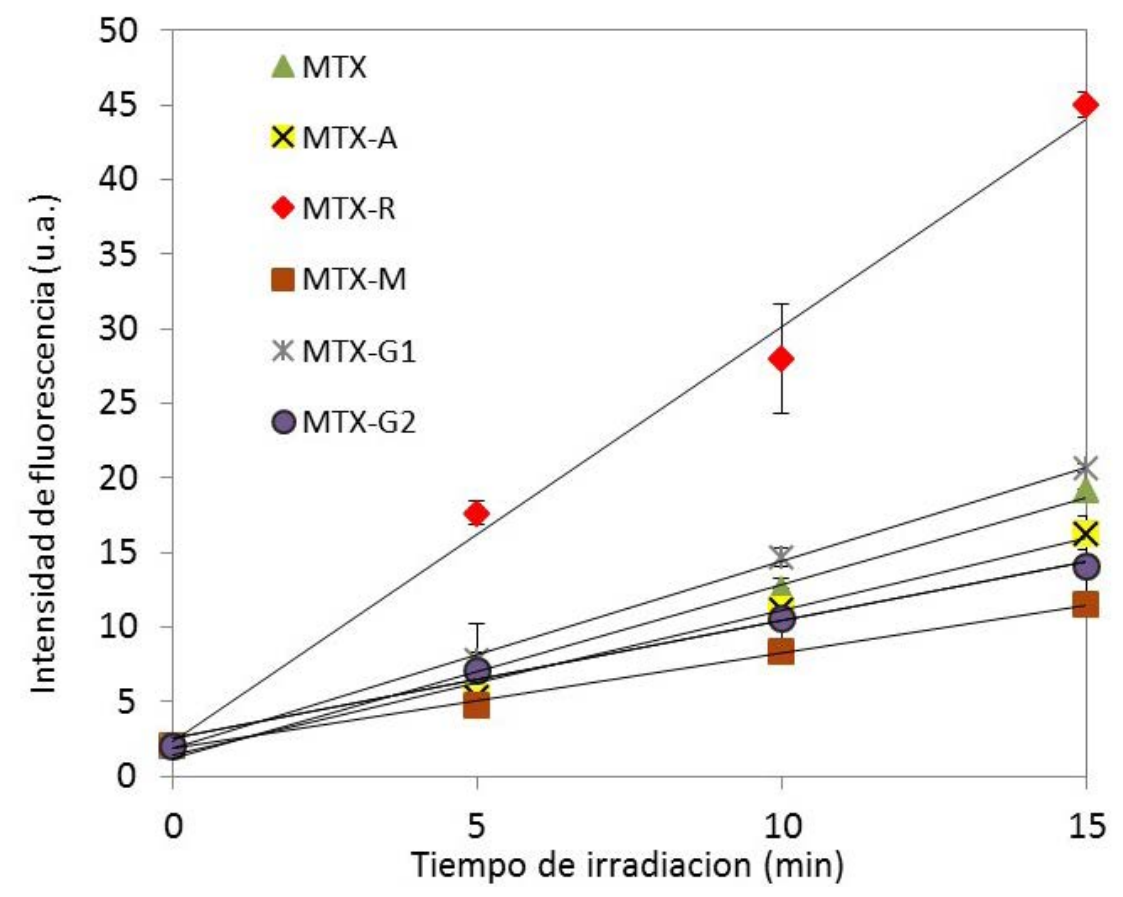

Fig 180. Curva de calibración de la intensidad de fluorescencia en función de la concentración de la disolución de $\mathrm{TaOH}$ a pH $(12,4 \pm 0,2)$
353 Fang, X., Mark, G.,

\& von Sonntag, C. (1996).

$\mathrm{OH}$ radical formation by ultrasound in aqueous solutions Part l: the chemistry underlying the terephthalate dosimeter Ultrasonics Sonochemistry, 3(1), 57-63.
Fig 181. Intensidad de la fluorescencia medida a $425 \mathrm{~nm}$ para las muestras de morteros fotocatalíticos para cada color de mortero, media de dos muestras. 
Representamos el valor de la pendiente de las rectas que son, la intensidad en función del tiempo para cada mortero fotocatalítico coloreado, tendríamos la siguiente figura.

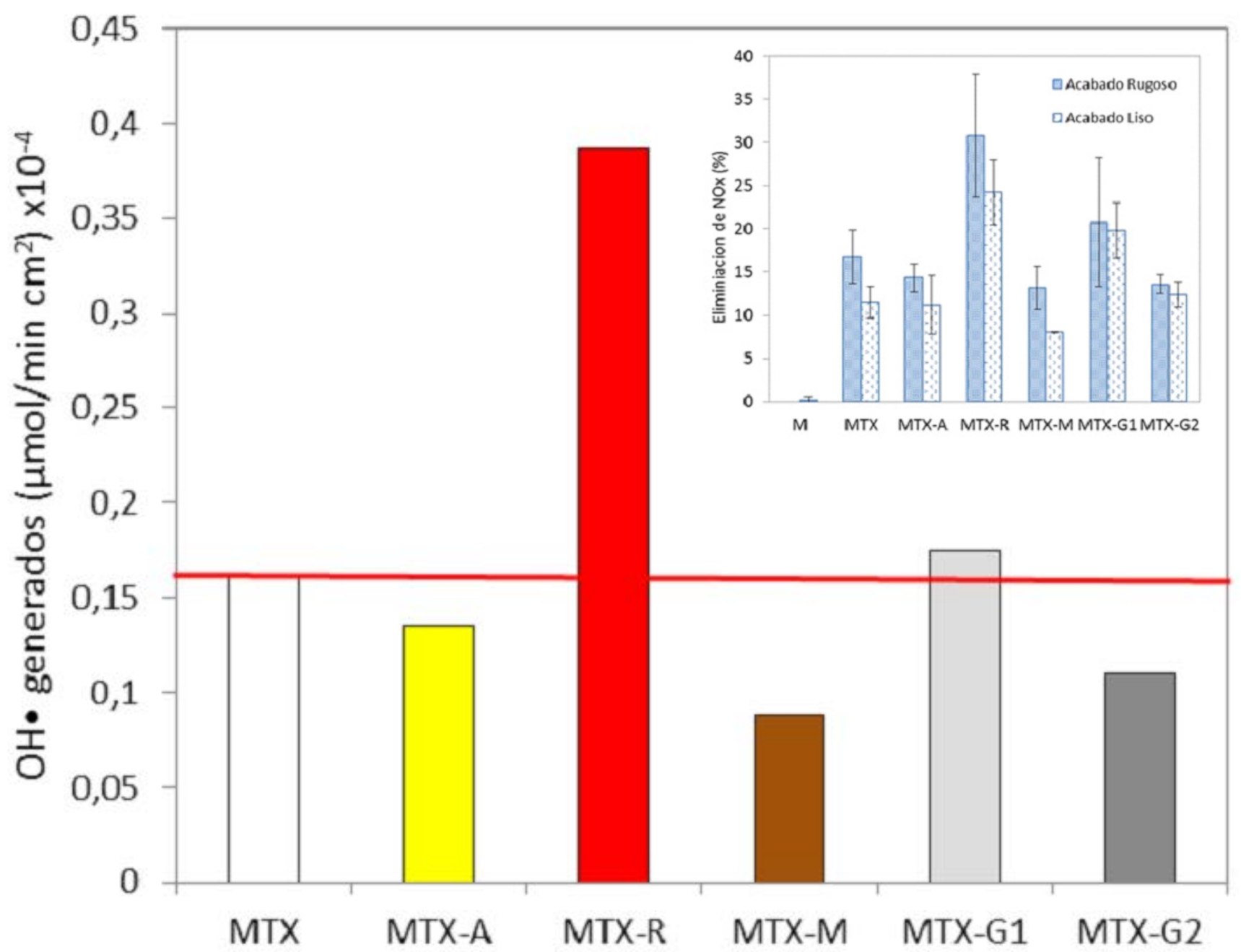

Fig 182. Producción de grupos $\mathrm{OH} \cdot$ para cada mortero fotocatalítico en función del color. 
De acuerdo con las Fig. se puede decir que, el mortero fotocatalítico de color rojo

(MTX-R) y el de color gris claro (MTX-G1), generaron mayor número de radicales en comparación con el mortero sin pigmento (MTX), a diferencia de los otros morteros coloreados. De mayor a menor, el orden es como sigue: MTX-R> MTX-G1> MTX > MTX-A> MTX-G2>MTX-M, que se corresponde exactamente con el orden de las muestras, ordenadas de mayor a menor valor, en la prueba de eliminación de $\mathrm{NO}_{\mathrm{x}}$. La relación directa con NOx apoya la idoneidad de este método para comparar el rendimiento fotocatalítico de muestras fotocatalíticas coloreadas visto en las figuras anteriores.

De acuerdo con esto, podría deducirse que, únicamente los morteros MTX-R y MTX-G1 disminuyen la tasa de la recombinación electrón/hueco, en comparación con las muestras sin pigmento (MTX), lo que se conduce a una mayor generación de $\mathrm{OH}^{\cdot}$ y por lo tanto mayor actividad fotocatalítica.

Si representamos los $\mathrm{OH}^{\cdot}$ generados, frente a los valores de la energía de fotoabsorción que habíamos sacado anteriormente, tenemos la siguiente figura donde se ha colocado una línea roja que dejaría por encima aquellos morteros coloreados con mayor tasa de $\mathrm{OH}^{\cdot}$ generados que el mortero fotocatalítico blanco (MTX). Entre los morteros coloreados vemos que hay una correlación inversa en la formación de radicales hidroxilo, a menor valor de band gap, menor tasa de generación, lo cual podemos atribuir a que la recombinación del par electrón-hueco es mayor.

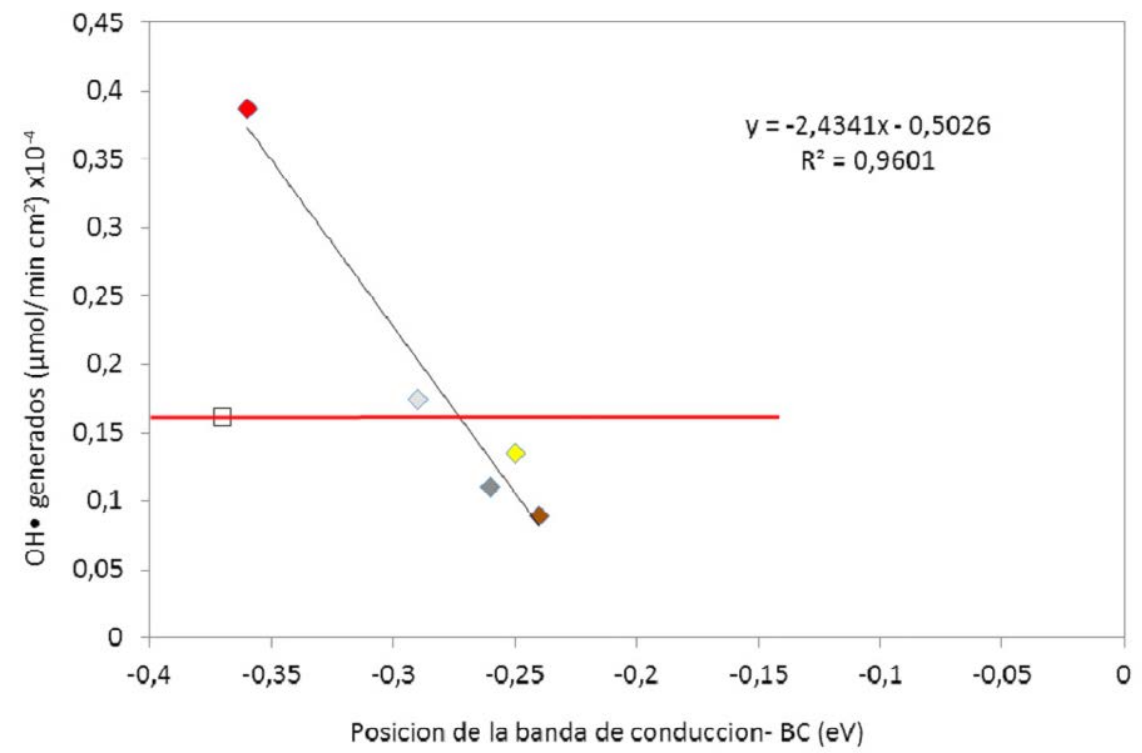

Fig 183. Producción de grupos $\mathrm{OH} \cdot$ para los morteros fotocatalíticos en función de la posición de la energía de la banda de conducción. 
354 Kohtani, S., Yoshida, K., Maekawa, T., Iwase, A., Kudo, A., Miyabe, $\mathrm{H}$., \& Nakagaki, R. (2008) Loading effects of silver oxides upon generation of reactive oxygen species in semiconductor photocatalysis. Physical Chemistry Chemical Physics, 10(20), 2986-2992.
Una explicación para esta relacion seria que, durante el proceso de la reacción fotocatalítica, cuando el $\mathrm{TiO}_{2}$ absorbe un fotón con energía igual o mayor que su energía de fotoabsorción $\left(E_{g}\right)$ genera un hueco $\left(h^{+}\right)$en la banda de valencia (Ec 23) que rápidamente genera un radical hidroxilo $\left(\mathrm{OH}^{\cdot}\right)$ por oxidación del agua quimisorbida sobre la superficie del catalizador, o de un $\left(\mathrm{OH}^{-}\right)\left(\mathrm{Ec}\right.$ 24). El rendimiento de la generación de radicales $\mathrm{OH}^{\prime}$, depende de la competencia entre la reacción de oxidación del agua adsorbida en la superficie y la recombinación del hueco-electrón (Ec 25). Por lo tanto, cuanto mayor sea la tasa de generacion de $\mathrm{OH}^{\prime}$, mayor sería la eficiencia de la separación hueco/electrón. Investigaciones previas demostraron que existe un equilibrio entre los $\mathrm{OH} \cdot$ libres producidos por la irradiación de una disolución de $\mathrm{TiO}_{2}$ y los huecos $\left(\mathrm{h}^{+}\right)$en la superficie ${ }^{352,354}$.

$$
\begin{aligned}
& \mathrm{TiO}_{2}+h v \rightarrow e^{-} \mathrm{TiO}_{2}+h^{+} \\
& h^{+}+\mathrm{H}_{2} \mathrm{O} / \mathrm{OH}^{-} \text {ads } \rightarrow \mathrm{OH}^{\cdot} \mathrm{ads} \\
& e^{-} \mathrm{TiO}_{2}+h^{+} \rightarrow \mathrm{TiO}_{2} \\
& \mathrm{Ti}^{4^{+}}+\mathrm{OH}^{\cdot} \leftrightarrow \mathrm{Ti}^{4+}+\mathrm{O}^{--}\left(=h^{+}\right)+H^{+}
\end{aligned}
$$
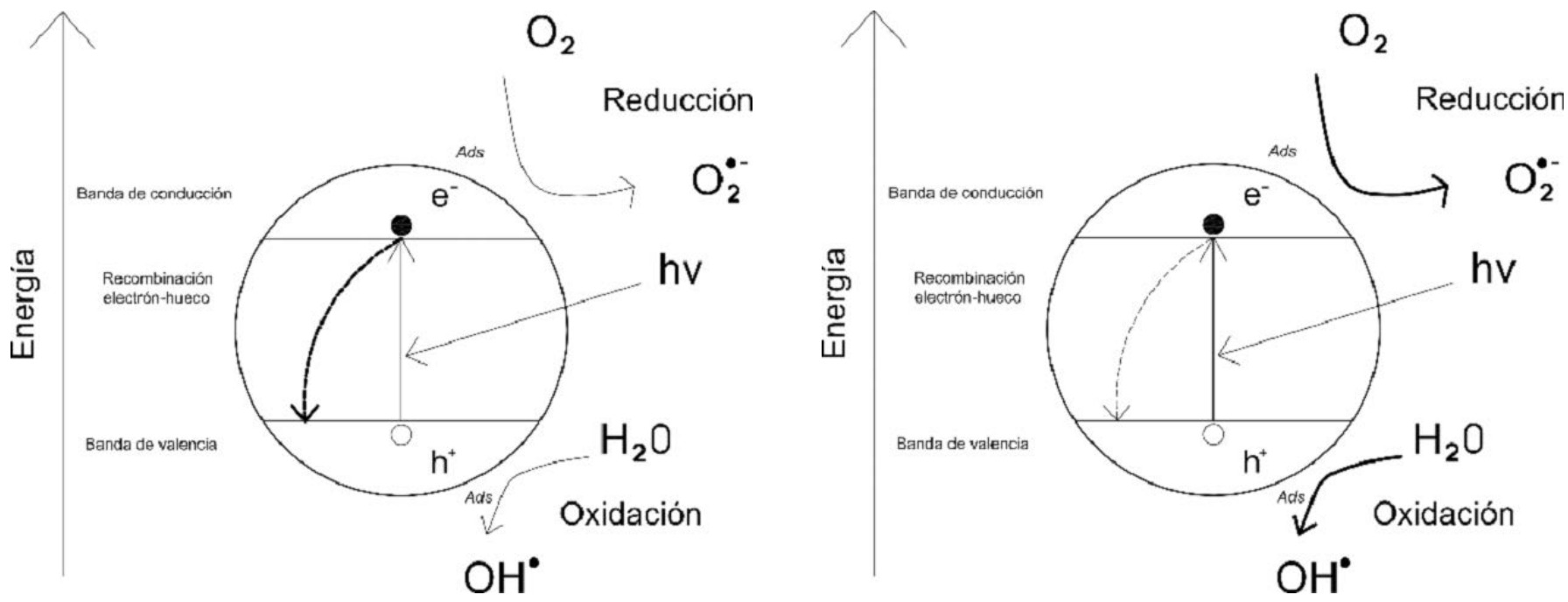

Fig 184. Esquema de excitación del electrón desde la banda de valencia a la de conducción y creación del par electrón/hueco, con las dos posibles vías, recombinación y formación de especies 
Por lo tanto, si conocemos el tipo y concentración del fotocatalizador y medimos la tasa de formación de $\mathrm{OH}^{\cdot}$ es posible evaluar el efecto del pigmento en la recombinación de los pares electrón-hueco.

Un parámetro importante para determinar la importancia de la recombinación o de la formación de especies reactivas es, como demuestran las diferencias que hay entre los morteros de color gris, MTX-G1 y MTX-G2 es el contenido de hierro con respecto al de Ti. Trabajos experimentales previos ${ }^{355,356}$ señalaron que para el dopaje del $\mathrm{TiO}_{2}$ hay una relacion con la que se consigue la separación fotoinducida electrón/hueco más eficiente.

\begin{tabular}{|r|c|c|}
\hline MTX & $\mathrm{Fe} / \mathrm{Ti}$ & $\begin{array}{c}\text { Tasa de } \mathrm{OH} \text { generados } \\
\left(\mu \mathrm{mol} / \mathrm{min}^{\mathrm{cm}}\right) \cdot 10^{-4}\end{array}$ \\
\hline MTX-R & 0,24 & 0,16 \\
\hline MTX-A & 0,26 & 0,39 \\
\hline MTX-M & 0,40 & 0,14 \\
\hline MTX-G1 & 0,56 & 0,09 \\
\hline MTX-G2 & 0,35 & 0,17 \\
\hline
\end{tabular}

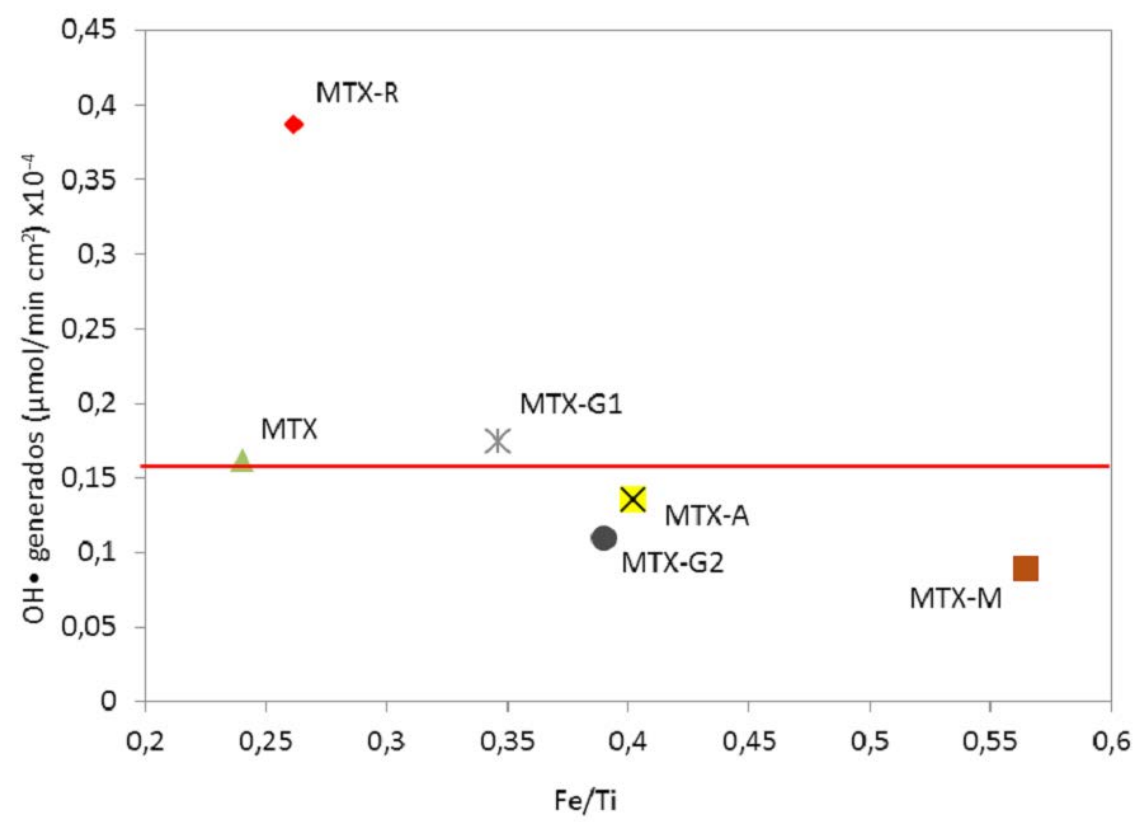

Vemos que, a medida que la relación $\mathrm{Fe} / \mathrm{TiO}_{2}$ crece, aumenta generación de $\mathrm{OH}^{\cdot}$ hasta un punto en el que cae dramáticamente. Hay por tanto, una cantidad de pigmento optimo como se puede ver en la siguiente gráfica, que muestra una clara relacion ente ambos características. En nuestro caso, solo los ratios $\mathrm{Fe} / \mathrm{TiO} \mathrm{O}_{2}<0,35$ (MTX-G1 y MTX-G2) muestran una actividad fotocatalítica superior a las de la muestra de mortero fotocatalítico sin pigmentos (MTX). En este caso, sólo las relaciones $\mathrm{Fe} / \mathrm{TiO} \mathrm{O}_{2}<0,35$ (MTX-G1 y MTX-R) condujo a una mayor actividad fotocatalítica con Respetar las muestras con sólo $\mathrm{TiO}_{2}$ (MTX).
${ }^{355}$ Xu, A. W., Gao, Y., \& Liu, H. Q. (2002).

The preparation, characterization, and their photocatalytic activities of rareearth-doped TiO2 nanoparticles. Journal of Catalysis, 207(2), 151-157.

${ }^{356}$ Sun, Q., Leng, W., Li, Z., \& Xu, Y. (2012) Effect of surface $\mathrm{Fe}_{2} \mathrm{O}_{3}$ clusters on the photocatalytic activity of $\mathrm{TiO}_{2}$ for phenol degradation in water. Journal of hazardous materials, 229, 224-232.

Tabla 33. Valores calculados de Fe/Ti y tasa de $\mathrm{OH}$. generados para cada mortero fotocatalítico.

Fig 185. Producción de grupos $\mathrm{OH} \cdot$ para cada mortero fotocatalítico en función del color por la relacion $\mathrm{Fe} / \mathrm{Ti}$. 
${ }^{357}$ Guo, M. Z., \& Poon, C. S. (2013). Photocatalytic NO removal of concrete surface layers intermixed with $\mathrm{TiO}_{2}$. Building and Environment, 70, 102-109.

${ }^{358}$ Xu, X., Ji, F., Fan, Z., \& He, L. (2011). Degradation of glyphosate in soil photocatalyzed by $\mathrm{Fe}_{3} \mathrm{O}_{4} / \mathrm{SiO}_{2} / \mathrm{TiO}_{2}$ under solar light. International journal of environmental research and public health, 8(4), 1258-1270.

${ }^{359}$ Xia, Y., \& Yin, L. (2013).

Core-shell structured $\boldsymbol{\alpha}-\mathrm{Fe}_{2} \mathrm{O}_{3} @$

$\mathrm{TiO}_{2}$ nanocomposites with improved photocatalytic activity in the visible light region. Physical Chemistry Chemical

Physics, 15(42), 18627-18634.

360 Barreca, D., Carraro, G., Gasparotto, A., Maccato, C., Warwick, M. E., Kaunisto, K., ... \& Borgese, L. (2015)

$\mathrm{Fe}_{2} \mathrm{O}_{3}-\mathrm{TiO}_{2}$ Nano-heterostructure Photoanodes for Highly Efficient Solar Water Oxidation. Advanced Materials Interfaces, 2(17).

${ }^{361}$ Luan, P., Xie, M., Liu, D., Fu, X., \& Jing, L. (2014). Effective charge separation in the rutile $\mathrm{TiO}_{2}$ nanorod-coupled $\boldsymbol{\alpha}-\mathrm{Fe}_{2} \mathrm{O}_{3}$ with exceptionally high visible activities. Scientific reports, 4, 6180

${ }^{362} \mathrm{Li}, \mathrm{X}$. , Lin, H., Chen, X., Niu, H.,

Liu, J., Zhang, T., \& Qu, F. (2016). Dendritic $\alpha-\mathrm{Fe}_{2} \mathrm{O}_{3} / \mathrm{TiO}_{2}$ nanocomposites with improved visible light photocatalytic activity. Physical Chemistry Chemical Physics, 18(13), 9176-9185.
Investigadores han propuesto diferentes teorías para explicar la variación de las propiedades fotocatalíticas al adicionar pigmentos a base de óxidos de hierro en morteros. Una de ellas, propone que los pigmentos podrían ocupar sitios activos en la superficie del $\mathrm{TiO}_{2}$ modificando la activación de las partículas de $\mathrm{TiO}_{2}{ }^{175,357}$ esto podria bloquear los poros en las capas superficiales del mortero, un apantallamiento que limitaría la difusión de los contaminantes gaseosos hacia los sitios activos. Un fenómeno físico que podria reducir la actividad fotocatalítica, aunque es poco probable.

Otros autores sin embargo, proponen que la presencia de esas partículas de óxido de hierro provocaría un desplazamiento de la banda de absorción hacia longitudes de onda más bajas, en el visible, mejorando sus capacidades. ${ }^{358,359,369}$.

Se ha comprobado que, reduciendo la recombinación de los pares electrón/ hueco fotogenerados en la interfase de nanocompuestos de óxido de hierro y un semiconductor, como $\mathrm{TiO}_{2} / \mathrm{FeOOH}$ ó $\mathrm{Fe}_{3} \mathrm{O}_{4} / \mathrm{SiO}_{2} / \mathrm{TiO}_{2}{ }^{358} \mathrm{y}$ $\mathrm{Fe}_{2} \mathrm{O}_{3} / \mathrm{TiO}_{2}{ }^{360,361}$ se consigue un aumento de la actividad fotocatalítica. Es necesario estudiar y entender las heteroestructuras que se forman entre el óxido metálico (pigmento) y el $\mathrm{TiO}_{2}$, sobre el sustrato del mortero de cemento y radiación visible y UV.

De forma genérica, cuando nanopartículas del óxido metálico se depositan en la superficie del fotocatalizador se forma una estructura heterogénea entre el óxido metálico y el semiconductor. Los integrantes de esta estructura compuesta, son capaces de absorber la energía de la radiación luminosa por separado, aprovechando la energía de los fotones absorbidos de una forma más eficaz. La nueva estructura de la banda electrónica limitaría la recombinación de los pares electrón/hueco generados porque, los electrones tienden a saltar desde los niveles más altos de la banda de conducción a valores más bajos entre las sustancias que han formado la heteroestructura, de esta forma se limita la recombinación y se mejora, el rendimiento de la reacción fotocatalítica.

En el caso de la hematita $\left(\mathrm{Fe}_{2} \mathrm{O}_{3}\right)$, que hemos determinado anteriormente que es el mineral que constituye el pigmento negro fundamentalmente, este tiene estados de alta energía de carácter aceptor en su banda de conducción (BC) $359,360,361,362$. Si irradiamos con luz visible se promocionan electrones desde la banda de valencia del $\mathrm{Fe}_{2} \mathrm{O}_{3}$ a la banda de conducción incluidas las zonas de alta energía. Una gran parte de esos electrones que ocupan estados de baja energía se recombinaran rápidamente, los electrones que estén en niveles de energía más altos de la banda de conducción del $\mathrm{Fe}_{2} \mathrm{O}_{3}$, podrían saltar a la banda de conducción del $\mathrm{TiO}_{2}$ en el mortero, produciéndose así una separación de carga más efectiva y eso reduciría la posibilidad de que caiga y se produzca recombinación. De esta manera, el hueco $\left(\mathrm{h}^{+}\right)$generado en la banda de valencia del pigmento de $\mathrm{Fe}_{2} \mathrm{O}_{3}$ sería capaz de oxidar los contaminantes adsorbidos, o de generar radicales $\mathrm{OH} \bullet$. 
El oxigeno adsorbido también puede ser reducido por los electrones fotogenerados, dando lugar a la especie $\mathrm{O}_{2}{ }^{\prime \cdots},\left(\mathrm{O}_{2} / \mathrm{O}_{2}{ }^{\cdots}=-0.33 \mathrm{eV}\right.$ vs $\left.\mathrm{ENH}\right)$, que también puede generar la degradación fotocatalítica de los compuestos adsorbidos.

Por otro lado, la radiación UV genera también pares electrón/hueco en el $\mathrm{TiO}_{2}$ del mortero, en este caso los electrones fotogenerados pasarían de la banda de conducción del $\mathrm{TiO}_{2}$ a la banda de conducción del $\mathrm{Fe}_{2} \mathrm{O}_{3}$. En esta tesis, como en las condiciones de ensayo se tenía irradiación con zona de UV y del Visible, lo que ha posibilitado que se hayan podido dar de forma sinérgica, las dos vías.

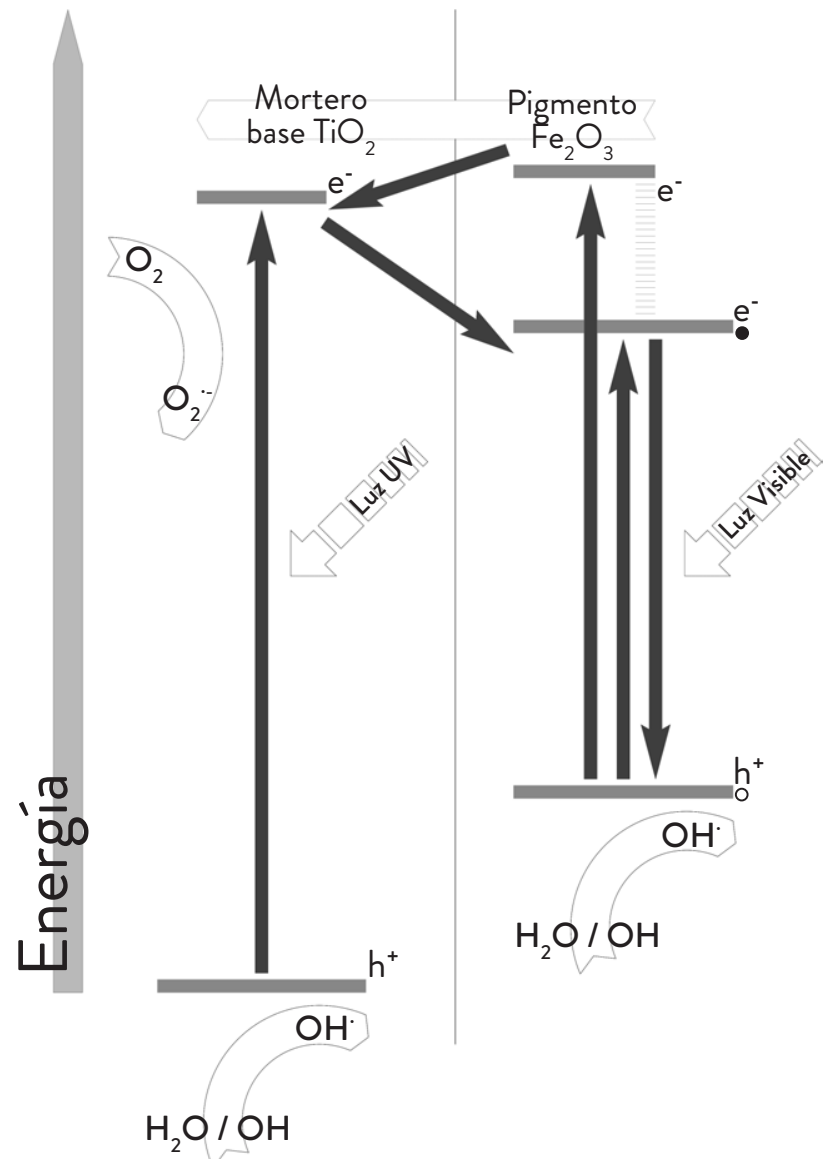

Que la separación de carga sea efectiva al producirse la transferencia de carga entre el $\mathrm{TiO}_{2}$ del mortero y el $\mathrm{Fe}_{2} \mathrm{O}_{3}$ del pigmento rojo, es la razón de la mayor actividad fotocatalítica de eliminación de $\mathrm{NO}_{x}$, esto queda justificado por la tasa de generación de $\mathrm{OH}$ ' medida, más alta para MTX-R y MTX G1, que la de los otros morteros y la del mortero fotocatalítico sin pigmento (MTX).

Esta teoría, por la cual el principal mecanismo de generación de los fotoelectrones es la transferencia de electrones desde la banda de conducción del $\mathrm{Fe}_{2} \mathrm{O}_{3}$ a la del $\mathrm{TiO}_{2}$, también estaría apoyado, por los datos de degradación fotocatalítica del ensayo de la rodamina. Este ensayo solo utiliza irradiación UV, y se han obtenido valores más bajos de los esperables, incluso en las muestras de morteros sin pigmentos (MTX), en comparación con la degradación de $\mathrm{NO}_{x}$ y los $\mathrm{OH} \cdot$ medidos, con la irradiación mixta UV-Vis lo que demuestra la existencia de los dos mecanismos actuando de forma sinérgica.
Fig 186. Representación del esquema propuesto de transferencia y separación de carga en los electrones excitados a la BC por radiación UV-VIS en las muestras de mortero fotocatalítico de color rojo (MTX-R)

Fuente:Elaboración propia 


\subsection{ANÁLISIS DE LOS RESULTADOS Y DISCUSIÓN DE LOS ENSAYOS A LOS ADITIVOS}

\subsubsection{MEDICIÓN DELACAPACIDAD FOTOCATALÍTICADEAUTOLIMPIEZA}

Entre las 24 series de probetas estudiadas, según los valores promedio de la degradación de cada serie, 22 de ellas se consideraran fotocatalíticas en el ensayo de eliminación de la Rodamina B, ya que:

$$
R_{4}>20 \% \text { y } R_{26}>50 \%
$$

Como era de esperar, la serie "mortero no fotocatalítico "no presenta propiedades fotocatalíticas, obteniéndose los valores más bajos de $R_{4}$ y $R_{26}$ y no mostrando degradación significativa de $\mathrm{NO}, \mathrm{NO}_{x} \circ \mathrm{NO}_{2}$.

La influencia del aditivo en la actividad fotocatalítica es evidente, habiendo aditivos que incrementan y otros que disminuyen la actividad fotocatalítica en comparación con la serie de probetas sin aditivos.

Para la degradación de Rodamina, en 10 de las series estudiadas la actividad fotocatalítica se incrementa tanto para $R_{4}$ como para $R_{26}$, ordenadas de mayor a menor actividad con el porcentaje de incremento respecto a la serie fotocatalítica sin aditivo entre paréntesis son:

LS $14(0,026)\left(R_{4}: 38 \%, R_{26}: 16 \%\right)-$ Mas $(0,05)\left(R_{4}: 35 \%, R_{26}: 19 \%\right)-$ $5010(2,14)\left(R_{4}: 42 \%, R_{26}: 15 \%\right)>554(14,29)\left(R_{4}: 29 \%, R_{26}: 13 \%\right)-$ LS $14(0,05)\left(R_{4}: 25 \%, R_{26}: 16 \%\right)>H 20(1,21)\left(R_{4}: 23 \%, R_{26}: 13 \%\right)>$ $15000(0,64)\left(R_{4}: 23 \%, R_{26}: 12 \%\right)-$ Mas $(0,026)\left(R_{4}: 19 \%, R_{26}: 13 \%\right)>$ Oleato $(0,6)\left(R_{4}: 13 \%, R_{26}: 7 \%\right)>\operatorname{Saf} 54(14,29)\left(R_{4}: 2 \%, R_{26}: 5 \%\right)$

Sin embargo, otras series ven disminuida su actividad fotocatalítica, llegando algunas de ellas a considerarse que no poseen propiedades fotocatalíticas al no sobrepasar los límites de $R_{4} \circ R_{26}$ indicados en la norma UNI - 11259. Ordenadas de mayor a menor actividad, con el porcentaje en negativo, de reducción respecto a la serie de mortero fotocatalíticos sin aditivos entre paréntesis, son:

Saf $54(3,57)\left(R_{4}:-4 \%, R_{26}:-3 \%\right)>M H 200(0,43)\left(R_{4}:-23 \%, R_{26}:-3 \%\right)>$ $H 20(0,43)\left(R_{4}:-25 \%, R_{26}:-7 \%\right)>554(5)\left(R_{4}:-25 \%, R_{26}:-12 \%\right)>$ $10012(0,64)\left(R_{4}:-17 \%, R_{26}:-13 \%\right)>M H 200(1,21)\left(R_{4}:-35 \%, R_{26}:-13 \%\right)>$ $15000(1,42)\left(R_{4}:-44 \%, R_{26}:-19 \%\right)-\operatorname{Saf} 54(7,14)\left(R_{4}:-40 \%, R_{26}:-28 \%\right)$

Cabe destacar que según la norma utilizada, 6 de las series serían descartables ya que al menos 2 de las cuatro probetas ensayadas presentan una dispersión mayor al $10 \%$ respecto a la media de la de los valores $R_{4} \circ R_{26}$. 


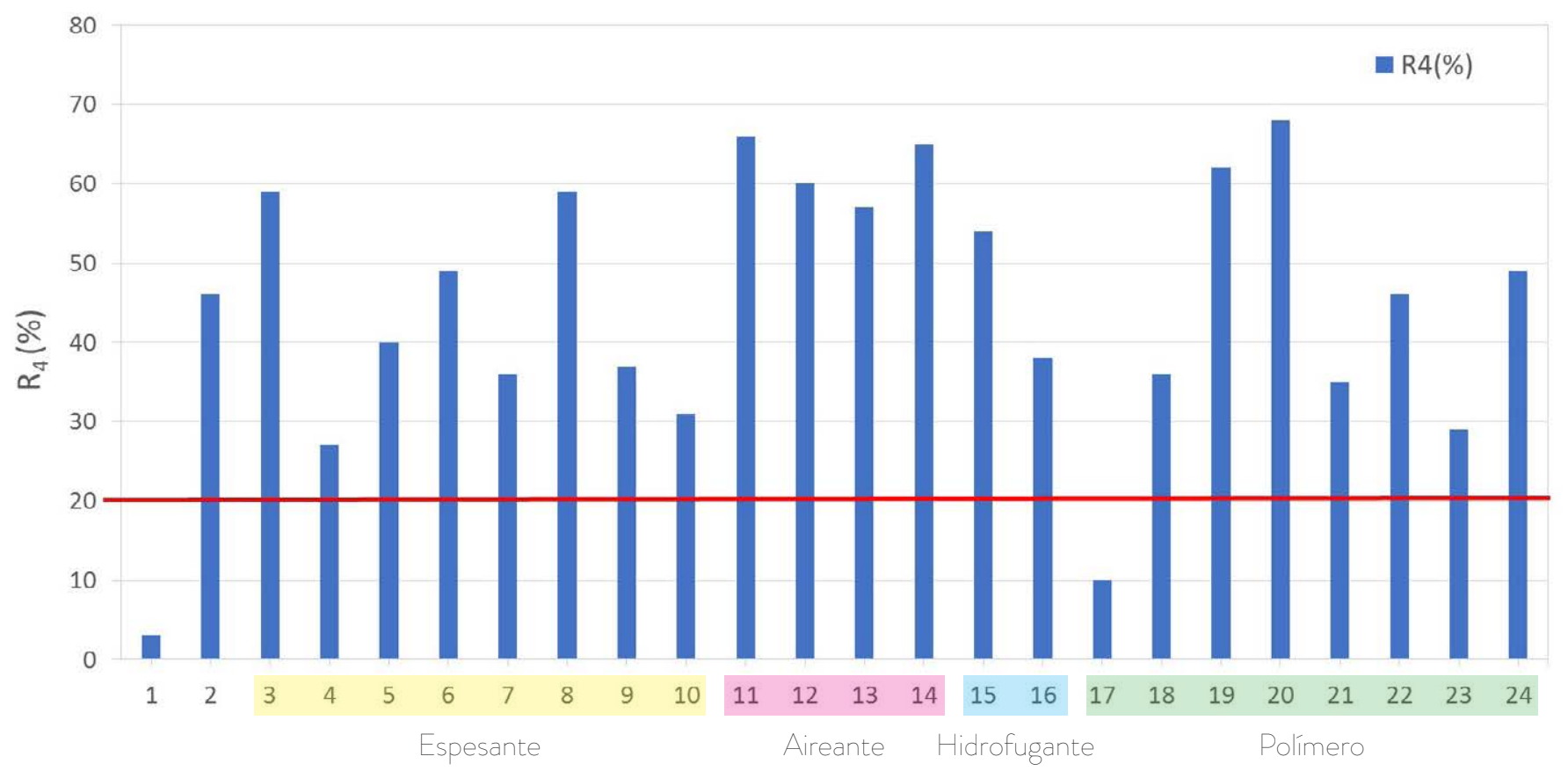

Fig 187. Promedios de $\mathrm{R}_{4}(\%)$ para cada aditivo, a partir de los valores de las cuatro probetas de cada serie. La línea roja representa el límite de actividad para considerar al material fotocatalítico.

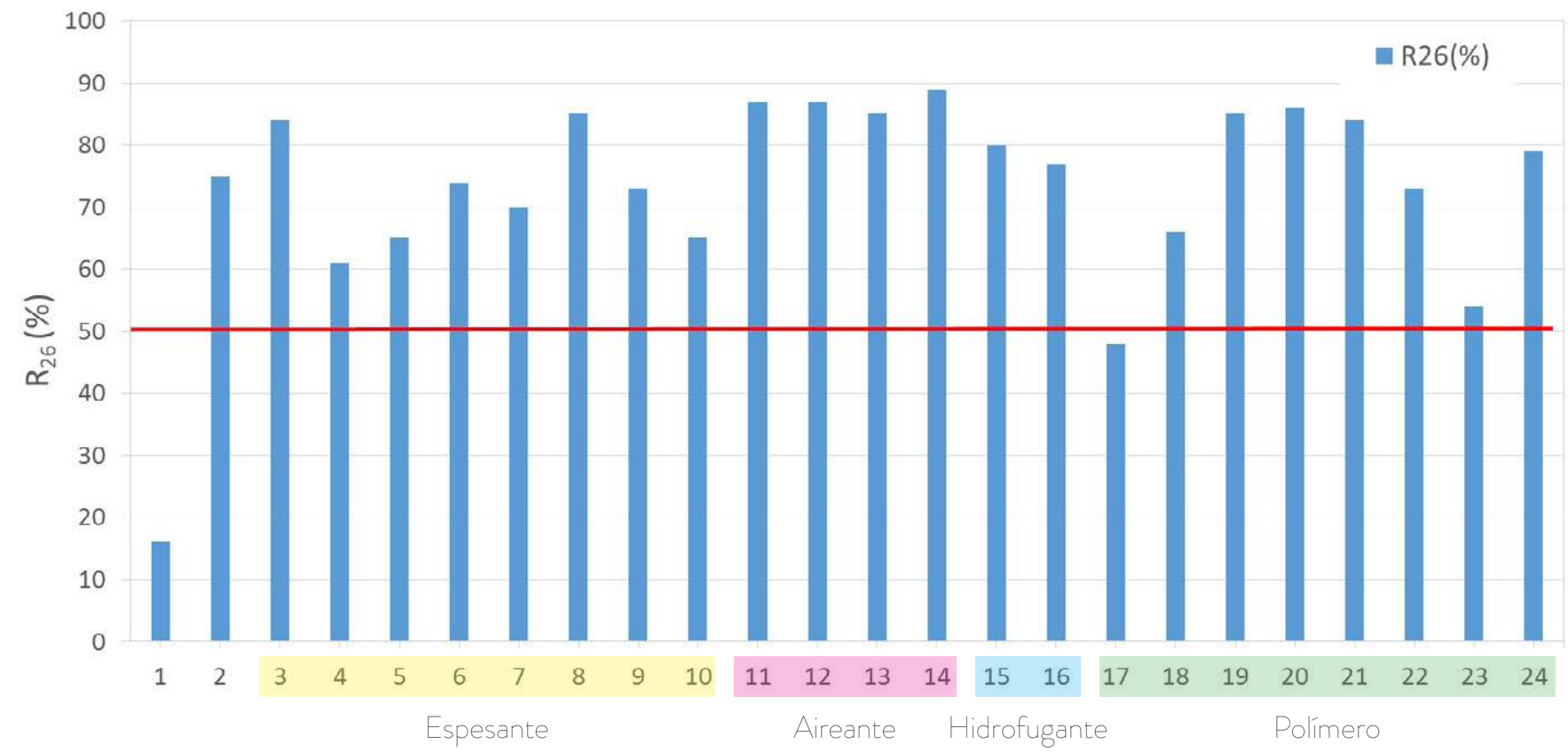

Fig 188. Promedios de $\mathrm{R}_{26}(\%)$ para cada aditivo, a partir de los valores de las cuatro probetas de cada serie. La línea roja representa el límite de actividad para considerar al material fotocatalítico.

En cuanto a la actividad fotocatalítica de las muestras en eliminación de óxidos de nitrógeno por vía fotocatalítica, los resultados indican una degradación de $\mathrm{NO}_{x}\left(\mathrm{NO}+\mathrm{NO}_{2}\right)$ en el rango entre el $1 \%$ y el $25 \%$, dependiendo del tipo y porcentaje de aditivo de la muestra mortero. La eliminación de $\mathrm{NO}_{x}$ del mortero no fotocatalítico es de un $0,2 \%$ frente al porcentaje del mortero fotocatalítico de un $6 \%$. En todos los casos excepto en el del $\mathrm{MH} 200-1,21(5 \%)$, el valor de $\mathrm{NO}_{\mathrm{x}}$ es superior al del mortero fotocatalítico sin aditivos 


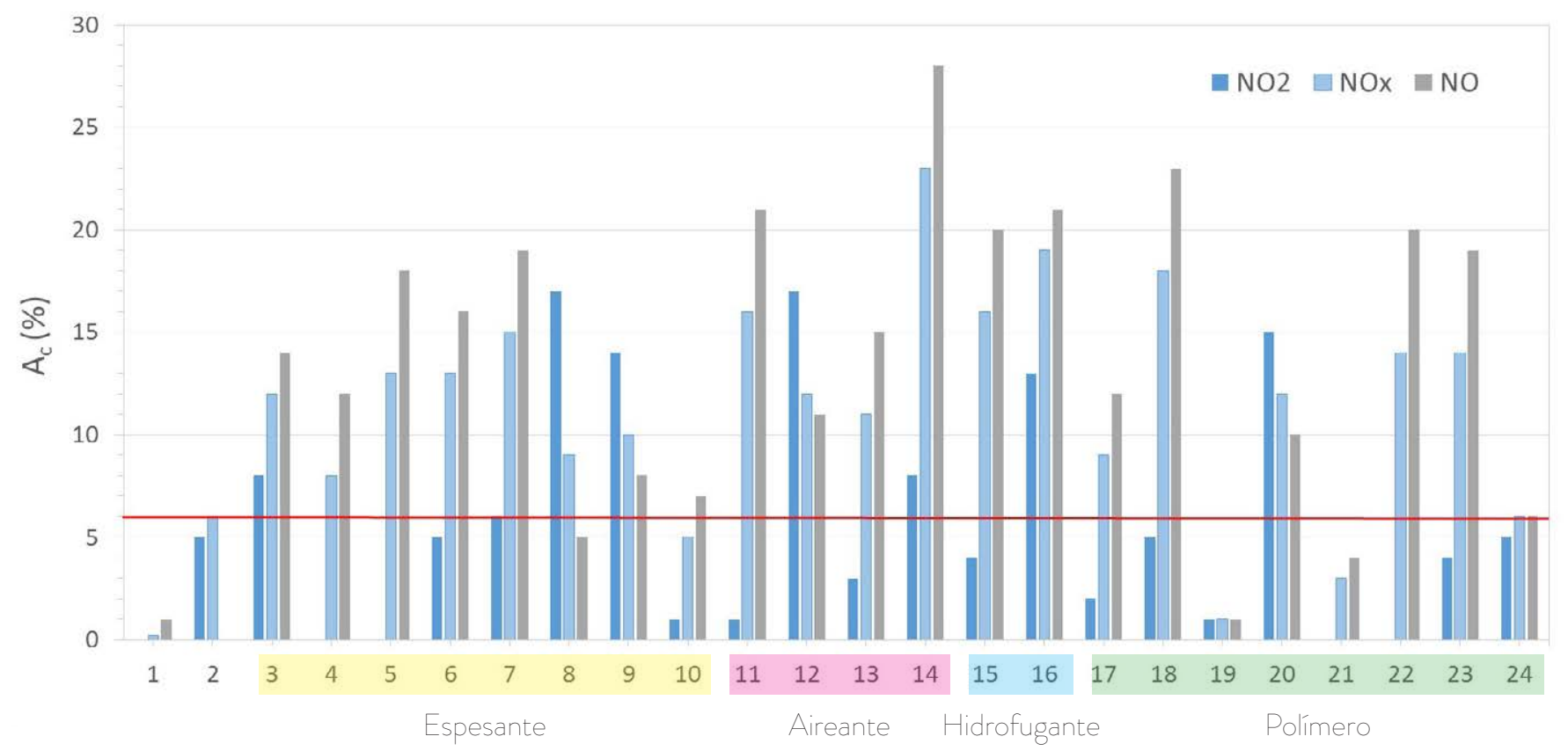

Fig 189. Representación gráfica de los promedios de degradación $\mathrm{A}_{c}(\%)$ de $\mathrm{NO}, \mathrm{NO}_{x}$ y $\mathrm{NO}_{2}$ para cada serie de probetas ensayadas. Señalado en rojo el valor de referencia de eliminación de $\mathrm{NO}_{x}$ para el mortero fotocatalítico sin aditivos.

\begin{tabular}{|c|c|}
\hline Serie & Referencia Aditivo (\% spc) \\
\hline 1 & Mortero No Fotocatalítico \\
\hline 3 & Mortero Fotoc. sin Aditivo \\
\hline 4 & $15000(0,64)$ \\
\hline 5 & $10012(0,64)$ \\
\hline 6 & $10012(1,42)$ \\
\hline 7 & H $20(0,43)$ \\
\hline 8 & H $20(1,21)$ \\
\hline 9 & MH 200 (0,43) \\
\hline 10 & MH 200 $(1,21)$ \\
\hline 11 & LS 14 $(0,026)$ \\
\hline 12 & LS 14 $(0,05)$ \\
\hline 13 & Mas $(0,026)$ \\
\hline 14 & Mas $(0,05)$ \\
\hline 15 & Oleato $(0,60)$ \\
\hline 16 & Oleato $(0,90)$ \\
\hline 17 & $554(2,14)$ \\
\hline 18 & $554(5,00)$ \\
\hline 19 & $554(14,29)$ \\
\hline 20 & $5010(2,14)$ \\
\hline 21 & $5010(5,00)$ \\
\hline 22 & Saf $54(3,57)$ \\
\hline 23 & Saf $54(7,14)$ \\
\hline 24 & Saf $54(14,29)$ \\
\hline
\end{tabular}

\subsubsection{MEDICIÓN DE LA CAPACIDAD FOTOCATALÍTICA DE ELIMINACIÓN DE NO.}

Para la degradación de $\mathrm{NO}_{x}$, la probeta de mortero fotocatalítico sin aditivo presenta una capacidad de eliminación de $\mathrm{NO}_{x}$ de $6 \%$. Los resultados nos dicen que, de las 23 series ensayadas, 18 tienen mayor actividad fotocatalítica que las probetas de mortero fotocatalítico sin aditivo, ordenadas de mayor a menor actividad, con el porcentaje de incremento respecto a la serie sin aditivos entre paréntesis, serian:

Mas $(0,05)(283 \%)>$ Oleato $(0,9)(217 \%)>554(5)(200 \%)>$
Oleato $(0,6)(167 \%)-\operatorname{LS} 14(0,026)(167 \%)>\operatorname{H} 20(0,43)(150 \%)>$
Saf $54(7,14)(133 \%)-\operatorname{Saf} 54(3,57)(133 \%)>10012(1,42)(117 \%)-$
$10012(0,64)(117 \%)>5010(2,14)(100 \%)-\operatorname{LS} 14(0,05)(100 \%)-$
$15000(0,64)(100 \%)>\operatorname{Mas}(0,026)(83 \%)>M H 200(0,43)(67 \%)>$
$554(2,14)(50 \%)-H 20(1,21)(50 \%)>15000(1,42)(33 \%)$

La actividad más alta la presenta las series de probetas: Mas $(0,05)$ con una eliminación de $\mathrm{NO}_{x}$ de $23 \%$. Como sucede en el método de la Rodamina, otras series ven disminuida su actividad fotocatalítica, si las colocamos ordenadas de mayor a menor actividad, con el porcentaje de disminución respecto a la serie sin aditivos entre paréntesis en negativo, serian:

Tabla 47. Código de aditivos 
MH $200(1,21)(-17 \%) 5010(5)(-50 \%)>554(14,29)(-83 \%)$

Si realizamos el análisis del comportamiento atendiendo a la familia de aditivo, podemos concluir que en relacion al ensayo de degradación de la rodamina:

En general, las tendencias que muestran en un mismo aditivo a $R_{4}$ se mantiene a $R_{26}$, y cuando se aumenta la dosificación del aditivo.

En el grupo de espesantes, al aumentar dosificación empeoran resultados 15000, y MH200, mejoran 10012 y MH200. Únicamente 1500-(0,64), 10012-(1,42), mejoran resultados respecto al mortero fotocatalítico sin aditivo.

En el grupo de aireantes, los aireantes mejoran los resultados respecto al mortero fotocatalítico sin aditivos, y las otras familias de aditivos.

En el grupo hidrófugante, ala aumentar dosificación empeoramos, solo la Oleato- $(0,6)$ mejora respecto al mortero fotocatalítico sin aditivos.

La tendencia mostrada en $\mathrm{R}_{4}$ es idéntica a la vista en de $\mathrm{NO}_{x}$, excepto en el caso del hidrófugante, en de $\mathrm{NO}_{x}$ al aumentar la dosificación experimenta una mejora pero, en autolimpieza a mayor hidrofugación se produce una pérdida de $\mathrm{R}_{4}$.

En el grupo de polímeros, mejoramos al aumentar la dosificación en el 554, hasta superar al mortero fotocatalítico sin aditivos. El único comportamiento anómalo que se sale de la serie es el del SAF 552, aditivo líquido que muestra valores de $R_{4}$ y $R_{26}$ superiores en los extremos del intervalo, hay que recordar que la probeta Saf54 $(14,29)$ tuvo problemas a la hora de impregnarla con la solución de rodamina, tal y como se indica en su apartado del plan de ensayo, y puede ser esta la causa de la mejora de los resultados.

Si realizamos el análisis del comportamiento atendiendo a la familia de aditivo, podemos concluir que en relacion al ensayo de eliminación de $\mathrm{NO}_{\mathrm{X}}$ :

En el grupo de espesantes, la serie 15000 al doblar dosificación se reduce el valor a $8 \%$, sin embargo ese valor es todavía superior al del mortero fotocatalítico sin aditivos. A la serie 10012 no le afecta el incremento de dosificación, Las series $\mathrm{H} 20$ y MH 200 muestran una tendencia similar al de la serie 15000 a mayor dosificación menor valor. La serie $\mathrm{MH}$ 200 tiene valores muy bajos en las dos dosificaciones parece que afecta negativamente en cualquier caso y no estaría aconsejado su uso.

En el grupo de aireantes., ambos aditivos que son de naturaleza química diferente, el primero un laurylsulfato de sodio y el segundo un alkylsulfato de sodio. Muestran tendencias contrapuestas, el denominado LS14 disminuye el valor al aumentar la concentración y el denominado Mas, dobla la actividad al doblar la dosificación 
En el grupo de hidrofugantes, vemos que al aumentar la dosificación permanece igual el valor de eliminación de $\mathrm{NO}$, pero aumenta el la tasa de eliminación de $\mathrm{NO}_{x}$.

En el grupo de los polímeros redispersables, el 554 al doblar la concentración dobla la tasa de eliminación de $\mathrm{NO}$, de $\mathrm{NO}_{x}$ y de $\mathrm{NO}_{2}$, sin embargo al triplicar, se produce una perdida dramática de la capacidad, se muestra un límite de dosificación para este aditivo en el que se pierde capacidad descontaminante. En el 5010, al contrario que en el 554, al doblar la dosificación se produce una pérdida del efecto descontaminante. En la dispersión acuosa Saf 54 al doblar la dosificación inicial no experimenta cambios y al triplicar se produce como en el 554, un disminución considerable de la capacidad descontaminante.

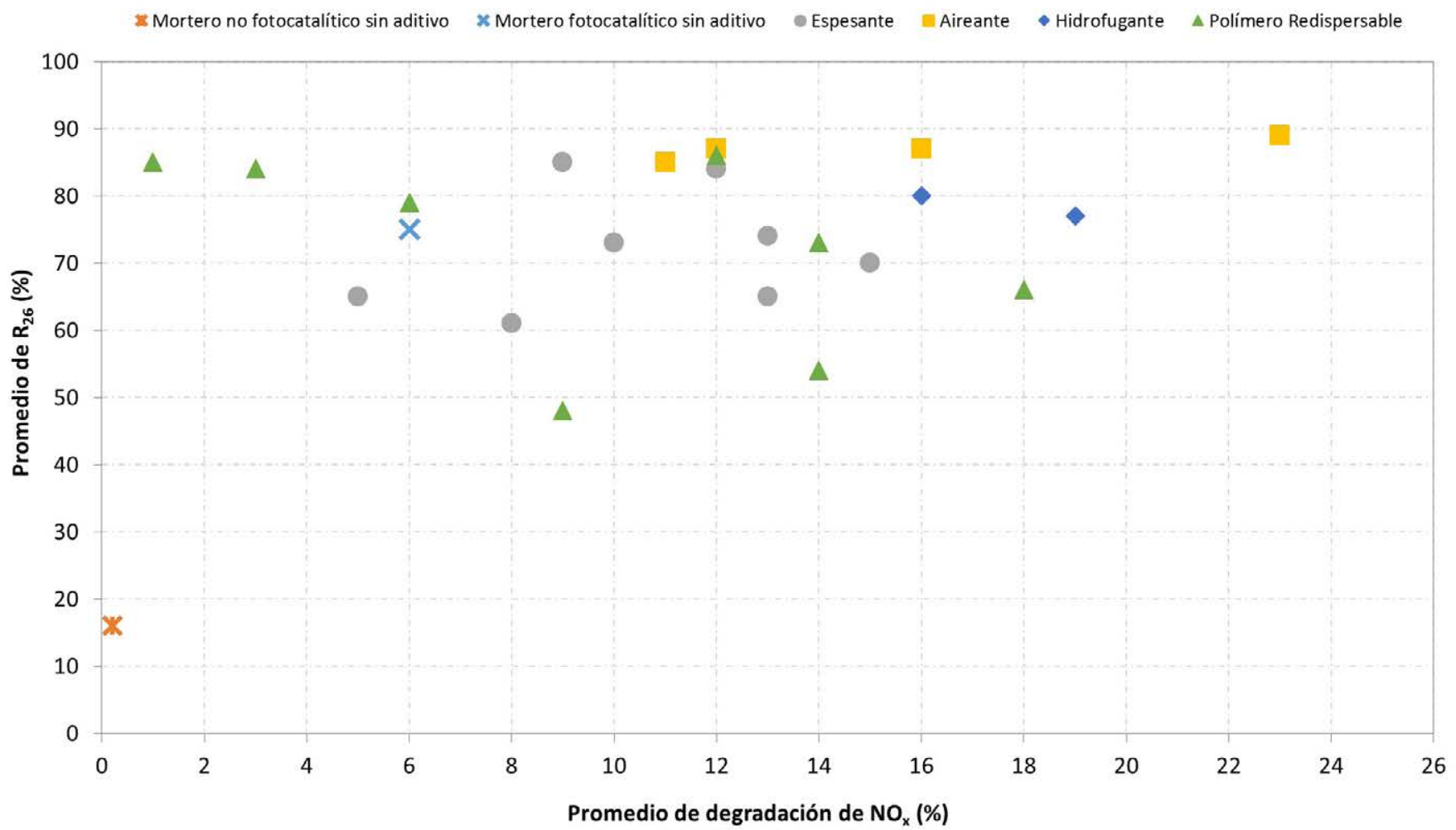

Fig 190. Representación gráfica de los promedios de $\mathrm{R}_{26}$ frente a los promedios de la degradación de $\mathrm{NO}_{x}, \mathrm{~A}_{c}(\%)$.
Se puede observar en la figura que no existe una relación clara y directa entre la influencia de un determinado aditivo en la actividad fotocatalítica de degradación de la rodamina y la eliminación de $\mathrm{NO}_{x}$, hemos visto aditivos que incrementan la actividad para la rodamina, respecto a la muestra fotocatalítica de referencia sin aditivo al mismo tiempo que disminuyen el porcentaje de $\mathrm{NO}_{x}$ eliminado, y viceversa. 
INFLUENCIA DEL COLOR Y ELACABADO SUPERFICIALENLASPROPIEDADES DE UN MORTERO FOTOCATALITICO COMO SOLUCIÓN DE ENVOLVENTE 
Este capítulo tiene como objetivo exponer las conclusiones finales de esta tesis doctoral. Son el resultado del análisis y discusión razonada, de los resultados obtenidos durante esta investigación. 
INFLUENCIA DEL COLOR Y ELACABADO SUPERFICIALEN LAS PROPIEDADES DE UN MORTERO FOTOCATALITICOCOMOSOLUCIÓNDE ENVOLVENTE 


\subsection{CONCLUSIONES}

Esta tesis doctoral ha demostrado como influyen los pigmentos, el acabado superficial y los aditivos para mortero, en las propiedades fotocatalíticas y la reflectancia de los morteros fotocatalíticos para envolventes en edificación.

Nomenclatura utilizada para los morteros:

\begin{tabular}{|c|c|c|c|}
\hline \multicolumn{2}{|l|}{ Mortero } & Color & Acabado \\
\hline Mortero fotocatalítico blanco & MTX & = Blanco & \multirow{6}{*}{$\begin{array}{l}R=\text { Rugoso } \\
L=\text { Liso }\end{array}$} \\
\hline & & $A=$ Amarillo & \\
\hline & & $R=$ Rojo & \\
\hline & & $M=$ Marrón & \\
\hline & & G1 = Gris claro & \\
\hline & & G2 = Gris oscuro & \\
\hline Mortero no fotocatalítico blanco & M & = Blanco & \multirow{2}{*}{$\begin{array}{l}R=\text { Rugoso } \\
L=\text { Liso }\end{array}$} \\
\hline Código: MTX-A-R & & & \\
\hline
\end{tabular}

Nomenclatura utilizada para los aditivos:

\begin{tabular}{|c|c|c|}
\hline & Referencia & $\begin{array}{c}\text { Dosificación Aditivo } \\
(\% \mathrm{spc})\end{array}$ \\
\hline \multirow{2}{*}{ Sin Aditivo } & Mortero No Fotoc. & - \\
\hline & Mortero Fotoc. $\sin$ Aditivo & - \\
\hline \multirow{8}{*}{ Espesante } & 15000 & 0,64 \\
\hline & 15000 & 1,42 \\
\hline & 10012 & 0,64 \\
\hline & 10012 & 1,42 \\
\hline & $\mathrm{H} 20$ & 0,43 \\
\hline & $\mathrm{H} 20$ & 1,21 \\
\hline & MH 200 & 0,43 \\
\hline & $\mathrm{MH} 200$ & 1,21 \\
\hline \multirow{4}{*}{ Aireante } & LS 14 & 0,026 \\
\hline & LS 14 & 0,05 \\
\hline & Mas & 0.026 \\
\hline & Mas & 0,05 \\
\hline \multirow{2}{*}{ Hidrofugante } & Oleato & 0,60 \\
\hline & Oleato & 0,90 \\
\hline \multirow{8}{*}{ Polimero } & 554 & 2,14 \\
\hline & 554 & 5,00 \\
\hline & 554 & 14,29 \\
\hline & 5010 & 2,14 \\
\hline & 5010 & 5,00 \\
\hline & Saf 54 & 3,57 \\
\hline & Saf 54 & 7,14 \\
\hline & Saf 54 & 14,29 \\
\hline
\end{tabular}

Código: REFERENCIA (\% dosificación) 
Más específicamente, en cuanto al color:

Se ha demostrado que no existe una relación clara y univoca entre la adición de pigmentos basados en óxidos de hierro y las propiedades fotocatalíticas de los morteros resultantes.

MTXR-L MTXG1-L MTX-L MTXA-L MTXG2-L MTXM-L $\quad$ M-L

\begin{tabular}{|r|r|r|r|r|r|r|r|}
\hline $\mathrm{NO}_{\mathbf{X}}(\%)$ & 24,22 & 19,84 & 11,51 & 11,21 & 12,39 & 8,02 & 0,17 \\
\hline $\mathbf{R}_{26}(\%)$ & 30,54 & 48,42 & 33,25 & 22,44 & 20,24 & 12,02 & 6,17 \\
\hline
\end{tabular}

La adición de pigmentos produce un desplazamiento del borde de absorción aparente hacia regiones de menor energía, sin tener por ello necesariamente una mayor actividad fotocatalítica

\begin{tabular}{|c|c|c|c|c|c|c|c|}
\hline \multicolumn{8}{|c|}{ Energía de absorción (eV) } \\
\hline $\mathbf{1}$ & M & MTX & MTXA & MTXR & MTXB & MTXG1 & MTXG2 \\
\hline $\mathbf{1}$ & $3,75^{*}$ & $3,20^{*}$ & 1,98 & 1,87 & 1,93 & $3,03^{*}$ & $2,975^{*}$ \\
\hline $\mathbf{3}$ & & & 2,20 & $3,18^{*}$ & $2,93^{*}$ & & \\
\hline
\end{tabular}

La fotoactividad es función de la tasa de recombinación electrón/hueco, que depende de las posiciones de las bandas de energía y de los acoplamientos que tienen lugar entre el pigmento de óxido de hierro y el semiconductor.

\begin{tabular}{|r|c|c|}
\hline & BC $(\mathrm{eV})$ & $\mathrm{BV}(\mathrm{eV})$ \\
\hline MTX & $-0,37$ & 2,83 \\
\hline MTX-A & $-0,25$ & 2,71 \\
\hline MTX-R & $-0,36$ & 2,82 \\
\hline MTX-M & $-0,24$ & 2,70 \\
\hline MTX-G1 & $-0,29$ & 2,75 \\
\hline MTX-G2 & $-0,26$ & 2,72 \\
\hline
\end{tabular}

Se ha demostrado que el ratio $\mathrm{Fe} / \mathrm{Ti}$ en la composición del mortero es un parámetro clave en la eficiencia resultante, ya que existe un óptimo entre la capacidad de transferencia de electrones con respecto a la recombinación electrón-hueco. La transferencia de los electrones de la banda de conducción de los óxidos de hierro que componen los pigmentos, a la del $\mathrm{TiO}^{2}$ y viceversa, es un factor clave a la hora de mejorar la eficiencia fotocatalítica de los morteros coloreados frente al mortero fotocatalítico sin pigmentos. 


\begin{tabular}{|r|c|c|}
\hline MTX & Fe/Ti & $\begin{array}{c}\text { Tasa de } \mathrm{OH} \text { generados } \\
\left(\mu \mathrm{mol} / \mathrm{min}_{\mathrm{cm}}\right)^{2} \cdot 10^{-4}\end{array}$ \\
\hline MTX-R & 0,24 & 0,16 \\
\hline MTX-A & 0,26 & 0,39 \\
\hline MTX-M & 0,40 & 0,14 \\
\hline MTX-G1 & 0,56 & 0,09 \\
\hline MTX-G2 & 0,35 & 0,17 \\
\hline
\end{tabular}

En cuanto al acabado superficial:

El rendimiento fotocatalítico es más alto en las muestras rugosas que en las que tiene un acabado liso. Esto es debido a la disponibilidad de mayor superficie activa para reaccionar por la rugosidad del sustrato.

\begin{tabular}{|l|c|c|c|c|c|c|c|}
\hline & MTXR-R & MTXG1-R & MTX-R & MTXA-R & MTXG2-R & MTXM-R & M-R \\
\hline NO $_{\mathbf{X}}(\%)$ & 30,80 & 20,76 & 16,74 & 14,33 & 13,58 & 13,18 & 0,00 \\
\hline & MTXR-L & MTXG1-L & MTX-L & MTXA-L & MTXG2-L & MTXM-L & M-L \\
\hline NO $_{\mathbf{X}}(\%)$ & 24,22 & 19,84 & 11,51 & 11,21 & 12,39 & 8,02 & 0,17 \\
\hline & MTXG1-R & MTX-R & MTXR-R & MTXG2-R & MTXA-R & M-R & MTXM-R \\
\hline $\mathbf{R}_{26}(\%)$ & 53,88 & 41,49 & 34,47 & 23,69 & 20,44 & 15,38 & 13,20 \\
\hline & MTXG1-L & MTX-L & MTXR-L & MTXA-L & MTXG2-L & MTXM-L & M-L \\
\hline & 48,42 & 33,25 & 30,54 & 22,44 & 20,24 & 12,02 & 6,17 \\
\hline
\end{tabular}

En cuanto a la reflectancia:

El color y acabado, producen cambios en la reflectancia espectral del mortero base, en la zona del espectro visible (VIS) y en la zona del infrarrojo cercano (NIR). La reflectancia en el visible de las muestras rugosa y lisa del mortero blanco fotocatalítico es superior con valores en torno al $3 \%$, a las de las muestras de mortero blanco no fotocatalítico MTX>M.

Las muestras de morteros grises con pigmento negro, muestran mayor reflectancia en el visible que en la zona del infrarrojo (790-1400 nm), al contrario que los otros morteros coloreados o blancos. 


\begin{tabular}{|r|c|c|c|c|}
\hline Muestra & $\begin{array}{c}\text { Reflec VIS (\%) } \\
\text { 380-780 nm }\end{array}$ & $\begin{array}{c}\text { Reflec VIS (\%) } \\
790-1400 \mathbf{n m}\end{array}$ & $\begin{array}{c}\text { Reflec VIS (\%) } \\
790-2500 \mathbf{n m}\end{array}$ & $\begin{array}{c}\text { Reflec VIS (\%) } \\
380-2500 \mathbf{n m}\end{array}$ \\
\hline MTX-L & 82,03 & 84,47 & 65,18 & 68,35 \\
\hline MTX-R & 81,95 & 84,02 & 71,70 & 73,63 \\
\hline M-L & 80,79 & 80,68 & 65,82 & 68,64 \\
\hline MTX-R & 79,78 & 82,15 & 71,78 & 73,29 \\
\hline MTXR-L & 75,05 & 84,48 & 73,79 & 74,03 \\
\hline MTXA-R & 74,43 & 84,40 & 74,33 & 74,35 \\
\hline MTXA-L & 72,86 & 81,51 & 69,18 & 70,34 \\
\hline MTXM-R & 66,77 & 80,76 & 65,18 & 66,61 \\
\hline MTXM-L & 65,02 & 78,66 & 67,83 & 67,95 \\
\hline MTXG1-R & 61,81 & 59,15 & 52,40 & 54,18 \\
\hline MTXG1-L & 60,33 & 58,51 & 51,91 & 53,50 \\
\hline MTXG2-R & 48,95 & 45,48 & 40,74 & 42,29 \\
\hline MTXG2-L & 42,25 & 40,92 & 36,81 & 37,83 \\
\hline
\end{tabular}

El resultado obtenido de las medidas de los morteros fotocatalíticos blanco y coloreados, es una alta reflectancia, ordenados de:

MTX > MTX-R > MTX-A > MTX-M > MTX-G1 > MTX-G2.

La textura superficial de la muestras, tiene poca influencia en la reflectancia, afectando de forma desigual según el color de la muestra. El efecto está relacionado con el proceso manual para realizar el acabado superficial de cada muestra y con el tamaño máximo del arido en el mortero.

\section{En cuanto a los aditivos:}

Se ha demostrado la influencia de los aditivos en las propiedades fotocatalíticas. Esta influencia es distinta dependiendo de la propiedad ensayada, autolimpieza o descontaminación, debido a los distintos mecanismos de las reacciones fotocatalíticas involucradas en los distintos procesos. Los aditivos muestran tendencias distintas en los dos ensayos, incluso en algunos casos, es contrapuesta.

Tanto para los ensayos de degradación de $\mathrm{NO}_{x}$, como para los de autolimpieza, la actividad aumenta en los morteros con aditivo, aunque en la mayor parte de las familias estudiadas hay un óptimo de concentración por encima del cual es efecto es perjudicial. 
CAPITTULO10: CONCLUSIONES

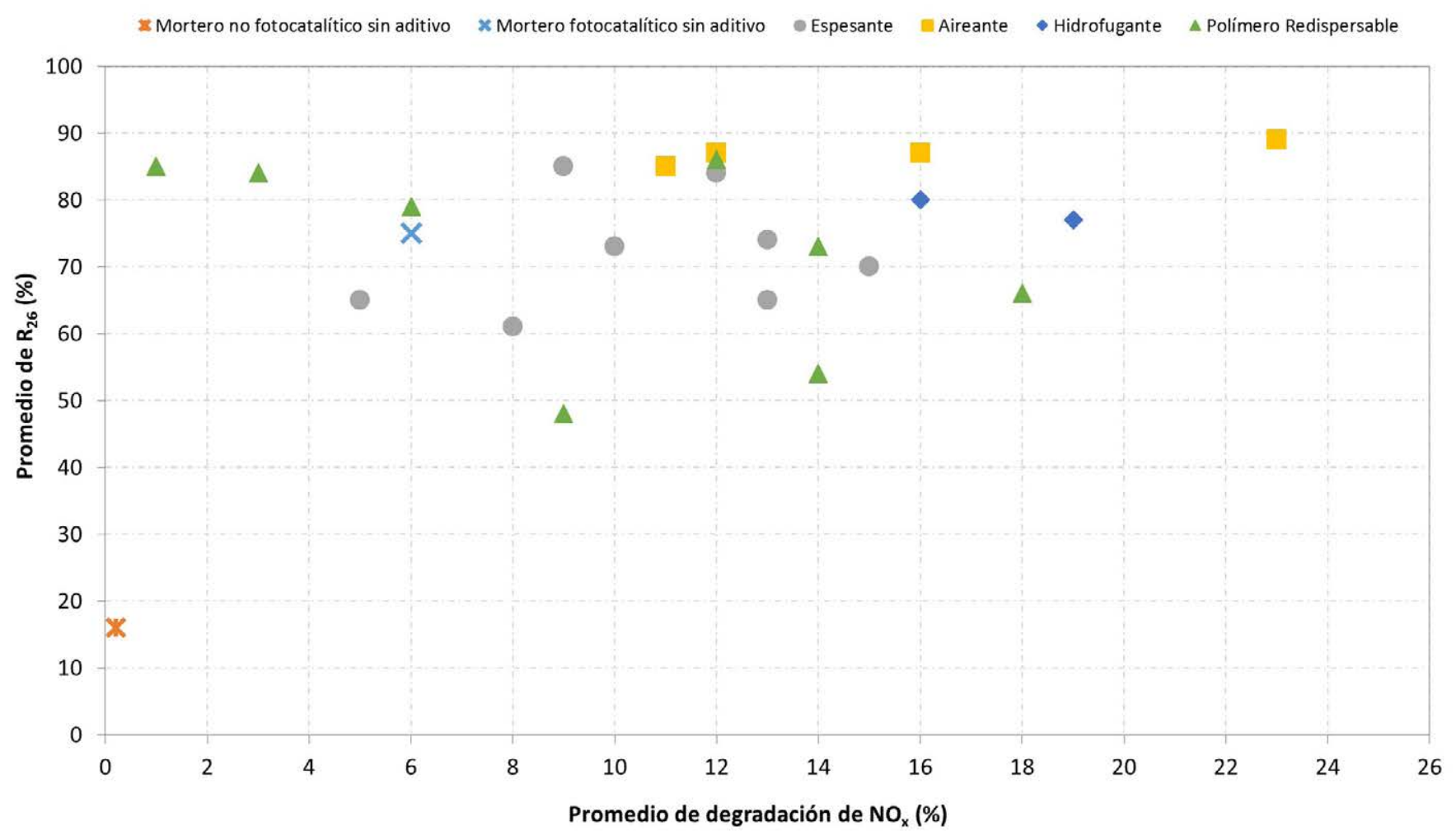


INFLUENCIA DEL COLOR Y ELACABADO SUPERFICIALENLASPROPIEDADES DE UN MORTERO FOTOCATALITICO COMO SOLUCIÓN DE ENVOLVENTE 
CAPÍTULO 11:

FUTURAS LIINEAS DE INVESTIGACIÓN 
INFLUENCIA DEL COLOR Y ELACABADO SUPERFICIALENLASPROPIEDADES DE UN MORTERO FOTOCATALITICO COMO SOLUCIÓN DE ENVOLVENTE 


\subsection{FUTURAS LÍNEAS DE INVESTIGACIÓN}

Estudio del mecanismo por el que interaccionan los aditivos con el fotocatalizador.

Estudio del comportamiento de pigmentos no basados en óxidos metálicos.

Evaluación sobre la influencia en la reducción del consumo energético necesario para refrigeración y su comportamiento en el tiempo. 

CAPÍTULO 12:

BIBLIOGRAFÍA 
INFLUENCIA DEL COLOR Y ELACABADO SUPERFICIALEN LAS PROPIEDADES DE UN MORTERO FOTOCATALITICOCOMOSOLUCIÓNDE ENVOLVENTE 
Adams, M., van Aatdenne, J., Kampbel, E., Tista, M., \& Zuber, A. (2012). European union emission inventory report 1990-2010 under the UNECE convention on long-range transboundary air pollution (LRTAP). ( No. 16). EEA. doi:10.2800/628267

Agencia Europea del Medioambiente. (2013). Cada vez que respiramos. mejorar la calidad del aire en europa. ( No. TH-AP-13-001-ES-C). Luxemburgo: Oficina de Publicaciones de la Unión Europea. doi:10.2800/83001 Agrios, A. G., \& Pichat, P. (2005). State of the art and perspectives on materials and applications of photocatalysis over TiO 2. Journal of Applied Electrochemistry, 35(7), 655-663.

Agrios, A. G., \& Pichat, P. (2005). State of the art and perspectives on materials and applications of photocatalysis over $\mathrm{TiO}_{2}$. Journal of Applied Electrochemistry, 35(7), 6

Águia, C., ngelo, J., Madeira, L. M., \& Mendes, A. (2010). Influence of photocatalytic paint components on the photoactivity of P25 towards NO abatement. Catalysis Today, 151(1), 77-83.

Aïssa, A. H., Puzenat, E., Plassais, A., Herrmann, J., Haehnel, C., \& Guillard, C. (2011). Characterization and photocatalytic performance in air of cementitious materials containing $\mathrm{TiO}_{2}$. case study of formaldehyde removal. Applied Catalysis B: Environmental, 107(1), 1-8.

Akbari, H. (2005). Energy saving potentials and air quality benefits of urban heat Island Mitigation. Lawrence Berkeley National Laboratory,

Akbari, H., Bretz, S., Kurn, D. M., \& Hanford, J. (1997). Peak power and cooling energy savings of high-albedo roofs. Energy and Buildings, 25(2), 117-126.

Akbari, H., Davis, S., Dorsano, S., Huang, J., \& Winnett, S. (1992). Cooling our communities. US Environmental Protection Agency, Report \# PM-221/22p-200,

Allen, N. S., Edge, M., Verran, J., Stratton, J., Maltby, J., \& Bygott, C. (2008). Photocatalytic titania based surfaces: Environmental benefits. Polymer Degradation and Stability, 93(9), 1632-1646.

Angelo, J., Andrade, L., \& Mendes, A. (2014). Highly active photocatalytic paint for $\mathrm{NO}_{x}$ abatement under real-outdoor conditions. Applied Catalysis A: General, 484, 17-25.

Anpo, M., Shima, T., Kodama, S., \& Kubokawa, Y. (1987). Photocatalytic hydrogen of $\mathrm{CH}_{3} / \mathrm{CCH}$ with $\mathrm{H}_{2} \mathrm{O}$ on small-particle $\mathrm{TiO}_{2}$ : Size quantization effects and reaction intermediates. J.Phys.Chem.;(United States), 91(16)

Ashby, M. F., \& Johnson, K. (2013). Materials and design: The art and science of material selection in product design. Butterworth-Heinemann.

Atkinson, R., \& Arey, J. (2003). Atmospheric degradation of volatile organic compounds. Chemical Reviews, 103(12), 4605-4638.

Augugliaro, V., Kisch, H., Loddo, V., López-Muñoz, M. J., Márquez-Álvarez, C., Palmisano, G., .. Yurdakal, S. (2008). Photocatalytic oxidation of aromatic alcohols to aldehydes in aqueous suspension of home prepared titanium dioxide: 2. intrinsic and surface features of catalysts. Applied Catalysis A: General, 349(1), 189-197.

Azzi, M., Johnson, G., \& Cope, M. (1992). An introduction to the generic reaction set photochemical smog mechanism. Proceedings of the 11th International Clean Air and Environment Conference, 
Balaras, C. A., Grossman, G., Henning, H., Ferreira, C. A. I., Podesser, E., Wang, L., \& Wiemken, E. (2007). Solar air conditioning in Europe-an overview. Renewable and Sustainable Energy Reviews, 11(2), 299-314.

Ballari, M. M., \& Brouwers, H. (2013). Full scale demonstration of air-purifying pavement. Journal of Hazardous Materials, 254, 406-414.

Ballari, M. M., Yu, Q., \& Brouwers, H. (2011). Experimental study of the $\mathrm{NO}$ and $\mathrm{NO}_{2}$ degradation by photocatalytically active concrete. Catalysis Today, 161(1), 175-180.

Ballester, F. (2005). Contaminación atmosférica, cambio climático y salud. Revista Española De Salud Pública, 79(2), 159-175.

Ballester, F., Medina, S., Boldo, E., Goodman, P., Neuberger, M., Iniguez, C., . . A Apheis network. (2008). Reducing ambient levels of fine particulates could substantially improve health: A mortality impact assessment for 26 european cities. Journal of Epidemiology and Community Health, 62(2), 98-105. doi:10.1136/ jech.2007.059857 [doi]

Banerjee, S., Dionysiou, D. D., \& Pillai, S. C. (2015). Self-cleaning applications of $\mathrm{TiO}_{2}$ by photo-induced hydrophilicity and photocatalysis. Applied Catalysis B: Environmental, 176, 396-428.

Banfield, J. (1998). Thermodynamic analysis of phase stability of nanocrystalline titania. Journal of Materials Chemistry, 8(9), 2073-2076.

Barbero-Barrera, M., Campos-Acosta, J., \& Neila-González, F. (2014). Reflectance properties analysis of mineral based mortars for renders: Research of their energy performance. Energy and Buildings, 76, 615-621.

Barreca, D., Carraro, G., Gasparotto, A., Maccato, C., Warwick, M. E., Kaunisto, K., . . Ruoko, T. (2015). $\mathrm{Fe}_{2} \mathrm{O}_{3}-\mathrm{TiO}_{2} \mathrm{Nano}-$ heterostructure photoanodes for highly efficient solar water oxidation. Advanced Materials Interfaces, 2(17)

Bascón, P. D. (2002). Clima regional y microclimas urbanos en la provincia de Córdoba, Universidad de Córdoba.

Beeldens, A., Cassar, L., Pimpinelli, N., \& Guerrini, G. (2007). Air purification by road materials: Results of the test project in antwerp-photocatalysis of cementitious materials.

Bengtsson, N., \& Castellote, M. (2014). Heterogeneous photocatalysis on construction materials: Effect of catalyst properties on the efficiency for degrading $\mathrm{NO}_{\mathrm{x}}$ and self cleaning. Materiales De Construcción, 64(314), 013.

Bengtsson, N. (2011). Photocatalytic contaminant abatement by $\mathrm{TiO}_{2}$ enriched construction materials: From a parametric study to an attempt to predict the photocatalytic activity.

Bengtsson, N., \& Castellote, M. (2010). Photocatalytic activity for NO degradation by construction materials: Parametric study andMultivariable correlations. Journal of Advanced Oxidation Technologies, 13(3), 341-349.

Bengtsson, N., Castellote, M., López-Muñoz, M. J., \& Cerro, L. (2009). Preparation of co-doped TiO2 for photocatalytic degradation of NOx in air under visible light. Journal of Advanced Oxidation Technologies, 12(1), 55-64.

Berdahl, P. (1995). Building energy efficiency and fire safety aspects of reflective coatings. Energy and Buildings, 22(3), 187-191. 
Berdahl, P., \& Bretz, S. E. (1997). Preliminary survey of the solar reflectance of cool roofing materials. Energy and Buildings, 25(2), 149-158.

Bermúdez-Polonio, J. (1967). Teoría y práctica de la espectroscopía de rayos X Alhambra.

Boixo, S., Diaz-Vicente, M., Colmenar, A., \& Castro, M. A. (2012). Potential energy savings from cool roofs in spain and andalusia. Energy, 38(1), 425-438.

Boldo, E., Linares, C., Lumbreras, J., Borge, R., Narros, A., García-Pérez, J., . . Ramis, R. (2011). Health impact assessment of a reduction in ambient PM 2.5 levels in spain. Environment International, 37(2), 342-348.

Boldo, E., Medina, S., Le Tertre, A., Hurley, F., Mücke, H., Ballester, F., \& Aguilera, I. (2006). Apheis: Health impact assessment of long-term exposure to PM2. 5 in 23 european cities. European Journal of Epidemiology, 21(6), 449-458.

Bonafous, L., Cassar, L., Cassat, P., Guillot, L., \& Colombet, P. (2007). Photocatalytic granular mixture for mortar and concrete and its use.

Boonen, E., \& Beeldens, A. (2014). Recent photocatalytic applications for air purification in belgium. Coatings, 4(3), 553-573.

Boonen, E., Beeldens, A., Dirkx, I., \& Bams, V. (2016). Durability of cementitious photocatalytic building materials. Catalysis Today,

Braslavsky, S. E., Braun, A. M., Cassano, A. E., Emeline, A. V., Litter, M. I., Palmisano, L., ... Serpone, N. (2011). Glossary of terms used in photocatalysis and radiation catalysis (IUPAC recommendations 2011). Pure and Applied Chemistry, 83(4), 931-1014.

Brauer, M., Freedman, G., Frostad, J., Van Donkelaar, A., Martin, R. V., Dentener, F., ... Apte, J. S. (2016). Ambient air pollution exposure estimation for the global burden of disease 2013. Environmental Science and Technology, 50(1), 79-88.

Bretz, S. E., \& Akbari, H. (1997). Long-term performance of high-albedo roof coatings. Energy and Buildings, 25(2), 159-167.

Bretz, S., \& Akbari, H. (1994). Durability of High-Albedo Roof Coatings and Implications for Cooling Energy Savings. Final Report,

Brimblecombe, P. (2000). Air pollution and architecture: Past, present and future. Journal of Architectural Conservation, 6(2), 30-46.

Brimblecombe, P., \& Grossi, C. M. (2008). Millennium-long recession of limestone facades in london. Environmental Geology, 56(3-4), 463-471.

Brimblecombe, P., \& Grossi, C. M. (2010). Potential damage to modern building materials from 21st century air pollution. Thescientificworldjournal, 10, 116-125. doi:10.1100/tsw.2010.17 [doi] 
Bubacz, K., Kusiak-Nejman, E., Tryba, B., \& Morawski, A. (2013). Investigation of OH radicals formation on the surface of $\mathrm{TiO}_{2} / \mathrm{N}$ photocatalyst at the presence of terephthalic acid solution. Estimation of optimal conditions. Journal of Photochemistry and Photobiology A: Chemistry, 261, 7-11.

Buildings, E. (2009). PPP research priorities for the definition of a multi-annual roadmap and longer term strategy. Ad-Hoc Industrial Advisory Group Energy-Efficient Buildings PPP,

Bygott, C. E., Maltby, J. E., Stratton, J. L., \& Mclntyre, R. (2016). Photocatalytic coatings for the construction industry. Newsletter,

Caillol, S. (2011). Fighting global warming: The potential of photocatalysis against $\mathrm{CO}_{2}, \mathrm{CH}_{4}, \mathrm{~N}_{2} \mathrm{O}, \mathrm{CFCs}$, tropospheric $\mathrm{O}_{3}, \mathrm{BC}$ and other major contributors to climate change. Journal of Photochemistry and Photobiology C: Photochemistry Reviews, 12(1), 1-19.

Callister, W. D., \& Rethwisch, D. G. (2012). Fundamentals of materials science and engineering: An integrated approach John Wiley \& Sons.

Campanella, L., Borzetti, F., \& Cassar, L. (2016). Photocatalytic cement: A new approach to environmental protection. Newsletter.

Carp, O., Huisman, C. L., \& Reller, A. (2004). Photoinduced reactivity of titanium dioxide. Progress in Solid State Chemistry, 32(1), 33-177.

Carpenter, L., Clemitshaw, K., Burgess, R., Penkett, S., Cape, J., \& McFadyen, G. (1998). Investigation and evaluation of the $\mathrm{NO}_{x} / \mathrm{O}_{3}$ photochemical steady state. Atmospheric Environment, 32(19), 3353-3365.

Cassar, L., Beeldens, A., Pimpinelli, N., \& Guerrini, G. (2007). Photocatalysis of cementitious materials. International RILEM Symposium on Photocatalysis, Environment and Construction Materials, 131-145.

Cassar, L., \& Pepe, C. (1997). Paving tile comprising an hydraulic binder and photocatalyst particles. Italcementi SpA, Bergamo, Italy, EP-Patent, (1600430A1)

Cassar, L., Pepe, C., Pimpinelli, N., Amadelli, R., \& Antolini, L. (1999). New cement-based materials and photocatalysis. Rebuilding the City of Tomorrow, 3rd Eur. Conf. REBUILD (Barcelona, Spain, 1999),

Cassar, L., Pepe, C., Pimpinelli, N., Amadelli, R., \& Bonato, T. (2000). Materiali cementizi e fotocatalisi. Seminario FAST" Materiali: Ricerca e Prospettive Tecnologiche Aile Soglie Del,

Cassar, L. (2004). Photocatalysis of cementitious materials: Clean buildings and clean air. MRS Bulletin, 29(05), 328-331.

Cassar, L., Pepe, C., Tognon, G., Guerrini, G. L., \& Amadelli, R. (2003). White cement for architectural concrete, possessing photocatalytic properties. Proceedings of the 11th International Congress on the Chemistry of Cement, , 4 2012-2021.

Castellote, M., \& Bengtsson, N. (2011). Principles of $\mathrm{TiO}_{2}$ photocatalysis. Applications of titanium dioxide photocatalysis to construction materials (pp. 5-10) Springer. 
Castellote, M., Botija, S., \& Andrade, C. (2006). Influencia del uso de material fotocatalítico como adición al cemento en la durabilidad de las armaduras embebidas en hormigón.

Castellote, M., Llorente, I., Andrade, C., Turrillas, X., Alonso, C., \& Campo, J. (2006). In-situ monitoring the realkalisation process by neutron diffraction: Electroosmotic flux and portlandite formation. Cement and Concrete Research, 36(5), 791-800.

Chen, J., Kou, S., \& Poon, C. (2011). Photocatalytic cement-based materials: Comparison of nitrogen oxides and toluene removal potentials and evaluation of self-cleaning performance. Building and Environment, 46(9), 1827-1833.

Chen, J., Kou, S., \& Poon, C. (2012). Hydration and properties of nano-TiO 2 blended cement composites. Cement and Concrete Composites, 34(5), 642-649.

Chen, J., \& Poon, C. (2009). Photocatalytic activity of titanium dioxide modified concrete materials-influence of utilizing recycled glass cullets as aggregates. Journal of Environmental Management, 90(11), 3436-3442.

Chen, J., \& Poon, C. (2009). Photocatalytic construction and building materials: From fundamentals to applications. Building and Environment, 44(9), 1899-1906.

CIE. (1979). Absolute methods for reflection measurements. ( No. 44-1979).

CIE. (1998). Absolute methods for reflection measurements. practical methods for the measurement of reflectance and transmittance. ( No. 130-1998).

CIE. (2016). Geometric tolerances for colour measurements. ( No. 176-2016).

Colombo, D. P., \& Bowman, R. M. (1996). Does interfacial charge transfer compete with charge carrier recombination? A femtosecond diffuse reflectance investigation of $\mathrm{TiO}_{2}$ nanoparticles. The Journal of Physical Chemistry, 100(47), 18445-18449.

De Luxán, M., Vázquez, M., Gómez, G., Román, E., \& Barbero, M. (2009). Actuaciones con criterios de sostenibilidad en la rehabilitación de viviendas en el centro de madrid. Madrid: Empresa Municipal De Vivienda y Suelo Del Ayuntamiento De Madrid,

Dell'Ambiente, M. (2001). Relazione sullo stato dell'ambiente. Ministero dell'Ambiente,

DESA, U. (2015). United nations, department of economic and social affairs, population division (2015). World urbanization prospects: The 2014 revision, (ST/ESA/SER.A/366).

DESA, U. (2016). United nations department of economic and social Affairs/Population division (20014): World population prospects: The 2014 revision, highlights (ST/ESA/SER.A/352).

Internet: Http://esa.Un.org/unpp (Gelesen Am 16),

Di Turo, F., Proietti, C., Screpanti, A., Fornasier, M. F., Cionni, I., Favero, G., \& De Marco, A. (2016). Impacts of air pollution on cultural heritage corrosion at european level: What has been achieved and what are the future scenarios. Environmental Pollution, 218, 586-594. 
Diamanti, M. V., Ormellese, M., \& Pedeferri, M. (2008). Characterization of photocatalytic and superhydrophilic properties of mortars containing titanium dioxide. Cement and Concrete Research, 38(11), 1349-1353.

Diamanti, M. V., Paolini, R., Rossini, M., Aslan, A. B., Zinzi, M., Poli, T., \& Pedeferri, M. P. (2015). Long term self-cleaning and photocatalytic performance of anatase added mortars exposed to the urban environment. Construction and Building Materials, 96, 270-278.

Diamanti, M., Del Curto, B., Ormellese, M., \& Pedeferri, M. (2013). Photocatalytic and self-cleaning activity of colored mortars containing $\mathrm{TiO}_{2}$. Construction and Building Materials, 46, 167-174.

Diamanti, M., Lollini, F., Pedeferri, M., \& Bertolini, L. (2013). Mutual interactions between carbonation and titanium dioxide photoactivity in concrete. Building and Environment, 62, 174-181.

Diebold, U. (2003). The surface science of titanium dioxide. Surface Science Reports, 48(5), 53-229.

Domen, K., Naito, S., Onishi, T., \& Tamaru, K. (1982). Photocatalytic hydrogen production from a mixture of water and 2-propanol on some semiconductors. Chemistry Letters, 11(4), 555-558.

Donachie, M. J. (2000). Titanium. A Technical Guide, ASM International, Materials Park, OH,

Doulos, L., Santamouris, M., \& Livada, I. (2004). Passive cooling of outdoor urban spaces. the role of materials. Solar Energy, 77(2), 231-249.

Doytchinov, S., Spezzano, P. :. S., A., \& Leggeri, G. (2013). UNECE international co-operative programme on effects on materials, including historic and cultural monument. in report no 73. pilot study on inventory and condition of stock of materials at risk at united nations educational, scientific and cultural organization (UNESCO) cultural heritage sites. part III economic evaluation. italian national agency for new technologies. pp. 2013. rome, italy: Energy and sustainable economic development (ENEA).

Dylla, H., Hassan, M. M., Schmitt, M., Rupnow, T., \& Mohammad, L. N. (2010). Laboratory investigation of the effect of mixed nitrogen dioxide and nitrogen oxide gases on titanium dioxide photocatalytic efficiency in concrete pavements. Journal of Materials in Civil Engineering, 23(7), 1087-1093.

Dylla, H., Hassan, M., Schmitt, M., Rupnow, T., Mohammad, L., \& Wright, E. (2011). Effects of roadway contaminants on titanium dioxide photodegradation of nitrogen oxides. Transportation Research Record: Journal of the Transportation Research Board, (2240), 22-29.

Ecologistas en Accion. (2016). La calidad del aire en el estado Español durante 2015. ().

Edwards, A. (1975). HP Klug and LE Alexander, x-Ray Diffraction Procedures for Polycrystalline and Amorphous Materials: Wiley-Interscience, New York, 2nd Edn., 1974, Xxv 966 Pp.PriceE 18.55,

EEA. (2013). EEA air quality in europe-2013. ( No. 9). doi:10.2800/92843

EEA. (2014). Air pollution fact sheet - Spain. ().

EEA. (2014). EEA air quality in Europe-2014. ( No. 5). doi:10.2800/22847

EEA. (2016). EEA air quality in Europe-2016. ( No. 28). doi:10.2800/413142 
EEA, E. (2013). EEA air pollutant emission inventory guidebook 2013, technical guidance to prepare national emission inventories. European Environment Agency, EEA Technical Report, (12)

Elder, S., Cot, F., Su, Y., Heald, S., Tyryshkin, A., Bowman, M., .. Kolwaite, A. C. (2000). The discovery and study of nanocrystalline $\mathrm{TiO}_{2}-\left(\mathrm{MoO}_{3}\right)$ core- shell materials. Journal of the American Chemical Society, 122(21), 5138-5146.

Enea, D., \& Guerrini, G. (2010). Photocatalytic properties of cement-based plasters and paints containing mineral pigments. Transportation Research Record: Journal of the Transportation Research Board, (2141), 52-60.

ESPAÑA, O. S. (2007). Calidad del aire en las ciudades: Clave de sostenibilidad urbana

Esplugues, A., Ballester, F., Estarlich, M., Llop, S., Fuentes, V., Mantilla, E., \& Iñiguez, C. (2010). Indoor and outdoor concentrations and determinants of $\mathrm{NO}_{2}$ in a cohort of 1-year-old children in Valencia, Spain. Indoor Air, 20(3), 213-223.

Europea, C. (2011). Progress report on Europe 2020 strategy.

European Lung Foundation. (2014). La salud pulmonar en europa. hechos y cifras. European Lung Foundation.

European Lung Foundation. (2017). Retrieved from http://www.erswhitebook.org/.

Fang, X., Mark, G., \& von Sonntag, C. (1996). OH radical formation by ultrasound in aqueous solutions part I: The chemistry underlying the terephthalate dosimeter. Ultrasonics Sonochemistry, 3(1), 57-63.

Faraldos, M., \& Goberna, C. (2002). Técnicas de análisis y caracterización de materiales. Consejo Superior de Investigaciones Científicas.

Faraldos, M., \& Goberna, C. (2011). Técnicas de análisis y caracterización de materiales.

Fernandes, V., Silva, L., Ferreira, V., \& Labrincha, J. (2005). Influence of the kneading water content in the behaviour of single-coat mortars. Cement and Concrete Research, 35(10), 1900-1908.

Feynman, R. P. (1960). There's plenty of room at the bottom. Engineering and Science, 23(5), 22-36.

FIEC. (2013). Construction in europe: Key figures. activity 2010. (). Brussels: Fogler, H. S. (1999). Elements of chemical reaction engineering.

Folli, A., Pade, C., Hansen, T. B., De Marco, T., \& Macphee, D. E. (2012). TiO 2 photocatalysis in cementitious systems: Insights into self-cleaning and depollution chemistry. Cement and Concrete Research, 42(3), 539-548.

Folli, A., Pochard, I., Nonat, A., Jakobsen, U. H., Shepherd, A. M., \& Macphee, D. E. (2010). Engineering photocatalytic cements: Understanding $\mathrm{TiO} 2$ surface chemistry to control and modulate photocatalytic performances. Journal of the American Ceramic Society, 93(10), 3360-3369.

Forouzanfar, M. H., Alexander, L., Anderson, H. R., Bachman, V. F., Biryukov, S., Brauer, M., ... Cohen, A. (2015). Global, regional, and national comparative risk assessment of 79 behavioural, environmental and occupational, and metabolic risks or clusters of risks in 188 countries, 1990-2013: A systematic analysis for the global burden of disease study 2013. The Lancet, 386(10010), 2287-2323. 
Franchi, M., Carrer, P., Kotzias, D., Rameckers, E., Seppänen, O., van Bronswijk, J., \& Viegi, G. (2003). Towards healthy air in dwellings in europe: The THADE report.

Fraunhofer. (2010). Clean air by airclean. Retrieved from http://www.ime.fraunhofer.de/content/dam/ime/de/ documents/AOe/2009_2010_Saubere\%20Luft\%20durch \%20Pflastersteine_s.pdf

Fujishima, A., Hashimoto, K., \& Watanabe, T. (1999). TiO 2 photocatalysis: Fundamentals and applications BKC Incorporated.

Fujishima, A., Rao, T. N., \& Tryk, D. A. (2000). Titanium dioxide photocatalysis. Journal of Photochemistry and Photobiology C: Photochemistry Reviews, 1(1), 1-21.

Fujishima, A., \& Zhang, X. (2006). Titanium dioxide photocatalysis: Present situation and future approaches. Comptes Rendus Chimie, 9(5), 750-760.

Fujishima, A., Zhang, X., \& Tryk, D. A. (2008). TiO 2 photocatalysis and related surface phenomena. Surface Science Reports, 63(12), 515-582.

Gago, E. J., Roldan, J., Pacheco-Torres, R., \& Ordoñez, J. (2013). The city and urban heat islands: A review of strategies to mitigate adverse effects. Renewable and Sustainable Energy Reviews, 25, 749-758.

Gallus, M., Akylas, V., Barmpas, F., Beeldens, A., Boonen, E., Boréave, A., .. Doussin, J. (2015). Photocatalytic de-pollution in the leopold II tunnel in brussels: $\mathrm{NO}_{x}$ abatement results. Building and Environment, 84, 125-133.

Gallus, M., Ciuraru, R., Mothes, F., Akylas, V., Barmpas, F., Beeldens, A., ... Cazaunau, M. (2015). Photocatalytic abatement results from a model street canyon. Environmental Science and Pollution Research, 22(22), 1818518196.

García, F. F., \& Álvarez, D. R. (2008). Olas de calor e influencia urbana en madrid y su área metropolitana. Estudios Geográficos, 69(265), 495-518.

García, F. F. (2007). Impactos del cambio climático en las áreas urbanas y rurales. Boletín De La Institución Libre De Enseñanza, (66-67)

Gaya, U. I., \& Abdullah, A. H. (2008). Heterogeneous photocatalytic degradation of organic contaminants over titanium dioxide: A review of fundamentals, progress and problems. Journal of Photochemistry and Photobiology C: Photochemistry Reviews, 9(1), 1-12.

Ghedini, N., Ozga, I., Bonazza, A., Dilillo, M., Cachier, H., \& Sabbioni, C. (2011). Atmospheric aerosol monitoring as a strategy for the preventive conservation of urban monumental heritage: The florence baptistery. Atmospheric Environment, 45(33), 5979-5987.

Goulding, J., Nadim, W., Petridis, P., \& Alshawi, M. (2012). Construction industry offsite production: A virtual reality interactive training environment prototype. Advanced Engineering Informatics, 26(1), 103-116.

Gray, K. A., \& Finster, M. E. (1999). The urban heat island, photochemical smog, and chicago: Local features of the problem and solution. Northwestern University, Department of Civil Engineering. 
Grøntoft, T. (2017). Conservation-restoration costs for limestone façades due to air pollution in krakow, poland, meeting european target values and expected climate change. Sustainable Cities and Society, 29, 169-177.

Grossi, C., \& Brimblecombe, P. (2008). Past and future colouring patterns of historic stone buildings. Materiales De Construcción, 58(289-290), 143-160.

Guan, K. (2005). Relationship between photocatalytic activity, hydrophilicity and self-cleaning effect of $\mathrm{TiO}_{2} /$ $\mathrm{SiO}_{2}$ films. Surface and Coatings Technology, 191(2), 155-160.

Guardino Sola, X. (1998). Calidad del aire interior. Volumen II. Enciclopedia De La Salud y Seguridad En El Trabajo. Ministerio De Trabajo y Asuntos Sociales.ISBN, , 84-8417.

Guerreiro, C. B., Foltescu, V., \& De Leeuw, F. (2014). Air quality status and trends in europe. Atmospheric Environment, 98, 376-384.

GUERRINI, G. L. (2009). Some observations regarding in-service performance: Photocatalytic paving block surfaces. Betonwerk Fertigteil-Technik, 75(5)

Guerrini, G. L. (2012). Photocatalytic performances in a city tunnel in rome: $\mathrm{NO}_{\mathrm{x}}$ monitoring results. Construction and Building Materials, 27(1), 165-175.

Guerrini, G. (2009). Photo catalytic paving block surfaces. some observations regarding in-service performance.

Guerrini, G. (2010). Photocatalytic cementitious Materials-Situation, challenges, and perspectives. World Cement. [Online] Available at: Http://www.Worldcement.com/documents/ltalcementi\% 20proof.Pdf [Accessed August 2011],

Guerrini, G. (2011). Development of photocatalytic cement-based materials: Situation and perspectives. 13th International Congress on the Chemistry of Cement, Madrid,

Guillard, C., Disdier, J., Herrmann, J., Lehaut, C., Chopin, T., Malato, S., \& Blanco, J. (1999). Comparison of various titania samples of industrial origin in the solar photocatalytic detoxification of water containing 4-chlorophenol. Catalysis Today, 54(2), 217-228.

Guo, M., Ling, T., \& Poon, C. (2013). Nano-TiO - -based architectural mortar for NO removal and bacteria inactivation: Influence of coating and weathering conditions. Cement and Concrete Composites, 36, 101-108.

Guo, M., \& Poon, C. (2013). Photocatalytic NO removal of concrete surface layers intermixed with $\mathrm{TiO}_{2}$. Building and Environment, 70, 102-109.

Hanus, M. J., \& Harris, A. T. (2013). Nanotechnology innovations for the construction industry. Progress in Materials Science, 58(7), 1056-1102.

Harrison, R. M., Brunekreef, B., Keuken, M., Denier Van Der Gon, Hugo, \& Querol, X. (2014). New directions: Cleaning the air-will the european Commission's clean air policy package of december 2013 deliver. Atmos Environ, 91, 172-174.

Hashimoto, K., Irie, H., \& Fujishima, A. (2005). TiO 2 photocatalysis: A historical overview and future prospects. Japanese Journal of Applied Physics, 44(12R), 8269. 
Hassan, M. M., Dylla, H., Mohammad, L. N., \& Rupnow, T. (2010). Evaluation of the durability of titanium dioxide photocatalyst coating for concrete pavement. Construction and Building Materials, 24(8), 1456-1461.

Hassid, S., Santamouris, M., Papanikolaou, N., Linardi, A., Klitsikas, N., Georgakis, C., \& Assimakopoulos, D. (2000). The effect of the athens heat island on air conditioning load. Energy and Buildings, 32(2), 131-141.

He, J., \& Hoyano, A. (2008). A numerical simulation method for analyzing the thermal improvement effect of super-hydrophilic photocatalyst-coated building surfaces with water film on the urban/built environment. Energy and Buildings, 40(6), 968-978.

Henderson, M. A. (2011). A surface science perspective on photocatalysis. Surface Science Reports, 66(6), 185297.

Herrmann, J. (2005). Heterogeneous photocatalysis: State of the art and present applications in honor of pr. RL burwell jr.(1912-2003), former head of ipatieff laboratories, northwestern university, evanston (ill). Topics in Catalysis, 34(1), 49-65.

Hirakawa, T., \& Nosaka, Y. (2002). Properties of $\mathrm{O}^{2 *-}$ and $\mathrm{OH}^{\cdot}$ formed in $\mathrm{TiO} 2$ aqueous suspensions by photocatalytic reaction and the influence of $\mathrm{H}_{2} \mathrm{O}_{2}$ and some ions. Langmuir, 18(8), 3247-3254.

Hisdal, B. J. (1965). Reflectance of perfect diffuse and specular samples in the integrating sphere. Josa, 55(9), $1122-1125$.

Holland, M., Haydock, H., CAPE, J., LEITH, I., LEWIS, P., FALLA, N., . . LEE, D. (2007). Ozone damage to paint and rubber goods in the UK. Pollution Atmosphérique, 49(OCT), 73-86.

Holland, M., Wagner, A., Davies, T., Spadaro, J., \& Adams, M. (2014). Costs of air pollution from european industrial facilities 2008-2012. (No. 20).EEA.

Hsien, Y., Chang, C., Chen, Y., \& Cheng, S. (2001). Photodegradation of aromatic pollutants in water over TiO 2 supported on molecular sieves. Applied Catalysis B: Environmental, 31(4), 241-249.

Hunger, M., Hüsken, G. G., \& Brouwers, H. J. (2008). Photocatalysis applied to concrete products-part 1: Principles and test procedure. ZKG International, 61(8), 77.

Hunger, M., Hüsken, G., \& Brouwers, H. (2009). Photocatalysis applied to concrete products-part 3: Practical relevance and modeling of the degradation process.

Hunger, M., Hüsken, G., \& Brouwers, J. (2008). Photocatalysis applied to concrete products. ZKG International, 61(10), 76-84.

Hunter, R. J. (2013). Zeta potential in colloid science: Principles and applications Academic press.

Hüsken, G., Hunger, M., \& Brouwers, H. (2009). Experimental study of photocatalytic concrete products for air purification. Building and Environment, 44(12), 2463-2474.

Hüsken, G., Hunger, M., \& Brouwers, H. J. (2007). Comparative study on cementitious products containing titanium dioxide as photo-catalyst. Proceedings of International RILEM Symposium on Photocatalysis, Environment and Construction Materials, 8-9. 
IPL. (2010). Dutch air quality innovation programme concluded. (Technical). Netherlands: IPL.

Ishibashi, K., Fujishima, A., Watanabe, T., \& Hashimoto, K. (2000). Detection of active oxidative species in $\mathrm{TiO} 2$ photocatalysis using the fluorescence technique. Electrochemistry Communications, 2(3), 207-210.

Ishibashi, K., Fujishima, A., Watanabe, T., \& Hashimoto, K. (2000). Quantum yields of active oxidative species formed on $\mathrm{TiO}_{2}$ photocatalyst. Journal of Photochemistry and Photobiology A: Chemistry, 134(1), 139-142.

Italcementi SpA. (2009). TX active. principio attivo fotocatalitico . Italia: Italcementi SpA.

Jacoby, W. A., Blake, D. M., Penned, J. A., Boulter, J. E., Vargo, L. M., George, M. C., \& Dolberg, S. K. (1996). Heterogeneous photocatalysis for control of volatile organic compounds in indoor air. Journal of the Air \& Waste Management Association, 46(9), 891-898.

Jamieson, J. C., Olinger, B., Dachille, F., Simons, P., \& Roy, R. (1969). Pressure-temperature studies of anatase, brookite rutile and tio2 (ii)-a discussion. American Mineralogist, 54(9-10), 1477-\&.

Janssen, N. A., Hoek, G., Simic-Lawson, M., Fischer, P., Van Bree, L., Ten Brink, H., . . Brunekreef, B. (2011). Black carbon as an additional indicator of the adverse health effects of airborne particles compared with $\mathrm{PM}_{10}$ and $\mathrm{PM}_{2.5}$. Environmental Health Perspectives, 119(12), 1691.

Jimenez-Relinque, E., \& Castellote, M. (2015). Quantification of hydroxyl radicals on cementitious materials by fluorescence spectrophotometry as a method to assess the photocatalytic activity. Cement and Concrete Research, 74, 108-115.

Jimenez-Relinque, E., Llorente, I., \& Castellote, M. (2017). $\mathrm{TiO}_{2}$ cement-based materials: Understanding optical properties and electronic band structure of complex matrices. Catalysis Today, 287, 203-209.

Jimenez-Relinque, E., Rodriguez-Garcia, J., Castillo, A., \& Castellote, M. (2015). Characteristics and efficiency of photocatalytic cementitious materials: Type of binder, roughness and microstructure. Cement and Concrete Research, 71, 124-131.

Kawakami, M., Furumura, T., \& Tokushige, H. (2007). NO removal effects and physical properties of cement mortar incorporating titanium dioxide powder.

Kennedy, I. M. (2007). The health effects of combustion-generated aerosols. Proceedings of the Combustion Institute, 31(2), 2757-2770.

Kim, H., Lee, S., Han, Y., \& Park, J. (2006). Preparation of dip-coated $\mathrm{TiO}_{2}$ photocatalyst on ceramic foam pellets. Journal of Materials Science, 41(18), 6150-6153.

Kimball, W. J. (2010). Acid rain. Retrieved from http://www.biology-pages.info/A/AcidRain.html

Kish, H. (1989). What is photocatalysis. Photocatalysis: Fundamentals and Applications, , 1-8.

Kittel, C. (1968). Introduction to solid state physics (3d ed.), john Wiley\&Sons. Inc., New York, London, Sydney, 
Kohtani, S., Yoshida, K., Maekawa, T., Iwase, A., Kudo, A., Miyabe, H., \& Nakagaki, R. (2008). Loading effects of silver oxides upon generation of reactive oxygen species in semiconductor photocatalysis. Physical Chemistry Chemical Physics, 10(20), 2986-2992.

Kolokotroni, M., Zhang, Y., \& Watkins, R. (2007). The london heat island and building cooling design. Solar Energy, 81(1), 102-110.

Kondo, H., \& Kikegawa, Y. (2003). Temperature variation in the urban canopy with anthropogenic energy use. Pure and Applied Geophysics, 160(1), 317-324.

Kubelka, P., \& Munk, F. (1931). An article on optics of paint layers. Z.Tech.Phys, 12(593-601)

Kucera, V., Tidblad, J., Kreislova, K., Knotkova, D., Faller, M., Reiss, D., .. . Schreiner, M. (2007). UN/ECE ICP materials dose-response functions for the multi-pollutant situation. Water, Air, \& Soil Pollution: Focus, 7(1-3), 249-258.

Kumar, K. P., Keizer, K., Burggraaf, A., Okubo, T., Nagamoto, H., \& Morooka, S. (1992). Densification of nanostructured titania assisted by a phase transformation. Nature, 358(6381), 48-51.

Kumar, P., \& Imam, B. (2013). Footprints of air pollution and changing environment on the sustainability of built infrastructure. Science of the Total Environment, 444, 85-101.

Kurth, J. C. (2008). Mitigating Biofilm Growth through the Modification of Concrete Design and Practice, Lackhoff, M., Prieto, X., Nestle, N., Dehn, F., \& Niessner, R. (2003). Photocatalytic activity of semiconductormodified cement-influence of semiconductor type and cement ageing. Applied Catalysis B: Environmental, 43(3), 205-216.

Laplaza, A., \& Castro, S. H. (2013). La fotocatálisis en los materiales de construcción base cemento: Fundamentos, métodos de medida y ejemplos de aplicación. Cemento Hormigón, (958), 12-22.

Lebental, B., Chainais, P., Chenevier, P., Chevalier, N., Delevoye, E., Fabbri, J., ... Ghis, A. (2011). Aligned carbon nanotube based ultrasonic microtransducers for durability monitoring in civil engineering. Nanotechnology, 22(39), 395501.

Lechtenböhmer, S., \& Schüring, A. (2011). The potential for large-scale savings from insulating residential buildings in the EU. Energy Efficiency, 4(2), 257-270.

Lee, D. S., Holland, M. R., \& Falla, N. (1996). The potential impact of ozone on materials in the UK. Atmospheric Environment, 30(7), 1053-1065.

Levinson, R., \& Akbari, H. (2002). Effects of composition and exposure on the solar reflectance of portland cement concrete. Cement and Concrete Research, 32(11), 1679-1698.

Levinson, R., \& Akbari, H. (2010). Potential benefits of cool roofs on commercial buildings: Conserving energy, saving money, and reducing emission of greenhouse gases and air pollutants. Energy Efficiency, 3(1), 53.

Levinson, R., Akbari, H., Berdahl, P., Wood, K., Skilton, W., \& Petersheim, J. (2010). A novel technique for the production of cool colored concrete tile and asphalt shingle roofing products. Solar Energy Materials and Solar Cells, 94(6), 946-954. 
Levinson, R., Berdahl, P., \& Akbari, H. (2005). Solar spectral optical properties of pigments-Part I: Model for deriving scattering and absorption coefficients from transmittance and reflectance measurements. Solar Energy Materials and Solar Cells, 89(4), 319-349.

Levinson, R., Berdahl, P., \& Akbari, H. (2005). Solar spectral optical properties of pigments-Part II: Survey of common colorants. Solar Energy Materials and Solar Cells, 89(4), 351-389.

Levinson, R., Berdahl, P., Akbari, H., Miller, W., Joedicke, I., Reilly, J., . . Vondran, M. (2007). Methods of creating solar-reflective nonwhite surfaces and their application to residential roofing materials. Solar Energy Materials and Solar Cells, 91(4), 304-314.

Li, D., Huang, H., Chen, X., Chen, Z., Li, W., Ye, D., \& Fu, X. (2007). New synthesis of excellent visible-light $\mathrm{TiO}_{2}-\mathrm{xNx}$ photocatalyst using a very simple method. Journal of Solid State Chemistry, 180(9), 2630-2634.

Li, X., Lin, H., Chen, X., Niu, H., Liu, J., Zhang, T., \& Qu, F. (2016). Dendritic $\alpha-\mathrm{Fe}_{2} \mathrm{O}_{3} / \mathrm{TiO}_{2}$ nanocomposites with improved visible light photocatalytic activity. Physical Chemistry Chemical Physics, 18(13), 9176-9185.

Linkous, C. A., Carter, G. J., Locuson, D. B., Ouellette, A. J., Slattery, D. K., \& Smitha, L. A. (2000). Photocatalytic inhibition of algae growth using $\mathrm{TiO}_{2}, \mathrm{WO}_{3}$, and cocatalyst modifications. Environmental Science \& Technology, 34(22), 4754-4758.

Linsebigler, A. L., Lu, G., \& Yates Jr, J. T. (1995). Photocatalysis on $\mathrm{TiO}_{2}$ surfaces: Principles, mechanisms, and selected results. Chemical Reviews, 95(3), 735-758.

Litter, M., \& Navio, J. A. (1996). Photocatalytic properties of iron-doped titania semiconductors. Journal of Photochemistry and Photobiology A: Chemistry, 98(3), 171-181.

Lopes, O. F., de Mendonça, V. R., Umar, A., Chuahan, M. S., Kumar, R., Chauhan, S., \& Ribeiro, C. (2015). Zinc hydroxide/oxide and zinc hydroxy stannate photocatalysts as potential scaffolds for environmental remediation. New Journal of Chemistry, 39(6), 4624-4630.

López Alonso, María del Mar. (2011). Comportamiento y compatibilidad de cementos y aditivos superplastificantes basados en policarboxilatos. Efectos de la naturaleza de los cementos y estructura de los aditivos.

Luan, P., Xie, M., Liu, D., Fu, X., \& Jing, L. (2014). Effective charge separation in the rutile TiO 2 nanorodcoupled $\alpha-\mathrm{Fe}_{2} \mathrm{O}_{3}$ with exceptionally high visible activities. Scientific Reports, 4, 6180.

Lucas, S., Ferreira, V., \& de Aguiar, J. B. (2013). Incorporation of titanium dioxide nanoparticles in mortarsInfluence of microstructure in the hardened state properties and photocatalytic activity. Cement and Concrete Research, 43, 112-120.

M Oymak, M., \& Uner, D. (2013). Patents on photocatalyst incorporated cement based materials. Recent Patents on Catalysis, 2(2), 116-129.

Ma, Y., \& Yao, J. (1999). Comparison of photodegradative rate of rhodamine $\mathrm{B}$ assisted by two kinds of $\mathrm{TiO}_{2}$ films. Chemosphere, 38(10), 2407-2414.

Madlener, R., \& Sunak, Y. (2011). Impacts of urbanization on urban structures and energy demand: What can we learn for urban energy planning and urbanization management? Sustainable Cities and Society, 1(1), 45-53. 
Maggos, T., Bartzis, J., Leva, P., \& Kotzias, D. (2007). Application of photocatalytic technology for $\mathrm{NO}_{\mathrm{x}}$ removal. Applied Physics A, 89(1), 81-84.

Maggos, T., Plassais, A., Bartzis, J., Vasilakos, C., Moussiopoulos, N., \& Bonafous, L. (2008). Photocatalytic degradation of $\mathrm{NOx}$ in a pilot street canyon configuration using $\mathrm{TiO}_{2}$-mortar panels. Environmental Monitoring and Assessment, 136(1-3), 35-44.

MAGRAMA. (2013). Plan nacional de calidad del aire y protección de la atmósfera 2013-2016. Plan AIRE.

Malato, S., Fernández-Ibáñez, P., Maldonado, M. I., Blanco, J., \& Gernjak, W. (2009). Decontamination and disinfection of water by solar photocatalysis: Recent overview and trends. Catalysis Today, 147(1), 1-59.

Martinez, T., Bertron, A., Ringot, E., \& Escadeillas, G. (2011). Degradation of NO using photocatalytic coatings applied to different substrates. Building and Environment, 46(9), 1808-1816.

Martuzzi, M., Galassi, C., Forastiere, F., \& Bertollini, R. (2002). Health impact assessment of air pollution in the eight major italian cities. Health impact assessment of air pollution in the eight major italian cities () OMS.

Matsumoto, Y. (1996). Energy positions of oxide semiconductors and photocatalysis with iron complex oxides. Journal of Solid State Chemistry, 126(2), 227-234.

Maury-Ramirez, A., Demeestere, K., \& De Belie, N. (2012). Photocatalytic activity of titanium dioxide nanoparticle coatings applied on autoclaved aerated concrete: Effect of weathering on coating physical characteristics and gaseous toluene removal. Journal of Hazardous Materials, 211, 218-225.

McGwin Jr, G., Lienert, J., \& Kennedy Jr, J. I. (2010). Formaldehyde exposure and asthma in children: A systematic review. Environmental Health Perspectives, 118(3), 313.

Meinhold, G. (2010). Rutile and its applications in earth sciences. Earth-Science Reviews, 102(1), 1-28.

Milani, R., Bertani, R., Cona, A., Fiorentin, P., Garau, G., Maragno, C., \& Paparella, R. (2009). Photocatalytic building products: Innovation and experimentations. Proc.of: SASBE2009 PROCEEDINGS.DEN HAAG: CIPData Koninklijke Bibliotheek,

Miller, W. A., Parker, D., \& Akbari, H. (2004). Painted metal roofs are energy-efficient, durable and sustainable. Performance of Exterior Envelopes of Whole Buildings, IX International Conference, Clearwater, FL,

Mills, A., Lee, S., \& Lepre, A. (2003). Photodecomposition of ozone sensitised by a film of titanium dioxide on glass. Journal of Photochemistry and Photobiology A: Chemistry, 155(1), 199-205.

Mills, G., \& Harmens, H. (2011). Ozone pollution: A hidden threat to food security NERC/Centre for Ecology \& Hydrology.

Mirzaei, P. A., \& Haghighat, F. (2010). Approaches to study urban heat island-abilities and limitations. Building and Environment, 45(10), 2192-2201.

Mitsuda, T., \& Taylor, H. (1978). Normal and anomalous tobermorites. Mineral.Mag, 42(322), 229-235. 
Mori, T., Suzuki, J., Fujimoto, K., Watanabe, M., \& Hasegawa, Y. (1999). Reductive decomposition of nitrate ion to nitrogen in water on a unique hollandite photocatalyst. Applied Catalysis B: Environmental, 23(4), 283-289.

Muilwijk, C., Schrijvers, P., Wuerz, S., \& Kenjereš, S. (2016). Simulations of photochemical smog formation in complex urban areas. Atmospheric Environment, 147, 470-484.

Murakami, M., Matsumoto, Y., Nakajima, K., Makino, T., Segawa, Y., Chikyow, T., . .. Koinuma, H. (2001). Anatase $\mathrm{TiO}_{2}$ thin films grown on lattice-matched $\mathrm{LaAlO} 3$ substrate by laser molecular-beam epitaxy. Applied Physics Letters, 78(18), 2664-2666.

Murray, J., \& Wriedt, H. (1987). The O- ti (oxygen-titanium) system. Journal of Phase Equilibria, 8(2), 148-165.

Nägele, E. (1985). The zeta-potential of cement. Cement and Concrete Research, 15(3), 453-462.

Nakato, Y., Tsumura, A., \& Tsubomura, H. (1983). Photo-and electroluminescence spectra from an n-TiO semiconductor electrode as related to the intermediates of the photoxidation reaction of water. J.Phys. Chem.;(United States), 87(13)

Navrotsky, A., Jamieson, J. C., \& Kleppa, O. J. (1967). Enthalpy of transformation of a high-pressure polymorph of titanium dioxide to the rutile modification. Science (New York, N.Y.), 158(3799), 388-389. doi:158/3799/388 [pii]

Nazari, A., \& Riahi, S. (2011). The effects of $\mathrm{TiO}_{2}$ nanoparticles on flexural damage of self-compacting concrete. International Journal of Damage Mechanics, 20(7), 1049-1072.

Nazari, A., \& Riahi, S. (2011). $\mathrm{TiO}_{2}$ nanoparticles effects on physical, thermal and mechanical properties of self compacting concrete with ground granulated blast furnace slag as binder. Energy and Buildings, 43(4), 995 1002.

Nazari, A., Riahi, S., Riahi, S., Shamekhi, S. F., \& Khademno, A. (2010). Improvement the mechanical properties of the cementitious composite by using $\mathrm{TiO}_{2}$ nanoparticles. Journal of American Science, 6(4), 98-101.

OECD. (2016). Air pollution to cause 6-9 million premature deaths and cost $1 \%$ GDP by 2060 . Retrieved from https://www.oecd.org/environment/air-pollution-to-cause-6-9-million-premature-deaths-and-cost-1-gdpby-2060.htm

OECD. (2016). OECD POLICY HIGHLIGHTS. the economic consequences of outdoor air pollution. doi:10.1787/9789264257474-en Ohama, Y., \& Van Gemert, D. (2011). Application of titanium dioxide photocatalysis to construction materials: State-of-the-art report of the RILEM technical committee 194-TDP Springer Science \& Business Media.

Ohno, T., Sarukawa, K., \& Matsumura, M. (2001). Photocatalytic activities of pure rutile particles isolated from $\mathrm{TiO} 2$ powder by dissolving the anatase component in HF solution. The Journal of Physical Chemistry B, 105(12), 2417-2420.

Ohtani, B., Zhang, S., Nishimoto, S., \& Kagiya, T. (1992). Catalytic and photocatalytic decomposition of ozone at room temperature over titanium (IV) oxide. Journal of the Chemical Society, Faraday Transactions, 88(7), 1049-1053. 
Oke, T. (1987). Boundary layer climates. 2nd. Methuen, 289p, OMS. (Septiembre 2016). Calidad del aire ambiente (exterior) y salud. nota descriptiva. Retrieved from http://www.who.int/mediacentre/factsheets/fs313/es/

Organisation mondiale de la santé. Bureau régional de l'Europe, \& Martuzzi, M. (2006). Health impact of PM 10 and ozone in 13 italian cities WHO Regional Office for Europe.

Organización Mundial de la Salud. (2006). Guías de calidad del aire de la OMS relativas al material particulado, el ozono, el dióxido de nitrógeno y el dióxido de azufre: Actualización mundial 2005. Resumen de evaluación de los riesgos.

Pacheco-Torgal, F. (2014). Eco-efficient construction and building materials research under the EU framework programme horizon 2020. Construction and Building Materials, 51, 151-162.

Pacheco-Torgal, F., \& Jalali, S. (2011). Nanotechnology: Advantages and drawbacks in the field of construction and building materials. Construction and Building Materials, 25(2), 582-590.

Panesar, D., \& Churchill, C. (2013). The influence of design variables and environmental factors on life-cycle cost assessment of concrete culverts. Structure and Infrastructure Engineering, 9(3), 201-213.

Pascal, M., Corso, M., Chanel, O., Declercq, C., Badaloni, C., Cesaroni, G., . . Martin-Olmedo, P. (2013). Assessing the public health impacts of urban air pollution in 25 european cities: Results of the aphekom project. Science of the Total Environment, 449, 390-400.

Paz, Y. (2010). Application of $\mathrm{TiO}_{2}$ photocatalysis for air treatment: Patents' overview. Applied Catalysis B: Environmental, 99(3), 448-460.

Pelizzetti, E., \& Serpone, N. (2012). Homogeneous and heterogeneous photocatalysis Springer Science \& Business Media.

Pérez, L., Sunyer, J., \& Künzli, N. (2009). Estimating the health and economic benefits associated with reducing air pollution in the barcelona metropolitan area (spain). Gaceta Sanitaria, 23(4), 287-294.

Pérez-Lombard, L., Ortiz, J., \& Pout, C. (2008). A review on buildings energy consumption information. Energy and Buildings, 40(3), 394-398.

Petrie, T., Atchley, J., Childs, P., \& Desjarlais, A. (2001). Effect of solar radiation control on energy costs: A radiation control fact sheet. Proceedings on CD of the Performance of the Exterior Envelopes of Whole Buildings VIII: Integrating Building Envelopes,

Photopaq. (2017). PHOTOPaq demonstration of photocatalytic remediation processes on air quality. Retrieved from http://photopaq.ircelyon.univ-lyon1.fr/

Picada. (2005). Picada project. Retrieved from http://www.picada-project.com/domino/SitePicada/Picada. nsf? OpenDataBase

Pichat, P., \& Herrmann, J. (1989). Photocatalysis: Fundamentals and applications. Wiley \& Sons.

Polonio, J. B. (1967). Teoría y práctica de la espectroscopia de rayos X Alhambra. 
Poon, C. S., \& Cheung, E. (2006). Performance of photo-catalytic paving blocks made from waste. Proceedings of the Institution of Civil Engineers-Waste and Resource Management, 159(4) 165-171.

Poon, C., \& Cheung, E. (2007). NO removal efficiency of photocatalytic paving blocks prepared with recycled materials. Construction and Building Materials, 21(8), 1746-1753.

Pope III, C. A., \& Dockery, D. W. (2006). Health effects of fine particulate air pollution: Lines that connect. Journal of the Air \& Waste Management Association, 56(6), 709-742.

Quagliarini, E., Bondioli, F., Goffredo, G. B., Licciulli, A., \& Munafò, P. (2012). Smart surfaces for architectural heritage: Preliminary results about the application of $\mathrm{TiO}_{2}$-based coatings on travertine. Journal of Cultural Heritage, 13(2), 204-209.

Rachel, A., Subrahmanyam, M., \& Boule, P. (2002). Comparison of photocatalytic efficiencies of $\mathrm{TiO}_{2}$ in suspended and immobilised form for the photocatalytic degradation of nitrobenzenesulfonic acids. Applied Catalysis B: Environmental, 37(4), 301-308.

Rajagopal, G., Maruthamuthu, S., Mohanan, S., \& Palaniswamy, N. (2006). Biocidal effects of photocatalytic semiconductor $\mathrm{TiO}_{2}$. Colloids and Surfaces B: Biointerfaces, 51(2), 107-111.

Ramirez, A. M., \& De Belie, N. (2009). Evaluation of the algaecide activity of titanium dioxide on autoclaved aerated concrete. Journal of Advanced Oxidation Technologies, 12(1), 100-104.

Ramirez, A. M., Demeestere, K., De Belie, N., Mäntylä, T., \& Levänen, E. (2010). Titanium dioxide coated cementitious materials for air purifying purposes: Preparation, characterization and toluene removal potential. Building and Environment, 45(4), 832-838.

Roadmap, E. E. (2011). 2050-com (2011) 885/2. Brussels: European Commission.

Roetzel, A., \& Tsangrassoulis, A. (2012). Impact of climate change on comfort and energy performance in offices. Building and Environment, 57, 349-361.

Rosenfeld, A. H., Akbari, H., Bretz, S., Fishman, B. L., Kurn, D. M., Sailor, D., \& Taha, H. (1995). Mitigation of urban heat islands: Materials, utility programs, updates. Energy and Buildings, 22(3), 255-265.

Rosenfeld, A. H., Akbari, H., Romm, J. J., \& Pomerantz, M. (1998). Cool communities: Strategies for heat island mitigation and smog reduction. Energy and Buildings, 28(1), 51-62.

Rosenfeld, A. H., Romm, J. J., Akbari, H., Pomerantz, M., \& Taha, H. (1996). Policies to reduce heat islands: Magnitudes of benefits and incentives to achieve them. Proceedings of the 1996 ACEEE Summer Study on Energy Efficiency in Buildings, 9177.

Ruot, B., Plassais, A., Olive, F., Guillot, L., \& Bonafous, L. (2009). $\mathrm{TiO}_{2}$-containing cement pastes and mortars: Measurements of the photocatalytic efficiency using a rhodamine B-based colourimetric test. Solar Energy, 83(10), 1794-1801.

Santamouris, M., Synnefa, A., Kolokotsa, D., Dimitriou, V., \& Apostolakis, K. (2008). Passive cooling of the built environment-use of innovative reflective materials to fight heat islands and decrease cooling needs. International Journal of Low-Carbon Technologies, 3(2), 71-82. 
Santamouris, M. (2007). Heat island research in europe: The state of the art. Advances in Building Energy Research, 1(1), 123-150.

Santamouris, M. (2009). Group building environmental studies, physics department, university of athens athens, greece. Green Cities, , 108.

Santamouris, M., Papanikolaou, N., Livada, I., Koronakis, I., Georgakis, C., Argiriou, A., \& Assimakopoulos, D. (2001). On the impact of urban climate on the energy consumption of buildings. Solar Energy, 70(3), 201-216.

Sapiña, M., Jimenez-Relinque, E., \& Castellote, M. (2013). Controlling the levels of airborne pollen: Can heterogeneous photocatalysis help? Environmental Science \& Technology, 47(20), 11711-11716.

Satterfield, C. N. (1991). Heterogeneous catalysis in industrial practice.

Satterthwaite, D. (2008). Cities' contribution to global warming: Notes on the allocation of greenhouse gas emissions. Environment and Urbanization, 20(2), 539-549.

SCHER-Scientific Committee on Health Environmental Risks. (2005). Opinion on "New evidence of air pollution effects on human health and the environment" european commission, health and consumer protection directorate", 1-15; 2005. (). European Commission.

Screpanti, A., \& De Marco, A. (2009). Corrosion on cultural heritage buildings in italy: A role for ozone? Environmental Pollution, 157(5), 1513-1520.

Seabra, M., Pires, R., \& Labrincha, J. (2011). Ceramic tiles for photodegradation of orange II solutions. Chemical Engineering Journal, 171(2), 692-702.

Sekiya, T., Igarashi, M., Kurita, S., Takekawa, S., \& Fujisawa, M. (1998). Structure dependence of reflection spectra of $\mathrm{TiO}_{2}$ single crystals. Journal of Electron Spectroscopy and Related Phenomena, 92(1), 247-250.

Senff, L., Hotza, D., Lucas, S., Ferreira, V., \& Labrincha, J. (2012). Effect of nano-SiO 2 and nano-TiO addition on the rheological behavior and the hardened properties of cement mortars. Materials Science and Engineering: A, 532, 354-361.

Serpone, N., \& Emeline, A. (2005). Modelling heterogeneous photocatalysis by metal-oxide nanostructured semiconductor and insulator materials: Factors that affect the activity and selectivity of photocatalysts. Research on Chemical Intermediates, 31(4), 391-432.

Serpone, N., \& Pelizzetti, E. (1989). Photocatalysis: Fundamentals and applications.

Shekari, A., \& Razzaghi, M. (2011). Influence of nano particles on durability and mechanical properties of high performance concrete. Procedia Engineering, 14, 3036-3041.

Sigma Aldrich. (2017). Rhodamine B base. Retrieved from http://www.sigmaaldrich.com/catalog/ product/aldrich/234141?lang=es\&region $=E S \&$ gclid $=C_{j w K E A j w 3 K D I B R C z O K v Z I J 7 k 4 T g S J A B D q O K 7 J z_{-}}$ rCbyBkeO9Fcl31f6T1PViJ9Ja14wvz9DIvP5QfRoCvKrw_wcB

Simpson, J., \& McPherson, E. (1997). The effects of roof albedo modification on cooling loads of scale model residences in tucson, arizona. Energy and Buildings, 25(2), 127-137. 
Skalny, J., Jawed, I., \& Taylor, H. (1978). Hydration of cement--recent developments. World Cement Technology, 9(6), 183-186.

Sleiman, M., Conchon, P., Ferronato, C., \& Chovelon, J. (2007). lodosulfuron degradation by TiO 2 photocatalysis: Kinetic and reactional pathway investigations. Applied Catalysis B: Environmental, 71(3), 279-290.

Smits, M., kit Chan, C., Tytgat, T., Craeye, B., Costarramone, N., Lacombe, S., \& Lenaerts, S. (2013). Photocatalytic degradation of soot deposition: Self-cleaning effect on titanium dioxide coated cementitious materials. Chemical Engineering Journal, 222, 411-418.

Smits, M., Vanpachtenbeke, F., Horemans, B., De Wael, K., Hauchecorne, B., Van Langenhove, H., ... Lenaerts, S. (2012). Effect of operating and sampling conditions on the exhaust gas composition of small-scale power generators. PloS One, 7(3), e32825.

Sobrino, J., SÒRIA, G., OLTRA-CARRIÓ, R., \& JIMÉNEZ-MUÑOZ, J. (2009). DESIREX 2008: Urban heat island analysis in the city of madrid. Revista De Teledetección, 31, 80-92.

Standard, A. (2012). G173-03 (reapproved 2012), standard tables for reference solar spectral irradiances: Direct normal and hemispherical on 37 tilted surface. West Conshohocken, PA: ASTM International,

Strini, A., Cassese, S., \& Schiavi, L. (2005). Measurement of benzene, toluene, ethylbenzene and o-xylene gas phase photodegradation by titanium dioxide dispersed in cementitious materials using a mixed flow reactor. Applied Catalysis B: Environmental, 61(1), 90-97.

Suárez-Cervera, M., Castells, T., Vega-Maray, A., Civantos, E., del Pozo, V., Fernández-González, D., ... Lahoz, C. (2008). Effects of air pollution on cup a 3 allergen in cupressus arizonica pollen grains. Annals of Allergy, Asthma \& Immunology, 101(1), 57-66.

Sugráñez Pérez, R. (2016). Nuevos materiales de construcción con propiedades auto-limpiantes y autodescontaminantes.

Sugrañez, R., Álvarez, J., Cruz-Yusta, M., Mármol, I., Morales, J., Vila, J., \& Sánchez, L. (2013). Enhanced photocatalytic degradation of $\mathrm{NO} \times$ gases by regulating the microstructure of mortar cement modified with titanium dioxide. Building and Environment, 69, 55-63.

Suh, H. H., Bahadori, T., Vallarino, J., \& Spengler, J. D. (2000). Criteria air pollutants and toxic air pollutants. Environmental Health Perspectives, 108 Suppl 4, 625-633. doi:sc271_5_1835 [pii]

Sun, Q., Leng, W., Li, Z., \& Xu, Y. (2012). Effect of surface Fe2O3 clusters on the photocatalytic activity of TiO 2 for phenol degradation in water. Journal of Hazardous Materials, 229, 224-232.

Synnefa, A., Saliari, M., \& Santamouris, M. (2012). Experimental and numerical assessment of the impact of increased roof reflectance on a school building in athens. Energy and Buildings, 55, 7-15.

Synnefa, A., Santamouris, M., \& Akbari, H. (2007). Estimating the effect of using cool coatings on energy loads and thermal comfort in residential buildings in various climatic conditions. Energy and Buildings, 39(11), 1167-1174. 
Synnefa, A., Santamouris, M., \& Livada, I. (2006). A study of the thermal performance of reflective coatings for the urban environment. Solar Energy, 80(8), 968-981.

Synnefa, A., Santamouris, M., \& Apostolakis, K. (2007). On the development, optical properties and thermal performance of cool colored coatings for the urban environment. Solar Energy, 81(4), 488-497.

Taha, H. (1997). Urban climates and heat islands: Albedo, evapotranspiration, and anthropogenic heat. Energy and Buildings, 25(2), 99-103.

Taha, H., Sailor, D., \& Akbari, H. (1992). High-Albedo Materials for Reducing Building Cooling Energy use,

Taniguchi, N. (1974). Japan society of precision engineering. On the Basic Concept of Nanotechnology: Proc. Intl. Conf. Prod. Eng. Tokyo.-1974.-Pt, , 2 122-126.

Taylor, A. H. (1920). Measurement of diffuse reflection factors: And a new absolute reflectometer US Government Printing Office.

Taylor, H. F., Rossi, F. R., Martínez, J. A. F., \& Montemayor, M. (1978). La química de los cementos Urmo, SA de Ediciones.

Taylor, J., Hanson, A., Clarke, P., Campos, J., Pons, A., Czepluch, W., ... Soares, O. (2000). Good practice guide to surface colour measurement. Publicación Europea SMT4-CT96-2140 EUR 19552EN,

Tidblad, J. (2016). Convention on long-range transboundary air pollution international co-operative programme on effects on materials, including historic and cultural monuments.technical manual for the trend exposure programme 2011-2015. ( No. 79). Sweden: Swerea KIMAB AB.

Tidblad, J. (2012). Atmospheric corrosion of metals in 2010-2039 and 2070-2099. Atmospheric Environment, $55,1-6$.

Tobias, A., Galan, I., Banegas, J. R., \& Aranguez, E. (2003). Short term effects of airborne pollen concentrations on asthma epidemic. Thorax, 58(8), 708-710.

Tseng, Y., \& Kuo, C. (2011). Photocatalytic degradation of dye and $\mathrm{NO} x$ using visible-light-responsive carboncontaining TiO 2. Catalysis Today, 174(1), 114-120.

Tumini, I. (2010). Estrategias para reducción del efecto isla de calor en los espacios urbanos. estudio aplicado al caso de madrid. Ponencia SB10 MAd, Edificación Sostenible, Revitalización y Rehabilitación De Barrios.Madrid, España,

UNE EN.197-1:2011 cemento. parte 1: Composición, especificaciones y criterios de conformidad de los cementos comunes.

UNE EN.80305:2012. cementos blancos.

UNE-EN.1015-11:2000/A1:2007 .métodos de ensayo de los morteros para albañilería. parte 11: Determinación de la resistencia a flexión y a compresión del mortero endurecido. 
UNE-EN.1015-2:1999/A1:2007. métodos de ensayo de los morteros para albañilería. parte 2: Toma de muestra total de morteros y preparación de los morteros para ensayo.

UNE-EN.1015-3:2000. métodos de ensayo para morteros de albañilería. parte 3: Determinación de la consistencia del mortero fresco (por la mesa de sacudidas.

UNE-EN.1015-6:1999/A1:2007. métodos de ensayo de los morteros para albañilería. parte 6: Determinación de la densidad aparente del mortero fresco.

UNE-EN.1015-7:1999.métodos de ensayo de los morteros para albañilería. parte 7: Determinación del contenido en aire en el mortero fresco.

UNE-EN.12504-4:2006 ensayos de hormigón en estructuras. parte 4: Determinación de la velocidad de los impulsos ultrasónicos.

UNE-EN.196-1: 2005. métodos de ensayo de cementos. parte 1: Determinación de resistencias mecánicas. UNE-EN.998-1: 2010 especificaciones de los morteros para albañilería.parte 1: Morteros para revoco y enlucido.

UNI 11259:2008 Determination Of The Photocatalytic Activity Of Hydraulic Binders - Rodammina Test Method. (2008).

Determination of the Catalytic Degradation of Nitrogen Oxides in the Air by inorganic photocatalytic Materials: Continuous Flow Test Method. (2010).

Vallee, F., Ruot, B., Bonafous, L., Guillot, L., Pimpinelli, N., Cassar, L., . . Gobin, C. (2004). Cementitious materials for self-cleaning and de-polluting facade surfaces. RILEM International Symposium on EnvironmentConscious Materials and Systems for Sustainable Development, 337-346.

van Broekhuizen, F., \& van Broekhuizen, P. (2009). Nano-products in the european construction industry. European Federation of Building and Wood Workers and European Construction Industry Federation,

Van Broekhuizen, P., van Broekhuizen, F., Cornelissen, R., \& Reijnders, L. (2011). Use of nanomaterials in the european construction industry and some occupational health aspects thereof. Journal of Nanoparticle Research, 13(2), 447-462.

Van Oss, H. (2009). US Geological Survey (USGS) Mineral Commodity Summaries: Cement,

Vinu, R., \& Madras, G. (2012). Environmental remediation by photocatalysis. Journal of the Indian Institute of Science, 90(2), 189-230.

Virta, R. L. (2002). US Geological Survey Minerals Yearbook-2002,

Wang, R., Hashimoto, K., Fujishima, A., Chikuni, M., Kojima, E., Kitamura, A., . . Watanabe, T. (1997). Lightinduced amphiphilic surfaces. Nature, 388(6641), 431.

Wang, R., Hashimoto, K., Fujishima, A., Chikuni, M., Kojima, E., Kitamura, A., . . . Watanabe, T. (1998). Photogeneration of highly amphiphilic $\mathrm{TiO}_{2}$ surfaces. Advanced Materials, 10(2), 135-138. 
WHO. (2011). New WHO database shows poor air quality in cities. Retrieved from http://www.euro.who.int/ en/data-and-evidence/environment-and-health-information-system-enhis/news/news/2011/09/new-who-databaseshows-poor-air-quality-in-cities

WHO Regional Office for Europe. (2013). doi:NBK361805 [bookaccession]

WHO Regional Office for Europe. (2013). Review of evidence on health aspects of air pollution - REVIHAAP” project: Final technical report. (). Copenhagen:

Wong, E. (2002). The US environmental protection Agency's heat island reduction initiative (HIRI): Status and future directions. US Environmental Protection Agency, , 1-11.

Wong, E., Akbari, H., Bell, R., \& Cole, D. (2011). Reducing urban heat islands: Compendium of strategies. Environmental Protection Agency, Retrieved may, 12, 2011.

World Bank and Institute for Health Metrics and Evaluation. (2016).

World bank and institute for health metrics and evaluation. 2016. The cost of air pollution: Strengthening the economic case for action. Washington, DC: World bank. license: Creative commons attribution CC BY 3.O IGO

World Health Organization.Air quality guidelines for europe. copenhagen: World health organization regional office for europe.

World Health Organization. (2006). WHO air quality guidelines for particulate matter, ozone, nitrogen dioxide and sulfur dioxide-global update 2005-summary of risk assessment, 2006. Geneva: WHO,

World Health Organization. (2009). Global health risks: Mortality and burden of disease attributable to selected major risks World Health Organization.

World Health Organization. (2015). Economic cost of the health impact of air pollution in europe: Clean air, health and wealth. WHO Regional Office for Europe, Copenhagen,

World Health Organization. (2016). Ambient air pollution: A global assessment of exposure and burden of disease. Ambient air pollution: A global assessment of exposure and burden of disease ()

World Health Organization Regional Office for Europe. (2006). Air quality guidelines for europe, 2000. global update 2005. 2nd Ed., 91

Xia, Y., \& Yin, L. (2013). Core-shell structured $\alpha-\mathrm{Fe}_{2} \mathrm{O}_{3} @ \mathrm{TiO}_{2}$ nanocomposites with improved photocatalytic activity in the visible light region. Physical Chemistry Chemical Physics, 15(42), 18627-18634.

Xiang, Q., Yu, J., \& Wong, P. K. (2011). Quantitative characterization of hydroxyl radicals produced by various photocatalysts. Journal of Colloid and Interface Science, 357(1), 163-167.

Xu, A., Gao, Y., \& Liu, H. (2002). The preparation, characterization, and their photocatalytic activities of rareearth-doped TiO2 nanoparticles. Journal of Catalysis, 207(2), 151-157.

Xu, X., Ji, F., Fan, Z., \& He, L. (2011). Degradation of glyphosate in soil photocatalyzed by Fe3O4/SiO2/TiO2 under solar light. International Journal of Environmental Research and Public Health, 8(4), 1258-1270. 
Yan, H., Wang, X., Yao, M., \& Yao, X. (2013). Band structure design of semiconductors for enhanced photocatalytic activity: The case of $\mathrm{TiO}_{2}$. Progress in Natural Science: Materials International, 23(4), 402-407.

Yang, X., \& Tamai, N. (2001). How fast is interfacial hole transfer? in situ monitoring of carrier dynamics in anatase $\mathrm{TiO}_{2}$ nanoparticles by femtosecond laser spectroscopy. Physical Chemistry Chemical Physics, 3(16), 3393-3398.

$\mathrm{Yu}, \mathrm{C}$. (2003). Deactivation and regeneration of environmentally exposed titanium dioxide $\left(\mathrm{TiO}_{2}\right)$ based products Department of Chemistry, Chinese University of Hong Kong.

Yu, Y., Pan, Y., Wu, Y., Lasek, J., \& Wu, J. C. (2011). Photocatalytic NO reduction with $\mathrm{C}_{3} \mathrm{H}_{8}$ using a monolith photoreactor. Catalysis Today, 174(1), 141-147.

Yuranova, T., Sarria, V., Jardim, W., Rengifo, J., Pulgarin, C., Trabesinger, G., \& Kiwi, J. (2007). Photocatalytic discoloration of organic compounds on outdoor building cement panels modified by photoactive coatings. Journal of Photochemistry and Photobiology A: Chemistry, 188(2), 334-341.

Zeitner, W. A., \& Tompkins, D. T. (2005). Shedding light on photocatalysis. ASHRAE Transactions, 111(2)

Zeta-Meter, I. (1997). Zeta-potential: A complete course in 5 minutes. Zeta-Meter Inc, , 1-8.

Zhang, H., \& Banfield, J. F. (2000). Understanding polymorphic phase transformation behavior during growth of nanocrystalline aggregates: Insights from $\mathrm{TiO}_{2}$. The Journal of Physical Chemistry B, 104(15), 3481-3487.

Zhang, M., \& Li, H. (2011). Pore structure and chloride permeability of concrete containing nano-particles for pavement. Construction and Building Materials, 25(2), 608-616.

Zhang, M., Tanadi, D., \& Li, W. (2010). Effect on photocatalyst $\mathrm{TiO}_{2}$ on workability, strength and self-cleaning efficiency of mortars for applications in tropical environment. 35th Conference on our World in Concrete \& Structures,

Zhao, J., \& Yang, X. (2003). Photocatalytic oxidation for indoor air purification: A literature review. Building and Environment, 38(5), 645-654.

Zhaoliang, Z., Jun, M., \& Xiyao, Y. (2003). Separate/simultaneous catalytic reduction of sulfur dioxide and/or nitric oxide by carbon monoxide over $\mathrm{TiO}_{2}$-promoted cobalt sulfides. Journal of Molecular Catalysis A: Chemical, 195(1), 189-200. 
INFLUENCIA DEL COLOR Y ELACABADO SUPERFICIALENLASPROPIEDADES DE UN MORTERO FOTOCATALITICO COMO SOLUCIÓN DE ENVOLVENTE 
CAPITTLO 13: ANEXOS

CAPITULO13:

ANEXOS 
INFLUENCIA DEL COLOR Y ELACABADO SUPERFICIALEN LAS PROPIEDADES DE UN MORTERO FOTOCATALITICO COMO SOLUCIÓN DE ENVOLVENTE 


\section{3 . 1. ENSAYOS REALIZADOS}

Serie probetas 1 Mortero no fotocatalítico

\begin{tabular}{|c|c|c|c|c|}
\hline Probeta & 1 & 2 & 3 & 4 \\
\hline Peso probeta (g) & 180 & 186 & 181 & 182 \\
\hline Consistencia mortero (mm) UNE-EN 1015-3 & \multicolumn{4}{|c|}{$114 / 112-108 / 108$} \\
\hline \multirow{3}{*}{$a^{*}(0 h):$ datos individuales } & 15,51 & 13,91 & 13,97 & 15,76 \\
\hline & 14,56 & 14,16 & 14,21 & 14,83 \\
\hline & 14,44 & 14,92 & 13,94 & 15,05 \\
\hline Promedio & 14,84 & 14,33 & 14,04 & 15,21 \\
\hline \multirow{3}{*}{$a^{*}(4 h):$ datos individuales } & 14,32 & 13,42 & 14,23 & 14,40 \\
\hline & 14,54 & 13,87 & 14,04 & 15,20 \\
\hline & 13,77 & 13,92 & 13,29 & 15,32 \\
\hline Promedio & 14,21 & 13,74 & 13,85 & 14,97 \\
\hline \multirow{3}{*}{$a^{*}(26 h)$ : datos individuales } & 11,88 & 12,18 & 12,74 & 13,00 \\
\hline & 12,50 & 11,70 & 12,25 & 12,83 \\
\hline & 12,35 & 12,39 & 12,22 & 12,77 \\
\hline Promedio & 12,24 & 12,09 & 12,40 & 12,87 \\
\hline \multirow{2}{*}{$\begin{array}{l}\text { Humedad }(\% \mathrm{RH}) \\
\text { Temperatura }\left({ }^{\circ} \mathrm{C}\right)\end{array}$} & 60 & 60 & 60 & 60 \\
\hline & 20 & 20 & 20 & 20 \\
\hline \multirow{2}{*}{$\begin{array}{l}\text { Iluminación }\left(\mu \mathrm{W} / \mathrm{cm}^{2}\right) \\
\text { Área coloreada }\left(\mathrm{cm}^{2}\right)\end{array}$} & 388 & 352 & 388 & 352 \\
\hline & 22 & 22 & 22 & 22 \\
\hline Fecha de la prueba & $27 / 08 / 2009$ & $27 / 08 / 2009$ & $27 / 08 / 2009$ & $27 / 08 / 2009$ \\
\hline \multirow{2}{*}{$\begin{array}{l}R_{4}(\%) \\
\text { Media de la } \pm 10 \%\end{array}$} & 4 & 4 & 1 & 2 \\
\hline & \multicolumn{4}{|l|}{$3 \pm 0(3-3)$} \\
\hline \multirow{2}{*}{$\begin{array}{l}\text { ¿Descartado? } \\
\text { Coeficiente de variación (\%) }\end{array}$} & Sí & Sí & Sí & Sí \\
\hline & \multicolumn{4}{|l|}{49} \\
\hline \multirow{2}{*}{$\begin{array}{l}R_{4}(\%) \\
\text { Media de la } \pm 10 \%\end{array}$} & 4 & 4 & & 2 \\
\hline & \multicolumn{4}{|l|}{$3 \pm 0(3-3)$} \\
\hline \multirow{2}{*}{$\begin{array}{l}\text { ¿Descartado? } \\
\text { Coeficiente de variación (\%) }\end{array}$} & sí & Sí & & Sí \\
\hline & \multicolumn{4}{|l|}{37} \\
\hline \multirow{2}{*}{$\begin{array}{l}R_{26}(\%) \\
\text { Media de la } \pm 10 \%\end{array}$} & 17 & 16 & 12 & 15 \\
\hline & \multicolumn{4}{|c|}{$15 \pm 2(13-17)$} \\
\hline \multirow{2}{*}{$\begin{array}{l}\text { ¿Descartado? } \\
\text { Coeficiente de variación }(\%)\end{array}$} & NO & NO & Sí & NO \\
\hline & \multicolumn{4}{|l|}{14} \\
\hline \multirow{5}{*}{$\begin{array}{l}R_{26}(\%) \\
\text { Media de la } \pm 10 \% \\
\text { ¿Descartado? } \\
\text { Coeficiente de variación }(\%) \\
\text { Resultado }\end{array}$} & 17 & 16 & & 15 \\
\hline & \multicolumn{4}{|c|}{$16 \pm 2(14-18)$} \\
\hline & NO & NO & & NO \\
\hline & \multicolumn{4}{|l|}{6} \\
\hline & \multicolumn{4}{|c|}{ Toda la serie descartable según UNI 11259} \\
\hline
\end{tabular}

Tabla. Detalles concretos del procedimiento experimental, así como los resultados obtenidos para las muestras denominadas Mortero no Fotocatalítico. 
Serie probetas 2 Mortero fotocatalítico sin aditivos

\begin{tabular}{|c|c|c|c|c|}
\hline Probeta & 1 & 2 & 3 & 4 \\
\hline Peso probeta $(\mathrm{g})$ & 188 & 180 & 171 & 176 \\
\hline Consistencia mortero (mm) UNE-EN 1015-3 & \multicolumn{4}{|c|}{$128 / 128-127 / 127$} \\
\hline \multirow{3}{*}{$a^{*}(0 h):$ datos individuales } & 15,29 & 13,92 & 14,91 & 14,62 \\
\hline & 15,24 & 15,88 & 16,78 & 13,36 \\
\hline & 15,61 & 14,21 & 14,07 & 12,96 \\
\hline Promedio & 15,38 & 14,67 & 15,25 & 13,65 \\
\hline \multirow{3}{*}{$a^{*}(4 h):$ datos individuales } & 7,41 & 7,24 & 6,64 & 6,95 \\
\hline & 8,95 & 8,06 & 6,05 & 8,17 \\
\hline & 8,51 & 8,09 & 7,70 & 7,92 \\
\hline Promedio & 8,29 & 7,80 & 6,80 & 7,68 \\
\hline \multirow{3}{*}{$a^{*}(26 h):$ datos individuales } & 3,90 & 3,86 & 3,06 & 3,69 \\
\hline & 3,93 & 3,52 & 3,32 & 3,78 \\
\hline & 4,06 & 3,77 & 3,45 & 3,90 \\
\hline Promedio & 3,96 & 3,72 & 3,28 & 3,79 \\
\hline \multirow{2}{*}{$\begin{array}{l}\text { Humedad }(\% \mathrm{RH}) \\
\text { Temperatura }\left({ }^{\circ} \mathrm{C}\right)\end{array}$} & 60 & 60 & 60 & 60 \\
\hline & 20 & 20 & 20 & 20 \\
\hline Iluminación $\left(\mu \mathrm{W} / \mathrm{cm}^{2}\right)$ & 391 & 364 & 378 & 375 \\
\hline Área coloreada $\left(\mathrm{cm}^{2}\right)$ & 22 & 22 & 22 & 22 \\
\hline Fecha de la prueba & $27 / 08 / 2009$ & $27 / 08 / 2009$ & $27 / 08 / 2009$ & $27 / 08 / 2009$ \\
\hline \multirow{4}{*}{$\begin{array}{l}R_{4}(\%) \\
\text { Media de la } \pm 10 \% \\
\text { ¿Descartado? } \\
\text { Coeficiente de variación }(\%)\end{array}$} & 46 & 47 & 55 & 44 \\
\hline & \multicolumn{4}{|c|}{$48 \pm 5(43-53)$} \\
\hline & NO & NO & Sí & NO \\
\hline & 9 & & & \\
\hline \multirow{4}{*}{$\begin{array}{l}R_{4}(\%) \\
\text { Media de la } \pm 10 \% \\
\text { ¿Descartado? } \\
\text { Coeficiente de variación }(\%)\end{array}$} & 46 & 47 & & 44 \\
\hline & \multicolumn{4}{|c|}{$46 \pm 5(41-51)$} \\
\hline & NO & NO & & NO \\
\hline & \multicolumn{4}{|l|}{3} \\
\hline \multirow{2}{*}{$\begin{array}{l}R_{26}(\%) \\
\text { Media de la } \pm 10 \%\end{array}$} & 74 & 75 & 79 & 72 \\
\hline & \multicolumn{4}{|c|}{$75 \pm 7(68-82)$} \\
\hline \multirow{3}{*}{$\begin{array}{l}\text { ¿Descartado? } \\
\text { Coeficiente de variación (\%) } \\
\text { Resultado }\end{array}$} & NO & NO & NO & NO \\
\hline & \multicolumn{4}{|l|}{3} \\
\hline & \multicolumn{4}{|c|}{ No se descarta los resultados según UNI 11259} \\
\hline
\end{tabular}

Tabla. Detalles concretos del procedimiento experimental, así como los resultados obtenidos para las muestras denominadas Mortero Fotocatalítico sin Aditivo. 
Serie probetas 3 $15000(0,64)$

\begin{tabular}{|c|c|c|c|c|}
\hline Probeta & 1 & 2 & 3 & 4 \\
\hline Peso probeta (g) & 132 & 129 & 129 & 125 \\
\hline Consistencia mortero (mm) UNE-EN 1015-3 & \multicolumn{4}{|c|}{$160 / 158-159 / 163$} \\
\hline \multirow{3}{*}{$a^{*}(0 h):$ datos individuales } & 7,58 & 10,55 & 9,00 & 6,54 \\
\hline & 7,47 & 9,44 & 9,59 & 6,44 \\
\hline & 7,36 & 9,24 & 9,93 & 6,22 \\
\hline Promedio & 7,47 & 9,74 & 9,51 & 6,40 \\
\hline \multirow{3}{*}{$a^{*}(4 h):$ datos individuales } & 3,94 & 3,49 & 3,84 & 2,45 \\
\hline & 4,70 & 3,22 & 4,46 & 2,89 \\
\hline & 3,99 & 4,59 & 4,54 & 2,44 \\
\hline Promedio & 4,21 & 3,77 & 4,28 & 2,59 \\
\hline \multirow{3}{*}{$a^{*}(26 h):$ datos individuales } & 1,02 & 1,55 & 1,55 & 1,01 \\
\hline & 1,18 & 1,29 & 1,56 & 1,18 \\
\hline & 1,09 & 1,36 & 1,54 & 1,21 \\
\hline Promedio & 1,10 & 1,40 & 1,55 & 1,13 \\
\hline \multirow{2}{*}{$\begin{array}{l}\text { Humedad }(\% \mathrm{RH}) \\
\text { Temperatura }\left({ }^{\circ} \mathrm{C}\right)\end{array}$} & 73 & 73 & 73 & 73 \\
\hline & 20 & 20 & 20 & 20 \\
\hline Iluminación $\left(\mu \mathrm{W} / \mathrm{cm}^{2}\right)$ & 362 & 372 & 358 & 363 \\
\hline Área coloreada $\left(\mathrm{cm}^{2}\right)$ & 22 & 22 & 22 & 22 \\
\hline Fecha de la prueba & $11 / 09 / 2008$ & $11 / 09 / 2008$ & $11 / 09 / 2008$ & $11 / 09 / 2008$ \\
\hline \multirow{2}{*}{$\begin{array}{l}R_{4}(\%) \\
\text { Media de la } \pm 10 \%\end{array}$} & 44 & 61 & 55 & 59 \\
\hline & $55 \pm 5(50$ & 60) & & \\
\hline \multirow{2}{*}{$\begin{array}{l}\text { ¿Descartado? } \\
\text { Coeficiente de variación (\%) }\end{array}$} & sí & Sí & NO & NO \\
\hline & 13 & & & \\
\hline \multirow{4}{*}{$\begin{array}{l}R_{4}(\%) \\
\text { Media de la } \pm 10 \% \\
\text { ¿Descartado? } \\
\text { Coeficiente de variación }(\%)\end{array}$} & & 61 & 55 & 59 \\
\hline & $59 \pm 6(53$ & 65) & & \\
\hline & & NO & NO & NO \\
\hline & 5 & & & \\
\hline \multirow{5}{*}{$\begin{array}{l}R_{26}(\%) \\
\text { Media de la } \pm 10 \% \\
\text { ¿Descartado? } \\
\text { Coeficiente de variación }(\%) \\
\text { Resultado }\end{array}$} & 85 & 86 & 84 & 82 \\
\hline & $84 \pm 8(76-$ & 92) & & \\
\hline & NO & NO & NO & NO \\
\hline & 2 & & & \\
\hline & No se desc & irta los resu & dos según & II 11259 \\
\hline
\end{tabular}

Tabla. Detalles concretos del procedimiento experimental, así como los resultados obtenidos para las muestras denominadas $15000(0,64)$. 
Serie probetas 4 $15000(1,42)$

\begin{tabular}{|c|c|c|c|c|}
\hline Probetas & 1 & 2 & 3 & 4 \\
\hline Peso probeta (g) & 122 & 123 & 119 & 121 \\
\hline Consistencia mortero (mm) UNE-EN 1015-3 & \multicolumn{4}{|c|}{$120 / 120-115 / 120$} \\
\hline \multirow{3}{*}{$a^{*}(0 h):$ datos individuales } & 7,36 & 7,71 & 10,05 & 9,56 \\
\hline & 7,54 & 7,43 & 10,54 & 10,19 \\
\hline & 7,08 & 8,10 & 9,93 & 10,48 \\
\hline Promedio & 7,33 & 7,75 & 10,17 & 10,08 \\
\hline \multirow{3}{*}{$a^{*}(4 h):$ datos individuales } & 4,19 & 4,49 & 8,07 & 5,40 \\
\hline & 4,75 & 4,81 & 8,64 & 4,84 \\
\hline & 7,25 & 5,52 & 8,16 & 5,88 \\
\hline Promedio & 5,40 & 4,94 & 8,29 & 5,37 \\
\hline \multirow{3}{*}{$a^{*}(26 h):$ datos individuales } & 2,57 & 2,48 & 4,75 & 2,77 \\
\hline & 2,93 & 2,52 & 5,00 & 2,22 \\
\hline & 2,64 & 2,41 & 4,54 & 3,28 \\
\hline Promedio & 2,71 & 2,47 & 4,76 & 2,76 \\
\hline \multirow{2}{*}{$\begin{array}{l}\text { Humedad }(\% \mathrm{RH}) \\
\text { Temperatura }\left({ }^{\circ} \mathrm{C}\right)\end{array}$} & 71 & 71 & 71 & 71 \\
\hline & 18 & 18 & 18 & 18 \\
\hline \multirow{2}{*}{$\begin{array}{l}\text { lluminación }\left(\mu \mathrm{W} / \mathrm{cm}^{2}\right) \\
\text { Área coloreada }\left(\mathrm{cm}^{2}\right)\end{array}$} & 380 & 355 & 362 & 372 \\
\hline & 22 & 22 & 22 & 22 \\
\hline Fecha de la prueba & $15 / 09 / 2008$ & $15 / 09 / 2008$ & $15 / 09 / 2008$ & $15 / 09 / 2008$ \\
\hline \multirow{4}{*}{$\begin{array}{l}R_{4}(\%) \\
\text { Media de la } \pm 10 \% \\
\text { ¿Descartado? } \\
\text { Coeficiente de variación }(\%)\end{array}$} & 26 & 36 & 19 & 47 \\
\hline & \multicolumn{4}{|c|}{$32 \pm 3(29-35)$} \\
\hline & sí & sí & sí & sí \\
\hline & \multicolumn{4}{|l|}{33} \\
\hline \multirow{4}{*}{$\begin{array}{l}R_{4}(\%) \\
\text { Media de la } \pm 10 \% \\
\text { ¿Descartado? } \\
\text { Coeficiente de variación }(\%)\end{array}$} & 26 & 36 & 19 & \\
\hline & \multicolumn{4}{|c|}{$27 \pm 3(24-30)$} \\
\hline & NO & sí & Sí & \\
\hline & \multicolumn{4}{|l|}{27} \\
\hline \multirow{4}{*}{$\begin{array}{l}R_{26}(\%) \\
\text { Media de la } \pm 10 \% \\
\text { ¿Descartado? } \\
\text { Coeficiente de variación }(\%)\end{array}$} & 63 & 68 & 53 & 73 \\
\hline & \multicolumn{4}{|c|}{$64 \pm 6(58-70)$} \\
\hline & NO & NO & sí & sí \\
\hline & \multicolumn{4}{|l|}{11} \\
\hline \multirow{5}{*}{$\begin{array}{l}R_{26}(\%) \\
\text { Media de la } \pm 10 \% \\
\text { ¿Descartado? } \\
\text { Coeficiente de variación }(\%) \\
\text { Resultado }\end{array}$} & 63 & 68 & 53 & 73 \\
\hline & \multicolumn{4}{|c|}{$61 \pm 6(55-66)$} \\
\hline & NO & sí & sí & sí \\
\hline & \multicolumn{4}{|l|}{10} \\
\hline & \multicolumn{4}{|c|}{ Toda la serie descartable según UNI 11259} \\
\hline
\end{tabular}

Tabla. Detalles concretos del procedimiento experimental, así como los resultados obtenidos para las muestras denominadas $15000(1,42)$. 
Serie probetas 5 $10012(0,64)$

\begin{tabular}{|l|l|l|l|l|}
\hline Probetas & 1 & 2 & 3 & 4 \\
\hline Peso probeta (g) & 126 & 124 & 122 & 124 \\
\hline Consistencia mortero (mm) UNE-EN 1015-3 & $162 / 159-161 / 165$ & \\
\cline { 2 - 5 }
\end{tabular}

$a^{*}(0 h):$ datos individuales

\begin{tabular}{|l|l|l|l|}
\hline 7,32 & 6,07 & 5,56 & 7,39 \\
\hline 8,24 & 6,15 & 6,32 & 7,10 \\
\hline 6,95 & 6,39 & 6,56 & 7,15 \\
\hline $\mathbf{7 , 5 0}$ & $\mathbf{6 , 2 0}$ & $\mathbf{6 , 1 5}$ & $\mathbf{7 , 2 1}$ \\
\hline
\end{tabular}

Promedio

\begin{tabular}{|l|l|l|l|}
\hline 4,58 & 3,70 & 3,74 & 4,75 \\
\hline 4,11 & 3,99 & 3,76 & 5,90 \\
\hline 4,58 & 3,76 & 3,65 & 5,04 \\
\hline $\mathbf{4 , 4 2}$ & $\mathbf{3 , 8 2}$ & $\mathbf{3 , 7 2}$ & $\mathbf{5 , 2 3}$ \\
\hline
\end{tabular}

Promedio

\begin{tabular}{|l|l|l|l|}
\hline 2,17 & 2,56 & 2,16 & 2,53 \\
\hline 2,63 & 1,93 & 2,19 & 2,56 \\
\hline 2,47 & 2,11 & 2,03 & 2,79 \\
\hline $\mathbf{2 , 4 2}$ & $\mathbf{2 , 2 0}$ & $\mathbf{2 , 1 3}$ & $\mathbf{2 , 6 3}$ \\
\hline
\end{tabular}

Promedio

\begin{tabular}{|l|l|l|l|}
\hline 69 & 69 & 69 & 69 \\
\hline 19 & 19 & 19 & 19 \\
\hline
\end{tabular}

Humedad (\% RH)

Temperatura $\left({ }^{\circ} \mathrm{C}\right)$

\begin{tabular}{|l|l|l|l|}
\hline 370 & 350 & 360 & 380 \\
\hline
\end{tabular}

lluminación $\left(\mu \mathrm{W} / \mathrm{cm}^{2}\right)$

\begin{tabular}{|l|l|l|l|}
\hline 22 & 22 & 22 & 22 \\
\hline
\end{tabular}

Fecha de la prueba

\begin{tabular}{|l|l|l|l|}
\hline $17 / 09 / 2008$ & $17 / 09 / 2008$ & $17 / 09 / 2008$ & $17 / 09 / 2008$ \\
\hline
\end{tabular}

$\mathbf{R}_{4}(\%)$

Media de la $\pm 10 \%$

¿Descartado?

Coeficiente de variación (\%)

\begin{tabular}{|l|l|l|l|}
\hline 41 & 38 & 40 & 27 \\
\hline $37 \pm 4(33-41)$ & \multicolumn{2}{|l|}{} \\
\hline NO & NO & NO & Sí \\
\hline 15 & & \\
\hline
\end{tabular}

$\mathbf{R}_{26}(\%)$

Media de la $\pm 10 \%$

¿Descartado?

Coeficiente de variación (\%)

\begin{tabular}{|l|l|l|l|}
\hline 41 & 38 & 40 & \\
\hline $40 \pm 4(36-44)$ & NO & NO & \\
\hline NO & NO \\
\hline 3 & \multicolumn{2}{|l|}{} \\
\hline
\end{tabular}

$\mathbf{R}_{26}(\%)$

Media de la $\pm 10 \%$

¿Descartado?

Coeficiente de variación (\%)

\begin{tabular}{|l|l|l|l|}
\hline 68 & 65 & 65 & 64 \\
\hline $65 \pm 7(58-72)$ & NO & NO \\
\hline NO & NO & NO \\
\hline 2
\end{tabular}

Resultado

No se descarta los resultados según UNI 11259

Tabla. Detalles concretos del procedimiento experimental, así como los resultados obtenidos para las muestras denominadas $10012(0,64)$. 
Serie probetas 6 $10012(1,42)$

\begin{tabular}{|c|c|c|c|c|}
\hline Probeta & 1 & 2 & 3 & 4 \\
\hline Peso probeta (g) & 121 & 123 & 124 & 126 \\
\hline Consistencia mortero (mm) UNE-EN 1015-3 & \multicolumn{4}{|c|}{$117 / 125-114 / 118$} \\
\hline \multirow{3}{*}{$a^{*}(0 h):$ datos individuales } & 8,39 & 14,84 & 5,62 & 6,22 \\
\hline & 8,74 & 14,20 & 5,66 & 6,28 \\
\hline & 8,33 & 14,97 & 6,01 & 6,46 \\
\hline Promedio & 8,49 & 14,67 & 5,76 & 6,32 \\
\hline \multirow{3}{*}{$a^{*}(4 h):$ datos individuales } & 3,90 & 10,43 & 2,76 & 3,03 \\
\hline & 4,80 & 10,69 & 3,11 & 2,82 \\
\hline & 4,07 & 11,25 & 3,46 & 3,69 \\
\hline Promedio & 4,26 & 10,79 & 3,11 & 3,18 \\
\hline \multirow{3}{*}{$a^{*}(26 h):$ datos individuales } & 1,80 & 6,58 & 1,93 & 1,50 \\
\hline & 1,88 & 6,65 & 1,61 & 1,78 \\
\hline & 1,67 & 5,33 & 1,67 & 1,69 \\
\hline Promedio & 1,78 & 6,19 & 1,74 & 1,66 \\
\hline \multirow{2}{*}{$\begin{array}{l}\text { Humedad }(\% \mathrm{RH}) \\
\text { Temperatura }\left({ }^{\circ} \mathrm{C}\right)\end{array}$} & 69 & 69 & 69 & 69 \\
\hline & 19 & 19 & 19 & 19 \\
\hline Iluminación $\left(\mu \mathrm{W} / \mathrm{cm}^{2}\right)$ & 360 & 370 & 360 & 360 \\
\hline Área coloreada $\left(\mathrm{cm}^{2}\right)$ & 22 & 22 & 22 & 22 \\
\hline Fecha de la prueba & $17 / 09 / 2008$ & $17 / 09 / 2008$ & $17 / 09 / 2008$ & $17 / 09 / 2008$ \\
\hline \multirow{4}{*}{$\begin{array}{l}R_{4}(\%) \\
\text { Media de la } \pm 10 \% \\
\text { ¿Descartado? } \\
\text { Coeficiente de variación }(\%)\end{array}$} & 50 & 26 & 46 & 50 \\
\hline & $43 \pm 4(39$ & 47) & & \\
\hline & sí & sí & NO & sí \\
\hline & 23 & & & \\
\hline \multirow{4}{*}{$\begin{array}{l}R_{4}(\%) \\
\text { Media de la } \pm 10 \% \\
\text { ¿Descartado? } \\
\text { Coeficiente de variación }(\%)\end{array}$} & 50 & & 46 & 50 \\
\hline & $49 \pm 5(44$ & 54) & & \\
\hline & NO & & NO & NO \\
\hline & 4 & & & \\
\hline \multirow{4}{*}{$\begin{array}{l}R_{26}(\%) \\
\text { Media de la } \pm 10 \% \\
\text { ¿Descartado? } \\
\text { Coeficiente de variación }(\%)\end{array}$} & 79 & 58 & 70 & 74 \\
\hline & $70 \pm 7(63$ & 77) & & \\
\hline & sí & sí & NO & NO \\
\hline & 11 & & & \\
\hline \multirow{5}{*}{$\begin{array}{l}R_{26}(\%) \\
\text { Media de la } \pm 10 \% \\
\text { ¿Descartado? } \\
\text { Coeficiente de variación }(\%) \\
\text { Resultado }\end{array}$} & 79 & & 70 & 74 \\
\hline & \multicolumn{4}{|c|}{$74 \pm 7(67-81)$} \\
\hline & NO & & NO & NO \\
\hline & \multicolumn{4}{|l|}{5} \\
\hline & \multicolumn{4}{|c|}{ No se descarta los resultados según UNI 11259} \\
\hline
\end{tabular}

Tabla. Detalles concretos del procedimiento experimental, así como los resultados obtenidos para las muestras denominadas $10012(1,42)$. 
Serie probetas 7 $\mathrm{H} 20(0,43)$

\begin{tabular}{|c|c|c|c|c|}
\hline Probeta & 1 & 2 & 3 & 4 \\
\hline Peso probeta (g) & 154 & 153 & 154 & 161 \\
\hline Consistencia mortero (mm) UNE-EN 1015-3 & \multicolumn{4}{|c|}{$195 / 192-185 / 185$} \\
\hline \multirow{3}{*}{$a^{*}(0 h):$ datos individuales } & 10,36 & 7,77 & 7,52 & 7,77 \\
\hline & 9,02 & 8,79 & 7,04 & 7,86 \\
\hline & 8,91 & 8,02 & 7,96 & 8,11 \\
\hline Promedio & 9,43 & 8,19 & 7,51 & 7,91 \\
\hline \multirow{3}{*}{$a^{*}(4 h):$ datos individuales } & 4,93 & 5,59 & 5,92 & 3,24 \\
\hline & 4,63 & 5,98 & 5,26 & 4,03 \\
\hline & 5,65 & 5,15 & 4,66 & 4,71 \\
\hline Promedio & 5,07 & 5,57 & 5,28 & 3,99 \\
\hline \multirow{3}{*}{$a^{*}(26 h):$ datos individuales } & 2,37 & 2,84 & 2,19 & 2,88 \\
\hline & 2,68 & 2,36 & 2,15 & 2,43 \\
\hline & 2,37 & 3,10 & 1,81 & 2,45 \\
\hline Promedio & 2,47 & 2,77 & 2,05 & 2,59 \\
\hline \multirow{2}{*}{$\begin{array}{l}\text { Humedad }(\% \mathrm{RH}) \\
\text { Temperatura }\left({ }^{\circ} \mathrm{C}\right)\end{array}$} & 69 & 69 & 69 & 69 \\
\hline & 19 & 19 & 19 & 19 \\
\hline Iluminación $\left(\mu \mathrm{W} / \mathrm{cm}^{2}\right)$ & 350 & 360 & 380 & 370 \\
\hline Área coloreada $\left(\mathrm{cm}^{2}\right)$ & 22 & 22 & 22 & 22 \\
\hline Fecha de la prueba & $17 / 09 / 2008$ & $17 / 09 / 2008$ & $17 / 09 / 2008$ & $17 / 09 / 2008$ \\
\hline \multirow{4}{*}{$\begin{array}{l}R_{4}(\%) \\
\text { Media de la } \pm 10 \% \\
\text { ¿Descartado? } \\
\text { Coeficiente de variación }(\%)\end{array}$} & 46 & 32 & 30 & 50 \\
\hline & $39 \pm 4(35-$ & 43) & & \\
\hline & Sí & sí & Sí & sí \\
\hline & 22 & & & \\
\hline \multirow{4}{*}{$\begin{array}{l}R_{4}(\%) \\
\text { Media de la } \pm 10 \% \\
\text { ¿Descartado? } \\
\text { Coeficiente de variación }(\%)\end{array}$} & 46 & 32 & 30 & \\
\hline & $36 \pm 4(32$ & 40) & & \\
\hline & sí & NO & sí & \\
\hline & 20 & & & \\
\hline \multirow{5}{*}{$\begin{array}{l}R_{26}(\%) \\
\text { Media de la } \pm 10 \% \\
\text { ¿Descartado? } \\
\text { Coeficiente de variación }(\%) \\
\text { Resultado }\end{array}$} & 74 & 66 & 73 & 67 \\
\hline & $70 \pm 7(63$ & 77) & & \\
\hline & NO & NO & NO & NO \\
\hline & 5 & & & \\
\hline & Toda la seri & descartab & egún UNI 11 & \\
\hline
\end{tabular}

Tabla. Detalles concretos del procedimiento experimental, así como los resultados obtenidos para las muestras denominadas $H 20(0,43)$. 
Serie probetas 8 $\mathrm{H} 20(1,21)$

\begin{tabular}{l|l|l|l|l|}
\hline Probetas & 1 & 2 & 3 & 4 \\
\hline Peso probeta (g) & 171 & 169 & 171 & 171 \\
\hline Consistencia mortero (mm) UNE-EN 1015-3 & $165 / 170-165 / 165$ & \\
\cline { 2 - 5 }
\end{tabular}

$a^{*}(0 h):$ datos individuales

\begin{tabular}{|l|l|l|l|}
\hline 10,08 & 9,66 & 8,95 & 9,32 \\
\hline $\mathbf{9 , 8 2}$ & 9,69 & 8,71 & 9,76 \\
\hline $\mathbf{9 , 3 4}$ & 9,52 & 5,65 & 9,43 \\
$\mathbf{9 , 7 5}$ & $\mathbf{9 , 6 2}$ & $\mathbf{7 , 7 7}$ & $\mathbf{9 , 5 0}$ \\
\hline
\end{tabular}

Promedio

\begin{tabular}{|l|l|l|l|}
\hline 5,52 & 3,46 & 2,64 & 2,90 \\
\hline 3,68 & 3,93 & 2,85 & 4,32 \\
\hline 4,11 & 3,27 & 2,97 & 5,29 \\
\hline $\mathbf{4 , 4 4}$ & $\mathbf{3 , 5 5}$ & $\mathbf{2 , 8 2}$ & $\mathbf{4 , 1 7}$ \\
\hline
\end{tabular}

Promedio

\begin{tabular}{|l|l|l|l|}
\hline 1,91 & 1,59 & 0,91 & 1,02 \\
\hline 1,61 & 1,71 & 1,01 & 1,10 \\
\hline 1,59 & 1,64 & 1,23 & 1,13 \\
\hline $\mathbf{1 , 7 0}$ & $\mathbf{1 , 6 5}$ & $\mathbf{1 , 0 5}$ & $\mathbf{1 , 0 8}$ \\
\hline
\end{tabular}

Promedio

\begin{tabular}{|l|l|l|l|}
\hline 68 & 68 & 68 & 68 \\
\hline 20 & 20 & 20 & 20 \\
\hline
\end{tabular}

Humedad (\%RH)

Temperatura $\left({ }^{\circ} \mathrm{C}\right)$

\begin{tabular}{|l|l|l|l|}
\hline 375 & 394 & 367 & 366 \\
\hline
\end{tabular}

lluminación $\left(\mu \mathrm{W} / \mathrm{cm}^{2}\right)$

\begin{tabular}{|l|l|l|l|}
\hline 22 & 22 & 22 & 22 \\
\hline
\end{tabular}

Fecha de la prueba

\begin{tabular}{|l|l|l|l|}
\hline $21 / 10 / 2008$ & $21 / 10 / 2008$ & $21 / 10 / 2008$ & $21 / 10 / 2008$ \\
\hline
\end{tabular}

$\mathbf{R}_{\mathbf{4}}(\%)$

Media de la $\pm 10 \%$

¿Descartado?

Coeficiente de variación (\%)

\begin{tabular}{|l|l|l|l|}
\hline 54 & 63 & 64 & 56 \\
\hline $59 \pm 6(53-65)$ & NO & NO \\
\hline NO & NO & \\
\hline 7 &
\end{tabular}

$\mathbf{R}_{26}(\%)$

Media de la $\pm 10 \%$

¿Descartado?

Coeficiente de variación (\%)

\begin{tabular}{|l|l|l|l|}
\hline 83 & 83 & 86 & 89 \\
\hline $85 \pm 9(76-94)$ & NO & NO \\
\hline NO & NO & \multicolumn{2}{|l|}{} \\
\hline 3
\end{tabular}

Resultado

No se descarta los resultados según UNI 11259

Tabla. Detalles concretos del procedimiento experimental, así como los resultados obtenidos para las muestras denominadas $H 20(1,21)$. 
Serie probetas 9 MH2O0 $(0,43)$

\begin{tabular}{|c|c|c|c|c|}
\hline Probetas & 1 & 2 & 3 & 4 \\
\hline Peso probeta (g) & 171 & 171 & 171 & 175 \\
\hline Consistencia mortero (mm) UNE-EN 1015-3 & \multicolumn{4}{|c|}{$123 / 123-122 / 123$} \\
\hline \multirow{3}{*}{$a^{*}(0 h):$ datos individuales } & 4,45 & 6,32 & 3,94 & 7,35 \\
\hline & 4,99 & 6,71 & 3,81 & 7,41 \\
\hline & 5,14 & 6,24 & 3,25 & 7,62 \\
\hline Promedio & 4,86 & 6,42 & 3,67 & 7,46 \\
\hline \multirow{3}{*}{$a^{*}(4 h):$ datos individuales } & 2,78 & 3,77 & 2,15 & 3,68 \\
\hline & 3,71 & 3,69 & 2,32 & 3,52 \\
\hline & 3,32 & 3,95 & 2,29 & \begin{tabular}{|l|}
3,21 \\
\end{tabular} \\
\hline Promedio & 3,27 & 3,80 & 2,25 & 3,47 \\
\hline \multirow{3}{*}{$a^{*}(26 h):$ datos individuales } & 1,42 & 1,82 & 1,06 & 1,50 \\
\hline & 1,59 & 1,60 & 1,14 & 1,76 \\
\hline & 1,55 & 1,79 & 0,91 & 1,63 \\
\hline Promedio & 1,52 & 1,74 & 1,04 & 1,63 \\
\hline \multirow{2}{*}{$\begin{array}{l}\text { Humedad }(\% \mathrm{RH}) \\
\text { Temperatura }\left({ }^{\circ} \mathrm{C}\right)\end{array}$} & 68 & 68 & 68 & 68 \\
\hline & 20 & 20 & 20 & 20 \\
\hline Iluminación $\left(\mu \mathrm{W} / \mathrm{cm}^{2}\right)$ & 368 & 370 & 365 & 371 \\
\hline Área coloreada $\left(\mathrm{cm}^{2}\right)$ & 22 & 22 & 22 & 22 \\
\hline Fecha de la prueba & $21 / 10 / 2008$ & $21 / 10 / 2008$ & $21 / 10 / 2008$ & $21 / 10 / 2008$ \\
\hline \multirow{2}{*}{$\begin{array}{l}R_{4}(\%) \\
\text { Media de la } \pm 10 \%\end{array}$} & 33 & 41 & 39 & 53 \\
\hline & $41 \pm 4(37$ & 45) & & \\
\hline \multirow{2}{*}{$\begin{array}{l}\text { ¿Descartado? } \\
\text { Coeficiente de variación (\%) }\end{array}$} & sí & NO & NO & sí \\
\hline & 18 & & & \\
\hline \multirow{4}{*}{$\begin{array}{l}R_{4}(\%) \\
\text { Media de la } \pm 10 \% \\
\text { ¿Descartado? } \\
\text { Coeficiente de variación }(\%)\end{array}$} & 33 & 41 & 39 & \\
\hline & $37 \pm 4(33$ & 41) & & \\
\hline & NO & NO & NO & \\
\hline & 9 & & & \\
\hline \multirow{4}{*}{$\begin{array}{l}\mathbf{R}_{26}(\%) \\
\text { Media de la } \pm 10 \% \\
\text { ¿Descartado? } \\
\text { Coeficiente de variación (\%) }\end{array}$} & 69 & 73 & 72 & 78 \\
\hline & $73 \pm 7(66$ & 80) & & \\
\hline & NO & NO & NO & NO \\
\hline & 5 & & & \\
\hline
\end{tabular}

Tabla. Detalles concretos del procedimiento experimental, así como los resultados obtenidos para las muestras denominadas $\mathrm{MH} 200(0,43)$. 
Serie probetas 10 $\mathrm{MH} 200(1,21)$

\begin{tabular}{|c|c|c|c|c|}
\hline Probetas & 1 & 2 & 3 & 4 \\
\hline Peso probeta (g) & 163 & 163 & 163 & 163 \\
\hline Consistencia mortero (mm) UNE-EN 1015-3 & \multicolumn{4}{|c|}{$125 / 128-121 / 122$} \\
\hline \multirow{3}{*}{$a^{*}(0 h):$ datos individuales } & 13,00 & 9,60 & 8,50 & 8,79 \\
\hline & 10,47 & 8,04 & 9,93 & 9,35 \\
\hline & 13,54 & 8,82 & 8,41 & 9,44 \\
\hline Promedio & 12,34 & 8,82 & 8,95 & 9,19 \\
\hline \multirow{3}{*}{$a^{*}(4 h):$ datos individuales } & 9,37 & 5,62 & 7,34 & 6,79 \\
\hline & 7,78 & 6,09 & 6,77 & 6,77 \\
\hline & 7,43 & 6,07 & 7,43 & 6,38 \\
\hline Promedio & 8,19 & 5,93 & 7,18 & 6,65 \\
\hline \multirow{3}{*}{$a^{*}(26 h):$ datos individuales } & 3,86 & 2,46 & 4,00 & 3,60 \\
\hline & 3,61 & 2,91 & 4,58 & 4,00 \\
\hline & 4,15 & 2,77 & 4,12 & 3,97 \\
\hline Promedio & 3,87 & 2,71 & 4,23 & 3,86 \\
\hline \multirow{2}{*}{$\begin{array}{l}\text { Humedad }(\% \mathrm{RH}) \\
\text { Temperatura }\left({ }^{\circ} \mathrm{C}\right)\end{array}$} & 68 & 68 & 68 & 68 \\
\hline & 20 & 20 & 20 & 20 \\
\hline Iluminación $\left(\mu \mathrm{W} / \mathrm{cm}^{2}\right)$ & 373 & 369 & 379 & 384 \\
\hline Área coloreada $\left(\mathrm{cm}^{2}\right)$ & 22 & 22 & 22 & 22 \\
\hline Fecha de la prueba & $17 / 11 / 2008$ & $17 / 11 / 2008$ & $17 / 11 / 2008$ & $17 / 11 / 2008$ \\
\hline \multirow{4}{*}{$\begin{array}{l}R_{4}(\%) \\
\text { Media de la } \pm 10 \% \\
\text { ¿Descartado? } \\
\text { Coeficiente de variación }(\%)\end{array}$} & 34 & 33 & 20 & 28 \\
\hline & $28 \pm 3(25$ & 31) & & \\
\hline & Sí & sí & Sí & Sí \\
\hline & 19 & & & \\
\hline \multirow{4}{*}{$\begin{array}{l}R_{4}(\%) \\
\text { Media de la } \pm 10 \% \\
\text { ¿Descartado? } \\
\text { Coeficiente de variación }(\%)\end{array}$} & 34 & 33 & & 28 \\
\hline & $31 \pm 3(28$ & 34) & & \\
\hline & NO & NO & & NO \\
\hline & 8 & & & \\
\hline \multirow{4}{*}{$\begin{array}{l}R_{26}(\%) \\
\text { Media de la } \pm 10 \% \\
\text { ¿Descartado? } \\
\text { Coeficiente de variación }(\%)\end{array}$} & 69 & 69 & 53 & 58 \\
\hline & $62 \pm 6(56$ & 68) & & \\
\hline & sí & sí & sí & NO \\
\hline & 11 & & & \\
\hline \multirow{5}{*}{$\begin{array}{l}R_{26}(\%) \\
\text { Media de la } \pm 10 \% \\
\text { ¿Descartado? } \\
\text { Coeficiente de variación }(\%) \\
\text { Resultado }\end{array}$} & 69 & 69 & & 58 \\
\hline & \multicolumn{4}{|c|}{$65 \pm 7(58-72)$} \\
\hline & NO & NO & & NO \\
\hline & \multicolumn{4}{|l|}{8} \\
\hline & \multicolumn{4}{|c|}{ No se descarta los resultados según UNI 11259} \\
\hline
\end{tabular}

Tabla. Detalles concretos del procedimiento experimental, así como los resultados obtenidos para las muestras denominadas $\mathrm{MH} 200$ (1,21). 
Serie probetas 11 LS $14(0,026)$

\begin{tabular}{|c|c|c|c|c|}
\hline Probetas & 1 & 2 & 3 & 4 \\
\hline Peso probeta (g) & 160 & 164 & 159 & 163 \\
\hline Consistencia mortero (mm) UNE-EN 1015-3 & \multicolumn{4}{|c|}{$150 / 152-150 / 150$} \\
\hline \multirow{3}{*}{$a^{*}(0 h):$ datos individuales } & 14,46 & 13,46 & 14,63 & 14,92 \\
\hline & 14,35 & 13,96 & 15,58 & 14,18 \\
\hline & 14,43 & 14,04 & 15,91 & 14,70 \\
\hline Promedio & 14,41 & 13,82 & 15,37 & 14,60 \\
\hline \multirow{3}{*}{$a^{*}(4 h):$ datos individuales } & 5,01 & 4,93 & 5,35 & 4,70 \\
\hline & 5,22 & 4,71 & 5,00 & 4,49 \\
\hline & 5,37 & 4,93 & 4,69 & 4,80 \\
\hline Promedio & 5,20 & 4,86 & 5,01 & 4,66 \\
\hline \multirow{3}{*}{$a^{*}(26 h):$ datos individuales } & 1,86 & 1,62 & 1,96 & 2,45 \\
\hline & 1,98 & 1,77 & 1,90 & 1,87 \\
\hline & 2,03 & 1,86 & 1,76 & 2,13 \\
\hline Promedio & 1,96 & 1,75 & 1,87 & 2,15 \\
\hline \multirow{2}{*}{$\begin{array}{l}\text { Humedad }(\% \mathbf{R H}) \\
\text { Temperatura }\left({ }^{\circ} \mathrm{C}\right)\end{array}$} & 73 & 73 & 73 & 73 \\
\hline & 20 & 20 & 20 & 20 \\
\hline Iluminación $\left(\mu \mathrm{W} / \mathrm{cm}^{2}\right)$ & 364 & 365 & 372 & 366 \\
\hline Área coloreada $\left(\mathrm{cm}^{2}\right)$ & 22 & 22 & 22 & 22 \\
\hline Fecha de la prueba & $27 / 10 / 2008$ & $27 / 10 / 2008$ & $27 / 10 / 2008$ & $27 / 10 / 2008$ \\
\hline \multirow{2}{*}{$\begin{array}{l}R_{4}(\%) \\
\text { Media de la } \pm 10 \%\end{array}$} & 64 & 65 & 67 & 68 \\
\hline & $66 \pm 7(59$ & 73) & & \\
\hline \multirow{2}{*}{$\begin{array}{l}\text { ¿Descartado? } \\
\text { Coeficiente de variación }(\%)\end{array}$} & NO & NO & NO & NO \\
\hline & 3 & & & \\
\hline \multirow{5}{*}{$\begin{array}{l}R_{26}(\%) \\
\text { Media de la } \pm 10 \% \\
\text { ¿Descartado? } \\
\text { Coeficiente de variación (\%) } \\
\text { Resultado }\end{array}$} & 86 & 87 & 88 & 85 \\
\hline & \multicolumn{4}{|c|}{$87 \pm 9(78-96)$} \\
\hline & NO & NO & NO & NO \\
\hline & \multicolumn{4}{|l|}{1} \\
\hline & \multicolumn{4}{|c|}{ No se descarta los resultados según UNI 11259} \\
\hline
\end{tabular}

Tabla. Detalles concretos del procedimiento experimental, así como los resultados obtenidos para las muestras denominadas LS $14(0,026)$. 
Serie probetas 12 LS $14(0,05)$

\begin{tabular}{|c|c|c|c|c|}
\hline Probetas & 1 & 2 & 3 & 4 \\
\hline Peso probeta (g) & 156 & 154 & 158 & 160 \\
\hline Consistencia mortero (mm) UNE-EN 1015-3 & \multicolumn{4}{|c|}{$150 / 150-150 / 150$} \\
\hline \multirow{3}{*}{$a^{*}(0 h):$ datos individuales } & 13,57 & 14,91 & 13,08 & 13,70 \\
\hline & 14,34 & 14,93 & 13,80 & 14,43 \\
\hline & 13,81 & 14,89 & 13,35 & 13,53 \\
\hline Promedio & 13,91 & 14,91 & 13,41 & 13,89 \\
\hline \multirow{3}{*}{$a^{*}(4 h):$ datos individuales } & 5,33 & 4,74 & 4,82 & 5,46 \\
\hline & 6,63 & 5,83 & 5,85 & 5,62 \\
\hline & 4,62 & 5,87 & 6,97 & 5,57 \\
\hline Promedio & 5,53 & 5,48 & 5,88 & 5,55 \\
\hline \multirow{3}{*}{$a^{*}(26 h):$ datos individuales } & 2,04 & 1,75 & 1,98 & 1,74 \\
\hline & 2,21 & 1,93 & 1,97 & 1,61 \\
\hline & 1,94 & 1,82 & 2,01 & 1,59 \\
\hline Promedio & 2,06 & 1,83 & 1,99 & 1,65 \\
\hline \multirow{2}{*}{$\begin{array}{l}\text { Humedad }(\% \mathrm{RH}) \\
\text { Temperatura }\left({ }^{\circ} \mathrm{C}\right)\end{array}$} & 68 & 68 & 68 & 68 \\
\hline & 20 & 20 & 20 & 20 \\
\hline Iluminación $\left(\mu \mathrm{W} / \mathrm{cm}^{2}\right)$ & 368 & 394 & 378 & 397 \\
\hline Área coloreada $\left(\mathrm{cm}^{2}\right)$ & 22 & 22 & 22 & 22 \\
\hline Fecha de la prueba & $21 / 10 / 2008$ & $21 / 10 / 2008$ & $21 / 10 / 2008$ & $21 / 10 / 2008$ \\
\hline \multirow{4}{*}{$\begin{array}{l}R_{4}(\%) \\
\text { Media de la } \pm 10 \% \\
\text { ¿Descartado? } \\
\text { Coeficiente de variación }(\%)\end{array}$} & 60 & 63 & 56 & 60 \\
\hline & \multicolumn{4}{|c|}{$60 \pm 6(54-66)$} \\
\hline & NO & NO & NO & NO \\
\hline & \multicolumn{4}{|l|}{4} \\
\hline \multirow{5}{*}{$\begin{array}{l}\mathbf{R}_{26}(\%) \\
\text { Media de la } \pm 10 \% \\
\text { ¿Descartado? } \\
\text { Coeficiente de variación }(\%) \\
\text { Resultado }\end{array}$} & 85 & 88 & 85 & 88 \\
\hline & \multicolumn{4}{|c|}{$87 \pm 9(78-96)$} \\
\hline & NO & NO & NO & NO \\
\hline & \multicolumn{4}{|l|}{2} \\
\hline & \multicolumn{4}{|c|}{ No se descarta los resultados según UNI 11259} \\
\hline
\end{tabular}

Tabla. Detalles concretos del procedimiento experimental, así como los resultados obtenidos para las muestras denominadas LS $14(0,05)$. 
Serie probetas 13 Mas $(0,026)$

Probetas

Peso probeta (g)

\begin{tabular}{|l|l|}
\hline 1 & 2 \\
\hline 160 & 160 \\
\hline
\end{tabular}

2

\begin{tabular}{|l|l|}
\hline 3 & 4 \\
\hline 157 & 159 \\
\hline
\end{tabular}

Consistencia mortero (mm) UNE-EN 1015-3

$150 / 153-150 / 150$ 159

\begin{tabular}{|c|c|c|c|c|}
\hline \multirow{3}{*}{$a^{*}(0 h):$ datos individuales } & 19,14 & 12,75 & 10,69 & 12,36 \\
\hline & 19,22 & 12,04 & 10,23 & 12,09 \\
\hline & 20,96 & 12,73 & 12,44 & 13,36 \\
\hline Promedio & 19,77 & 12,51 & 11,12 & 12,60 \\
\hline \multirow{3}{*}{$a^{*}(4 h):$ datos individuales } & 8,13 & 5,48 & 5,08 & 4,62 \\
\hline & 7,52 & 5,25 & 5,38 & 5,25 \\
\hline & 8,81 & 5,76 & 5,12 & 5,18 \\
\hline Promedio & 8,15 & 5,50 & 5,19 & 5,02 \\
\hline \multirow{3}{*}{$a^{*}(26 h):$ datos individuales } & 3,25 & 1,65 & 1,67 & 1,74 \\
\hline & 3,08 & 1,96 & 1,76 & 1,95 \\
\hline & 3,17 & 1,89 & 1,61 & 1,67 \\
\hline Promedio & 3,17 & 1,83 & 1,68 & 1,79 \\
\hline \multirow{2}{*}{$\begin{array}{l}\text { Humedad }(\% \mathrm{RH}) \\
\text { Temperatura }\left({ }^{\circ} \mathrm{C}\right)\end{array}$} & 71 & 71 & 71 & 71 \\
\hline & 20 & 20 & 20 & 20 \\
\hline Iluminación $\left(\boldsymbol{\mu W} / \mathrm{cm}^{2}\right)$ & 364 & 388 & 379 & 375 \\
\hline Área coloreada $\left(\mathrm{cm}^{2}\right)$ & 22 & 22 & 22 & 22 \\
\hline Fecha de la prueba & $23 / 10 / 2008$ & $23 / 10 / 2008$ & $23 / 10 / 2008$ & $23 / 10 / 2008$ \\
\hline \multirow{4}{*}{$\begin{array}{l}R_{4}(\%) \\
\text { Media de la } \pm 10 \% \\
\text { ¿Descartado? } \\
\text { Coeficiente de variación }(\%)\end{array}$} & 59 & 56 & 53 & 60 \\
\hline & \multicolumn{4}{|c|}{$57 \pm 6(51-63)$} \\
\hline & NO & NO & NO & NO \\
\hline & \multicolumn{4}{|l|}{5} \\
\hline \multirow{5}{*}{$\begin{array}{l}R_{26}(\%) \\
\text { Media de la } \pm 10 \% \\
\text { ¿Descartado? } \\
\text { Coeficiente de variación }(\%) \\
\text { Resultado }\end{array}$} & 84 & 85 & 85 & 86 \\
\hline & \multicolumn{4}{|c|}{$85 \pm 9(76-94)$} \\
\hline & NO & NO & NO & NO \\
\hline & \multicolumn{4}{|l|}{1} \\
\hline & \multicolumn{4}{|c|}{ No se descarta los resultados según UNI 11259} \\
\hline
\end{tabular}

Tabla. Detalles concretos del procedimiento experimental, así como los resultados obtenidos para las muestras denominadas Mas (0,026). 
Serie probetas 14 Mas $(0,05)$

Probeta

\begin{tabular}{|l|l|l|l|}
\hline 1 & 2 & 3 & 4 \\
\hline 155 & 154 & 157 & 157 \\
\hline
\end{tabular}

$a^{*}(0 h)$ : datos individuales

\begin{tabular}{|l|l|l|l|}
\hline 14,89 & 14,25 & 13,22 & 14,37 \\
\hline 13,49 & 14,11 & 13,15 & 12,59 \\
\hline 12,51 & 12,48 & 13,82 & 11,53 \\
\hline $\mathbf{1 3 , 6 3}$ & $\mathbf{1 3 , 6 1}$ & $\mathbf{1 3 , 4 0}$ & $\mathbf{1 2 , 8 3}$ \\
\hline
\end{tabular}

Promedio

\begin{tabular}{|l|l|l|l|}
\hline 4,11 & 5,55 & 7,12 & 3,84 \\
\hline 5,04 & 5,03 & 8,55 & 3,90 \\
\hline 4,62 & 5,74 & 8,98 & 4,12 \\
\hline $\mathbf{4 , 5 9}$ & $\mathbf{5 , 4 4}$ & $\mathbf{8 , 2 2}$ & $\mathbf{3 , 9 5}$ \\
\hline
\end{tabular}

Promedio

\begin{tabular}{|l|l|l|l|}
\hline 1,91 & 1,33 & 1,82 & 1,41 \\
\hline 1,24 & 1,26 & 1,79 & 1,25 \\
\hline 1,23 & 1,28 & 1,47 & 1,24 \\
\hline $\mathbf{1 , 4 6}$ & $\mathbf{1 , 2 9}$ & $\mathbf{1 , 6 9}$ & $\mathbf{1 , 3 0}$ \\
\hline
\end{tabular}

Promedio

\begin{tabular}{|l|l|l|l|}
\hline 71 & 71 & 71 & 71 \\
\hline 20 & 20 & 20 & 20 \\
\hline
\end{tabular}

Humedad (\%RH)

Temperatura $\left({ }^{\circ} \mathrm{C}\right)$

\begin{tabular}{|l|l|l|l|}
\hline 365 & 369 & 377 & 372 \\
\hline \multicolumn{3}{|l|}{} \\
\hline
\end{tabular}

Área coloreada $\left(\mathrm{cm}^{2}\right)$

\begin{tabular}{|c|c|c|c|}
\hline 22 & 22 & 22 & 22 \\
\hline $23 / 10 / 2008$ & $23 / 10 / 2008$ & $23 / 10 / 2008$ & $23 / 10 / 2008$ \\
\hline
\end{tabular}

$\mathbf{R}_{\mathbf{4}}(\%)$

Media de la $\pm 10 \%$

¿Descartado?

Coeficiente de variación (\%)

\begin{tabular}{|l|l|l|l|}
\hline 66 & 60 & 39 & 69 \\
\hline $59 \pm 6(53-65)$ & NO & Sí & NO \\
\hline Sí & \multicolumn{2}{l|}{} \\
\hline 20 &
\end{tabular}

$\mathbf{R}_{4}(\%)$

Media de la $\pm 10 \%$

¿Descartado?

Coeficiente de variación (\%)

\begin{tabular}{|l|l|l|l|}
\hline 66 & 60 & & 69 \\
\hline $65 \pm 7(58-72)$ & & NO \\
\hline NO & NO & \\
\hline 6
\end{tabular}

$\mathbf{R}_{26}(\%)$

Media de la $\pm 10 \%$

¿Descartado?

Coeficiente de variación (\%)

Resultado

\begin{tabular}{|l|l|l|l|}
\hline 89 & 91 & 87 & 90 \\
\hline $89 \pm 9(80-98)$ & NO & NO \\
\hline NO & NO & NO \\
\hline 1 & \\
\hline
\end{tabular}

Tabla. Detalles concretos del procedimiento experimental, así como los resultados obtenidos para las muestras denominadas Mas $(0,05)$. 
Serie probetas 15

\begin{tabular}{|c|c|c|c|c|}
\hline Probeta & 1 & 2 & 3 & 4 \\
\hline Peso probeta (g) & 160 & 167 & 164 & 161 \\
\hline Consistencia mortero (mm) UNE-EN 1015-3 & \multicolumn{4}{|c|}{$144 / 143-144 / 144$} \\
\hline \multirow{3}{*}{$a^{*}(0 h):$ datos individuales } & 24,28 & 25,53 & 21,12 & 24,66 \\
\hline & 21,91 & 25,64 & 19,07 & 26,14 \\
\hline & 25,25 & 27,48 & 21,22 & 26,69 \\
\hline Promedio & 23,81 & 26,22 & 20,47 & 25,83 \\
\hline \multirow{3}{*}{$a^{*}(4 h):$ datos individuales } & 10,16 & 14,91 & 8,98 & 12,27 \\
\hline & 11,67 & 13,56 & 9,69 & 10,97 \\
\hline & 10,74 & 14,03 & 10,19 & 12,53 \\
\hline Promedio & 10,86 & 14,17 & 9,62 & 11,92 \\
\hline \multirow{3}{*}{$a^{*}(26 h):$ datos individuales } & 4,43 & 6,51 & 3,48 & 5,75 \\
\hline & 4,33 & 6,84 & 3,82 & 5,35 \\
\hline & 3,91 & 6,71 & 3,29 & 5,31 \\
\hline Promedio & 4,22 & 6,69 & 3,53 & 5,47 \\
\hline \multirow{2}{*}{$\begin{array}{l}\text { Humedad }(\% \mathrm{RH}) \\
\text { Temperatura }\left({ }^{\circ} \mathrm{C}\right)\end{array}$} & 71 & 71 & 71 & 71 \\
\hline & 20 & 20 & 20 & 20 \\
\hline Iluminación $\left(\mu \mathrm{W} / \mathrm{cm}^{2}\right)$ & 356 & 382 & 374 & 391 \\
\hline Área coloreada $\left(\mathrm{cm}^{2}\right)$ & 22 & 22 & 22 & 22 \\
\hline Fecha de la prueba & $23 / 10 / 2008$ & $23 / 10 / 2008$ & $23 / 10 / 2008$ & $23 / 10 / 2008$ \\
\hline \multirow{4}{*}{$\begin{array}{l}R_{4}(\%) \\
\text { Media de la } \pm 10 \% \\
\text { ¿Descartado? } \\
\text { Coeficiente de variación }(\%)\end{array}$} & 54 & 46 & 53 & 54 \\
\hline & \multicolumn{4}{|c|}{$52 \pm 5(47-57)$} \\
\hline & NO & sí & NO & NO \\
\hline & \multicolumn{4}{|l|}{7} \\
\hline \multirow{4}{*}{$\begin{array}{l}R_{4}(\%) \\
\text { Media de la } \pm 10 \% \\
\text { ¿Descartado? } \\
\text { Coeficiente de variación }(\%)\end{array}$} & 54 & & 53 & 54 \\
\hline & \multicolumn{4}{|c|}{$54 \pm 5(49-59)$} \\
\hline & NO & & NO & NO \\
\hline & \multicolumn{4}{|l|}{1} \\
\hline \multirow{5}{*}{$\begin{array}{l}R_{26}(\%) \\
\text { Media de la } \pm 10 \% \\
\text { ¿Descartado? } \\
\text { Coeficiente de variación }(\%) \\
\text { Resultado }\end{array}$} & 82 & 74 & 83 & 79 \\
\hline & \multicolumn{4}{|c|}{$80 \pm 8(72-88)$} \\
\hline & NO & NO & NO & NO \\
\hline & \multicolumn{4}{|l|}{4} \\
\hline & \multicolumn{4}{|c|}{ No se descarta los resultados según UNI 11259} \\
\hline
\end{tabular}

Tabla. Detalles concretos del procedimiento experimental, así como los resultados obtenidos para las muestras denominadas Oleato $(0,60)$. 
Serie probetas 16 Oleato $(0,90)$

\begin{tabular}{|c|c|c|c|c|}
\hline Probeta & 1 & 2 & 3 & 4 \\
\hline Peso probeta (g) & 171 & 170 & 170 & 171 \\
\hline Consistencia mortero (mm) UNE-EN 1015-3 & \multicolumn{4}{|c|}{$134 / 133-130 / 131$} \\
\hline \multirow{3}{*}{$a^{*}(0 h):$ datos individuales } & 27,69 & 27,21 & 25,08 & 21,64 \\
\hline & 28,15 & 26,09 & 26,06 & 20,23 \\
\hline & 26,01 & 25,51 & 25,55 & 20,78 \\
\hline Promedio & 27,28 & 26,27 & 25,56 & 20,88 \\
\hline \multirow{3}{*}{$a^{*}(4 h):$ datos individuales } & 18,50 & 16,61 & 13,81 & 10,30 \\
\hline & 18,04 & 17,01 & 14,41 & 9,27 \\
\hline & 18,01 & 16,39 & 13,86 & 10,79 \\
\hline Promedio & 18,18 & 16,67 & 14,03 & 10,12 \\
\hline \multirow{3}{*}{$a^{*}(26 h):$ datos individuales } & 6,32 & 6,89 & 5,53 & 4,21 \\
\hline & 6,24 & 6,07 & 5,68 & 4,94 \\
\hline & 6,08 & 5,81 & 5,10 & 5,28 \\
\hline Promedio & 6,21 & 6,26 & 5,44 & 4,81 \\
\hline \multirow{2}{*}{$\begin{array}{l}\text { Humedad }(\% \mathrm{RH}) \\
\text { Temperatura }\left({ }^{\circ} \mathrm{C}\right)\end{array}$} & 71 & 71 & 71 & 71 \\
\hline & 19 & 19 & 19 & 19 \\
\hline lluminación $\left(\mu \mathrm{W} / \mathrm{cm}^{2}\right)$ & 366 & 387 & 372 & 359 \\
\hline Área coloreada $\left(\mathrm{cm}^{2}\right)$ & 22 & 22 & 22 & 22 \\
\hline Fecha de la prueba & $23 / 09 / 2008$ & $23 / 09 / 2008$ & $23 / 09 / 2008$ & $23 / 09 / 2008$ \\
\hline \multirow{4}{*}{$\begin{array}{l}R_{4}(\%) \\
\text { Media de la } \pm 10 \% \\
\text { ¿Descartado? } \\
\text { Coeficiente de variación }(\%)\end{array}$} & 33 & 37 & 45 & 52 \\
\hline & $42 \pm 4(38$ & 46) & & \\
\hline & sí & sí & NO & sí \\
\hline & 17 & & & \\
\hline \multirow{4}{*}{$\begin{array}{l}R_{4}(\%) \\
\text { Media de la } \pm 10 \% \\
\text { ¿Descartado? } \\
\text { Coeficiente de variación }(\%)\end{array}$} & 33 & 37 & 45 & \\
\hline & $38 \pm 4(34$ & 42) & & \\
\hline & Sí & NO & Sí & \\
\hline & 13 & & & \\
\hline \multirow{5}{*}{$\begin{array}{l}R_{26}(\%) \\
\text { Media de la } \pm 10 \% \\
\text { ¿Descartado? } \\
\text { Coeficiente de variación }(\%) \\
\text { Resultado }\end{array}$} & 77 & 76 & 79 & 77 \\
\hline & $77 \pm 8(69$ & 85) & & \\
\hline & NO & NO & NO & NO \\
\hline & 1 & & & \\
\hline & Toda la seri & descartab & egún UNI 11 & \\
\hline
\end{tabular}

Tabla. Detalles concretos del procedimiento experimental, así como los resultados obtenidos para las muestras denominadas Oleato $(0,90)$. 
Serie probetas 17 $554(2,14)$

\begin{tabular}{|c|c|c|c|c|}
\hline Probeta & 1 & 2 & 3 & 4 \\
\hline Peso probeta (g) & 141 & 145 & 146 & 147 \\
\hline Consistencia mortero (mm) UNE-EN 1015-3 & \multicolumn{4}{|c|}{$165 / 160-155 / 155$} \\
\hline \multirow{3}{*}{$a^{*}(0 h):$ datos individuales } & 23,53 & 21,87 & 21,24 & 25,11 \\
\hline & 24,28 & 22,00 & 21,21 & 24,55 \\
\hline & 24,45 & 21,77 & 22,47 & 25,01 \\
\hline Promedio & 24,09 & 21,88 & 21,64 & 24,89 \\
\hline \multirow{3}{*}{$a^{*}(4 h):$ datos individuales } & 22,29 & 20,40 & 19,15 & 20,35 \\
\hline & 22,16 & 20,45 & 18,64 & 20,79 \\
\hline & 22,49 & 18,98 & 18,84 & 21,42 \\
\hline Promedio & 22,31 & 19,94 & 18,88 & 20,85 \\
\hline \multirow{3}{*}{$a^{*}(26 h):$ datos individuales } & 12,34 & 12,35 & 11,08 & 11,78 \\
\hline & 12,77 & 12,64 & 11,43 & 11,50 \\
\hline & 12,66 & 11,79 & 11,73 & 11,61 \\
\hline Promedio & 12,59 & 12,26 & 11,41 & 11,63 \\
\hline \multirow{2}{*}{$\begin{array}{l}\text { Humedad }(\% \mathrm{RH}) \\
\text { Temperatura }\left({ }^{\circ} \mathrm{C}\right)\end{array}$} & 80 & 80 & 80 & 80 \\
\hline & 20 & 20 & 20 & 20 \\
\hline Iluminación $\left(\mu \mathrm{W} / \mathrm{cm}^{2}\right)$ & 396 & 394 & 389 & 388 \\
\hline Área coloreada $\left(\mathrm{cm}^{2}\right)$ & 22 & 22 & 22 & 22 \\
\hline Fecha de la prueba & $04 / 12 / 2008$ & $04 / 12 / 2008$ & $04 / 12 / 2008$ & $04 / 12 / 2008$ \\
\hline \multirow{4}{*}{$\begin{array}{l}R_{4}(\%) \\
\text { Media de la } \pm 10 \% \\
\text { ¿Descartado? } \\
\text { Coeficiente de variación }(\%)\end{array}$} & 7 & 9 & 13 & 16 \\
\hline & $11 \pm 1(10$ & 12) & & \\
\hline & Sí & sí & sí & sí \\
\hline & 31 & & & \\
\hline \multirow{4}{*}{$\begin{array}{l}R_{4}(\%) \\
\text { Media de la } \pm 10 \% \\
\text { ¿Descartado? } \\
\text { Coeficiente de variación }(\%)\end{array}$} & 7 & 9 & 13 & \\
\hline & $10 \pm 1(9-$ & & & \\
\hline & sí & NO & sí & \\
\hline & 24 & & & \\
\hline \multirow{5}{*}{$\begin{array}{l}R_{26}(\%) \\
\text { Media de la } \pm 10 \% \\
\text { ¿Descartado? } \\
\text { Coeficiente de variación (\%) } \\
\text { Resultado }\end{array}$} & 48 & 44 & 47 & 53 \\
\hline & $48 \pm 5(43$ & 53) & & \\
\hline & NO & NO & NO & NO \\
\hline & 7 & & & \\
\hline & Toda la ser & descartab & egún UNI 11 & \\
\hline
\end{tabular}

Tabla. Detalles concretos del procedimiento experimental, así como los resultados obtenidos para las muestras denominadas $554(2,14)$. 
Serie probetas 18 $554(5)$

Probeta

Peso probeta (g)

\begin{tabular}{|l|l|l|l|}
\hline 1 & 2 & 3 & 4 \\
\hline 128 & 128 & 129 & 134 \\
\hline
\end{tabular}

$\mathrm{a}^{*}(\mathrm{Oh})$ : datos individuales

\begin{tabular}{|l|l|l|l|}
\hline 15,43 & 14,70 & 15,47 & 16,92 \\
\hline 14,68 & 13,59 & 16,34 & 17,57 \\
\hline 15,94 & 14,54 & 16,20 & 17,00 \\
\hline $\mathbf{1 5 , 3 5}$ & $\mathbf{1 4 , 2 8}$ & $\mathbf{1 6 , 0 0}$ & $\mathbf{1 7 , 1 6}$ \\
\hline
\end{tabular}

Promedio

\begin{tabular}{|l|l|l|l|}
\hline 11,57 & 11,12 & 9,26 & 11,04 \\
\hline 10,48 & 11,70 & 9,50 & 9,58 \\
\hline 10,98 & 12,00 & 10,26 & 9,43 \\
\hline $\mathbf{1 1 , 0 1}$ & $\mathbf{1 1 , 6 1}$ & $\mathbf{9 , 6 7}$ & $\mathbf{1 0 , 0 2}$ \\
\hline
\end{tabular}

Promedio

\begin{tabular}{|l|l|l|l|}
\hline 5,41 & 4,76 & 5,54 & 5,74 \\
\hline 5,61 & 4,84 & 5,80 & 5,03 \\
\hline 5,31 & 4,95 & 5,34 & 4,90 \\
\hline $\mathbf{5 , 4 4}$ & $\mathbf{4 , 8 5}$ & $\mathbf{5 , 5 6}$ & $\mathbf{5 , 2 2}$ \\
\hline
\end{tabular}

Promedio

\begin{tabular}{|l|l|l|l|}
\hline 71 & 71 & 71 & 71 \\
\hline 19 & 19 & 19 & 19 \\
\hline
\end{tabular}

Humedad (\%RH)

Temperatura $\left({ }^{\circ} \mathrm{C}\right)$

\begin{tabular}{|l|l|l|l|}
\hline 360 & 389 & 390 & 372 \\
\hline
\end{tabular}

Área coloreada $\left(\mathrm{cm}^{2}\right)$

\begin{tabular}{|l|l|l|l|}
\hline 22 & 22 & 22 & 22 \\
\hline
\end{tabular}

Fecha de la prueba

\begin{tabular}{|l|l|l|l|}
\hline $23 / 09 / 2008$ & $23 / 09 / 2008$ & $23 / 09 / 2008$ & $23 / 09 / 2008$ \\
\hline
\end{tabular}

$\mathbf{R}_{\mathbf{4}}(\%)$

Media de la $\pm 10 \%$

¿Descartado?

Coeficiente de variación (\%)

\begin{tabular}{|l|l|l|l|}
\hline 28 & 19 & 40 & 42 \\
\hline $32 \pm 3(29-35)$ & sí & sí & sí \\
\hline Sí & \multicolumn{2}{|l|}{} \\
\hline 29 &
\end{tabular}

$\mathbf{R}_{4}(\%)$

Media de la $\pm 10 \%$

¿Descartado?

Coeficiente de variación (\%)

\begin{tabular}{|c|c|c|c|}
\hline 28 & & 40 & 42 \\
\hline \multicolumn{4}{|c|}{$36 \pm 4(32-40)$} \\
\hline Sí & sí & NO & sí \\
\hline
\end{tabular}

$\mathbf{R}_{26}(\%)$

Media de la $\pm 10 \%$

¿Descartado?

Coeficiente de variación (\%)

Resultado

\begin{tabular}{|l|l|l|l|}
\hline 65 & 66 & 65 & 70 \\
\hline $66 \pm 7(59-73)$ & NO & NO \\
\hline NO & NO & \\
\hline 3 & \multicolumn{3}{|l|}{} \\
\hline \multicolumn{4}{|l|}{ Toda la serie descartable según UNI 11259 } \\
\hline
\end{tabular}

Tabla. Detalles concretos del procedimiento experimental, así como los resultados obtenidos para las muestras denominadas 554 (5). 
Serie probetas 19 $554(14,29)$

Probeta

\begin{tabular}{|l|l|l|l|}
\hline 1 & 2 & 3 & 4 \\
\hline 155 & 156 & 163 & 159 \\
\hline
\end{tabular}

Consistencia mortero (mm) UNE-EN 1015-3

\begin{tabular}{|l|l|l|l|}
\hline 23,35 & 19,15 & 21,68 & 19,23 \\
\hline 20,74 & 20,94 & 20,67 & 22,16 \\
\hline 19,98 & 21,06 & 19,27 & 21,01 \\
\hline $\mathbf{2 1 , 3 6}$ & $\mathbf{2 0 , 3 8}$ & $\mathbf{2 0 , 5 4}$ & $\mathbf{2 0 , 8 0}$ \\
\hline
\end{tabular}

Promedio

\begin{tabular}{|l|l|l|l|}
\hline 11,99 & 6,85 & 7,46 & 8,10 \\
\hline 10,86 & 7,59 & 8,52 & 8,42 \\
\hline 11,53 & 7,50 & 6,80 & 8,70 \\
\hline $\mathbf{1 1 , 4 6}$ & $\mathbf{7 , 3 1}$ & $\mathbf{7 , 5 9}$ & $\mathbf{8 , 4 1}$ \\
\hline
\end{tabular}

Promedio

\begin{tabular}{|l|l|l|l|}
\hline 4,27 & 4,27 & 2,02 & 2,72 \\
\hline 4,50 & 2,90 & 2,03 & 2,25 \\
\hline 5,14 & 2,58 & 2,08 & 2,88 \\
\hline $\mathbf{4 , 6 4}$ & $\mathbf{3 , 2 5}$ & $\mathbf{2 , 0 4}$ & $\mathbf{2 , 6 2}$ \\
\hline
\end{tabular}

Promedio

\begin{tabular}{|l|l|l|l|}
\hline 77 & 77 & 77 & 77 \\
\hline 19 & 19 & 19 & 19 \\
\hline
\end{tabular}

Humedad $(\% \mathrm{RH})$

Temperatura $\left({ }^{\circ} \mathrm{C}\right)$

\begin{tabular}{l|l|l|l|}
\hline 365 & 372 & 371 & 363 \\
\hline \multicolumn{4}{|l|}{} \\
\begin{tabular}{|l|l|l|l|}
\hline 22 & 22 & 22 & 22 \\
\hline
\end{tabular}
\end{tabular}

Área coloreada $\left(\mathrm{cm}^{2}\right)$

\begin{tabular}{|l|l|l|l|}
\hline $10 / 09 / 2008$ & $10 / 09 / 2008$ & $10 / 09 / 2008$ & $10 / 09 / 2008$ \\
\hline
\end{tabular}

$\mathbf{R}_{\mathbf{4}}(\%)$

Media de la $\pm 10 \%$

¿Descartado?

Coeficiente de variación (\%)

\begin{tabular}{|l|l|l|l|}
\hline 46 & 64 & 63 & 60 \\
\hline $58 \pm 6(52-64)$ & NO & NO \\
\hline Sí & NO & \multicolumn{2}{l|}{} \\
\hline 12 &
\end{tabular}

$\mathbf{R}_{4}(\%)$

Media de la $\pm 10 \%$

¿Descartado?

Coeficiente de variación (\%)

\begin{tabular}{|l|l|l|l|}
\hline & 64 & 63 & 60 \\
\hline $62 \pm 6(56-68)$ & NO & NO \\
\hline \multicolumn{3}{|l}{} \\
\hline 3 & NO & N
\end{tabular}

$\mathbf{R}_{26}(\%)$

Media de la $\pm 10 \%$

¿Descartado?

Coeficiente de variación (\%)

Resultado

\begin{tabular}{|l|l|l|l|}
\hline 78 & 84 & 90 & 87 \\
\hline $85 \pm 8(77-93)$ & NO & NO & NO \\
\hline NO & & \\
\hline 5 & No se descarta los resultados según UNI 11259 \\
\hline
\end{tabular}

Tabla. Detalles concretos del procedimiento experimental, así como los resultados obtenidos para las muestras denominadas 554 (14,29). 
Serie probetas 20 $5010(2,14)$

\begin{tabular}{|c|c|c|c|c|}
\hline Probeta & 1 & 2 & 3 & 4 \\
\hline Peso probeta (g) & 174 & 173 & 177 & 172 \\
\hline Consistencia mortero (mm) UNE-EN 1015-3 & \multicolumn{4}{|c|}{$160 / 158-155 / 155$} \\
\hline \multirow{3}{*}{$a^{*}(0 h):$ datos individuales } & 14,89 & 15,10 & 17,22 & 17,48 \\
\hline & 13,96 & 14,70 & 16,22 & 16,59 \\
\hline & 16,99 & 17,26 & 16,64 & 15,46 \\
\hline Promedio & 15,28 & 15,69 & 16,69 & 16,51 \\
\hline \multirow{3}{*}{$a^{*}(4 h):$ datos individuales } & 4,25 & 4,59 & 5,49 & 5,00 \\
\hline & 4,79 & 4,95 & 5,59 & 5,56 \\
\hline & 4,56 & 4,97 & 5,44 & 5,62 \\
\hline Promedio & 4,53 & 4,84 & 5,51 & 5,39 \\
\hline \multirow{3}{*}{$a^{*}(26 h):$ datos individuales } & 1,88 & 2,10 & 2,28 & 2,28 \\
\hline & 1,86 & 2,03 & 2,13 & 2,76 \\
\hline & 2,23 & 2,21 & 2,32 & 2,10 \\
\hline Promedio & 1,99 & 2,11 & 2,24 & 2,38 \\
\hline \multirow{2}{*}{$\begin{array}{l}\text { Humedad }(\% \mathbf{R H}) \\
\text { Temperatura }\left({ }^{\circ} \mathrm{C}\right)\end{array}$} & 76 & 76 & 76 & 76 \\
\hline & 19 & 19 & 19 & 19 \\
\hline Iluminación $\left(\mu \mathrm{W} / \mathrm{cm}^{2}\right)$ & 371 & 383 & 373 & 377 \\
\hline Área coloreada $\left(\mathrm{cm}^{2}\right)$ & 22 & 22 & 22 & 22 \\
\hline Fecha de la prueba & $20 / 10 / 2008$ & $20 / 10 / 2008$ & $20 / 10 / 2008$ & $20 / 10 / 2008$ \\
\hline \multirow{2}{*}{$\begin{array}{l}R_{4}(\%) \\
\text { Media de la } \pm 10 \%\end{array}$} & 70 & 69 & 67 & 67 \\
\hline & $68 \pm 7(61$ & 75) & & \\
\hline \multirow{2}{*}{$\begin{array}{l}\text { ¿Descartado? } \\
\text { Coeficiente de variación }(\%)\end{array}$} & NO & NO & NO & NO \\
\hline & 2 & & & \\
\hline \multirow{5}{*}{$\begin{array}{l}R_{26}(\%) \\
\text { Media de la } \pm 10 \% \\
\text { ¿Descartado? } \\
\text { Coeficiente de variación }(\%) \\
\text { Resultado }\end{array}$} & 87 & 87 & 87 & 86 \\
\hline & \multicolumn{4}{|c|}{$86 \pm 9(77-95)$} \\
\hline & NO & NO & NO & NO \\
\hline & \multicolumn{4}{|l|}{1} \\
\hline & \multicolumn{4}{|c|}{ No se descarta los resultados según UNI 11259} \\
\hline
\end{tabular}

Tabla. Detalles concretos del procedimiento experimental, así como los resultados obtenidos para las muestras denominadas $5010(2,14)$. 
Serie probetas 21 $5010(5)$

Probeta

Peso probeta (g)

\begin{tabular}{|l|l|}
\hline 1 & 2 \\
\hline 167 & 174 \\
\hline
\end{tabular}

$150 / 153-148 / 145$

\begin{tabular}{|l|l|}
\hline 3 & 4 \\
\hline 174 & 177
\end{tabular}

Consistencia mortero ( $\mathrm{mm}$ ) UNE-EN 1015-3

\begin{tabular}{|l|l|l|l|}
\hline 17,13 & 16,39 & 15,33 & 17,50 \\
\hline 16,32 & 17,10 & 15,79 & 16,49 \\
\hline 16,51 & 16,73 & 14,35 & 17,55 \\
\hline $\mathbf{1 6 , 6 5}$ & $\mathbf{1 6 , 7 4}$ & $\mathbf{1 5 , 1 6}$ & $\mathbf{1 7 , 1 8}$ \\
\hline
\end{tabular}

Promedio

\begin{tabular}{|l|l|l|l|}
\hline 10,19 & 8,89 & 10,93 & 11,46 \\
\hline 9,72 & 8,80 & 11,25 & 11,45 \\
\hline 10,12 & 9,50 & 10,14 & 10,55 \\
\hline $\mathbf{1 0 , 0 1}$ & $\mathbf{9 , 0 6}$ & $\mathbf{1 0 , 7 7}$ & $\mathbf{1 1 , 1 5}$ \\
\hline
\end{tabular}

Promedio

\begin{tabular}{|l|l|l|l|}
\hline 3,27 & 2,85 & 2,93 & 2,26 \\
\hline 2,93 & 2,59 & 2,76 & 2,30 \\
\hline 2,47 & 2,47 & 2,75 & 2,82 \\
\hline 2,89 & $\mathbf{2 , 6 4}$ & $\mathbf{2 , 8 1}$ & $\mathbf{2 , 4 6}$ \\
\hline
\end{tabular}

Promedio

\begin{tabular}{|l|l|l|l|}
\hline 76 & 76 & 76 & 76 \\
\hline 19 & 19 & 19 & 19 \\
\hline
\end{tabular}

Humedad (\%RH)

Temperatura $\left({ }^{\circ} \mathrm{C}\right)$

\begin{tabular}{|l|l|l|l|}
\hline 370 & 379 & 384 & 373 \\
\hline \multicolumn{4}{|l|}{} \\
\hline 22 & 22 & 22 & 22 \\
\hline
\end{tabular}

Área coloreada $\left(\mathrm{cm}^{2}\right)$

\begin{tabular}{|l|l|l|l|}
\hline $20 / 10 / 2008$ & $20 / 10 / 2008$ & $20 / 10 / 2008$ & $20 / 10 / 2008$ \\
\hline
\end{tabular}

$\mathbf{R}_{4}(\%)$

Media de la $\pm 10 \%$

¿Descartado?

Coeficiente de variación (\%)

\begin{tabular}{|l|l|l|l|}
\hline 40 & 46 & 29 & 35 \\
\hline $37 \pm 4(33-41)$ & sí & sí & NO \\
\hline NO & \multicolumn{2}{|l|}{} \\
\hline 17 &
\end{tabular}

$R_{4}(\%)$

Media de la $\pm 10 \%$

¿Descartado?

Coeficiente de variación (\%)

\begin{tabular}{|l|l|l|l|}
\hline 40 & & 29 & 35 \\
\hline $35 \pm 3(32-38)$ & sí & NO \\
\hline sí & \multicolumn{2}{|l}{} \\
\hline 13 & \multicolumn{3}{|l|}{} \\
\hline
\end{tabular}

$\mathbf{R}_{26}(\%)$

Media de la $\pm 10 \%$

¿Descartado?

Coeficiente de variación (\%)

Resultado

\begin{tabular}{|l|l|l|l|}
\hline 83 & 84 & 81 & 86 \\
\hline $84 \pm 8(76-92)$ & NO & NO \\
\hline NO & NO & N \\
\hline 2 & \multicolumn{3}{|l|}{} \\
\hline \multicolumn{4}{|l|}{ Toda la serie descartable según UNI 11259 } \\
\hline
\end{tabular}

Tabla. Detalles concretos del procedimiento experimental, así como los resultados obtenidos para las muestras denominadas 5010 (5). 
Serie probetas 22 Saf $54(3,75)$

\begin{tabular}{|c|c|c|c|c|}
\hline Probeta & 1 & 2 & 3 & 4 \\
\hline Peso probeta (g) & 143 & 144 & 147 & 149 \\
\hline Consistencia mortero (mm) UNE-EN 1015-3 & \multicolumn{4}{|c|}{$225 / 230-225 / 225$} \\
\hline \multirow{3}{*}{$a^{*}(0 h):$ datos individuales } & 12,36 & 12,71 & 12,06 & 11,19 \\
\hline & 12,99 & 14,14 & 13,08 & 11,07 \\
\hline & 13,21 & 12,15 & 12,02 & 11,15 \\
\hline Promedio & 12,85 & 13,00 & 12,39 & 11,14 \\
\hline \multirow{3}{*}{$a^{*}(4 h):$ datos individuales } & 6,13 & 6,53 & 6,97 & 6,96 \\
\hline & 7,08 & 7,38 & 6,72 & 6,27 \\
\hline & 7,17 & 7,14 & 6,57 & 5,34 \\
\hline Promedio & 6,79 & 7,02 & 6,75 & 6,19 \\
\hline \multirow{3}{*}{$a^{*}(26 h):$ datos individuales } & 3,53 & 3,28 & 3,63 & 2,53 \\
\hline & 3,61 & 3,84 & 3,01 & 3,24 \\
\hline & 3,07 & 3,48 & 4,16 & 3,18 \\
\hline Promedio & 3,40 & 3,53 & 3,60 & 2,98 \\
\hline \multirow{2}{*}{$\begin{array}{l}\text { Humedad }(\% \mathrm{RH}) \\
\text { Temperatura }\left({ }^{\circ} \mathrm{C}\right)\end{array}$} & 77 & 77 & 77 & 77 \\
\hline & 19 & 19 & 19 & 19 \\
\hline Iluminación $\left(\mu \mathrm{W} / \mathrm{cm}^{2}\right)$ & 375 & 381 & 380 & 385 \\
\hline Área coloreada $\left(\mathrm{cm}^{2}\right)$ & 22 & 22 & 22 & 22 \\
\hline Fecha de la prueba & $10 / 09 / 2008$ & $10 / 09 / 2008$ & $10 / 09 / 2008$ & $10 / 09 / 2008$ \\
\hline \multirow{2}{*}{$\begin{array}{l}R_{4}(\%) \\
\text { Media de la } \pm 10 \%\end{array}$} & 47 & 46 & 45 & 44 \\
\hline & $46 \pm 5(41$ & 51) & & \\
\hline \multirow{2}{*}{$\begin{array}{l}\text { ¿Descartado? } \\
\text { Coeficiente de variación }(\%)\end{array}$} & NO & NO & NO & NO \\
\hline & 2 & & & \\
\hline \multirow{5}{*}{$\begin{array}{l}R_{26}(\%) \\
\text { Media de la } \pm 10 \% \\
\text { ¿Descartado? } \\
\text { Coeficiente de variación }(\%) \\
\text { Resultado }\end{array}$} & 74 & 73 & 71 & 73 \\
\hline & \multicolumn{4}{|c|}{$73 \pm 7(66-80)$} \\
\hline & NO & NO & NO & NO \\
\hline & \multicolumn{4}{|l|}{1} \\
\hline & \multicolumn{4}{|c|}{ No se descarta los resultados según UNI 11259} \\
\hline
\end{tabular}

Tabla. Detalles concretos del procedimiento experimental, así como los resultados obtenidos para las muestras denominadas Saf 54 (3,75). 
Serie probetas 23

Saf $54(7,14)$

Probeta

Peso probeta (g)

\begin{tabular}{|l|l|}
\hline 1 & 2 \\
\hline 142 & 145
\end{tabular}

Consistencia mortero ( $\mathrm{mm}$ ) UNE-EN 1015-3

215/215 - 215/220

\begin{tabular}{|l|l|l|}
\hline 2 & 3 & 4 \\
\hline 145 & 142 & 146 \\
\hline
\end{tabular}

$\mathrm{a}^{*}(\mathrm{Oh})$ : datos individuales

\begin{tabular}{|l|l|l|l|}
\hline 13,78 & 12,21 & 9,77 & 11,75 \\
\hline 14,77 & 12,68 & 10,13 & 11,64 \\
\hline 15,65 & 12,18 & 11,20 & 11,34 \\
\hline $\mathbf{1 4 , 7 3}$ & $\mathbf{1 2 , 3 6}$ & $\mathbf{1 0 , 3 7}$ & $\mathbf{1 1 , 5 8}$ \\
\hline
\end{tabular}

Promedio

\begin{tabular}{|l|l|l|l|}
\hline 10,36 & 9,48 & 7,41 & 8,18 \\
\hline 10,06 & 9,25 & 6,98 & 8,39 \\
\hline 9,46 & 8,84 & 7,77 & 8,55 \\
\hline $\mathbf{9 , 9 6}$ & $\mathbf{9 , 1 9}$ & $\mathbf{7 , 3 9}$ & $\mathbf{8 , 3 7}$ \\
\hline
\end{tabular}

Promedio

\begin{tabular}{|l|l|l|l|}
\hline 6,45 & 4,68 & 5,51 & 3,92 \\
\hline 7,45 & 5,22 & 5,30 & 3,84 \\
\hline 6,71 & 5,58 & 4,58 & 3,90 \\
\hline $\mathbf{6 , 8 7}$ & $\mathbf{5 , 1 6}$ & $\mathbf{5 , 1 3}$ & $\mathbf{3 , 8 9}$ \\
\hline
\end{tabular}

Promedio

\begin{tabular}{|l|l|l|l|}
\hline 68 & 68 & 68 & 74 \\
\hline 20 & 20 & 20 & 20 \\
\hline
\end{tabular}

Humedad (\%RH)

Temperatura $\left({ }^{\circ} \mathrm{C}\right)$

\begin{tabular}{|l|l|l|l|}
\hline 377 & 377 & 375 & 389 \\
\hline
\end{tabular}

lluminación $\left(\mu \mathrm{W} / \mathrm{cm}^{2}\right)$

\begin{tabular}{|l|l|l|l|}
\hline \multicolumn{5}{|l|}{22} & 22 & 22 & 22 \\
\hline \multicolumn{4}{|l|}{} \\
\hline $17 / 11 / 2008$ & $17 / 11 / 2008$ & $17 / 11 / 2008$ & $23 / 01 / 2009$ \\
\hline
\end{tabular}

$\mathbf{R}_{\mathbf{4}}(\%)$

Media de la $\pm 10 \%$

¿Descartado?

Coeficiente de variación (\%)

\begin{tabular}{|l|l|l|l|}
\hline 32 & 26 & 29 & 28 \\
\hline $29 \pm 3(26-32)$ & NO & NO \\
\hline NO & NO & \\
\hline 9 &
\end{tabular}

$\mathbf{R}_{26}(\%)$

Media de la $\pm 10 \%$

¿Descartado?

Coeficiente de variación (\%)

\begin{tabular}{|l|l|l|l|}
\hline 53 & 58 & 51 & 66 \\
\hline $57 \pm 6(51-63)$ & NO & Sí \\
\hline NO & NO & \\
\hline 11
\end{tabular}

$\mathbf{R}_{26}(\%)$

Media de la $\pm 10 \%$

¿Descartado?

Coeficiente de variación (\%)

Resultado

\begin{tabular}{|l|l|l|l|}
\hline 53 & 58 & 51 & \\
\hline $54 \pm 5(49-59)$ & NO & \\
\hline NO & NO & NO \\
\hline 6 & \multicolumn{3}{|l|}{} \\
\hline \multicolumn{4}{|l|}{ No se descarta los resultados según UNI 11259 } \\
\hline
\end{tabular}

Tabla. Detalles concretos del procedimiento experimental, así como los resultados obtenidos para las muestras denominadas Saf $54(7,14)$. 
Serie probetas 24 Saf $54(14,29)$

\begin{tabular}{|c|c|c|c|c|}
\hline Probeta & 1 & 2 & 3 & 4 \\
\hline Peso probeta (g) & 164 & 140 & 153 & 161 \\
\hline Consistencia mortero (mm) UNE-EN 1015-3 & \multicolumn{4}{|c|}{ Mortero no suficiente viscoso } \\
\hline \multirow{3}{*}{$a^{*}(0 h):$ datos individuales } & 16,90 & 14,67 & 15,18 & 15,79 \\
\hline & 17,87 & 16,78 & 15,93 & 14,47 \\
\hline & 17,87 & 16,13 & 15,57 & 15,24 \\
\hline Promedio & 17,55 & 15,86 & 15,56 & 15,17 \\
\hline \multirow{3}{*}{$a^{*}(4 h):$ datos individuales } & 8,64 & 7,07 & 7,89 & 7,29 \\
\hline & 8,23 & 7,58 & 8,46 & 8,95 \\
\hline & 8,24 & 6,27 & 8,21 & 8,27 \\
\hline Promedio & 8,37 & 6,97 & 8,19 & 8,17 \\
\hline \multirow{3}{*}{$a^{*}(26 h):$ datos individuales } & 3,39 & 3,02 & 3,88 & 2,83 \\
\hline & 3,56 & 2,73 & 3,90 & 3,62 \\
\hline & 3,65 & 3,02 & 3,38 & 3,11 \\
\hline Promedio & 3,53 & 2,92 & 3,72 & 3,19 \\
\hline \multirow{2}{*}{$\begin{array}{l}\text { Humedad }(\% \mathrm{RH}) \\
\text { Temperatura }\left({ }^{\circ} \mathrm{C}\right)\end{array}$} & 73 & 73 & 73 & 73 \\
\hline & 20 & 20 & 20 & 20 \\
\hline Iluminación $\left(\mu \mathrm{W} / \mathrm{cm}^{2}\right)$ & 370 & 371 & 384 & 377 \\
\hline Área coloreada $\left(\mathrm{cm}^{2}\right)$ & 22 & 22 & 22 & 22 \\
\hline Fecha de la prueba & $11 / 09 / 2008$ & $11 / 09 / 2008$ & $11 / 09 / 2008$ & $11 / 09 / 2008$ \\
\hline \multirow{4}{*}{$\begin{array}{l}R_{4}(\%) \\
\text { Media de la } \pm 10 \% \\
\text { ¿Descartado? } \\
\text { Coeficiente de variación }(\%)\end{array}$} & 52 & 56 & 47 & 46 \\
\hline & $50 \pm 5(45-$ & 55) & & \\
\hline & NO & sí & NO & NO \\
\hline & 8 & & & \\
\hline \multirow{4}{*}{$\begin{array}{l}R_{4}(\%) \\
\text { Media de la } \pm 10 \% \\
\text { ¿Descartado? } \\
\text { Coeficiente de variación }(\%)\end{array}$} & 52 & & 47 & 46 \\
\hline & $49 \pm 5(44$ & 54) & & \\
\hline & NO & & NO & NO \\
\hline & 5 & & & \\
\hline \multirow{5}{*}{$\begin{array}{l}R_{26}(\%) \\
\text { Media de la } \pm 10 \% \\
\text { ¿Descartado? } \\
\text { Coeficiente de variación }(\%) \\
\text { Resultado }\end{array}$} & 80 & 82 & 76 & 79 \\
\hline & $79 \pm 8(71$ & 87) & & \\
\hline & NO & NO & NO & NO \\
\hline & 3 & & & \\
\hline & No se desc & rta los resu & dos según U & 11259 \\
\hline
\end{tabular}

Tabla. Detalles concretos del procedimiento experimental, así como los resultados obtenidos para las muestras denominadas Saf $54(14,29)$. 


\begin{tabular}{|c|c|c|c|c|c|c|}
\hline Serie probetas 1 & \multicolumn{6}{|c|}{ Mortero no fotocatalítico } \\
\hline Probeta & \multicolumn{3}{|c|}{5} & \multicolumn{3}{|c|}{6} \\
\hline Peso probeta (g) & \multicolumn{3}{|c|}{176} & \multicolumn{3}{|c|}{172} \\
\hline Consistencia argamasa $(\mathrm{mm})$ UNE-EN 1019 & \multicolumn{6}{|c|}{$114 / 112-108 / 108$} \\
\hline Fecha de ensayo & \multicolumn{3}{|c|}{$02 / 06 / 2009$} & \multicolumn{3}{|c|}{$02 / 06 / 2009$} \\
\hline Área muestra $\left(\mathrm{m}^{2}\right)$ & \multicolumn{3}{|c|}{0,0061} & \multicolumn{3}{|c|}{0,0061} \\
\hline Flujo $\left(\mathrm{m}^{3} / \mathrm{h}\right)$ & \multicolumn{3}{|c|}{0,09} & \multicolumn{3}{|c|}{0,09} \\
\hline \multirow[t]{2}{*}{ Intensidad luz ultravioleta (W/m²) } & \multicolumn{3}{|c|}{20,02} & \multicolumn{3}{|c|}{20,02} \\
\hline & NO & NOx & $\mathrm{NO}_{2}$ & NO & NOx & $\mathrm{NO}_{2}$ \\
\hline$C_{A}(p p b)$ & 393,1 & 537,8 & 144,7 & 384,3 & 533,1 & 148,8 \\
\hline$C_{B}(p p b)$ & 389,2 & 503,9 & 114,7 & 378,8 & 506,4 & 127,6 \\
\hline$C_{L}(p p b)$ & 383,0 & 503,0 & 120,0 & 377,6 & 506,1 & 128,5 \\
\hline A (\%) & 1,6 & 0,2 & $-4,6$ & 0,3 & 0,1 & $-0,7$ \\
\hline$A_{F}(m / h)$ & 12 & 1 & -34 & 2 & 0 & -5 \\
\hline ¿Resultado valido? & $\mathrm{NO}$ & NO & NO & $\mathrm{NO}$ & NO & $\mathrm{NO}$ \\
\hline & \multicolumn{2}{|c|}{ NO } & \multicolumn{2}{|c|}{ NOx } & \multicolumn{2}{|c|}{$\mathrm{NO}_{2}$} \\
\hline Media de la serie $(\%) \pm 10 \%$ & \multicolumn{2}{|c|}{$\begin{array}{c}1,0 \pm 0,1 \\
(0,9-1,1) \\
\end{array}$} & \multicolumn{2}{|c|}{$\begin{array}{c}0,1 \pm 0,0 \\
(0,1-0,1)\end{array}$} & \multicolumn{2}{|c|}{$\begin{array}{c}-2,7 \pm 0,3 \\
(-3,0--2,4)\end{array}$} \\
\hline Media de la serie (AF) $\pm 10 \%$ & \multicolumn{2}{|c|}{$\begin{array}{c}7,0 \pm 0,7 \\
(6,3-7,7)\end{array}$} & \multicolumn{2}{|c|}{$\begin{array}{c}0,9 \pm 0,1 \\
(0,8-1,0)\end{array}$} & \multicolumn{2}{|c|}{$\begin{array}{c}-19,6 \pm 2,0 \\
(-21,6--17,6)\end{array}$} \\
\hline Coeficiente de variación (\%) & \multicolumn{2}{|c|}{67} & \multicolumn{2}{|c|}{50} & \multicolumn{2}{|r|}{74} \\
\hline Humedad relativa (HR \%) & \multicolumn{3}{|c|}{44} & \multicolumn{3}{|c|}{44} \\
\hline Temperatura $\left({ }^{\circ} \mathrm{C}\right)$ & \multicolumn{3}{|c|}{25} & \multicolumn{3}{|c|}{25} \\
\hline
\end{tabular}

Tabla. Detalles concretos del procedimiento experimental, así como los resultados obtenidos para las muestras 5 y 6 de la serie denominada Mortero no Fotocatalítico blanco. 


\begin{tabular}{|c|c|c|c|c|c|c|}
\hline Serie probetas 2 & \multicolumn{6}{|c|}{ Mortero fotocatalítico sin aditivo } \\
\hline Probeta & \multicolumn{3}{|c|}{5} & \multicolumn{3}{|c|}{6} \\
\hline Peso probeta & \multicolumn{3}{|c|}{181} & \multicolumn{3}{|c|}{186} \\
\hline Consistencia argamasa (mm) UNE-EN 1014 & \multicolumn{6}{|c|}{$128 / 128-127 / 127$} \\
\hline Fecha de ensayo & \multicolumn{3}{|c|}{$31 / 08 / 2009$} & \multicolumn{3}{|c|}{ 31/08/2009 } \\
\hline Área muestra $\left(\mathrm{m}^{2}\right)$ & \multicolumn{3}{|c|}{0,0061} & \multicolumn{3}{|c|}{0,0061} \\
\hline Flujo $\left(\mathrm{m}^{3} / \mathrm{h}\right)$ & \multicolumn{3}{|c|}{0,09} & \multicolumn{3}{|c|}{0,09} \\
\hline \multirow[t]{2}{*}{ Intensidad luz ultravioleta (W/m²) } & \multicolumn{3}{|c|}{20,02} & \multicolumn{3}{|c|}{20,02} \\
\hline & NO & NOx & $\mathrm{NO}_{2}$ & NO & NOx & $\mathrm{NO}_{2}$ \\
\hline$C_{A}(p p b)$ & 370,8 & 569,0 & 198,2 & 378,7 & $\begin{array}{c}570 \\
4\end{array}$ & 191,7 \\
\hline $\mathrm{C}_{\mathrm{B}}(\mathrm{ppb})$ & 367,5 & 548,4 & 180,9 & 372,8 & $\begin{array}{c}551, \\
9\end{array}$ & 179,1 \\
\hline$C_{L}(p p b)$ & 339,5 & 514,7 & 175,2 & 347,3 & $\begin{array}{c}515 \\
8 \\
\end{array}$ & 168,5 \\
\hline$A(\%)$ & 7,6 & 6,1 & 3,2 & 6,8 & 6,5 & 5,9 \\
\hline$A_{F}(m / h)$ & 56 & 45 & 23 & 50 & 48 & 44 \\
\hline ¿Resultado valido? & Sí & sí & NO & Sí & sí & NO \\
\hline & \multicolumn{2}{|c|}{ NO } & \multicolumn{2}{|c|}{ NOx } & \multicolumn{2}{|c|}{$\mathrm{NO}_{2}$} \\
\hline Media de la serie $(\%) \pm 10 \%$ & \multicolumn{2}{|c|}{$\begin{array}{l}7,2 \pm 0,7 \\
(6,5-7,9) \\
\end{array}$} & \multicolumn{2}{|c|}{$\begin{array}{c}6,3 \pm 0,6 \\
(5,7-6,9) \\
\end{array}$} & \multicolumn{2}{|c|}{$\begin{array}{c}4,5 \pm 0,5 \\
(4,0-5,0)\end{array}$} \\
\hline Media de la serie $(A F) \pm 10 \%$ & \multicolumn{2}{|c|}{$\begin{array}{c}53,3 \pm 5,3 \\
(48,0-58,6)\end{array}$} & \multicolumn{2}{|c|}{$\begin{array}{c}46,7 \pm 4,7 \\
(42,0-51,4)\end{array}$} & \multicolumn{2}{|c|}{$\begin{array}{c}33,4 \pm 3,3 \\
(30,1-36,7)\end{array}$} \\
\hline Coeficiente de variación (\%) & \multicolumn{2}{|c|}{5} & \multicolumn{2}{|c|}{3} & \multicolumn{2}{|c|}{31} \\
\hline Humedad relativa (HR \%) & \multicolumn{3}{|c|}{53} & \multicolumn{3}{|c|}{54} \\
\hline Temperatura $\left({ }^{\circ} \mathrm{C}\right)$ & \multicolumn{3}{|c|}{30} & \multicolumn{3}{|c|}{31} \\
\hline
\end{tabular}

Tabla. Detalles concretos del procedimiento experimental, asi como los resultados obtenidos para las muestras 5 y 6 de la serie denominada Mortero Fotocatalítico blanco sin aditivo. 


\begin{tabular}{|c|c|c|c|c|c|c|}
\hline Serie probetas 3 & \multicolumn{6}{|c|}{$15000(0,64)$} \\
\hline Probeta & \multicolumn{3}{|c|}{5} & \multicolumn{3}{|c|}{6} \\
\hline Peso probeta & \multicolumn{3}{|c|}{131} & \multicolumn{3}{|c|}{130} \\
\hline Consistencia argamasa (mm) UNE-EN 1019 & \multicolumn{6}{|c|}{$160 / 158-159 / 163$} \\
\hline Fecha de ensayo & \multicolumn{3}{|c|}{$22 / 05 / 2009$} & \multicolumn{3}{|c|}{$27 / 05 / 2009$} \\
\hline Área muestra $\left(m^{2}\right)$ & \multicolumn{3}{|c|}{0,0061} & \multicolumn{3}{|c|}{0,0061} \\
\hline Flujo $\left(\mathrm{m}^{3} / \mathrm{h}\right)$ & \multicolumn{3}{|c|}{0,09} & \multicolumn{3}{|c|}{0,09} \\
\hline Intensidad luz ultravioleta $\left(\mathrm{W} / \mathrm{m}^{2}\right)$ & \multicolumn{3}{|c|}{20,03} & \multicolumn{3}{|c|}{20,01} \\
\hline & NO & NOx & $\mathrm{NO}_{2}$ & NO & NOx & $\mathrm{NO}_{2}$ \\
\hline $\mathrm{C}_{\mathrm{A}}(\mathrm{ppb})$ & 370,1 & 522,3 & 152,2 & 413,5 & $\begin{array}{c}558 \\
3 \\
\end{array}$ & 144,8 \\
\hline$C_{B}(p p b)$ & 362,9 & 510,4 & 147,5 & 405,0 & $\begin{array}{c}541, \\
6 \\
\end{array}$ & 136,6 \\
\hline$C_{L}(p p b)$ & 321,9 & 449,0 & 127,1 & 341,1 & $\begin{array}{c}474 \\
5\end{array}$ & 133,4 \\
\hline$A(\%)$ & 11,3 & 12,0 & 13,8 & 15,8 & 12,4 & 2,3 \\
\hline$A_{F}(m / h)$ & 83 & 89 & 102 & 116 & 91 & 17 \\
\hline \multirow[t]{2}{*}{ ¿Resultado valido? } & NO & sí & NO & NO & Sí & NO \\
\hline & \multicolumn{2}{|c|}{ NO } & \multicolumn{2}{|c|}{ NOx } & \multicolumn{2}{|r|}{$\mathrm{NO}_{2}$} \\
\hline Media de la serie $(\%) \pm 10 \%$ & \multicolumn{2}{|c|}{$\begin{array}{c}13,5 \pm 1,4 \\
(12,1-14,9) \\
\end{array}$} & \multicolumn{2}{|c|}{$\begin{array}{c}12,2 \pm 1,2 \\
(11,0-13,4)\end{array}$} & \multicolumn{2}{|c|}{$\begin{array}{c}8,1 \pm 0,8 \\
(7,3-8,9)\end{array}$} \\
\hline Media de la serie (AF) $\pm 10 \%$ & \multicolumn{2}{|c|}{$\begin{array}{c}99,8 \pm 10,0 \\
(89,8-109,9)\end{array}$} & \multicolumn{2}{|c|}{$\begin{array}{c}90,0 \pm 9,0 \\
(81,0-99,0)\end{array}$} & \multicolumn{2}{|c|}{$\begin{array}{c}59,6 \pm 6,0 \\
(53,6-65,6)\end{array}$} \\
\hline Coeficiente de variación (\%) & \multicolumn{2}{|c|}{17} & \multicolumn{2}{|c|}{2} & \multicolumn{2}{|c|}{71} \\
\hline Humedad relativa (HR \%) & \multicolumn{3}{|c|}{54} & \multicolumn{3}{|c|}{52} \\
\hline Temperatura $\left({ }^{\circ} \mathrm{C}\right)$ & \multicolumn{3}{|c|}{27} & \multicolumn{3}{|c|}{22} \\
\hline
\end{tabular}

Tabla. Detalles concretos del procedimiento experimental, asi como los resultados obtenidos para las muestras 5 y 6 de la serie denominada $15000(0,64)$. 


\begin{tabular}{|c|c|c|c|c|c|c|}
\hline Serie probetas 4 & \multicolumn{6}{|c|}{$15000(1,42)$} \\
\hline Probeta & \multicolumn{3}{|c|}{5} & \multicolumn{3}{|c|}{6} \\
\hline Peso probeta & \multicolumn{3}{|c|}{123} & \multicolumn{3}{|c|}{126} \\
\hline Consistencia argamasa $(\mathrm{mm})$ UNE-EN 1014 & \multicolumn{6}{|c|}{$120 / 120-115 / 120$} \\
\hline Fecha de ensayo & \multicolumn{3}{|c|}{ 11/11/2008 } & \multicolumn{3}{|c|}{$07 / 11 / 2008$} \\
\hline Área muestra $\left(\mathrm{m}^{2}\right)$ & \multicolumn{3}{|c|}{0,0061} & \multicolumn{3}{|c|}{0,0061} \\
\hline Flujo $\left(\mathrm{m}^{3} / \mathrm{h}\right)$ & \multicolumn{3}{|c|}{0,09} & \multicolumn{3}{|c|}{0,09} \\
\hline Intensidad luz ultravioleta $\left(\mathrm{W} / \mathrm{m}^{2}\right)$ & \multicolumn{3}{|c|}{20,02} & \multicolumn{3}{|c|}{20,03} \\
\hline & NO & NOx & $\mathrm{NO}_{2}$ & NO & NOx & $\mathrm{NO}_{2}$ \\
\hline$C_{A}(p p b)$ & 396,3 & 554,9 & 158,6 & 386,5 & 552,5 & 166,0 \\
\hline$C_{B}$ (ppb) & 385,7 & 535,3 & 149,6 & 377,4 & 529,1 & 151,7 \\
\hline$C_{L}(p p b)$ & 340,0 & 494,6 & 154,6 & 333,4 & 488,4 & 155,0 \\
\hline A (\%) & 11,8 & 7,6 & $-3,3$ & 11,7 & 7,7 & $-2,2$ \\
\hline$A_{F}(m / h)$ & 87 & 56 & -25 & 86 & 57 & -16 \\
\hline \multirow[t]{2}{*}{ ¿Resultado valido? } & Sí & Sí & $\mathrm{NO}$ & Sí & Sí & NO \\
\hline & \multicolumn{2}{|c|}{ NO } & \multicolumn{2}{|c|}{ NOx } & \multicolumn{2}{|c|}{$\mathrm{NO}_{2}$} \\
\hline Media de la serie $(\%) \pm 10 \%$ & \multicolumn{2}{|c|}{$\begin{array}{c}11,8 \pm 1,2 \\
(10,6-13,0)\end{array}$} & \multicolumn{2}{|c|}{$\begin{array}{c}7,6 \pm 0,8 \\
(6,8-8,4)\end{array}$} & \multicolumn{2}{|c|}{$\begin{array}{c}-2,8 \pm 0,3 \\
(-3,1--2,5)\end{array}$} \\
\hline Media de la serie (AF) $\pm 10 \%$ & \multicolumn{2}{|c|}{$\begin{array}{c}86,6 \pm 8,7 \\
(77,9-95,3)\end{array}$} & \multicolumn{2}{|c|}{$\begin{array}{c}56,3 \pm 5,6 \\
(50,7-61,9)\end{array}$} & \multicolumn{2}{|c|}{$\begin{array}{c}-20,3 \pm 2,0 \\
(-22,3--18,3)\end{array}$} \\
\hline Coeficiente de variación (\%) & \multicolumn{2}{|c|}{1} & \multicolumn{2}{|c|}{1} & \multicolumn{2}{|c|}{21} \\
\hline Humedad relativa (HR \%) & \multicolumn{3}{|c|}{52} & \multicolumn{3}{|c|}{51} \\
\hline Temperatura $\left({ }^{\circ} \mathrm{C}\right)$ & \multicolumn{3}{|c|}{20} & \multicolumn{3}{|c|}{21} \\
\hline
\end{tabular}

Tabla. Detalles concretos del procedimiento experimental, asi como los resultados obtenidos para las muestras 5 y 6 de la serie denominada $15000(1,42)$. 


\begin{tabular}{|c|c|c|c|c|c|c|}
\hline Serie probetas 5 & \multicolumn{6}{|c|}{$10012(0,64)$} \\
\hline Probeta & \multicolumn{3}{|c|}{5} & \multicolumn{3}{|c|}{6} \\
\hline Peso probeta & \multicolumn{3}{|c|}{126} & \multicolumn{3}{|c|}{125} \\
\hline Consistencia argamasa (mm) UNE-EN 1014 & \multicolumn{6}{|c|}{$162 / 159-161 / 165$} \\
\hline Fecha de ensayo & \multicolumn{3}{|c|}{$26 / 11 / 2008$} & \multicolumn{3}{|c|}{$28 / 11 / 2008$} \\
\hline Área muestra $\left(\mathrm{m}^{2}\right)$ & \multicolumn{3}{|c|}{0,0061} & \multicolumn{3}{|c|}{0,0061} \\
\hline Flujo $\left(\mathrm{m}^{3} / \mathrm{h}\right)$ & \multicolumn{3}{|c|}{0,09} & \multicolumn{3}{|c|}{0,09} \\
\hline Intensidad luz ultravioleta (W/m²) & \multicolumn{3}{|c|}{20,02} & \multicolumn{3}{|c|}{20,02} \\
\hline & NO & NOx & $\mathrm{NO}_{2}$ & NO & NOx & $\mathrm{NO}_{2}$ \\
\hline$C_{A}(p p b)$ & 406,3 & 559,5 & 153,2 & 399,3 & 549,8 & 150,5 \\
\hline$C_{B}(p p b)$ & 390,3 & 532,3 & 142,0 & 382,8 & 517,3 & 134,5 \\
\hline$C_{L}$ (ppb) & 317,6 & 453,1 & 135,5 & 321,4 & 464,1 & 142,7 \\
\hline$A(\%)$ & 18,6 & 14,9 & 4,6 & 16,0 & 10,3 & $-6,1$ \\
\hline$A_{F}(m / h)$ & 137 & 110 & 34 & 118 & 76 & -45 \\
\hline \multirow[t]{2}{*}{ ¿Resultado valido? } & Sí & $\mathrm{NO}$ & NO & Sí & $\mathrm{NO}$ & $\mathrm{NO}$ \\
\hline & \multicolumn{2}{|c|}{ NO } & \multicolumn{2}{|c|}{ NOx } & \multicolumn{2}{|c|}{$\mathrm{NO}_{2}$} \\
\hline Media de la serie $(\%) \pm 10 \%$ & \multicolumn{2}{|c|}{$\begin{array}{c}17,3 \pm 1,7 \\
(15,6-19,0)\end{array}$} & \multicolumn{2}{|c|}{$\begin{array}{c}12,6 \pm 1,3 \\
(11,3-13,9)\end{array}$} & \multicolumn{2}{|c|}{$\begin{array}{c}-0,8 \pm 0,1 \\
(-0,9--0,7)\end{array}$} \\
\hline Media de la serie (AF) $\pm 10 \%$ & \multicolumn{2}{|c|}{$\begin{array}{c}127,7 \pm 12,7 \\
(114,3-139,7)\end{array}$} & \multicolumn{2}{|c|}{$\begin{array}{c}92,7 \pm 9,3 \\
(83,4-102,0)\end{array}$} & \multicolumn{2}{|c|}{$\begin{array}{c}-5,6 \pm 5 \\
(-6,2--5,0)\end{array}$} \\
\hline Coeficiente de variación (\%) & \multicolumn{2}{|c|}{7} & \multicolumn{2}{|c|}{18} & \multicolumn{2}{|c|}{150} \\
\hline Humedad relativa (HR \%) & \multicolumn{3}{|c|}{48} & \multicolumn{3}{|c|}{53} \\
\hline Temperatura $\left({ }^{\circ} \mathrm{C}\right)$ & \multicolumn{3}{|c|}{21} & \multicolumn{3}{|c|}{20} \\
\hline
\end{tabular}

Tabla. Detalles concretos del procedimiento experimental, asi como los resultados obtenidos para las muestras 5 y 6 de la serie denominada $10012(0,64)$. 


\begin{tabular}{|c|c|c|c|c|c|c|}
\hline Serie probetas 6 & \multicolumn{6}{|c|}{$10012(1,42)$} \\
\hline Probeta & \multicolumn{3}{|c|}{5} & \multicolumn{3}{|c|}{6} \\
\hline Peso probeta & \multicolumn{3}{|c|}{128} & \multicolumn{3}{|c|}{131} \\
\hline Consistencia argamasa $(\mathrm{mm})$ UNE-EN 101 & \multicolumn{6}{|c|}{$117 / 125-114 / 118$} \\
\hline Fecha de ensayo & \multicolumn{3}{|c|}{ 02/03/2009 } & \multicolumn{3}{|c|}{$13 / 02 / 2009$} \\
\hline Área muestra $\left(\mathrm{m}^{2}\right)$ & \multicolumn{3}{|c|}{0,0061} & \multicolumn{3}{|c|}{0,0061} \\
\hline Flujo $\left(\mathrm{m}^{3} / \mathrm{h}\right)$ & \multicolumn{3}{|c|}{0,09} & \multicolumn{3}{|c|}{0,09} \\
\hline \multirow[t]{2}{*}{ Intensidad luz ultravioleta $\left(\mathrm{W} / \mathrm{m}^{2}\right)$} & \multicolumn{3}{|c|}{20,02} & \multicolumn{3}{|c|}{20,02} \\
\hline & NO & NOx & $\mathrm{NO}_{2}$ & NO & NOx & $\mathrm{NO}_{2}$ \\
\hline$C_{A}(p p b)$ & 398,3 & 577,5 & 179,2 & 373,7 & 520,2 & 146,5 \\
\hline$C_{B}(p p b)$ & 394,8 & 562,9 & 168,1 & 367,5 & 501,5 & 134,0 \\
\hline$C_{L}(p p b)$ & 328,5 & 486,5 & 158,0 & 317,2 & 447,0 & 129,8 \\
\hline A (\%) & 16,8 & 13,6 & 6,0 & 13,7 & 10,9 & 3,1 \\
\hline$A_{F}(m / h)$ & 124 & 100 & 44 & 101 & 80 & 23 \\
\hline ¿Resultado valido? & $\mathrm{NO}$ & $\mathrm{NO}$ & $\mathrm{NO}$ & Sí & $\mathrm{NO}$ & $\mathrm{NO}$ \\
\hline & \multicolumn{2}{|c|}{ NO } & \multicolumn{2}{|c|}{ NOx } & \multicolumn{2}{|c|}{$\mathrm{NO}_{2}$} \\
\hline Media de la serie $(\%) \pm 10 \%$ & \multicolumn{2}{|c|}{$\begin{array}{c}15,2 \pm 1,5 \\
(13,7-16,7) \\
\end{array}$} & \multicolumn{2}{|c|}{$\begin{array}{c}12,2 \pm 1,2 \\
(11,0-13,4)\end{array}$} & \multicolumn{2}{|c|}{$\begin{array}{c}4,6 \pm 0,5 \\
(4,1-5,1) \\
\end{array}$} \\
\hline Media de la serie (AF) $\pm 10 \%$ & \multicolumn{2}{|c|}{$\begin{array}{c}112,3 \pm 11,2 \\
(101,1-123,5)\end{array}$} & \multicolumn{2}{|c|}{$\begin{array}{c}90,1 \pm 9,0 \\
(81,1-99,1)\end{array}$} & \multicolumn{2}{|c|}{$\begin{array}{c}33,7 \pm 3,4 \\
(30,3-37,1)\end{array}$} \\
\hline Coeficiente de variación (\%) & \multicolumn{2}{|c|}{10} & \multicolumn{2}{|c|}{11} & \multicolumn{2}{|c|}{31} \\
\hline Humedad relativa (HR \%) & \multicolumn{3}{|c|}{53} & \multicolumn{3}{|c|}{56} \\
\hline Temperatura $\left({ }^{\circ} \mathrm{C}\right)$ & \multicolumn{3}{|c|}{20} & \multicolumn{3}{|c|}{21} \\
\hline
\end{tabular}

Tabla. Detalles concretos del procedimiento experimental, asi como los resultados obtenidos para las muestras 5 y 6 de la serie denominada $10012(1,42)$. 


\begin{tabular}{|c|c|c|c|c|c|c|}
\hline erie probetas 7 & \multicolumn{6}{|c|}{$\mathrm{H} 20(0,43)$} \\
\hline Probeta & \multicolumn{3}{|c|}{5} & \multicolumn{3}{|c|}{6} \\
\hline Peso probeta & \multicolumn{3}{|c|}{156} & \multicolumn{3}{|c|}{162} \\
\hline Consistencia argamasa (mm) UNE-EN 1015 & \multicolumn{6}{|c|}{$195 / 192-185 / 185$} \\
\hline Fecha de ensayo & \multicolumn{3}{|c|}{$02 / 03 / 2009$} & \multicolumn{3}{|c|}{$21 / 11 / 2008$} \\
\hline Área muestra $\left(\mathrm{m}^{2}\right)$ & \multicolumn{3}{|c|}{0,0061} & \multicolumn{3}{|c|}{0,0061} \\
\hline Flujo $\left(\mathrm{m}^{3} / \mathrm{h}\right)$ & \multicolumn{3}{|c|}{0,09} & \multicolumn{3}{|c|}{0,09} \\
\hline Intensidad luz ultravioleta (W/m²) & \multicolumn{3}{|c|}{20,02} & \multicolumn{3}{|c|}{20,04} \\
\hline & NO & NOx & $\mathrm{NO}_{2}$ & NO & NOx & $\mathrm{NO}_{2}$ \\
\hline $\mathrm{C}_{\mathrm{A}}$ (ppb) & 400,9 & 577,0 & 176,1 & 375,2 & 537,4 & 162,2 \\
\hline $\mathrm{C}_{\mathrm{B}}(\mathrm{ppb})$ & 394,8 & 560,4 & 165,6 & 369,2 & 521,1 & 151,9 \\
\hline$C_{L}(p p b)$ & 316,6 & 466,7 & 150,1 & 304,1 & 451,2 & 147,1 \\
\hline$A(\%)$ & 19,8 & 16,7 & 9,4 & 17,6 & 13,4 & 3,2 \\
\hline$A_{F}(m / h)$ & 146 & 123 & 69 & 130 & 99 & 23 \\
\hline \multirow[t]{2}{*}{ ¿Resultado valido? } & Sí & $\mathrm{NO}$ & $\mathrm{NO}$ & Sí & $\mathrm{NO}$ & $\mathrm{NO}$ \\
\hline & \multicolumn{2}{|c|}{ NO } & \multicolumn{2}{|c|}{ NOx } & \multicolumn{2}{|c|}{$\mathrm{NO}_{2}$} \\
\hline Media de la serie $(\%) \pm 10 \%$ & \multicolumn{2}{|c|}{$\begin{array}{c}18,7 \pm 1,9 \\
(16,8-20,6)\end{array}$} & \multicolumn{2}{|c|}{$\begin{array}{c}15,1 \pm 1,5 \\
(13,6-16,6)\end{array}$} & \multicolumn{2}{|c|}{$\begin{array}{c}6,3 \pm 0,6 \\
(5,7-6,9)\end{array}$} \\
\hline Media de la serie $(A F) \pm 10 \%$ & \multicolumn{2}{|c|}{$\begin{array}{c}137,9 \pm 13,8 \\
(124,1-151,7)\end{array}$} & \multicolumn{2}{|c|}{$\begin{array}{c}111,0 \pm 11,1 \\
(99,9-122,1\end{array}$} & \multicolumn{2}{|c|}{$\begin{array}{c}46,1 \pm 4,6 \\
(41,5-50,7)\end{array}$} \\
\hline Coeficiente de variación (\%) & \multicolumn{2}{|c|}{6} & \multicolumn{2}{|c|}{11} & \multicolumn{2}{|c|}{50} \\
\hline Humedad relativa (HR \%) & \multicolumn{3}{|c|}{51} & \multicolumn{3}{|c|}{55} \\
\hline Temperatura $\left({ }^{\circ} \mathrm{C}\right)$ & \multicolumn{3}{|c|}{20} & \multicolumn{3}{|c|}{22} \\
\hline
\end{tabular}

Tabla. Detalles concretos del procedimiento experimental, así como los resultados obtenidos para las muestras 5 y 6 de la serie denominada $H 20(0,43)$. 


\begin{tabular}{|c|c|c|c|c|c|c|}
\hline Serie probetas 8 & \multicolumn{6}{|c|}{$\mathrm{H} 20(1,21)$} \\
\hline Probeta & \multicolumn{3}{|c|}{5} & \multicolumn{3}{|c|}{6} \\
\hline Peso probeta & \multicolumn{3}{|c|}{173} & \multicolumn{3}{|c|}{170} \\
\hline Consistencia argamasa (mm) UNE-EN 1019 & \multicolumn{6}{|c|}{$165 / 170-165 / 165$} \\
\hline Fecha de ensayo & \multicolumn{3}{|c|}{$03 / 04 / 2009$} & \multicolumn{3}{|c|}{$03 / 04 / 2009$} \\
\hline Área muestra $\left(\mathrm{m}^{2}\right)$ & \multicolumn{3}{|c|}{0,0061} & \multicolumn{3}{|c|}{0,0061} \\
\hline Flujo $\left(\mathrm{m}^{3} / \mathrm{h}\right)$ & \multicolumn{3}{|c|}{0,09} & \multicolumn{3}{|c|}{0,09} \\
\hline Intensidad luz ultravioleta (W/m²) & \multicolumn{3}{|c|}{20,02} & \multicolumn{3}{|c|}{20,02} \\
\hline & NO & NOx & $\mathrm{NO}_{2}$ & NO & NOx & $\mathrm{NO}_{2}$ \\
\hline$C_{A}(p p b)$ & 371,2 & 529,5 & 158,3 & 378,4 & 527,4 & 149,0 \\
\hline$C_{B}(p p b)$ & 369,6 & 517,0 & 147,4 & 373,9 & 512,0 & 138,1 \\
\hline$C_{L}(p p b)$ & 354,4 & 472,1 & 117,7 & 354,1 & 473,0 & 118,9 \\
\hline$A(\%)$ & 4,1 & 8,7 & 20,1 & 5,3 & 7,6 & 13,9 \\
\hline$A_{F}(m / h)$ & 30 & 64 & 148 & 39 & 56 & 102 \\
\hline \multirow[t]{2}{*}{ ¿Resultado valido? } & NO & Sí & NO & $\mathrm{NO}$ & Sí & $\mathrm{NO}$ \\
\hline & \multicolumn{2}{|c|}{ NO } & \multicolumn{2}{|c|}{ NOx } & \multicolumn{2}{|c|}{$\mathrm{NO}_{2}$} \\
\hline Media de la serie $(\%) \pm 10 \%$ & \multicolumn{2}{|c|}{$\begin{array}{c}4,7 \pm 0,5 \\
(4,2-5,2) \\
\end{array}$} & \multicolumn{2}{|c|}{$\begin{array}{c}8,2 \pm 0,8 \\
(7,4-9,0)\end{array}$} & \multicolumn{2}{|c|}{$\begin{array}{c}17,0 \pm 1,7 \\
(15,3-18,7)\end{array}$} \\
\hline Media de la serie $(A F) \pm 10 \%$ & \multicolumn{2}{|c|}{$\begin{array}{c}34,7 \pm 3,5 \\
(31,2-38,2)\end{array}$} & \multicolumn{2}{|c|}{$\begin{array}{c}60,1 \pm 6,0 \\
(54,1-66,1)\end{array}$} & \multicolumn{2}{|c|}{$\begin{array}{c}125,5 \pm 12,6 \\
(113,0-138,1)\end{array}$} \\
\hline Coeficiente de variación (\%) & \multicolumn{2}{|c|}{13} & \multicolumn{2}{|c|}{7} & \multicolumn{2}{|c|}{18} \\
\hline Humedad relativa (HR \%) & \multicolumn{3}{|c|}{50} & \multicolumn{3}{|c|}{51} \\
\hline Temperatura $\left({ }^{\circ} \mathrm{C}\right)$ & \multicolumn{3}{|c|}{23} & \multicolumn{3}{|c|}{23} \\
\hline
\end{tabular}

Tabla. Detalles concretos del procedimiento experimental, asi como los resultados obtenidos para las muestras 5 y 6 de la serie denominada $H 20(1,21)$. 


\begin{tabular}{|c|c|c|c|c|c|c|}
\hline Serie probetas 9 & \multicolumn{6}{|c|}{ MH2O0 $(0,43)$} \\
\hline Probeta & \multicolumn{3}{|c|}{5} & \multicolumn{3}{|c|}{6} \\
\hline Peso probeta & \multicolumn{3}{|c|}{165} & \multicolumn{3}{|c|}{170} \\
\hline Consistencia argamasa (mm) UNE-EN 101 & \multicolumn{6}{|c|}{$123 / 123-122 / 123$} \\
\hline Fecha de ensayo & \multicolumn{3}{|c|}{$03 / 04 / 2009$} & \multicolumn{3}{|c|}{$03 / 04 / 2009$} \\
\hline Área muestra $\left(\mathrm{m}^{2}\right)$ & \multicolumn{3}{|c|}{0,0061} & \multicolumn{3}{|c|}{0,0061} \\
\hline Flujo $\left(\mathrm{m}^{3} / \mathrm{h}\right)$ & \multicolumn{3}{|c|}{0,09} & \multicolumn{3}{|c|}{0,09} \\
\hline Intensidad luz ultravioleta $\left(\mathrm{W} / \mathrm{m}^{2}\right)$ & \multicolumn{3}{|c|}{20,02} & \multicolumn{3}{|c|}{20,02} \\
\hline & NO & NOx & $\mathrm{NO}_{2}$ & NO & NOx & $\mathrm{NO}_{2}$ \\
\hline$C_{A}(p p b)$ & 378,4 & 529,8 & 151,4 & 376,6 & 532,7 & 156,1 \\
\hline$C_{B}(p p b)$ & 374,2 & 516,3 & 142,1 & 368,9 & 513,5 & 144,6 \\
\hline$C_{L}(p p b)$ & 353,8 & 480,6 & 126,8 & 332,3 & 454,2 & 121,9 \\
\hline A (\%) & 5,5 & 6,9 & 10,8 & 9,9 & 11,5 & 15,7 \\
\hline$A_{F}(m / h)$ & 40 & 51 & 79 & 73 & 85 & 116 \\
\hline \multirow[t]{2}{*}{ ¿Resultado valido? } & NO & NO & NO & NO & NO & NO \\
\hline & \multicolumn{2}{|c|}{ NO } & \multicolumn{2}{|c|}{ NOx } & \multicolumn{2}{|c|}{$\mathrm{NO}_{2}$} \\
\hline Media de la serie $(\%) \pm 10 \%$ & \multicolumn{2}{|c|}{$\begin{array}{c}7,7 \pm 0,8 \\
(6,9-8,5) \\
\end{array}$} & \multicolumn{2}{|c|}{$\begin{array}{c}9,2 \pm 0,9 \\
(8,3-10,1)\end{array}$} & \multicolumn{2}{|c|}{$\begin{array}{c}13,2 \pm 1,3 \\
(11,9-14,5)\end{array}$} \\
\hline Media de la serie $(A F) \pm 10 \%$ & \multicolumn{2}{|c|}{$\begin{array}{c}56,6 \pm 5,7 \\
(50,9-62,3)\end{array}$} & \multicolumn{2}{|c|}{$\begin{array}{c}68,0 \pm 6,8 \\
(61,2-74,8)\end{array}$} & \multicolumn{2}{|c|}{$\begin{array}{c}97,5 \pm 9,8 \\
(87,8-107,3)\end{array}$} \\
\hline Coeficiente de variación (\%) & \multicolumn{2}{|c|}{29} & \multicolumn{2}{|c|}{25} & \multicolumn{2}{|c|}{19} \\
\hline Humedad relativa (HR \%) & \multicolumn{3}{|c|}{51} & \multicolumn{3}{|c|}{52} \\
\hline Temperatura $\left({ }^{\circ} \mathrm{C}\right)$ & \multicolumn{3}{|c|}{23} & \multicolumn{3}{|c|}{24} \\
\hline
\end{tabular}

Tabla. Detalles concretos del procedimiento experimental, asi como los resultados obtenidos para las muestras 5 y 6 de la serie denominada $\mathrm{MH} 200(0,43)$. 


\begin{tabular}{|c|c|c|c|c|c|c|}
\hline Serie probetas 10 & \multicolumn{6}{|c|}{ MH200 (1,21) } \\
\hline Probeta & \multicolumn{3}{|c|}{5} & \multicolumn{3}{|c|}{6} \\
\hline Peso probeta & \multicolumn{3}{|c|}{163} & \multicolumn{3}{|c|}{160} \\
\hline Consistencia argamasa (mm) UNE-EN 101 & \multicolumn{6}{|c|}{$125 / 128-121 / 122$} \\
\hline Fecha de ensayo & \multicolumn{3}{|c|}{$05 / 11 / 2008$} & \multicolumn{3}{|c|}{$06 / 11 / 2008$} \\
\hline Área muestra $\left(\mathrm{m}^{2}\right)$ & \multicolumn{3}{|c|}{0,0061} & \multicolumn{3}{|c|}{0,0061} \\
\hline Flujo $\left(\mathrm{m}^{3} / \mathrm{h}\right)$ & \multicolumn{3}{|c|}{0,09} & \multicolumn{3}{|c|}{0,09} \\
\hline \multirow[t]{2}{*}{ Intensidad luz ultravioleta $\left(\mathrm{W} / \mathrm{m}^{2}\right)$} & \multicolumn{3}{|c|}{20,01} & \multicolumn{3}{|c|}{20} \\
\hline & NO & NOx & $\mathrm{NO}_{2}$ & NO & NOx & $\mathrm{NO}_{2}$ \\
\hline$C_{A}(p p b)$ & 409,5 & 557,6 & 148,1 & 398,0 & 554,1 & 156,1 \\
\hline$C_{B}(p p b)$ & 397,1 & 536,9 & 139,8 & 389,6 & 536,8 & 147,2 \\
\hline$C_{L}(p p b)$ & 373,4 & 511,2 & 137,8 & 362,1 & 508,6 & 146,5 \\
\hline$A(\%)$ & 6,0 & 4,8 & 1,4 & 7,1 & 5,3 & 0,5 \\
\hline$A_{F}(m / h)$ & 44 & 35 & 11 & 52 & 39 & 4 \\
\hline \multirow[t]{2}{*}{ ¿Resultado valido? } & Sí & Sí & NO & Sí & Sí & $\mathrm{NO}$ \\
\hline & \multicolumn{2}{|c|}{ NO } & \multicolumn{2}{|c|}{ NOx } & \multicolumn{2}{|c|}{$\mathrm{NO}_{2}$} \\
\hline Media de la serie $(\%) \pm 10 \%$ & \multicolumn{2}{|c|}{$\begin{array}{c}6,5 \pm 0,7 \\
(5,9-7,2) \\
\end{array}$} & \multicolumn{2}{|c|}{$\begin{array}{c}5,0 \pm 0,5 \\
(4,5-5,5)\end{array}$} & \multicolumn{2}{|c|}{$\begin{array}{c}1,0 \pm 0,1 \\
(0,9-1,1)\end{array}$} \\
\hline Media de la serie $(A F) \pm 10 \%$ & \multicolumn{2}{|c|}{$\begin{array}{c}48,0 \pm 4,8 \\
(43,2-52,8)\end{array}$} & \multicolumn{2}{|c|}{$\begin{array}{c}37,0 \pm 3,7 \\
(33,3-40,7)\end{array}$} & \multicolumn{2}{|c|}{$\begin{array}{c}7,0 \pm 0,7 \\
(6,3-7,7)\end{array}$} \\
\hline Coeficiente de variación (\%) & \multicolumn{2}{|c|}{8} & \multicolumn{2}{|c|}{5} & \multicolumn{2}{|c|}{50} \\
\hline Humedad relativa (HR \%) & \multicolumn{3}{|c|}{54} & \multicolumn{3}{|c|}{46} \\
\hline Temperatura $\left({ }^{\circ} \mathrm{C}\right)$ & \multicolumn{3}{|c|}{19} & \multicolumn{3}{|c|}{21} \\
\hline
\end{tabular}

Tabla. Detalles concretos del procedimiento experimental, asi como los resultados obtenidos para las muestras 5 y 6 de la serie denominada $\mathrm{MH} 200(1,21)$. 


\begin{tabular}{|c|c|c|c|c|c|c|}
\hline Serie probetas 11 & \multicolumn{6}{|c|}{ LS $14(0,026)$} \\
\hline Probeta & \multicolumn{3}{|c|}{5} & \multicolumn{3}{|c|}{6} \\
\hline Peso probeta & \multicolumn{3}{|c|}{155} & \multicolumn{3}{|c|}{162} \\
\hline Consistencia argamasa (mm) UNE-EN 1015 & \multicolumn{6}{|c|}{$150 / 152-150 / 150$} \\
\hline Fecha de ensayo & \multicolumn{3}{|c|}{ 12/03/2009 } & \multicolumn{3}{|c|}{$13 / 03 / 2009$} \\
\hline Área muestra $\left(\mathrm{m}^{2}\right)$ & \multicolumn{3}{|c|}{0,0061} & \multicolumn{3}{|c|}{0,0061} \\
\hline Flujo $\left(\mathrm{m}^{3} / \mathrm{h}\right)$ & \multicolumn{3}{|c|}{0,09} & \multicolumn{3}{|c|}{0,09} \\
\hline Intensidad luz ultravioleta (W/m²) & \multicolumn{3}{|c|}{20} & \multicolumn{3}{|c|}{20} \\
\hline & NO & NOx & $\mathrm{NO}_{2}$ & NO & NOx & $\mathrm{NO}_{2}$ \\
\hline$C_{A}(p p b)$ & 396,0 & 572,2 & 176,2 & 382,5 & 547,6 & 165,1 \\
\hline$C_{B}(p p b)$ & 390,4 & 555,7 & 165,3 & 378,6 & 533,4 & 154,8 \\
\hline$C_{L}(p p b)$ & 312,1 & 474,1 & 162,0 & 295,4 & 450,0 & 154,6 \\
\hline $\mathrm{A}(\%)$ & 20,1 & 14,7 & 2,0 & 22,0 & 15,6 & 0,1 \\
\hline$A_{F}(m / h)$ & 148 & 108 & 15 & 162 & 115 & 1 \\
\hline \multirow[t]{2}{*}{ ¿Resultado valido? } & Sí & Sí & $\mathrm{NO}$ & Sí & sí & $\mathrm{NO}$ \\
\hline & \multicolumn{2}{|c|}{ NO } & \multicolumn{2}{|c|}{ NOx } & \multicolumn{2}{|c|}{$\mathrm{NO}_{2}$} \\
\hline Media de la serie $(\%) \pm 10 \%$ & \multicolumn{2}{|c|}{$\begin{array}{c}21,0 \pm 2,1 \\
(18,9-23,1)\end{array}$} & \multicolumn{2}{|c|}{$\begin{array}{c}15,2 \pm 1,5 \\
(13,7-16,7)\end{array}$} & \multicolumn{2}{|c|}{$\begin{array}{c}1,1 \pm 0,1 \\
(1,0-1,2)\end{array}$} \\
\hline Media de la serie $(A F) \pm 10 \%$ & \multicolumn{2}{|c|}{$\begin{array}{c}155,0 \pm 15,5 \\
(139.5-170,5)\end{array}$} & \multicolumn{2}{|c|}{$\begin{array}{c}111,8 \pm 11,2 \\
(100,6-123,0)\end{array}$} & \multicolumn{2}{|c|}{$\begin{array}{c}7,8 \pm 0,8 \\
(7,0-8,6)\end{array}$} \\
\hline Coeficiente de variación (\%) & \multicolumn{2}{|c|}{5} & \multicolumn{2}{|c|}{3} & \multicolumn{2}{|c|}{88} \\
\hline Humedad relativa (HR \%) & \multicolumn{3}{|c|}{43} & \multicolumn{3}{|c|}{49} \\
\hline Temperatura $\left({ }^{\circ} \mathrm{C}\right)$ & \multicolumn{3}{|c|}{22} & \multicolumn{3}{|c|}{25} \\
\hline
\end{tabular}

Tabla. Detalles concretos del procedimiento experimental, asi como los resultados obtenidos para las muestras 5 y 6 de la serie denominada LS $14(0,026)$. 


\begin{tabular}{|c|c|c|c|c|c|c|}
\hline Serie probetas 13 & \multicolumn{6}{|c|}{ LS14 $(0,05)$} \\
\hline Probeta & \multicolumn{3}{|c|}{5} & \multicolumn{3}{|c|}{6} \\
\hline Peso probeta & \multicolumn{3}{|c|}{158} & \multicolumn{3}{|c|}{159} \\
\hline Consistencia argamasa (mm) UNE-EN 1019 & \multicolumn{6}{|c|}{$150 / 150-150 / 150$} \\
\hline Fecha de ensayo & \multicolumn{3}{|c|}{$08 / 05 / 2009$} & \multicolumn{3}{|c|}{$14 / 04 / 2009$} \\
\hline Área muestra $\left(\mathrm{m}^{2}\right)$ & \multicolumn{3}{|c|}{0,0061} & \multicolumn{3}{|c|}{0,0061} \\
\hline Flujo $\left(\mathrm{m}^{3} / \mathrm{h}\right)$ & \multicolumn{3}{|c|}{0,09} & \multicolumn{3}{|c|}{0,09} \\
\hline \multirow[t]{2}{*}{ Intensidad luz ultravioleta (W/m²) } & \multicolumn{3}{|c|}{20} & \multicolumn{3}{|c|}{20,01} \\
\hline & NO & NOx & $\mathrm{NO}_{2}$ & NO & NOx & $\mathrm{NO}_{2}$ \\
\hline$C_{A}(p p b)$ & 389,2 & 554,6 & 165,4 & 380,8 & 542,4 & 161,6 \\
\hline$C_{B}$ (ppb) & 382,8 & 531,6 & 148,8 & 377,7 & 531,9 & 154,2 \\
\hline$C_{L}(p p b)$ & 337,8 & 460,4 & 122,6 & 343,8 & 474,3 & 130,5 \\
\hline$A(\%)$ & 11,8 & 13,4 & 17,6 & 9,0 & 10,8 & 15,4 \\
\hline$A_{F}(m / h)$ & 87 & 99 & 130 & 66 & 80 & 113 \\
\hline \multirow[t]{2}{*}{ ¿Resultado valido? } & NO & NO & Sí & NO & $\mathrm{NO}$ & Sí \\
\hline & \multicolumn{2}{|c|}{ NO } & \multicolumn{2}{|c|}{ NOx } & \multicolumn{2}{|c|}{$\mathrm{NO}_{2}$} \\
\hline Media de la serie $(\%) \pm 10 \%$ & \multicolumn{2}{|c|}{$\begin{array}{c}10,4 \pm 1,0 \\
(9,4-11,4)\end{array}$} & \multicolumn{2}{|c|}{$\begin{array}{c}12,1 \pm 1,2 \\
(10,9-13,3)\end{array}$} & \multicolumn{2}{|c|}{$\begin{array}{c}16,5 \pm 1,7 \\
(14,9-18,2)\end{array}$} \\
\hline Media de la serie $(A F) \pm 10 \%$ & \multicolumn{2}{|c|}{$\begin{array}{c}76,4 \pm 7,6 \\
.(68,8-84,0)\end{array}$} & \multicolumn{2}{|c|}{$\begin{array}{c}89,3 \pm 8,9 \\
(80,4-98,2)\end{array}$} & \multicolumn{2}{|c|}{$\begin{array}{c}121,6 \pm 12,2 \\
(109,4-133,8)\end{array}$} \\
\hline Coeficiente de variación (\%) & \multicolumn{2}{|c|}{13} & \multicolumn{2}{|c|}{11} & \multicolumn{2}{|c|}{7} \\
\hline Humedad relativa (HR \%) & \multicolumn{3}{|c|}{47} & \multicolumn{3}{|c|}{54} \\
\hline Temperatura $\left({ }^{\circ} \mathrm{C}\right)$ & \multicolumn{3}{|c|}{25} & \multicolumn{3}{|c|}{21} \\
\hline
\end{tabular}

Tabla. Detalles concretos del procedimiento experimental, asi como los resultados obtenidos para las muestras 5 y 6 de la serie denominada LS 14 (0,05). 


\begin{tabular}{|c|c|c|c|c|c|c|}
\hline Serie probetas 14 & \multicolumn{6}{|c|}{ Mas $(0,026)$} \\
\hline Probeta & \multicolumn{3}{|c|}{5} & \multicolumn{3}{|c|}{6} \\
\hline Peso probeta & \multicolumn{3}{|c|}{163} & \multicolumn{3}{|c|}{162} \\
\hline Consistencia argamasa (mm) UNE-EN 1014 & \multicolumn{6}{|c|}{$150 / 153-150 / 150$} \\
\hline Fecha de ensayo & \multicolumn{3}{|c|}{$14 / 03 / 2009$} & \multicolumn{3}{|c|}{$17 / 03 / 2009$} \\
\hline Área muestra $\left(\mathrm{m}^{2}\right)$ & \multicolumn{3}{|c|}{0,0061} & \multicolumn{3}{|c|}{0,0061} \\
\hline Flujo $\left(\mathrm{m}^{3} / \mathrm{h}\right)$ & \multicolumn{3}{|c|}{0,09} & \multicolumn{3}{|c|}{0,09} \\
\hline Intensidad luz ultravioleta (W/m²) & \multicolumn{3}{|c|}{20,03} & \multicolumn{3}{|c|}{20,03} \\
\hline & NO & NOx & $\mathrm{NO}_{2}$ & NO & NOx & $\mathrm{NO}_{2}$ \\
\hline$C_{A}(p p b)$ & 378,0 & 542,3 & 164,3 & 374,5 & 543,0 & 168,5 \\
\hline$C_{B}$ (ppb) & 372,7 & 526,6 & 153,9 & 371,1 & 532,5 & 161,4 \\
\hline$C_{L}$ (ppb) & 311,0 & 462,0 & 151,0 & 322,5 & 479,2 & 156,7 \\
\hline$A(\%)$ & 16,6 & 12,3 & 1,9 & 13,1 & 10,0 & 2,9 \\
\hline$A_{F}(m / h)$ & 122 & 90 & 14 & 96 & 74 & 21 \\
\hline \multirow[t]{2}{*}{ ¿Resultado valido? } & NO & Sí & NO & NO & Sí & NO \\
\hline & \multicolumn{2}{|c|}{ NO } & \multicolumn{2}{|c|}{ NOx } & \multicolumn{2}{|c|}{$\mathrm{NO}_{2}$} \\
\hline Media de la serie $(\%) \pm 10 \%$ & \multicolumn{2}{|c|}{$\begin{array}{c}14,8 \pm 1,5 \\
(13,3-16,3\end{array}$} & \multicolumn{2}{|c|}{$\begin{array}{c}11,1 \pm 1,1 \\
(10,0-12,2)\end{array}$} & \multicolumn{2}{|c|}{$\begin{array}{c}2,4 \pm 0,2 \\
(2,2-2,6)\end{array}$} \\
\hline Media de la serie $(A F) \pm 10 \%$ & \multicolumn{2}{|c|}{$\begin{array}{c}109,2 \pm 10,9 \\
(98,3-120,1)\end{array}$} & \multicolumn{2}{|c|}{$\begin{array}{c}82,0 \pm 8,2 \\
(73,8-90,2)\end{array}$} & \multicolumn{2}{|c|}{$\begin{array}{c}17,7 \pm 1,8 \\
(15,9-19,5)\end{array}$} \\
\hline Coeficiente de variación (\%) & \multicolumn{2}{|c|}{12} & \multicolumn{2}{|c|}{10} & \multicolumn{2}{|c|}{21} \\
\hline Humedad relativa (HR \%) & \multicolumn{3}{|c|}{48} & \multicolumn{3}{|c|}{47} \\
\hline Temperatura $\left({ }^{\circ} \mathrm{C}\right)$ & \multicolumn{3}{|c|}{23} & \multicolumn{3}{|c|}{23} \\
\hline
\end{tabular}

Tabla. Detalles concretos del procedimiento experimental, así como los resultados obtenidos para las muestras 5 y 6 de la serie denominada Mas $(0,026)$. 


\begin{tabular}{|c|c|c|c|c|c|c|}
\hline Serie probetas 15 & \multicolumn{6}{|c|}{ Mas $(0,05)$} \\
\hline Probeta & \multicolumn{3}{|c|}{5} & \multicolumn{3}{|c|}{6} \\
\hline Peso probeta & \multicolumn{3}{|c|}{156} & \multicolumn{3}{|c|}{161} \\
\hline Consistencia argamasa (mm) UNE-EN 1014 & \multicolumn{6}{|c|}{$147 / 146-146 / 149$} \\
\hline Fecha de ensayo & \multicolumn{3}{|c|}{$12 / 03 / 2009$} & \multicolumn{3}{|c|}{$12 / 03 / 2009$} \\
\hline Área muestra $\left(\mathrm{m}^{2}\right)$ & \multicolumn{3}{|c|}{0,0061} & \multicolumn{3}{|c|}{0,0061} \\
\hline Flujo $\left(\mathrm{m}^{3} / \mathrm{h}\right)$ & \multicolumn{3}{|c|}{0,09} & \multicolumn{3}{|c|}{0,09} \\
\hline \multirow[t]{2}{*}{ Intensidad luz ultravioleta (W/m²) } & \multicolumn{3}{|c|}{20} & \multicolumn{3}{|c|}{20} \\
\hline & NO & NOx & $\mathrm{NO}_{2}$ & NO & NOx & $\mathrm{NO}_{2}$ \\
\hline$C_{A}(p p b)$ & 367,9 & 530,6 & 162,7 & 394,4 & 567,4 & 173,0 \\
\hline$C_{B}$ (ppb) & 354,5 & 498,2 & 143,7 & 390,3 & 553,3 & 163,0 \\
\hline$C_{L}(p p b)$ & 252,3 & 385,9 & 133,6 & 284,6 & 433,5 & 148,9 \\
\hline$A(\%)$ & 28,8 & 22,5 & 7,0 & 27,1 & 21,7 & 8,7 \\
\hline$A_{F}(m / h)$ & 213 & 166 & 52 & 200 & 160 & 64 \\
\hline \multirow[t]{2}{*}{ ¿Resultado valido? } & Sí & Sí & Sí & Sí & Sí & Sí \\
\hline & \multicolumn{2}{|c|}{ NO } & \multicolumn{2}{|c|}{ NOx } & \multicolumn{2}{|c|}{$\mathrm{NO}_{2}$} \\
\hline Media de la serie $(\%) \pm 10 \%$ & \multicolumn{2}{|c|}{$\begin{array}{c}28,0 \pm 2,8 \\
(25,2-30,8)\end{array}$} & \multicolumn{2}{|c|}{$\begin{array}{c}22,1 \pm 2,2 \\
(19,9-24,3)\end{array}$} & \multicolumn{2}{|c|}{$\begin{array}{c}7,8 \pm 0,8 \\
(7,0-8,6)\end{array}$} \\
\hline Media de la serie $(A F) \pm 10 \%$ & \multicolumn{2}{|c|}{$\begin{array}{c}206,2 \pm 20,6 \\
(185,6-226,8)\end{array}$} & \multicolumn{2}{|c|}{$\begin{array}{c}163,0 \pm 16,3 \\
(146,7-179,3)\end{array}$} & \multicolumn{2}{|c|}{$\begin{array}{c}57,8 \pm 5,8 \\
(52,0-63,3)\end{array}$} \\
\hline Coeficiente de variación (\%) & \multicolumn{2}{|c|}{3} & \multicolumn{2}{|c|}{2} & \multicolumn{2}{|c|}{10} \\
\hline Humedad relativa (HR \%) & \multicolumn{3}{|c|}{56} & \multicolumn{3}{|c|}{47} \\
\hline Temperatura $\left({ }^{\circ} \mathrm{C}\right)$ & \multicolumn{3}{|c|}{23} & \multicolumn{3}{|c|}{23} \\
\hline
\end{tabular}

Tabla. Detalles concretos del procedimiento experimental, asi como los resultados obtenidos para las muestras 5 y 6 de la serie denominada Mas $(0,05)$. 


\begin{tabular}{|c|c|c|c|c|c|c|}
\hline Serie probetas 16 & \multicolumn{6}{|c|}{ Oleato $(0,60)$} \\
\hline Probeta & \multicolumn{3}{|c|}{5} & \multicolumn{3}{|c|}{6} \\
\hline Peso probeta & \multicolumn{3}{|c|}{170} & \multicolumn{3}{|c|}{169} \\
\hline Consistencia argamasa (mm) UNE-EN 1014 & \multicolumn{6}{|c|}{$144 / 143-144 / 144$} \\
\hline Fecha de ensayo & \multicolumn{3}{|c|}{$20 / 11 / 2008$} & \multicolumn{3}{|c|}{$21 / 11 / 2008$} \\
\hline Área muestra $\left(\mathrm{m}^{2}\right)$ & \multicolumn{3}{|c|}{0,0061} & \multicolumn{3}{|c|}{0,0061} \\
\hline Flujo $\left(\mathrm{m}^{3} / \mathrm{h}\right)$ & \multicolumn{3}{|c|}{0,09} & \multicolumn{3}{|c|}{0,09} \\
\hline Intensidad luz ultravioleta (W/m²) & \multicolumn{3}{|c|}{20,3} & \multicolumn{3}{|c|}{20,01} \\
\hline & NO & NOx & $\mathrm{NO}_{2}$ & NO & NOx & $\mathrm{NO}_{2}$ \\
\hline$C_{A}(p p b)$ & 384,7 & 550,1 & 165,4 & 389,0 & 549,3 & 160,3 \\
\hline$C_{B}(p p b)$ & 374,6 & 526,1 & 151,5 & 375,2 & 519,8 & 144,6 \\
\hline$C_{L}(p p b)$ & 296,2 & 441,8 & 145,6 & 303,0 & 441,1 & 138,1 \\
\hline A (\%) & 20,9 & 16,0 & 3,9 & 19,2 & 15,1 & 4,5 \\
\hline$A_{F}(m / h)$ & 152 & 116 & 28 & 142 & 112 & 33 \\
\hline \multirow[t]{2}{*}{ ¿Resultado valido? } & Sí & Sí & Sí & Sí & Sí & sí \\
\hline & \multicolumn{2}{|c|}{ NO } & \multicolumn{2}{|c|}{ NOx } & \multicolumn{2}{|c|}{$\mathrm{NO}_{2}$} \\
\hline Media de la serie $(\%) \pm 10 \%$ & \multicolumn{2}{|c|}{$\begin{array}{c}20,1 \pm 2,0 \\
(18,1-22,1)\end{array}$} & \multicolumn{2}{|c|}{$\begin{array}{c}15,6 \pm 1,6 \\
(14,0-17,2)\end{array}$} & \multicolumn{2}{|c|}{$\begin{array}{c}4,2 \pm 0,4 \\
(3,8-4,6)\end{array}$} \\
\hline Media de la serie $(A F) \pm 10 \%$ & \multicolumn{2}{|c|}{$\begin{array}{c}147,0 \pm 14,7 \\
(132,3-161,7)\end{array}$} & \multicolumn{2}{|c|}{$\begin{array}{c}114,0 \pm 11,4 \\
(102,6-125,4)\end{array}$} & \multicolumn{2}{|c|}{$\begin{array}{c}30,7 \pm 3,1 \\
(27,6-33,8)\end{array}$} \\
\hline Coeficiente de variación (\%) & \multicolumn{2}{|c|}{3} & \multicolumn{2}{|c|}{2} & \multicolumn{2}{|c|}{8} \\
\hline Humedad relativa (HR \%) & \multicolumn{3}{|c|}{51} & \multicolumn{3}{|c|}{53} \\
\hline Temperatura $\left({ }^{\circ} \mathrm{C}\right)$ & \multicolumn{3}{|c|}{20} & \multicolumn{3}{|c|}{21} \\
\hline
\end{tabular}

Tabla. Detalles concretos del procedimiento experimental, así como los resultados obtenidos para las muestras 5 y 6 de la serie denominada Oleato $(0,60)$. 


\begin{tabular}{|c|c|c|c|c|c|c|}
\hline Serie probetas 17 & \multicolumn{6}{|c|}{ Oleato $(0,90)$} \\
\hline Probeta & \multicolumn{3}{|c|}{5} & \multicolumn{3}{|c|}{6} \\
\hline Peso probeta & \multicolumn{3}{|c|}{176} & \multicolumn{3}{|c|}{171} \\
\hline Consistencia argamasa (mm) UNE-EN 1015 & \multicolumn{6}{|c|}{$134 / 133-130 / 131$} \\
\hline Fecha de ensayo & \multicolumn{3}{|c|}{$24 / 01 / 2009$} & \multicolumn{3}{|c|}{$07 / 05 / 2009$} \\
\hline Área muestra $\left(\mathrm{m}^{2}\right)$ & \multicolumn{3}{|c|}{0,0061} & \multicolumn{3}{|c|}{0,0061} \\
\hline Flujo $\left(\mathrm{m}^{3} / \mathrm{h}\right)$ & \multicolumn{3}{|c|}{0,09} & \multicolumn{3}{|c|}{0,09} \\
\hline \multirow[t]{2}{*}{ Intensidad luz ultravioleta (W/m²) } & \multicolumn{3}{|c|}{20,02} & \multicolumn{3}{|c|}{20,02} \\
\hline & NO & NOx & $\mathrm{NO}_{2}$ & NO & NOx & $\mathrm{NO}_{2}$ \\
\hline$C_{A}(p p b)$ & 390,0 & 579,1 & 189,1 & 395,0 & 554,1 & 159,1 \\
\hline$C_{B}(p p b)$ & 348,5 & 506,1 & 157,6 & 377,3 & 511,8 & 134,5 \\
\hline$C_{L}(p p b)$ & 285,5 & 433,6 & 148,1 & 285,5 & 392,9 & 107,4 \\
\hline$A(\%)$ & 18,1 & 14,3 & 6,0 & 24,3 & 23,2 & 20,1 \\
\hline$A_{F}(m / h)$ & 133 & 106 & 44 & 179 & 171 & 148 \\
\hline \multirow[t]{2}{*}{ ¿Resultado valido? } & NO & $\mathrm{NO}$ & NO & $\mathrm{NO}$ & NO & $\mathrm{NO}$ \\
\hline & \multicolumn{2}{|c|}{ NO } & \multicolumn{2}{|c|}{ NOx } & \multicolumn{2}{|c|}{$\mathrm{NO}_{2}$} \\
\hline Media de la serie $(\%) \pm 10 \%$ & \multicolumn{2}{|c|}{$\begin{array}{c}21,2 \pm 2,1 \\
(19,1-23,3) \\
\end{array}$} & \multicolumn{2}{|c|}{$\begin{array}{c}18,8 \pm 1,9 \\
(16,9-20,7)\end{array}$} & \multicolumn{2}{|c|}{$\begin{array}{c}13,1 \pm 1,3 \\
(11,8-14,4)\end{array}$} \\
\hline Media de la serie (AF) $\pm 10 \%$ & \multicolumn{2}{|c|}{$\begin{array}{c}156,3 \pm 15,6 \\
(140,7-171,9)\end{array}$} & \multicolumn{2}{|c|}{$\begin{array}{c}138,4 \pm 13,8 \\
(124,6-152,2)\end{array}$} & \multicolumn{2}{|c|}{$\begin{array}{c}96,5 \pm 9,7 \\
(86,9-106,2)\end{array}$} \\
\hline Coeficiente de variación (\%) & \multicolumn{2}{|c|}{15} & \multicolumn{2}{|c|}{24} & \multicolumn{2}{|c|}{54} \\
\hline Humedad relativa (HR \%) & \multicolumn{3}{|c|}{46} & \multicolumn{3}{|c|}{46} \\
\hline Temperatura $\left({ }^{\circ} \mathrm{C}\right)$ & \multicolumn{3}{|c|}{24} & \multicolumn{3}{|c|}{25} \\
\hline
\end{tabular}

Tabla. Detalles concretos del procedimiento experimental, asi como los resultados obtenidos para las muestras 5 y 6 de la serie denominada Oleato $(0,90)$. 


\begin{tabular}{|c|c|c|c|c|c|c|}
\hline Serie probetas 18 & \multicolumn{6}{|c|}{$554(2,14)$} \\
\hline Probeta & \multicolumn{3}{|c|}{5} & \multicolumn{3}{|c|}{6} \\
\hline Peso probeta & \multicolumn{3}{|c|}{142} & \multicolumn{3}{|c|}{145} \\
\hline Consistencia argamasa $(\mathrm{mm})$ UNE-EN 1015 & \multicolumn{6}{|c|}{$165 / 160-155 / 155$} \\
\hline Fecha de ensayo & \multicolumn{3}{|c|}{ 10/11/2008 } & \multicolumn{3}{|c|}{$10 / 11 / 2008$} \\
\hline Área muestra $\left(\mathrm{m}^{2}\right)$ & \multicolumn{3}{|c|}{0,0061} & \multicolumn{3}{|c|}{0,0061} \\
\hline Flujo $\left(\mathrm{m}^{3} / \mathrm{h}\right)$ & \multicolumn{3}{|c|}{0,09} & \multicolumn{3}{|c|}{0,09} \\
\hline Intensidad luz ultravioleta (W/m²) & \multicolumn{3}{|c|}{20,02} & \multicolumn{3}{|c|}{20,03} \\
\hline & NO & NOx & $\mathrm{NO}_{2}$ & NO & NOx & $\mathrm{NO}_{2}$ \\
\hline$C_{A}(p p b)$ & 412,7 & 554,4 & 141,7 & 392,8 & 549,6 & 156,8 \\
\hline$C_{B}(p p b)$ & 398,5 & 526,9 & 128,4 & 384,6 & 534,7 & 150,1 \\
\hline$C_{L}(p p b)$ & 355,5 & 484,8 & 129,3 & 339,0 & 481,4 & 142,4 \\
\hline$A(\%)$ & 10,8 & 8,0 & $-0,7$ & 11,9 & 10,0 & 5,1 \\
\hline$A_{F}(m / h)$ & 80 & 59 & -5 & 87 & 73 & 38 \\
\hline \multirow[t]{2}{*}{ ¿Resultado valido? } & Sí & NO & NO & Sí & $\mathrm{NO}$ & $\mathrm{NO}$ \\
\hline & \multicolumn{2}{|c|}{ NO } & \multicolumn{2}{|c|}{ NOx } & \multicolumn{2}{|c|}{$\mathrm{NO}_{2}$} \\
\hline Media de la serie $(\%) \pm 10 \%$ & \multicolumn{2}{|c|}{$\begin{array}{c}11,3 \pm 1,1 \\
(10,2-12,4) \\
\end{array}$} & \multicolumn{2}{|c|}{$\begin{array}{c}9,0 \pm 0,9 \\
(8,1-9,9)\end{array}$} & \multicolumn{2}{|c|}{$\begin{array}{c}2,2 \pm 0,2 \\
(2,0-2,4)\end{array}$} \\
\hline Media de la serie $(A F) \pm 10 \%$ & \multicolumn{2}{|c|}{$\begin{array}{c}83,4 \pm 8,3 \\
(75,1-91,7)\end{array}$} & \multicolumn{2}{|c|}{$\begin{array}{c}66,2 \pm 6,6 \\
(59,6-72,8)\end{array}$} & \multicolumn{2}{|c|}{$\begin{array}{c}16,3 \pm 1,6 \\
(14,7-17,9)\end{array}$} \\
\hline Coeficiente de variación (\%) & \multicolumn{2}{|c|}{5} & \multicolumn{2}{|c|}{11} & \multicolumn{2}{|c|}{101} \\
\hline Humedad relativa (HR \%) & \multicolumn{3}{|c|}{42} & \multicolumn{3}{|c|}{49} \\
\hline Temperatura $\left({ }^{\circ} \mathrm{C}\right)$ & \multicolumn{3}{|c|}{22} & \multicolumn{3}{|c|}{20} \\
\hline
\end{tabular}

Tabla. Detalles concretos del procedimiento experimental, asi como los resultados obtenidos para las muestras 5 y 6 de la serie denominada $554(2,14)$. 


\begin{tabular}{|c|c|c|c|c|c|c|}
\hline Serie probetas 19 & \multicolumn{6}{|c|}{$554(5)$} \\
\hline Probeta & \multicolumn{3}{|c|}{5} & \multicolumn{3}{|c|}{6} \\
\hline Peso probeta & \multicolumn{3}{|c|}{127} & \multicolumn{3}{|c|}{143} \\
\hline Consistencia argamasa $(\mathrm{mm})$ UNE-EN 1015 & \multicolumn{6}{|c|}{$153 / 150-145 / 148$} \\
\hline Fecha de ensayo & \multicolumn{3}{|c|}{$13 / 03 / 2009$} & \multicolumn{3}{|c|}{$13 / 03 / 2009$} \\
\hline Área muestra $\left(\mathrm{m}^{2}\right)$ & \multicolumn{3}{|c|}{0,0061} & \multicolumn{3}{|c|}{0,0061} \\
\hline Flujo $\left(\mathrm{m}^{3} / \mathrm{h}\right)$ & \multicolumn{3}{|c|}{0,09} & \multicolumn{3}{|c|}{0,09} \\
\hline \multirow[t]{2}{*}{ Intensidad luz ultravioleta (W/m²) } & \multicolumn{3}{|c|}{20,00} & \multicolumn{3}{|c|}{20,00} \\
\hline & NO & NOx & $\mathrm{NO}_{2}$ & NO & NOx & $\mathrm{NO}_{2}$ \\
\hline$C_{A}(p p b)$ & 392,9 & 562,9 & 170,0 & 384,0 & 546,6 & 162,6 \\
\hline$C_{B}(p p b)$ & 377,6 & 528,9 & 151,3 & 377,7 & 532,2 & 154,5 \\
\hline$C_{L}(p p b)$ & 328,1 & 470,0 & 141,9 & 253,1 & 402,0 & 148,9 \\
\hline$A(\%)$ & 13,1 & 11,1 & 6,2 & 33,0 & 24,5 & 3,6 \\
\hline$A_{F}(m / h)$ & 97 & 82 & 46 & 243 & 180 & 27 \\
\hline \multirow[t]{2}{*}{ ¿Resultado valido? } & NO & NO & NO & NO & $\mathrm{NO}$ & $\mathrm{NO}$ \\
\hline & \multicolumn{2}{|c|}{ NO } & \multicolumn{2}{|c|}{ NOx } & \multicolumn{2}{|c|}{$\mathrm{NO}_{2}$} \\
\hline Media de la serie $(\%) \pm 10 \%$ & \multicolumn{2}{|c|}{$\begin{array}{c}23,0 \pm 2,3 \\
(20,7-25,3) \\
\end{array}$} & \multicolumn{2}{|c|}{$\begin{array}{c}17,8 \pm 1,8 \\
(16,0-19,6)\end{array}$} & \multicolumn{2}{|c|}{$\begin{array}{c}4,9 \pm 0,5 \\
(4,4-5,4) \\
\end{array}$} \\
\hline Media de la serie (AF) $\pm 10 \%$ & \multicolumn{2}{|c|}{$\begin{array}{c}170,0 \pm 17,0 \\
(153,0-187,0) \\
\end{array}$} & \multicolumn{2}{|c|}{$\begin{array}{c}131,3 \pm 13,1 \\
(118,2-144,4)\end{array}$} & \multicolumn{2}{|c|}{$\begin{array}{c}36,3 \pm 3,6 \\
(32,7-39,9)\end{array}$} \\
\hline Coeficiente de variación (\%) & \multicolumn{2}{|c|}{43} & \multicolumn{2}{|c|}{37} & \multicolumn{2}{|c|}{26} \\
\hline Humedad relativa (HR \%) & \multicolumn{3}{|c|}{49} & \multicolumn{3}{|c|}{48} \\
\hline Temperatura $\left({ }^{\circ} \mathrm{C}\right)$ & \multicolumn{3}{|c|}{25} & \multicolumn{3}{|c|}{25} \\
\hline
\end{tabular}

Tabla. Detalles concretos del procedimiento experimental, asi como los resultados obtenidos para las muestras 5 y 6 de la serie denominada 554 (5). 


\begin{tabular}{|c|c|c|c|c|c|c|}
\hline Serie probetas 20 & \multicolumn{6}{|c|}{$554(14,29)$} \\
\hline Probeta & \multicolumn{3}{|c|}{5} & \multicolumn{3}{|c|}{6} \\
\hline Peso probeta & \multicolumn{3}{|c|}{151} & \multicolumn{3}{|c|}{148} \\
\hline Consistencia argamasa $(\mathrm{mm})$ UNE-EN 1014 & \multicolumn{6}{|c|}{$161 / 159-152 / 153$} \\
\hline Fecha de ensayo & \multicolumn{3}{|c|}{$21 / 05 / 2009$} & \multicolumn{3}{|c|}{$21 / 05 / 2009$} \\
\hline Área muestra $\left(\mathrm{m}^{2}\right)$ & \multicolumn{3}{|c|}{0,0061} & \multicolumn{3}{|c|}{0,0061} \\
\hline Flujo $\left(\mathrm{m}^{3} / \mathrm{h}\right)$ & \multicolumn{3}{|c|}{0,09} & \multicolumn{3}{|c|}{0,09} \\
\hline Intensidad luz ultravioleta (W/m²) & \multicolumn{3}{|c|}{20,03} & \multicolumn{3}{|c|}{20,03} \\
\hline & NO & NOx & $\mathrm{NO}_{2}$ & NO & NOx & $\mathrm{NO}_{2}$ \\
\hline$C_{A}(p p b)$ & 384,0 & 537,4 & 153,4 & 380,0 & 541,7 & 161,7 \\
\hline$C_{B}(p p b)$ & 379,4 & 520,9 & 141,5 & 376,4 & 531,7 & 155,3 \\
\hline$C_{L}$ (ppb) & 375,9 & 518,1 & 142,2 & 375,9 & 527,7 & 151,8 \\
\hline A (\%) & 0,9 & 0,5 & $-0,5$ & 0,1 & 0,8 & 2,3 \\
\hline$A_{F}(m / h)$ & 7 & 4 & -4 & 1 & 6 & 17 \\
\hline \multirow[t]{2}{*}{ ¿Resultado valido? } & $\mathrm{NO}$ & NO & NO & $\mathrm{NO}$ & $\mathrm{NO}$ & NO \\
\hline & \multicolumn{2}{|c|}{ NO } & \multicolumn{2}{|c|}{ NOx } & \multicolumn{2}{|c|}{$\mathrm{NO}_{2}$} \\
\hline Media de la serie $(\%) \pm 10 \%$ & \multicolumn{2}{|c|}{$\begin{array}{c}0,5 \pm 0,1 \\
(0,4-0,6)\end{array}$} & \multicolumn{2}{|c|}{$\begin{array}{c}0,6 \pm 0,1 \\
(0,5-0,7)\end{array}$} & \multicolumn{2}{|c|}{$\begin{array}{c}0,9 \pm 0,1 \\
(0,8-1,0)\end{array}$} \\
\hline Media de la serie (AF) $\pm 10 \%$ & \multicolumn{2}{|c|}{$\begin{array}{c}3,9 \pm 0,4 \\
(3,5-4,3)\end{array}$} & \multicolumn{2}{|c|}{$\begin{array}{c}4,8 \pm 0,5 \\
(4,3-5,3)\end{array}$} & \multicolumn{2}{|c|}{$\begin{array}{c}6,5 \pm 0,7 \\
(5,9-7,2)\end{array}$} \\
\hline Coeficiente de variación (\%) & \multicolumn{2}{|c|}{75} & \multicolumn{2}{|c|}{17} & \multicolumn{2}{|c|}{156} \\
\hline Humedad relativa (HR \%) & \multicolumn{3}{|c|}{52} & \multicolumn{3}{|c|}{52} \\
\hline Temperatura $\left({ }^{\circ} \mathrm{C}\right)$ & \multicolumn{3}{|c|}{26} & \multicolumn{3}{|c|}{26} \\
\hline
\end{tabular}

Tabla. Detalles concretos del procedimiento experimental, así como los resultados obtenidos para las muestras 5 y 6 de la serie denominada $554(14,29)$. 


\begin{tabular}{|c|c|c|c|c|c|c|}
\hline Serie probetas 21 & \multicolumn{6}{|c|}{$5010(2,14)$} \\
\hline Probeta & \multicolumn{3}{|c|}{5} & \multicolumn{3}{|c|}{6} \\
\hline Peso probeta & \multicolumn{3}{|c|}{172} & \multicolumn{3}{|c|}{176} \\
\hline Consistencia argamasa $(\mathrm{mm})$ UNE-EN $101 \mathfrak{a}$ & \multicolumn{6}{|c|}{$160 / 158-155 / 155$} \\
\hline Fecha de ensayo & \multicolumn{3}{|c|}{$07 / 05 / 2009$} & \multicolumn{3}{|c|}{$08 / 05 / 2009$} \\
\hline Área muestra $\left(\mathrm{m}^{2}\right)$ & \multicolumn{3}{|c|}{0,0061} & \multicolumn{3}{|c|}{0,0061} \\
\hline Flujo $\left(\mathrm{m}^{3} / \mathrm{h}\right)$ & \multicolumn{3}{|c|}{0,09} & \multicolumn{3}{|c|}{0,09} \\
\hline Intensidad luz ultravioleta (W/m²) & \multicolumn{3}{|c|}{20,02} & \multicolumn{3}{|c|}{20,00} \\
\hline & NO & NOx & $\mathrm{NO}_{2}$ & NO & NOx & $\mathrm{NO}_{2}$ \\
\hline$C_{A}(p p b)$ & 397,4 & 555,8 & 158,4 & 387,1 & 550,9 & 163,8 \\
\hline$C_{B}(p p b)$ & 374,2 & 514,2 & 140,0 & 380,0 & 530,5 & 150,5 \\
\hline$C_{L}$ (ppb) & 347,4 & 471,9 & 124,5 & 328,8 & 450,0 & 121,2 \\
\hline$A(\%)$ & 7,2 & 8,2 & 11,1 & 13,5 & 15,2 & 19,5 \\
\hline$A_{F}(m / h)$ & 53 & 61 & 82 & 99 & 112 & 144 \\
\hline \multirow[t]{2}{*}{ ¿Resultado valido? } & $\mathrm{NO}$ & NO & NO & $\mathrm{NO}$ & $\mathrm{NO}$ & $\mathrm{NO}$ \\
\hline & \multicolumn{2}{|c|}{ NO } & \multicolumn{2}{|c|}{ NOx } & \multicolumn{2}{|c|}{$\mathrm{NO}_{2}$} \\
\hline Media de la serie $(\%) \pm 10 \%$ & \multicolumn{2}{|c|}{$\begin{array}{c}10,3 \pm 1,0 \\
(9,3-11,3)\end{array}$} & \multicolumn{2}{|c|}{$\begin{array}{c}11,7 \pm 1,2 \\
(10,5-12,9)\end{array}$} & \multicolumn{2}{|c|}{$\begin{array}{c}15,3 \pm 1,5 \\
(13,8-16,8)\end{array}$} \\
\hline Media de la serie (AF) $\pm 10 \%$ & \multicolumn{2}{|c|}{$\begin{array}{c}76,1 \pm 7,6 \\
(68,5-83,7)\end{array}$} & \multicolumn{2}{|c|}{$\begin{array}{c}86,3 \pm 8,6 \\
(77,7-94,9)\end{array}$} & \multicolumn{2}{|c|}{$\begin{array}{c}112,6 \pm 11,3 \\
(101,3-123,9\end{array}$} \\
\hline Coeficiente de variación (\%) & \multicolumn{2}{|c|}{31} & \multicolumn{2}{|c|}{30} & \multicolumn{2}{|c|}{28} \\
\hline Humedad relativa (HR \%) & \multicolumn{3}{|c|}{46} & \multicolumn{3}{|c|}{47} \\
\hline Temperatura $\left({ }^{\circ} \mathrm{C}\right)$ & \multicolumn{3}{|c|}{25} & \multicolumn{3}{|c|}{25} \\
\hline
\end{tabular}

Tabla. Detalles concretos del procedimiento experimental, asi como los resultados obtenidos para las muestras 5 y 6 de la serie denominada 5010 (2,14). 


\begin{tabular}{|c|c|c|c|c|c|c|}
\hline Serie probetas 21 & \multicolumn{6}{|c|}{$5010(5)$} \\
\hline Probeta & \multicolumn{3}{|c|}{5} & \multicolumn{3}{|c|}{6} \\
\hline Peso probeta & \multicolumn{3}{|c|}{172} & \multicolumn{3}{|c|}{174} \\
\hline Consistencia argamasa (mm) UNE-EN 1015 & \multicolumn{6}{|c|}{$150 / 153-148 / 145$} \\
\hline Fecha de ensayo & \multicolumn{3}{|c|}{$19 / 11 / 2008$} & \multicolumn{3}{|c|}{$20 / 11 / 2008$} \\
\hline Área muestra $\left(\mathrm{m}^{2}\right)$ & \multicolumn{3}{|c|}{0,0061} & \multicolumn{3}{|c|}{0,0061} \\
\hline Flujo $\left(\mathrm{m}^{3} / \mathrm{h}\right)$ & \multicolumn{3}{|c|}{0,09} & \multicolumn{3}{|c|}{0,09} \\
\hline Intensidad luz ultravioleta $\left(\mathrm{W} / \mathrm{m}^{2}\right)$ & \multicolumn{3}{|c|}{20,01} & \multicolumn{3}{|c|}{20,20} \\
\hline & NO & NOx & $\mathrm{NO}_{2}$ & NO & NOx & $\mathrm{NO}_{2}$ \\
\hline$C_{A}(p p b)$ & 403,3 & 545,4 & 142,1 & 389,2 & 542,7 & 153,5 \\
\hline $\mathrm{C}_{\mathrm{B}}(\mathrm{ppb})$ & 393,1 & 529,6 & 136,5 & 385,6 & 537,2 & 151,6 \\
\hline$C_{L}(p p b)$ & 375,5 & 516,1 & 140,6 & 369,9 & 523,0 & 153,1 \\
\hline$A(\%)$ & 4,5 & 2,5 & $-3,0$ & 4,1 & 2,6 & $-1,0$ \\
\hline$A_{F}(m / h)$ & 33 & 19 & -22 & 30 & 19 & -7 \\
\hline \multirow[t]{2}{*}{ ¿Resultado valido? } & Sí & Sí & $\mathrm{NO}$ & Sí & Sí & NO \\
\hline & \multicolumn{2}{|c|}{ NO } & \multicolumn{2}{|c|}{ NOx } & \multicolumn{2}{|c|}{$\mathrm{NO}_{2}$} \\
\hline Media de la serie $(\%) \pm 10 \%$ & \multicolumn{2}{|c|}{$\begin{array}{c}4,3 \pm 0,4 \\
(3,9-4,7)\end{array}$} & \multicolumn{2}{|c|}{$\begin{array}{c}2,6 \pm 0,3 \\
(2,3-2,9)\end{array}$} & \multicolumn{2}{|c|}{$\begin{array}{c}-2,0 \pm 0,2 \\
(-2,2--1,8)\end{array}$} \\
\hline Media de la serie $(A F) \pm 10 \%$ & \multicolumn{2}{|c|}{$\begin{array}{c}31,4 \pm 3,1 \\
(28,3-34,5)\end{array}$} & \multicolumn{2}{|c|}{$\begin{array}{c}19,1 \pm 1,9 \\
(17,2-21,0)\end{array}$} & \multicolumn{2}{|c|}{$\begin{array}{c}-14,7 \pm 1,5 \\
(-16,2--13,2)\end{array}$} \\
\hline Coeficiente de variación (\%) & \multicolumn{2}{|c|}{5} & \multicolumn{2}{|c|}{1} & \multicolumn{2}{|c|}{51} \\
\hline Humedad relativa (HR \%) & \multicolumn{3}{|c|}{57} & \multicolumn{3}{|c|}{53} \\
\hline Temperatura $\left({ }^{\circ} \mathrm{C}\right)$ & \multicolumn{3}{|c|}{22} & \multicolumn{3}{|c|}{21} \\
\hline
\end{tabular}

Tabla. Detalles concretos del procedimiento experimental, así como los resultados obtenidos para las muestras 5 y 6 de la serie denominada 5010 (5). 


\begin{tabular}{|c|c|c|c|c|c|c|}
\hline Serie probetas 22 & \multicolumn{6}{|c|}{ Saf $54(3,75)$} \\
\hline Probeta & \multicolumn{3}{|c|}{5} & \multicolumn{3}{|c|}{6} \\
\hline Peso probeta & \multicolumn{3}{|c|}{151} & \multicolumn{3}{|c|}{150} \\
\hline Consistencia argamasa $(\mathrm{mm})$ UNE-EN 1015 & \multicolumn{6}{|c|}{$225 / 230-225 / 225$} \\
\hline Fecha de ensayo & \multicolumn{3}{|c|}{$12 / 11 / 2008$} & \multicolumn{3}{|c|}{$12 / 11 / 2008$} \\
\hline Área muestra $\left(\mathrm{m}^{2}\right)$ & \multicolumn{3}{|c|}{0,0061} & \multicolumn{3}{|c|}{0,0061} \\
\hline Flujo $\left(\mathrm{m}^{3} / \mathrm{h}\right)$ & \multicolumn{3}{|c|}{0,09} & \multicolumn{3}{|c|}{0,09} \\
\hline Intensidad luz ultravioleta (W/m²) & \multicolumn{3}{|c|}{20,01} & \multicolumn{3}{|c|}{20,02} \\
\hline & NO & NOx & $\mathrm{NO}_{2}$ & NO & NOx & $\mathrm{NO}_{2}$ \\
\hline$C_{A}(p p b)$ & 384,2 & 552,5 & 168,3 & 385,7 & 557,0 & 171,3 \\
\hline$C_{B}(p p b)$ & 369,7 & 513,4 & 143,7 & 378,6 & 517,2 & 138,6 \\
\hline$C_{L}(p p b)$ & 296,5 & 440,4 & 143,9 & 302,4 & 443,5 & 141,1 \\
\hline A (\%) & 19,8 & 14,2 & $-0,1$ & 20,1 & 14,2 & $-1,8$ \\
\hline$A_{F}(m / h)$ & 146 & 105 & -1 & 148 & 105 & -13 \\
\hline \multirow[t]{2}{*}{ ¿Resultado valido? } & Sí & Sí & NO & Sí & Sí & NO \\
\hline & \multicolumn{2}{|c|}{ NO } & \multicolumn{2}{|c|}{ NOx } & \multicolumn{2}{|c|}{$\mathrm{NO}_{2}$} \\
\hline Media de la serie $(\%) \pm 10 \%$ & \multicolumn{2}{|c|}{$\begin{array}{c}20,0 \pm 2,0 \\
(18,0-22,0)\end{array}$} & \multicolumn{2}{|c|}{$\begin{array}{c}14,2 \pm 1,4 \\
(12,8-15,6)\end{array}$} & \multicolumn{2}{|c|}{$\begin{array}{c}-1,0 \pm 0,1 \\
(-1,1--0,9)\end{array}$} \\
\hline Media de la serie (AF) $\pm 10 \%$ & \multicolumn{2}{|c|}{$\begin{array}{c}147,2 \pm 14,7 \\
(132,5-161,9)\end{array}$} & \multicolumn{2}{|c|}{$\begin{array}{c}104,9 \pm 10,5 \\
(94,4-115,4)\end{array}$} & \multicolumn{2}{|c|}{$\begin{array}{c}-7,2 \pm 0,7 \\
(-7,9--6,5)\end{array}$} \\
\hline Coeficiente de variación (\%) & \multicolumn{2}{|c|}{1} & \multicolumn{2}{|c|}{0} & \multicolumn{2}{|c|}{86} \\
\hline Humedad relativa (HR \%) & \multicolumn{3}{|c|}{53} & \multicolumn{3}{|c|}{50} \\
\hline Temperatura $\left({ }^{\circ} \mathrm{C}\right)$ & \multicolumn{3}{|c|}{21} & \multicolumn{3}{|c|}{22} \\
\hline
\end{tabular}

Tabla. Detalles concretos del procedimiento experimental, asi como los resultados obtenidos para las muestras 5 y 6 de la serie denominada Saf 54 (3,75). 


\begin{tabular}{|c|c|c|c|c|c|c|}
\hline Serie probetas 23 & \multicolumn{6}{|c|}{ Saf $(7,14)$} \\
\hline Probeta & \multicolumn{3}{|c|}{5} & \multicolumn{3}{|c|}{6} \\
\hline Peso probeta & \multicolumn{3}{|c|}{145} & \multicolumn{3}{|c|}{143} \\
\hline Consistencia argamasa $(\mathrm{mm})$ UNE-EN 101 & \multicolumn{6}{|c|}{$215 / 215-215 / 220$} \\
\hline Fecha de ensayo & \multicolumn{3}{|c|}{$02 / 03 / 2009$} & \multicolumn{3}{|c|}{$26 / 01 / 2009$} \\
\hline Área muestra $\left(\mathrm{m}^{2}\right)$ & \multicolumn{3}{|c|}{0,0061} & \multicolumn{3}{|c|}{0,0061} \\
\hline Flujo $\left(\mathrm{m}^{3} / \mathrm{h}\right)$ & \multicolumn{3}{|c|}{0,09} & \multicolumn{3}{|c|}{0,09} \\
\hline \multirow[t]{2}{*}{ Intensidad luz ultravioleta (W/m²) } & \multicolumn{3}{|c|}{20,02} & \multicolumn{3}{|c|}{20,02} \\
\hline & NO & NOx & $\mathrm{NO}_{2}$ & NO & NOx & $\mathrm{NO}_{2}$ \\
\hline$C_{A}(p p b)$ & 397,8 & 580,9 & 183,1 & 390,9 & 571,6 & 180,7 \\
\hline$C_{B}(p p b)$ & 367,3 & 525,0 & 157,7 & 384,2 & 552,5 & 168,3 \\
\hline$C_{L}$ (ppb) & 302,0 & 449,4 & 147,4 & 307,2 & 475,7 & 168,5 \\
\hline$A(\%)$ & 17,8 & 14,4 & 6,5 & 20,0 & 13,9 & $-0,1$ \\
\hline$A_{F}(m / h)$ & 131 & 106 & 48 & 148 & 102 & -1 \\
\hline ¿Resultado valido? & Sí & Sí & NO & Sí & sí & NO \\
\hline & \multicolumn{2}{|c|}{ NO } & \multicolumn{2}{|c|}{ NOx } & \multicolumn{2}{|c|}{$\mathrm{NO}_{2}$} \\
\hline Media de la serie $(\%) \pm 10 \%$ & \multicolumn{2}{|c|}{$\begin{array}{c}18,9 \pm 1,9 \\
(17,0-20,8)\end{array}$} & \multicolumn{2}{|c|}{$\begin{array}{c}14,2 \pm 1,4 \\
(12,8-15,6) \\
\end{array}$} & \multicolumn{2}{|c|}{$\begin{array}{c}3,2 \pm 0,3 \\
(2,9-3,5)\end{array}$} \\
\hline Media de la serie $(A F) \pm 10 \%$ & \multicolumn{2}{|c|}{$\begin{array}{c}139,4 \pm 13,9 \\
(125,5-153,3)\end{array}$} & \multicolumn{2}{|c|}{$\begin{array}{c}104,3 \pm 10,4 \\
(93,9-114,7) \\
\end{array}$} & \multicolumn{2}{|c|}{$\begin{array}{c}23,6 \pm 2,4 \\
(21,2-26,0) \\
\end{array}$} \\
\hline Coeficiente de variación (\%) & \multicolumn{2}{|c|}{6} & \multicolumn{2}{|c|}{2} & \multicolumn{2}{|c|}{104} \\
\hline Humedad relativa (HR \%) & \multicolumn{3}{|c|}{52} & \multicolumn{3}{|c|}{54} \\
\hline Temperatura $\left({ }^{\circ} \mathrm{C}\right)$ & \multicolumn{3}{|c|}{20} & \multicolumn{3}{|c|}{21} \\
\hline
\end{tabular}

Tabla. Detalles concretos del procedimiento experimental, asi como los resultados obtenidos para las muestras 5 y 6 de la serie denominada Saf $54(7,14)$. 


\begin{tabular}{|c|c|c|c|c|c|c|}
\hline Serie probetas 24 & \multicolumn{6}{|c|}{ Saf $54(14,29)$} \\
\hline Probeta & \multicolumn{3}{|c|}{5} & \multicolumn{3}{|c|}{6} \\
\hline Peso probeta & \multicolumn{3}{|c|}{159} & \multicolumn{3}{|c|}{162} \\
\hline Consistencia argamasa (mm) UNE-EN 1014 & \multicolumn{6}{|c|}{ Argamasa no suficiente viscoso } \\
\hline Fecha de ensayo & \multicolumn{3}{|c|}{$12 / 05 / 2009$} & \multicolumn{3}{|c|}{$11 / 05 / 2009$} \\
\hline Área muestra $\left(\mathrm{m}^{2}\right)$ & \multicolumn{3}{|c|}{0,0061} & \multicolumn{3}{|c|}{0,0061} \\
\hline Flujo $\left(\mathrm{m}^{3} / \mathrm{h}\right)$ & \multicolumn{3}{|c|}{0,09} & \multicolumn{3}{|c|}{0,09} \\
\hline Intensidad luz ultravioleta (W/m²) & \multicolumn{3}{|c|}{20,00} & \multicolumn{3}{|c|}{20,01} \\
\hline & NO & NOx & $\mathrm{NO}_{2}$ & NO & NOx & $\mathrm{NO}_{2}$ \\
\hline$C_{A}(p p b)$ & 396,2 & 558,0 & 161,8 & 392,0 & 558,9 & 166,9 \\
\hline$C_{B}(p p b)$ & 371,2 & 518,5 & 147,3 & 382,2 & 538,6 & 156,4 \\
\hline$C_{L}$ (ppb) & 345,7 & 484,8 & 139,1 & 362,9 & 513,5 & 150,6 \\
\hline$A(\%)$ & 6,9 & 6,5 & 5,6 & 5,0 & 4,7 & 3,7 \\
\hline$A_{F}(m / h)$ & 51 & 48 & 41 & 37 & 34 & 27 \\
\hline \multirow[t]{2}{*}{ ¿Resultado valido? } & NO & $\mathrm{NO}$ & NO & NO & $\mathrm{NO}$ & NO \\
\hline & \multicolumn{2}{|c|}{ NO } & \multicolumn{2}{|c|}{ NOx } & \multicolumn{2}{|c|}{$\mathrm{NO}_{2}$} \\
\hline Media de la serie $(\%) \pm 10 \%$ & \multicolumn{2}{|c|}{$\begin{array}{c}6,0 \pm 0,6 \\
(5,4-6,6)\end{array}$} & \multicolumn{2}{|c|}{$\begin{array}{c}5,6 \pm 0,6 \\
(5,0-6,2)\end{array}$} & \multicolumn{2}{|c|}{$\begin{array}{c}4,6 \pm 0,5 \\
(4,1-5,1)\end{array}$} \\
\hline Media de la serie (AF) $\pm 10 \%$ & \multicolumn{2}{|c|}{$\begin{array}{c}44,0 \pm 4,4 \\
(39,6-48,4)\end{array}$} & \multicolumn{2}{|c|}{$\begin{array}{c}41,2 \pm 4,1 \\
(37,1-45,3)\end{array}$} & \multicolumn{2}{|c|}{$\begin{array}{c}34,2 \pm 34,2 \\
(30,8-37,6)\end{array}$} \\
\hline Coeficiente de variación (\%) & \multicolumn{2}{|c|}{15} & \multicolumn{2}{|c|}{17} & \multicolumn{2}{|c|}{20} \\
\hline Humedad relativa (HR \%) & \multicolumn{3}{|c|}{48} & \multicolumn{3}{|c|}{47} \\
\hline Temperatura $\left({ }^{\circ} \mathrm{C}\right)$ & \multicolumn{3}{|c|}{23} & \multicolumn{3}{|c|}{24} \\
\hline
\end{tabular}

Tabla. Detalles concretos del procedimiento experimental, asi como los resultados obtenidos para las muestras 5 y 6 de la serie denominada Saf 54 (14,29). 


\section{2 . FIGURAS}

Fig 1. (a) Citas por año del artículo de 1972 publicado en la revista Nature: "Electrochemical photolysis of water at a semiconductor electrode"; (b) Número de artículos de investigación publicados sobre fotocatálisis por año: resultados de la búsqueda en el período de 1972-2007 en "Web of Science" (Barras azules) por la palabra clave "photocataly"; (Barras verdes) palabras clave "TiO 2 AND photocataly"”.

Fig 2. crecimiento de las patentes relacionadas con nanomateriales periodo 2000-2006. Fuente: Paz, Y. (2010)

Fig 3. Estadísticas 2003-2013 por disciplina. 68.874 resultados a la búsqueda de la palabra "nanomaterials. Fuente: SCOPUS. 15 de Abril 2013

Fig 4. Diagrama con los rangos de conductividad eléctrica a temperatura ambiente para metales, cerámicas, polímeros y materiales semiconductores

Fig 5. Niveles energéticos: (a) átomo (b) molecula pequeña (c) molecula grande (d) bandas de energía en un sólido.

Fig 6. Distribución de las bandas de conducción y de valencia en distintos materiales. a) sólido conductor con el nivel de fermi en una banda semillena b) sólido conductor con la BC y BV solapadas c) sólido semiconductor d) sólido aislante.

Fig 7. Espectro electromagnético visible por el ojo humano.

Fig 8. ASTM G173-03. Espectro Global de Irradiación total en la superficie inclinada $37^{\circ}$ respecto al sol.

Fig 9. Representacion de los pasos en la reacción catalítica heterogénea. A esta figura se hace referencia en la página 20.

Fuente. Fogler et al.

Fig 10. Esquema de la promoción de un electrón y mecanismo de reducción-oxidación de las moléculas de oxígeno y agua.

Fuente: Elaboracion propia.

Fig 11. Estructura electrónica del $\mathrm{TiO}_{2}$ Fuente: Sugrañez Pérez, R 25.

Fig 12. Situacion de las bandas de conducción (BC) y valencia (BV) en óxidos metálicos semiconductores a pH 0 . La escala de la izquierda representa las energías internas en el vacío. La escala de la derecha es la escala normal del electrodo del hidrógeno que permite valorar el potencial de reducción y oxidación de cada óxido.

Fig 13. Potenciales redox respecto al ENH para las $\mathrm{BC}$ y $\mathrm{BV}$ de las fases anatasa $\left(\mathrm{TiO}_{2}-\mathrm{A}\right)$ y rutilo $\left(\mathrm{TiO}_{2}-\mathrm{R}\right)$. Fuente: Elaboración propia.

Fig 14. Ilustración esquemática del mecanismo básico de un proceso de fotocatalísis heterogénea. Sistema TiO 2 bajo irradiación de luz U.V.

Fig 14. Diagrama de los procesos primarios implicados en la fotomineralización de compuestos orgánicos.

Fig 16. Diagrama de fases de TiO a diferentes temperaturas.

Fig 17. Digrama de equilibrios de fase en el $\mathrm{TiO}_{2}$, entre la Anatasa, Rutilo y Srilankita.

Fig 18. Estructuras cristalinas de, Anatasa (a), Rutilo (b) y Brookita (c). Fuente: Carp et al. 
I NFLUENCIA DEL COLOR Y EL ACABADO SUPERFICIALEN LASPROPIEDADES DE UN MORTEROFOTOCATALITICOCOMOSOLUCIÓN DE ENVOLVENTE

Fig 19. Esquema de funcionamiento de las propiedades de autolimpieza y descontaminación sobre la envolvente de un edificio.

Fig 20. Esquema de un sistema de ahorro de energía con luz solar y agua de lluvia almacenada.

Fig 21. Simulacion térmica del uso de un revestimiento superhidrófilo para disminuir la temperatura superficial de un edificio.

Fig 22. Prueba de campo con baldosas de hormigón resistentes a las manchas causadas por el aire urbano contaminado.

Fig 23. Esquema del proceso de descontaminación y de autolimpieza en una superficie fotocatalítica Superhidrófila.

Fig 24. Ángulo de contacto para superficies hidrofóbicas, superhidrófobas, hidrofilicas y superhidrofílicas.

Fig 25. Superficie de $\mathrm{TiO}_{2}$ hidrófila fotoinducida.

Fig 26. La imagen muestra cómo se limpia una superficie debido a la propiedad de la superhidrofilia.

Fig 27. Segmentación del mercado Italiano, por productos fabricados con cemento fotocatalítico en el periodo 2006-2009.

Fig 28. Fotos de las muestra de mortero gris revestida con $\mathrm{TiO}_{2}-$ Degussa $\mathrm{P} 25$ (A) Muestra de mortero con $\mathrm{TiO}_{2}$ (B) después de la aplicación del hollín pero antes de la irradiación (C) después de $42 \mathrm{~h}$ de irradiación (D) después de 420 h de irradiación. Fuente: Smits et al.

Fig 29. Mecanismo de la fotocatálisis aplicada a los materiales de cemento que contienen $\mathrm{TiO}_{2}$. Fuente Hanus et al.

Fig 30. La estructura del cemento endurecido que contiene (a) partículas de $\mathrm{TiO}_{2}$ de tamaño micrométrico $\left(\mathrm{m}-\mathrm{TiO}_{2}\right)(\mathrm{b})$ nanopartículas de $\mathrm{TiO}_{2}\left(\mathrm{n}-\mathrm{TiO}_{2}\right)$.

Fig 31. Variación de la medida de color de las muestras después de 4 h y $26 \mathrm{~h}$ de irradiación, la cantidad de rodamina utilizada es $\mathrm{RhB}=4,2 \mu \mathrm{g} / \mathrm{cm}^{2}$.

Fig 32. Distribución de la contaminación atmosférica como consecuencia de la acción conjunta del viento y el tráfico en una calle estrecha con edificios altos. Fuente Italcementi SpA.

Fig 33. Calle Borgo Palazzo con prefabricados fotocatalíticos en acera y calzada. Fuente. Italcementi SpA.

Fig 34. Resumen de los resultados de las pruebas según el color de la losa y condiciones de uso de la muestra.

Fig 35. Esquema de la distribución de los bloques extraídos para realizar las medidas.

Fig 36. Configuración de las calles cañón, montaje en Guerville. Fuente. Italcementi.

Fig 37. Disposición de los equipos de generación y medida de la contaminación. Fuente. Italcementi.

Fig 38. Situación del Túnel Umberto I. Fuente. Italcementi

Fig 39. Túnel Umberto I después de la rehabilitación. Fuente. Italcementi.

Fig 40. Aplicación del producto fotocatalítico e instalación de las lámparas UV en el túnel Leopold II en Bruselas, en el marco de PhotoPAQ. 
Fig 41. Iglesia Dives in Misericordia (Roma). Fuente. Italcementi.

Fig 42. Iglesia Dives in Misericordia (Roma). Fuente. Italcementi.

Fig 43. Esquema de los puntos de toma de medida colorimétrica en la estructura del edificio.

Fig 44. Cité de la Musique et des Beaux-Arts. Fuente. Italcementi.

Fig 45. Cité de la Musique et des Beaux-Arts. Fuente. Italcementi.

Fig 46. Toma de medidas sobre las superficies. Fuente. Italcementi.

Fig 47. Medidas de Luminancia L*, de las 4 fachadas del edificio principal después de 101 meses.

Fig 48. La evolución de la ingeniería de los materiales con el tiempo

Fig 49. Consumo Mundial de Cemento en (MTns). Fuente: ICR research.

Fig 50. Evolución del consumo de cemento en Europa (MTn). Fuente: ICR research.

Fig 51. Tasas de crecimiento (2014-2030) previstas de las concentraciones urbanas. Fuente: World Urbanization Prospects: The 2014 Revision.

Fig 52. Porcentaje de concentración urbana y población urbana por clase y tamaño en 2014. Fuente: World Urbanization Prospects: The 2014 Revision.

Fig 53. Efectos de la contaminación atmosférica para la salud. Los contaminantes atmosféricos pueden tener graves efectos para la salud de las personas. Los niños los mayores son grupos especialmente vulnerables. Fuente. AEMA186

Fig 54. Concentraciones medias anuales de partículas fina $\mathrm{PM}_{2,5}$. Fuente: $\mathrm{OMS}$

Fig 55. Proyección del aumento de las emisiones de contaminantes respecto a 2010. Fuente: OECD POLICY HIGHLIGHTS The economic consequences of outdoor air pollution.

Fig 56. Impacto macroeconómico previsto a determinados impactos de la contaminación atmosférica. Fuente: OECD POLICY HIGHLIGHTS The economic consequences of outdoor air pollution.

Fig 57. A la izquierda, predicciones de las concentraciones de $\mathrm{PM}_{2,5}$ de origen antropogénico, representadas en $\mu \mathrm{g} / \mathrm{m}^{3}$, a la derecha está representado el valor máximo de la media máxima horaria de 6 meses en la concentración de Ozono, valores en ppb. Fuente: OECD POLICY HIGHLIGHTS The economic consequences of outdoor air pollution.

Fig 58. Muertes atribuidas a la contaminación del aire ambiente en 2012. Fuente: OMS.

Fig 59. Porcentaje de muertes atribuibles a nivel mundial en 2013 por factor de riesgo. Fuente: World Bank and IHME, using data from IHME, GBD 2013.

Fig 60. Valores medios anuales en 2013 de $\mathrm{PM}_{2,5}$. Fuente: Brauer et al.

Fig 61. Relaciones entre impactos, calidad del aire y contaminantes. Fuente. Air pollution fact sheet - Spain 
Fig 62. Valores medios anuales de las concentración de $\mathrm{PM}_{2,5}$ en UE en 2014 Fuente. EEA Report Air quality in Europe - 2016.

Fig 63. Contaminación sobre Barcelona en el año 2013.

Fig 64. Representación esquemática de las reacciones químicas implicadas en modelo fotoquímico de estado de equilibrio en el sistema $\mathrm{NO}_{x} / \mathrm{O}^{3}$. Fuente. Muilwijk, C., et al.

Fig 65. Formación de smog fotoquímico. Fuente: Sugrañez.

Fig 66. Este mapa global muestra la concentración promedio de dióxido de nitrógeno en 2014 medido en la troposfera por el Ozone Monitoring Instrument a bordo del satélite Aura. Fuente https://svs.gsfc.nasa.gov/12094. Consultado Febrero 2017.

Fig 67. El mapa muestra el cambio de tendencias de Europa en las concentraciones de dióxido de nitrógeno de 2005 a 2014 . Fuente: https://svs.gsfc.nasa.gov/12094. Consultado Febrero 2017.

Fig 68. Emisiones en (\%) del sector del Transporte. Fuente: EEA Report. Air quality in Europe - 2016.

Fig 69. Emisiones en (\%) del sector del Comercial, Público y Particular. Fuente: EEA Report. Air quality in Europe - 2016.

Fig 70. Emisiones en (\%) del sector de Producción y Distribución de energía. Fuente: EEA Report. Air quality in Europe - 2016.

Fig 71. Emisiones en (\%) del sector Industrial. Fuente: EEA Report. Air quality in Europe - 2016.

Fig 72. Emisiones de EU-28 en 2000-2014 (\% de 2000)- $\mathrm{SO}_{x}, \mathrm{NO}_{x}, \mathrm{NH}_{3}, \mathrm{PM}_{10}, \mathrm{PM}_{2,5}, \mathrm{COVNM}, \mathrm{CO}, \mathrm{CH}_{4}$ e inquemados. Fuente: EEA Report. Air quality in Europe - 2016. No 28/2016.

Fig 73. Capacidad de entrada de las partículas en el organismo en función de su tamaño. Fuente. Calidad del aire interior. Ministerio de Trabajo y Asuntos Sociales.

Fig 74. Porcentaje de población urbana expuesta a valores superiores a los indicados por la OMS. Fuente: EEA. (2014). Air pollution fact sheet - Spain.

Fig 75. Mapa de estaciones de medición de contaminación atmosférica en España. Fuente. Plan nacional de calidad del aire y protección de la atmósfera 2013-2016.

Fig 76. Impactos e interacciones de los contaminantes atmosféricos y parámetros climáticos en las Infraestructuras.

Fig 77. Ahorro de costes en conservaciónrestauración por cada $500 €$ de inversión, como porcentaje de un coste total estimado de $336 €$ por la contaminación atmosférica de Cracovia por contaminante y por el total de contaminantes, para una fachada de caliza a partir de los valores mediados en Cracovia. Comparado con los niveles estimados para el periodo 2020 y 2050 en la directiva de la UE sobre la calidad del aire de 2008 y el aumento previsto de los costes debido al cambio climático hasta el período 2081-2100.

Fig 78. Ahorro de costes en conservaciónrestauración por cada $500 €$ de inversión en una fachada de piedra caliza debido a una reducción de $1 \mu \mathrm{g} / \mathrm{m}^{3}$ en la concentración de dióxido de azufre $\left(\mathrm{SO}_{2}\right)$, dióxido de nitrógeno $\left(\mathrm{NO}_{2}\right)$ y partículas finas $\left(P \mathrm{M}_{10}\right)$. Los valores de contaminación en la ciudad de Cracovia, están representados por las líneas verticales de puntos. 
Fig 79. Imagen sobre la entrada de un castillo en Westfalia, Alemania. Hecha en piedra arenisca en 1702. Imagen izquierda tomada en 1908, imagen derecha tomada en 1969.

Fig 80. Isla de calor urbano. Variación de la temperatura superficial y atmosférica. Fuente: Reducing Urban Heat Island: Compendium of Strategies, Eva Wong.

Fig 81. Vista de las fachadas en Vejer de la Frontera horizontal. Fuente: Panoramio.

Fig 82. Temperatura fisiológica en Madrid y su área metropolitana durante los meses de julio y agosto de 2003.

Fig 83. Imágenes infrarroja (b) imágenes visibles de cuatro tejas de hormigón pintadas con recubrimientos blancos "fríos" (1 y 4), un recubrimiento negro (2) y una sin pintar (3).

Fig 84. Viviendas en las Islas Bermudas. 2010. Fuente: Flickr, Vadim Klochko.

Fig 85. Cubiertas en Vejer de la Frontera. Fuente: Flickr.

Fig 86. Equipo de Fluorescencia por Rayos X

Fig 87. Representación de la difracción de rayos $\mathrm{X}$ por un sólido cristalino.

Fig 88. Equipo de medida DRX BRUKER AXS D8 Advance.

Fig 89. Estructura molecular de rodamina B. Fuente. www.sigmaaldrich.com

Fig 90. Espacio de color CIE Lab.

Fig 91. Muestra antes y después de manchar con Rodamina.

Fig 92. Equipo Konica Minolta CM-2300d.

Fig 93. Montaje experimental para ensayo eliminación fotocatalítica de óxidos de nitrógeno $\left(\mathrm{NO}_{\mathrm{x}}\right)$.

Fig 94. Reactor y sistema de irradiación de la muestra.

Fig 95. Analizador de $\mathrm{NO}_{x}$ y sistema de control para los medidores de flujo másico.

Fig 96. Gráfica típica de evolución de concentraciones de $\mathrm{NO}, \mathrm{NO}_{2}$ y $\mathrm{NO}_{x}$ durante un ensayo

Fig 97. Diagrama de medida de la reflectancia con una esfera integradora, con geometría de medición $8^{\circ}:$ d.

Fig 98. Equipo con una muestra de mortero colocada en el puerto durante una medida.

Fig 99. Distribución de iones positivos y negativos alrededor del coloide Fuente. Zeta Potential: A Complete Course in 5 Minutes, Zeta-Meter Inc.

Fig 100. Medición de ultrasonidos.

Fig 101. Equipo de medida de aire ocluido para morteros. 
Fig 102. Dispositivo de carga para la determinación de la resistencia a flexión. Fuente UNE EN 1015-11.

Fig 103. Amasado del mortero.

Fig 104. Medida de la consistencia.

Fig 105. Toma de muestra del mortero amasado.

Fig 106. Medida de la consistencia en mesa de sacudidas.

Fig 107. Determinación de la densidad en fresco, medida del peso del mortero a un volumen conocido según UNE EN $1015-6$.

Fig 108. Equipo de medida de aire ocluido.

Fig 109. Proceso de amasado del mortero.

Fig 110. (Izq) Llana metálica para el acabado fino; (Der) Fratás de esponja para acabado rugoso.

Fig 111. Probetas fabricadas en cada amasada.

Fig 112. Máquina de ensayo de flexión y compresión para probetas de mortero.

Fig 113. Equipo utilizado en las medidas, Zeta Meter 3.0+ con el microscopio y la celda micro-electroforética y electrodos utilizados en las medidas de potencial zeta.

Fig 114. Equipo utilizado en las medidas, Zeta Meter 3.0+ con el microscopio y la celda micro-electroforética y electrodos utilizados en las medidas de potencial zeta.

Fig 115. Difractogramas del pigmento amarillo analizado.

Fig 116. Difractogramas del pigmento rojo analizado.

Fig 117. Difractogramas del pigmento marrón analizado.

Fig 118. Difractogramas del pigmento negro analizado.

Fig 119. Aspecto de las probetas ensayadas de mortero fotocatalítico blanco a los distintos tiempos de irradiación, MTX (L10, L9) y $\operatorname{MTX}(\mathrm{R} 2, \mathrm{R} 3)$.

Fig 120. Aspecto de las probetas ensayadas de mortero no fotocatalítico blanco a los distintos tiempos de irradiación, M (L30, L31) y $M(R 20, R 21)$.

Fig 121. Gráfica con la evolución de concentraciones de NO durante el ensayo de la muestra de mortero no fotocatalítico liso (M-L). A) Inyección de gas al reactor. B) Comienzo de la iluminación. C) Fin de la iluminación)

Fig 122. Gráfica con la evolución de concentraciones de NO durante el ensayo de la muestra de mortero fotocatalítico liso (MTX-L). A) Inyección de gas al reactor. B) Comienzo de la iluminación. C) Fin de la iluminación) 
Fig 123. Gráfica con la evolución de concentraciones de NO durante el ensayo de la muestra de mortero fotocatalítico amarillo liso (MTX-A-L).

Fig 124. Gráfica con la evolución de concentraciones de NO durante el ensayo de la muestra de mortero fotocatalítico rojo liso (MTX-R-L).

Fig 125. Gráfica con la evolución de concentraciones de NO durante el ensayo de la muestra de mortero fotocatalítico marrón liso (MTX-M-L).

Fig 126. Gráfica con la evolución de concentraciones de NO durante el ensayo de la muestra de mortero fotocatalítico G1 liso (MTX-G1-L).

Fig 127. Gráfica con la evolución de concentraciones de NO durante el ensayo de la muestra de mortero fotocatalítico G2 liso (MTX-G2-L).

Fig 128. Gráfica con la evolución de concentraciones de NO durante el ensayo de la muestra de mortero no fotocatalítico rugoso (M-R).

Fig 129. Gráfica con la evolución de concentraciones de NO durante el ensayo de la muestra de mortero fotocatalítico blanco rugoso (MTX-R).

Fig 130. Gráfica con la evolución de concentraciones de NO durante el ensayo de la muestra de mortero fotocatalítico amarillo rugoso (MTX-A-R).

Fig 131. Gráfica con la evolución de concentraciones de NO durante el ensayo de la muestra de mortero fotocatalítico rojo rugoso (MTX-R-R).

Fig 132. Gráfica con la evolución de concentraciones de NO durante el ensayo de la muestra de mortero fotocatalítico marrón rugoso (MTX-M-R).

Fig 133. Gráfica con la evolución de concentraciones de NO durante el ensayo de la muestra de mortero fotocatalítico G1 rugoso (MTX-G1-R).

Fig 134. Gráfica con la evolución de concentraciones de NO durante el ensayo de la muestra de mortero fotocatalítico G2 rugoso (MTX-G2-R).

Fig 135. Espectrofotómetro PerkinElmer UV-Vis-NIR, mod. Lambda 900 utilizado.

Fig 136. Cerámica blanca serie CCS-II, utilizada como patrón.

Fig 137. (lzq) Detalle del puerto de medida (Der) Detalle de la posición de la muestra MTX-R23 para una medida.

Fig 138. Muestras de mortero ensayadas.

Fig 139. Espectros de reflectancia para los morteros fotocatalíticos según acabado superficial y color.

Fig 140. Curvas de absorción Kubelka-Munk, detalle ampliado con los espectros de absorción entre 350 y 600 nm.

Fig 141. Curvas de todos los morteros al representar la ecuación de Tauc, $(F(R) h v) 1 / n$ frente a la energía absorbida hu(eV)

Fig 142. Esquema de la célula de ensayo.

Fig 142. Aspecto de las probetas fabricadas y curadas en el IETcc. Cada imagen es una muestra de cada una de las series de probetas con distinto aditivo añadido. Su porcentaje en peso sobre cemento se indica entre paréntesis.

Fig 143. Aspecto de las probetas fabricadas y curadas en el IETcc. Cada imagen es una muestra de cada una de las series de probetas con distinto aditivo añadido. Su porcentaje en peso sobre cemento se indica entre paréntesis.

Fig 144. Superposición de los difractogramas de los pigmentos analizados.

Fig 145. Página Izquierda Composición elemental de los pigmentos referida a su óxido correspondiente. 
I NFLUENCIA DEL COLOR Y ELACABADO SUPERFICIALEN LAS PROPIEDADES DE UN MORTEROFOTOCATALITICOCOMOSOLUCIÓN DE ENVOLVENTE

Fig 146. Página Izquierda Composición elemental de los morteros referida a su óxido correspondiente.

Fig 147. Irradiancia solar y porcentaje de la cantidad de radiación electromagnética en las zonas UV, Vis y NIR del espectro.

Fig 148. Reflectancia del mortero fotocatalítico blanco acabado liso, superpuesto al espectro de irradiancia solar.

Fig 149. Reflectancia de todas las muestras de morteros fotocatalítico en los dos acabados.

Fig 150. Reflectancia de las muestras lisas blancas de mortero fotocatalítico blanco, (MTX-26) el mortero no fotocatalítico (M-L11) comparadas con el patrón BK 97.

Fig 151. Diferencia de reflectancia entre las muestras lisas de mortero fotocatalítico blanco (MTX-L26) y mortero no fotocatalítico (M-L11).

Fig 152. Reflectancia de las muestras rugosas blancas de mortero fotocatalítico blanco, (MTX23) y el mortero no fotocatalítico (MR13) comparadas con el patrón BK 97.

Fig 153. Diferencia de reflectancia entre las muestras rugosas de mortero fotocatalítico blanco (MTX-R23) y mortero no fotocatalítico (M-R13).

Fig 154. Diferencias entre $\Delta$ Reflectancia (MTX-L26 y MT-L11) y $\Delta$ Reflectancia (MTX-R23 y MT-R13).

Fig 155. Reflectancia de las muestras de morteros con acabado LISO.

Fig 156. Reflectancia de las muestras de morteros con acabado RUGOSO.

Fig 157. Reflectancia de las muestras de morteros fotocatalíticos blancos (MTX) y gris claro (MTX-G1).

Fig 158. Cantidad de la radiación electromagnética reflejada ordenada de mayor a menor, para todos los morteros, por color y acabado. Intervalo visible (380-780 nm) y NIR (790-1400nm).

Fig 159. Reflectancia en la banda del espectro (380-780nm) para cada mortero según el acabado superficial.

Fig 160. Reflectancia en la banda del espectro (790-1400nm) para cada mortero según el acabado superficial.

Fig 161. Representación de la ecuación de Tauc frente a la energía absorbida, detalle de lectura de la energía de band gap en la curva de absorción del mortero fotocatalítico de color rojo (MTX-R).

Fig 162. Espectros de absorción del mortero no fotocatalítico blanco (M) y del mortero fotocatalítico blanco (MTX).

Fig 163. Espectros de absorción de los morteros fotocatalíticos pigmentados.

Fig 164. Espectros de absorción de los morteros fotocatalíticos pigmentados grises (MTXG1 y MTXG2) y el mortero fotocatalítico blanco (MTX).

Fig 165. Espectros de absorción de los morteros fotocatalíticos coloreados amarillo, rojo, marrón y gris claro, con el mortero fotocatalítico blanco (MTX).

Fig 166. Espectros de absorción de los morteros fotocatalíticos coloreados amarillo, rojo, marrón, blanco y el mortero no fotocatalítico (M). 
Fig 167. Energía de absorción (eV) para el mortero no fotocatalítico blanco (M-1).

Fig 168. Energía de absorción (eV) para el mortero fotocatalítico blanco (MTX-22).

Fig 169. Energías de absorción (eV) para el mortero fotocatalítico amarillo (MTXA-43).

Fig 170. Energías de absorción (eV) para el mortero fotocatalítico rojo (MTXR-11).

Fig 171. Energías de absorción (eV) para el mortero fotocatalítico marrón (MTXM-8).

Fig 172. Energía de absorción (eV) para el mortero fotocatalítico gris claro (MTXG1-8).

Fig 173. Energía de absorción (eV) para el mortero fotocatalítico gris oscuro (MTXG2-20).

Fig 174. Diagrama con las bandas de valencia (BV) y bandas de conducción (BC) de los morteros fotocatalíticos y líneas de equilibrio correspondientes a $\mathrm{OH} / \mathrm{OH} \cdot$ y $\mathrm{O}_{2} / \mathrm{O}_{2} \cdot-$ a $\mathrm{pH} 12-14$.

Fig 175. Valores de eliminación de $\mathrm{NO}_{\mathrm{x}}$ para todos los morteros por color y acabado con intervalos de error.

Fig 176. Eliminación de $\mathrm{NO}_{x}$ de las muestras fotocatalíticas según el acabado en función de la energía de absorción o band gap (Eg).

Fig 177. Valores de autolimpieza, a las $26 \mathrm{~h}$ de exposición -R26 (\%), para todos los morteros por color y acabado, con intervalos de error.

Fig 178. Relación de los datos de eliminación de $\mathrm{NO}_{x}, \mathrm{AC}(\%)$ y los de autolimpieza $\mathrm{R} 26$ (\%) en relacion al color.

Fig 179. Curvas de intensidad de fluorescencia medidas a $\lambda=425 \mathrm{~nm}$, a distintos tiempos de irradiación a $\lambda=315 \mathrm{~nm}$, de la solución de $\mathrm{TaOH}$ sobre la muestra de mortero fotocatalítico amarillo (MTX-A).

Fig 180. Curva de calibración de la intensidad de fluorescencia en función de la concentración de la disolución de $\mathrm{TaOH}$ a pH (12,4 $\pm 0,2)$

Fig 181. Intensidad de la fluorescencia medida a $425 \mathrm{~nm}$ para las muestras de morteros fotocatalíticos para cada color de mortero, media de dos muestras.

Fig 182. Producción de grupos $\mathrm{OH} \cdot$ para cada mortero fotocatalítico en función del color.

Fig 183. Producción de grupos $\mathrm{OH}$ · para los morteros fotocatalíticos en función de la posición de la energía de la banda de conducción.

Fig 184. Esquema de excitación del electrón desde la banda de valencia a la de conducción y creación del par electrón/hueco, con las dos posibles vías, recombinación y formación de especies Reactivas.

Fig 185. Producción de grupos $\mathrm{OH}^{\cdot}$ para cada mortero fotocatalítico en función del color por la relacion Fe/Ti.

Fig 186. Representación del esquema propuesto de transferencia y separación de carga en los electrones excitados a la BC por radiación UV-VIS en las muestras de mortero fotocatalítico de color rojo (MTX-R) Fuente:Elaboración propia.

Fig 187. Promedios de R4 (\%) para cada aditivo, a partir de los valores de las cuatro probetas de cada serie. La línea roja representa el límite de actividad para considerar al material fotocatalítico. 
I NFLUENCIA DEL COLOR Y EL ACABADO SUPERFICIALEN LASPROPIEDADES DE UN MORTERO FOTOCATALITICO COMO SOLUCIÓN DE ENVOLVENTE

Fig 188. Promedios de R26(\%) para cada aditivo, a partir de los valores de las cuatro probetas de cada serie. La línea roja representa el límite de actividad para considerar al material fotocatalítico.

Fig 189. Representación gráfica de los promedios de degradación $\mathrm{AC}(\%)$ de $\mathrm{NO}, \mathrm{NO}_{x}$ y $\mathrm{NO}_{2}$ para cada serie de probetas ensayadas. Señalado en rojo el valor de referencia de eliminación de $\mathrm{NO}_{x}$ para el mortero fotocatalítico sin aditivos.

Fig 190. Representación gráfica de los promedios de R26 frente a los promedios de la degradación de $\mathrm{NO}_{\mathrm{x}}, \mathrm{AC}(\%)$. 


\section{3 . TABLAS}

Tabla 1. Clasificación del tipo de radiación relativa a las longitudes de onda

Tabla 2. Potenciales de oxidación de diversas especies.

Tabla 3. Parámetros físicos del $\mathrm{TiO}_{2}$. Fuente: Carp et al.

Tabla 4. Relaciones entre los óxidos en la composición química del clínker.

Tabla 5. Composición química del clínker de cemento Portland

Tabla 6. Fases mineralógicas que componen el clínker de cemento Portland

Tabla 7. Cementos comunes definidos en la norma UNE-EN 197-1:2011.

Tabla 8. Porcentaje de la población de la UE-28 expuesta a concentraciones de contaminantes atmosféricos por encima de las concentración de referencia de la UE y de la OMS (2102-2014). Fuente: Tabla ES.1. EEA Report Air quality in Europe 2016 report.

Tabla 9. Lista y fuentes de los contaminantes atmosféricos más significativos para la calidad del aire urbano. Fuente Ballester et al.

Tabla 10. Incumplimientos frecuentes de los contaminantes atmosféricos. Fuente. Plan nacional de calidad del aire y protección de la atmósfera 2013-2016.

Tabla 11. Superficie afectada y población censada en zonas con incumplimientos. Fuente. Plan nacional de calidad del aire y protección de la atmósfera 2013-2016.

Tabla 12. Sensibilidad a la corrosión de diversos materiales hacia contaminantes atmosféricos y parámetros climáticos.

Tabla 13. Morteros.

Tabla 14. Aditivos.

Tabla 15. Listado de las referencias de aditivo ensayadas.

Tabla 16. Porcentaje de pigmento por amasada (\% sobre peso de mortero).

Tabla 17. Velocidades de la amasadora indicadas en la norma UNE-EN 196-1.

Tabla 19. Características de los morteros en estado fresco.

Tabla 120. Listado de probetas y denominación de las mismas para cada amasada.

Tabla 21. Valores de las resistencias mecánicas a 28 días de los morteros.

Tabla 22. Medidas obtenidas en las probetas de 7,5x15 cm para el cálculo del módulo elasticidad dinámico de los morteros. 
Tabla 23. Valores de las resistencias mecánicas a 28 días de los morteros.

Tabla 24. Datos experimentales para las medida del pH y conductividad específica, con los datos de potencial Z, su desviación estándar y coeficiente de variación para $n=10$.

Tabla 25. Composición elemental de los pigmentos referida a su oxido correspondiente.

Tabla 26. Composición elemental de los morteros referida a su oxido correspondiente.

Tabla 27. Valores de las coordenadas colorimétricas para cada color en los dos acabados, rugoso (R) y liso (L).

Tabla 28. Medidas de las coordenadas colorimétricas a tiempos de exposición Oh, 4 h y $26 \mathrm{~h}$.

Tabla 29. Parámetros de ensayo del procedimiento experimental de las probetas ensayadas.

Tabla 30. Resultados obtenidos, según norma UNI-11247 para las probetas ensayadas de acabado LISO.

Tabla 31. Resultados obtenidos, según norma UNI-11247 para las probetas ensayadas de acabado RUGOSO.

Tabla 32. Resultados promedio de la Intensidad de Fluorescencia para los morteros fotocatalíticos en cada tiempo de medida.

Tabla 33. Valores de calculados del ratio $\mathrm{Fe} / \mathrm{TiO}_{2}$ y de la generación de $(\mathrm{OH} \cdot)$ para cada mortero fotocatalítico coloreado.

Tabla 34. Referencias y características de las probetas por tipo y cantidad de aditivo en porcentaje sobre el peso de cemento.

Tabla 35. Composición exacta de cada serie de probetas.

Tabla 36. Resultados de las series de autolimpieza.

Tabla 37. Resultados expresados como $A_{C}(\%)$ y $A_{F}$ para las probetas dentro de la misma serie.

Tabla 38. Parámetros físicos de los pigmentos.

Tabla 41. Resumen de los resultados obtenidos en los ensayos físicos de los morteros y el agua de amasado y dosificación de pigmento para cada uno.

Tabla 42. Datos de $\mathrm{pH}$, conductividad y Potencial Z (valor medio, con su desviación estándar, $\mathrm{n}=10$ ).

Tabla 43. Cantidad de la radiación electromagnética reflejada ordenada de mayor a menor, para todos los morteros, por color y acabado.

Tabla 44. Valores de la energía de absorción necesaria para promocionar un electrón a la banda de conducción para cada mortero.

Tabla 45. Energía de la radiación de longitud de onda indicada, en el límite UV-Vis y Vis-IR.

Tabla 46. Valores calculados de las bandas de conducción (BC) y de la banda de valencia (BV) para cada mortero fotocatalítico coloreado. 
Tabla 47. Valores de la actividad fotocatalítica de reducción de óxidos de nitrógeno Ac (\%) y desviación estándar para los morteros según el color y su acabado superficial.

Tabla 48. Cálculo de los valores para R4 y R26 y desviación estándar, a partir de las medias para cada mortero y acabado en cada coordenada colorimétrica.

Tabla 49. Código de aditivos. 